\title{
HIGH LEVEL WASTE (HLW) SLUDGE BATCH 4 (SB4) VARIABILITY STUDY
}

K.M. Fox

T.B. Edwards

D.K. Peeler

D.R. Best

I.A. Reamer

R.J. Workman

October 2006

Process Science and Engineering Section Savannah River National Laboratory Aiken, SC 29808

Prepared for the U.S. Department of Energy Under Contract Number DEAC09-96SR18500

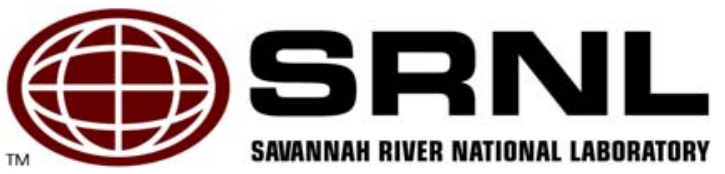


WSRC-STI-2006-00204

Revision 0

\section{DISCLAIMER}

This report was prepared by Washington Savannah River Company (WSRC) for the United States Department of Energy under Contract No. DE-AC09-96SR18500 and is an account of work performed under that contract. Neither the United States Department of Energy, nor WSRC, nor any of their employees makes any warranty, expressed or implied, or assumes any legal liability or responsibility for the accuracy, completeness, or usefulness, of any information, apparatus, or product or process disclosed herein or represents that its use will not infringe privately owned rights. Reference herein to any specific commercial product, process, or service by trademark, name, manufacturer or otherwise does not necessarily constitute or imply endorsement, recommendation, or favoring of same by WSRC or by the United States Government or any agency thereof. The views and opinions of the authors expressed herein do not necessarily state or reflect those of the United States Government or any agency thereof.

\section{Printed in the United States of America \\ Prepared For U.S. Department of Energy}

The Savannah River National Laboratory is operated for the U.S. Department of Energy by Washington Savannah River Company. 
Keywords: high level waste, glass, SB4, variability, durability

Retention: permanent

\section{HIGH LEVEL WASTE (HLW) SLUDGE BATCH 4 (SB4) VARIABILITY STUDY}

K.M. Fox

T.B. Edwards

D.K. Peeler

D.R. Best

I.A. Reamer

R.J. Workman

October 2006

Process Science and Engineering Section Savannah River National Laboratory Aiken, SC 29808

Prepared for the U.S. Department of Energy Under Contract Number DEAC09-96SR18500

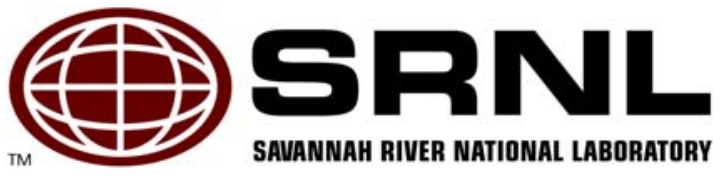


WSRC-STI-2006-00204

Revision 0

\section{REVIEWS AND APPROVALS}

\section{AUTHORS:}

K.M. Fox, Materials Science and Technology Section

Date

T.B. Edwards, Statistical Consulting Section

Date

D.K. Peeler, Process Science and Engineering Section

Date

D.R. Best, Process Science and Engineering Section

Date

I.A. Reamer, Process Science and Engineering Section

Date

R.J. Workman, Process Science and Engineering Section

Date

TECHNICAL REVIEWER:

M.E. Smith, Process Science and Engineering Section

Date

APPROVERS:

R.E. Edwards, Manager, Process Science and Engineering Section

Date

C.C. Herman, Manager, Process Engineering Technology Group

Date

J.E. Occhipinti, Manager, DWPF Process Engineering

Date 
WSRC-STI-2006-00204

Revision 0

\section{EXECUTIVE SUMMARY}

The Defense Waste Processing Facility (DWPF) is preparing for vitrification of High Level Waste (HLW) Sludge Batch 4 (SB4) in early FY2007. To support this process, the Savannah River National Laboratory (SRNL) has provided a recommendation to utilize Frit 503 for vitrifying this sludge batch, based on the composition projection provided by the Liquid Waste Organization on June 22, 2006. Frit 418 was also recommended for possible use during the transition from SB3 to SB4. A critical step in the SB4 qualification process is to demonstrate the applicability of the durability models, which are used as part of the DWPF's process control strategy, to the glass system of interest via a variability study. A variability study is an experimentally-driven assessment of the predictability and acceptability of the quality of the vitrified waste product that is anticipated from the processing of a sludge batch. At the DWPF, the durability of the vitrified waste product is not directly measured. Instead, the durability is predicted using a set of models that relate the Product Consistency Test (PCT) response of a glass to the chemical composition of that glass. In addition, a glass sample is taken during the processing of that sludge batch, the sample is transmitted to SRNL, and the durability is measured to confirm acceptance. The objective of a variability study is to demonstrate that these models are applicable to the glass composition region anticipated during the processing of the sludge batch - in this case the Frit 503 - SB4 compositional region. The success of this demonstration allows the DWPF to confidently rely on the predictions of the durability/composition models as they are used in the control of the DWPF process.

The glass region for the SB4 variability study was determined using the June 22, 2006 projections of the SB4 composition that led to SRNL's frit recommendation memorandum. Variation was introduced into the composition of the sludge to account for the uncertainty present in these projections as well as for process variation that may be experienced at the DWPF during its normal operations (e.g., a range of waste loadings were covered). The glasses chosen for the variability study were fabricated by SRNL. Both quenched and centerline canister-cooled (ccc) heat treatments were performed, and chemical compositions were verified. The PCT was used to gauge the durability of each glass based on both quenched and ccc heat treatments. X-ray diffraction (XRD) was used to assess the possible formation of crystalline phases in the ccc-based glasses.

The results of the variability study show that vitrifying SB4 with Frit 503 will produce glasses with durabilities that are both predictable by the DWPF Product Composition Control System (PCCS) models and acceptable as compared to the Environmental Assessment (EA) glass, within the range of sludge compositions and waste loadings included in the study. All 35 of the glasses fabricated had durabilities that were very acceptable as compared to the EA glass for both quenched and ccc heat treatments. Two of the variability study glasses fell outside of the $95 \%$ confidence interval for the free energy of hydration durability model. One of these glasses had a high (more positive) $\Delta \mathrm{G}_{\mathrm{P}}$ value and an acceptable durability (more than an order of magnitude below that of the EA benchmark glass). This type of response has been seen in past studies and is not a cause for concern. The second of the glasses that fell outside of the $95 \%$ confidence interval was found to be prone to nepheline crystallization based on the measured composition, and therefore would not have passed the DWPF PCCS Measurement Acceptability Region (MAR). This glass showed a statistically significant decrease in durability after the ccc heat treatment due to nepheline crystallization. However, both the quenched and ccc versions of this glass were very acceptable when compared to the durability of the EA glass. 
The glasses formulated with SB4 and Frit 418 were both predictable and acceptable. This frit is considered an option for DWPF processing during the transition from SB3 to SB4.

Chemical composition measurements of the variability study glasses indicate that the sulfate limit of $0.60 \mathrm{wt} \%$ in glass is viable for the Frit 503 / SB4 system, based on the nominal SB4 composition projections used as the technical basis for this study. 


\section{TABLE OF CONTENTS}

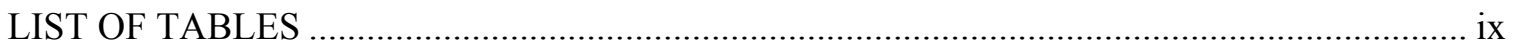

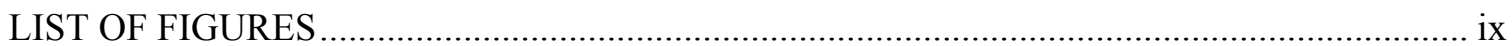

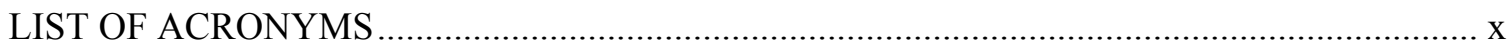

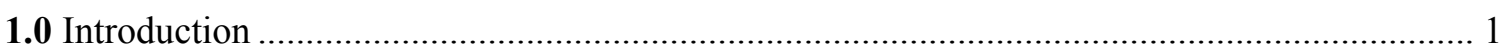

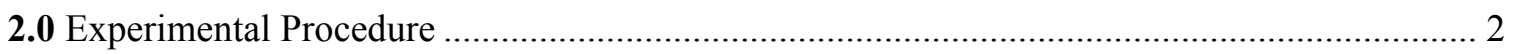

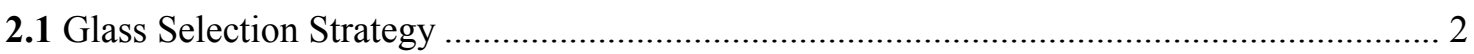

2.2 Target Compositions of Selected Glasses....................................................................... 4

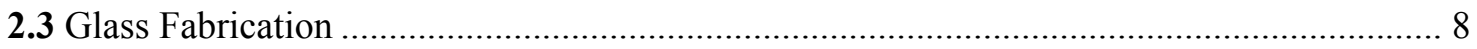

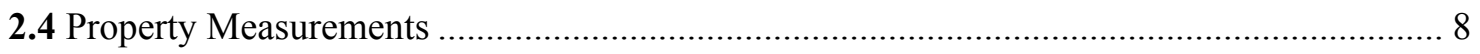

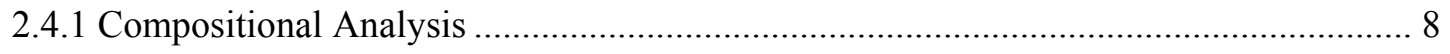

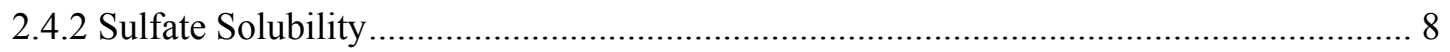

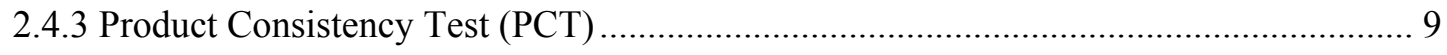

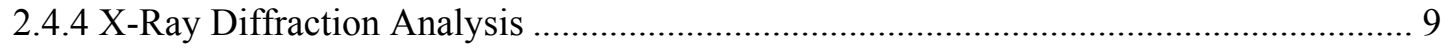

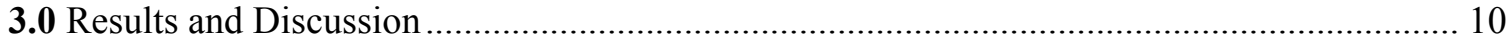

3.1 A Statistical Review of the Chemical Composition Measurements of the SB4 Variability

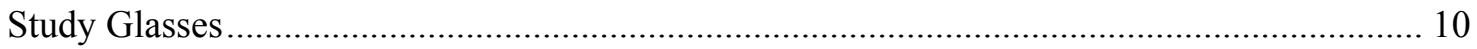

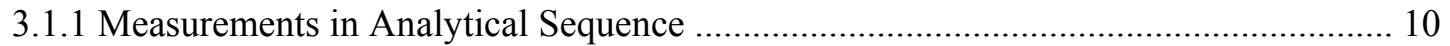

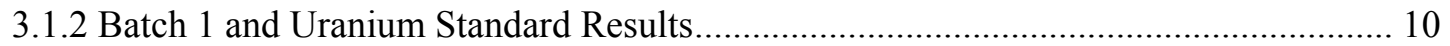

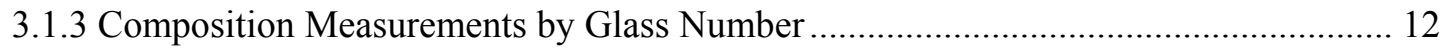

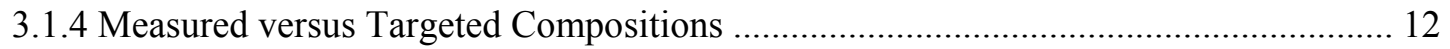

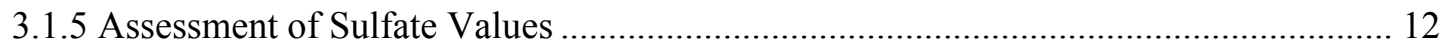

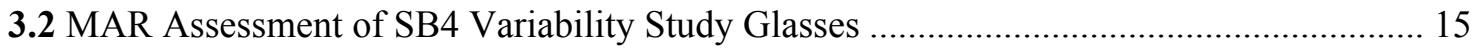

3.3 A Statistical Review of the SB4 Variability Study PCT Results ......................................... 19

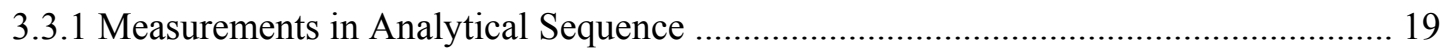

3.3.2 Results for the Samples of the Multi-Element Solution Standard................................. 19

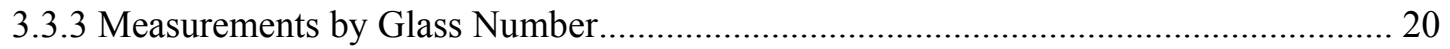

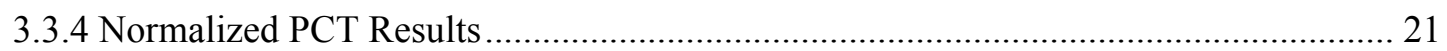

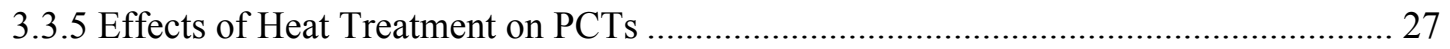

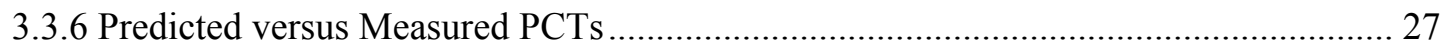

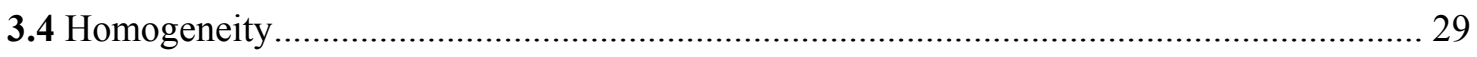

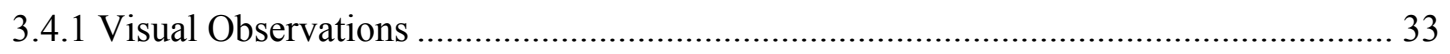

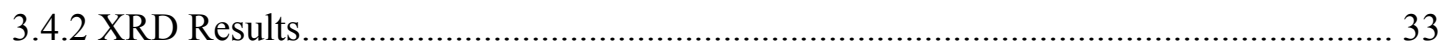




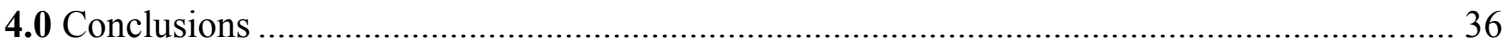

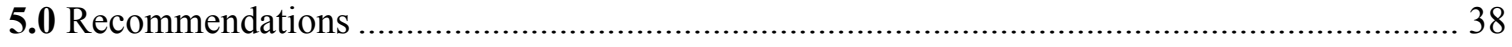

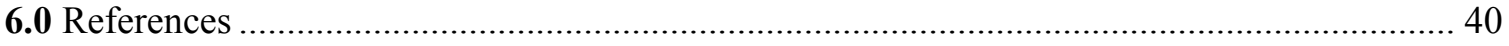

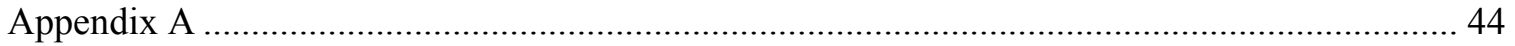

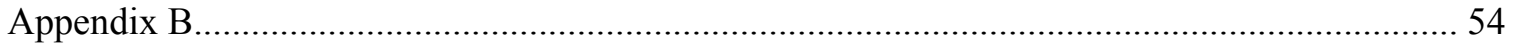

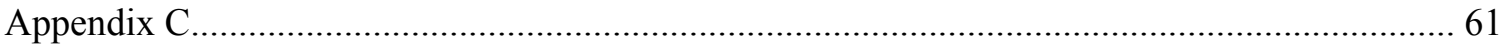

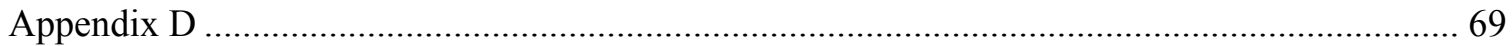

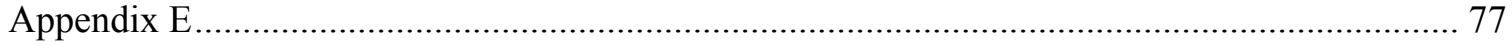

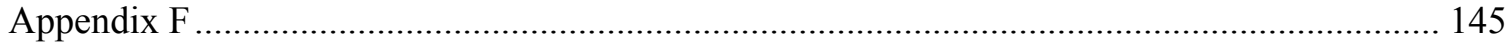




\section{LIST OF TABLES}

Table 2-1. Compositions (in wt\%) of the Frits Recommended for SB4 Processing. 2

Table 2-2. Nominal SB4 Composition Projections and Sludge Composition Space with Traditional EVs Applied. 3

Table 2-3. Minor Oxides Included in the Composition of "Others" (in wt\%). ............................. 3

Table 2-4. Target Compositions (in wt $\%$ ) of the SB4 Variability Study Glasses. ........................ 5

Table 3-1. Results of MAR Assessment of SB4 Variability Study Glasses for Measured, BiasCorrected, and Targeted Compositional Views. ................................................................. 16

Table 3-2. Results from Samples of the Multi-Element Solution Standard. ............................... 20

Table 3-3. Results from PCT Reruns for the ccc Versions of SB4VS-02, SB4VS-05, and SB4VS-09.

Table 3-4. Normalized PCTs by Glass ID and Compositional View......................................... 23

Table 3-5. Visual Observations and XRD Results for the Variability Study Glasses................. 30

\section{LIST OF FIGURES}

Figure 3-1. Measured Sulfate Values for the Variability Study Glasses by Glass Number ......... 13

Figure 3-2. Measured versus Targeted Sulfate Concentration for Study Glasses ....................... 14

Figure 3-3. NL [B] versus $\Delta \mathrm{G}_{\mathrm{p}}$ for the SB4 Variability Study Glasses................................... 28

Figure 3-4. XRD Pattern for the ccc Version of Glass SB4VS-01 .............................................. 34

Figure 3-5. XRD Pattern for the ccc Version of Glass SB4VS-09............................................ 35 


\section{LIST OF ACRONYMS}

AD

ANOVA

ARM

ASTM

bc

$\mathrm{ccc}$

DWPF

EA

HLW

ICP-AES

LM

MAR

NL

PAR

PCCS

PCT

PF

ppm

PSAL

SB3

SB4

SME

SRNL

WL

XRD
Analytical Development

ANalysis Of VAriance

Approved Reference Material

American Society for Testing and Materials

bias-corrected

centerline canister-cooled

Defense Waste Processing Facility

Environmental Assessment glass

High Level Waste

Inductively Coupled Plasma - Atomic Emission Spectroscopy

Lithium Metaborate

Measurement Acceptability Region

Normalized Leachate

Property Acceptability Region

Product Composition Control System

Product Consistency Test

Peroxide Fusion

parts per million

Process Science Analytical Laboratory

Sludge Batch 3

Sludge Batch 4

Slurry Mix Evaporator

Savannah River National Laboratory

Waste Loading (weight percent)

X-Ray Diffraction 


\subsection{Introduction}

The Defense Waste Processing Facility (DWPF) is preparing for vitrification of High Level Waste (HLW) Sludge Batch 4 (SB4) in early FY2007. To support this process, the Savannah River National Laboratory (SRNL) has provided a recommendation to utilize Frit 503 for vitrifying this sludge batch. ${ }^{1}$ This recommendation was based on the composition projections for SB4 available at that time, ${ }^{\text {a }}$ assessments of operating windows in waste loading (WL) space, ${ }^{2}$ melt rate data, ${ }^{3}$ and the potential for nepheline formation (which reduces durability). ${ }^{4-11}$

A critical step in the SB4 qualification process is to demonstrate the applicability of the durability models, ${ }^{12}$ which are used as part of the DWPF's process control strategy, to the glass system of interest via a variability study. A variability study is an experimentally-driven assessment of the predictability and acceptability of the quality of the vitrified waste product that is anticipated from the processing of a sludge batch. The quality of the waste form is a measure of its durability as determined by the Product Consistency Test (PCT). ${ }^{13}$ At the DWPF, the durability of the vitrified waste product is not directly measured by this test during normal operation. Instead, the durability is predicted using a set of models that relate the PCT response of a glass to the chemical composition of that glass. In addition, a glass sample is taken during the processing of that sludge batch, the sample is transmitted to SRNL, and the durability is measured to confirm acceptance. The objective of a variability study is to demonstrate that these models are applicable to the glass composition region anticipated during the processing of the sludge batch - in this case the Frit 503 - SB4 compositional region. The success of this demonstration allows the DWPF to confidently rely on the predictions of the durability/composition models as they are used in the control of the DWPF process.

The glass region for the SB4 variability study was determined using the latest projections of the SB4 composition that led to SRNL's frit recommendation memorandum. ${ }^{1}$ Variation was introduced into the composition of the sludge to account for the uncertainty present in these projections as well as for process variation that may be experienced at the DWPF during its normal operations (e.g., a range of waste loadings were covered). The primary focus of the variability study will be on the use of Frit 503, as this frit was recommended for SB4 processing. ${ }^{1}$ However, the recommendation memorandum also stated that Frit 418 is a viable option for DWPF processing, especially during the transition from Sludge Batch 3 (SB3) to SB4 (i.e., an acceptable product can be produced with both SB3 and SB4 when Frit 418 is used). ${ }^{b}$ As a result, additional glasses representing the SB4 / Frit 418 system were also chosen for the variability study.

The glasses chosen for the variability study were fabricated by SRNL. Both quenched and centerline canister-cooled (ccc) heat treatments were performed, and chemical compositions were verified. The PCT was used to gauge the durability of each glass based on both quenched and ccc heat treatments. X-ray diffraction (XRD) was used to assess the possible formation of crystalline phases in the ccc-based glasses.

The results of this variability study will provide guidance to DWPF on the applicability of the durability models to the frit / SB4 systems of interest. This work was initiated by a DWPF Technical Task Request ${ }^{14}$ and is performed under a SRNL Task Technical and Quality Assurance Plan. ${ }^{15}$

aPersonal communication with H. B. Shah, via email, on June 22, 2006 (see WSRC-NB-2006-00017 for details).

$b_{\text {Frit }} 503$ was recommended for the majority of SB4 processing since this higher $\mathrm{B}_{2} \mathrm{O}_{3}$-containing frit has advantages over Frit 418 in melt rate and is less prone to nepheline crystallization. ${ }^{1}$ 
WSRC-STI-2006-00204

Revision 0

\subsection{Experimental Procedure}

\subsection{Glass Selection Strategy}

The strategy used in selecting glasses for the SB4 variability study was described in a previous report, ${ }^{16}$ however, a brief overview of the process will be provided here. The two frits described in SRNL's frit recommendation for SB4 processing, ${ }^{1}$ Frits 418 and 503, were utilized in this variability study. The frit selection memorandum stated that Frit 418 is viable for use during the transition from SB3 to SB4, should DWPF choose to exhaust its remaining stock of this frit during the changeover period. Frit 503 was recommended for SB4 processing due to advantages over Frit 418 in melt rate, suppression of nepheline crystallization to higher WLs, and projected operating windows in terms of WL. ${ }^{1,3,8}$ The nominal compositions of these frits are listed in Table 2-1.

Table 2-1. Compositions (in wt\%) of the Frits Recommended for SB4 Processing.

\begin{tabular}{||c|c|c|c|c||}
\hline Frit ID & $\mathbf{B}_{\mathbf{2}} \mathbf{O}_{\mathbf{3}}$ & $\mathbf{L i}_{\mathbf{2}} \mathbf{O}$ & $\mathbf{N a}_{\mathbf{2}} \mathbf{O}$ & $\mathbf{S i O}_{\mathbf{2}}$ \\
\hline 418 & 8 & 8 & 8 & 76 \\
\hline 503 & 14 & 8 & 4 & 74 \\
\hline
\end{tabular}

Two nominal composition projections for SB4, Blend 1 (i.e., SB4 after transferring to a $~ 113$ ” heel of SB3) a were used as the technical basis for defining the sludge compositional region of interest. The first nominal composition was referred to as the $0.92 \mathrm{M} \mathrm{Na}^{+}$with $12.2 \mathrm{wt} \%$ solids option. The second nominal composition was referred to as the $0.912 \mathrm{M} \mathrm{Na}^{+}$with $12.6 \mathrm{wt} \%$ solids option.

Table 2-2 provides the nominal compositions for these two projections. The minor oxide components in the sludge (those oxides present in the sludge that will result in concentrations less than $0.5 \mathrm{wt} \%$ in the glass) were grouped into an "Others" category. The relative contribution of the minor oxide components to the "Others" grouping is the same for the two composition projections, as indicated in Table 2-3.

\footnotetext{
a Personal communication with H. B. Shah, via email, on June 22, 2006 (see WSRC-NB-2006-00017 for details).
} 
Table 2-2. Nominal SB4 Composition Projections and Sludge Composition Space with Traditional EVs Applied.

\begin{tabular}{|c|c|c|}
\hline $\begin{array}{c}\text { Oxide } \\
\text { Component }\end{array}$ & $\begin{array}{c}\text { SB4 Blend-1 } \\
12.2 \mathrm{wt}^{\circ} \text { o solids } \\
0.92 \mathrm{M} \mathrm{Na}^{+} \\
\text {nominal composition }\end{array}$ & $\begin{array}{c}\text { SB4 Blend-1 } \\
12.6 \mathrm{wt}^{\circ} \% \text { solids } \\
0.912 \mathrm{M} \mathrm{Na}^{+} \\
\text {nominal composition }\end{array}$ \\
\hline & $(w t \%)$ & $(w t \%)$ \\
\hline $\mathrm{Al}_{2} \mathrm{O}_{3}$ & 23.617 & 23.831 \\
\hline $\mathrm{CaO}$ & 2.350 & 2.371 \\
\hline $\mathrm{Fe}_{2} \mathrm{O}_{3}$ & 26.017 & 26.253 \\
\hline $\mathrm{MgO}$ & 2.480 & 2.502 \\
\hline $\mathrm{MnO}$ & 5.394 & 5.442 \\
\hline $\mathrm{Na}_{2} \mathrm{O}$ & 23.753 & 23.131 \\
\hline $\mathrm{NiO}$ & 1.545 & 1.559 \\
\hline $\mathrm{SO}_{4}{ }^{2-}$ & 1.417 & 1.368 \\
\hline $\mathrm{SiO}_{2}$ & 3.963 & 3.998 \\
\hline $\mathrm{U}_{3} \mathrm{O}_{8}$ & 7.563 & 7.632 \\
\hline Others & 1.486 & 1.500 \\
\hline
\end{tabular}

Table 2-3. Minor Oxides Included in the Composition of "Others" (in wt\%).

\begin{tabular}{|c|c|c||}
\hline $\begin{array}{c}\text { Oxide Component } \\
\text { in "Others" }\end{array}$ & $\begin{array}{c}\text { SB4 Blend-1 } \\
\mathbf{1 2 . 2} \text { wt\% solids } \\
\mathbf{0 . 9 2} \mathbf{~ M ~ N a}^{+}\end{array}$ & $\begin{array}{c}\text { SB4 Blend-1 } \\
\mathbf{1 2 . 6} \text { wt\% solids } \\
\mathbf{0 . 9 1 2} \mathbf{~ M ~ N a}^{+}\end{array}$ \\
\hline $\mathrm{BaO}$ & 8.335 & 8.335 \\
\hline $\mathrm{Ce}_{2} \mathrm{O}_{3}$ & 10.088 & 10.088 \\
\hline $\mathrm{Cr}_{2} \mathrm{O}_{3}$ & 13.975 & 13.975 \\
\hline $\mathrm{CuO}$ & 4.028 & 4.028 \\
\hline $\mathrm{K}_{2} \mathrm{O}$ & 22.153 & 22.153 \\
\hline $\mathrm{La}_{2} \mathrm{O}_{3}$ & 7.123 & 7.123 \\
\hline $\mathrm{PbO}_{\mathrm{ThO}}$ & 6.099 & 6.099 \\
\hline $\mathrm{TiO}_{2}$ & 4.22 & 4.22 \\
\hline $\mathrm{ZnO}$ & 1.757 & 1.757 \\
\hline $\mathrm{ZrO}$ & 6.576 & 6.576 \\
\hline $\mathrm{Others}$ & 15.645 & 15.645 \\
\hline
\end{tabular}

As seen in Tables 2-2 and 2-3, the two nominal SB4 composition projections are very similar and have relatively high concentrations of $\mathrm{Al}_{2} \mathrm{O}_{3}, \mathrm{Na}_{2} \mathrm{O}$, and $\mathrm{SO}_{4}{ }^{2-}$, and relatively low concentrations of $\mathrm{Fe}_{2} \mathrm{O}_{3}$ (as compared to previous sludge batches processed in DWPF). Based on the minimal differences in composition, the two projections were combined into a single SB4 composition region for the variability study.

A statistical analysis approach was used to optimally select Frit 503-based glasses that cover this SB4 composition region at a series of WLs likely to be processed at DWPF. ${ }^{16}$ The goal was to 
maximize the compositional range studied to adequately address the effect of the potential variation on the applicability of the durability models while limiting the number of glasses to be fabricated in the laboratory. The glass selection process led to the identification of 35 glasses to support the study objectives. Thirty-one glasses were selected from the Frit 503 / SB4 glass compositional region (identified as SB4VS-05 through SB4VS-35 in Table 2-4). In addition, four Frit 418 / SB4 glasses (identified as SB4VS-01 through SB4VS-04 in Table 2-4) were selected using the SB4 centroid composition. The glass compositions selected met all of the DWPF Product Composition Control System (PCCS) Measurement Acceptability Region (MAR) criteria based on their targeted compositions. ${ }^{16}$

\subsection{Target Compositions of Selected Glasses}

The target compositions of the SB4 variability study glasses are presented in Table 2-4. Note that some of the selected glass compositions have $\mathrm{SO}_{4}{ }^{2-}$ concentrations in excess of the $0.60 \mathrm{wt} \%$ limit established previously for SB3 / Frit 418 processing. ${ }^{17}$ This is not seen as a threat to the success of the variability study, but could provide valuable feedback into the $\mathrm{SO}_{4}{ }^{2-}$ retention issue given that uncertainty exists in the projected $\mathrm{SO}_{4}{ }^{2-}$ concentration in SB4. 
Table 2-4. Target Compositions (in wt\%) of the SB4 Variability Study Glasses.

\begin{tabular}{|c|c|c|c|c|c|c|c|c|c|c|c|c|c|c|}
\hline Glass ID & 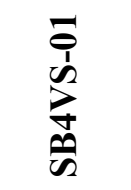 & 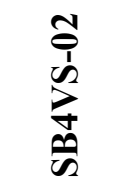 & 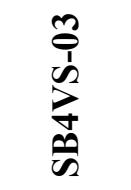 & 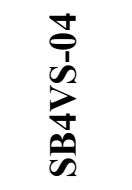 & 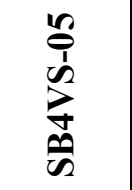 & 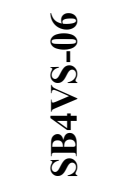 & 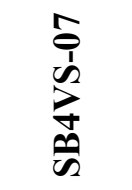 & 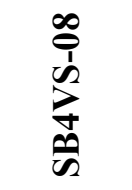 & 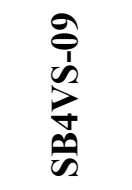 & 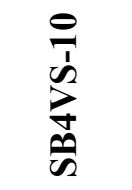 & 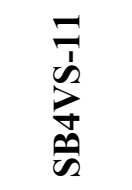 & 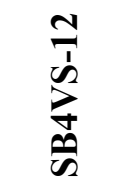 & $\begin{array}{l}\frac{m}{n} \\
\frac{1}{b} \\
\frac{0}{\omega}\end{array}$ & 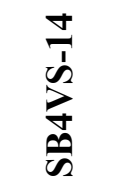 \\
\hline Frit & 418 & 418 & 418 & 418 & 503 & 503 & 503 & 503 & 503 & 503 & 503 & 503 & 503 & 503 \\
\hline WL & 32 & 36 & 40 & 44 & 30 & 34 & 38 & 42 & 46 & 42 & 42 & 40 & 40 & 38 \\
\hline $\mathrm{Al}_{2} \mathrm{O}_{3}$ & 7.631 & 8.585 & 9.539 & 10.493 & 7.154 & 8.108 & 9.062 & 10.016 & 10.970 & 10.047 & 10.422 & 9.926 & 9.926 & 8.709 \\
\hline $\mathrm{B}_{2} \mathrm{O}_{3}$ & 5.440 & 5.120 & 4.800 & 4.480 & 9.800 & 9.240 & 8.680 & 8.120 & 7.560 & 8.120 & 8.120 & 8.400 & 8.400 & 8.680 \\
\hline $\mathrm{BaO}$ & 0.040 & 0.045 & 0.050 & 0.055 & 0.037 & 0.042 & 0.047 & 0.052 & 0.057 & 0.057 & 0.048 & 0.054 & 0.046 & 0.043 \\
\hline $\mathrm{CaO}$ & 0.756 & 0.850 & 0.944 & 1.039 & 0.708 & 0.803 & 0.897 & 0.992 & 1.086 & 1.046 & 0.937 & 0.892 & 0.996 & 0.947 \\
\hline $\mathrm{Ce}_{2} \mathrm{O}_{3}$ & 0.048 & 0.054 & 0.060 & 0.066 & 0.045 & 0.051 & 0.057 & 0.063 & 0.069 & 0.069 & 0.058 & 0.066 & 0.055 & 0.052 \\
\hline $\mathrm{Cr}_{2} \mathrm{O}_{3}$ & 0.067 & 0.075 & 0.084 & 0.092 & 0.063 & 0.071 & 0.079 & 0.088 & 0.096 & 0.095 & 0.080 & 0.091 & 0.076 & 0.073 \\
\hline $\mathrm{CuO}$ & 0.019 & 0.022 & 0.024 & 0.026 & 0.018 & 0.021 & 0.023 & 0.025 & 0.028 & 0.027 & 0.023 & 0.026 & 0.022 & 0.021 \\
\hline $\mathrm{Fe}_{2} \mathrm{O}_{3}$ & 8.407 & 9.458 & 10.509 & 11.560 & 7.882 & 8.933 & 9.984 & 11.035 & 12.086 & 10.604 & 10.604 & 10.408 & 10.611 & 10.013 \\
\hline $\mathrm{K}_{2} \mathrm{O}$ & 0.106 & 0.119 & 0.132 & 0.146 & 0.099 & 0.113 & 0.126 & 0.139 & 0.152 & 0.151 & 0.127 & 0.144 & 0.121 & 0.115 \\
\hline $\mathrm{La}_{2} \mathrm{O}_{3}$ & 0.034 & 0.038 & 0.043 & 0.047 & 0.032 & 0.036 & 0.040 & 0.045 & 0.049 & 0.049 & 0.041 & 0.046 & 0.039 & 0.037 \\
\hline $\mathrm{Li}_{2} \mathrm{O}$ & 5.440 & 5.120 & 4.800 & 4.480 & 5.600 & 5.280 & 4.960 & 4.640 & 4.320 & 4.640 & 4.640 & 4.800 & 4.800 & 4.960 \\
\hline $\mathrm{MgO}$ & 0.797 & 0.897 & 0.997 & 1.096 & 0.748 & 0.847 & 0.947 & 1.047 & 1.146 & 0.992 & 0.992 & 1.049 & 1.049 & 0.897 \\
\hline $\mathrm{MnO}$ & 1.734 & 1.951 & 2.167 & 2.384 & 1.626 & 1.842 & 2.059 & 2.276 & 2.493 & 2.218 & 2.333 & 2.222 & 2.112 & 2.111 \\
\hline $\mathrm{Na}_{2} \mathrm{O}$ & 12.989 & 13.612 & 14.236 & 14.859 & 9.877 & 10.660 & 11.444 & 12.228 & 13.011 & 12.668 & 12.329 & 11.423 & 11.423 & 11.843 \\
\hline $\mathrm{NiC}$ & 0.497 & & 0.621 & 0.683 & 0.466 & 0.528 & & 0.652 & 0.714 & 0.706 & 0.706 & 0.672 & 0.570 & 0.541 \\
\hline $\mathrm{PbO}$ & 0.029 & 0.033 & 0.036 & 0.040 & 0.027 & 0.031 & 0.035 & 0.038 & 0.042 & 0.042 & 0.035 & 0.040 & 0.033 & 0.032 \\
\hline $\mathrm{SO}_{4}{ }^{2-}$ & 0.446 & 0.501 & 0.557 & 0.613 & 0.418 & 0.474 & 0.529 & 0.585 & 0.641 & 0.611 & 0.559 & 0.532 & 0.532 & 0.505 \\
\hline $\mathrm{SiO}_{2}$ & 52.954 & 50.073 & 47.192 & 44.312 & 52.994 & 50.194 & 47.393 & 44.592 & 41.791 & 44.536 & 44.536 & 46.046 & 45.939 & 47.443 \\
\hline $\mathrm{ThO}_{2}$ & 0.020 & 0.023 & 0.025 & 0.028 & 0.019 & 0.021 & 0.024 & 0.027 & 0.029 & 0.029 & 0.024 & 0.027 & 0.023 & 0.022 \\
\hline $\mathrm{TiO}_{2}$ & 0.008 & 0.009 & 0.011 & 0.012 & 0.008 & 0.009 & 0.010 & 0.011 & 0.012 & 0.012 & 0.010 & 0.011 & 0.010 & 0.009 \\
\hline $\mathrm{U}_{3} \mathrm{O}_{8}$ & 2.431 & 2.735 & 3.039 & 3.343 & 2.279 & 2.583 & 2.887 & 3.191 & 3.495 & 3.131 & 3.251 & 2.982 & 3.096 & 2.833 \\
\hline $\mathrm{ZnO}$ & 0.031 & 0.035 & 0.039 & 0.043 & 0.030 & 0.033 & 0.037 & 0.041 & 0.045 & 0.045 & 0.038 & 0.043 & 0.036 & 0.034 \\
\hline $\mathrm{ZrO}_{2}$ & 0.075 & 0.084 & 0.094 & 0.103 & 0.070 & 0.080 & 0.089 & 0.098 & 0.108 & 0.107 & 0.090 & 0.102 & 0.085 & 0.081 \\
\hline
\end{tabular}


Table 2-4. Target Compositions (in wt\%) of the SB4 Variability Study Glasses. (continued)

\begin{tabular}{|c|c|c|c|c|c|c|c|c|c|c|c|c|c|c|}
\hline Glass & $\begin{array}{l}\frac{n}{1} \\
\frac{1}{2} \\
\frac{m}{a}\end{array}$ & $\begin{array}{l}\frac{0}{7} \\
\frac{1}{2} \\
\frac{m}{a}\end{array}$ & $\frac{n}{n}$ & 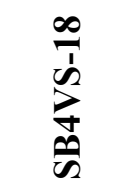 & 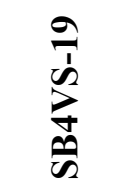 & 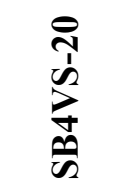 & $\begin{array}{l}\vec{\pi} \\
\frac{\pi}{2} \\
\frac{m}{a}\end{array}$ & 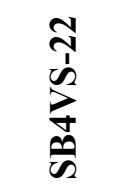 & 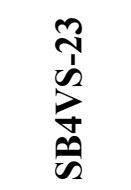 & 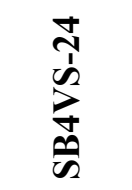 & \begin{tabular}{l}
$n$ \\
$\tilde{n}$ \\
\multirow{2}{*}{} \\
\multirow{2}{*}{}
\end{tabular} & 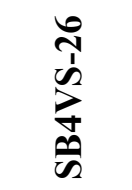 & 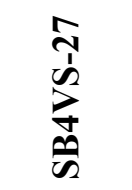 & 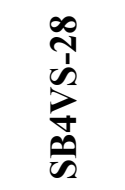 \\
\hline Frit & 503 & 503 & 503 & 503 & 503 & 503 & 503 & 503 & 503 & 503 & 503 & 503 & 503 & 503 \\
\hline WL & 38 & 36 & 36 & 34 & 34 & 32 & 32 & 42 & 40 & 40 & 38 & 38 & 36 & 36 \\
\hline $\mathrm{Al}_{2} \mathrm{O}_{3}$ & 8.709 & 8.250 & 8.933 & 8.036 & 7.792 & 7.516 & 7.941 & 10.820 & 9.286 & 8.788 & 8.696 & 8.348 & 8.821 & 7.909 \\
\hline $\mathrm{B}_{2} \mathrm{O}_{3}$ & 8.680 & 8.960 & 8.960 & 9.240 & 9.240 & 9.520 & 9.520 & 8.120 & 8.400 & 8.400 & 8.680 & 8.680 & 8.960 & 8.960 \\
\hline $\mathrm{BaO}$ & 0.051 & 0.049 & 0.041 & 0.039 & 0.039 & 0.043 & 0.043 & 0.061 & 0.058 & 0.041 & 0.039 & 0.055 & 0.037 & 0.053 \\
\hline $\mathrm{CaO}$ & 0.847 & 0.803 & 0.803 & 0.847 & 0.758 & 0.797 & 0.797 & 0.882 & 1.048 & 1.048 & 0.798 & 0.996 & 0.944 & 0.756 \\
\hline $\mathrm{Ce}_{2} \mathrm{O}_{3}$ & 0.062 & 0.059 & 0.050 & 0.047 & 0.047 & 0.052 & 0.052 & 0.074 & 0.071 & 0.050 & 0.047 & 0.067 & 0.045 & 0.064 \\
\hline $\mathrm{Cr}_{2} \mathrm{O}_{3}$ & 0.086 & 0.082 & 0.069 & 0.065 & 0.065 & 0.073 & 0.073 & 0.103 & 0.098 & 0.069 & 0.066 & 0.093 & 0.062 & 0.088 \\
\hline $\mathrm{CuO}$ & 0.025 & 0.024 & 0.020 & 0.019 & 0.019 & 0.021 & 0.021 & 0.030 & 0.028 & 0.020 & 0.019 & 0.027 & 0.018 & 0.025 \\
\hline $\mathrm{Fe}_{2} \mathrm{O}_{3}$ & 10.388 & 9.588 & 9.700 & 9.294 & 8.825 & 8.748 & 8.079 & 10.165 & 9.681 & 10.571 & 9.197 & 9.644 & 8.713 & 10.217 \\
\hline $\mathrm{K}_{2} \mathrm{O}$ & 0.137 & 0.129 & 0.109 & 0.103 & 0.103 & 0.115 & 0.115 & 0.163 & 0.155 & 0.110 & 0.104 & 0.147 & 0.099 & 0.140 \\
\hline $\mathrm{La}_{2} \mathrm{O}_{3}$ & 0.044 & 0.042 & 0.035 & 0.033 & 0.033 & 0.037 & 0.037 & 0.052 & 0.050 & 0.035 & 0.034 & 0.047 & 0.032 & 0.045 \\
\hline $\mathrm{Li}_{2} \mathrm{O}$ & 4.960 & 5.120 & 5.120 & 5.280 & 5.280 & 5.440 & 5.440 & 4.640 & 4.800 & 4.800 & 4.960 & 4.960 & 5.120 & 5.120 \\
\hline $\mathrm{MgO}$ & 0.897 & 0.944 & 0.850 & 0.892 & 0.892 & 0.756 & 0.839 & 0.937 & 1.101 & 0.892 & 1.046 & 1.046 & 0.803 & 0.991 \\
\hline $\mathrm{MnO}$ & 2.111 & 1.901 & 1.901 & 1.889 & 1.796 & 1.690 & 1.778 & 2.391 & 2.058 & 2.058 & 2.163 & 2.163 & 2.049 & 1.852 \\
\hline $\mathrm{Na}_{2} \mathrm{O}$ & 11.415 & 11.430 & 10.681 & 10.310 & 11.017 & 9.939 & 10.053 & 12.459 & 12.672 & 12.672 & 12.238 & 12.238 & 11.804 & 11.031 \\
\hline $\mathrm{NiO}$ & 0.541 & 0.513 & 0.513 & 0.572 & 0.572 & 0.538 & 0.456 & 0.544 & 0.724 & 0.518 & 0.687 & 0.492 & 0.466 & 0.466 \\
\hline $\mathrm{PbO}$ & 0.038 & 0.036 & 0.030 & 0.028 & 0.028 & 0.032 & 0.032 & 0.045 & 0.043 & 0.030 & 0.029 & 0.041 & 0.027 & 0.038 \\
\hline $\mathrm{SO}_{4}{ }^{2-}$ & 0.553 & 0.479 & 0.524 & 0.495 & 0.495 & 0.426 & 0.466 & 0.533 & 0.507 & 0.507 & 0.577 & 0.482 & 0.546 & 0.546 \\
\hline $\mathrm{SiO}_{2}$ & 47.342 & 48.745 & 48.841 & 50.148 & 50.239 & 51.637 & 51.637 & 44.704 & 46.099 & 46.099 & 47.494 & 47.291 & 48.697 & 48.889 \\
\hline $\mathrm{ThO}_{2}$ & 0.026 & 0.025 & 0.021 & 0.020 & 0.020 & 0.022 & 0.022 & 0.031 & 0.030 & 0.021 & 0.020 & 0.028 & 0.019 & 0.027 \\
\hline $\mathrm{TiO}_{2}$ & 0.011 & 0.010 & 0.009 & 0.008 & 0.008 & 0.009 & 0.009 & 0.013 & 0.012 & 0.009 & 0.008 & 0.012 & 0.008 & 0.011 \\
\hline $\mathrm{U}_{3} \mathrm{O}_{8}$ & 2.941 & 2.684 & 2.684 & 2.535 & 2.632 & 2.477 & 2.477 & 3.072 & 2.925 & 3.153 & 2.995 & 2.995 & 2.633 & 2.633 \\
\hline $\mathrm{ZnO}$ & 0.041 & 0.038 & 0.032 & 0.031 & 0.031 & 0.034 & 0.034 & 0.048 & 0.046 & 0.033 & 0.031 & 0.044 & 0.029 & 0.041 \\
\hline $\mathrm{ZrO}_{2}$ & 0.096 & 0.091 & 0.077 & 0.073 & 0.073 & 0.081 & 0.081 & 0.115 & 0.110 & 0.077 & 0.074 & 0.104 & 0.070 & 0.099 \\
\hline
\end{tabular}


Table 2-4. Target Compositions (in wt\%) of the SB4 Variability Study Glasses. (continued)

\begin{tabular}{|c|c|c|c|c|c|c|c|}
\hline Glass ID & 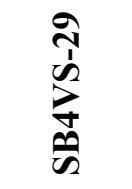 & 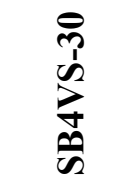 & $\begin{array}{l}\vec{p} \\
\dot{n} \\
\vec{b} \\
\overrightarrow{0}\end{array}$ & 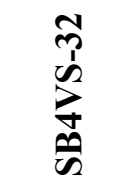 & 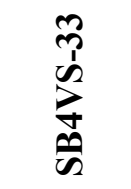 & 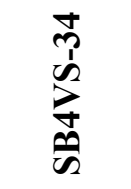 & 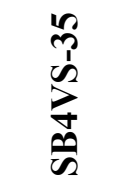 \\
\hline Frit & 503 & 503 & 503 & 503 & 503 & 503 & 503 \\
\hline WL & 34 & 34 & 32 & 40 & 38 & 36 & 34 \\
\hline $\mathrm{Al}_{2} \mathrm{O}_{3}$ & 8.151 & 7.470 & 7.030 & 8.400 & 9.880 & 9.360 & 7.140 \\
\hline $\mathrm{B}_{2} \mathrm{O}_{3}$ & 9.240 & 9.240 & 9.520 & 8.400 & 8.680 & 8.960 & 9.240 \\
\hline $\mathrm{BaO}$ & 0.050 & 0.035 & 0.047 & 0.067 & 0.032 & 0.030 & 0.057 \\
\hline $\mathrm{CaO}$ & 0.714 & 0.714 & 0.839 & 1.200 & 1.140 & 0.720 & 0.680 \\
\hline $\mathrm{Ce}_{2} \mathrm{O}_{3}$ & 0.060 & 0.042 & 0.057 & 0.081 & 0.038 & 0.036 & 0.069 \\
\hline $\mathrm{Cr}_{2} \mathrm{O}_{3}$ & 0.083 & 0.059 & 0.078 & 0.112 & 0.053 & 0.050 & 0.095 \\
\hline $\mathrm{CuO}$ & 0.024 & 0.017 & 0.023 & 0.032 & 0.015 & 0.015 & 0.027 \\
\hline $\mathrm{Fe}_{2} \mathrm{O}_{3}$ & 8.229 & 9.650 & 9.082 & 10.800 & 9.120 & 10.080 & 8.500 \\
\hline $\mathrm{K}_{2} \mathrm{O}$ & 0.132 & 0.093 & 0.124 & 0.177 & 0.084 & 0.080 & 0.151 \\
\hline $\mathrm{La}_{2} \mathrm{O}_{3}$ & 0.042 & 0.030 & 0.040 & 0.057 & 0.027 & 0.026 & 0.048 \\
\hline $\mathrm{Li}_{2} \mathrm{O}$ & 5.280 & 5.280 & 5.440 & 4.800 & 4.960 & 5.120 & 5.280 \\
\hline $\mathrm{MgO}$ & 0.758 & 0.758 & 0.714 & 0.800 & 1.140 & 1.080 & 0.680 \\
\hline $\mathrm{MnO}$ & 1.749 & 1.935 & 1.821 & 2.000 & 2.280 & 1.800 & 2.040 \\
\hline $\mathrm{Na}_{2} \mathrm{O}$ & 11.371 & 10.898 & 9.728 & 12.800 & 10.460 & 10.120 & 11.480 \\
\hline $\mathrm{NiO}$ & 0.615 & 0.615 & 0.579 & 0.800 & 0.760 & 0.360 & 0.340 \\
\hline $\mathrm{PbO}$ & 0.036 & 0.026 & 0.034 & 0.049 & 0.023 & 0.022 & 0.042 \\
\hline $\mathrm{SO}_{4}{ }^{2-}$ & 0.516 & 0.431 & 0.485 & 0.800 & 0.760 & 0.720 & 0.680 \\
\hline $\mathrm{SiO}_{2}$ & 50.102 & 50.102 & 51.679 & 45.600 & 47.780 & 48.440 & 50.540 \\
\hline $\mathrm{ThO}_{2}$ & 0.025 & 0.018 & 0.024 & 0.034 & 0.016 & 0.015 & 0.029 \\
\hline $\mathrm{TiO}_{2}$ & 0.011 & 0.007 & 0.010 & 0.014 & 0.007 & 0.006 & 0.012 \\
\hline $\mathrm{U}_{3} \mathrm{O}_{8}$ & 2.680 & 2.486 & 2.522 & 2.800 & 2.660 & 2.880 & 2.720 \\
\hline $\mathrm{ZnO}$ & 0.039 & 0.028 & 0.037 & 0.053 & 0.025 & 0.024 & 0.045 \\
\hline $\mathrm{ZrO}_{2}$ & 0.093 & 0.066 & 0.088 & 0.125 & 0.060 & 0.056 & 0.106 \\
\hline
\end{tabular}




\subsection{Glass Fabrication}

Each variability study glass was prepared from the proper proportions of reagent-grade metal oxides, carbonates, $\mathrm{H}_{3} \mathrm{BO}_{3}$, and salts in $150 \mathrm{~g}$ batches. ${ }^{18}$ The raw materials were thoroughly mixed and placed into a $95 \%$ platinum / $5 \%$ gold, $250 \mathrm{ml}$ crucible. The batch was placed into a high-temperature furnace at the target melt temperature of $1150^{\circ} \mathrm{C} .{ }^{19}$ The crucible was removed from the furnace after an isothermal hold at $1150^{\circ} \mathrm{C}$ for 1 hour. The glass was poured onto a clean, stainless steel plate and allowed to air cool (quench). The glass pour patty was used as a sampling stock for the various property measurements (i.e., chemical composition and durability testing).

Approximately $25 \mathrm{~g}$ of each glass was heat-treated to simulate cooling along the centerline of a DWPF-type canister ${ }^{20}$ to gauge the effects of thermal history on the product performance. This cooling schedule is referred to as the ccc curve. Visual observations on both quenched and ccc glasses were documented. ${ }^{\mathrm{a}}$

\subsection{Property Measurements}

This section provides a general discussion of the chemical composition analyses, the PCTs, and the XRD analyses of the SB4 VS glasses.

\subsubsection{Compositional Analysis}

To confirm that the as-fabricated glasses met the target compositions, a representative sample from each glass was submitted to the SRNL Process Science Analytical Laboratory (PSAL) for chemical analysis under the auspices of an analytical plan. The plan (see Appendix A) identified the cations to be analyzed and the dissolution techniques (i.e., sodium peroxide fusion $[\mathrm{PF}]$ and lithium-metaborate $[\mathrm{LM}]$ ) to be used. The samples prepared by LM were used to measure for barium $(\mathrm{Ba})$, calcium $(\mathrm{Ca})$, cerium $(\mathrm{Ce})$, chromium $(\mathrm{Cr})$, copper $(\mathrm{Cu})$, potassium $(\mathrm{K})$, lanthanum $(\mathrm{La})$, magnesium $(\mathrm{Mg})$, sodium $(\mathrm{Na})$, lead $(\mathrm{Pb})$, sulfur $(\mathrm{S})$, thorium $(\mathrm{Th})$, titanium $(\mathrm{Ti})$, zinc $(\mathrm{Zn})$, and zirconium $(\mathrm{Zr})$ concentrations. Samples prepared by PF were used to measure for aluminum $(\mathrm{Al})$, boron $(\mathrm{B})$, iron $(\mathrm{Fe})$, lithium $(\mathrm{Li})$, manganese $(\mathrm{Mn})$, nickel $(\mathrm{Ni})$, silicon $(\mathrm{Si})$, and uranium (U) concentrations. Each glass was prepared in duplicate for each cation dissolution technique (PF and LM). All of the prepared samples were analyzed (twice for each element of interest) by Inductively Coupled Plasma - Atomic Emission Spectroscopy (ICP-AES) with the instrumentation being re-calibrated between the duplicate analyses. The analytical plan was developed in such a way as to provide the opportunity to evaluate potential sources of bias and error. Glass standards were also intermittently measured to assess the performance of the ICPAES instrument over the course of these analyses.

\subsubsection{Sulfate Solubility}

Sulfate retention is a secondary interest in this study. The applicability of the current $0.6 \mathrm{wt} \%$ $\mathrm{SO}_{4}{ }^{2-}$ limit (established for the Frit $418-\mathrm{SB} 3 \mathrm{system}^{17}$ ) to SB4 was investigated. From Table 2-4, the targeted $\mathrm{SO}_{4}{ }^{2-}$ concentrations in the variability study glasses range from 0.42 to $0.80 \mathrm{wt} \%$. Since the variability study glasses cover a range of $\mathrm{SO}_{4}{ }^{2-}$ concentrations (some exceeding the current PCCS limit), the ability of the glasses to retain the targeted $\mathrm{SO}_{4}{ }^{2-}$ concentrations will provide valuable insight into the applicability of the $\mathrm{SO}_{4}{ }^{2-}$ limit to $\mathrm{SB} 4$. Both visual observations (i.e., formation of a salt layer on the surface of the glass indicating that the $\mathrm{SO}_{4}{ }^{2-}$ limit has been

\footnotetext{
${ }^{\text {a } W S R C-N B-2004-00135}$ contains the visual observations of the quenched and ccc glasses.
} 
exceeded) and a comparison of measured versus targeted $\mathrm{SO}_{4}{ }^{2-}$ concentrations were used to support this assessment.

\subsubsection{Product Consistency Test (PCT)}

The $\mathrm{PCT}^{13}$ was performed in triplicate on each quenched and ccc glass to assess chemical durability. Also included in the experimental test matrix was the Environmental Assessment (EA) glass, ${ }^{21}$ the Approved Reference Material (ARM) glass, and blanks from the sample cleaning batch. Samples were ground, washed, and prepared according to the standard procedure. ${ }^{13}$ Fifteen milliliters of Type I American Society for Testing and Materials (ASTM) water were added to $1.5 \mathrm{~g}$ of glass in stainless steel vessels. The vessels were closed, sealed, and placed in an oven at $90 \pm 2{ }^{\circ} \mathrm{C}$ where the samples were maintained at temperature for 7 days. Once cooled, the resulting solutions were sampled (filtered and acidified), then labeled and analyzed by PSAL under the auspices of three analytical plans (see Appendices B, C and D). ${ }^{\mathrm{a}}$ The aim of the plans was to provide an opportunity to assess the consistency (repeatability) of the PCT and analytical procedures in evaluating the chemical durability of the glasses. Normalized release rates were calculated based on target, measured, and bias-corrected (bc) compositions using the average of the logs of the leachate concentrations.

\subsubsection{X-Ray Diffraction Analysis}

Although visual observations for crystallization were performed and documented, representative samples for all ccc glasses were submitted to SRNL Analytical Development (AD) for X-ray diffraction (XRD) analysis. Based on both visual observations and PCT responses (as will be discussed), there was no technical driver to submit the quenched samples for XRD analysis. Samples were run under conditions providing a detection limit of approximately $0.5 \mathrm{vol} \%$. That is, if crystals (or undissolved solids) were present at $0.5 \mathrm{vol} \%$ or greater, the diffractometer would not only be capable of detecting the crystals but would also allow a qualitative determination of the type of crystal(s) present. Otherwise, a characteristically high background devoid of crystalline spectral peaks indicates that the glass product is amorphous, suggesting either a completely amorphous product or that the degree of crystallization is below the detection limit.

\footnotetext{
a Analyses of the PCT solutions were divided into three sets due to the large number of glasses studied and limitations in the amount of laboratory equipment available.
} 
WSRC-STI-2006-00204

Revision 0

\subsection{Results and Discussion}

\subsection{A Statistical Review of the Chemical Composition Measurements of the SB4 Variability Study Glasses}

In this section, the targeted and measured compositions of the 35 SB4 variability study glasses are presented and compared. The targeted compositions for these glasses are provided in Table E1 of Appendix E. A sum of oxides column is provided in this table as well. Chemical composition measurements for these glasses were conducted by the PSAL following the analytical plan provided in Appendix A. For each study glass, measurements were obtained from samples prepared in duplicate by both the LM and PF dissolution methods. All of the prepared samples were analyzed (twice for each element of interest) by ICP-AES.

Table E2 in Appendix E provides the elemental concentration measurements derived from the samples prepared using LM, and Table E3 in Appendix E provides the measurements derived from the samples prepared using PF. Measurements for standards (Batch 1 and a uranium standard, $\mathrm{U}_{\mathrm{std}}$ ) that were included in the PSAL analytical plan along with the study glasses are also provided in these two tables.

The elemental concentrations were converted to oxide concentrations by multiplying the values for each element by the gravimetric factor for the corresponding oxide. During this process, an elemental concentration that was determined to be below the detection limit of the analytical procedures used by the PSAL was reduced to half of that detection limit as the oxide concentration was determined.

In the sections that follow, the analytical sequences of the measurements are explored, the measurements of the standards are investigated and used for bias correction, the measurements for each glass are reviewed, the average chemical compositions (measured and bias-corrected) for each glass are determined, and comparisons are made between the measured and the targeted compositions of the glasses.

\subsubsection{Measurements in Analytical Sequence}

Exhibit E1 in Appendix E provides plots of the measurements generated by the PSAL for samples prepared using the LM method. The plots are in analytical sequence with different symbols and colors being used to represent each of the study and standard glasses. Similar plots for the samples prepared using the PF method are provided in Exhibit E2 in Appendix E. These plots include all of the measurement data from Tables E2 and E3. A review of these plots indicates no significant patterns or trends in the analytical process over the course of these measurements. No obvious outliers are apparent in the chemical composition measurements.

\subsubsection{Batch 1 and Uranium Standard Results}

In this section, the PSAL measurements of the chemical compositions of the Batch 1 and uranium standard $\left(\mathrm{U}_{\text {std }}\right)$ glasses are reviewed. These measurements are investigated across the ICP-AES analytical blocks, and the results are used to bias correct the measurements for the study glasses.

Exhibit E3 in Appendix E provides statistical analyses of the Batch 1 and $\mathrm{U}_{\text {std }}$ results generated by the LM prep method by block/sub-block for each oxide of interest. The results include analysis of variance (ANOVA) investigations looking for statistically significant differences 
between the means of these groups for each of the oxides for each of the standards. The results from the statistical tests for the Batch 1 standard may be summarized as follows: $\mathrm{BaO}, \mathrm{CaO}$, $\mathrm{Cr}_{2} \mathrm{O}_{3}, \mathrm{CuO}, \mathrm{MgO}, \mathrm{TiO}_{2}$, and $\mathrm{ZrO}_{2}$ have measurements that indicate a significant ICP-AES calibration effect on the block averages at the 5\% significance level. For the $\mathrm{U}_{\text {std }}, \mathrm{CaO}, \mathrm{Cr}_{2} \mathrm{O}_{3}$, $\mathrm{CuO}, \mathrm{MgO}$, and $\mathrm{TiO}_{2}$ have measurements that indicate a significant ICP-AES calibration effect on the block averages at the 5\% significance level. The reference values for the oxide concentrations of the standard are given in the header for each set of measurements in the exhibit.

Exhibit E4 in Appendix E provides a similar set of analyses for the measurements derived from samples prepared via the PF method. The results from the statistical tests for the Batch 1 standard may be summarized as follows: $\mathrm{Li}_{2} \mathrm{O}, \mathrm{NiO}$ and $\mathrm{SiO}_{2}$ have measurements that indicate significant ICP-AES calibration effects on the block averages at the 5\% significance level. For the $\mathrm{U}_{\text {std }}$, none of the oxides have measurements that indicate a significant ICP-AES calibration effect on the block averages at the 5\% significance level. The reference values for the oxide concentrations of the standard are given in the headers for each set of measurements in the exhibit.

Thus, some of these results provide incentive for adjusting the measurements by the effects of the ICP-AES calibration. Therefore, the oxide measurements of the study glasses are to be bias corrected for the effect of the ICP-AES calibration on each of the analytical blocks and subblocks. The basis for this bias correction is presented as part of Exhibits $\mathrm{E} 3$ and E4: the average measurement for Batch 1 for each ICP-AES block/sub-block for the $\mathrm{Al}_{2} \mathrm{O}_{3}, \mathrm{~B}_{2} \mathrm{O}_{3}, \mathrm{BaO}, \mathrm{CaO}$, $\mathrm{Cr}_{2} \mathrm{O}_{3}, \mathrm{CuO}, \mathrm{Fe}_{2} \mathrm{O}_{3}, \mathrm{Li}_{2} \mathrm{O}, \mathrm{MgO}, \mathrm{MnO}, \mathrm{Na}_{2} \mathrm{O}, \mathrm{NiO}, \mathrm{SiO}_{2}$, and $\mathrm{TiO}_{2}$ concentrations and the average measurement for $\mathrm{U}_{\text {std }}$ for each ICP-AES set/block for the $\mathrm{U}_{3} \mathrm{O}_{8}$ concentration. The Batch 1 results served as the basis for bias correcting all of the oxides (that were bias corrected) except uranium. The $\mathrm{U}_{\text {std }}$ results were used to bias correct for uranium. For the other oxides, the Batch 1 results were used to conduct the bias correction as long as the reference value for the oxide concentration in the Batch 1 glass was greater than or equal to $0.1 \mathrm{wt} \%$. Thus, applying this approach and based upon the information in the exhibits, the Batch 1 results were used to bias correct the $\mathrm{Al}_{2} \mathrm{O}_{3}, \mathrm{~B}_{2} \mathrm{O}_{3}, \mathrm{BaO}, \mathrm{CaO}, \mathrm{Cr}_{2} \mathrm{O}_{3}, \mathrm{CuO}, \mathrm{Fe}_{2} \mathrm{O}_{3}, \mathrm{~K}_{2} \mathrm{O}, \mathrm{Li}_{2} \mathrm{O}, \mathrm{MgO}, \mathrm{MnO}, \mathrm{Na}_{2} \mathrm{O}, \mathrm{NiO}$, $\mathrm{SiO}_{2}$, and $\mathrm{TiO}_{2}$ measurements. No bias correction was conducted for the $\mathrm{Ce}_{2} \mathrm{O}_{3}, \mathrm{La}_{2} \mathrm{O}_{3}, \mathrm{PbO}$, $\mathrm{SO}_{4}{ }^{2-}, \mathrm{ThO}_{2}, \mathrm{ZnO}$, or $\mathrm{ZrO}_{2}$ measurements.

The bias correction was conducted as follows: For each oxide, let $\bar{a}_{i j}$ be the average measurement for the $i^{\text {th }}$ oxide at analytical block $j$ for Batch 1 (or $\mathrm{U}_{\text {std }}$ for uranium), and let $t_{i}$ be the reference value for the $i^{\text {th }}$ oxide for Batch 1 (or for $\mathrm{U}_{\text {std }}$ if uranium). The averages and reference values are provided in Exhibits E3 and E4. Let $\bar{c}_{i j k}$ be the average measurement for the $i^{\text {th }}$ oxide at analytical block $j$ for the $k^{\text {th }}$ glass. The bias adjustment was conducted as follows:

$$
\bar{c}_{i j k} \bullet\left(1-\frac{\bar{a}_{i j}-t_{i}}{\bar{a}_{i j}}\right)=\bar{c}_{i j k} \bullet \frac{t_{i}}{\bar{a}_{i j}}
$$

Bias-corrected measurements are indicated by a "bc" suffix. Both measured and measured-bc values are included in the discussion that follows. In these discussions, bias-corrected values for $\mathrm{Ce}_{2} \mathrm{O}_{3}, \mathrm{La}_{2} \mathrm{O}_{3}, \mathrm{PbO}, \mathrm{SO}_{4}{ }^{2-}, \mathrm{ThO}_{2}, \mathrm{ZnO}$, and $\mathrm{ZrO}_{2}$ are included for completeness (e.g., to allow a sum of oxides to be computed for the bias-corrected results). However, these bias-corrected values are the same as the original, measured $\mathrm{Ce}_{2} \mathrm{O}_{3}, \mathrm{La}_{2} \mathrm{O}_{3}, \mathrm{PbO}, \mathrm{SO}_{4}{ }^{2-}, \mathrm{ThO}_{2}, \mathrm{ZnO}$, and $\mathrm{ZrO}_{2}$ values. 


\subsubsection{Composition Measurements by Glass Number}

Exhibits E5 and E6 in Appendix E provide plots of the oxide concentration measurements by Glass ID (including Batch 1, labeled as glass number 100, $\mathrm{U}_{\text {std }}$, labeled as glass number 200, and LRM, labeled as glass number 300) for the measured and bias-corrected values for the LM and PF preparation methods, respectively. Different symbols and colors are used to represent the different glasses. These plots show the individual measurements across the duplicates of each preparation method and the two ICP-AES calibrations. A review of the plots presented in these exhibits reveals good repeatability of the four individual, oxide values for each glass. There appears to be a good bit of scatter in the $\mathrm{SiO}_{2}$ value, and some of the replicate $\mathrm{ThO}_{2}$ measurements for some of the study glasses are significantly lower than the other measurements. There is some scatter in the $\mathrm{ZnO}_{2}$ values for glass SB4VS-09. These issues will not have a significant effect on the outcome of the variability study (i.e., the applicability of the durability models to the frit - SB4 compositional region of interest will be addressed via all three compositional views - target, measured, and measured-biased corrected).

\subsubsection{Measured versus Targeted Compositions}

The four measurements for each oxide for each glass (over both preparation methods) were averaged to determine a representative chemical composition for each glass. These determinations were conducted both for the measured and for the bias-corrected data. A sum of oxides was also computed for each glass based upon both the measured and bias-corrected values. Exhibit E7 in Appendix E provides plots showing results for each glass for each oxide to help highlight the comparisons among the measured, bias-corrected, and targeted values.

Some observations from the plots of Exhibit E7 are offered: For nearly every SB4 variability study glass except SB4VS-02, the average measured and measured-bc $\mathrm{Al}_{2} \mathrm{O}_{3}$ values are above the targeted values. Several of the glasses have measured and measured-bc $\mathrm{CaO}$ values that are above the targeted values. The average measured $\mathrm{Fe}_{2} \mathrm{O}_{3}$ and $\mathrm{NiO}$ values are less than their respective targeted concentrations for nearly every glass. Concentrations of $\mathrm{ThO}_{2}$ for each glass are slightly higher than the targeted values. The $\mathrm{SO}_{4}{ }^{2-}$ concentrations will be discussed in further detail below. These variations from the target compositions are relatively minor and should not have a significant effect on the outcome of the variability study.

Table E4 in Appendix E provides a summary of the average compositions as well as the targeted compositions and some associated differences and relative differences. Notice that the targeted sums of oxides for the standard glasses do not sum to $100 \%$ due to an incomplete coverage of the oxides in the Batch 1 (glass \# 100) and $U_{\text {std }}$ (glass \# 200) glasses. All of the sums of oxides (both measured and bias-corrected) for the study glasses fall within the interval of 95 to $105 \mathrm{wt} \%$. Entries in Table E4 show the relative differences between the measured or bias-corrected values and the targeted values. These differences are shaded when they are greater than or equal to 5\%. Overall, these comparisons between the measured and targeted compositions suggest only minor difficulties in attaining the targeted compositions for some of the oxides for some of the glasses, none of which should have a significant effect on the results of the variability study.

\subsubsection{Assessment of Sulfate Values}

Figure 3-1 provides a pair of plots of the $\mathrm{SO}_{4}{ }^{2-}$ values evaluated in this study. Part A shows the individual measurements by Glass ID (including the multiple measurements of the LRM glass labeled as 300). Part $\mathrm{B}$ shows the average measured value versus the targeted $\mathrm{SO}_{4}{ }^{2-}$ concentration for each of the variability study glasses as well as samples of the LRM glass (LRM-01 through LRM-08). From Table E4, the average $\mathrm{SO}_{4}{ }^{2-}$ value for the LRM glass samples is $0.23 \mathrm{wt} \%$, which is only $0.01 \mathrm{wt} \%$ (or $4.2 \%$ ) below the reference value for $\mathrm{SO}_{4}{ }^{2-}$ of $0.24 \mathrm{wt} \%$ for this 
WSRC-STI-2006-00204

Revision 0

glass. ${ }^{22}$ This suggests that the preparation method and analytical data should provide a relatively accurate measurement of the $\mathrm{SO}_{4}{ }^{2-}$ retention for the variability study glasses.

Part A: Variability Chart for Individual $\mathrm{SO}_{4}{ }^{2-}(\mathrm{wt} \%)$ Measurements by Glass \# and ID

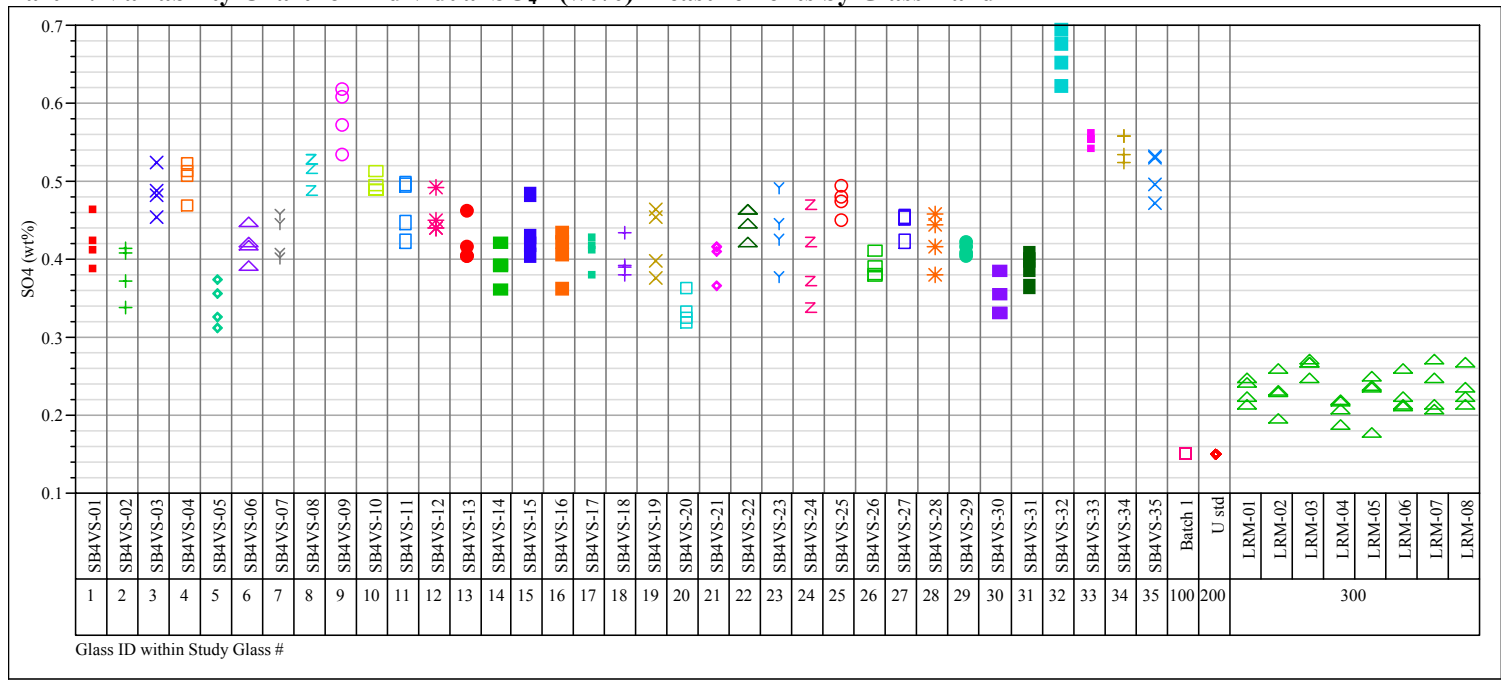

Part B: Overlay Plot of Average $\mathrm{SO}_{4}{ }^{2-}$ (wt\%) Concentrations by Glass ID

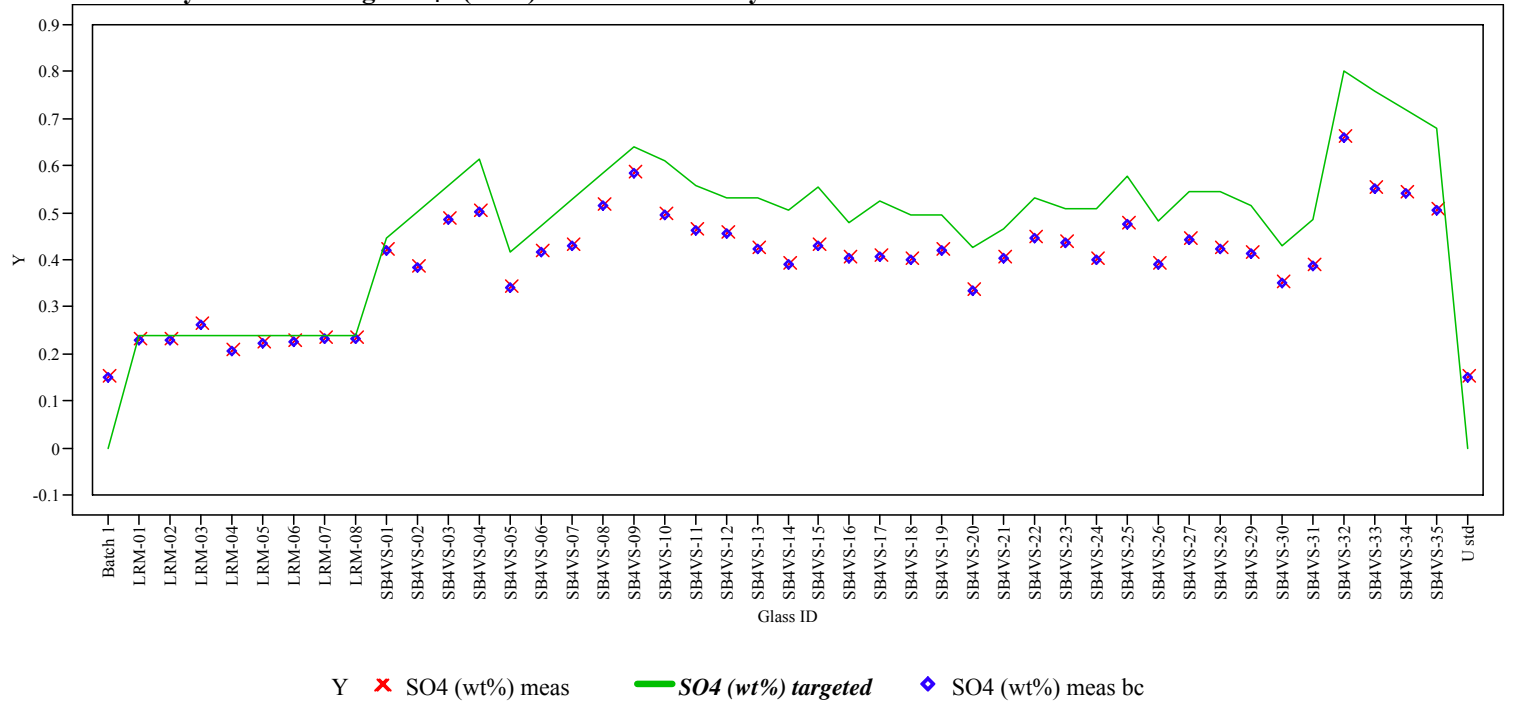

(100 - Batch 1; 200 - Ustd; and 300 - LRM)

Figure 3-1. Measured Sulfate Values for the Variability Study Glasses by Glass Number

For all of the study glasses (SB4VS-01 through SB4VS-35), the average measured $\mathrm{SO}_{4}{ }^{2-}$ values fall below the targeted concentrations. From Table E4, the percent differences range from a low of $5.8 \%$ for SB4VS-01 to a high of $27.6 \%$ for SB4VS-33. Given the results of the LRM analyses, the probability of the measured $\mathrm{SO}_{4}{ }^{2-}$ values for the study glasses being biased low is remote. Therefore, the difference between target and measured $\mathrm{SO}_{4}{ }^{2-}$ concentrations is most likely due to volatilization during melting. This difference has been observed in past experiments with opencrucible melts in the laboratory in the SB4 system. ${ }^{8,9,11}$ Note that sulfate volatility from a slurryfed melter has been estimated to be $40-70 \%{ }^{23}$ Previous work has also indicated that as melting 
conditions become more reducing (as is found in the melter at DWPF), sulfur volatility is expected to increase, with sulfur volatilizing primarily as $\mathrm{SO}_{2}$ rather than $\mathrm{Na}_{2} \mathrm{SO}_{4}$ vapor. ${ }^{23}$ Therefore, the oxidizing fabrication conditions used in this study should help to reduce volatility (i.e., the percent differences in sulfate concentration due to volatility are lower than those expected during actual DWPF melter operation) and be conservative with regard to the amount of sulfate volatility expected at DWPF.

Figure 3-2 provides a closer look at the measured versus targeted $\mathrm{SO}_{4}{ }^{2-}$ values for the 35 study glasses. If the measured values showed a full recovery of the targeted $\mathrm{SO}_{4}{ }^{2-}$ values, the plotted points would fall along the diagonal line of the plot. However, as seen Figure 3-1 Part B above, the measured values consistently fall below the diagonal line. The results of Figure 3-2 indicate that, on average, the measured values are equal to $\sim 81 \%$ of their targets.

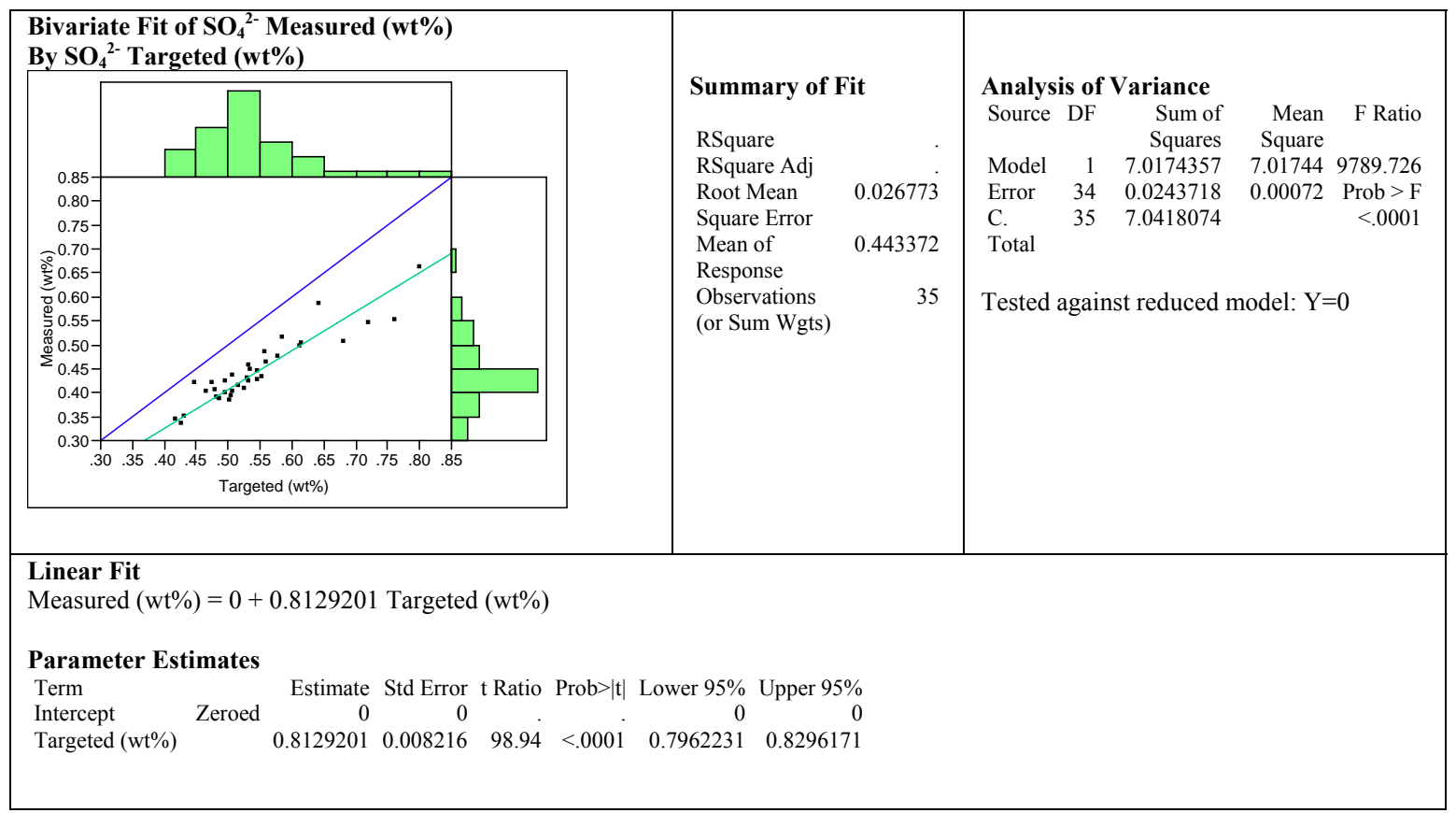

Figure 3-2. Measured versus Targeted Sulfate Concentration for Study Glasses

Note that some of the variability study glasses targeted $\mathrm{SO}_{4}{ }^{2-}$ concentrations above the limit of

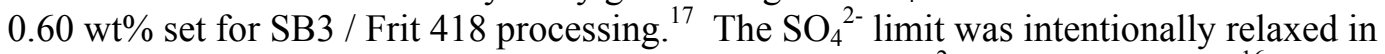
selecting the variability study glasses to further evaluate $\mathrm{SO}_{4}{ }^{2-}$ retention for SB4. ${ }^{16}$ For example, SB4VS-32 had the highest targeted $\mathrm{SO}_{4}{ }^{2-}$ concentration at $0.80 \mathrm{wt} \%$ and returned a measured value of $0.659 \mathrm{wt} \% \mathrm{SO}_{4}{ }^{2-}$ (well above the $0.6 \mathrm{wt} \%$ PCCS limit). As will be discussed in Section 3.4, there was no sign of a salt layer on the surface of this glass. In fact, none of the study glasses had a visible salt layer on the surface. Five other SB4VS glasses $(-04,-09,-33,-34$, and 35 ) had targeted $\mathrm{SO}_{4}{ }^{2-}$ concentrations above the $0.6 \mathrm{wt} \%$ limit $(0.61,0.64,0.76,0.72$, and 0.68 $\mathrm{wt} \%$, respectively). Based on the measured values, $\mathrm{SO}_{4}{ }^{2-}$ retention in these glasses ranged from $0.50-0.58 \mathrm{wt} \%$. It should be noted that $\mathrm{SO}_{4}{ }^{2-}$ solubility or retention is a function of overall glass composition, so the variation in the percentage retained is not surprising. 
Based on the nominal compositions of the two projected sludges that formed the basis of this study, WLs of approximately $42 \%$ to $44 \%$ would be required to exceed the $0.6 \mathrm{wt} \% \mathrm{SO}_{4}{ }^{2-}$ limit currently defined in PCCS. This being the case, the likelihood of DWPF challenging the current $0.6 \mathrm{wt} \%$ limit is remote as other factors such as melt rate or waste throughput will be more restrictive in targeting higher WLs. If WLs of $42 \%$ or higher are desired, then the $0.6 \mathrm{wt} \%$ limit would become a limiting constraint. The $42 \%$ WL limit does not account for the volatilization that has been observed in the crucible scale studies supporting this task as well as (and perhaps more importantly) in actual melter tests. ${ }^{23}$

\subsection{MAR Assessment of SB4 Variability Study Glasses}

Another assessment that can be made for these SB4 variability study glasses is how well they satisfy the MAR criteria of DWPF's PCCS. All of the glasses that were selected for this study satisfied these criteria. That is, the targeted composition for each of these glasses fell within the MAR of PCCS. ${ }^{16}$ In this section, the results of the MAR assessment of the measured and measured bias-corrected compositions for these glasses are presented along with the results for the targeted compositions. Table 3-1 provides this information. The columns in the table give the WL (in wt $\%$ ), the frit identifier, the glass identifier with compositional view, the $\Delta \mathrm{G}_{\mathrm{P}}$ value for boron (B $\Delta \mathrm{G}_{\mathrm{P}}$ Value), the normalized leachate for boron (NL[B $\left.(\mathrm{g} / \mathrm{L})\right]$ ), the liquidus temperature prediction $\left(\mathrm{T}_{\mathrm{L}}\right.$ Pred $\left({ }^{\circ} \mathrm{C}\right)$ ), the viscosity prediction (Visc Pred $(\mathrm{P})$ ), the sum of oxides (in $\mathrm{wt} \%$ ), the $\mathrm{Al}_{2} \mathrm{O}_{3}$ concentration (in $\mathrm{wt} \%$ ), the $\mathrm{Na}_{2} \mathrm{SO}_{4}$ concentration (in wt $\%$ ), the total alkali concentration $\left(\mathrm{R}_{2} \mathrm{O}\right.$, in wt\%), the nepheline discriminator value, and the overall MAR assessment excluding any limitation on $\mathrm{Na}_{2} \mathrm{SO}_{4}$. A blank entry in this last column indicates that the glass satisfies all of the MAR criteria. The only glass that does not satisfy all of the MAR criteria is SB4VS-09, based on the measured composition view. The measured composition of this glass fails the MAR criterion for the nepheline discriminator and therefore would be classified as an unacceptable glass during DWPF PCCS Slurry Mix Evaporator (SME) acceptability decisions. The nepheline discriminator value for SB4VS-09 is 0.619, which also does not satisfy the nepheline discriminator Property Acceptability Region (PAR) of 0.620. All of the other results for these glasses indicate that they would pass the PCCS MAR and be deemed processable by and acceptable for the DWPF. 
Table 3-1. Results of MAR Assessment of SB4 Variability Study Glasses for Measured, Bias-Corrected, and Targeted Compositional Views.

\begin{tabular}{|c|c|c|c|c|c|c|c|c|c|c|c|c|}
\hline$\% W L$ & Frit & $\begin{array}{c}\text { Glass ID/ } \\
\text { Compositional View }\end{array}$ & $\begin{array}{l}\mathbf{B} \Delta \mathbf{G}_{\mathbf{P}} \\
\text { Value }\end{array}$ & $\mathbf{N L}[B(g / L)]$ & $\begin{array}{c}T_{L} \text { Pred } \\
\left({ }^{\circ} \mathrm{C}\right)\end{array}$ & $\begin{array}{c}\text { Visc Pred } \\
\text { (P) }\end{array}$ & $\begin{array}{l}\text { Sum of } \\
\text { Oxides }\end{array}$ & $\begin{array}{l}\mathrm{Al}_{2} \mathrm{O}_{3} \\
\mathrm{wt} \% \\
\end{array}$ & $\begin{array}{c}\mathrm{Na}_{2} \mathrm{SO}_{4} \\
\mathrm{wt} \% \\
\end{array}$ & $\begin{array}{r}R_{2} O \\
w t \% \\
\end{array}$ & $\begin{array}{c}\text { Nepheline } \\
\text { Discriminator }\end{array}$ & MAR Status w/o $\mathrm{Na}_{2} \mathrm{SO}_{4}$ \\
\hline 32 & 418 & SB4VS-01/measured & -10.395 & 0.96 & 821.7 & 63.78 & 98.94 & 8.871 & 0.621 & 19.065 & 0.697 & \\
\hline 36 & 418 & SB4VS-02/measured & -10.681 & 1.08 & 849.2 & 46.75 & 97.68 & 8.092 & 0.566 & 18.950 & 0.694 & \\
\hline 40 & 418 & SB4VS-03/measured & -10.980 & 1.23 & 890.2 & 44.18 & 100.14 & 9.995 & 0.717 & 19.966 & 0.655 & \\
\hline 30 & 503 & SB4VS-05/measured & -8.638 & 0.46 & 838.7 & 69.92 & 99.26 & 7.586 & 0.506 & 15.888 & 0.747 & \\
\hline 34 & 503 & SB4VS-06/measured & -8.962 & 0.53 & 886.5 & 60.44 & 100.57 & 8.555 & 0.618 & 16.511 & 0.720 & \\
\hline 38 & 503 & SB4VS-07/measured & -8.707 & 0.47 & 921.0 & 59.54 & 101.56 & 9.920 & 0.634 & 16.789 & 0.695 & \\
\hline 42 & 503 & SB4VS-08/measured & -9.364 & 0.62 & 953.7 & 43.91 & 100.36 & 10.501 & 0.761 & 17.505 & 0.661 & \\
\hline 42 & 503 & SB4VS-10/measured & -10.037 & 0.83 & 940.6 & 37.18 & 99.95 & 10.638 & 0.733 & 18.309 & 0.649 & \\
\hline 42 & 503 & SB4VS-11/measured & -9.560 & 0.68 & 933.4 & 44.83 & 99.69 & 10.765 & 0.683 & 17.727 & 0.655 & \\
\hline 40 & 503 & SB4VS-12/measured & -9.033 & 0.54 & 937.1 & 46.91 & 97.47 & 10.142 & 0.674 & 16.835 & 0.671 & \\
\hline 40 & 503 & SB4VS-13/measured & -8.653 & 0.46 & 936.3 & 57.07 & 99.53 & 10.411 & 0.624 & 16.685 & 0.674 & \\
\hline 38 & 503 & SB4VS-14/measured & -9.869 & 0.77 & 893.1 & 40.30 & 98.23 & 8.933 & 0.577 & 17.403 & 0.685 & \\
\hline 38 & 503 & SB4VS-15/measured & -9.395 & 0.63 & 900.2 & 47.46 & 98.42 & 9.046 & 0.637 & 17.050 & 0.691 & \\
\hline 36 & 503 & SB4VS-16/measured & -9.981 & 0.81 & 876.4 & 42.31 & 98.24 & 8.555 & 0.597 & 17.466 & 0.696 & \\
\hline 36 & 503 & SB4VS-17/measured & -8.697 & 0.47 & 894.3 & 60.79 & 99.45 & 9.282 & 0.603 & 16.473 & 0.706 & \\
\hline 34 & 503 & SB4VS-18/measured & -8.771 & 0.49 & 892.3 & 57.50 & 97.70 & 8.233 & 0.590 & 16.081 & 0.721 & \\
\hline 32 & 503 & SB4VS-21/measured & -8.907 & 0.52 & 850.3 & 67.63 & 98.64 & 8.276 & 0.595 & 16.327 & 0.729 & \\
\hline 42 & 503 & SB4VS-22/measured & -9.109 & 0.56 & 939.3 & 49.76 & 99.76 & 11.351 & 0.660 & 17.499 & 0.652 & \\
\hline 40 & 503 & SB4VS-23/measured & -10.383 & 0.95 & 916.5 & 40.16 & 99.94 & 9.655 & 0.644 & 18.330 & 0.668 & \\
\hline 40 & 503 & SB4VS-24/measured & -10.190 & 0.88 & 897.2 & 37.03 & 99.28 & 9.126 & 0.593 & 17.977 & 0.674 & \\
\hline 38 & 503 & SB4VS-25/measured & -9.951 & 0.80 & 893.5 & 47.62 & 99.97 & 9.107 & 0.701 & 17.658 & 0.689 & \\
\hline 38 & 503 & SB4VS-26/measured & -9.392 & 0.63 & 903.8 & 51.26 & 99.71 & 8.753 & 0.576 & 16.901 & 0.702 & \\
\hline 36 & 503 & SB4VS-27/measured & -9.483 & 0.66 & 864.1 & 53.93 & 98.73 & 9.178 & 0.655 & 17.181 & 0.696 & \\
\hline 36 & 503 & SB4VS-28/measured & -9.215 & 0.59 & 893.4 & 51.85 & 99.35 & 8.285 & 0.628 & 16.693 & 0.715 & \\
\hline 34 & 503 & SB4VS-29/measured & -9.502 & 0.66 & 860.5 & 54.17 & 98.13 & 8.399 & 0.610 & 17.049 & 0.710 & \\
\hline 34 & 503 & SB4VS-30/measured & -9.343 & 0.62 & 876.4 & 45.81 & 95.96 & 7.601 & 0.516 & 16.347 & 0.718 & \\
\hline 32 & 503 & SB4VS-31/measured & -8.754 & 0.48 & 881.6 & 58.85 & 99.48 & 7.407 & 0.572 & 15.857 & 0.743 & \\
\hline 40 & 503 & SB4VS-32/measured & -10.423 & 0.97 & 913.2 & 35.05 & 97.97 & 8.890 & 0.975 & 18.106 & 0.673 & \\
\hline 38 & 503 & SB4VS-33/measured & -8.120 & 0.37 & 940.8 & 72.33 & 101.13 & 10.378 & 0.814 & 15.990 & 0.697 & \\
\hline 36 & 503 & SB4VS-34/measured & -7.433 & 0.28 & 924.3 & 76.06 & 100.34 & 10.066 & 0.803 & 15.456 & 0.710 & \\
\hline 34 & 503 & SB4VS-35/measured & -9.998 & 0.81 & 833.0 & 52.26 & 100.01 & 7.780 & 0.748 & 17.335 & 0.721 & \\
\hline 32 & 418 & SB4VS-01/targeted & -10.224 & 0.89 & 835.1 & 60.53 & 99.55 & 7.631 & 0.660 & 18.535 & 0.720 & \\
\hline 36 & 418 & SB4VS-02/targeted & -10.331 & 0.93 & 879.6 & 51.79 & 99.50 & 8.585 & 0.741 & 18.851 & 0.693 & \\
\hline
\end{tabular}


Table 3-1. Results of MAR Assessment of SB4 Variability Study Glasses for Measured, Bias-Corrected, and Targeted Compositional Views. (continued)

\begin{tabular}{|c|c|c|c|c|c|c|c|c|c|c|c|c|}
\hline$\% \mathrm{WL}$ & Frit & $\begin{array}{c}\text { Glass ID/ } \\
\text { Compositional View }\end{array}$ & $\begin{array}{c}\text { B Del Gp } \\
\text { Value }\end{array}$ & NL[B (g/L)] & $\begin{array}{l}\text { T }_{L} \text { Pred } \\
\left({ }^{\circ} \mathrm{C}\right)\end{array}$ & $\begin{array}{l}\text { Visc Pred } \\
\text { (P) }\end{array}$ & $\begin{array}{l}\text { Sum of } \\
\text { Oxides }\end{array}$ & $\begin{array}{l}\text { Al2O3 } \\
\text { wt\% }\end{array}$ & $\begin{array}{c}\mathrm{Na} 2 \mathrm{SO} 4 \\
\mathrm{wt} \% \\
\end{array}$ & $\begin{array}{l}\mathrm{R} 2 \mathrm{O} \\
\mathrm{wt} \% \\
\end{array}$ & $\begin{array}{c}\text { Nepheline } \\
\text { Discriminator }\end{array}$ & MAR Status w/o Na2SO4 \\
\hline 40 & 418 & SB4VS-03/targeted & -10.438 & 0.98 & 920.2 & 43.47 & 99.44 & 9.539 & 0.824 & 19.168 & 0.665 & \\
\hline 44 & 418 & SB4VS-04/targeted & -10.546 & 1.02 & 956.7 & 35.67 & 99.39 & 10.493 & 0.907 & 19.485 & 0.636 & \\
\hline 30 & 503 & SB4VS-05/targeted & -8.495 & 0.43 & 864.1 & 67.62 & 99.58 & 7.154 & 0.618 & 15.576 & 0.757 & \\
\hline 34 & 503 & SB4VS-06/targeted & -8.698 & 0.47 & 908.4 & 58.10 & 99.52 & 8.108 & 0.701 & 16.053 & 0.728 & \\
\hline 38 & 503 & SB4VS-07/targeted & -8.901 & 0.51 & 947.7 & 49.04 & 99.47 & 9.062 & 0.782 & 16.530 & 0.698 & \\
\hline 42 & 503 & SB4VS-08/targeted & -9.105 & 0.56 & 983.2 & 40.51 & 99.41 & 10.016 & 0.865 & 17.007 & 0.667 & \\
\hline 46 & 503 & SB4VS-09/targeted & -9.307 & 0.61 & 1014.7 & 32.63 & 99.36 & 10.970 & 0.948 & 17.483 & 0.635 & \\
\hline 42 & 503 & SB4VS-10/targeted & -9.505 & 0.66 & 972.3 & 38.56 & 99.39 & 10.047 & 0.904 & 17.459 & 0.662 & \\
\hline 40 & 503 & SB4VS-12/targeted & -8.534 & 0.44 & 983.9 & 50.20 & 99.47 & 9.926 & 0.787 & 16.367 & 0.683 & \\
\hline 40 & 503 & SB4VS-13/targeted & -8.496 & 0.43 & 974.6 & 49.24 & 99.47 & 9.926 & 0.787 & 16.344 & 0.683 & \\
\hline 38 & 503 & SB4VS-14/targeted & -9.380 & 0.63 & 928.9 & 44.63 & 99.49 & 8.709 & 0.747 & 16.918 & 0.698 & \\
\hline 38 & 503 & SB4VS-15/targeted & -8.982 & 0.53 & 949.1 & 46.19 & 99.45 & 8.709 & 0.818 & 16.512 & 0.702 & \\
\hline 36 & 503 & SB4VS-16/targeted & -9.224 & 0.59 & 919.9 & 48.29 & 99.52 & 8.250 & 0.708 & 16.679 & 0.712 & \\
\hline 36 & 503 & SB4VS-17/targeted & -8.283 & 0.40 & 937.4 & 57.98 & 99.48 & 8.933 & 0.775 & 15.910 & 0.713 & \\
\hline 34 & 503 & SB4VS-18/targeted & -8.420 & 0.42 & 924.9 & 59.43 & 99.51 & 8.036 & 0.732 & 15.693 & 0.732 & \\
\hline 34 & 503 & SB4VS-19/targeted & -9.102 & 0.56 & 897.6 & 54.07 & 99.51 & 7.792 & 0.732 & 16.400 & 0.728 & \\
\hline 32 & 503 & SB4VS-20/targeted & -8.320 & 0.40 & 903.7 & 64.13 & 99.58 & 7.516 & 0.630 & 15.494 & 0.747 & \\
\hline 40 & 503 & SB4VS-23/targeted & -9.900 & 0.78 & 947.5 & 40.33 & 99.49 & 9.286 & 0.750 & 17.627 & 0.677 & \\
\hline 40 & 503 & SB4VS-24/targeted & -9.941 & 0.79 & 926.7 & 36.45 & 99.49 & 8.788 & 0.750 & 17.582 & 0.682 & \\
\hline 38 & 503 & SB4VS-25/targeted & -9.795 & 0.75 & 918.5 & 44.26 & 99.42 & 8.696 & 0.853 & 17.302 & 0.694 & \\
\hline 38 & 503 & SB4VS-26/targeted & -9.979 & 0.81 & 917.1 & 40.74 & 99.52 & 8.348 & 0.713 & 17.345 & 0.697 & \\
\hline 36 & 503 & SB4VS-27/targeted & -9.455 & 0.65 & 887.3 & 50.65 & 99.46 & 8.821 & 0.808 & 17.023 & 0.702 & \\
\hline 36 & 503 & SB4VS-28/targeted & -8.928 & 0.52 & 935.5 & 48.40 & 99.45 & 7.909 & 0.808 & 16.291 & 0.721 & \\
\hline 34 & 503 & SB4VS-29/targeted & -9.311 & 0.61 & 889.2 & 54.14 & 99.48 & 8.151 & 0.763 & 16.783 & 0.720 & \\
\hline 34 & 503 & SB4VS-30/targeted & -9.056 & 0.55 & 909.9 & 50.47 & 99.57 & 7.470 & 0.637 & 16.271 & 0.732 & \\
\hline 32 & 503 & SB4VS-31/targeted & -8.342 & 0.41 & 912.0 & 62.28 & 99.51 & 7.030 & 0.717 & 15.292 & 0.755 & \\
\hline 40 & 503 & SB4VS-32/targeted & -10.250 & 0.90 & 958.0 & 32.09 & 99.20 & 8.400 & 1.183 & 17.777 & 0.683 & \\
\hline 38 & 503 & SB4VS-33/targeted & -7.936 & 0.34 & 968.9 & 67.68 & 99.24 & 9.880 & 1.124 & 15.504 & 0.701 & \\
\hline 36 & 503 & SB4VS-34/targeted & -7.603 & 0.30 & 948.8 & 62.65 & 99.28 & 9.360 & 1.065 & 15.320 & 0.713 & \\
\hline 34 & 503 & SB4VS-35/targeted & -9.820 & 0.76 & 855.2 & 49.32 & 99.32 & 7.140 & 1.006 & 16.911 & 0.731 & \\
\hline 32 & 418 & SB4VS-01/measured bc & -9.802 & 0.75 & 844.5 & 69.29 & 98.55 & 8.933 & 0.621 & 18.399 & 0.703 & \\
\hline 36 & 418 & SB4VS-02/measured bc & -9.951 & 0.80 & 871.2 & 57.45 & 98.41 & 8.069 & 0.566 & 18.233 & 0.707 & \\
\hline 40 & 418 & SB4VS-03/measured bc & -10.082 & 0.84 & 918.6 & 50.94 & 99.47 & 10.065 & 0.717 & 18.970 & 0.663 & \\
\hline 44 & 418 & SB4VS-04/measured bc & -10.255 & 0.91 & 953.6 & 41.68 & 99.68 & 10.952 & 0.742 & 19.275 & 0.636 & \\
\hline 30 & 503 & SB4VS-05/measured bc & -8.097 & 0.37 & 862.9 & 75.70 & 99.02 & 7.649 & 0.506 & 15.292 & 0.753 & \\
\hline
\end{tabular}


Table 3-1. Results of MAR Assessment of SB4 Variability Study Glasses for Measured, Bias-Corrected, and Targeted Compositional Views. (continued)

\begin{tabular}{|c|c|c|c|c|c|c|c|c|c|c|c|c|}
\hline$\% \mathrm{WL}$ & Frit & $\begin{array}{c}\text { Glass ID/ } \\
\text { Compositional View }\end{array}$ & $\begin{array}{c}\text { B Del Gp } \\
\text { Value }\end{array}$ & $N L[B(g / L)]$ & $\begin{array}{c}T_{L} \text { Pred } \\
\left({ }^{\circ} \mathrm{C}\right)\end{array}$ & $\begin{array}{l}\text { Visc Pred } \\
\text { (P) }\end{array}$ & $\begin{array}{l}\text { Sum of } \\
\text { Oxides }\end{array}$ & $\begin{array}{l}\mathrm{Al2O3} \\
\text { wt\% }\end{array}$ & $\begin{array}{c}\mathrm{Na} 2 \mathrm{SO} 4 \\
\mathrm{wt} \%\end{array}$ & $\begin{array}{l}\text { R2O } \\
\text { wt\% }\end{array}$ & $\begin{array}{c}\text { Nepheline } \\
\text { Discriminator }\end{array}$ & MAR Status w/o Na2SO4 \\
\hline 34 & 503 & SB4VS-06/measured bc & -8.301 & 0.40 & 912.0 & 66.50 & 100.03 & 8.614 & 0.618 & 15.796 & 0.727 & \\
\hline 38 & 503 & SB4VS-07/measured bc & -8.058 & 0.36 & 948.6 & 64.90 & 100.64 & 9.969 & 0.634 & 16.031 & 0.700 & \\
\hline 42 & 503 & SB4VS-08/measured bc & -8.798 & 0.49 & 978.9 & 48.37 & 100.28 & 10.588 & 0.761 & 16.890 & 0.667 & \\
\hline 46 & 503 & SB4VS-09/measured bc & -9.046 & 0.55 & 992.8 & 39.22 & 97.98 & 11.263 & 0.862 & 17.253 & 0.634 & \\
\hline 42 & 503 & SB4VS-10/measured bc & -9.224 & 0.59 & 968.6 & 42.89 & 99.52 & 10.726 & 0.733 & 17.432 & 0.656 & \\
\hline 42 & 503 & SB4VS-11/measured bc & -8.766 & 0.49 & 961.4 & 50.38 & 98.63 & 10.819 & 0.683 & 16.836 & 0.661 & \\
\hline 40 & 503 & SB4VS-12/measured bc & -8.249 & 0.39 & 964.0 & 59.40 & 97.97 & 10.114 & 0.674 & 16.055 & 0.685 & \\
\hline 40 & 503 & SB4VS-13/measured bc & -8.182 & 0.38 & 959.4 & 61.90 & 99.56 & 10.497 & 0.624 & 16.160 & 0.678 & \\
\hline 38 & 503 & SB4VS-15/measured bc & -8.668 & 0.47 & 926.4 & 52.39 & 97.32 & 9.091 & 0.637 & 16.231 & 0.697 & \\
\hline 36 & 503 & SB4VS-16/measured bc & -9.109 & 0.56 & 899.4 & 53.97 & 98.55 & 8.531 & 0.597 & 16.626 & 0.710 & \\
\hline 36 & 503 & SB4VS-17/measured bc & -8.193 & 0.38 & 916.6 & 65.40 & 99.16 & 9.346 & 0.603 & 15.925 & 0.711 & \\
\hline 34 & 503 & SB4VS-18/measured bc & -8.188 & 0.38 & 920.5 & 62.85 & 97.34 & 8.291 & 0.590 & 15.428 & 0.727 & \\
\hline 34 & 503 & SB4VS-19/measured bc & -8.940 & 0.52 & 882.3 & 60.30 & 99.17 & 8.292 & 0.623 & 16.388 & 0.724 & \\
\hline 32 & 503 & SB4VS-20/measured bc & -8.069 & 0.36 & 889.6 & 72.85 & 99.19 & 7.916 & 0.494 & 15.345 & 0.746 & \\
\hline 32 & 503 & SB4VS-21/measured bc & -8.277 & 0.40 & 873.4 & 74.26 & 98.25 & 8.344 & 0.595 & 15.653 & 0.736 & \\
\hline 42 & 503 & SB4VS-22/measured bc & -8.538 & 0.44 & 962.1 & 54.92 & 99.63 & 11.445 & 0.660 & 16.882 & 0.658 & \\
\hline 40 & 503 & SB4VS-23/measured bc & -9.577 & 0.68 & 946.7 & 45.82 & 99.34 & 9.723 & 0.644 & 17.447 & 0.675 & \\
\hline 38 & 503 & SB4VS-26/measured bc & -8.751 & 0.48 & 933.3 & 56.69 & 99.35 & 8.814 & 0.576 & 16.177 & 0.709 & \\
\hline 36 & 503 & SB4VS-27/measured bc & -8.817 & 0.50 & 890.8 & 59.05 & 97.72 & 9.224 & 0.655 & 16.405 & 0.701 & \\
\hline 36 & 503 & SB4VS-28/measured bc & -8.759 & 0.49 & 917.6 & 54.59 & 98.61 & 8.327 & 0.628 & 16.145 & 0.718 & \\
\hline 34 & 503 & SB4VS-29/measured bc & -8.981 & 0.53 & 884.5 & 58.47 & 97.81 & 8.458 & 0.610 & 16.477 & 0.715 & \\
\hline 34 & 503 & SB4VS-30/measured bc & -8.766 & 0.49 & 897.4 & 55.62 & 96.69 & 7.579 & 0.516 & 15.817 & 0.729 & \\
\hline 32 & 503 & SB4VS-31/measured bc & -8.181 & 0.38 & 909.9 & 63.01 & 98.53 & 7.444 & 0.572 & 15.189 & 0.748 & \\
\hline 40 & 503 & SB4VS-32/measured bc & -9.813 & 0.75 & 940.8 & 37.96 & 97.11 & 8.934 & 0.975 & 17.405 & 0.678 & \\
\hline 38 & 503 & SB4VS-33/measured bc & -7.640 & 0.30 & 964.5 & 77.95 & 101.09 & 10.464 & 0.814 & 15.478 & 0.702 & \\
\hline 36 & 503 & SB4VS-34/measured bc & -7.036 & 0.24 & 944.8 & 80.57 & 100.25 & 10.136 & 0.803 & 15.011 & 0.713 & \\
\hline 34 & 503 & SB4VS-35/measured bc & -9.521 & 0.67 & 855.7 & 55.12 & 99.18 & 7.819 & 0.748 & 16.763 & 0.725 & \\
\hline
\end{tabular}


WSRC-STI-2006-00204

Revision 0

\subsection{A Statistical Review of the SB4 Variability Study PCT Results}

The variability study glasses, after being batched and fabricated, were subjected to the 7-day PCT Method $\mathrm{A}^{13}$ to assess their durability. Durability is the critical product quality metric for DWPF glass studies. Both heat treatments for each study glass (quenched and ccc) were subjected to the PCT in triplicate. In addition, PCTs were conducted in triplicate for samples of the EA and ARM glasses. Blanks (samples consisting only of ASTM Type I water) were also submitted for the PCT.

Three analytical plans, presented in Appendices B, C and D, were provided to the PSAL to support the measurement of the compositions of the solutions resulting from the PCTs. Samples of a multi-element, standard solution were also included in the analytical plans as a check on the accuracy of the ICP-AES used for these measurements. In this and the following sections, the measurements generated by the PSAL for these PCTs are presented and reviewed.

Table F1 in Appendix F provides the elemental leachate concentration measurements determined by the PSAL for the solution samples generated by the PCTs. One of the quality control checkpoints for the PCT procedure is solution-weight loss over the course of the 7-day test. None of these PCT results indicated a solution-weight loss problem. Any measurement in Table F1 below the detection limit of the analytical procedure (indicated by a " $<$ ") was replaced by one half of the detection limit in subsequent analyses. In addition to adjustments for detection limits, the values were adjusted for the dilution factors: The values for the study glasses, the blanks, and the ARM glass in Table F1 were multiplied by 1.6667 to determine the values in parts per million (ppm) and the values for EA were multiplied by 16.6667. Table F2 in Appendix F provides the resulting measurements. All of the measurements for the ARM specimens fall within the control limits (in ppm) for this glass, ${ }^{12}$ indicating reliable measurements.

In the sections that follow, the analytical sequence of the measurements is explored, the measurements of the multi-element standards are investigated and used to assess the overall accuracy of the ICP-AES measurement process, the measurements for each glass are reviewed, plots are provided that explore the effects of heat treatment on the PCTs for these glasses, the PCTs are normalized using the compositions (targeted, measured, and bias-corrected) presented in Table E4, and the normalized PCTs are compared to durability predictions for these compositions generated from the current DWPF models. ${ }^{12}$

\subsubsection{Measurements in Analytical Sequence}

Exhibits F1 and F2 in Appendix F provide plots of the leachate (ppm) concentrations in analytical sequence as generated by the PSAL for all of the data and for the data from only the study glasses, respectively. A different color and symbol are used for each study glass or standard. No problems are seen in these plots.

\subsubsection{Results for the Samples of the Multi-Element Solution Standard}

Exhibit F3 in Appendix F provides analyses of the PSAL measurements of the samples of the multi-element solution standard by ICP-AES analytical (or calibration) block by analytical set. An ANOVA investigating for statistically significant differences among the set/block averages for these samples for each element of interest is included in this exhibit. These results indicate a statistically significant (at approximately a 5\% level) difference among the average measurements of $\mathrm{Al}, \mathrm{B}, \mathrm{Fe}, \mathrm{Li}, \mathrm{Na}$ and $\mathrm{Si}$ over these sets/blocks. However, no bias correction of the PCT results 
for the study glasses was conducted. This approach was taken since the triplicate PCTs for a single study glass were placed in different ICP-AES blocks. Averaging the ppm values for each set of triplicates helps to minimize the impact of the ICP-AES bias effects.

Table 3-2 summarizes the average measurements and the reference values for the four primary elements of interest. The results indicate consistent and accurate measurements from the PSAL processes used to conduct these analyses.

Table 3-2. Results from Samples of the Multi-Element Solution Standard.

\begin{tabular}{|c|c|c|c|c||}
\hline $\begin{array}{c}\text { Analytical } \\
\text { Part/Block }\end{array}$ & $\begin{array}{c}\text { Avg B } \\
\text { (ppm) }\end{array}$ & $\begin{array}{c}\text { Avg Li } \\
\text { (ppm) }\end{array}$ & $\begin{array}{c}\text { Avg Na } \\
\text { (ppm) }\end{array}$ & $\begin{array}{c}\text { Avg Si } \\
\text { (ppm) }\end{array}$ \\
\hline $1 / 1$ & 21.4 & 9.9 & 83.0 & 49.9 \\
\hline $1 / 2$ & 21.2 & 9.9 & 80.7 & 49.8 \\
\hline $1 / 3$ & 21.4 & 9.9 & 82.5 & 50.3 \\
\hline $2 / 1$ & 20.5 & 9.8 & 81.0 & 47.4 \\
\hline $2 / 2$ & 20.4 & 10.0 & 85.8 & 49.2 \\
\hline $2 / 3$ & 21.4 & 10.0 & 84.3 & 49.5 \\
\hline $2 / 4$ & 21.2 & 9.8 & 81.9 & 48.7 \\
\hline $2 / 5$ & 20.7 & 9.7 & 81.3 & 47.9 \\
\hline $2 / 6$ & 20.7 & 10.0 & 80.8 & 46.1 \\
\hline $3 / 1$ & 20.8 & 9.7 & 81.9 & 49.9 \\
\hline $3 / 2$ & 20.8 & 9.7 & 81.4 & 49.6 \\
\hline $3 / 3$ & 20.5 & 9.6 & 83.1 & 48.8 \\
\hline $3 / 4$ & 20.1 & 9.8 & 82.8 & 49.1 \\
\hline $3 / 5$ & 20.8 & 9.9 & 82.7 & 51.3 \\
\hline $3 / 6$ & 20.7 & 9.7 & 83.0 & 50.9 \\
\hline $\begin{array}{c}\text { Grand } \\
\text { Average }\end{array}$ & $\mathbf{2 0 . 8}$ & $\mathbf{9 . 8}$ & $\mathbf{8 2 . 4}$ & $\mathbf{4 9 . 2}$ \\
\hline $\begin{array}{c}\text { Reference } \\
\text { Value }\end{array}$ & $\mathbf{2 0}$ & $\mathbf{1 0}$ & $\mathbf{8 1}$ & $\mathbf{5 0}$ \\
\hline \% difference & $\mathbf{4 . 2 \%}$ & $\mathbf{- 1 . 7 \%}$ & $\mathbf{1 . 7 \%}$ & $\mathbf{- 1 . 5 \%}$ \\
\hline \multicolumn{2}{|l|}{} \\
\hline
\end{tabular}

\subsubsection{Measurements by Glass Number}

Exhibit F4 in Appendix F provide plots of the leachate concentrations for each type of submitted sample: the study glasses and the standards (EA (101), ARM (102), the multi-element solution standard (100), and blanks (103)). Exhibit F5 in Appendix F provide plots of the leachate concentrations for the PCT results of the study glasses by heat treatment. These plots allow for the assessment of the repeatability of the measurements, which suggests some scatter in the triplicate values for some analytes for some of the glasses. Also, note that some differences between the values for the two heat treatments for some glasses are evident. Specifically, SB4VS-02 and SB4VS-09 show the most scatter in their values over their ccc triplicates for B, Li, and $\mathrm{Na}$, and these glasses also show the biggest differences between their quenched and ccc counterparts for these elements. As a result of these differences, the PCTs for the ccc versions of three glasses, SB4VS-02, SB4VS-05, and SB4VS-09, were rerun with outcomes as given in Table 3-3. 
WSRC-STI-2006-00204

Revision 0

Table 3-3. Results from PCT Reruns for the ccc Versions of SB4VS-02, SB4VS-05, and SB4VS-09.

\begin{tabular}{||c|c|c|c|c|c||}
\hline Sample ID & Lab ID & B & Li & Na & Si \\
\hline cust std 10x & & 20.9 & 9.7 & 79.3 & 48.3 \\
\hline VS-2CCC-1 & $2202-06$ & 8.15 & 11.7 & 46.1 & 73.5 \\
\hline VS-2CCC-2 & $2203-06$ & 7.79 & 11.7 & 46.2 & 73.0 \\
\hline VS-2CCC-3 & $2204-06$ & 7.51 & 11.6 & 45.7 & 72.2 \\
\hline VS-5-CCC-1 & $2205-06$ & 11.5 & 11.4 & 22.3 & 64.8 \\
\hline VS-5-CCC-2 & $2206-06$ & 11.3 & 11.3 & 22.4 & 64.2 \\
\hline VS-5-CCC-3 & $2207-06$ & 11.5 & 11.5 & 22.6 & 65.1 \\
\hline VS-9-CCC-1 & $2208-06$ & 23.0 & 18.0 & 63.6 & 65.8 \\
\hline VS-9-CCC-2 & $2209-06$ & 24.3 & 18.5 & 65.9 & 68.9 \\
\hline VS-9-CCC-3 & $2210-06$ & 23.8 & 18.2 & 64.7 & 68.2 \\
\hline
\end{tabular}

As demonstrated by the values in Table 3-3, the PCT results for each of these ccc glasses are more consistent than the initial set of results, which are given in Table F1 in Appendix F. In the discussion that follows, the values of Table 3-3 will be used to represent the PCT response for these three glasses.

\subsubsection{Normalized PCT Results}

PCT leachate concentrations are typically normalized using the cation composition (expressed as a weight percent) in the glass to obtain a grams per liter $(\mathrm{g} / \mathrm{L})$ leachate concentration. The normalization of the PCTs is usually conducted using the measured compositions of the glasses. This is the preferred normalization process for the PCTs. For completeness, the targeted and the bias-corrected cation compositions were also used to conduct this normalization.

As is the usual convention, the common logarithm of the normalized PCT (normalized leachate, $\mathrm{NL}$ ) for each element of interest was determined and used for comparison. To accomplish this computation, one must:

1.Determine the common logarithm of the elemental ppm leachate concentration for each of the triplicates and each of the elements of interest (these values are provided in Table F2 of Appendix F),

2. Average the common logarithms over the triplicates for each element of interest, and then:

Normalizing Using Measured Composition (preferred method)

3. Subtract a quantity equal to 1 plus the common logarithm of the average cation measured concentration (expressed as a weight percent of the glass) from the average computed in step 2.

Or Normalizing Using Target Composition

3. Subtract a quantity equal to 1 plus the common logarithm of the target cation concentration (expressed as a weight percent of the glass) from the average computed in step 2 . 


\section{Or Normalizing Using Measured Bias-Corrected Composition}

3. Subtract a quantity equal to 1 plus the common logarithm of the measured bias-corrected cation concentration (expressed as a weight percent of the glass) from the average computed in step 2.

Exhibit F6 in Appendix F provides scatter plots for these results and offers an opportunity to investigate the consistency in the leaching across the elements for the glasses of this study. All combinations of the normalizations of the PCTs (i.e., those generated using the targeted, measured, and bias-corrected compositional views) and both heat treatments are represented in the series of scatter plots. Consistency in the leaching across the elements is typically demonstrated by a high degree of linear correlation among the values for pairs of these elements. The smallest correlation in this plot is that for $\mathrm{Na}$ and $\mathrm{Li}$, with a value of $\sim 94 \%$, indicating good consistency.

Table 3-4 summarizes the normalized PCTs for the glasses of this study. The glasses are listed by glass identifier, heat treatment and compositional view. A high level review of the PCT data shows that all glasses (regardless of heat treatment) are very acceptable as compared to the benchmark NL [B] of $16.695 \mathrm{~g} / \mathrm{L}$ for the EA glass. ${ }^{21}$ All of the quenched variability study glasses have NL [B] values of less than $0.9 \mathrm{~g} / \mathrm{L}$, regardless of compositional view. All of the ccc variability study glasses have $\mathrm{NL}[\mathrm{B}]$ values of less than $1.8 \mathrm{~g} / \mathrm{L}$, regardless of compositional view. Note that the sample of EA glass measured with set 1 has a low NL [B] value of $13.89 \mathrm{~g} / \mathrm{L}$. This is likely due to an issue with this particular sample of the EA glass rather than an error in measurement, since the values for the ARM glass for set 1 are within the control limits. ${ }^{12}$ Therefore, this discrepancy will not have an effect on the results of the variability study. 
Table 3-4. Normalized PCTs by Glass ID and Compositional View.

\begin{tabular}{|c|c|c|c|c|c|c|c|c|c|c|}
\hline $\begin{array}{c}\text { Glass } \\
\text { ID } \\
\end{array}$ & $\begin{array}{c}\text { Heat } \\
\text { Treatment } \\
\end{array}$ & Composition & $\begin{array}{c}\log N L \\
{[B(g / L)]} \\
\end{array}$ & $\begin{array}{c}\log N L \\
{[\mathrm{Li}(\mathrm{g} / \mathrm{L})]} \\
\end{array}$ & \begin{tabular}{|c|}
$\log \mathrm{NL}$ \\
{$[\mathrm{Na}(\mathrm{g} / \mathrm{L})]$} \\
\end{tabular} & \begin{tabular}{|c|}
$\log \mathbf{N L}$ \\
{$[\mathrm{Si}(\mathrm{g} / \mathrm{L})]$} \\
\end{tabular} & $\begin{array}{c}\mathbf{N L} \\
\mathrm{B}(\mathrm{g} / \mathrm{L}) \\
\end{array}$ & $\begin{array}{c}\text { NL } \\
\text { Li(g/L) } \\
\end{array}$ & \begin{tabular}{c|}
$\mathrm{NL}$ \\
$\mathrm{Na}(\mathrm{g} / \mathrm{L})$ \\
\end{tabular} & \begin{tabular}{|c|} 
NL \\
Si(g/L) \\
\end{tabular} \\
\hline ARM & Set 1 & reference & -0.260 & -0.215 & -0.262 & -0.533 & 0.55 & 0.61 & 0.55 & 0.29 \\
\hline EA & Set 1 & reference & 1.143 & 0.894 & 1.020 & 0.526 & 13.89 & 7.84 & 10.48 & 3.35 \\
\hline ARM & Set 2 & reference & -0.312 & -0.245 & -0.307 & -0.579 & 0.49 & 0.57 & 0.49 & 0.26 \\
\hline EA & Set 2 & reference & 1.245 & 0.966 & 1.126 & 0.573 & 17.58 & 9.24 & 13.37 & 3.74 \\
\hline ARM & Set 3 & reference & -0.281 & -0.232 & -0.288 & -0.549 & 0.52 & 0.59 & 0.51 & 0.28 \\
\hline EA & Set 3 & reference & 1.239 & 0.955 & 1.110 & 0.578 & 17.35 & 9.01 & 12.89 & 3.79 \\
\hline SB4VS-01 & $\mathrm{ccc}$ & measured & -0.154 & -0.101 & -0.120 & -0.292 & 0.70 & 0.79 & 0.76 & 0.51 \\
\hline SB4VS-02 & $\mathrm{ccc}$ & measured & -0.127 & -0.094 & -0.122 & -0.280 & 0.75 & 0.81 & 0.75 & 0.52 \\
\hline SB4VS-03 & $\mathrm{ccc}$ & measured & -0.082 & -0.060 & -0.057 & -0.260 & 0.83 & 0.87 & 0.88 & 0.55 \\
\hline SB4VS-04 & $\mathrm{ccc}$ & measured & -0.026 & -0.038 & -0.011 & -0.244 & 0.94 & 0.92 & 0.98 & 0.57 \\
\hline SB4VS-05 & $\mathrm{ccc}$ & measured & -0.198 & -0.129 & -0.311 & -0.360 & 0.63 & 0.74 & 0.49 & 0.44 \\
\hline SB4VS-06 & $\mathrm{ccc}$ & measured & -0.200 & -0.169 & -0.275 & -0.371 & 0.63 & 0.68 & 0.53 & 0.43 \\
\hline SB4VS-07 & $\mathrm{ccc}$ & measured & -0.185 & -0.169 & -0.224 & -0.378 & 0.65 & 0.68 & 0.60 & 0.42 \\
\hline SB4VS-08 & $\mathrm{ccc}$ & measured & -0.175 & -0.159 & -0.206 & -0.376 & 0.67 & 0.69 & 0.62 & 0.42 \\
\hline SB4VS-09 & $\mathrm{ccc}$ & measured & 0.224 & 0.182 & 0.024 & -0.228 & 1.68 & 1.52 & 1.06 & 0.59 \\
\hline SB4VS-10 & $\mathrm{ccc}$ & measured & -0.145 & -0.146 & -0.196 & -0.372 & 0.72 & 0.71 & 0.64 & 0.42 \\
\hline SB4VS-11 & $\mathrm{ccc}$ & measured & -0.145 & -0.133 & -0.195 & -0.366 & 0.72 & 0.74 & 0.64 & 0.43 \\
\hline SB4VS-12 & $\mathrm{ccc}$ & measured & -0.166 & -0.140 & -0.227 & -0.359 & 0.68 & 0.72 & 0.59 & 0.44 \\
\hline SB4VS-13 & $\mathrm{ccc}$ & measured & -0.178 & -0.152 & -0.258 & -0.384 & 0.66 & 0.71 & 0.55 & 0.41 \\
\hline SB4VS-14 & $\mathrm{ccc}$ & measured & -0.172 & -0.142 & -0.218 & -0.348 & 0.67 & 0.72 & 0.60 & 0.45 \\
\hline SB4VS-15 & $\mathrm{ccc}$ & measured & -0.140 & -0.129 & -0.230 & -0.350 & 0.72 & 0.74 & 0.59 & 0.45 \\
\hline SB4VS-16 & $\mathrm{ccc}$ & measured & -0.189 & -0.169 & -0.261 & -0.362 & 0.65 & 0.68 & 0.55 & 0.43 \\
\hline SB4VS-17 & $\mathrm{ccc}$ & measured & -0.215 & -0.182 & -0.307 & -0.398 & 0.61 & 0.66 & 0.49 & 0.40 \\
\hline SB4VS-18 & $\mathrm{ccc}$ & measured & -0.193 & -0.164 & -0.298 & -0.376 & 0.64 & 0.69 & 0.50 & 0.42 \\
\hline SB4VS-19 & $\mathrm{ccc}$ & measured & -0.193 & -0.168 & -0.275 & -0.372 & 0.64 & 0.68 & 0.53 & 0.42 \\
\hline SB4VS-20 & ccc & measured & -0.209 & -0.168 & -0.319 & -0.384 & 0.62 & 0.68 & 0.48 & 0.41 \\
\hline SB4VS-21 & $\mathrm{ccc}$ & measured & -0.215 & -0.182 & -0.343 & -0.393 & 0.61 & 0.66 & 0.45 & 0.40 \\
\hline SB4VS-22 & $\mathrm{ccc}$ & measured & -0.177 & -0.164 & -0.207 & -0.376 & 0.67 & 0.69 & 0.62 & 0.42 \\
\hline SB4VS-23 & $\mathrm{ccc}$ & measured & -0.146 & -0.144 & -0.175 & -0.359 & 0.72 & 0.72 & 0.67 & 0.44 \\
\hline SB4VS-24 & $\mathrm{ccc}$ & measured & -0.147 & -0.147 & -0.187 & -0.344 & 0.71 & 0.71 & 0.65 & 0.45 \\
\hline SB4VS-25 & $\mathrm{ccc}$ & measured & -0.140 & -0.150 & -0.200 & -0.358 & 0.72 & 0.71 & 0.63 & 0.44 \\
\hline SB4VS-26 & $\mathrm{ccc}$ & measured & -0.173 & -0.158 & -0.196 & -0.366 & 0.67 & 0.69 & 0.64 & 0.43 \\
\hline SB4VS-27 & $\mathrm{ccc}$ & measured & -0.196 & -0.176 & -0.243 & -0.374 & 0.64 & 0.67 & 0.57 & 0.42 \\
\hline SB4VS-28 & $\mathrm{ccc}$ & measured & -0.187 & -0.176 & -0.266 & -0.376 & 0.65 & 0.67 & 0.54 & 0.42 \\
\hline SB4VS-29 & $\mathrm{ccc}$ & measured & -0.183 & -0.155 & -0.250 & -0.357 & 0.66 & 0.70 & 0.56 & 0.44 \\
\hline SB4VS-30 & $\mathrm{ccc}$ & measured & -0.165 & -0.136 & -0.239 & -0.321 & 0.68 & 0.73 & 0.58 & 0.48 \\
\hline SB4VS-31 & $\mathrm{ccc}$ & measured & -0.206 & -0.155 & -0.312 & -0.361 & 0.62 & 0.70 & 0.49 & 0.44 \\
\hline SB4VS-32 & $\mathrm{ccc}$ & measured & -0.095 & -0.119 & -0.135 & -0.334 & 0.80 & 0.76 & 0.73 & 0.46 \\
\hline SB4VS-33 & $\mathrm{ccc}$ & measured & -0.219 & -0.181 & -0.301 & -0.413 & 0.60 & 0.66 & 0.50 & 0.39 \\
\hline SB4VS-34 & $\mathrm{ccc}$ & measured & -0.179 & -0.142 & -0.288 & -0.367 & 0.66 & 0.72 & 0.51 & 0.43 \\
\hline SB4VS-35 & $\mathrm{ccc}$ & measured & -0.166 & -0.145 & -0.219 & -0.350 & 0.68 & 0.72 & 0.60 & 0.45 \\
\hline SB4VS-01 & quenched & measured & -0.156 & -0.101 & -0.087 & -0.289 & 0.70 & 0.79 & 0.82 & 0.51 \\
\hline SB4VS-02 & quenched & measured & -0.148 & -0.095 & -0.082 & -0.263 & 0.71 & 0.80 & 0.83 & 0.55 \\
\hline SB4VS-03 & quenched & measured & -0.070 & -0.064 & -0.066 & -0.253 & 0.85 & 0.86 & 0.86 & 0.56 \\
\hline SB4VS-04 & quenched & measured & -0.071 & -0.080 & -0.004 & -0.266 & 0.85 & 0.83 & 0.99 & 0.54 \\
\hline SB4VS-05 & quenched & measured & -0.197 & -0.143 & -0.291 & -0.351 & 0.64 & 0.72 & 0.51 & 0.45 \\
\hline SB4VS-06 & quenched & measured & -0.182 & -0.151 & -0.281 & -0.366 & 0.66 & 0.71 & 0.52 & 0.43 \\
\hline SB4VS-07 & quenched & measured & -0.167 & -0.153 & -0.220 & -0.374 & 0.68 & 0.70 & 0.60 & 0.42 \\
\hline SB4VS-08 & quenched & measured & -0.174 & -0.155 & -0.203 & -0.376 & 0.67 & 0.70 & 0.63 & 0.42 \\
\hline SB4VS-09 & quenched & measured & -0.108 & -0.123 & -0.135 & -0.327 & 0.78 & 0.75 & 0.73 & 0.47 \\
\hline SB4VS-10 & quenched & measured & -0.127 & -0.127 & -0.167 & -0.365 & 0.75 & 0.75 & 0.68 & 0.43 \\
\hline SB4VS-11 & quenched & measured & -0.136 & -0.129 & -0.182 & -0.362 & 0.73 & 0.74 & 0.66 & 0.43 \\
\hline SB4VS-12 & quenched & measured & -0.160 & -0.125 & -0.208 & -0.354 & 0.69 & 0.75 & 0.62 & 0.44 \\
\hline SB4VS-13 & quenched & measured & -0.162 & -0.127 & -0.242 & -0.381 & 0.69 & 0.75 & 0.57 & 0.42 \\
\hline SB4VS-14 & quenched & measured & -0.148 & -0.115 & -0.195 & -0.338 & 0.71 & 0.77 & 0.64 & 0.46 \\
\hline SB4VS-15 & quenched & measured & -0.145 & -0.116 & -0.218 & -0.353 & 0.72 & 0.77 & 0.61 & 0.44 \\
\hline SB4VS-16 & quenched & measured & -0.159 & -0.124 & -0.223 & -0.346 & 0.69 & 0.75 & 0.60 & 0.45 \\
\hline SB4VS-17 & quenched & measured & -0.224 & -0.168 & -0.307 & -0.403 & 0.60 & 0.68 & 0.49 & 0.40 \\
\hline SB4VS-18 & quenched & measured & -0.186 & -0.144 & -0.305 & -0.376 & 0.65 & 0.72 & 0.50 & 0.42 \\
\hline SB4VS-19 & quenched & measured & -0.174 & -0.150 & -0.269 & -0.372 & 0.67 & 0.71 & 0.54 & 0.42 \\
\hline
\end{tabular}


Table 3-4. Normalized PCTs by Glass ID and Compositional View. (continued)

\begin{tabular}{|c|c|c|c|c|c|c|c|c|c|c|}
\hline $\begin{array}{c}\text { Glass } \\
\text { ID } \\
\end{array}$ & $\begin{array}{c}\text { Heat } \\
\text { Treatment } \\
\end{array}$ & Composition & $\begin{array}{c}\log \mathbf{N L} \\
{[\mathrm{B}(\mathrm{g} / \mathrm{L})]} \\
\end{array}$ & $\begin{array}{c}\log \mathbf{N L} \\
{[\mathrm{Li}(\mathrm{g} / \mathrm{L})]} \\
\end{array}$ & \begin{tabular}{|c|}
$\log \mathrm{NL}$ \\
{$[\mathrm{Na}(\mathrm{g} / \mathrm{L})]$} \\
\end{tabular} & \begin{tabular}{|c|}
$\log \mathbf{N L}$ \\
{$[\mathrm{Si}(\mathrm{g} / \mathrm{L})]$} \\
\end{tabular} & $\begin{array}{c}\text { NL } \\
\mathbf{B}(\mathrm{g} / \mathrm{L}) \\
\end{array}$ & $\begin{array}{c}\text { NL } \\
\mathrm{Li}(\mathrm{g} / \mathrm{L}) \\
\end{array}$ & $\begin{array}{c}\mathrm{NL} \\
\mathrm{Na}(\mathrm{g} / \mathrm{L}) \\
\end{array}$ & \begin{tabular}{|c|} 
NL \\
Si $(g / L)$ \\
\end{tabular} \\
\hline SB4VS-20 & quenched & measured & -0.209 & -0.156 & -0.325 & -0.388 & 0.62 & 0.70 & 0.47 & 0.41 \\
\hline SB4VS-21 & quenched & measured & -0.200 & -0.157 & -0.345 & -0.388 & 0.63 & 0.70 & 0.45 & 0.41 \\
\hline SB4VS-22 & quenched & measured & -0.187 & -0.183 & -0.214 & -0.390 & 0.65 & 0.66 & 0.61 & 0.41 \\
\hline SB4VS-23 & quenched & measured & -0.154 & -0.160 & -0.181 & -0.368 & 0.70 & 0.69 & 0.66 & 0.43 \\
\hline SB4VS-24 & quenched & measured & -0.139 & -0.145 & -0.140 & -0.350 & 0.73 & 0.72 & 0.72 & 0.45 \\
\hline SB4VS-25 & quenched & measured & -0.164 & -0.164 & -0.203 & -0.371 & 0.69 & 0.69 & 0.63 & 0.43 \\
\hline SB4VS-26 & quenched & measured & -0.162 & -0.152 & -0.186 & -0.370 & 0.69 & 0.70 & 0.65 & 0.43 \\
\hline SB4VS-27 & quenched & measured & -0.176 & -0.151 & -0.229 & -0.363 & 0.67 & 0.71 & 0.59 & 0.43 \\
\hline SB4VS-28 & quenched & measured & -0.177 & -0.158 & -0.259 & -0.370 & 0.66 & 0.70 & 0.55 & 0.43 \\
\hline SB4VS-29 & quenched & measured & -0.179 & -0.142 & -0.251 & -0.357 & 0.66 & 0.72 & 0.56 & 0.44 \\
\hline SB4VS-30 & quenched & measured & -0.158 & -0.129 & -0.246 & -0.328 & 0.69 & 0.74 & 0.57 & 0.47 \\
\hline SB4VS-31 & quenched & measured & -0.212 & -0.150 & -0.335 & -0.363 & 0.61 & 0.71 & 0.46 & 0.43 \\
\hline SB4VS-32 & quenched & measured & -0.113 & -0.133 & -0.136 & -0.343 & 0.77 & 0.74 & 0.73 & 0.45 \\
\hline SB4VS-33 & quenched & measured & -0.205 & -0.149 & -0.304 & -0.403 & 0.62 & 0.71 & 0.50 & 0.40 \\
\hline SB4VS-34 & quenched & measured & -0.161 & -0.115 & -0.300 & -0.353 & 0.69 & 0.77 & 0.50 & 0.44 \\
\hline SB4VS-35 & quenched & measured & -0.144 & -0.129 & -0.214 & -0.344 & 0.72 & 0.74 & 0.61 & 0.45 \\
\hline SB4VS-01 & $\mathrm{ccc}$ & targeted & -0.192 & -0.110 & -0.098 & -0.301 & 0.64 & 0.78 & 0.80 & 0.50 \\
\hline SB4VS-02 & $\mathrm{ccc}$ & targeted & -0.087 & -0.087 & -0.120 & -0.285 & 0.82 & 0.82 & 0.76 & 0.52 \\
\hline SB4VS-03 & $\mathrm{ccc}$ & targeted & -0.087 & -0.066 & -0.031 & -0.255 & 0.82 & 0.86 & 0.93 & 0.56 \\
\hline SB4VS-04 & $\mathrm{ccc}$ & targeted & -0.017 & -0.040 & 0.005 & -0.236 & 0.96 & 0.91 & 1.01 & 0.58 \\
\hline SB4VS-05 & $\mathrm{ccc}$ & targeted & -0.203 & -0.136 & -0.292 & -0.361 & 0.63 & 0.73 & 0.51 & 0.44 \\
\hline SB4VS-06 & $\mathrm{ccc}$ & targeted & -0.195 & -0.171 & -0.254 & -0.366 & 0.64 & 0.67 & 0.56 & 0.43 \\
\hline SB4VS-07 & $\mathrm{ccc}$ & targeted & -0.179 & -0.167 & -0.216 & -0.362 & 0.66 & 0.68 & 0.61 & 0.43 \\
\hline SB4VS-08 & $\mathrm{ccc}$ & targeted & -0.173 & -0.160 & -0.188 & -0.369 & 0.67 & 0.69 & 0.65 & 0.43 \\
\hline SB4VS-09 & $\operatorname{ccc}$ & targeted & 0.226 & 0.180 & 0.048 & -0.239 & 1.68 & 1.51 & 1.12 & 0.58 \\
\hline SB4VS-10 & $\operatorname{ccc}$ & targeted & -0.151 & -0.147 & -0.168 & -0.372 & 0.71 & 0.71 & 0.68 & 0.43 \\
\hline SB4VS-11 & $\mathrm{ccc}$ & targeted & -0.143 & -0.136 & -0.172 & -0.361 & 0.72 & 0.73 & 0.67 & 0.44 \\
\hline SB4VS-12 & $\mathrm{ccc}$ & targeted & -0.160 & -0.140 & -0.210 & -0.370 & 0.69 & 0.72 & 0.62 & 0.43 \\
\hline SB4VS-13 & $\mathrm{ccc}$ & targeted & -0.180 & -0.179 & -0.232 & -0.379 & 0.66 & 0.66 & 0.59 & 0.42 \\
\hline SB4VS-14 & $\mathrm{ccc}$ & targeted & -0.162 & -0.143 & -0.199 & -0.357 & 0.69 & 0.72 & 0.63 & 0.44 \\
\hline SB4VS-15 & $\mathrm{ccc}$ & targeted & -0.150 & -0.132 & -0.206 & -0.351 & 0.71 & 0.74 & 0.62 & 0.45 \\
\hline SB4VS-16 & $\mathrm{ccc}$ & targeted & -0.184 & -0.169 & -0.233 & -0.373 & 0.65 & 0.68 & 0.58 & 0.42 \\
\hline SB4VS-17 & $\mathrm{ccc}$ & targeted & -0.217 & -0.184 & -0.284 & -0.394 & 0.61 & 0.65 & 0.52 & 0.40 \\
\hline SB4VS-18 & $\mathrm{ccc}$ & targeted & -0.207 & -0.172 & -0.276 & -0.385 & 0.62 & 0.67 & 0.53 & 0.41 \\
\hline SB4VS-19 & $\mathrm{ccc}$ & targeted & -0.199 & -0.166 & -0.247 & -0.371 & 0.63 & 0.68 & 0.57 & 0.43 \\
\hline SB4VS-20 & $\mathrm{ccc}$ & targeted & -0.213 & -0.169 & -0.298 & -0.381 & 0.61 & 0.68 & 0.50 & 0.42 \\
\hline SB4VS-21 & $\mathrm{ccc}$ & targeted & -0.233 & -0.186 & -0.310 & -0.396 & 0.58 & 0.65 & 0.49 & 0.40 \\
\hline SB4VS-22 & $\mathrm{ccc}$ & targeted & -0.178 & -0.165 & -0.198 & -0.372 & 0.66 & 0.68 & 0.63 & 0.43 \\
\hline SB4VS-23 & $\mathrm{ccc}$ & targeted & -0.148 & -0.149 & -0.150 & -0.356 & 0.71 & 0.71 & 0.71 & 0.44 \\
\hline SB4VS-24 & $\mathrm{ccc}$ & targeted & -0.146 & -0.151 & -0.171 & -0.344 & 0.72 & 0.71 & 0.67 & 0.45 \\
\hline SB4VS-25 & $\mathrm{ccc}$ & targeted & -0.138 & -0.150 & -0.186 & -0.352 & 0.73 & 0.71 & 0.65 & 0.44 \\
\hline SB4VS-26 & $\mathrm{ccc}$ & targeted & -0.169 & -0.157 & -0.212 & -0.356 & 0.68 & 0.70 & 0.61 & 0.44 \\
\hline SB4VS-27 & $\operatorname{ccc}$ & targeted & -0.200 & -0.184 & -0.232 & -0.374 & 0.63 & 0.65 & 0.59 & 0.42 \\
\hline SB4VS-28 & $\mathrm{ccc}$ & targeted & -0.187 & -0.175 & -0.251 & -0.372 & 0.65 & 0.67 & 0.56 & 0.42 \\
\hline SB4VS-29 & $\mathrm{ccc}$ & targeted & -0.193 & -0.167 & -0.235 & -0.363 & 0.64 & 0.68 & 0.58 & 0.43 \\
\hline SB4VS-30 & $\mathrm{ccc}$ & targeted & -0.170 & -0.147 & -0.229 & -0.342 & 0.68 & 0.71 & 0.59 & 0.46 \\
\hline SB4VS-31 & $\mathrm{ccc}$ & targeted & -0.198 & -0.158 & -0.286 & -0.364 & 0.63 & 0.69 & 0.52 & 0.43 \\
\hline SB4VS-32 & $\mathrm{ccc}$ & targeted & -0.108 & -0.124 & -0.123 & -0.335 & 0.78 & 0.75 & 0.75 & 0.46 \\
\hline SB4VS-33 & $\mathrm{ccc}$ & targeted & -0.208 & -0.182 & -0.280 & -0.401 & 0.62 & 0.66 & 0.52 & 0.40 \\
\hline SB4VS-34 & $\operatorname{ccc}$ & targeted & -0.183 & -0.144 & -0.281 & -0.355 & 0.66 & 0.72 & 0.52 & 0.44 \\
\hline SB4VS-35 & $\mathrm{ccc}$ & targeted & -0.165 & -0.145 & -0.203 & -0.347 & 0.68 & 0.72 & 0.63 & 0.45 \\
\hline SB4VS-01 & quenched & targeted & -0.194 & -0.110 & -0.065 & -0.298 & 0.64 & 0.78 & 0.86 & 0.50 \\
\hline SB4VS-02 & quenched & targeted & -0.108 & -0.089 & -0.079 & -0.268 & 0.78 & 0.82 & 0.83 & 0.54 \\
\hline SB4VS-03 & quenched & targeted & -0.074 & -0.070 & -0.040 & -0.249 & 0.84 & 0.85 & 0.91 & 0.56 \\
\hline SB4VS-04 & quenched & targeted & -0.062 & -0.082 & 0.012 & -0.258 & 0.87 & 0.83 & 1.03 & 0.55 \\
\hline SB4VS-05 & quenched & targeted & -0.202 & -0.151 & -0.272 & -0.352 & 0.63 & 0.71 & 0.53 & 0.44 \\
\hline SB4VS-06 & quenched & targeted & -0.177 & -0.154 & -0.260 & -0.361 & 0.67 & 0.70 & 0.55 & 0.44 \\
\hline SB4VS-07 & quenched & targeted & -0.162 & -0.151 & -0.212 & -0.358 & 0.69 & 0.71 & 0.61 & 0.44 \\
\hline SB4VS-08 & quenched & targeted & -0.173 & -0.156 & -0.186 & -0.369 & 0.67 & 0.70 & 0.65 & 0.43 \\
\hline SB4VS-09 & quenched & targeted & -0.106 & -0.124 & -0.111 & -0.338 & 0.78 & 0.75 & 0.77 & 0.46 \\
\hline
\end{tabular}


Table 3-4. Normalized PCTs by Glass ID and Compositional View. (continued)

\begin{tabular}{|c|c|c|c|c|c|c|c|c|c|c|}
\hline $\begin{array}{c}\text { Glass } \\
\text { ID } \\
\end{array}$ & $\begin{array}{c}\text { Heat } \\
\text { Treatment } \\
\end{array}$ & Composition & $\begin{array}{c}\log \mathbf{N L} \\
{[\mathrm{B}(\mathrm{g} / \mathrm{L})]} \\
\end{array}$ & $\begin{array}{c}\log \mathbf{N L} \\
{[\mathrm{Li}(\mathrm{g} / \mathrm{L})]} \\
\end{array}$ & \begin{tabular}{|c|}
$\log \mathrm{NL}$ \\
{$[\mathrm{Na}(\mathrm{g} / \mathrm{L})]$} \\
\end{tabular} & \begin{tabular}{|c|}
$\log \mathbf{N L}$ \\
{$[\mathrm{Si}(\mathrm{g} / \mathrm{L})]$} \\
\end{tabular} & $\begin{array}{c}\text { NL } \\
\mathbf{B}(\mathrm{g} / \mathrm{L}) \\
\end{array}$ & $\begin{array}{c}\text { NL } \\
\mathrm{Li}(\mathrm{g} / \mathrm{L}) \\
\end{array}$ & $\begin{array}{c}\mathrm{NL} \\
\mathrm{Na}(\mathrm{g} / \mathrm{L}) \\
\end{array}$ & \begin{tabular}{|c|} 
NL \\
Si $(g / L)$ \\
\end{tabular} \\
\hline SB4VS-10 & quenched & targeted & -0.132 & -0.128 & -0.139 & -0.365 & 0.74 & 0.74 & 0.73 & 0.43 \\
\hline SB4VS-11 & quenched & targeted & -0.133 & -0.132 & -0.160 & -0.356 & 0.74 & 0.74 & 0.69 & 0.44 \\
\hline SB4VS-12 & quenched & targeted & -0.155 & -0.125 & -0.191 & -0.364 & 0.70 & 0.75 & 0.64 & 0.43 \\
\hline SB4VS-13 & quenched & targeted & -0.164 & -0.154 & -0.216 & -0.376 & 0.69 & 0.70 & 0.61 & 0.42 \\
\hline SB4VS-14 & quenched & targeted & -0.138 & -0.115 & -0.175 & -0.347 & 0.73 & 0.77 & 0.67 & 0.45 \\
\hline SB4VS-15 & quenched & targeted & -0.155 & -0.119 & -0.194 & -0.354 & 0.70 & 0.76 & 0.64 & 0.44 \\
\hline SB4VS-16 & quenched & targeted & -0.154 & -0.124 & -0.195 & -0.357 & 0.70 & 0.75 & 0.64 & 0.44 \\
\hline SB4VS-17 & quenched & targeted & -0.226 & -0.170 & -0.284 & -0.400 & 0.59 & 0.68 & 0.52 & 0.40 \\
\hline SB4VS-18 & quenched & targeted & -0.200 & -0.152 & -0.284 & -0.384 & 0.63 & 0.70 & 0.52 & 0.41 \\
\hline SB4VS-19 & quenched & targeted & -0.181 & -0.148 & -0.241 & -0.370 & 0.66 & 0.71 & 0.57 & 0.43 \\
\hline SB4VS-20 & quenched & targeted & -0.213 & -0.157 & -0.304 & -0.385 & 0.61 & 0.70 & 0.50 & 0.41 \\
\hline SB4VS-21 & quenched & targeted & -0.219 & -0.161 & -0.311 & -0.391 & 0.60 & 0.69 & 0.49 & 0.41 \\
\hline SB4VS-22 & quenched & targeted & -0.187 & -0.184 & -0.206 & -0.386 & 0.65 & 0.65 & 0.62 & 0.41 \\
\hline SB4VS-23 & quenched & targeted & -0.156 & -0.165 & -0.156 & -0.366 & 0.70 & 0.68 & 0.70 & 0.43 \\
\hline SB4VS-24 & quenched & targeted & -0.138 & -0.150 & -0.125 & -0.350 & 0.73 & 0.71 & 0.75 & 0.45 \\
\hline SB4VS-25 & quenched & targeted & -0.162 & -0.164 & -0.189 & -0.365 & 0.69 & 0.69 & 0.65 & 0.43 \\
\hline SB4VS-26 & quenched & targeted & -0.158 & -0.151 & -0.202 & -0.360 & 0.69 & 0.71 & 0.63 & 0.44 \\
\hline SB4VS-27 & quenched & targeted & -0.180 & -0.160 & -0.219 & -0.364 & 0.66 & 0.69 & 0.60 & 0.43 \\
\hline SB4VS-28 & quenched & targeted & -0.177 & -0.156 & -0.245 & -0.366 & 0.66 & 0.70 & 0.57 & 0.43 \\
\hline SB4VS-29 & quenched & targeted & -0.189 & -0.154 & -0.236 & -0.364 & 0.65 & 0.70 & 0.58 & 0.43 \\
\hline SB4VS-30 & quenched & targeted & -0.163 & -0.140 & -0.237 & -0.349 & 0.69 & 0.72 & 0.58 & 0.45 \\
\hline SB4VS-31 & quenched & targeted & -0.204 & -0.153 & -0.309 & -0.366 & 0.63 & 0.70 & 0.49 & 0.43 \\
\hline SB4VS-32 & quenched & targeted & -0.126 & -0.137 & -0.124 & -0.345 & 0.75 & 0.73 & 0.75 & 0.45 \\
\hline SB4VS-33 & quenched & targeted & -0.193 & -0.149 & -0.284 & -0.391 & 0.64 & 0.71 & 0.52 & 0.41 \\
\hline SB4VS-34 & quenched & targeted & -0.165 & -0.117 & -0.292 & -0.342 & 0.68 & 0.76 & 0.51 & 0.46 \\
\hline SB4VS-35 & quenched & targeted & -0.144 & -0.129 & -0.198 & -0.341 & 0.72 & 0.74 & 0.63 & 0.46 \\
\hline SB4VS-01 & $\mathrm{ccc}$ & measured bc & -0.147 & -0.106 & -0.097 & -0.291 & 0.71 & 0.78 & 0.80 & 0.51 \\
\hline SB4VS-02 & $\mathrm{ccc}$ & measured bc & -0.106 & -0.095 & -0.099 & -0.291 & 0.78 & 0.80 & 0.80 & 0.51 \\
\hline SB4VS-03 & $\mathrm{ccc}$ & measured bc & -0.076 & -0.065 & -0.026 & -0.259 & 0.84 & 0.86 & 0.94 & 0.55 \\
\hline SB4VS-04 & $\mathrm{ccc}$ & measured bc & -0.015 & -0.039 & 0.011 & -0.239 & 0.97 & 0.91 & 1.03 & 0.58 \\
\hline SB4VS-05 & $\mathrm{ccc}$ & measured bc & -0.193 & -0.136 & -0.282 & -0.360 & 0.64 & 0.73 & 0.52 & 0.44 \\
\hline SB4VS-06 & $\mathrm{ccc}$ & measured bc & -0.194 & -0.174 & -0.244 & -0.370 & 0.64 & 0.67 & 0.57 & 0.43 \\
\hline SB4VS-07 & $\mathrm{ccc}$ & measured bc & -0.174 & -0.171 & -0.195 & -0.373 & 0.67 & 0.68 & 0.64 & 0.42 \\
\hline SB4VS-08 & $\mathrm{ccc}$ & measured bc & -0.170 & -0.166 & -0.182 & -0.376 & 0.68 & 0.68 & 0.66 & 0.42 \\
\hline SB4VS-09 & $\operatorname{ccc}$ & measured bc & 0.246 & 0.181 & 0.055 & -0.239 & 1.76 & 1.52 & 1.14 & 0.58 \\
\hline SB4VS-10 & $\mathrm{ccc}$ & measured bc & -0.140 & -0.153 & -0.165 & -0.372 & 0.72 & 0.70 & 0.68 & 0.43 \\
\hline SB4VS-11 & $\operatorname{ccc}$ & measured bc & -0.135 & -0.135 & -0.164 & -0.361 & 0.73 & 0.73 & 0.69 & 0.44 \\
\hline SB4VS-12 & $\mathrm{ccc}$ & measured bc & -0.144 & -0.141 & -0.198 & -0.370 & 0.72 & 0.72 & 0.63 & 0.43 \\
\hline SB4VS-13 & $\mathrm{ccc}$ & measured bc & -0.173 & -0.158 & -0.236 & -0.384 & 0.67 & 0.69 & 0.58 & 0.41 \\
\hline SB4VS-14 & $\mathrm{ccc}$ & measured bc & -0.150 & -0.143 & -0.197 & -0.359 & 0.71 & 0.72 & 0.64 & 0.44 \\
\hline SB4VS-15 & $\mathrm{ccc}$ & measured bc & -0.130 & -0.130 & -0.199 & -0.345 & 0.74 & 0.74 & 0.63 & 0.45 \\
\hline SB4VS-16 & $\mathrm{ccc}$ & measured bc & -0.167 & -0.170 & -0.230 & -0.373 & 0.68 & 0.68 & 0.59 & 0.42 \\
\hline SB4VS-17 & $\operatorname{ccc}$ & measured bc & -0.209 & -0.187 & -0.284 & -0.397 & 0.62 & 0.65 & 0.52 & 0.40 \\
\hline SB4VS-18 & $\mathrm{ccc}$ & measured bc & -0.186 & -0.169 & -0.268 & -0.375 & 0.65 & 0.68 & 0.54 & 0.42 \\
\hline SB4VS-19 & $\mathrm{ccc}$ & measured bc & -0.187 & -0.174 & -0.244 & -0.372 & 0.65 & 0.67 & 0.57 & 0.42 \\
\hline SB4VS-20 & $\mathrm{ccc}$ & measured bc & -0.203 & -0.175 & -0.290 & -0.383 & 0.63 & 0.67 & 0.51 & 0.41 \\
\hline SB4VS-21 & $\mathrm{ccc}$ & measured bc & -0.209 & -0.189 & -0.312 & -0.393 & 0.62 & 0.65 & 0.49 & 0.40 \\
\hline SB4VS-22 & $\mathrm{ccc}$ & measured bc & -0.171 & -0.171 & -0.183 & -0.376 & 0.67 & 0.68 & 0.66 & 0.42 \\
\hline SB4VS-23 & $\mathrm{ccc}$ & measured bc & -0.139 & -0.149 & -0.144 & -0.358 & 0.73 & 0.71 & 0.72 & 0.44 \\
\hline SB4VS-24 & $\operatorname{ccc}$ & measured bc & -0.137 & -0.148 & -0.165 & -0.339 & 0.73 & 0.71 & 0.68 & 0.46 \\
\hline SB4VS-25 & $\mathrm{ccc}$ & measured bc & -0.129 & -0.151 & -0.176 & -0.353 & 0.74 & 0.71 & 0.67 & 0.44 \\
\hline SB4VS-26 & $\mathrm{ccc}$ & measured bc & -0.166 & -0.163 & -0.167 & -0.365 & 0.68 & 0.69 & 0.68 & 0.43 \\
\hline SB4VS-27 & $\mathrm{ccc}$ & measured bc & -0.186 & -0.177 & -0.214 & -0.369 & 0.65 & 0.67 & 0.61 & 0.43 \\
\hline SB4VS-28 & $\mathrm{ccc}$ & measured bc & -0.176 & -0.178 & -0.245 & -0.371 & 0.67 & 0.66 & 0.57 & 0.43 \\
\hline SB4VS-29 & $\mathrm{ccc}$ & measured bc & -0.177 & -0.160 & -0.227 & -0.356 & 0.67 & 0.69 & 0.59 & 0.44 \\
\hline SB4VS-30 & $\mathrm{ccc}$ & measured bc & -0.144 & -0.137 & -0.217 & -0.331 & 0.72 & 0.73 & 0.61 & 0.47 \\
\hline SB4VS-31 & $\mathrm{ccc}$ & measured bc & -0.196 & -0.156 & -0.282 & -0.356 & 0.64 & 0.70 & 0.52 & 0.44 \\
\hline SB4VS-32 & $\mathrm{ccc}$ & measured bc & -0.084 & -0.121 & -0.111 & -0.329 & 0.82 & 0.76 & 0.77 & 0.47 \\
\hline SB4VS-33 & $\mathrm{ccc}$ & measured bc & -0.214 & -0.188 & -0.277 & -0.413 & 0.61 & 0.65 & 0.53 & 0.39 \\
\hline SB4VS-34 & $\mathrm{ccc}$ & measured bc & -0.173 & -0.148 & -0.267 & -0.366 & 0.67 & 0.71 & 0.54 & 0.43 \\
\hline
\end{tabular}


Table 3-4. Normalized PCTs by Glass ID and Compositional View. (continued)

\begin{tabular}{|c|c|c|c|c|c|c|c|c|c|c|}
\hline $\begin{array}{c}\text { Glass } \\
\text { ID } \\
\end{array}$ & $\begin{array}{c}\text { Heat } \\
\text { Treatment } \\
\end{array}$ & Composition & $\begin{array}{c}\log \mathbf{N L} \\
{[\mathrm{B}(\mathrm{g} / \mathrm{L})]} \\
\end{array}$ & $\begin{array}{c}\log N \mathrm{~L} \\
{[\mathrm{Li}(\mathrm{g} / \mathrm{L})]} \\
\end{array}$ & \begin{tabular}{|c|}
$\log \mathrm{NL}$ \\
{$[\mathrm{Na}(\mathrm{g} / \mathrm{L})]$} \\
\end{tabular} & \begin{tabular}{|c|}
$\log \mathrm{NL}$ \\
{$[\mathrm{Si}(\mathrm{g} / \mathrm{L})]$} \\
\end{tabular} & $\begin{array}{c}\text { NL } \\
\mathbf{B}(\mathrm{g} / \mathrm{L}) \\
\end{array}$ & $\begin{array}{c}\text { NL } \\
\mathrm{Li}(\mathrm{g} / \mathrm{L}) \\
\end{array}$ & \begin{tabular}{c|}
$\mathrm{NL}$ \\
$\mathrm{Na}(\mathrm{g} / \mathrm{L})$ \\
\end{tabular} & $\begin{array}{c}\text { NL } \\
\text { Si(g/L) } \\
\end{array}$ \\
\hline SB4VS-35 & $\mathrm{ccc}$ & measured bc & -0.155 & -0.147 & -0.197 & -0.345 & 0.70 & 0.71 & 0.64 & 0.45 \\
\hline SB4VS-01 & quenched & measured bc & -0.150 & -0.106 & -0.064 & -0.288 & 0.71 & 0.78 & 0.86 & 0.52 \\
\hline SB4VS-02 & quenched & measured bc & -0.127 & -0.096 & -0.058 & -0.274 & 0.75 & 0.80 & 0.87 & 0.53 \\
\hline SB4VS-03 & quenched & measured bc & -0.063 & -0.069 & -0.035 & -0.252 & 0.86 & 0.85 & 0.92 & 0.56 \\
\hline SB4VS-04 & quenched & measured bc & -0.060 & -0.082 & 0.018 & -0.261 & 0.87 & 0.83 & 1.04 & 0.55 \\
\hline SB4VS-05 & quenched & measured bc & -0.192 & -0.150 & -0.262 & -0.351 & 0.64 & 0.71 & 0.55 & 0.45 \\
\hline SB4VS-06 & quenched & measured bc & -0.176 & -0.156 & -0.250 & -0.365 & 0.67 & 0.70 & 0.56 & 0.43 \\
\hline SB4VS-07 & quenched & measured bc & -0.157 & -0.155 & -0.191 & -0.369 & 0.70 & 0.70 & 0.64 & 0.43 \\
\hline SB4VS-08 & quenched & measured bc & -0.169 & -0.161 & -0.180 & -0.376 & 0.68 & 0.69 & 0.66 & 0.42 \\
\hline SB4VS-09 & quenched & measured bc & -0.086 & -0.124 & -0.104 & -0.338 & 0.82 & 0.75 & 0.79 & 0.46 \\
\hline SB4VS-10 & quenched & measured bc & -0.122 & -0.134 & -0.136 & -0.365 & 0.76 & 0.73 & 0.73 & 0.43 \\
\hline SB4VS-11 & quenched & measured bc & -0.125 & -0.130 & -0.151 & -0.357 & 0.75 & 0.74 & 0.71 & 0.44 \\
\hline SB4VS-12 & quenched & measured bc & -0.139 & -0.126 & -0.179 & -0.365 & 0.73 & 0.75 & 0.66 & 0.43 \\
\hline SB4VS-13 & quenched & measured bc & -0.156 & -0.133 & -0.220 & -0.381 & 0.70 & 0.74 & 0.60 & 0.42 \\
\hline SB4VS-14 & quenched & measured bc & -0.126 & -0.116 & -0.173 & -0.348 & 0.75 & 0.77 & 0.67 & 0.45 \\
\hline SB4VS-15 & quenched & measured bc & -0.134 & -0.118 & -0.187 & -0.348 & 0.73 & 0.76 & 0.65 & 0.45 \\
\hline SB4VS-16 & quenched & measured bc & -0.137 & -0.126 & -0.192 & -0.357 & 0.73 & 0.75 & 0.64 & 0.44 \\
\hline SB4VS-17 & quenched & measured bc & -0.217 & -0.173 & -0.284 & -0.402 & 0.61 & 0.67 & 0.52 & 0.40 \\
\hline SB4VS-18 & quenched & measured bc & -0.179 & -0.149 & -0.276 & -0.375 & 0.66 & 0.71 & 0.53 & 0.42 \\
\hline SB4VS-19 & quenched & measured bc & -0.169 & -0.156 & -0.238 & -0.372 & 0.68 & 0.70 & 0.58 & 0.42 \\
\hline SB4VS-20 & quenched & measured bc & -0.203 & -0.162 & -0.296 & -0.388 & 0.63 & 0.69 & 0.51 & 0.41 \\
\hline SB4VS-21 & quenched & measured bc & -0.195 & -0.163 & -0.314 & -0.388 & 0.64 & 0.69 & 0.49 & 0.41 \\
\hline SB4VS-22 & quenched & measured bc & -0.181 & -0.189 & -0.191 & -0.390 & 0.66 & 0.65 & 0.64 & 0.41 \\
\hline SB4VS-23 & quenched & measured bc & -0.147 & -0.165 & -0.150 & -0.367 & 0.71 & 0.68 & 0.71 & 0.43 \\
\hline SB4VS-24 & quenched & measured bc & -0.129 & -0.147 & -0.119 & -0.345 & 0.74 & 0.71 & 0.76 & 0.45 \\
\hline SB4VS-25 & quenched & measured bc & -0.153 & -0.166 & -0.179 & -0.366 & 0.70 & 0.68 & 0.66 & 0.43 \\
\hline SB4VS-26 & quenched & measured bc & -0.156 & -0.157 & -0.157 & -0.369 & 0.70 & 0.70 & 0.70 & 0.43 \\
\hline SB4VS-27 & quenched & measured bc & -0.165 & -0.153 & -0.200 & -0.358 & 0.68 & 0.70 & 0.63 & 0.44 \\
\hline SB4VS-28 & quenched & measured bc & -0.167 & -0.159 & -0.238 & -0.365 & 0.68 & 0.69 & 0.58 & 0.43 \\
\hline SB4VS-29 & quenched & measured bc & -0.173 & -0.147 & -0.228 & -0.356 & 0.67 & 0.71 & 0.59 & 0.44 \\
\hline SB4VS-30 & quenched & measured bc & -0.136 & -0.131 & -0.224 & -0.338 & 0.73 & 0.74 & 0.60 & 0.46 \\
\hline SB4VS-31 & quenched & measured bc & -0.201 & -0.151 & -0.306 & -0.358 & 0.63 & 0.71 & 0.49 & 0.44 \\
\hline SB4VS-32 & quenched & measured bc & -0.102 & -0.134 & -0.112 & -0.339 & 0.79 & 0.73 & 0.77 & 0.46 \\
\hline SB4VS-33 & quenched & measured bc & -0.200 & -0.155 & -0.281 & -0.402 & 0.63 & 0.70 & 0.52 & 0.40 \\
\hline SB4VS-34 & quenched & measured bc & -0.155 & -0.120 & -0.278 & -0.352 & 0.70 & 0.76 & 0.53 & 0.44 \\
\hline SB4VS-35 & quenched & measured bc & -0.134 & -0.131 & -0.192 & -0.340 & 0.74 & 0.74 & 0.64 & 0.46 \\
\hline
\end{tabular}




\subsubsection{Effects of Heat Treatment on PCTs}

Exhibit F7 in Appendix F provides a series of plots and statistical comparisons that show the effects of heat treatment on the common logarithm ppm responses over the triplicate PCTs for each element for each study glass. The ccc version of a given glass yielded measurements indicating a significantly (at the 5\% significance level) larger mean $\log (\mathrm{ppm})$ response than the quenched version of the glass for a given element if the $\mathbf{P r o b}<\mathbf{t}$ value in the exhibit is 0.05 or smaller. This is true for SB4VS-09, which shows a statistically significant decrease in durability between the ccc and quenched versions for all four elements of interest.

Exhibit F8 in Appendix F provides a series of plots that show the effects of heat treatment on the PCT response based on the three different compositional views: measured, measured biascorrected, and targeted. These plots allow for an assessment of the differences in PCT responses from a practical perspective. Again, the ccc version of SB4VS-09 stands out as having a reduced durability compared to the quenched version of this glass.

The slow cooling associated with the ccc heat treatment can provide the opportunity for thermodynamically favorable crystallization to occur. Historically, the ccc heat treatment has fostered the formation of spinels and/or nepheline in SB4 based glasses. ${ }^{8,9,11}$ The highest NL [B] value, $1.42 \mathrm{~g} / \mathrm{L}$ (based on the measured-bc compositional view), was measured for SB4VS-09ccc. This glass consists of Frit 503 coupled with the centroid SB4 sludge composition at $46 \% \mathrm{WL}$. As noted in the selection report, the Frit 503 centroid system becomes $\mathrm{T}_{\mathrm{L}}$ and nepheline limited at $47 \%$ WL. ${ }^{16}$ This glass is PCCS MAR acceptable based on the target composition but fails the nepheline discriminator when the measured composition is used in the MAR assessments (see Table 3-1). Although this glass would not be deemed processable based on the measured composition, its normalized release is still very acceptable relative to the EA benchmark of

$16.695 \mathrm{~g} / \mathrm{L} .{ }^{21}$ In addition, other factors (e.g., melt rate and/or waste throughput issues) will likely limit DWPF from targeting WLs greater than $40 \%$ for the SB4 system. SB4VS-02ccc is the only other ccc based glass with a NL [B] value greater than $1.0 \mathrm{~g} / \mathrm{L}$ (e.g., $1.08 \mathrm{~g} / \mathrm{L}$ based on the measured-bc compositional view). All other ccc glasses have NL [B] values of less than $1.0 \mathrm{~g} / \mathrm{L}$, which is very acceptable compared to the EA benchmark.

Based solely on the PCT responses (in terms of the NL [B] as compared to the EA benchmark), both Frit 418 and Frit 503 will produce very acceptable glasses within the SB4 compositional region bounded by this variability study.

\subsubsection{Predicted versus Measured PCTs}

As shown earlier in Table 3-4, the durabilities for the SB4 variability study glasses are all very acceptable when compared to the durability of the EA glass. Exhibit F9 in Appendix F provides plots of the DWPF models that relate the logarithm of the normalized PCT results (for each element of interest) to a linear function of a free energy of hydration term $\left(\Delta \mathrm{G}_{\mathrm{p}}, \mathrm{kcal} / 100 \mathrm{~g}\right.$ glass $)$ derived from all of the glass compositional views and heat treatments. ${ }^{12}$ Prediction limits (at a 95\% confidence) for an individual PCT result are also plotted along with the linear fit. The EA and ARM results are indicated on these plots. Exhibit F10 in Appendix F provides a version of these plots for the quenched glasses only, while Exhibit F11 in Appendix F provides a version for the ccc glasses only. 
Figure 3-3 is the plot associated with the NL [B] versus $\Delta \mathrm{G}_{\mathrm{p}}$ for the study glasses, both quenched (open circles) and ccc (closed circles) for all of the compositional views. ${ }^{\text {a }}$ The quenched glasses all have acceptable PCT responses and with the exception of SB4VS-34, all are predictable (i.e., within the $95 \%$ prediction intervals). Glass SB4VS-34 is a Frit 503 composition at 36\% WL. The quenched and ccc versions of SB4VS-34 (based on the measured-bc compositional view) lie outside the upper $95 \%$ prediction interval indicating that these glasses are not predictable, although they are very acceptable. From Table 3-1, the $\Delta \mathrm{G}_{\mathrm{p}}$ value for the quenched version of SB4VS-34 (based on the measured-bc view) is $-7.036 \mathrm{kcal} / \mathrm{mol}$ and from Table 3-3, its NL [B] is $0.7 \mathrm{~g} / \mathrm{L}$. The ccc version of SB4VS-34 (based on the measured-bc view) lies at the same $\Delta \mathrm{G}_{\mathrm{p}}$ value but has a NL [B] of $0.67 \mathrm{~g} / \mathrm{L}$, which also pushes it slightly above the upper $95 \%$ confidence band. Historically, glasses with more positive $\Delta \mathrm{G}_{\mathrm{p}}$ values have demonstrated this same response. $^{7,24}$

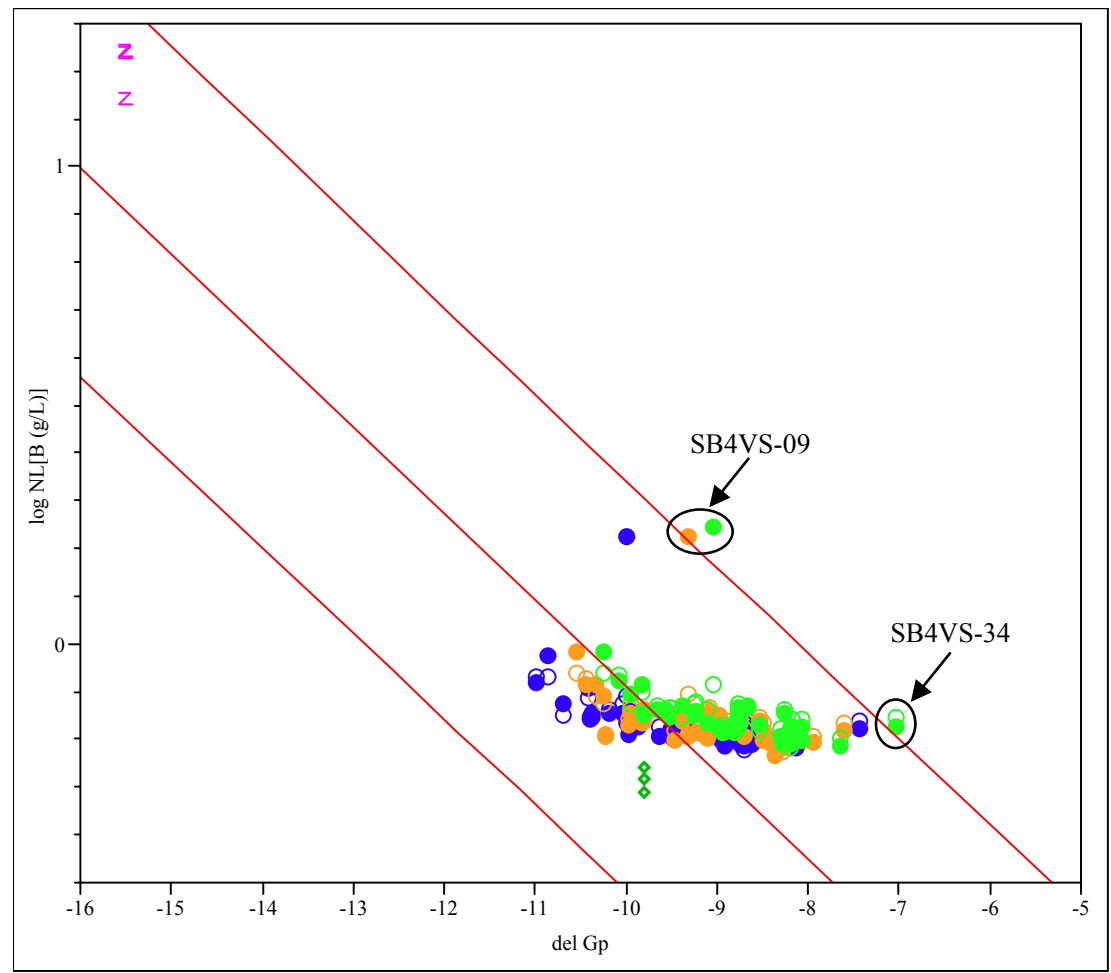

Figure 3-3. NL [B] versus $\Delta G_{p}$ for the SB4 Variability Study Glasses.

The glass of most interest is SB4VS-09ccc (a Frit 503 / SB4 centroid composition targeting $46 \% \mathrm{WL}$ ) represented by the three points which are well above all the other study glasses in Figure 3-3. Specifically, those three points having a log [NL [B]] of approximately 0.13 to $0.15 \mathrm{~g} / \mathrm{L}$ with corresponding $\Delta \mathrm{G}_{\mathrm{p}}$ values of -10 to $-9 \mathrm{kcal} / \mathrm{mol}$. Two of the three compositional views (target and measured-bias corrected) are above the $95 \%$ confidence band indicating that their PCT responses are unpredictable by the current models. The PCT response based on the measured composition is predictable. In comparison to the EA benchmark, SB4VS-09ccc is very acceptable with a NL [B] of 1.35 to $1.42 \mathrm{~g} / \mathrm{L}$ (based on the compositional view used to normalize

a Orange indicates the target compositional view; blue indicates the measured compositional view; and green represents the measured bias corrected compositional view. 
the response), which again is the highest release or least durable glass from the SB4 variability study.

As shown in Table 3-1, SB4VS-09 would not be classified as a MAR acceptable glass based on the measured composition. More specifically, predictions of nepheline formation would restrict this glass from being processed in DWPF as the 0.62 discriminator value was not met. That being said, if SB4VS-09 represented a Frit 503 / SB4 melter feed (or SME batch), based on the compositional analysis this feed would not be classified as processable, even though the PCT response is very acceptable. Although not intentionally planned as part of the variability study, this glass shows the effectiveness of the nepheline discriminator in identifying potentially nondurable glasses based on the possibility of nepheline formation. In fact, in Section 3.4.2, XRD results will indicate that the ccc version of SB4VS-09 did contain nepheline (as expected based on the measured composition) which is responsible for the statistically significant difference in PCT response between the quenched and ccc version of this glass (i.e., NL [B] value of approximately $0.7 \mathrm{~g} / \mathrm{L}$ for the quenched version compared to $1.4 \mathrm{~g} / \mathrm{L}$ for its ccc counterpart). It should be noted that based on the MAR assessments, the Frit 503 / SB4 centroid composition was nepheline limited at $47 \% \mathrm{WL}$. With SB4VS-09 targeting $46 \% \mathrm{WL}$, it is not surprising that the measured composition suggested that nepheline formation was an issue.

\subsection{Homogeneity}

Table 3-5 lists the visual and XRD results for the quenched and ccc versions of the variability study glasses. These results will be summarized below. For a more detailed description of the visual observations and XRD results, see WSRC-NB-2004-00135. 
Table 3-5. Visual Observations and XRD Results for the Variability Study Glasses.

\begin{tabular}{|c|c|c|c|c|c|}
\hline Glass & $\begin{array}{c}\text { Frit } \\
\text { ID }\end{array}$ & $\begin{array}{c}\text { Target } \\
\text { WL }\end{array}$ & $\begin{array}{c}\text { Heat } \\
\text { Treatment }\end{array}$ & Visual Observations & XRD \\
\hline \multirow{2}{*}{ SB4VS-01 } & \multirow{2}{*}{418} & \multirow{2}{*}{32} & quenched & Surface: Clean, homogeneous & \\
\hline & & & $\operatorname{ccc}$ & Surface: Hazy with metallic swirls; Bulk: Black and shiny, clean & amorphous \\
\hline SB4VS-02 & 418 & 36 & $\operatorname{ccc}$ & Surface: Hazy with metallic swirls; Bulk: Black and shiny, clean & amorphous \\
\hline \multirow{2}{*}{ SB4VS-03 } & \multirow{2}{*}{418} & \multirow{2}{*}{40} & quenched & Surface: Clean, homogeneous & \\
\hline & & & $\operatorname{ccc}$ & Surface: Dull haze with metallic swirls; Bulk: Black and shiny, clean & amorphous \\
\hline \multirow{2}{*}{ SB4VS-04 } & \multirow{2}{*}{418} & \multirow{2}{*}{44} & quenched & Surface: Light metallic swirls on surface, otherwise clean & \\
\hline & & & $\operatorname{ccc}$ & Surface: Dull, devitrified; Bulk: Black, shiny and clean & amorphous \\
\hline \multirow{2}{*}{ SB4VS-05 } & \multirow{2}{*}{503} & \multirow{2}{*}{30} & quenched & Surface: Clean, homogeneous & \\
\hline & & & ccc & Surface: Black, shiny and clean; Bulk: Black, shiny and clean & amorphous \\
\hline \multirow{2}{*}{ SB4VS-06 } & \multirow{2}{*}{503} & \multirow{2}{*}{34} & quenched & Surface: Clean, homogeneous & \\
\hline & & & $\operatorname{ccc}$ & Surface: Black, shiny and clean; Bulk: Black, shiny and clean & amorphous \\
\hline \multirow{2}{*}{ SB4VS-07 } & \multirow{2}{*}{503} & \multirow{2}{*}{38} & quenched & Surface: Clean, homogeneous & \\
\hline & & & $\operatorname{ccc}$ & Surface: Shiny haze with brown swirls; Bulk: Black, shiny and clean & amorphous \\
\hline SB4VS-08 & 503 & 42 & quenched & Surface: Clean, homogeneous & \\
\hline \multirow{2}{*}{ SB4VS-09 } & \multirow{2}{*}{503} & \multirow{2}{*}{46} & quenched & Surface: Clean, homogeneous & \\
\hline & & & $\operatorname{ccc}$ & Surface: Dull with large clusters of crystals; Bulk: Black, shiny and clean & $\mathrm{NaAlSiO}_{4}$ \\
\hline \multirow{2}{*}{ SB4VS-10 } & \multirow{2}{*}{503} & \multirow{2}{*}{42} & quenched & Surface: Clean, homogeneous & \\
\hline & & & $\operatorname{ccc}$ & Surface: Milky, metallic haze; Bulk: Clean & amorphous \\
\hline \multirow{2}{*}{ SB4VS-11 } & 503 & 12 & quenched & Surface: Black and shiny with some shiny metallic spots & \\
\hline & 503 & 42 & $\operatorname{ccc}$ & Surface: Milky, metallic haze; Bulk: Clean & amorphous \\
\hline SPAVS 12 & 503 & 10 & quenched & Surface: Clean, homogeneous & \\
\hline SB4VS-12 & 503 & 40 & $\operatorname{ccc}$ & Surface: Shiny, metallic with small amount of crystal swirls; Bulk: Clean & amorphous \\
\hline CDAVC 12 & 503 & 10 & quenched & Surface: Black and shiny with approx. five metallic spots & \\
\hline SB4VS-13 & 503 & 40 & ccc & Surface: Shiny, metallic with small amount of crystal swirls; Bulk: Clean & amorphous \\
\hline CDAVC 14 & 503 & 30 & quenched & Surface: Clean, homogeneous & \\
\hline SB4VS-14 & 503 & 38 & cec & Surface: Shiny, metallic with small amount of crystal swirls; Bulk: Clean & amorphous \\
\hline SR4VS-15 & 503 & 38 & quenched & Surface: Clean, homogeneous & \\
\hline SB4VS-15 & 503 & 38 & ccc & Surface: Shiny, metallic with small amount of crystal swirls; Bulk: Clean & amorphous \\
\hline
\end{tabular}


Table 3-5. Visual Observations and XRD Results for the Variability Study Glasses. (continued)

\begin{tabular}{|c|c|c|c|c|c|}
\hline Glass & $\begin{array}{c}\text { Frit } \\
\text { ID }\end{array}$ & $\begin{array}{c}\text { Target } \\
\text { WL }\end{array}$ & $\begin{array}{c}\text { Heat } \\
\text { Treatment }\end{array}$ & Visual Observations & XRD \\
\hline \multirow{2}{*}{ SB4VS-16 } & \multirow{2}{*}{503} & \multirow{2}{*}{36} & quenched & Surface: Clean, homogeneous & \\
\hline & & & $\operatorname{ccc}$ & Surface: Shiny, metallic with small amount of crystal swirls; Bulk: Clean & amorphous \\
\hline SB4VS-17 & 503 & 36 & $\operatorname{ccc}$ & Surface: Black and shiny with a very small amount of crystals; Bulk: Clean & amorphous \\
\hline \multirow{2}{*}{ SB4VS-18 } & \multirow{2}{*}{503} & \multirow{2}{*}{34} & quenched & Surface: Clean, homogeneous & \\
\hline & & & $\operatorname{ccc}$ & Surface: Black and shiny with a very small amount of crystals; Bulk: Clean & amorphous \\
\hline SB4VS-19 & 503 & 34 & $\operatorname{ccc}$ & Surface: Clean, black and shiny; Bulk: Clean & amorphous \\
\hline \multirow{2}{*}{ SB4VS-20 } & \multirow{2}{*}{503} & \multirow{2}{*}{32} & quenched & Surface: Clean, homogeneous & \\
\hline & & & $\mathrm{ccc}$ & Surface: Clean, black and shiny; Bulk: Clean & amorphous \\
\hline \multirow{2}{*}{ SB4VS-21 } & \multirow{2}{*}{503} & \multirow{2}{*}{32} & quenched & Surface: Clean, homogeneous & \\
\hline & & & $\mathrm{ccc}$ & Surface: Clean, black and shiny; Bulk: Clean & amorphous \\
\hline \multirow{2}{*}{ SB4VS-22 } & \multirow{2}{*}{503} & \multirow{2}{*}{42} & quenched & Surface: Clean and shiny & \\
\hline & & & $\operatorname{ccc}$ & Surface: Hazy with small clusters of silver crystals; Bulk: Clean & amorphous \\
\hline SB4VS-23 & 503 & 40 & quenched & Surface: Clean and shiny & \\
\hline \multirow{2}{*}{ SB4VS-24 } & \multirow{2}{*}{503} & \multirow{2}{*}{40} & quenched & Surface: Clean, black and shiny & \\
\hline & & & $\operatorname{ccc}$ & Surface: Shiny, milky haze; Bulk: Clean & amorphous \\
\hline \multirow{2}{*}{ SB4VS-25 } & \multirow{2}{*}{503} & \multirow{2}{*}{38} & quenched & Surface: Clean, black and shiny & \\
\hline & & & $\operatorname{ccc}$ & Surface: Shiny, milky haze; Bulk: Clean & amorphous \\
\hline \multirow{2}{*}{ SB4VS-26 } & \multirow{2}{*}{503} & \multirow{2}{*}{38} & quenched & Surface: Clean, black and shiny & \\
\hline & & & $\operatorname{ccc}$ & Surface: Shiny film with crystals; Bulk: Clean & amorphous \\
\hline & & & quenched & Surface: Clean, black and shiny & \\
\hline SB4VS-27 & 503 & 36 & $\operatorname{ccc}$ & Surface: Haze with crystals; Bulk: Clean & amorphous \\
\hline SR4VS_28 & 503 & 36 & quenched & Surface: Clean, black and shiny & \\
\hline SB4VS-28 & 503 & 30 & $\operatorname{ccc}$ & Surface: Shiny, hazy; Bulk: Clean & amorphous \\
\hline
\end{tabular}


Table 3-5. Visual Observations and XRD Results for the Variability Study Glasses. (continued)

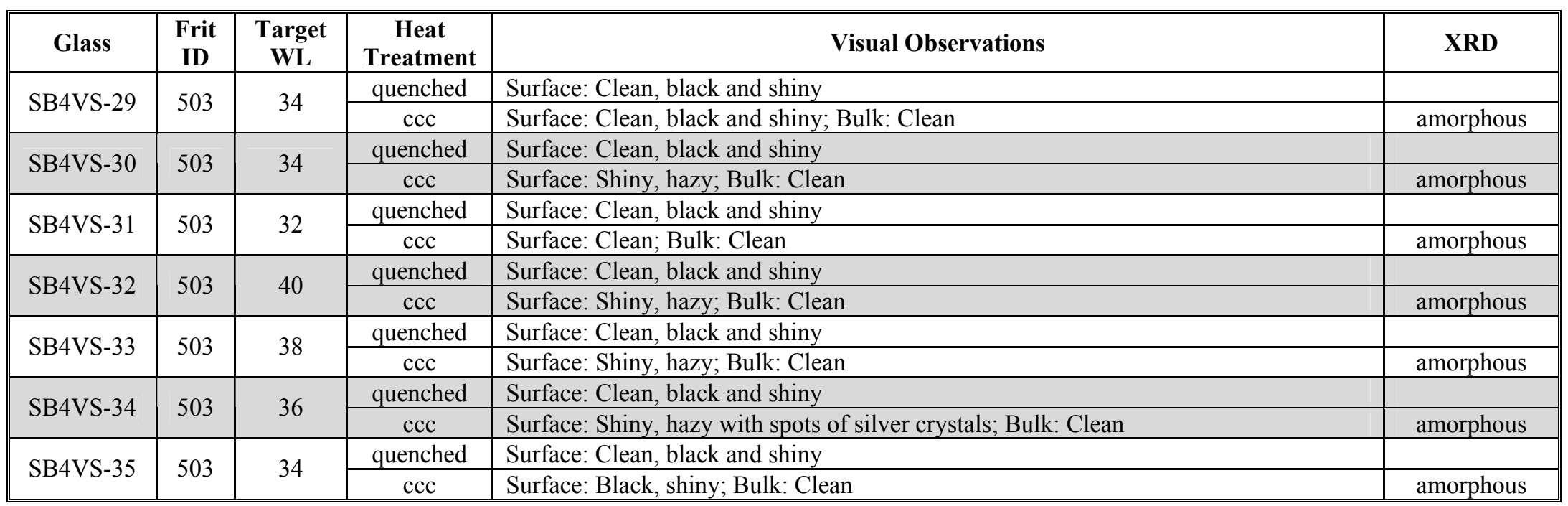


WSRC-STI-2006-00204

Revision 0

\subsubsection{Visual Observations}

Prior to discussing the visual observations, a few words regarding the terminology used are warranted. The term "surface" refers to the surface of the quenched pour patty or glass sample after the ccc heat treatment. The term "bulk" refers to the cross-section of the quenched pour patty or glass sample after the ccc heat treatment. The use of "homogeneous" indicates that the sample was classified as a single-phase system (i.e., no evidence of crystallization). Other terms such as "swirls", "haze", "clusters", "milky", and/or "metallic spots" imply that the surface or bulk of the glass was characterized by the presence of crystallization or some other characteristic feature.

Visual observations of the quenched variability study glasses indicate that 32 of the glasses were homogeneous, while the remaining three glasses were characterized by metallic spots or swirls on the surface, with the bulk (cross-section) being homogeneous (Table 3-5). The three quenched glasses (SB4-VS-04, -11, and -13) with surface crystallization had generally higher WLs (i.e., $\geq$ $40 \% \mathrm{WL}$ ). Use of descriptions such as a metallic-like surface or spots is common for DWPFtype glasses targeting higher WLs. Previous XRD analyses have indicated that the metallic-like surface features are typically a result of spinels that precipitate during the cooling process. This follows glass theory which suggests that as WL increases, the concentrations of $\mathrm{Fe}_{2} \mathrm{O}_{3}, \mathrm{NiO}$, $\mathrm{Cr}_{2} \mathrm{O}_{3}$, and/or $\mathrm{MnO}$ also increase, enhancing the likelihood of spinel devitrification. Based on the PCT responses for the quenched glasses, spinel formation on the surface resulting in metallic spots and swirls is reasonable as spinels have been shown to have minimal impact on the durability response. ${ }^{25}$ In addition, the XRD results discussed in Section 3.4.2 will show that no spinels were present in the quenched glasses at levels greater than the detection limit of $0.5 \mathrm{vol} \%$.

A metallic haze, either somewhat shiny or dull, characterized the surface of all but eight of the ccc glasses (Table 3-5). This behavior again is indicative of the formation of spinels, though the XRD results will show that no spinels were present in the ccc glasses at levels greater than the detection limit of $0.5 \mathrm{vol} \%$. Devitrification at the surface was more prevalent in the ccc glasses than in the quenched glasses. This crystallization is expected, given kinetics are more favorable for devitrification during the slower cooling cycle. However, the bulk (cross-section) of each of the ccc glasses was free of any visible crystallization. Note though that nepheline crystallization, if present, is typically not visible. Based on these observations, XRD analysis of the ccc glasses was warranted.

\subsubsection{XRD Results}

The XRD results are included in Table 3-5, and provide qualitative results regarding crystallization in the variability study glasses. Only the ccc versions of the glasses were submitted for XRD analysis given that the visual observations and durability responses suggested no significant crystallization in the quenched glasses. That is, with normalized boron releases ranging from $\sim 0.6$ to $0.9 \mathrm{~g} / \mathrm{L}$, there is no evidence of nepheline formation in the quenched glasses.

All but one of the cce glasses was found to be amorphous by XRD. Though visual observations indicated crystallization on the surface of several of the ccc glasses, they also indicated that the bulk, or cross-section of each glass was free of visible crystallization. The XRD results indicate that the amount of crystallization seen on the surface of some of the ccc glasses made up less than $0.5 \mathrm{vol} \%$ of the specimen. XRD results for glass SB4VS-01 ccc are shown in Figure 3-4. The characteristically high background devoid of crystalline spectral lines indicates that this glass is either amorphous, or has a crystalline content below the detection limit of $0.5 \mathrm{vol} \%$. This pattern is representative of all of the ccc glasses in the variability study except for SB4VS-09. 
WSRC-STI-2006-00204

Revision 0

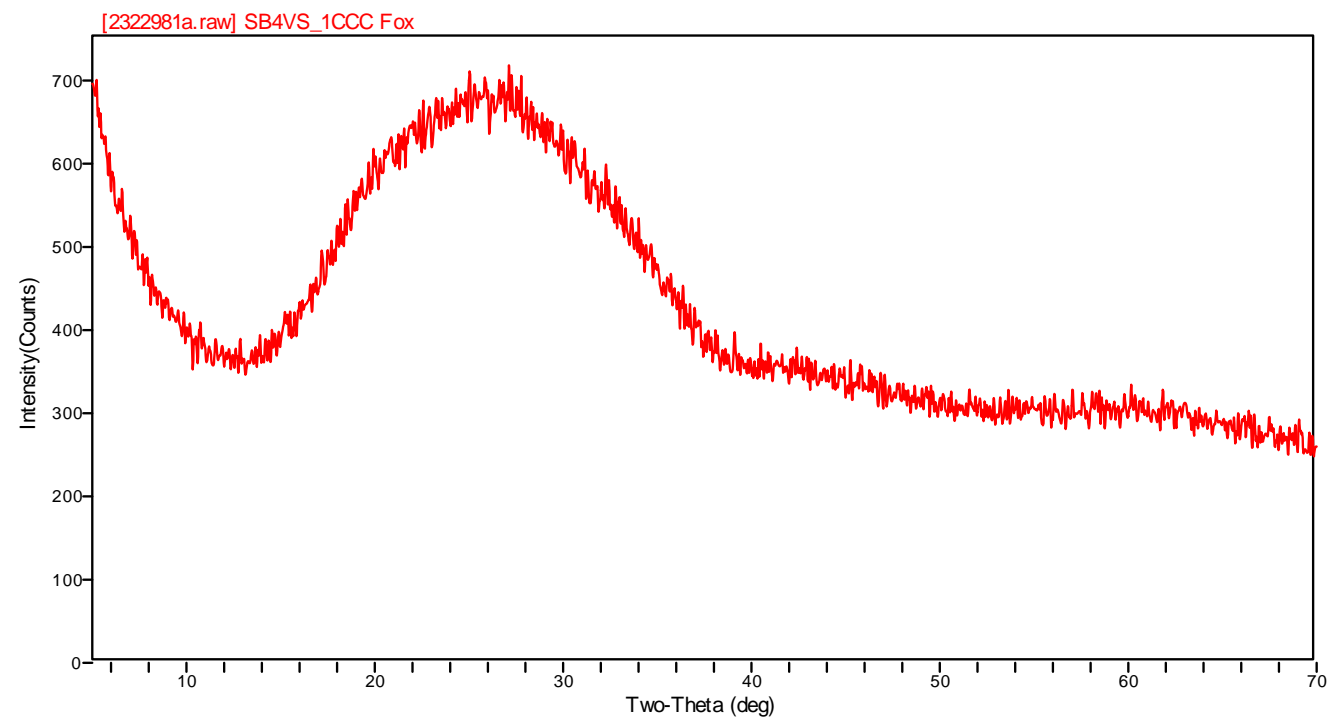

Figure 3-4. XRD Pattern for the cce Version of Glass SB4VS-01.

Nepheline $\left(\mathrm{NaAlSiO}_{4}\right)$ was identified by XRD in the ccc version of glass SB4VS-09. The XRD pattern for this glass is shown in Figure 3-5. The target composition of this glass results in a nepheline discriminator value of 0.635 , which is the lowest value for all of the variability study glasses. Recent work has shown that glass compositions with a nepheline discriminator value of 0.62 or less are prone to nepheline crystallization upon the ccc heat treatment. ${ }^{4-11}$ When the nepheline discriminator for SB4VS-09 is calculated using the measured composition, the result is 0.619 . Therefore, based on the critical value for the nepheline discriminator of 0.62 , it is not surprising that some nepheline was detected in this glass via XRD. This serves as the technical basis for the statistically significant difference in PCT response between the quenched and ccc version of this glass. As discussed in Sections 3.2 and 3.3.6, SB4VS-09 would not be classified as a MAR acceptable glass based on the measured composition. More specifically, predictions of nepheline formation would restrict this glass from being processed in DWPF as the 0.62

discriminator value was not met. Although SB4VS-09 was not intentionally selected to challenge the ability of the nepheline discriminator, the results do demonstrate its effectiveness. 
WSRC-STI-2006-00204

Revision 0

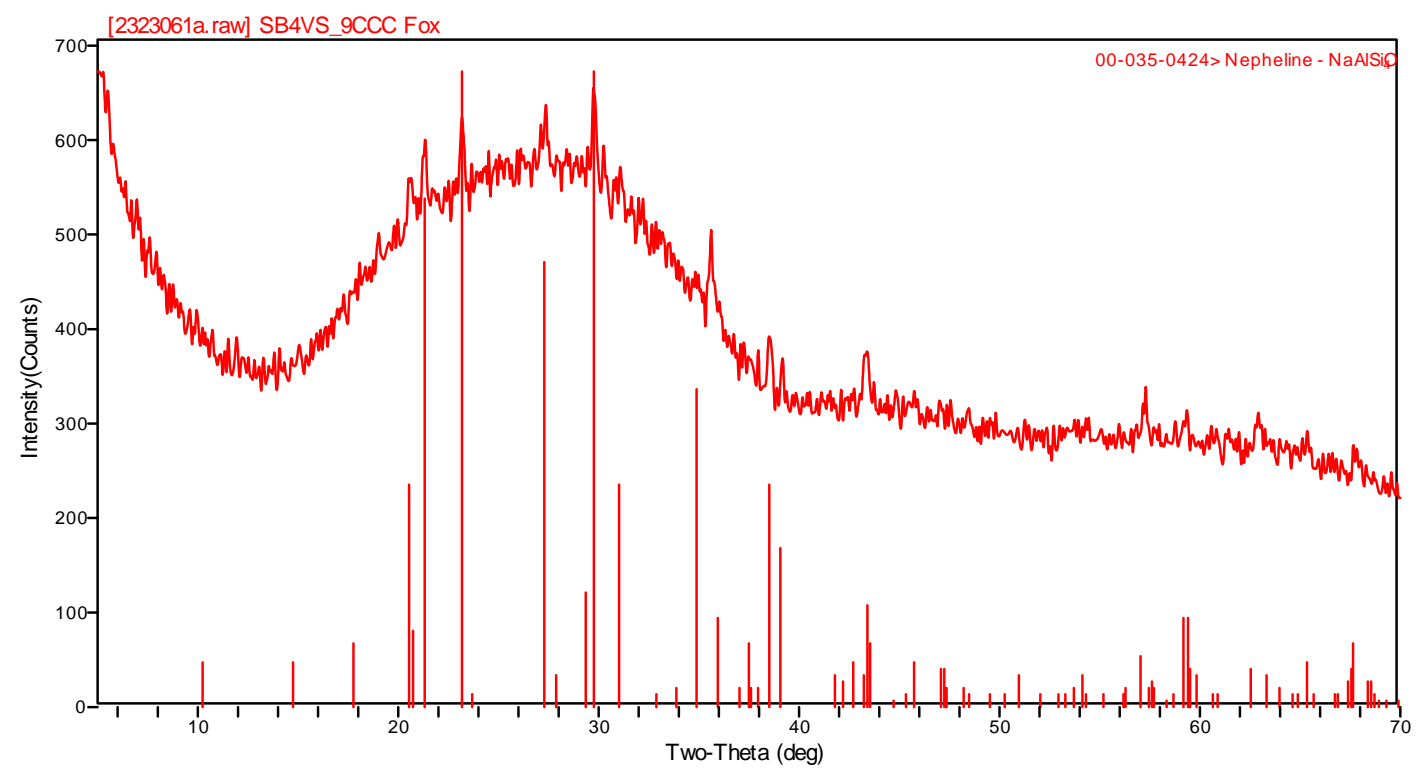

Figure 3-5. XRD Pattern for the cce Version of Glass SB4VS-09. 


\subsection{Conclusions}

The results of the variability study show that vitrifying SB4 with Frit 503 will produce glasses with durabilities that are both predictable by the DWPF PCCS models and acceptable as compared to the EA glass, within the range of sludge compositions and waste loadings included in the study. All 35 of the glasses fabricated had durabilities that were very acceptable as compared to the EA glass for both quenched and ccc heat treatments. Two of the variability study glasses (SB4VS-09 and SB4VS-34) fell outside of the 95\% confidence interval for the free energy of hydration durability model. One of these glasses had a high (more positive) $\Delta \mathrm{G}_{\mathrm{P}}$ value and an acceptable durability (more than an order of magnitude below that of the EA benchmark glass). This type of response has been seen in past studies and is not a cause for concern. The second of the glasses that fell outside of the $95 \%$ confidence interval was found to be prone to nepheline crystallization based on the measured composition, and therefore would not have passed the DWPF PCCS MAR. This glass showed a statistically significant decrease in durability after the ccc heat treatment due to nepheline crystallization. However, both the quenched and ccc versions of this glass were very acceptable when compared to the durability of the EA glass.

The glasses formulated with SB4 and Frit 418 were both predictable and acceptable. This frit is considered an option for DWPF processing during the transition from SB3 to SB4.

Chemical composition measurements of the variability study glasses indicate that the sulfate limit of $0.60 \mathrm{wt} \%$ in glass is viable for the Frit 503 / SB4 system, based on the nominal SB4 composition projections used as the technical basis for this study. 
WSRC-STI-2006-00204

Revision 0

This page intentionally left blank. 


\subsection{Recommendations}

Based on the results and observations of this study, the following recommendations are made:

$>$ Utilize Frit 503 to process SB4 in DWPF given the projected sludge compositions.

$>$ Utilize Frit 418 during the transition from SB3 to SB4, if warranted.

$>$ Maintain the PCCS SO ${ }_{4}{ }^{2-}$ limit for the Frit $503 / \mathrm{SB} 4$ system at $0.60 \mathrm{wt} \%$. 
WSRC-STI-2006-00204

Revision 0

This page intentionally left blank. 
WSRC-STI-2006-00204

Revision 0

\subsection{References}

1. Peeler, D. K., T. B. Edwards and K. M. Fox, "Frit Recommendation for SB4," U.S. Department of Energy Report SRNL-PSE-2006-00128, Washington Savannah River Company, Aiken, South Carolina (2006).

2. Peeler, D. K. and T. B. Edwards, "Model Based Assessments of the Final SB4 Projections Compositions Leading to the Frit Recommendation," U.S. Department of Energy Report WSRCTR-2006-00269, Revision 0, Washington Savannah River Company, Aiken, South Carolina (2006).

3. Smith, M. E., M. E. Stone, T. M. Jones, D. H. Miller and P. R. Burket, "SB4 MRF and SMRF Tests with Frits 418, 425, and 503 (U)," U.S. Department of Energy Report WSRC-STI-200600015, Revision 0, Washington Savannah River Company, Aiken, South Carolina (2006).

4. Edwards, T. B. and D. K. Peeler, "Nepheline Formation Potential in Sludge Batch 4 (SB4) and Its Impact on Durability: Selecting Glasses for a Phase 2 Study," U.S. Department of Energy Report WSRC-TR-2005-00370, Revision 0, Westinghouse Savannah River Company, Aiken, South Carolina (2005).

5. Edwards, T. B., D. K. Peeler and K. M. Fox, "The Nepheline Discriminator: Justification and DWPF PCCS Implementation Details," U.S. Department of Energy Report WSRC-STI-200600014, Revision 0, Washington Savannah River Company, Aiken, South Carolina (2006).

6. Fox, K. M., T. B. Edwards and D. K. Peeler, "Nepheline Formation Potential in Sludge Batch 4 (SB4) and Its Impact on Durability: Selecting Glasses for a Phase 3 Study," U.S. Department of Energy Report WSRC-TR-2006-00053, Revision 0, Washington Savannah River Company, Aiken, South Carolina (2006).

7. Fox, K. M., T. B. Edwards, D. K. Peeler, D. R. Best, I. A. Reamer and R. J. Workman, "Durability and Nepheline Crystallization Study for High Level Waste (HLW) Sludge Batch 4 (SB4) Glasses Formulated with Frit 503," U.S. Department of Energy Report WSRC-STI-200600009, Revision 0, Washington Savannah River Company, Aiken, South Carolina (2006).

8. Fox, K. M., D. K. Peeler, T. B. Edwards, D. R. Best, I. A. Reamer and R. J. Workman, "Nepheline Formation Study for Sludge Batch 4 (SB4): Phase 3 Experimental Results," U.S. Department of Energy Report WSRC-TR-2006-00093, Revision 0, Washington Savannah River Company, Aiken, South Carolina (2006).

9. Peeler, D. K., T. B. Edwards, D. R. Best, I. A. Reamer and R. J. Workman, "Nepheline Formation Study for Sludge Batch 4 (SB4): Phase 2 Experimental Results," U.S. Department of Energy Report WSRC-TR-2006-00006, Revision 0, Washington Savannah River Company, Aiken, South Carolina (2006).

10. Peeler, D. K., T. B. Edwards and T. H. Lorier, "Nepheline Formation Potential in Sludge Batch (SB4) Glasses," U.S. Department of Energy Report WSRC-TR-2005-00153, Revision 0, Westinghouse Savannah River Company, Aiken, South Carolina (2005). 
WSRC-STI-2006-00204

Revision 0

11. Peeler, D. K., T. B. Edwards, I. A. Reamer and R. J. Workman, "Nepheline Formation Study for Sludge Batch 4 (SB4): Phase 1 Experimental Results," U.S. Department of Energy Report WSRC-TR-2005-00371, Revision 0, Westinghouse Savannah River Company, Aiken, South Carolina (2005).

12. Jantzen, C. M., J. B. Picket, K. G. Brown, T. B. Edwards and D. C. Beam, "Process/Product Models for the Defense Waste Processing Facility (DWPF): Part I. Predicting Glass Durability from Composition Using a Thermodynamic Hydration Energy Reaction Model (THERMO)," U.S. Department of Energy Report WSRC-TR-93-672, Revision 1, Westinghouse Savannah River Company, Aiken, South Carolina (1995).

13. ASTM, "Standard Test Methods for Determining Chemical Durability of Nuclear Waste Glasses: The Product Consistency Test (PCT)," U.S. Department of Energy Report ASTM C1285-2002, (2002).

14. Washburn, F. A., "Technical Task Request: Sludge Batch 4 and MCU Frit Optimization," U.S. Department of Energy Report HLW/DWPF/TTR-2004-0026, Revision 0, Westinghouse Savannah River Company, Aiken, South Carolina (2004).

15. Peeler, D. K., "Task Technical \& QA Plan: Sludge Batch and MCU Frit Optimization," U.S. Department of Energy Report WSRC-RP-2004-00746, Revision 0, Westinghouse Savannah River Company, Aiken, South Carolina (2004).

16. Fox, K. M., T. B. Edwards and D. K. Peeler, "High Level Waste (HLW) Sludge Batch 4 (SB4): Selecting Glasses for a Variability Study," U.S. Department of Energy Report WSRC-STI2006-00039, Revision 0, Washington Savannah River Company, Aiken, South Carolina (2006).

17. Peeler, D. K., C. C. Herman, M. E. Smith, T. H. Lorier, D. R. Best, T. B. Edwards and M. A. Baich, "An Assessment of the Sulfate Solubility Limit for the Frit 418 - Sludge Batch 2/3 System," U.S. Department of Energy Report WSRC-TR-2004-00081, Revision 0, Westinghouse Savannah River Company, Aiken, South Carolina (2004).

18. SRNL, "Glass Batching," U.S. Department of Energy Report SRTC Procedure Manual, L29, ITS-0001, Westinghouse Savannah River Company, Aiken, South Carolina (2002).

19. SRNL, "Glass Melting," U.S. Department of Energy Report SRTC Procedure Manual, L29, ITS-0003, Westinghouse Savannah River Company, Aiken, South Carolina (2002).

20. Marra, S. L. and C. M. Jantzen, "Characterization of Projected DWPF Glass Heat Treated to Simulate Canister Centerline Cooling," U.S. Department of Energy Report WSRC-TR-92-142, Revision 1, Westinghouse Savannah River Company, Aiken, South Carolina (1993).

21. Jantzen, C. M., N. E. Bibler, D. C. Beam, C. L. Crawford and M. A. Pickett, "Characterization of the Defense Waste Processing Facility (DWPF) Environmental Assessment (EA) Glass Standard Reference Material," U.S. Department of Energy Report WSRC-TR-92-346, Revision 1, Westinghouse Savannah River Company, Aiken, South Carolina (1993).

22. Ebert, W. L. and S. F. Wolfe, "Round-robin Testing of a Reference Glass for Low-Activity Waste Forms," U.S. Department of Energy Report ANL-99/22, Argonne National Laboratory, Argonne, Illinois (1999). 
23. Jantzen, C. M. and M. E. Smith, "Revision of the Defense Waste Processing Facility (DWPF) Sulfate Solubility Limit," U.S. Department of Energy Report WSRC-TR-2003-00518, Revision 0, Westinghouse Savannah River Company, Aiken, South Carolina (2003).

24. Harbour, J. R., T. B. Edwards and R. J. Workman, "Summary of Results for Macrobatch 3 Variability Study," U.S. Department of Energy Report WSRC-TR-2000-00351, Revision 0, Westinghouse Savannah River Company, Aiken, South Carolina (2000).

25. Bickford, D. F. and C. M. Jantzen, "Devitrification of SRL Defense Waste Glass," Sci. Basis for Nuclear Waste Management VII, edited by G. L. McVay. Elsevier, New York, pp. 557-565 (1984). 
WSRC-STI-2006-00204

Revision 0

This page intentionally left blank. 


\section{Appendix A}

\section{An Analytical Plan for Measuring the Chemical Compositions of Glasses from the SB4 Variability Study (U)}

(SRNL-SCS-2006-00030) 
August 14, 2006

To: K. M. Fox, SRNL

cc:
R. A. Baker, 773-42A
D. R. Best, 786-1A (wo)
C. C. Herman, 999-W
D. K. Peeler, 999-W

I. A. Reamer, 999-1W

P. A. Toole, 786-1A (wo)

R. C. Tuckfield, 773-42A

R. J. Workman, 999-1W

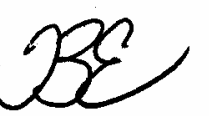

From: T. B. Edwards, 773-42A (5-5148)

Statistical Consulting Section

wo - without glass identifiers
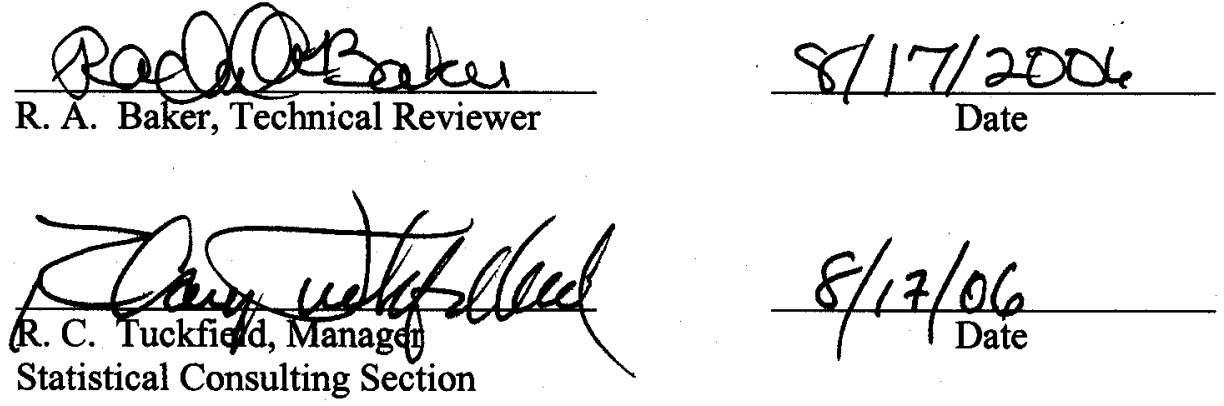

\section{An Analytical Plan for Measuring the Chemical Compositions of Glasses from the SB4 Variability Study (U)}




\subsection{EXECUTIVE SUMMARY}

A glass variability study is underway at the Savannah River National Laboratory (SRNL) to support the processing of Sludge Batch 4 (SB4) at the Defense Waste Processing Facility (DWPF). Thirty-five (35) glasses have been selected to be batched and fabricated as part of this study. The chemical composition of these glasses is to be analyzed by SRNL's Process Science Analytical Laboratory (PSAL). This memorandum provides an analytical plan for the measurements by PSAL. 
WSRC-STI-2006-00204

Revision 0

Appendix A (SRNL-SCS-2006-00030)

\subsection{INTRODUCTION}

A glass variability study is underway at the Savannah River National Laboratory (SRNL) to support the processing of Sludge Batch 4 (SB4) at the Defense Waste Processing Facility (DWPF) [1]. Thirty-five (35) glasses have been selected to be batched and fabricated as part of this study. The chemical composition of these glasses is to be analyzed by SRNL's Process Science Analytical Laboratory (PSAL). This memorandum provides an analytical plan for the measurements by PSAL.

\subsection{Analytical Plan}

The analytical procedures used by PSAL to determine cation concentrations for a glass sample include steps for sample preparation and for instrument calibration. Each glass is to be prepared in duplicate by each of two dissolution methods: lithium metaborate fusion (LM) and sodium peroxide fusion $(\mathrm{PF})$.

The primary measurements of interest are to be acquired as follows. The samples prepared by $\mathrm{LM}$ are to be measured for barium $(\mathrm{Ba})$, calcium $(\mathrm{Ca})$, cerium $(\mathrm{Ce})$, chromium $(\mathrm{Cr})$, copper $(\mathrm{Cu})$, potassium $(\mathrm{K})$, lanthanum $(\mathrm{La})$, magnesium $(\mathrm{Mg})$, manganese $(\mathrm{Mn})$, sodium $(\mathrm{Na})$, lead $(\mathrm{Pb})$, sulfur $(\mathrm{S})$, thorium $(\mathrm{Th})$, titanium $(\mathrm{Ti})$, zinc $(\mathrm{Zn})$, and zirconium $(\mathrm{Zr})$ concentrations. Samples prepared by $\mathrm{PF}$ are to be measured for aluminum (Al), boron (B), iron (Fe), lithium ( $\mathrm{Li})$, nickel (Ni), silicon (Si), and uranium (U) concentrations. Samples dissolved by both preparation methods are to be measured using Inductively Coupled Plasma - Atomic Emission Spectrometry (ICP-AES). It should be noted that some of these elements are minor components that may be near the detection limits for most, if not all, of the study glasses.

Randomizing the preparation steps and blocking and randomizing the measurements for the ICPAES are of primary concern in the development of this analytical plan. The sources of uncertainty for the analytical procedure used by PSAL to determine the cation concentrations for the submitted glass samples are dominated by the dissolution step in the preparation of the sample and by the calibrations of the ICP-AES.

Samples of glass standards will be included in the analytical plan to provide an opportunity for checking the performance of the instrumentation over the course of the analyses and for potential bias correction. Specifically, several samples of Waste Compliance Plan (WCP) Batch 1 (BCH) [2] and a uranium standard glass (Ustd) are included in this analytical plan. The reference compositions of these glasses are provided in Table 1.

In addition, samples of the Low-Activity Reference Material (LRM) standard glass (which contains sulfur - see [3] for details on the chemical composition of this glass) are to be included in the set of samples submitted to PSAL. The measurements of this glass will be used to provide insight into the uncertainty of PSAL's sulfur measurements. The LRM samples are to be labeled in the same manner as the study glasses, but with their labels known. The labels are being provided to assist in the interpretation of the sums of oxides for the glasses. Since some of the elements present in LRM will not be measured by PSAL, the measured sum of oxides for LRM may fall below $95 \%$ (i.e., the target sum of oxides for LRM for the elements listed above is only around $97.7 \%$ ). 
WSRC-STI-2006-00204

Revision 0

Appendix A (SRNL-SCS-2006-00030)

Table 1: Oxide Compositions of WCP Batch 1 (BCH) and Ustd

\begin{tabular}{|c|c|c||}
\hline $\begin{array}{c}\text { Oxide/ } \\
\text { Anion }\end{array}$ & $\begin{array}{c}\text { BCH } \\
\text { (wt \%) }\end{array}$ & $\begin{array}{c}\text { Ustd } \\
\text { (wt \%) }\end{array}$ \\
\hline $\mathrm{Al}_{2} \mathrm{O}_{3}$ & 4.877 & 4.1 \\
\hline $\mathrm{B}_{2} \mathrm{O}_{3}$ & 7.777 & 9.209 \\
\hline $\mathrm{BaO}$ & 0.151 & 0 \\
\hline $\mathrm{CaO}$ & 1.22 & 1.301 \\
\hline $\mathrm{Cr}_{2} \mathrm{O}_{3}$ & 0.107 & 0 \\
\hline $\mathrm{Cs}_{2} \mathrm{O}$ & 0.06 & 0 \\
\hline $\mathrm{CuO}_{\mathrm{Fe}} \mathrm{O}_{3}$ & 0.399 & 0 \\
\hline $\mathrm{K}_{2} \mathrm{O}$ & 12.839 & 13.196 \\
\hline $\mathrm{Li}_{2} \mathrm{O}$ & 3.327 & 2.999 \\
\hline $\mathrm{MgO} \mathrm{O} O$ & 3.057 \\
\hline $\mathrm{MnO}_{\mathrm{Na} O}$ & 1.429 & 1.21 \\
\hline $\mathrm{Na}_{2} \mathrm{O}$ & 1.726 & 2.892 \\
\hline $\mathrm{Nd}_{2} \mathrm{O}_{3}$ & 9.003 & 11.795 \\
\hline $\mathrm{NiO}_{\mathrm{RuO}}$ & 0.147 & 0 \\
\hline $\mathrm{RiO}_{2}$ & 0.751 & 1.12 \\
\hline $\mathrm{SO}_{3}$ & 0.0214 & 0 \\
\hline $\mathrm{TiO}_{2}$ & 50.22 & 45.353 \\
\hline $\mathrm{U}_{3} \mathrm{O}_{8}$ & 0 & 0 \\
\hline $\mathrm{ZrO}_{2}$ & 0.098 & 2.406 \\
\hline
\end{tabular}

Each glass sample submitted to PSAL will be prepared in duplicate by the LM and PF dissolution methods. Every prepared sample will be read twice by ICP-AES, with the instrument being calibrated before each of these two sets of readings. This will lead to four measurements for each cation of interest for each submitted glass.

Table 2 presents identifying codes, U01 through U43, for the 35 glasses fabricated for this study and the 8 samples of the LRM standard that have been included. The table provides a naming convention that is to be used in analyzing the glasses and reporting the measurements of their compositions. ${ }^{\text {a }}$

a Renaming these samples helps to ensure that they will be processed as blind samples within PSAL. Table 2 is not shown in its entirety in the copies going to PSAL. However, note that the LRM glasses are to be identified. 
WSRC-STI-2006-00204

Revision 0

Appendix A (SRNL-SCS-2006-00030)

Table 2: Glass Identifiers to Establish Blind Samples for PSAL

\begin{tabular}{||c|c||c|c||c|c||}
\hline Glass ID & Sample ID & Glass ID & Sample ID & Glass ID & Sample ID \\
\hline SB4VS-01 & U07 & SB4VS-16 & U11 & SB4VS-31 & U17 \\
\hline SB4VS-02 & U15 & SB4VS-17 & U38 & SB4VS-32 & U10 \\
\hline SB4VS-03 & U22 & SB4VS-18 & U02 & SB4VS-33 & U30 \\
\hline SB4VS-04 & U21 & SB4VS-19 & U18 & SB4VS-34 & U04 \\
\hline SB4VS-05 & U13 & SB4VS-20 & U42 & SB4VS-35 & U41 \\
\hline SB4VS-06 & U24 & SB4VS-21 & U01 & LRM-01 & U26 \\
\hline SB4VS-07 & U27 & SB4VS-22 & U23 & LRM-02 & U33 \\
\hline SB4VS-08 & U37 & SB4VS-23 & U19 & LRM-03 & U34 \\
\hline SB4VS-09 & U06 & SB4VS-24 & U12 & LRM-04 & U08 \\
\hline SB4VS-10 & U39 & SB4VS-25 & U16 & LRM-05 & U03 \\
\hline SB4VS-11 & U28 & SB4VS-26 & U29 & LRM-06 & U36 \\
\hline SB4VS-12 & U14 & SB4VS-27 & U05 & LRM-07 & U40 \\
\hline SB4VS-13 & U32 & SB4VS-28 & U35 & LRM-08 & U31 \\
\hline SB4VS-14 & U09 & SB4VS-29 & U43 & & \\
\hline SB4VS-15 & U25 & SB4VS-30 & U20 & & \\
\hline \hline
\end{tabular}

\subsection{PREPARATION OF THE SAMPLES}

Each of the 43 glasses included in this analytical plan is to be prepared in duplicate by the LM and PF dissolution methods. Thus, the total number of prepared glass samples is determined by $43 \cdot 2 \cdot 2=172$, not including the samples of the $\mathrm{BCH}$ and Ustd glass standards.

Table 3 provides blocking and (random) sequencing schema for conducting the preparation steps of the analytical procedures. Four blocks of preparation work are provided for each preparation method to facilitate the scheduling of activities by work shift. The identifier for each of the prepared samples indicates the sample identifier (ID), preparation method, and duplicate number.

Table 3: Preparation Blocks by Dissolution Method

\begin{tabular}{|c|c|c|c|c|c|c|c|}
\hline \multicolumn{4}{|c|}{ LM (Lithium Metaborate) Blocks } & \multicolumn{4}{|c|}{ PF (Peroxide Fusion) Blocks } \\
\hline 1 & 2 & 3 & 4 & 1 & 2 & 3 & 4 \\
\hline U26LM1 & U04LM1 & U34LM1 & U38LM1 & U14PF1 & U31PF1 & U33PF1 & U08PF1 \\
\hline U32LM1 & U05LM1 & U21LM1 & U20LM1 & U11PF1 & U27PF1 & U39PF1 & U08PF2 \\
\hline U30LM1 & U16LM1 & U15LM1 & U12LM1 & U11PF2 & U31PF2 & U39PF2 & U34PF1 \\
\hline U27LM1 & U19LM1 & U21LM2 & U38LM2 & U12PF1 & U27PF2 & U18PF1 & $\mathrm{U} 15 \mathrm{PF} 1$ \\
\hline U31LM1 & U16LM2 & U34LM2 & U20LM2 & U14PF2 & U21PF1 & U18PF2 & U34PF2 \\
\hline U02LM1 & U07LM1 & U15LM2 & U12LM2 & U17PF1 & U41PF1 & U23PF1 & U03PF1 \\
\hline U30LM2 & U19LM2 & U36LM1 & U28LM1 & U05PF1 & U26PF1 & U24PF1 & U09PF1 \\
\hline U26LM2 & U07LM2 & U25LM1 & U10LM1 & U37PF1 & U42PF1 & U33PF2 & U03PF2 \\
\hline U02LM2 & U04LM2 & U06LM1 & U11LM1 & U36PF1 & U21PF2 & U23PF2 & U43PF1 \\
\hline U35LM1 & U22LM1 & U13LM1 & U33LM1 & U12PF2 & U35PF1 & U20PF1 & U15PF2 \\
\hline U27LM2 & U05LM2 & U09LM1 & U03LM1 & U30PF1 & U19PF1 & U13PF1 & U04PF1 \\
\hline U31LM2 & U42LM1 & U40LM1 & U10LM2 & U17PF2 & U38PF1 & U02PF1 & U43PF2 \\
\hline U35LM2 & U22LM2 & U40LM2 & U33LM2 & U22PF1 & U29PF1 & U13PF2 & U09PF2 \\
\hline U32LM2 & U29LM1 & U36LM2 & U39LM1 & U22PF2 & U35PF2 & U24PF2 & U28PF1 \\
\hline U17LM1 & U23LM1 & U25LM2 & U28LM2 & U05PF2 & U19PF2 & U07PF1 & U10PF1 \\
\hline U08LM1 & U23LM2 & U18LM1 & U11LM2 & U32PF1 & U42PF2 & U07PF2 & U06PF1 \\
\hline U24LM1 & U37LM1 & U14LM1 & U39LM2 & U40PF1 & U41PF2 & U20PF2 & U06PF2 \\
\hline U01LM1 & U42LM2 & U09LM2 & U43LM1 & U32PF2 & U16PF1 & U25PF1 & U04PF2 \\
\hline U24LM2 & U41LM1 & U14LM2 & U03LM2 & U37PF2 & U26PF2 & U01PF1 & U10PF2 \\
\hline U17LM2 & U41LM2 & U06LM2 & U43LM2 & U36PF2 & U16PF2 & U25PF2 & U28PF2 \\
\hline U01LM2 & U37LM2 & U13LM2 & & U40PF2 & U38PF2 & U02PF2 & \\
\hline U08LM2 & U29LM2 & U18LM2 & & U30PF2 & U29PF2 & U01PF2 & \\
\hline
\end{tabular}


WSRC-STI-2006-00204

Revision 0

Appendix A (SRNL-SCS-2006-00030)

\subsection{ICP-AES CALIBRATION BLOCKS}

The glass samples prepared by the LM and PF dissolution methods are to be analyzed using ICPAES instrumentation calibrated for the particular preparation method. After the initial set of cation concentration measurements, the ICP-AES instrumentation is to be recalibrated and a second set of concentration measurements for the cations determined.

Randomized plans for measuring cation concentrations in the LM-prepared and PF-prepared samples are provided in Table 4. The cations to be measured are specified as part of the table. In the tables, the sample identifiers for the study glasses have been modified by the addition of a suffix (a "1"or a " 2 ") to indicate whether the measurement was made during the first or second (respectively) calibration of the ICP-AES instrumentation. The identifiers for the BCH and Ustd samples have been modified to indicate the ICP-AES calibration block and sub-block and that each of these prepared samples is to be read 3 times (mirrored in the corresponding suffix of 1,2 , or 3) per calibration block.

Table 4: ICP-AES Blocks \& Calibration Groups by Preparation Method

\begin{tabular}{|c|c|c|c|c|c|c|c|}
\hline \multicolumn{8}{|c|}{ LM Glass Samples } \\
\hline \multicolumn{8}{|c|}{ Used to Measure Elemental $\mathrm{Ba}, \mathrm{Ca}, \mathrm{Ce}, \mathrm{Cr}, \mathrm{Cu}, \mathrm{K}, \mathrm{La}, \mathrm{Mg}, \mathrm{Mn}, \mathrm{Na}, \mathrm{Pb}, \mathrm{S}, \mathrm{Th}, \mathrm{Ti}, \mathrm{Zn}, \& \mathrm{Zr}$} \\
\hline Block 1-1 & Block 1-2 & Block 2-1 & Block 2-2 & Block 3-1 & Block 3-2 & Block 4-1 & Block 4-2 \\
\hline BCHLM111 & BCHLM121 & BCHLM211 & BCHLM221 & BCHLM311 & BCHLM321 & BCHLM411 & BCHLM421 \\
\hline UstdLM111 & UstdLM121 & UstdLM211 & UstdLM221 & UstdLM311 & UstdLM321 & UstdLM411 & UstdLM421 \\
\hline U02LM11 & U33LM12 & U32LM11 & U03LM22 & U22LM21 & U24LM12 & U37LM11 & U34LM12 \\
\hline U14LM11 & U27LM12 & U03LM21 & U35LM12 & U28LM21 & U28LM12 & U23LM21 & U10LM12 \\
\hline U33LM11 & U31LM22 & U32LM21 & U35LM22 & U19LM11 & U24LM22 & U43LM21 & U30LM22 \\
\hline U14LM21 & U14LM22 & U12LM11 & U32LM12 & U24LM11 & U39LM12 & U38LM11 & U34LM22 \\
\hline U31LM11 & U36LM22 & U04LM21 & U20LM22 & U01LM11 & U18LM12 & U34LM11 & M22 \\
\hline U36LM21 & U42LM12 & U40LM11 & U20LM12 & U39LM11 & U11LM12 & U23LM11 & U15LM22 \\
\hline U29LM21 & U02LM22 & U21LM21 & U41LM12 & U39LM21 & U06LM22 & U15LM11 & M12 \\
\hline U42LM11 & $\mathrm{U} 31$ & 121 & U41 & M11 & U28LM22 & U07LM21 & M22 \\
\hline U31LM21 & U05LM22 & U09LM11 & U04 & $\mathrm{M} 21$ & U25LM12 & U34LM21 & M12 \\
\hline U36LM11 & U14LM12 & U04LM11 & U21LM22 & U06LM11 & U01LM22 & U43LM11 & U07LM12 \\
\hline U13LM21 & U17LM12 & U08LM21 & U04LM12 & U18LM11 & U25LM22 & U16LM11 & U16LM22 \\
\hline BCHLM112 & $\mathrm{BCHI}$ & $\mathrm{BCH}$ & $\mathrm{BCHI}$ & $\mathrm{BCH}$ & BCHLM322 & BCHLM412 & $\mathrm{BC}$ \\
\hline UstdLM112 & UstdLM122 & UstdLM212 & UstdLM222 & UstdLM312 & UstdLM322 & UstdLM412 & UstdLM422 \\
\hline U27LM11 & U29LM22 & U09LM21 & U09LM22 & \begin{tabular}{|l|} 
U11LM11 \\
\end{tabular} & U11LM22 & U30LM21 & U37LM12 \\
\hline U02LM21 & U17LM22 & U40LM21 & U12LM12 & U18LM21 & U22LM22 & U10LM21 & U16LM12 \\
\hline U42LM21 & $\mathrm{U} 27$ & & $\mathrm{U} 03$ & & $\mathrm{U} 2 \mathrm{C}$ & & \\
\hline U05LM11 & $\mathrm{U} 021$ & I11 & $\mathrm{U} 40 \mathrm{I}$ & $\mathrm{U} 0$ & U22LM12 & U15LM21 & M22 \\
\hline U33LM21 & U29LM12 & U21LM11 & U08LM22 & U26LM21 & U06LM12 & U30LM11 & U43LM22 \\
\hline U17LM21 & U13LM12 & U03LM11 & U08LM12 & U19LM21 & U26LM12 & U16LM21 & U23LM22 \\
\hline U29LM11 & U33LM22 & U12LM21 & U09LM12 & U24LM21 & U39LM22 & U37LM21 & U38LM12 \\
\hline & & & $\overline{\mathrm{U} 21 \mathrm{LM} 12}$ & & U19LM22 & U38LM21 & U30LM12 \\
\hline U13LM11 & U05LM12 & U35LM11 & U12LM22 & U22LM11 & U18LM22 & U07LM11 & U43LM12 \\
\hline U27LM21 & U42LM22 & U08LM11 & U40LM12 & U26LM11 & U01LM12 & BCHLM413 & BCHLM423 \\
\hline U05LM21 & U13LM22 & U41LM21 & U32LM22 & U06LM21 & U19LM12 & UstdLM413 & UstdLM423 \\
\hline BCHLM113 & BCHLM123 & BCHLM213 & BCHLM223 & BCHLM313 & BCHLM323 & & \\
\hline UstdLM113 & UstdLM123 & UstdLM213 & UstdLM223 & UstdLM313 & UstdLM323 & & \\
\hline
\end{tabular}


WSRC-STI-2006-00204

Revision 0

Appendix A (SRNL-SCS-2006-00030)

Table 4: ICP-AES Blocks \& Calibration Groups by Preparation Method

(Continued)

\begin{tabular}{|c|c|c|c|c|c|c|c|}
\hline \multicolumn{8}{|c|}{ PF Glass Samples } \\
\hline \multicolumn{8}{|c|}{ Used to Measure Elemental Al, B, Fe, Li, Ni, Si, \& U } \\
\hline Block 1-1 & Block 1-2 & Block 2-1 & Block 2-2 & Block 3-1 & Block 3-2 & Block 4-1 & Block 4-2 \\
\hline BCHPF111 & BCHPF121 & BCHPF211 & BCHPF221 & BCHPF311 & BCHPF321 & BCHPF411 & BCHPF421 \\
\hline UstdPF111 & UstdPF121 & UstdPF211 & UstdPF221 & UstdPF311 & UstdPF321 & UstdPF411 & UstdPF421 \\
\hline U36PF21 & U40PF22 & U28PF11 & U05PF12 & U23PF11 & U30PF22 & U24PF21 & U24PF12 \\
\hline U15PF21 & U08PF12 & U16PF21 & U17PF22 & U37PF11 & U39PF22 & U38PF11 & U07PF12 \\
\hline U06PF11 & U09PF22 & U21PF21 & U27PF22 & U18PF21 & U23PF12 & U29PF11 & U07PF22 \\
\hline U33PF11 & U33PF22 & U41PF11 & U27PF12 & U39PF11 & U30PF12 & U07PF11 & U02PF12 \\
\hline U09PF21 & U11PF12 & U16PF11 & U12PF12 & U13PF11 & U39PF12 & U24PF11 & U43PF12 \\
\hline U36PF11 & U11PF22 & U12PF21 & U41PF22 & U13PF21 & U37PF22 & U29PF21 & U22PF22 \\
\hline U14PF21 & $\begin{array}{l}\text { U15PF12 } \\
\end{array}$ & U10PF21 & U05PF22 & U01PF21 & U01PF22 & U31PF21 & U24PF22 \\
\hline U11PF11 & U15PF22 & U35PF21 & U35PF12 & U32PF21 & U18PF22 & U02PF11 & U38PF22 \\
\hline U20PF11 & U08PF22 & U25PF21 & U25PF12 & U26PF21 & U37PF12 & U04PF11 & U04PF12 \\
\hline U06PF21 & U20PF22 & U27PF11 & U21PF22 & $\begin{array}{l}\text { U37PF21 } \\
\end{array}$ & U01PF12 & U07PF21 & U43PF22 \\
\hline U09PF11 & U14PF12 & U21PF11 & U12PF22 & U42PF21 & U03PF12 & U19PF11 & U38PF12 \\
\hline BCHPF112 & BCHPF122 & BCHPF212 & BCHPF222 & BCHPF312 & BCHPF322 & \begin{tabular}{|l|} 
BCHPF412 \\
\end{tabular} & BCHPF422 \\
\hline UstdPF112 & UstdPF122 & UstdPF212 & UstdPF222 & UstdPF312 & UstdPF322 & \begin{tabular}{|l|} 
UstdPF412 \\
\end{tabular} & UstdPF422 \\
\hline U08PF11 & U34PF22 & U17PF11 & U16PF22 & U18PF11 & U26PF12 & U38PF21 & U19PF12 \\
\hline U08PF21 & U40PF12 & U27PF21 & U25PF22 & U23PF21 & U03PF22 & U19PF21 & U31PF12 \\
\hline U20PF21 & U06PF12 & U05PF21 & U17PF12 & U30PF21 & U32PF22 & U43PF21 & U29PF12 \\
\hline U34PF21 & U20PF12 & U25PF11 & U10PF22 & U42PF11 & U26PF22 & U43PF11 & U19PF22 \\
\hline U15PF11 & U33PF12 & U10PF11 & U21PF12 & U32PF11 & U13PF22 & U04PF21 & U31PF22 \\
\hline U40PF11 & U36PF22 & U35PF11 & U28PF12 & U39PF21 & U42PF12 & U31PF11 & U22PF12 \\
\hline U33PF21 & U06PF22 & $\overline{\mathrm{U} 41 \mathrm{PF} 21}$ & U28PF22 & U03PF11 & U42PF22 & U22PF21 & U02PF22 \\
\hline U34PF11 & U09PF12 & U05PF11 & U41PF12 & U30PF11 & U13PF12 & U22PF11 & U04PF22 \\
\hline U40PF21 & U14PF22 & U12PF11 & U10PF12 & U26PF11 & U18PF12 & U02PF21 & U29PF22 \\
\hline U14PF11 & U36PF12 & U28PF21 & U35PF22 & $\begin{array}{l}\text { U01PF11 } \\
\end{array}$ & U32PF12 & \begin{tabular}{|l|} 
BCHPF413 \\
\end{tabular} & BCHPF423 \\
\hline U11PF21 & U34PF12 & $\begin{array}{l}\text { U17PF21 } \\
\end{array}$ & U16PF12 & U03PF21 & U23PF22 & \begin{tabular}{|l|l|} 
UstdPF413 \\
\end{tabular} & UstdPF423 \\
\hline BCHPF113 & BCHPF123 & BCHPF213 & BCHPF223 & BCHPF313 & BCHPF323 & & \\
\hline UstdPF113 & UstdPF123 & UstdPF213 & UstdPF223 & UstdPF313 & UstdPF323 & & \\
\hline
\end{tabular}

\subsection{CONCLUding COMments}

In summary, this analytical plan identifies eight preparation blocks in Table 3 and sixteen ICPAES calibration blocks in Table 4 for use by PSAL. The sequencing of the activities associated with each of the steps in the analytical procedures has been randomized. The size of each of the blocks was selected so that it could be completed in a single work shift.

If a problem is discovered while measuring samples in a calibration block, the instrument should be re-calibrated and the block of samples re-measured in its entirety. If for some reason the measurements are not conducted in the sequences presented in this report, a record should be made of the actual order used along with any explanative comments.

The analytical plan indicated in the preceding tables should be modified by the personnel of PSAL to include any calibration check standards and/or other standards that are part of their routine operating procedures. It is also recommended that the solutions resulting from each of the prepared samples be archived for some period, considering the "shelf-life" of the solutions, in case questions arise during data analysis. This would allow for the solutions to be rerun without additional preparations, thus minimizing cost. 


\subsection{REFERENCES}

[1] Fox, K.M., T.B. Edwards, D.K. Peeler, "High Level Waste (HLW) Sludge Batch 4 (SB4): Selecting Glasses for a Variability Study,” WSRC-STI-2006-00039, July 2006.

[2] Jantzen, C.M., J.B. Pickett, K.G. Brown, T.B. Edwards, and D.C. Beam, "Process/ Product Models for the Defense Waste Processing Facility (DWPF): Part I.

Predicting Glass Durability from Composition Using a Thermodynamic Hydration Energy Reaction Model (THERMO ${ }^{\mathrm{TM}}$ ) (U)," WSRC-TR-93-673, Revision 1, Volume 2, Table B.1, pp. B.9, 1995.

[3] Ebert, W.L. and S.F. Wolf, "Round-Robin Testing of a Reference Glass for LowActivity Waste Forms," ANL-99/22, Argonne National Laboratory, Argonne, IL, October 1999. 
WSRC-STI-2006-00204

Revision 0

This page intentionally left blank. 


\section{Appendix B}

\section{An Analytical Plan for Measuring the First Set of PCT Solutions for SB4 Variability Study (U) (SRNL-SCS-2006-00026)}


July 31,2006

To:

K. M. Fox, SRNL

cc:

R. A. Baker, 773-42A

I. A. Reamer, 999-1W

D. R. Best, 786-1A (wo)

P. A. Toole, 786-1A (wo)

C. C. Herman, 999-W

R. C. Tuckfield, 773-42A

D. K. Peeler, 999-W

R. J. Workman, 999-1W

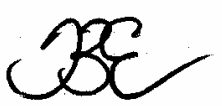

From: $\quad$ T. B. Edwards, 773-42A (5-5148)

Statistical Consulting Section

wo - without glass identifiers
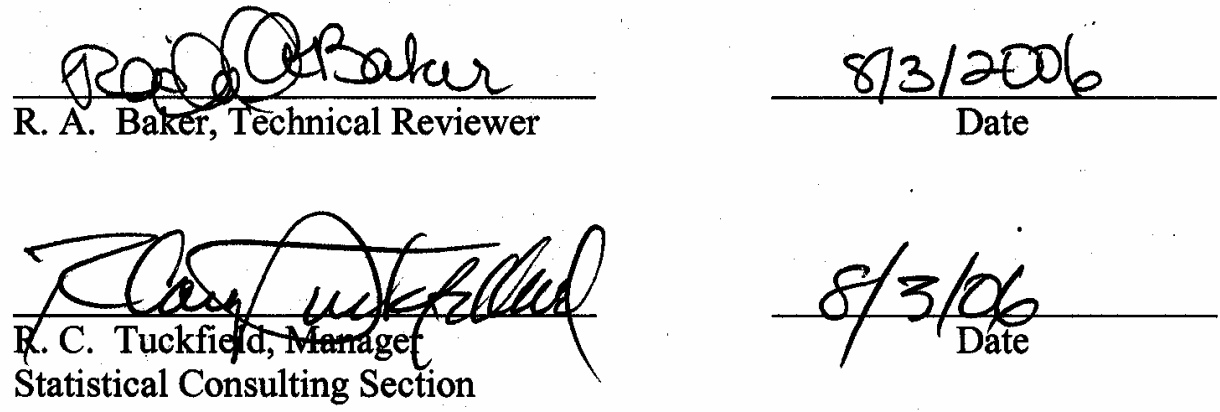

\section{An Analytical Plan for Measuring the First Set of PCT Solutions for SB4 Variability Study (U)}




\subsection{EXECUTIVE SUMMARY}

A glass variability study is underway at the Savannah River National Laboratory (SRNL) to support the processing of Sludge Batch 4 (SB4) at the Defense Waste Processing Facility (DWPF). Thirty-five (35) glasses have been selected to be batched and fabricated as part of this study. The durabilities of the glasses are to be measured using the Product Consistency Test (PCT) as defined in ASTM C-1285-2002. Two heat treatments are to be utilized during the fabrication of each of these glasses. Specifically, each of the glasses is to be quenched (i.e., rapidly cooled) and cooled in accordance with the centerline-canister-cooling (ccc) regime. Both heat treatments of each glass are to be subjected to the PCT. The PCT solutions are to be analyzed by SRNL's Process Science Analytical Laboratory (PSAL).

Due to the large number of glasses in this study, the PCTs for the variability study are to be grouped into three sets. This memorandum provides an analytical plan for the measurement of the PCTs by PSAL for the first set of glasses, which are labeled as SB4VS-01 through SB4VS-09. 
WSRC-STI-2006-00204

Revision 0

Appendix B (SRNL-SCS-2006-00026)

\subsection{INTRODUCTION}

A glass variability study is underway at the Savannah River National Laboratory (SRNL) to support the processing of Sludge Batch 4 (SB4) at the Defense Waste Processing Facility (DWPF) [1]. Thirty-five (35) glasses have been selected to be batched and fabricated as part of this study. The durabilities of the glasses are to be measured using the Product Consistency Test (PCT) as defined in ASTM C-1285-2002 [2]. Two heat treatments are to be utilized during the fabrication of each of these glasses. Specifically, each of the glasses is to be quenched (i.e., rapidly cooled) and cooled in accordance with the centerline-canister-cooling (ccc) regime. Both heat treatments of each glass are to be subjected to the PCT. The PCT solutions are to be analyzed by SRNL's Process Science Analytical Laboratory (PSAL).

Due to the large number of glasses in this study, the PCTs are to be grouped into three sets. This memorandum provides an analytical plan for the measurement of the PCTs by PSAL for the first set of glasses. Table 1 presents a listing of the glasses covered by this memorandum.

Table 1: Identifiers for Glasses Covered by this Plan

\begin{tabular}{||c|c||}
\hline SB4VS-01 & SB4VS-06 \\
\hline SB4VS-01ccc & SB4VS-06ccc \\
\hline SB4VS-02 & SB4VS-07 \\
\hline SB4VS-02ccc & SB4VS-07ccc \\
\hline SB4VS-03 & SB4VS-08 \\
\hline SB4VS-03ccc & SB4VS-08ccc \\
\hline SB4VS-04 & SB4VS-09 \\
\hline SB4VS-04ccc & SB4VS-09ccc \\
\hline SB4VS-05 & \\
\hline SB4VS-05ccc & \\
\hline
\end{tabular}

\subsection{DISCUSSION}

Each of the 18 study glasses of Table 1 is to be subjected to the PCT in triplicate. In addition to PCTs for the study glasses, triplicate PCTs are to be conducted on a sample of the Approved Reference Material - One (ARM-1) glass and a sample of the Environmental Assessment (EA) glass. Two reagent blank samples are also to be included in these tests. This results in 62 sample solutions being required to complete these PCTs.

The leachates from these tests will be diluted by adding $4 \mathrm{~mL}$ of $0.4 \mathrm{M} \mathrm{HNO}_{3}$ to $6 \mathrm{~mL}$ of the leachate (a 6:10 volume to volume, v:v, dilution) before being submitted to PSAL. The leachates of EA will be further diluted $(1: 10 \mathrm{v}: \mathrm{v})$ with deionized water prior to submission to PSAL in order to prevent problems with the nebulizer. Note that additional dilutions for the ccc versions of one or more of the study glasses may be needed due to a possible low durability of some of the glasses. Upon termination of the PCT, a decision is to be made (by the technicians and a PSAL representative, if called by the technician) as to whether any other dilutions are needed for these solutions to mitigate any potential gelling issues. Any extra dilutions are to be reported, and guidance is to be given as to how the dilutions are to be handled in the statistical assessment of the measurement data. More specifically, PSAL will be responsible for indicating if any additional dilutions were made and how they were, or how they should be, accounted for in the reported measurements. 
WSRC-STI-2006-00204

Revision 0

Appendix B (SRNL-SCS-2006-00026)

Table 2 presents identifying codes, R01 through R62, for the individual solutions required for the PCTs of the select study glasses and of the standards (EA, ARM-1, and blanks). This provides a naming convention that is to be used by PSAL in analyzing the solutions and reporting the relevant concentration measurements. ${ }^{\mathrm{a}}$

Table 2: Identifiers for the PCT Solutions Covered by this Plan

\begin{tabular}{|c|c|c|c|c|c|}
\hline $\begin{array}{c}\text { Original } \\
\text { Sample }\end{array}$ & $\begin{array}{c}\text { Solution } \\
\text { Identifier }\end{array}$ & $\begin{array}{c}\text { Original } \\
\text { Sample }\end{array}$ & $\begin{array}{c}\text { Solution } \\
\text { Identifier }\end{array}$ & $\begin{array}{c}\text { Original } \\
\text { Sample }\end{array}$ & $\begin{array}{c}\text { Solution } \\
\text { Identifier }\end{array}$ \\
\hline SB4VS-01 & R29 & SB4VS-04ccc & R52 & SB4VS-08 & R51 \\
\hline SB4VS-01 & R45 & SB4VS-04ccc & R36 & SB4VS-08 & R16 \\
\hline SB4VS-01 & R35 & SB4VS-04ccc & R02 & SB4VS-08 & R34 \\
\hline SB4VS-01ccc & R08 & SB4VS-05 & R42 & SB4VS-08ccc & R23 \\
\hline SB4VS-01ccc & R21 & SB4VS-05 & R12 & SB4VS-08ccc & R10 \\
\hline SB4VS-01ccc & R57 & SB4VS-05 & R44 & SB4VS-08ccc & R31 \\
\hline SB4VS-02 & R46 & SB4VS-05ccc & R19 & SB4VS-09 & R22 \\
\hline SB4VS-02 & R37 & SB4VS-05ccc & R58 & SB4VS-09 & R11 \\
\hline SB4VS-02 & R18 & SB4VS-05ccc & R53 & SB4VS-09 & R07 \\
\hline SB4VS-02ccc & R54 & SB4VS-06 & R38 & SB4VS-09ccc & R60 \\
\hline SB4VS-02ccc & R56 & SB4VS-06 & R39 & SB4VS-09ccc & R27 \\
\hline SB4VS-02ccc & R14 & SB4VS-06 & R24 & SB4VS-09ccc & R59 \\
\hline SB4VS-03 & R32 & SB4VS-06ccc & R40 & EA & R30 \\
\hline SB4VS-03 & R50 & SB4VS-06ccc & R04 & EA & R20 \\
\hline SB4VS-03 & R55 & SB4VS-06ccc & R33 & EA & R25 \\
\hline SB4VS-03ccc & R06 & SB4VS-07 & R17 & ARM-1 & R05 \\
\hline SB4VS-03ccc & R01 & SB4VS-07 & R62 & ARM-1 & R61 \\
\hline SB4VS-03ccc & R28 & SB4VS-07 & R26 & ARM-1 & R09 \\
\hline SB4VS-04 & R13 & SB4VS-07ccc & R43 & blank & R49 \\
\hline SB4VS-04 & R48 & SB4VS-07ccc & R47 & blank & R03 \\
\hline SB4VS-04 & R15 & SB4VS-07ccc & R41 & & \\
\hline
\end{tabular}

\subsection{Analytical Plan}

The analytical plan for PSAL is provided in this section. Each of the solution samples submitted to PSAL is to be analyzed only once for each of the following: boron (B), barium (Ba), cadmium $(\mathrm{Cd})$, chromium $(\mathrm{Cr})$, iron $(\mathrm{Fe})$, lithium $(\mathrm{Li})$, sodium $(\mathrm{Na})$, lead $(\mathrm{Pb})$, silicon $(\mathrm{Si})$, thorium $(\mathrm{Th})$, and uranium (U) concentrations. $\mathrm{B}, \mathrm{Li}, \mathrm{Na}$, and $\mathrm{Si}$ are the elements that are to be used in the assessment of glass durability; the other elements are being monitored to address solution disposal issues in SRNL upon termination of the PCTs. The measurements are to be made in parts per million ( $\mathrm{ppm})$. The analytical procedure used by PSAL to determine the concentrations utilizes an Inductively Coupled Plasma - Atomic Emission Spectrometer (ICP-AES). The PCT solutions (as identified in Table 2) are grouped in three ICP-AES blocks for processing by PSAL in Table 3. Each block requires a different calibration of the ICP-AES.

a Renaming these samples ensures that they will be processed as blind samples by PSAL. This table does not contain the solution identifiers for those on the distribution list with a "wo" following their names. 
WSRC-STI-2006-00204

Revision 0

Appendix B (SRNL-SCS-2006-00026)

Table 3: ICP-AES Calibration Blocks for Leachate Measurements

\begin{tabular}{|c|c|c|}
\hline Block 1 & Block 2 & Block 3 \\
\hline std-b1-1 & std-b2-1 & std-b3-1 \\
\hline R38 & R39 & R24 \\
\hline R40 & R04 & R33 \\
\hline R29 & R45 & R03 \\
\hline R08 & R21 & R35 \\
\hline R49 & R16 & R57 \\
\hline R51 & R10 & R34 \\
\hline R23 & R37 & R31 \\
\hline R46 & R56 & R18 \\
\hline R54 & R48 & R14 \\
\hline R13 & R36 & R15 \\
\hline std-b1-2 & std-b2-2 & std-b3-2 \\
\hline R52 & R62 & R02 \\
\hline R17 & R47 & R26 \\
\hline R43 & R12 & R41 \\
\hline R42 & R58 & R44 \\
\hline R19 & R20 & R53 \\
\hline R30 & R61 & R25 \\
\hline R05 & R11 & R09 \\
\hline R22 & R27 & R07 \\
\hline R60 & R50 & R59 \\
\hline R32 & R01 & R55 \\
\hline R06 & std-b2-3 & R28 \\
\hline std-b1-3 & & std-b3-3 \\
\hline
\end{tabular}

A multi-element solution standard (denoted by "std-bi-j" where $i=1$ to 3 represents the block number and $\mathrm{j}=1,2$, and 3 represents the position in the block) was added at the beginning, middle, and end of each of the three blocks. This standard may be useful in checking and correcting for bias in the concentration measurements arising from the ICP calibrations.

\subsection{SUMMARY}

In summary, this analytical plan provides identifiers for the PCT solutions in Table 2 and three ICP-AES calibration blocks in Table 3 for PSAL to use in conducting the boron (B), barium (Ba), cadmium $(\mathrm{Cd})$, chromium $(\mathrm{Cr})$, iron $(\mathrm{Fe})$, lithium $(\mathrm{Li})$, sodium $(\mathrm{Na})$, lead $(\mathrm{Pb})$, silicon $(\mathrm{Si})$, thorium (Th), and uranium (U) concentration measurements for this PCT study. The sequencing of the activities associated with each of the steps in the analytical procedure has been randomized. The size of the blocks was selected so that each block could be completed in a single work shift. If for some reason the measurements are not conducted in the sequence presented in this memorandum, the actual order should be recorded along with any explanative comments.

The analytical plan indicated in the preceding tables should be modified by the personnel of PSAL to include any calibration check standards and/or other standards that are part of their standard operating procedures. 
WSRC-STI-2006-00204

Revision 0

Appendix B (SRNL-SCS-2006-00026)

\subsection{REFERENCES}

[1] Fox, K.M., T.B. Edwards, D.K. Peeler, "High Level Waste (HLW) Sludge Batch 4 (SB4): Selecting Glasses for a Variability Study,” WSRC-STI-2006-00039, July 2006.

[2] ASTM C-1285-2002, "Standard Test Methods for Determining Chemical Durability of Nuclear Waste Glasses: The Product Consistency Test (PCT)," ASTM, 2002. 


\section{Appendix C}

\section{An Analytical Plan for Measuring the Second Set of PCT Solutions for the SB4 Variability Study (U) (SRNL-SCS-2006-00028)}


SRNL-SCS-2006-00028

August 9, 2006

To:

K. M. Fox, SRNL

cc:
R. A. Baker, 773-42A
D. R. Best, 786-1A (wo)
C. C. Herman, 999-W
D. K. Peeler, 999-W

I. A. Reamer, 999-1W

P. A. Toole, 786-1A (wo)

R. C. Tuckfield, 773-42A

R. J. Workman, 999-1W

From: T. B. Edwards, 773-42A (5-5148)

Statistical Consulting Section

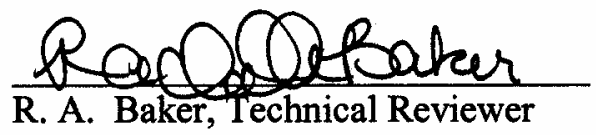

wo - without glass identifiers

R. A. Baker, Technical Reviewer
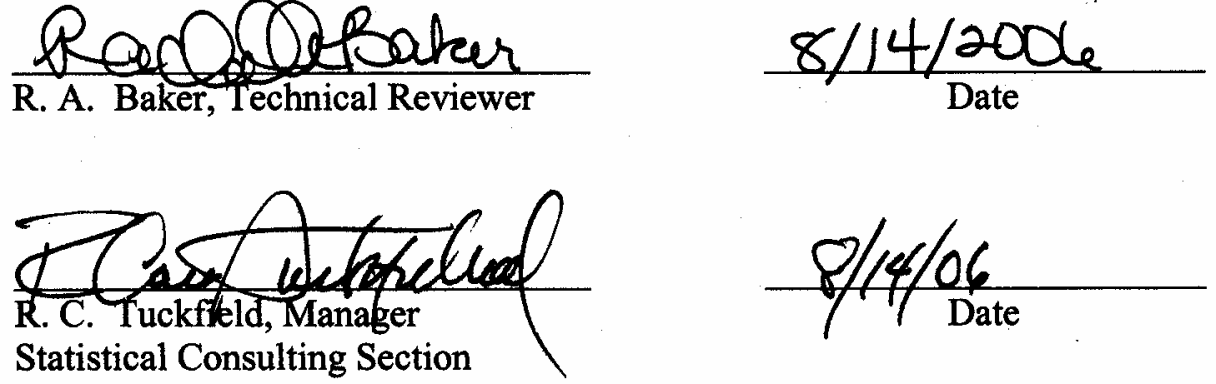

\section{An Analytical Plan for Measuring the Second Set of PCT Solutions for the SB4 Variability Study (U)}


WSRC-STI-2006-00204

Revision 0

Appendix C (SRNL-SCS-2006-00028)

\subsection{EXECUTIVE SUMMARY}

A glass variability study is underway at the Savannah River National Laboratory (SRNL) to support the processing of Sludge Batch 4 (SB4) at the Defense Waste Processing Facility (DWPF). Thirty-five (35) glasses have been selected to be batched and fabricated as part of this study. The durabilities of the glasses are to be measured using the Product Consistency Test (PCT) as defined in ASTM C-1285-2002. Two heat treatments are to be utilized during the fabrication of each of these glasses. Specifically, each of the glasses is to be quenched (i.e., rapidly cooled) and cooled in accordance with the centerline-canister-cooling (ccc) regime. Both heat treatments of each glass are to be subjected to the PCT. The PCT solutions are to be analyzed by SRNL's Process Science Analytical Laboratory (PSAL).

Due to the large number of glasses in this study, the PCTs for the variability study are to be grouped into three sets. This memorandum provides an analytical plan for the measurement of the PCTs by PSAL for the second set of glasses, which are labeled as SB4VS-10 through SB4VS-21. 
WSRC-STI-2006-00204

Revision 0

Appendix C (SRNL-SCS-2006-00028)

\subsection{INTRODUCTION}

A glass variability study is underway at the Savannah River National Laboratory (SRNL) to support the processing of Sludge Batch 4 (SB4) at the Defense Waste Processing Facility (DWPF) [1]. Thirty-five (35) glasses have been selected to be batched and fabricated as part of this study. The durabilities of the glasses are to be measured using the Product Consistency Test (PCT) as defined in ASTM C-1285-2002 [2]. Two heat treatments are to be utilized during the fabrication of each of these glasses. Specifically, each of the glasses is to be quenched (i.e., rapidly cooled) and cooled in accordance with the centerline-canister-cooling (ccc) regime. Both heat treatments of each glass are to be subjected to the PCT. The PCT solutions are to be analyzed by SRNL's Process Science Analytical Laboratory (PSAL).

Due to the large number of glasses in this study, the PCTs are to be grouped into three sets. This memorandum provides an analytical plan for the measurement of the PCTs by PSAL for the second set of glasses. Table 1 presents a listing of the glasses covered by this memorandum.

Table 1: Identifiers for Glasses Covered by this Plan

\begin{tabular}{||c|c||}
\hline SB4VS-10 & SB4VS-16 \\
\hline SB4VS-10ccc & SB4VS-16ccc \\
\hline SB4VS-11 & SB4VS-17 \\
\hline SB4VS-11ccc & SB4VS-17ccc \\
\hline SB4VS-12 & SB4VS-18 \\
\hline SB4VS-12ccc & SB4VS-18ccc \\
\hline SB4VS-13 & SB4VS-19 \\
\hline SB4VS-13ccc & SB4VS-19ccc \\
\hline SB4VS-14 & SB4VS-20 \\
\hline SB4VS-14ccc & SB4VS-20ccc \\
\hline SB4VS-15 & SB4VS-21 \\
\hline SB4VS-15ccc & SB4VS-21ccc \\
\hline
\end{tabular}

\subsection{DISCUSSION}

Each of the 24 study glasses of Table 1 is to be subjected to the PCT in triplicate. In addition to PCTs for the study glasses, triplicate PCTs are to be conducted on a sample of the Approved Reference Material - One (ARM-1) glass and a sample of the Environmental Assessment (EA) glass. Two reagent blank samples are also to be included in these tests. This results in 80 sample solutions being required to complete these PCTs.

The leachates from these tests will be diluted by adding $4 \mathrm{~mL}$ of $0.4 \mathrm{M} \mathrm{HNO}_{3}$ to $6 \mathrm{~mL}$ of the leachate (a 6:10 volume to volume, v:v, dilution) before being submitted to PSAL. The leachates of EA will be further diluted $(1: 10 \mathrm{v}: \mathrm{v})$ with deionized water prior to submission to PSAL in order to prevent problems with the nebulizer. Note that additional dilutions for the ccc versions of one or more of the study glasses may be needed due to a possible low durability of some of the glasses. Upon termination of the PCT, a decision is to be made (by the technicians and a PSAL representative, if called by the technician) as to whether any other dilutions are needed for these solutions to mitigate any potential gelling issues. Any extra dilutions are to be reported, and guidance is to be given as to how the dilutions are to be handled in the statistical assessment of the measurement data. More specifically, PSAL will be responsible for indicating if any 
additional dilutions were made and how they were, or how they should be, accounted for in the reported measurements.

Table 2 presents identifying codes, S01 through S80, for the individual solutions required for the PCTs of the select study glasses and of the standards (EA, ARM-1, and blanks). This provides a naming convention that is to be used by PSAL in analyzing the solutions and reporting the relevant concentration measurements. ${ }^{\text {a }}$

Table 2: Identifiers for the PCT Solutions Covered by this Plan

\begin{tabular}{|c|c|c|c|c|c|}
\hline $\begin{array}{l}\text { Original } \\
\text { Sample }\end{array}$ & $\begin{array}{l}\text { Solution } \\
\text { Identifier }\end{array}$ & $\begin{array}{l}\text { Original } \\
\text { Sample }\end{array}$ & $\begin{array}{l}\text { Solution } \\
\text { Identifier }\end{array}$ & $\begin{array}{l}\text { Original } \\
\text { Sample }\end{array}$ & $\begin{array}{l}\text { Solution } \\
\text { Identifier }\end{array}$ \\
\hline SB4VS-10 & S52 & SB4VS-14ccc & S05 & SB4VS-19 & S51 \\
\hline SB4VS-10 & S24 & SB4VS-14ccc & S64 & SB4VS-19 & S15 \\
\hline SB4VS-10 & S47 & SB4VS-14ccc & S17 & SB4VS-19 & $\mathrm{S} 72$ \\
\hline SB4VS-10ccc & S10 & SB4VS-15 & S74 & SB4VS-19ccc & S65 \\
\hline SB4VS-10 ccc & S03 & SB4VS-15 & S27 & SB4VS-19ccc & S50 \\
\hline SB4VS-10ccc & S08 & SB4VS-15 & S49 & SB4VS-19ccc & S73 \\
\hline SB4VS-11 & S20 & SB4VS-15ccc & S40 & SB4VS-20 & S33 \\
\hline SB4VS-11 & S13 & SB4VS-15ccc & S36 & SB4VS-20 & S42 \\
\hline SB4VS-11 & S31 & SB4VS-15ccc & S46 & SB4VS-20 & S71 \\
\hline SB4VS-11ccc & S48 & SB4VS-16 & S12 & SB4VS-20ccc & S78 \\
\hline SB4VS-11ccc & S34 & SB4VS-16 & S75 & SB4VS-20ccc & S06 \\
\hline SB4VS-11ccc & S77 & SB4VS-16 & S18 & SB4VS-20ccc & S32 \\
\hline SB4VS-12 & $\mathrm{S} 25$ & SB4VS-16ccc & S61 & SB4VS-21 & S29 \\
\hline SB4VS-12 & S54 & SB4VS-16ccc & S14 & SB4VS-21 & S16 \\
\hline SB4VS-12 & S59 & SB4VS-16ccc & S35 & SB4VS-21 & S63 \\
\hline SB4VS-12ccc & S80 & SB4VS-17 & S28 & SB4VS-21ccc & $\begin{array}{l}\text { S01 } \\
\end{array}$ \\
\hline SB4VS-12ccc & S57 & SB4VS-17 & S58 & SB4VS-21ccc & S45 \\
\hline SB4VS-12ccc & S70 & SB4VS-17 & S43 & SB4VS-21ccc & S09 \\
\hline SB4VS-13 & S04 & SB4VS-17ccc & S44 & EA & S07 \\
\hline SB4VS-13 & S69 & SB4VS-17ccc & S38 & EA & S30 \\
\hline SB4VS-13 & S55 & SB4VS-17ccc & S11 & EA & S68 \\
\hline SB4VS-13ccc & S66 & SB4VS-18 & S56 & ARM-1 & S37 \\
\hline SB4VS-13ccc & S02 & SB4VS-18 & $\begin{array}{l}\text { S53 } \\
\end{array}$ & ARM-1 & S67 \\
\hline SB4VS-13ccc & S23 & SB4VS-18 & S22 & ARM-1 & S76 \\
\hline SB4VS-14 & S41 & SB4VS-18ccc & S79 & blank & S26 \\
\hline SB4VS-14 & S60 & SB4VS-18ccc & S19 & blank & S21 \\
\hline SB4VS-14 & S62 & SB4VS-18ccc & S39 & & \\
\hline
\end{tabular}

a Renaming these samples ensures that they will be processed as blind samples by PSAL. This table does not contain the solution identifiers for those on the distribution list with a "wo" following their names. 
WSRC-STI-2006-00204

Revision 0

Appendix C (SRNL-SCS-2006-00028)

\subsection{Analytical Plan}

The analytical plan for PSAL is provided in this section. Each of the solution samples submitted to PSAL is to be analyzed only once for each of the following: aluminum (Al), boron (B), barium $(\mathrm{Ba})$, cadmium $(\mathrm{Cd})$, chromium $(\mathrm{Cr})$, iron $(\mathrm{Fe})$, lithium $(\mathrm{Li})$, sodium $(\mathrm{Na})$, lead $(\mathrm{Pb})$, silicon $(\mathrm{Si})$, thorium (Th), and uranium (U) concentrations. B, Li, Na, and Si are the elements that are to be used in the assessment of glass durability; the other elements are being monitored to address solution disposal issues in SRNL upon termination of the PCTs. The measurements are to be made in parts per million (ppm). The analytical procedure used by PSAL to determine the concentrations utilizes an Inductively Coupled Plasma - Atomic Emission Spectrometer (ICPAES). The PCT solutions (as identified in Table 2) are grouped in six ICP-AES blocks for processing by PSAL in Table 3. Each block requires a different calibration of the ICP-AES.

Table 3: ICP-AES Calibration Blocks for Leachate Measurements

\begin{tabular}{|c|c|c|c|c|c|}
\hline Block 1 & Block 2 & Block 3 & Block 4 & Block 5 & Block 6 \\
\hline std-b1-1 & std-b2-1 & std-b3-1 & std-b4-1 & std-b5-1 & std-b6-1 \\
\hline S79 & S13 & S31 & S61 & S03 & S11 \\
\hline S26 & S34 & S70 & S05 & S06 & S46 \\
\hline S51 & S57 & S73 & S78 & S38 & S32 \\
\hline S29 & S45 & S55 & S44 & S24 & S62 \\
\hline S80 & S53 & S63 & S52 & S64 & S08 \\
\hline S07 & S54 & S23 & S10 & S60 & S47 \\
\hline S04 & S16 & S59 & S41 & S42 & S17 \\
\hline std-b1-2 & std-b2-2 & std-b3-2 & std-b4-2 & std-b5-2 & std-b6-2 \\
\hline S20 & S50 & S72 & S33 & S36 & S35 \\
\hline S01 & S69 & S09 & S12 & S58 & S18 \\
\hline S56 & S30 & S39 & S40 & S27 & S71 \\
\hline S48 & S02 & S68 & S74 & S14 & S21 \\
\hline S66 & S19 & S77 & S28 & S75 & S49 \\
\hline S25 & S15 & S22 & S37 & S67 & S43 \\
\hline S65 & std-b2-3 & std-b3-3 & std-b4-3 & std-b5-3 & S76 \\
\hline std-b1-3 & & & & & std-b6-3 \\
\hline
\end{tabular}

A multi-element solution standard (denoted by "std-bi-j" where $i=1$ to 6 represents the block number and $\mathrm{j}=1,2$, and 3 represents the position in the block) was added at the beginning, middle, and end of each of the three blocks. This standard may be useful in checking and correcting for bias in the concentration measurements arising from the ICP calibrations.

\subsection{SUMMARY}

In summary, this analytical plan provides identifiers for the PCT solutions in Table 2 and six ICPAES calibration blocks in Table 3 for PSAL to use in conducting the aluminum (Al), boron (B), barium $(\mathrm{Ba})$, cadmium $(\mathrm{Cd})$, chromium $(\mathrm{Cr})$, iron $(\mathrm{Fe})$, lithium $(\mathrm{Li})$, sodium $(\mathrm{Na})$, lead $(\mathrm{Pb})$, silicon ( $\mathrm{Si}$ ), thorium $(\mathrm{Th})$, and uranium $(\mathrm{U})$ concentration measurements for this PCT study. The sequencing of the activities associated with each of the steps in the analytical procedure has been randomized. The size of the blocks was selected so that each block could be completed in a 
single work shift. If for some reason the measurements are not conducted in the sequence presented in this memorandum, the actual order should be recorded along with any explanative comments.

The analytical plan indicated in the preceding tables should be modified by the personnel of PSAL to include any calibration check standards and/or other standards that are part of their standard operating procedures.

\subsection{REFERENCES}

[1] Fox, K.M., T.B. Edwards, D.K. Peeler, "High Level Waste (HLW) Sludge Batch 4 (SB4): Selecting Glasses for a Variability Study,” WSRC-STI-2006-00039, July 2006.

[2] ASTM C-1285-2002, "Standard Test Methods for Determining Chemical Durability of Nuclear Waste Glasses: The Product Consistency Test (PCT)," ASTM, 2002. 
WSRC-STI-2006-00204

Revision 0

This page intentionally left blank. 
Appendix D

\section{An Analytical Plan for Measuring the Third Set of PCT Solutions for the SB4 Variability Study (U) (SRNL-SCS-2006-00031)}


SRNL-SCS-2006-00031

August 18, 2006

To: $\quad$ K. M. Fox, SRNL

cc:
R. A. Baker, 773-42A
D. R. Best, 786-1A (wo)
C. C. Herman, 999-W
D. K. Peeler, 999-W

I. A. Reamer, 999-1W

P. A. Toole, 786-1A (wo)

R. C. Tuckfield, 773-42A

R. J. Workman, 999-1W

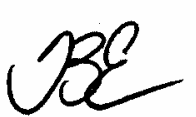

From: $\quad$ T. B. Edwards, 773-42A (5-5148)

Statistical Consulting Section

wo - without glass identifiers
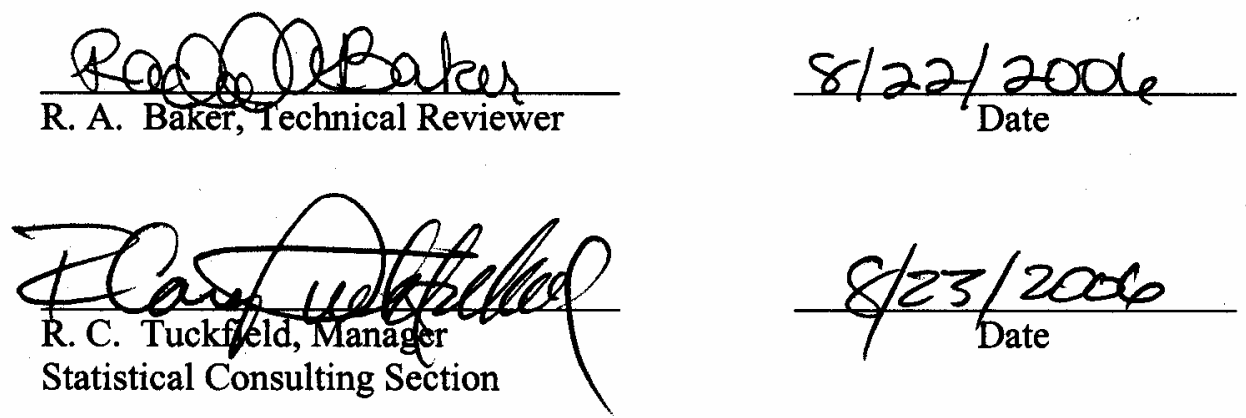

\section{An Analytical Plan for Measuring the Third Set of PCT Solutions for the SB4 Variability Study (U)}


WSRC-STI-2006-00204

Revision 0

Appendix D (SRNL-SCS-2006-00031)

\subsection{EXECUTIVE SUMMARY}

A glass variability study is underway at the Savannah River National Laboratory (SRNL) to support the processing of Sludge Batch 4 (SB4) at the Defense Waste Processing Facility (DWPF). Thirty-five (35) glasses have been selected to be batched and fabricated as part of this study. The durabilities of the glasses are to be measured using the Product Consistency Test (PCT) as defined in ASTM C-1285-2002. Two heat treatments are to be utilized during the fabrication of each of these glasses. Specifically, each of the glasses is to be quenched (i.e., rapidly cooled) and cooled in accordance with the centerline-canister-cooling (ccc) regime. Both heat treatments of each glass are to be subjected to the PCT. The PCT solutions are to be analyzed by SRNL's Process Science Analytical Laboratory (PSAL).

Due to the large number of glasses in this study, the PCTs for the variability study are to be grouped into three sets. This memorandum provides an analytical plan for the measurement of the PCTs by PSAL for the third (and last) set of glasses, which are labeled as SB4VS-22 through SB4VS-35. 
WSRC-STI-2006-00204

Revision 0

Appendix D (SRNL-SCS-2006-00031)

\subsection{INTRODUCTION}

A glass variability study is underway at the Savannah River National Laboratory (SRNL) to support the processing of Sludge Batch 4 (SB4) at the Defense Waste Processing Facility (DWPF) [1]. Thirty-five (35) glasses have been selected to be batched and fabricated as part of this study. The durabilities of the glasses are to be measured using the Product Consistency Test (PCT) as defined in ASTM C-1285-2002 [2]. Two heat treatments are to be utilized during the fabrication of each of these glasses. Specifically, each of the glasses is to be quenched (i.e., rapidly cooled) and cooled in accordance with the centerline-canister-cooling (ccc) regime. Both heat treatments of each glass are to be subjected to the PCT. The PCT solutions are to be analyzed by SRNL's Process Science Analytical Laboratory (PSAL).

Due to the large number of glasses in this study, the PCTs are to be grouped into three sets. This memorandum provides an analytical plan for the measurement of the PCTs by PSAL for the third (and last) set of glasses. Table 1 presents a listing of the glasses covered by this memorandum.

Table 1: Identifiers for Glasses Covered by this Plan

\begin{tabular}{||c|c||}
\hline SB4VS-22 & SB4VS-29 \\
\hline SB4VS-22ccc & SB4VS-29ccc \\
\hline SB4VS-23 & SB4VS-30 \\
\hline SB4VS-23ccc & SB4VS-30ccc \\
\hline SB4VS-24 & SB4VS-31 \\
\hline SB4VS-24ccc & SB4VS-31ccc \\
\hline SB4VS-25 & SB4VS-32 \\
\hline SB4VS-25ccc & SB4VS-32ccc \\
\hline SB4VS-26 & SB4VS-33 \\
\hline SB4VS-26ccc & SB4VS-33ccc \\
\hline SB4VS-27 & SB4VS-34 \\
\hline SB4VS-27ccc & SB4VS-34ccc \\
\hline SB4VS-28 & SB4VS-35 \\
\hline SB4VS-28ccc & SB4VS-35ccc \\
\hline
\end{tabular}

\subsection{DisCUSSION}

Each of the 28 study glasses of Table 1 is to be subjected to the PCT in triplicate. In addition to PCTs for the study glasses, triplicate PCTs are to be conducted on a sample of the Approved Reference Material - One (ARM-1) glass and a sample of the Environmental Assessment (EA) glass. Two reagent blank samples are also to be included in these tests. This results in 92 sample solutions being required to complete these PCTs.

The leachates from these tests will be diluted by adding $4 \mathrm{~mL}$ of $0.4 \mathrm{M} \mathrm{HNO}_{3}$ to $6 \mathrm{~mL}$ of the leachate (a 6:10 volume to volume, v:v, dilution) before being submitted to PSAL. The leachates of EA will be further diluted (1:10 v:v) with deionized water prior to submission to PSAL in order to prevent problems with the nebulizer. Note that additional dilutions for the ccc versions of one or more of the study glasses may be needed due to a possible low durability of some of the glasses. Upon termination of the PCT, a decision is to be made (by the technicians and a PSAL 
representative, if called by the technician) as to whether any other dilutions are needed for these solutions to mitigate any potential gelling issues. Any extra dilutions are to be reported, and guidance is to be given as to how the dilutions are to be handled in the statistical assessment of the measurement data. More specifically, PSAL will be responsible for indicating if any additional dilutions were made and how they were, or how they should be, accounted for in the reported measurements.

Table 2 presents identifying codes, T01 through T92, for the individual solutions required for the PCTs of the select study glasses and of the standards (EA, ARM-1, and blanks). This provides a naming convention that is to be used by PSAL in analyzing the solutions and reporting the relevant concentration measurements. ${ }^{\text {a }}$

Table 2: Identifiers for the PCT Solutions Covered by this Plan

\begin{tabular}{|c|c|c|c|c|c|}
\hline $\begin{array}{l}\text { Original } \\
\text { Sample }\end{array}$ & $\begin{array}{l}\text { Solution } \\
\text { Identifier }\end{array}$ & $\begin{array}{l}\text { Original } \\
\text { Sample }\end{array}$ & $\begin{array}{l}\text { Solution } \\
\text { Identifier }\end{array}$ & $\begin{array}{l}\text { Original } \\
\text { Sample }\end{array}$ & $\begin{array}{l}\text { Solution } \\
\text { Identifier }\end{array}$ \\
\hline SB4VS-22 & T15 & SB4VS-27ccc & T76 & SB4VS-33 & T31 \\
\hline SB4VS-22 & T69 & SB4VS-27ccc & $\mathrm{T} 02$ & SB4VS-33 & $\mathrm{T} 38$ \\
\hline SB4VS-22 & T50 & SB4VS-27ccc & T42 & SB4VS-33 & T40 \\
\hline SB4VS-22ccc & T35 & SB4VS-28 & $\mathrm{T} 88$ & SB4VS-33ccc & T37 \\
\hline SB4VS-22ccc & T36 & SB4VS-28 & T03 & SB4VS-33ccc & T92 \\
\hline SB4VS-22ccc & T44 & SB4VS-28 & T20 & SB4VS-33ccc & T53 \\
\hline SB4VS-23 & T47 & SB4VS-28ccc & T82 & SB4VS-34 & T61 \\
\hline SB4VS-23 & T08 & SB4VS-28ccc & T41 & SB4VS-34 & $\mathrm{T} 25$ \\
\hline SB4VS-23 & T54 & SB4VS-28ccc & T46 & SB4VS-34 & T80 \\
\hline SB4VS-23ccc & T05 & SB4VS-29 & T18 & SB4VS-34ccc & $\mathrm{T} 21$ \\
\hline SB4VS-23ccc & $\mathrm{T} 75$ & SB4VS-29 & T63 & SB4VS-34ccc & T06 \\
\hline SB4VS-23ccc & $\mathrm{T} 10$ & SB4VS-29 & T58 & SB4VS-34ccc & T33 \\
\hline SB4VS-24 & T48 & SB4VS-29ccc & $\mathrm{T} 13$ & SB4VS-35 & T11 \\
\hline SB4VS-24 & $\mathrm{T} 72$ & SB4VS-29ccc & $\mathrm{T} 79$ & SB4VS-35 & $\mathrm{T} 27$ \\
\hline SB4VS-24 & T39 & SB4VS-29ccc & $\mathrm{T} 73$ & SB4VS-35 & T51 \\
\hline SB4VS-24ccc & T16 & SB4VS-30 & T01 & SB4VS-35ccc & T70 \\
\hline SB4VS-24ccc & T57 & SB4VS-30 & T84 & SB4VS-35ccc & T43 \\
\hline SB4VS-24ccc & T64 & SB4VS-30 & T62 & SB4VS-35ccc & T68 \\
\hline SB4VS-25 & T52 & SB4VS-30ccc & $\mathrm{T} 81$ & EA & $\mathrm{T} 77$ \\
\hline SB4VS-25 & T87 & SB4VS-30ccc & $\mathrm{T} 24$ & EA & T66 \\
\hline SB4VS-25 & T59 & SB4VS-30ccc & T32 & EA & T12 \\
\hline SB4VS-25ccc & T71 & SB4VS-31 & T65 & ARM-1 & T91 \\
\hline SB4VS-25ccc & T30 & SB4VS-31 & T67 & ARM-1 & $\mathrm{T} 83$ \\
\hline SB4VS-25ccc & T34 & SB4VS-31 & T56 & ARM-1 & $\mathrm{T} 74$ \\
\hline SB4VS-26 & T85 & SB4VS-31ccc & T55 & blank & T14 \\
\hline SB4VS-26 & T19 & SB4VS-31ccc & T60 & blank & T90 \\
\hline SB4VS-26 & T86 & SB4VS-31ccc & $\mathrm{T} 78$ & & \\
\hline SB4VS-26ccc & T29 & SB4VS-32 & T09 & & \\
\hline SB4VS-26ccc & T07 & SB4VS-32 & T04 & & \\
\hline SB4VS-26ccc & $\mathrm{T} 45$ & SB4VS-32 & $\mathrm{T} 22$ & & \\
\hline SB4VS-27 & T26 & SB4VS-32ccc & T89 & & \\
\hline SB4VS-27 & T49 & SB4VS-32ccc & $\mathrm{T} 17$ & & \\
\hline SB4VS-27 & T28 & SB4VS-32ccc & $\mathrm{T} 23$ & & \\
\hline
\end{tabular}

a Renaming these samples ensures that they will be processed as blind samples by PSAL. This table does not contain the solution identifiers for those on the distribution list with a "wo" following their names. 


\subsection{Analytical Plan}

The analytical plan for PSAL is provided in this section. Each of the solution samples submitted to PSAL is to be analyzed only once for each of the following: aluminum (Al), boron (B), iron $(\mathrm{Fe})$, lithium $(\mathrm{Li})$, sodium $(\mathrm{Na})$, silicon $(\mathrm{Si})$, thorium $(\mathrm{Th})$, and uranium $(\mathrm{U})$ concentrations. B, Li, $\mathrm{Na}$, and $\mathrm{Si}$ are the elements that are to be used in the assessment of glass durability. The measurements are to be made in parts per million ( $\mathrm{ppm})$. The analytical procedure used by PSAL to determine the concentrations utilizes an Inductively Coupled Plasma - Atomic Emission Spectrometer (ICP-AES). The PCT solutions (as identified in Table 2) are grouped in six ICPAES blocks for processing by PSAL in Table 3. Each block requires a different calibration of the ICP-AES.

Table 3: ICP-AES Calibration Blocks for Leachate Measurements

\begin{tabular}{|c|c|c|c|c|c|}
\hline Block 1 & Block 2 & Block 3 & Block 4 & Block 5 & Block 6 \\
\hline std-b1-1 & std-b2-1 & std-b3-1 & std-b4-1 & std-b5-1 & std-b6-1 \\
\hline T48 & $\mathrm{T} 87$ & T34 & T05 & T67 & T50 \\
\hline T01 & T66 & T64 & T21 & T79 & T56 \\
\hline T77 & T84 & T32 & T11 & T36 & T44 \\
\hline T37 & T03 & T62 & T61 & T07 & T74 \\
\hline T26 & T30 & T20 & T55 & T60 & T51 \\
\hline T81 & $\mathrm{T} 24$ & $\mathrm{~T} 40$ & T18 & T69 & T58 \\
\hline T89 & T57 & T28 & T29 & T63 & T33 \\
\hline $\mathrm{T} 88$ & T92 & T12 & $\mathrm{T} 35$ & $\mathrm{~T} 43$ & T90 \\
\hline std-b1-2 & std-b2-2 & std-b3-2 & std-b4-2 & std-b5-2 & std-b6-2 \\
\hline T71 & T17 & T46 & T85 & $\mathrm{T} 27$ & $\mathrm{~T} 80$ \\
\hline T16 & T72 & T39 & T47 & T08 & T10 \\
\hline T82 & T04 & T23 & T15 & T83 & $\mathrm{T} 73$ \\
\hline T76 & T41 & T42 & T65 & T06 & T54 \\
\hline T09 & T02 & T22 & T13 & T19 & T45 \\
\hline T31 & T49 & T53 & T70 & T75 & T78 \\
\hline T52 & T38 & T59 & T91 & $\mathrm{T} 25$ & $\mathrm{~T} 86$ \\
\hline $\mathrm{T} 14$ & std-b2-3 & std-b3-3 & std-b4-3 & std-b5-3 & T68 \\
\hline std-b1-3 & & & & & std-b6-3 \\
\hline
\end{tabular}

A multi-element solution standard (denoted by "std-bi-j" where $\mathrm{i}=1$ to 6 represents the block number and $\mathrm{j}=1,2$, and 3 represents the position in the block) was added at the beginning, middle, and end of each of the three blocks. This standard may be useful in checking and correcting for bias in the concentration measurements arising from the ICP calibrations.

\subsection{SUMMARY}

In summary, this analytical plan provides identifiers for the PCT solutions in Table 2 and six ICPAES calibration blocks in Table 3 for PSAL to use in conducting the aluminum (Al), boron (B), iron $(\mathrm{Fe})$, lithium $(\mathrm{Li})$, sodium $(\mathrm{Na})$, silicon $(\mathrm{Si})$, thorium $(\mathrm{Th})$, and uranium $(\mathrm{U})$ concentration measurements for this PCT study. The sequencing of the activities associated with each of the steps in the analytical procedure has been randomized. The size of the blocks was selected so that each block could be completed in a single work shift. If for some reason the measurements are 
WSRC-STI-2006-00204

Revision 0

Appendix D (SRNL-SCS-2006-00031)

not conducted in the sequence presented in this memorandum, the actual order should be recorded along with any explanative comments.

The analytical plan indicated in the preceding tables should be modified by the personnel of PSAL to include any calibration check standards and/or other standards that are part of their standard operating procedures.

\subsection{REFERENCES}

[1] Fox, K.M., T.B. Edwards, D.K. Peeler, "High Level Waste (HLW) Sludge Batch 4 (SB4): Selecting Glasses for a Variability Study,” WSRC-STI-2006-00039, July 2006.

[2] ASTM C-1285-2002, "Standard Test Methods for Determining Chemical Durability of Nuclear Waste Glasses: The Product Consistency Test (PCT)," ASTM, 2002. 
WSRC-STI-2006-00204

Revision 0

This page intentionally left blank. 
Appendix E

\section{Tables and Exhibits Supporting the Analysis of the Chemical Composition Measurements of the SB4 Variability Study Glasses}


Table E1. Targeted Oxide Concentrations (in wt\%) for the SB4 Variability Study Glasses

\begin{tabular}{|c|c|c|c|c|c|c|c|c|c|c|c|c|c|c|c|c|c|c|c|c|c|c|c|c|}
\hline & $\overline{2 \mathbf{O}_{3}}$ & $\overline{2}$ & $\overline{\mathrm{aO}}$ & \begin{tabular}{l|l|}
$\mathrm{aO}$ \\
\end{tabular} & 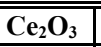 & $\overline{\mathrm{Cr}_{2} \mathrm{O}_{3}}$ & uO & $\mathrm{e}_{2} \mathrm{O}_{3}$ & $\overline{2 \mathbf{O}}$ & $\overline{\mathrm{L}} \mathrm{La}_{2} \mathrm{O}_{3}$ & $\overline{\mathbf{L i}_{2} \mathbf{O}}$ & MgO & no & $\overline{\mathrm{a}_{2} \mathrm{O}}$ & $\overline{\mathrm{iO}}$ & $\begin{array}{l}\mathrm{PbO} \\
\end{array}$ & $\overline{\mathrm{SO}_{4}{ }^{2-}}$ & 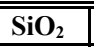 & \begin{tabular}{l|l|}
$\mathrm{ThO}_{2}$ \\
\end{tabular} & $\overline{\mathrm{TiO}_{2}}$ & $\overline{\mathbf{U}_{3} \mathbf{O}_{8}}$ & $\overline{\mathrm{ZnO}}$ & $\mathrm{ZrO}_{2}$ & Sum \\
\hline SB4VS-01 & 631 & 5.440 & .040 & 756 & 48 & 067 & 019 & 7 & 106 & 34 & 440 & & & & 107 & 020 & 446 & & & 008 & 2.431 & 31 & & 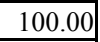 \\
\hline$+v$ & & 120 & 45 & 350 & & 75 & & 0 & 19 & & 120 & 97 & & 612 & 559 & & 501 & .073 & 023 & 009 & 735 & 035 & & 0.00 \\
\hline & 539 & 800 & 50 & 944 & & & & .509 & 32 & & 4.800 & 997 & & 1.236 & 621 & & 57 & 7.192 & 25 & .011 & 039 & 39 & & \\
\hline & & & & & & & & & & & & 96 & & & & & 613 & & & 012 & & & & \\
\hline & & & & & & & & & & & & & & & 466 & & & 94 & & 008 & & 30 & & \\
\hline & & 240 & 42 & 803 & & 71 & & & & & .280 & 47 & & 660 & 528 & & 474 & .194 & 21 & .009 & 583 & 33 & & \\
\hline & 062 & 8.680 & 047 & 897 & & 79 & & .984 & 26 & & 4.960 & 947 & & & .590 & & \begin{tabular}{l|l}
529 \\
\end{tabular} & 7.393 & .024 & 0.010 & .887 & .037 & & \\
\hline & 016 & 8.120 & 052 & 992 & & & & .035 & & & 4.640 & 047 & & & 652 & & & & & .011 & 191 & & & \\
\hline & & 560 & \begin{tabular}{l|l|}
57 \\
\end{tabular} & .086 & & 96 & 28 & & & & 320 & 146 & 93 & & 714 & & 641 & .791 & 229 & .012 & 495 & 45 & & \\
\hline & & 120 & 57 & 046 & & & & & & & 640 & & & & & & & 6 & & 012 & 31 & & & \\
\hline & 422 & 120 & 948 & 937 & & 80 & & 604 & & & 4.640 & 992 & & & 706 & & 559 & 4.536 & 024 & .010 & 251 & 38 & & \\
\hline & 926 & 8.400 & 054 & 0.892 & & 91 & 0.026 & .408 & 44 & & 4.800 & 049 & & & 672 & & 532 & 46.046 & 27 & 0.011 & 982 & 43 & & \\
\hline & 9926 & 8.400 & 0.046 & 0.996 & & 76 & 22 & .611 & 121 & & 4.800 & 1.049 & & & 70 & & 32 & .939 & 23 & 0.010 & .096 & 36 & & \\
\hline & & 80 & & 947 & & & & & & & 60 & & & & & & & & & 99 & & & & \\
\hline & 09 & 680 & 131 & 847 & & & & 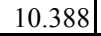 & & & 4.960 & 897 & & & 541 & & & 7.342 & & 011 & 941 & 41 & & \\
\hline & 250 & 8.960 & 049 & 803 & & 82 & 4 & 9.588 & & & 5.120 & 94 & & & 513 & & \begin{tabular}{l|l|}
479 \\
\end{tabular} & 48.745 & & 0.010 & 684 & 38 & & \\
\hline & 33 & 8.960 & 0.041 & 803 & & 69 & & 9.700 & & & 5.120 & 850 & & & 513 & & 524 & 8.841 & & 0.009 & 684 & 32 & & \\
\hline & 036 & 9.240 & \begin{tabular}{l|l|}
0.039 \\
\end{tabular} & 847 & & 065 & 0.019 & 9.294 & 103 & & 5.280 & \begin{tabular}{l|l|}
0.892 \\
\end{tabular} & & & 572 & & 495 & 50.148 & 20 & 0.008 & 2.535 & 31 & & \\
\hline & & 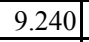 & & & & & & & & & 280 & & & & & & & & & 000 & & & & \\
\hline & 6 & 520 & 443] & 797 & & & & & & & 5.440 & 756 & & & & & 26 & 37 & & .009 & 477 & & & \\
\hline & 941 & 9.520 & 0.043 & 0.797 & & 73 & 21 & 079 & 15 & & 5.440 & \begin{tabular}{|l|l|}
0.839 \\
\end{tabular} & 778 & 53 & 456 & 32 & 466 & 51.637 & 022 & 0.009 & .477 & 334 & & \\
\hline & 820 & 120 & 0.061 & 0.882 & & 103 & 0.030 & .165 & & & 4.640 & 0.937 & & & .544 & & 0.533 & 4.704 & 031 & 0.013 & 072 & 48 & & \\
\hline & 286 & 8.400 & \begin{tabular}{l|l}
0.058 \\
\end{tabular} & 1.048 & & & & & & & 4.800 & & & & & & & 46.099 & & 0.012 & & & & \\
\hline & 001 & 8.400 & 1 & & & & & 1 & & & 4.800 & 0.892 & & & & & & 6.099 & & .009 & & 33 & & \\
\hline & 50 & 680 & \begin{tabular}{l|l|}
0.039 \\
\end{tabular} & 0.798 & & 6 & & 97 & & & 4.960 & 1.046 & & & 37 & 29 & 577 & 47.494 & 20 & 0.008 & 95 & 31 & & \\
\hline & 348 & 8.680 & 0.055 & 0.996 & 1 & 93 & 0.1 & 644 & 47 & 17 & 4.960 & 1.046 & 2.163 & 38 & 492 & 0.041 & 482 & 47.291 & & 0.012 & 995 & 44 & & \\
\hline & 8.821 & 8.960 & 0.037 & 0.944 & & \begin{tabular}{l|l|}
0.062 \\
\end{tabular} & 0.018 & 8.713 & \begin{tabular}{ll|}
0.099 \\
\end{tabular} & & 5.120 & \begin{tabular}{l|l}
0.803 \\
\end{tabular} & 2.049 & & 0.466 & & 0.546 & 48.697 & 019 & 0.008 & 2.633 & 29 & & \\
\hline & 7.909 & 8.960 & 0.053 & 0.756 & & & 0.025 & 217 & & & 5.120 & 0.991 & & & 0.466 & & 0.546 & 48.889 & 27 & 0.011 & 33 & 41 & & \\
\hline & & $3.2+4$ & & & & & & & & & & & & & & & & & & & & & & \\
\hline & 470 & 9.240 & 0.035 & 0.714 & & 059 & 0.017 & 650 & 093 & 030 & 5.280 & 0.758 & 1.935 & 10.898 & 0.615 & 0.026 & 0.431 & 50.102 & .018 & 0.007 & 2.486 & 0.028 & & \\
\hline & 7.030 & 9.520 & 0.047 & 0.839 & & 0.078 & 0.023 & 9.082 & 0.124 & 0.040 & 5.440 & 0.714 & 1.821 & 9.728 & 0.579 & 0.034 & 0.485 & 51.679 & 0.024 & 0.010 & 2.522 & 0.037 & & 100.00 \\
\hline & 8.400 & 8.400 & 0.067 & 1.200 & & 0.112 & 0.032 & 10.800 & 0.177 & & 4.800 & \begin{tabular}{l|l}
0.800 \\
\end{tabular} & 2.000 & 12.800 & 0.800 & 0.049 & 0.800 & 45.600 & .034 & 0.014 & 2.800 & .053 & & 100.00 \\
\hline & 880 & 8.680 & 0.032 & 1.140 & & 53 & 0.015 & 9.120 & 084 & & 4.960 & 1.140 & 2.280 & 10.460 & 0.760 & 0. & 0.760 & 47.780 & 0.016 & 0.007 & 2.660 & 025 & 60 & \\
\hline & & 8.960 & 0.030 & 0.720 & & & & & & & & & & & & & & & & 0.006 & & & & \\
\hline SB4VS-35 & 140 & 9.240 & 0.057 & 0.680 & 069 & 0.095 & 0.027 & 8.500 & .151 & 0.048 & 5.280 & 0.680 & 2.040 & 11.480 & 0.340 & 0.042 & 0.680 & 50.540 & 0.029 & 0.012 & 2.720 & 0.045 & 0.106 & 100.0 \\
\hline
\end{tabular}


Table E2. Measured Elemental Concentrations (wt\%) for Samples Prepared Using Lithium Metaborate

\begin{tabular}{|c|c|c|c|c|c|c|c|c|c|c|c|c|c|c|c|c|c|c|c|c|}
\hline Glass ID & Laboratory ID & Block & Sub-Block & $\begin{array}{l}\text { Analytical } \\
\text { Sequence }\end{array}$ & $\mathbf{B a}$ & $\mathrm{Ca}$ & $\mathrm{Ce}$ & $\mathrm{Cr}$ & $\mathrm{Cu}$ & $\mathbf{K}$ & La & Mg & Mn & $\mathbf{N a}$ & $\mathbf{P b}$ & $\mathbf{S}$ & Th & $\mathrm{Ti}$ & $\mathbf{Z n}$ & $\mathrm{Zr}$ \\
\hline Batch 1 & BCHLM111 & 1 & 1 & 1 & 0.119 & 0.863 & 0.002 & 0.064 & 0.318 & 3.16 & $<0.010$ & 0.774 & 1.38 & 7.18 & $<0.010$ & $<0.100$ & $<0.100$ & 0.375 & $<0.010$ & 0.065 \\
\hline U std & UstdLM111 & 1 & 1 & 2 & $<0.010$ & 0.909 & $<0.010$ & 0.153 & 0.006 & 2.7 & $<0.010$ & 0.647 & 2.21 & 8.63 & $<0.010$ & $<0.100$ & $<0.100$ & 0.53 & $<0.010$ & $<0.010$ \\
\hline SB4VS-18 & U02LM11 & 1 & 1 & 3 & 0.028 & 0.6 & 0.016 & 0.043 & 0.018 & $<0.100$ & 0.025 & 0.503 & 1.5 & 8.02 & 0.028 & 0.145 & $<0.100$ & $<0.010$ & 0.023 & 0.045 \\
\hline SB4VS-12 & U14LM11 & 1 & 1 & 4 & 0.04 & 0.638 & 0.032 & 0.053 & 0.025 & 0.133 & 0.032 & 0.551 & 1.72 & 8.69 & 0.032 & 0.164 & 0.107 & $<0.010$ & 0.031 & 0.058 \\
\hline LRM-02 & U33LM11 & 1 & 1 & 5 & $<0.010$ & 0.367 & $<0.010$ & 0.124 & 0.001 & 1.32 & $<0.010$ & 0.054 & 0.051 & 15.5 & 0.073 & 0.077 & $<0.100$ & 0.054 & $<0.010$ & 0.66 \\
\hline SB4VS-12 & U14LM21 & 1 & 1 & 6 & 0.04 & 0.646 & 0.031 & 0.052 & 0.025 & 0.138 & 0.032 & 0.549 & 1.69 & 8.75 & 0.031 & 0.147 & 0.106 & $<0.010$ & 0.039 & 0.059 \\
\hline LRM-08 & U31LM11 & 1 & 1 & 7 & $<0.010$ & 0.383 & $<0.010$ & 0.112 & 0.003 & 1.33 & $<0.010$ & 0.05 & 0.047 & 15.4 & 0.063 & 0.089 & $<0.100$ & 0.05 & 0.003 & 0.595 \\
\hline LRM-06 & U36LM21 & 1 & 1 & 8 & $<0.010$ & 0.352 & $<0.010$ & 0.121 & 0.003 & 1.27 & $<0.010$ & 0.054 & 0.052 & 15 & 0.071 & 0.071 & $<0.100$ & 0.054 & 0.001 & 0.671 \\
\hline SB4VS-26 & U29LM21 & 1 & 1 & 9 & 0.047 & 0.671 & 0.05 & 0.064 & 0.024 & 0.111 & 0.031 & 0.584 & 1.66 & 8.7 & 0.037 & 0.137 & 0.118 & 0.01 & 0.031 & 0.071 \\
\hline SB4VS-20 & U42LM11 & 1 & 1 & 10 & 0.032 & 0.58 & 0.029 & 0.044 & 0.018 & 0.102 & 0.027 & 0.407 & 1.29 & 7.67 & 0.023 & 0.111 & $<0.100$ & $<0.010$ & 0.025 & 0.046 \\
\hline LRM-08 & U31LM21 & 1 & 1 & 11 & $<0.010$ & 0.354 & $<0.010$ & 0.121 & 0.003 & 1.3 & $<0.010$ & 0.054 & 0.052 & 15.2 & 0.073 & 0.071 & $<0.100$ & 0.054 & $<0.010$ & 0.661 \\
\hline LRM-06 & U36LM11 & 1 & 1 & 12 & $<0.010$ & 0.36 & $<0.010$ & 0.122 & 0.002 & 1.31 & $<0.010$ & 0.054 & 0.052 & 15.4 & 0.073 & 0.086 & $<0.100$ & 0.055 & $<0.010$ & 0.648 \\
\hline SB4VS-05 & U13LM21 & 1 & 1 & 13 & 0.027 & 0.509 & 0.029 & 0.038 & 0.016 & $<0.100$ & 0.022 & 0.41 & 1.25 & 7.47 & 0.024 & 0.109 & $<0.100$ & $<0.010$ & 0.025 & 0.045 \\
\hline Batch 1 & BCHLM112 & 1 & 1 & 14 & 0.119 & 0.851 & $<0.010$ & 0.063 & 0.316 & 3.11 & $<0.010$ & 0.766 & 1.31 & 6.96 & $<0.010$ & $<0.100$ & $<0.100$ & 0.37 & $<0.010$ & 0.065 \\
\hline U std & USTDLM112 & 1 & 1 & 15 & $<0.010$ & 0.898 & $<0.010$ & 0.15 & 0.006 & 2.79 & $<0.010$ & 0.629 & 2.11 & 8.81 & $<0.010$ & $<0.100$ & $<0.100$ & 0.525 & $<0.010$ & $<0.010$ \\
\hline SB4VS-07 & U27LM11 & 1 & 1 & 16 & 0.034 & 0.639 & 0.032 & 0.038 & 0.019 & 0.114 & 0.028 & 0.495 & 1.54 & 8.56 & 0.028 & 0.153 & 0.102 & $<0.010$ & 0.027 & 0.056 \\
\hline SB4VS-18 & U02LM21 & 1 & 1 & 17 & 0.026 & 0.67 & 0.015 & 0.046 & 0.019 & 0.1 & 0.022 & 0.448 & 1.42 & 7.95 & 0.021 & 0.130 & $<0.100$ & $<0.010$ & 0.024 & 0.043 \\
\hline SB4VS-20 & U42LM21 & 1 & 1 & 18 & 0.033 & 0.56 & 0.029 & 0.045 & 0.017 & $<0.100$ & 0.027 & 0.415 & 1.27 & 7.63 & 0.029 & 0.108 & $<0.100$ & $<0.010$ & 0.025 & 0.046 \\
\hline SB4VS-27 & U05LM11 & 1 & 1 & 19 & 0.028 & 0.659 & 0.026 & 0.044 & 0.016 & $<0.100$ & 0.021 & 0.431 & 1.54 & 8.95 & 0.024 & 0.151 & $<0.100$ & $<0.010$ & 0.021 & 0.046 \\
\hline LRM-02 & U33LM21 & 1 & 1 & 20 & $<0.010$ & 0.352 & $<0.010$ & 0.119 & 0.002 & 1.31 & $<0.010$ & 0.053 & 0.051 & 15.4 & 0.072 & 0.065 & $<0.100$ & 0.054 & $<0.010$ & 0.662 \\
\hline SB4VS-31 & U17LM21 & 1 & 2 & 21 & 0.033 & 0.607 & 0.032 & 0.046 & 0.019 & 0.105 & 0.028 & 0.374 & 1.36 & 7.6 & 0.026 & 0.132 & $<0.100$ & $<0.010$ & 0.026 & 0.06 \\
\hline SB4VS-26 & U29LM11 & 1 & 1 & 22 & 0.042 & 0.704 & 0.046 & 0.059 & 0.022 & 0.13 & 0.028 & 0.52 & 1.58 & 8.62 & 0.032 & 0.126 & 0.108 & $<0.010$ & 0.028 & 0.066 \\
\hline SB4VS-31 & U17LM11 & 1 & 1 & 23 & 0.032 & 0.618 & 0.032 & 0.044 & 0.018 & 0.119 & 0.027 & 0.357 & 1.37 & 7.62 & 0.02 & 0.121 & $<0.100$ & $<0.010$ & 0.027 & 0.057 \\
\hline SB4VS-05 & U13LM11 & 1 & 1 & 24 & 0.027 & 0.51 & 0.029 & 0.037 & 0.016 & $<0.100$ & 0.022 & 0.412 & 1.23 & 7.56 & 0.023 & 0.119 & $<0.100$ & $<0.010$ & 0.027 & 0.044 \\
\hline SB4VS-07 & U27LM21 & 1 & 1 & 25 & 0.033 & 0.675 & 0.031 & 0.037 & 0.019 & 0.126 & 0.027 & 0.469 & 1.53 & 8.59 & 0.023 & 0.134 & $<0.100$ & $<0.010$ & 0.027 & 0.056 \\
\hline SB4VS-27 & U05LM21 & 1 & 1 & 26 & 0.026 & 0.685 & 0.025 & 0.042 & 0.017 & $<0.100$ & 0.02 & 0.407 & 1.52 & 8.89 & 0.023 & 0.150 & $<0.100$ & $<0.010$ & 0.024 & 0.045 \\
\hline Batch 1 & BCHLM113 & 1 & 1 & 27 & 0.112 & 0.855 & $<0.010$ & 0.061 & 0.315 & 3.15 & $<0.010$ & 0.73 & 1.3 & 7.07 & $<0.010$ & $<0.100$ & $<0.100$ & 0.356 & $<0.010$ & 0.063 \\
\hline U std & USTDLM113 & 1 & 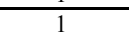 & 28 & $<0.010$ & 0.892 & $<0.010$ & 0.148 & 0.006 & 2.72 & $<0.010$ & 0.626 & 2.13 & 8.75 & $<0.010$ & $<0.100$ & $<0.100$ & 0.516 & $<0.010$ & $<0.010$ \\
\hline Batch 1 & BCHLM121 & 1 & 2 & 1 & 0.122 & 0.857 & $<0.010$ & 0.066 & 0.317 & 3.14 & $<0.010$ & 0.785 & 1.36 & 7.17 & $<0.010$ & $<0.100$ & $<0.100$ & 0.374 & $<0.010$ & 0.066 \\
\hline U std & USTDLM121 & 1 & 2 & 2 & $<0.010$ & 0.905 & $<0.010$ & 0.159 & 0.005 & 2.78 & $<0.010$ & 0.657 & 2.2 & 8.92 & $<0.010$ & $<0.100$ & $<0.100$ & 0.539 & 0.004 & 0.002 \\
\hline LRM-02 & U33LM12 & 1 & $=$ & 3 & $<0.010$ & 0.368 & $<0.010$ & 0.128 & 0.001 & 1.33 & $<0.010$ & 0.058 & 0.053 & 15.8 & 0.073 & 0.086 & $<0.100$ & 0.057 & $<0.010$ & 0.667 \\
\hline SB4VS-07 & U27LM12 & 1 & 2 & 4 & 0.037 & 0.643 & 0.033 & 0.041 & 0.018 & 0.111 & 0.03 & 0.514 & 1.65 & 8.64 & 0.032 & 0.149 & 0.108 & 0.01 & 0.029 & 0.059 \\
\hline LRM-08 & U31LM22 & 1 & 2 & 5 & $<0.010$ & 0.357 & $<0.010$ & 0.124 & 0.002 & 1.28 & $<0.010$ & 0.058 & 0.054 & 15.5 & 0.073 & 0.074 & $<0.100$ & 0.057 & 0.004 & 0.665 \\
\hline SB4VS-12 & 2514502 & 1 & 2 & 6 & 0.043 & 0.648 & 0.032 & 0.055 & 0.024 & 0.134 & 0.034 & 0.56 & 1.76 & 8.94 & 0.03 & 0.150 & 0.111 & 0.011 & 0.04 & 0.06 \\
\hline LRM-06 & U36LM22 & 1 & 2 & 7 & $<0.010$ & 0.356 & $<0.010$ & 0.123 & 0.002 & 1.28 & $<0.010$ & 0.058 & 0.054 & 15.4 & 0.075 & 0.070 & $<0.100$ & 0.057 & $<0.010$ & 0.677 \\
\hline SB4VS-20 & U42LM12 & 1 & 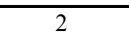 & 8 & 0.034 & 0.588 & 0.029 & 0.047 & 0.017 & 0.1 & 0.028 & 0.415 & 1.36 & 7.77 & 0.027 & 0.121 & $<0.100$ & 0.01 & 0.026 & 0.047 \\
\hline SB4VS-18 & U02LM22 & 1 & 2 & 9 & 0.029 & 0.676 & 0.016 & 0.049 & 0.018 & $<0.100$ & 0.024 & 0.466 & 1.49 & 8.05 & 0.024 & 0.127 & $<0.100$ & $<0.010$ & 0.025 & 0.044 \\
\hline LRM-08 & U31LM12 & 1 & 2 & 10 & $<0.010$ & 0.383 & $<0.010$ & 0.116 & 0.002 & 1.32 & $<0.010$ & 0.054 & 0.05 & 15.7 & 0.067 & 0.078 & $<0.100$ & 0.053 & 0.004 & 0.593 \\
\hline SB4VS-27 & U05LM22 & 1 & 2 & 11 & 0.03 & 0.695 & 0.026 & 0.046 & 0.016 & $<0.100$ & 0.023 & 0.436 & 1.61 & 8.99 & 0.023 & 0.150 & $<0.100$ & $<0.010$ & 0.026 & 0.048 \\
\hline SB4VS-12 & U14LM12 & 1 & 2 & 12 & 0.042 & 0.641 & 0.032 & 0.054 & 0.024 & 0.129 & 0.033 & 0.555 & 1.74 & 8.85 & 0.033 & 0.147 & 0.112 & 0.011 & 0.032 & 0.059 \\
\hline SB4VS-31 & U17LM12 & 1 & 2 & 13 & 0.036 & 0.631 & 0.033 & 0.047 & 0.018 & 0.116 & 0.029 & 0.367 & 1.43 & 7.69 & 0.028 & 0.135 & $<0.100$ & $<0.010$ & 0.028 & 0.059 \\
\hline Batch 1 & BCHLM122 & 1 & $\frac{\pi}{2}$ & 14 & 0.122 & 0.862 & $<0.010$ & 0.066 & 0.316 & 3.1 & $<0.010$ & 0.79 & 1.37 & 7.09 & $<0.010$ & $<0.100$ & $<0.100$ & 0.379 & $<0.010$ & 0.067 \\
\hline U std & USTDLM122 & 1 & 2 & 15 & $<0.010$ & 0.912 & $<0.010$ & 0.156 & 0.006 & 2.73 & $<0.010$ & 0.648 & 2.21 & 8.91 & $<0.010$ & $<0.100$ & $<0.100$ & 0.529 & $<0.010$ & $<0.010$ \\
\hline SB4VS-26 & U29LM22 & 1 & $\frac{5}{2}$ & 16 & 0.048 & 0.676 & 0.05 & 0.066 & 0.024 & 0.107 & 0.032 & 0.579 & 1.72 & 8.98 & 0.039 & 0.130 & 0.125 & 0.012 & 0.031 & 0.07 \\
\hline
\end{tabular}




\section{Table E2. Measured Elemental Concentrations (wt\%) for Samples Prepared Using Lithium Metaborate (continued)}

\begin{tabular}{|c|c|c|c|c|c|c|c|c|c|c|c|c|c|c|c|c|c|c|c|c|}
\hline Glass ID & Laboratory ID & Block & Sub-Block & $\begin{array}{c}\text { Analytical } \\
\text { Sequence }\end{array}$ & $\mathbf{B a}$ & $\mathrm{Ca}$ & $\mathrm{Ce}$ & $\mathrm{Cr}$ & $\mathrm{Cu}$ & $\mathbf{K}$ & La & Mg & Mn & $\mathrm{Na}$ & $\mathbf{P b}$ & $\mathbf{S}$ & Th & $\mathbf{T i}$ & $\mathbf{Z n}$ & $\mathrm{Zr}$ \\
\hline SB4VS-31 & U17LM22 & 1 & 2 & 17 & 0.036 & 0.616 & 0.033 & 0.047 & 0.018 & 0.103 & $<0.010$ & 0.376 & 1.42 & 7.73 & 0.027 & 0.128 & $<0.100$ & $<0.010$ & 0.027 & 0.06 \\
\hline SB4VS-07 & U27LM22 & 1 & 2 & 18 & 0.035 & 0.682 & 0.032 & 0.04 & 0.019 & 0.123 & 0.028 & 0.482 & 1.58 & 8.8 & 0.024 & \begin{tabular}{|l|}
0.136 \\
\end{tabular} & 0.102 & 0.01 & 0.029 & 0.058 \\
\hline SB4VS-18 & U02LM12 & 1 & 2 & 19 & 0.03 & 0.599 & 0.016 & 0.044 & 0.018 & $<0.100$ & 0.026 & 0.506 & 1.51 & 8.11 & 0.031 & 0.131 & 0.1 & $<0.010$ & 0.024 & 0.046 \\
\hline SB4VS-26 & U29LM12 & 1 & 2 & 20 & 0.045 & 0.713 & 0.047 & 0.062 & 0.021 & 0.128 & 0.03 & 0.53 & 1.65 & 8.67 & 0.034 & \begin{tabular}{|l|}
0.127 \\
\end{tabular} & 0.115 & 0.011 & 0.029 & 0.068 \\
\hline SB4VS-05 & U13LM12 & 1 & 2 & 21 & 0.03 & 0.518 & 0.029 & 0.039 & 0.015 & $<0.100$ & 0.024 & 0.422 & 1.29 & 7.73 & 0.026 & 0.104 & $<0.100$ & 0.01 & 0.028 & 0.045 \\
\hline LRM-02 & U33LM22 & 1 & 2 & 22 & $<0.010$ & 0.356 & $\begin{array}{l}<0.010 \\
\end{array}$ & 0.123 & 0.002 & 1.3 & $<0.010$ & 0.057 & 0.053 & 15.7 & 0.075 & 0.076 & $<0.100$ & 0.057 & $<0.010$ & 0.671 \\
\hline LRM-06 & U36LM12 & 1 & 2 & 23 & $<0.010$ & 0.364 & $\begin{array}{l}<0.010 \\
\end{array}$ & 0.125 & 0.001 & 1.35 & $<0.010$ & 0.057 & 0.054 & 16.1 & 0.073 & \begin{tabular}{|l|}
0.074 \\
\end{tabular} & $<0.100$ & 0.057 & $<0.010$ & 0.65 \\
\hline SB4VS-27 & U05LM12 & 1 & 2 & 24 & 0.029 & 0.673 & \begin{tabular}{|l|}
0.026 \\
\end{tabular} & 0.047 & 0.016 & $<<0.100$ & 0.022 & 0.429 & 1.6 & 9.09 & 0.025 & \begin{tabular}{|l|}
0.140 \\
\end{tabular} & $<0.100$ & $<0.010$ & 0.022 & 0.047 \\
\hline SB4VS-20 & U42LM22 & 1 & 2 & 25 & 0.034 & 0.569 & 0.03 & 0.047 & 0.017 & $<0.100$ & 0.029 & 0.419 & 1.32 & 7.9 & 0.027 & \begin{tabular}{|l|}
0.106 \\
\end{tabular} & $<0.100$ & 0.01 & 0.026 & 0.047 \\
\hline SB4VS-05 & U13LM22 & 1 & 2 & 26 & 0.03 & 0.515 & \begin{tabular}{|l|}
0.029 \\
\end{tabular} & 0.04 & 0.015 & $<<0.100$ & 0.024 & 0.42 & 1.26 & 7.87 & 0.027 & \begin{tabular}{|l|}
0.125 \\
\end{tabular} & $<0.100$ & 0.01 & 0.026 & 0.045 \\
\hline Batch 1 & BCHLM123 & 1 & 2 & 27 & 0.118 & 0.868 & $\begin{array}{l}<0.010 \\
\end{array}$ & 0.065 & 0.317 & 3.21 & $<0.010$ & 0.761 & 1.31 & 7.39 & $<0.010$ & $\begin{array}{l}<0.100 \\
\end{array}$ & $<0.100$ & 0.37 & $<0.010$ & 0.065 \\
\hline U std & \begin{tabular}{|l|} 
USTDLM123 \\
\end{tabular} & 1 & 2 & 28 & $<0.010$ & 0.911 & $\begin{array}{c}<0.010 \\
\end{array}$ & 0.156 & 0.005 & 2.83 & $<0.010$ & 0.646 & 2.14 & 9.24 & $<0.010$ & $<<0.100$ & $<0.100$ & 0.53 & $<0.010$ & $<0.010$ \\
\hline Batch 1 & BCHLM211 & 2 & 1 & 1 & 0.124 & 0.852 & $\begin{array}{l}<0.010 \\
\end{array}$ & 0.068 & 0.317 & 3.08 & $<0.010$ & 0.806 & 1.27 & 6.84 & $<0.010$ & $\begin{array}{l}<0.100 \\
\end{array}$ & $<0.100$ & 0.382 & $<0.010$ & 0.067 \\
\hline U std & USTDLM211 & 2 & 1 & 2 & $<0.010$ & 0.908 & $\begin{array}{l}<0.010 \\
\end{array}$ & 0.159 & 0.006 & 2.7 & $<0.010$ & 0.665 & 2.07 & 8.61 & $<0.010$ & $<<0.100$ & $<0.100$ & 0.55 & $<0.010$ & $<0.010$ \\
\hline SB4VS-13 & U32LM11 & 2 & 1 & 3 & 0.036 & 0.717 & \begin{tabular}{|l|}
0.033 \\
\end{tabular} & 0.048 & 0.02 & $<<0.100$ & 0.028 & 0.584 & 1.59 & 8.91 & 0.031 & \begin{tabular}{|l|}
0.135 \\
\end{tabular} & 0.115 & $<0.010$ & 0.026 & 0.049 \\
\hline LRM-05 & U03LM21 & 2 & 1 & 4 & $<0.010$ & 0.404 & $\begin{array}{l}<0.010 \\
\end{array}$ & 0.125 & 0.001 & 1.32 & $<0.010$ & 0.061 & 0.052 & 14.9 & 0.073 & \begin{tabular}{|l|}
0.083 \\
\end{tabular} & $<0.100$ & 0.056 & 0.02 & 0.641 \\
\hline SB4VS-13 & U32LM21 & 2 & 1 & 5 & 0.035 & 0.753 & \begin{tabular}{|l|}
0.032 \\
\end{tabular} & 0.046 & 0.019 & $<0.100$ & 0.027 & 0.566 & 1.57 & 8.65 & 0.03 & \begin{tabular}{|l|}
0.154 \\
\end{tabular} & 0.112 & $<0.010$ & 0.032 & 0.05 \\
\hline SB4VS-24 & U12LM11 & 2 & 1 & 6 & 0.034 & 0.745 & 0.033 & 0.046 & 0.019 & $<0.100$ & 0.024 & 0.492 & 1.52 & 9.55 & 0.025 & \begin{tabular}{|l|}
0.157 \\
\end{tabular} & 0.117 & $<0.010$ & 0.025 & 0.052 \\
\hline SB4VS-34 & U04LM21 & 2 & 1 & 7 & 0.024 & 0.526 & \begin{tabular}{|l|}
0.022 \\
\end{tabular} & 0.039 & 0.014 & $<0.100$ & 0.019 & 0.613 & 1.31 & 7.55 & 0.026 & $\begin{array}{l}0.175 \\
\end{array}$ & 0.107 & $<0.010$ & 0.02 & 0.042 \\
\hline LRM-07 & U40LM11 & 2 & 1 & 8 & $\begin{array}{l}<0.010 \\
\end{array}$ & 0.364 & $\begin{array}{l}<0.010 \\
\end{array}$ & 0.126 & 0.001 & 1.28 & $<0.010$ & 0.055 & 0.053 & 14.4 & 0.073 & \begin{tabular}{|l|}
0.082 \\
\end{tabular} & $<0.100$ & 0.057 & $<0.010$ & 0.683 \\
\hline SB4VS-04 & U21LM21 & 2 & 1 & 9 & 0.044 & 0.728 & \begin{tabular}{|l|}
0.032 \\
\end{tabular} & 0.055 & 0.022 & 0.126 & 0.034 & 0.625 & 1.75 & 11.1 & 0.034 & \begin{tabular}{|l|}
0.171 \\
\end{tabular} & 0.131 & 0.021 & 0.032 & 0.079 \\
\hline SB4VS-30 & U20LM21 & 2 & 1 & 10 & 0.028 & 0.523 & \begin{tabular}{|l|}
0.028 \\
\end{tabular} & 0.038 & 0.014 & $<0.100$ & 0.038 & 0.424 & 1.45 & 8.18 & 0.021 & 0.128 & $<0.100$ & $<0.010$ & 0.022 & 0.041 \\
\hline SB4VS-14 & U09LM11 & 2 & 1 & 11 & 0.033 & 0.681 & 0.032 & 0.047 & 0.018 & $<0.100$ & 0.025 & 0.501 & 1.6 & 8.92 & 0.028 & 0.130 & 0.108 & $<0.010$ & 0.025 & 0.05 \\
\hline SB4VS-34 & U04LM11 & 2 & 1 & 12 & 0.024 & 0.51 & \begin{tabular}{|l|}
0.023 \\
\end{tabular} & 0.037 & 0.015 & $<0.100$ & 0.019 & 0.62 & 1.36 & 7.51 & 0.025 & \begin{tabular}{|l|}
0.186 \\
\end{tabular} & 0.108 & $<0.010$ & 0.017 & 0.043 \\
\hline LRM-04 & U08LM21 & 2 & 1 & 13 & $<0.010$ & 0.376 & $\begin{array}{l}<0.010 \\
\end{array}$ & 0.128 & 0.002 & 1.34 & $<0.010$ & 0.055 & 0.053 & 15.2 & 0.076 & \begin{tabular}{|l|}
0.069 \\
\end{tabular} & $<0.100$ & 0.057 & $<0.010$ & 0.668 \\
\hline Batch 1 & BCHLM212 & 2 & 1 & 14 & 0.12 & 0.864 & $\begin{array}{l}<0.010 \\
\end{array}$ & 0.065 & 0.318 & 3.1 & $<0.010$ & 0.774 & 1.26 & 6.93 & $<0.010$ & $\begin{array}{l}<0.100 \\
\end{array}$ & $<0.100$ & 0.377 & $<0.010$ & 0.067 \\
\hline U std & USTDLM212 & 2 & 1 & 15 & $<0.010$ & 0.914 & $\begin{array}{l}<0.010 \\
\end{array}$ & 0.155 & 0.006 & 2.74 & $<0.010$ & 0.647 & 2 & 8.69 & $<0.010$ & $<<0.100$ & $<0.100$ & 0.536 & $<0.010$ & 0.002 \\
\hline SB4VS-14 & U09LM21 & 2 & 1 & 16 & 0.032 & 0.696 & \begin{tabular}{|l|}
0.031 \\
\end{tabular} & 0.046 & 0.021 & $<0.100$ & 0.024 & 0.473 & 1.53 & 8.97 & 0.022 & \begin{tabular}{|l|}
0.140 \\
\end{tabular} & 0.102 & $<0.010$ & 0.025 & 0.053 \\
\hline LRM-07 & U40LM21 & 2 & 1 & 17 & $<0.010$ & 0.367 & $\begin{array}{l}<0.010 \\
\end{array}$ & 0.122 & 0.002 & 1.31 & $<0.010$ & 0.054 & 0.052 & 15 & 0.072 & \begin{tabular}{|l|}
0.071 \\
\end{tabular} & $<0.100$ & 0.057 & $<0.010$ & 0.652 \\
\hline SB4VS-28 & U35LM21 & 2 & 1 & 18 & 0.043 & 0.555 & \begin{tabular}{|l|}
0.039 \\
\end{tabular} & 0.053 & 0.022 & 0.118 & 0.033 & 0.575 & 1.49 & 8.46 & 0.04 & \begin{tabular}{|l|}
0.153 \\
\end{tabular} & 0.109 & 0.01 & 0.032 & 0.072 \\
\hline SB4VS-30 & U20LM11 & 2 & 1 & 19 & 0.028 & 0.516 & \begin{tabular}{|l|}
0.029 \\
\end{tabular} & 0.039 & 0.016 & $<0.100$ & 0.038 & 0.432 & 1.52 & 8.19 & 0.02 & 0.110 & $<0.100$ & $<0.010$ & 0.02 & 0.042 \\
\hline SB4VS-04 & U21LM11 & 2 & 1 & 20 & 0.044 & 0.75 & \begin{tabular}{|l|}
0.088 \\
\end{tabular} & 0.056 & 0.02 & 0.134 & 0.034 & 0.601 & 1.88 & 11.3 & 0.031 & 0.174 & 0.126 & $<0.010$ & 0.032 & 0.068 \\
\hline LRM-05 & U03LM11 & 2 & 1 & 21 & $<0.010$ & 0.497 & $\begin{array}{l}<0.010 \\
\end{array}$ & 0.116 & 0.001 & 1.32 & $<0.010$ & 0.052 & 0.048 & 15.2 & 0.06 & \begin{tabular}{|l|}
0.079 \\
\end{tabular} & $<0.100$ & 0.053 & 0.022 & 0.598 \\
\hline SB4VS-24 & U12LM21 & 2 & 1 & 22 & 0.032 & 0.751 & \begin{tabular}{|l|}
0.032 \\
\end{tabular} & 0.044 & 0.018 & 0.094 & 0.024 & 0.478 & 1.62 & 9.37 & 0.027 & \begin{tabular}{|l|}
0.113 \\
\end{tabular} & 0.113 & $<0.010$ & 0.024 & 0.052 \\
\hline SB4VS-35 & U41LM11 & 2 & 1 & 23 & 0.043 & 0.488 & \begin{tabular}{|l|}
0.043 \\
\end{tabular} & 0.065 & 0.024 & 0.123 & 0.037 & 0.392 & 1.63 & 8.71 & 0.039 & \begin{tabular}{|l|}
0.177 \\
\end{tabular} & 0.115 & 0.011 & 0.032 & 0.074 \\
\hline SB4VS-28 & U35LM11 & 2 & 1 & 24 & 0.041 & 0.572 & \begin{tabular}{|l|}
0.038 \\
\end{tabular} & 0.05 & 0.022 & 0.128 & 0.032 & 0.536 & 1.46 & 8.5 & 0.039 & \begin{tabular}{|l|}
0.148 \\
\end{tabular} & 0.103 & 0.01 & 0.03 & 0.067 \\
\hline LRM-04 & U08LM11 & 2 & 1 & 25 & $<0.010$ & 0.373 & $\begin{array}{l}<0.010 \\
\end{array}$ & 0.127 & 0.002 & 1.29 & $<0.010$ & 0.053 & 0.05 & 15.2 & 0.069 & \begin{tabular}{|l|}
0.072 \\
\end{tabular} & $<0.100$ & 0.055 & $<0.010$ & 0.645 \\
\hline SB4VS-35 & U41LM21 & 2 & 1 & 26 & 0.042 & 0.494 & \begin{tabular}{|l|}
0.043 \\
\end{tabular} & 0.064 & 0.024 & 0.126 & 0.036 & 0.384 & 1.56 & 8.98 & 0.034 & \begin{tabular}{|l|}
0.176 \\
\end{tabular} & 0.112 & 0.013 & 0.033 & 0.074 \\
\hline Batch 1 & BCHLM213 & 2 & 1 & 27 & 0.119 & 0.864 & $\begin{array}{l}<0.010 \\
\end{array}$ & 0.065 & 0.317 & 3.05 & $<0.010$ & 0.775 & 1.3 & 7.01 & $<0.010$ & $\begin{array}{l}<0.100 \\
\end{array}$ & $<0.100$ & 0.374 & $<0.010$ & 0.066 \\
\hline U std & USTDLM213 & 2 & 1 & 28 & $<0.010$ & 0.907 & $<<0.010$ & 0.154 & 0.005 & 2.71 & $<0.010$ & 0.649 & 2.07 & 8.81 & $<0.010$ & $<0.100$ & $<0.100$ & 0.524 & $<0.010$ & $<0.010$ \\
\hline Batch 1 & BCHLM221 & 2 & 2 & 1 & \begin{tabular}{|l|}
0.119 \\
\end{tabular} & 0.894 & \begin{tabular}{|l|}
$<0.010$ \\
\end{tabular} & 0.064 & 0.323 & 3.12 & $<0.010$ & 0.785 & 1.31 & 6.92 & $<0.010$ & $\begin{array}{l}<0.100 \\
\end{array}$ & $<0.100$ & 0.379 & $<0.010$ & 0.065 \\
\hline U std & USTDLM221 & 2 & 2 & 2 & $<0.010$ & 0.933 & $\begin{array}{l}<0.010 \\
\end{array}$ & 0.152 & 0.005 & 2.71 & $<0.010$ & 0.636 & 2.17 & 8.65 & $<0.010$ & $\begin{array}{l}<0.100 \\
\end{array}$ & $<0.100$ & 0.539 & $<0.010$ & $<0.010$ \\
\hline LRM-05 & U03LM22 & 2 & 2 & 3 & $<0.010$ & 0.437 & $<0.010$ & 0.115 & 0.001 & 1.31 & $<0.010$ & 0.053 & 0.046 & 15.1 & 0.062 & $\begin{array}{l}0.059 \\
\end{array}$ & $<0.100$ & 0.053 & 0.017 & 0.619 \\
\hline SB4VS-28 & U35LM12 & 2 & 2 & 4 & 0.036 & 0.59 & \begin{tabular}{|l|}
0.036 \\
\end{tabular} & 0.047 & 0.021 & 0.132 & 0.028 & 0.517 & 1.51 & 8.45 & 0.029 & 0.127 & 0.107 & $<0.010$ & 0.027 & 0.065 \\
\hline SB4VS-28 & U35LM22 & 2 & 2 & 5 & 0.037 & 0.572 & 0.037 & 0.049 & 0.022 & 0.122 & 0.029 & 0.548 & 1.56 & 8.44 & 0.035 & 0.139 & 0.113 & $<0.010$ & 0.028 & 0.069 \\
\hline
\end{tabular}




\section{Table E2. Measured Elemental Concentrations (wt\%) for Samples Prepared Using Lithium Metaborate (continued)}

\begin{tabular}{|c|c|c|c|c|c|c|c|c|c|c|c|c|c|c|c|c|c|c|c|c|}
\hline Glass ID & Laboratory ID & Block & Sub-Block & $\begin{array}{c}\text { Analytical } \\
\text { Sequence }\end{array}$ & $\mathbf{B a}$ & $\mathrm{Ca}$ & $\mathrm{Ce}$ & $\mathrm{Cr}$ & $\mathrm{Cu}$ & $\mathbf{K}$ & La & Mg & Mn & $\mathrm{Na}$ & $\mathbf{P b}$ & $\mathbf{S}$ & Th & $\mathbf{T i}$ & $\mathbf{Z n}$ & $\mathrm{Zr}$ \\
\hline SB4VS-13 & U32LM12 & 2 & 2 & 6 & 0.03 & 0.761 & 0.031 & 0.044 & 0.019 & $<0.100$ & 0.024 & 0.543 & 1.76 & 9.15 & 0.024 & 0.139 & 0.12 & $<0.010$ & 0.023 & 0.047 \\
\hline SB4VS-30 & U20LM22 & 2 & 2 & 7 & 0.023 & 0.549 & 0.026 & 0.035 & 0.014 & $<0.100$ & 0.033 & 0.399 & 1.63 & 8.36 & 0.016 & 0.110 & $<0.100$ & $<0.010$ & 0.019 & 0.039 \\
\hline SB4VS-30 & U20LM12 & 2 & 2 & 8 & 0.024 & 0.534 & 0.027 & 0.037 & 0.016 & $<0.100$ & 0.035 & 0.422 & 1.62 & 8.3 & 0.017 & 0.118 & $<0.100$ & $<0.010$ & 0.017 & 0.04 \\
\hline SB4VS-35 & U41LM12 & 2 & 2 & 9 & 0.039 & 0.509 & 0.041 & 0.063 & 0.024 & 0.126 & 0.033 & 0.384 & 1.73 & 8.82 & 0.033 & 0.165 & 0.12 & 0.01 & 0.029 & 0.072 \\
\hline SB4VS-35 & U41LM22 & 2 & 2 & 10 & 0.038 & 0.517 & 0.041 & 0.062 & 0.023 & 0.13 & 0.032 & 0.373 & 1.75 & 8.81 & 0.033 & 0.157 & 0.115 & 0.012 & 0.03 & 0.071 \\
\hline SB4VS-34 & U04LM22 & 2 & 2 & 11 & 0.019 & 0.546 & 0.02 & 0.038 & 0.014 & $<0.100$ & 0.016 & 0.593 & 1.52 & 7.59 & 0.02 & 0.178 & 0.114 & $<0.010$ & 0.017 & 0.04 \\
\hline SB4VS-04 & U21LM22 & 2 & 2 & 12 & 0.04 & 0.758 & 0.03 & 0.053 & 0.022 & 0.13 & 0.031 & 0.612 & 2.02 & 11.5 & 0.027 & 0.169 & 0.138 & 0.019 & 0.03 & 0.075 \\
\hline SB4VS-34 & U04LM12 & 2 & 2 & 13 & 0.019 & 0.534 & 0.02 & 0.035 & 0.014 & $<0.100$ & 0.016 & 0.603 & 1.56 & 7.91 & 0.023 & 0.186 & 0.113 & $<0.010$ & 0.015 & 0.041 \\
\hline Batch 1 & BCHLM 222 & 2 & 2 & 14 & 0.114 & 0.891 & \begin{tabular}{|l|}
$<0.010$ \\
\end{tabular} & 0.063 & 0.319 & 3.12 & $<0.010$ & 0.765 & 1.42 & 7.11 & $<0.010$ & \begin{tabular}{|l|}
$<0.100$ \\
\end{tabular} & $<0.100$ & 0.372 & 0.005 & 0.064 \\
\hline U std & USTDLM222 & 2 & 2 & 15 & $<0.010$ & 0.929 & \begin{tabular}{|c|}
$<0.010$ \\
\end{tabular} & 0.151 & 0.005 & 2.73 & $<0.010$ & 0.641 & 2.25 & 9 & $<0.010$ & \begin{tabular}{|c|}
$<0.100$ \\
\end{tabular} & $<0.100$ & 0.531 & 0.001 & 0.001 \\
\hline SB4VS-14 & U09LM22 & 2 & 2 & 16 & \begin{tabular}{|l|}
0.027 \\
\end{tabular} & 0.73 & \begin{tabular}{|l|}
0.029 \\
\end{tabular} & 0.043 & 0.021 & $<<0.100$ & 0.021 & 0.453 & 1.69 & 9.3 & 0.017 & \begin{tabular}{|l|}
0.120 \\
\end{tabular} & 0.109 & $<0.010$ & 0.022 & 0.05 \\
\hline SB4VS-24 & U12LM12 & 2 & 2 & 17 & 0.028 & 0.788 & 0.03 & 0.042 & 0.019 & $<0.100$ & 0.02 & 0.461 & 1.65 & 10.1 & 0.02 & \begin{tabular}{|l|}
0.124 \\
\end{tabular} & 0.12 & $<0.010$ & 0.022 & 0.048 \\
\hline LRM-05 & U03LM12 & 2 & 2 & 18 & $<0.010$ & 0.523 & $\begin{array}{l}<0.010 \\
\end{array}$ & 0.113 & 0.001 & 1.36 & $<0.010$ & 0.049 & 0.045 & 16 & 0.057 & 0.078 & $<0.100$ & 0.052 & 0.02 & 0.594 \\
\hline LRM-07 & U40LM22 & 2 & 2 & 19 & $<0.010$ & 0.387 & $\begin{array}{l}<0.010 \\
\end{array}$ & 0.116 & 0.001 & 1.32 & $<0.010$ & 0.049 & 0.048 & 15.8 & 0.067 & 0.069 & $<0.100$ & 0.054 & $<0.010$ & 0.642 \\
\hline LRM-04 & U08LM22 & 2 & 2 & 20 & $<0.010$ & 0.401 & $\begin{array}{l}<0.010 \\
\end{array}$ & 0.122 & 0.001 & 1.35 & $<0.010$ & 0.049 & 0.048 & 16 & 0.065 & 0.062 & $<0.100$ & 0.055 & $<0.010$ & 0.655 \\
\hline LRM-04 & U08LM12 & 2 & 2 & 21 & $<0.010$ & 0.399 & $\begin{array}{l}<0.010 \\
\end{array}$ & 0.125 & 0.002 & 1.33 & $<0.010$ & 0.048 & 0.047 & 15.7 & 0.063 & 0.073 & $<0.100$ & 0.053 & $<0.010$ & 0.636 \\
\hline SB4VS-14 & U09LM12 & 2 & 2 & 22 & 0.028 & 0.717 & \begin{tabular}{|l|}
0.03 \\
\end{tabular} & 0.045 & 0.017 & $<0.100$ & 0.021 & 0.481 & 1.66 & 9.58 & 0.023 & 0.131 & 0.113 & $<0.010$ & 0.022 & 0.05 \\
\hline SB4VS-04 & U21LM12 & 2 & 2 & 23 & 0.039 & 0.775 & 0.086 & 0.053 & 0.02 & 0.138 & 0.03 & 0.582 & 1.85 & 11.8 & 0.026 & 0.156 & 0.131 & $<0.010$ & 0.029 & 0.066 \\
\hline SB4VS-24 & U12LM22 & 2 & 2 & 24 & 0.028 & 0.785 & 0.03 & 0.042 & 0.017 & 0.098 & 0.02 & 0.458 & 1.54 & 9.96 & 0.022 & 0.141 & 0.123 & $<0.010$ & 0.021 & 0.049 \\
\hline LRM-07 & U40LM12 & 2 & 2 & 25 & $\begin{array}{l}<0.010 \\
\end{array}$ & 0.385 & \begin{tabular}{|l|}
$<0.010$ \\
\end{tabular} & 0.12 & 0 & 1.31 & $<0.010$ & 0.049 & 0.049 & 15.7 & 0.067 & 0.090 & $<0.100$ & 0.055 & $<0.010$ & 0.669 \\
\hline SB4VS-13 & U32LM22 & 2 & 2 & 26 & 0.03 & 0.796 & \begin{tabular}{|l|}
0.029 \\
\end{tabular} & 0.042 & 0.019 & $<0.100$ & 0.023 & 0.528 & 1.61 & 9.24 & 0.023 & \begin{tabular}{|l|}
0.135 \\
\end{tabular} & 0.115 & $<0.010$ & 0.029 & 0.047 \\
\hline Batch 1 & BCHLM 223 & 2 & 2 & 27 & 0.113 & 0.89 & $\begin{array}{l}<0.010 \\
\end{array}$ & 0.061 & 0.319 & 3.14 & $<0.010$ & 0.74 & 1.29 & 7.3 & $<0.010$ & \begin{tabular}{|l|}
$<0.100$ \\
\end{tabular} & $<0.100$ & 0.373 & $<0.010$ & 0.064 \\
\hline U std & USTDLM 223 & 2 & 2 & 28 & $<0.010$ & 0.94 & \begin{tabular}{|c|}
$<0.010$ \\
\end{tabular} & 0.15 & 0.005 & 2.85 & $<0.010$ & 0.623 & 2.05 & 9.31 & $<0.010$ & $\begin{array}{l}<0.100 \\
\end{array}$ & $<0.100$ & 0.525 & $<0.010$ & $<0.010$ \\
\hline Batch 1 & BCHLM311 & 3 & 1 & 1 & 0.123 & 0.88 & $\begin{array}{l}<0.010 \\
\end{array}$ & 0.066 & 0.316 & 3.04 & $<0.010$ & 0.803 & 1.41 & 6.91 & $<0.010$ & $\begin{array}{l}<0.100 \\
\end{array}$ & $<0.100$ & 0.384 & $<0.010$ & 0.066 \\
\hline U std & \begin{tabular}{|l|l} 
USTDLM311 \\
\end{tabular} & 3 & 1 & 2 & $<0.010$ & 0.922 & $\begin{array}{l}<0.010 \\
\end{array}$ & 0.158 & 0.005 & 2.67 & $<0.010$ & 0.653 & 2.28 & 8.75 & $<0.010$ & $\begin{array}{l}<0.100 \\
\end{array}$ & $<0.100$ & 0.546 & $<0.010$ & $<0.010$ \\
\hline SB4VS-03 & U22LM21 & 3 & 1 & 3 & 0.04 & 0.667 & \begin{tabular}{|l|}
0.032 \\
\end{tabular} & 0.062 & 0.019 & 0.102 & 0.031 & 0.594 & 1.7 & 11.1 & 0.028 & \begin{tabular}{|l|}
0.151 \\
\end{tabular} & 0.13 & $<0.010$ & 0.027 & 0.062 \\
\hline SB4VS-11 & U28LM21 & 3 & 1 & 4 & 0.036 & 0.727 & \begin{tabular}{|l|}
0.025 \\
\end{tabular} & 0.05 & 0.019 & 0.122 & 0.027 & 0.525 & 1.8 & 9.48 & 0.027 & \begin{tabular}{|l|}
0.140 \\
\end{tabular} & 0.126 & $<0.010$ & 0.034 & 0.058 \\
\hline SB4VS-23 & U19LM11 & 3 & 1 & 5 & 0.046 & 0.749 & \begin{tabular}{|l|}
0.042 \\
\end{tabular} & 0.07 & 0.021 & 0.128 & 0.036 & 0.649 & 1.61 & 9.81 & 0.034 & 0.126 & 0.13 & 0.01 & 0.033 & 0.075 \\
\hline SB4VS-06 & U24LM11 & 3 & 1 & 6 & 0.032 & 0.597 & 0.024 & 0.055 & 0.018 & $<0.100$ & 0.024 & 0.482 & 1.44 & 8.32 & 0.027 & \begin{tabular}{|l|}
0.140 \\
\end{tabular} & 0.106 & $<0.010$ & 0.025 & 0.047 \\
\hline SB4VS-21 & U01LM11 & 3 & 1 & 7 & 0.034 & 0.601 & \begin{tabular}{|l|}
0.027 \\
\end{tabular} & 0.057 & 0.015 & 0.102 & 0.026 & 0.476 & 1.35 & 8.06 & 0.023 & \begin{tabular}{|l|}
0.122 \\
\end{tabular} & 0.102 & $<0.010$ & 0.024 & 0.049 \\
\hline SB4VS-10 & U39LM11 & 3 & 1 & 8 & 0.044 & 0.808 & 0.038 & 0.058 & 0.023 & \begin{tabular}{|l|}
0.149 \\
\end{tabular} & 0.033 & 0.529 & 1.7 & 9.95 & 0.03 & 0.163 & 0.127 & $<0.010$ & 0.035 & 0.069 \\
\hline SB4VS-10 & U39LM21 & 3 & 1 & 9 & 0.045 & 0.822 & \begin{tabular}{|l|}
0.039 \\
\end{tabular} & 0.058 & 0.023 & 0.138 & 0.034 & 0.55 & 1.68 & 9.88 & 0.03 & 0.163 & 0.133 & $<0.010$ & 0.041 & 0.071 \\
\hline SB4VS-15 & U25LM11 & 3 & 1 & 10 & 0.036 & 0.633 & \begin{tabular}{|l|}
0.036 \\
\end{tabular} & 0.049 & 0.019 & $<0.100$ & 0.028 & 0.476 & 1.6 & 8.96 & 0.024 & 0.134 & 0.118 & $<0.010$ & 0.03 & 0.061 \\
\hline SB4VS-16 & U11LM21 & 3 & 1 & 11 & 0.037 & 0.629 & 0.027 & 0.052 & 0.02 & 0.117 & 0.027 & 0.524 & 1.45 & 8.94 & 0.027 & 0.135 & 0.11 & $<0.010$ & 0.032 & 0.062 \\
\hline SB4VS-09 & U06LM11 & 3 & 1 & 12 & 0.045 & 0.784 & \begin{tabular}{|l|}
0.036 \\
\end{tabular} & 0.057 & 0.025 & 0.126 & 0.033 & 0.707 & 1.85 & 10 & 0.034 & 0.203 & 0.157 & 0.01 & 0.103 & 0.077 \\
\hline SB4VS-19 & U18LM11 & 3 & 1 & 13 & 0.028 & 0.584 & \begin{tabular}{|l|}
0.026 \\
\end{tabular} & 0.042 & 0.015 & 0.092 & 0.021 & 0.498 & 1.43 & 8.65 & 0.018 & 0.125 & 0.107 & $<0.010$ & 0.023 & 0.043 \\
\hline Batch 1 & BCHLM312 & 3 & 1 & 14 & 0.126 & 0.877 & $\begin{array}{l}<0.010 \\
\end{array}$ & 0.068 & 0.316 & 3.07 & $<0.010$ & 0.822 & 1.35 & 7.12 & $<0.010$ & $\begin{array}{l}<0.100 \\
\end{array}$ & $<0.100$ & 0.398 & $<0.010$ & 0.067 \\
\hline U std & \begin{tabular}{|l|l|} 
USTDLM312 \\
\end{tabular} & 3 & 1 & 15 & $<0.010$ & 0.92 & $\begin{array}{l}<0.010 \\
\end{array}$ & 0.164 & 0.004 & 2.78 & $<0.010$ & 0.688 & 2.13 & 9.09 & $<0.010$ & $\begin{array}{l}<0.100 \\
\end{array}$ & $<0.100$ & 0.553 & $<0.010$ & $<0.010$ \\
\hline SB4VS-16 & U11LM11 & 3 & 1 & 16 & 0.038 & 0.641 & 0.027 & 0.054 & 0.02 & 0.124 & 0.028 & 0.525 & 1.49 & 9.04 & 0.026 & 0.120 & 0.113 & $<0.010$ & 0.033 & 0.061 \\
\hline SB4VS-19 & U18LM21 & 3 & 1 & 17 & 0.03 & 0.565 & 0.027 & 0.044 & 0.015 & $<0.100$ & 0.022 & 0.528 & 1.41 & 8.75 & 0.02 & 0.132 & 0.111 & $<0.010$ & 0.027 & 0.045 \\
\hline SB4VS-15 & U25LM21 & 3 & 1 & 18 & 0.04 & 0.642 & \begin{tabular}{|l|}
0.038 \\
\end{tabular} & 0.053 & 0.019 & $<0.100$ & 0.03 & 0.513 & 1.62 & 9.02 & 0.025 & 0.139 & 0.126 & $<0.010$ & 0.031 & 0.065 \\
\hline SB4VS-21 & U01LM21 & 3 & 1 & 19 & 0.035 & 0.591 & \begin{tabular}{|l|}
0.027 \\
\end{tabular} & 0.056 & 0.015 & $<0.100$ & 0.027 & 0.491 & 1.4 & 7.96 & 0.025 & \begin{tabular}{|l|}
0.137 \\
\end{tabular} & 0.106 & $<0.010$ & 0.025 & 0.05 \\
\hline LRM-01 & U26LM21 & 3 & 1 & 20 & $<0.010$ & 0.38 & $\begin{array}{c}<0.010 \\
\end{array}$ & 0.131 & 0.001 & 1.3 & $<0.010$ & 0.06 & 0.054 & 15.9 & 0.073 & 0.071 & $<0.100$ & 0.058 & $<0.010$ & 0.674 \\
\hline SB4VS-23 & U19LM21 & 3 & 1 & 21 & 0.046 & 0.741 & \begin{tabular}{|l|}
0.043 \\
\end{tabular} & 0.066 & 0.021 & 0.127 & 0.036 & 0.646 & 1.59 & 9.74 & 0.036 & 0.149 & 0.129 & 0.01 & 0.034 & 0.075 \\
\hline SB4VS-06 & U24LM21 & 3 & 1 & 22 & 0.034 & 0.604 & 0.058 & 0.056 & 0.018 & $<0.100$ & 0.025 & 0.5 & 1.49 & 8.38 & 0.028 & 0.130 & 0.11 & $<0.010$ & 0.025 & 0.049 \\
\hline
\end{tabular}




\section{Table E2. Measured Elemental Concentrations (wt\%) for Samples Prepared Using Lithium Metaborate (continued)}

\begin{tabular}{|c|c|c|c|c|c|c|c|c|c|c|c|c|c|c|c|c|c|c|c|c|}
\hline Glass ID & Laboratory ID & Block & Sub-Block & $\begin{array}{c}\text { Analytical } \\
\text { Sequence }\end{array}$ & $\mathbf{B a}$ & $\mathrm{Ca}$ & $\mathrm{Ce}$ & $\mathrm{Cr}$ & $\mathrm{Cu}$ & $\mathbf{K}$ & La & Mg & Mn & $\mathrm{Na}$ & $\mathbf{P b}$ & $\mathbf{S}$ & Th & $\mathrm{Ti}$ & $\mathbf{Z n}$ & $\mathrm{Zr}$ \\
\hline SB4VS-11 & U28LM11 & 3 & 1 & 23 & 0.038 & 0.703 & 0.026 & 0.052 & 0.019 & 0.113 & 0.029 & 0.577 & 1.9 & 9.83 & 0.031 & 0.148 & 0.135 & $<0.010$ & 0.028 & 0.063 \\
\hline SB4VS-03 & U22LM11 & 3 & 1 & 24 & 0.04 & 0.679 & 0.032 & 0.062 & 0.019 & 0.108 & 0.031 & 0.603 & 1.74 & 11.3 & 0.027 & 0.162 & 0.131 & $<0.010$ & 0.027 & 0.067 \\
\hline LRM-01 & U26LM11 & 3 & 1 & 25 & $<<0.010$ & 0.419 & $\begin{array}{l}<0.010 \\
\end{array}$ & 0.128 & 0.001 & 1.3 & $<0.010$ & 0.057 & 0.053 & 15.9 & 0.07 & 0.082 & $<0.100$ & 0.057 & 0.005 & 0.65 \\
\hline SB4VS-09 & U06LM21 & 3 & 1 & 26 & 0.046 & 0.784 & \begin{tabular}{|l|}
0.036 \\
\end{tabular} & 0.058 & 0.025 & 0.127 & 0.033 & 0.684 & 2.01 & 10.3 & 0.033 & 0.178 & 0.153 & 0.01 & 0.033 & 0.078 \\
\hline Batch 1 & BCHLM313 & 3 & 1 & 27 & 0.129 & 0.881 & $\begin{array}{l}<0.010 \\
\end{array}$ & 0.069 & 0.319 & 3.21 & $<0.010$ & 0.831 & 1.38 & 7.52 & $<0.010$ & $\begin{array}{l}<0.100 \\
\end{array}$ & $<0.100$ & 0.401 & $<0.010$ & 0.068 \\
\hline U std & USTDLM313 & 3 & 1 & 28 & $<0.010$ & 0.919 & $\begin{array}{l}<0.010 \\
\end{array}$ & 0.167 & 0.004 & 2.75 & $<0.010$ & 0.691 & 2.18 & 9.27 & $<0.010$ & $\begin{array}{l}<0.100 \\
\end{array}$ & $<0.100$ & 0.557 & $<0.010$ & $<0.010$ \\
\hline Batch 1 & BCHLM321 & 3 & 2 & 1 & 0.124 & 0.863 & $\begin{array}{l}<0.010 \\
\end{array}$ & 0.067 & 0.318 & 3.06 & $<0.010$ & 0.792 & 1.37 & 6.96 & $<0.010$ & $\begin{array}{l}<0.100 \\
\end{array}$ & $<0.100$ & 0.377 & $<0.010$ & 0.066 \\
\hline U std & USTDLM321 & 3 & 2 & 2 & $<0.010$ & 0.907 & $\begin{array}{l}<0.010 \\
\end{array}$ & 0.159 & 0.005 & 2.65 & $<0.010$ & 0.662 & 2.21 & 8.71 & $<0.010$ & $\begin{array}{l}<0.100 \\
\end{array}$ & $<0.100$ & 0.545 & $<0.010$ & $<0.010$ \\
\hline SB4VS-06 & U24LM12 & 3 & 2 & 3 & 0.034 & 0.589 & \begin{tabular}{|l|}
0.025 \\
\end{tabular} & 0.053 & 0.02 & $<0.100$ & 0.027 & 0.476 & 1.49 & 8.17 & 0.027 & \begin{tabular}{|l|}
0.149 \\
\end{tabular} & 0.101 & 0.01 & 0.027 & 0.047 \\
\hline SB4VS-11 & U28LM12 & 3 & 2 & 4 & 0.038 & 0.691 & \begin{tabular}{|c|}
$<0.010$ \\
\end{tabular} & 0.05 & 0.02 & 0.115 & 0.031 & 0.545 & 1.9 & 9.5 & 0.032 & 0.165 & 0.124 & 0.01 & 0.029 & 0.061 \\
\hline SB4VS-06 & U24LM22 & 3 & 2 & 5 & 0.034 & 0.597 & \begin{tabular}{|l|}
0.058 \\
\end{tabular} & 0.051 & 0.019 & 0.103 & 0.027 & 0.47 & 1.48 & 8.31 & 0.031 & 0.139 & $<0.100$ & 0.01 & 0.026 & 0.047 \\
\hline SB4VS-10 & U39LM12 & 3 & 2 & 6 & 0.045 & 0.788 & \begin{tabular}{|l|}
0.039 \\
\end{tabular} & 0.057 & 0.024 & 0.153 & 0.035 & 0.514 & 1.74 & 9.95 & 0.033 & 0.165 & 0.118 & 0.01 & 0.037 & 0.068 \\
\hline SB4VS-19 & U18LM12 & 3 & 2 & 7 & 0.03 & 0.583 & 0.027 & 0.041 & 0.017 & $<0.100$ & 0.023 & 0.484 & 1.43 & 8.51 & 0.022 & 0.151 & $<0.100$ & $<0.010$ & 0.025 & 0.043 \\
\hline SB4VS-16 & U11LM12 & 3 & 2 & 8 & 0.039 & 0.631 & 0.027 & 0.052 & 0.021 & 0.127 & 0.03 & 0.508 & 1.54 & 9.08 & 0.03 & 0.140 & 0.101 & $<0.010$ & 0.034 & 0.061 \\
\hline SB4VS-09 & U06LM22 & 3 & 2 & 9 & 0.046 & 0.762 & 0.035 & 0.055 & 0.026 & 0.127 & 0.034 & 0.654 & 1.98 & 10 & 0.036 & 0.191 & 0.139 & 0.012 & 0.035 & 0.076 \\
\hline SB4VS-11 & U28LM22 & 3 & 2 & 10 & 0.038 & 0.702 & 0.026 & 0.049 & 0.02 & 0.123 & 0.029 & 0.516 & 1.82 & 9.7 & 0.026 & 0.164 & 0.114 & $<0.010$ & 0.036 & 0.058 \\
\hline SB4VS-15 & U25LM12 & 3 & 2 & 11 & 0.038 & 0.609 & 0.037 & 0.049 & 0.02 & $<0.100$ & 0.03 & 0.473 & 1.7 & 8.88 & 0.029 & 0.142 & 0.112 & 0.01 & 0.031 & 0.062 \\
\hline SB4VS-21 & U01LM22 & 3 & 2 & 12 & 0.036 & 0.581 & 0.028 & 0.054 & 0.016 & $<0.100$ & 0.03 & 0.477 & 1.44 & 7.85 & 0.028 & 0.139 & $<0.100$ & $<0.010$ & 0.027 & 0.05 \\
\hline SB4VS-15 & U25LM22 & 3 & 2 & 13 & 0.04 & 0.623 & 0.038 & 0.05 & 0.02 & $<0.100$ & 0.032 & 0.49 & 1.67 & 8.94 & 0.027 & 0.160 & 0.114 & 0.011 & 0.033 & 0.064 \\
\hline Batch 1 & BCHLM322 & 3 & 2 & 14 & 0.125 & 0.871 & \begin{tabular}{|l|}
$<0.010$ \\
\end{tabular} & 0.067 & 0.319 & 3.07 & $<0.010$ & 0.809 & 1.34 & 7.09 & $<0.010$ & \begin{tabular}{|l|}
$<0.100$ \\
\end{tabular} & $<0.100$ & 0.382 & $<0.010$ & 0.067 \\
\hline U std & USTDLM322 & 3 & 2 & 15 & $<0.010$ & 0.914 & \begin{tabular}{|l|}
$<0.010$ \\
\end{tabular} & 0.16 & 0.006 & 2.76 & $<0.010$ & 0.663 & 2.15 & 9.12 & $<0.010$ & \begin{tabular}{|l|}
$<0.100$ \\
\end{tabular} & $<0.100$ & 0.546 & $<0.010$ & $<0.010$ \\
\hline SB4VS-16 & U11LM22 & 3 & 2 & 16 & 0.041 & 0.606 & \begin{tabular}{|l|}
0.027 \\
\end{tabular} & 0.053 & 0.021 & 0.117 & 0.03 & 0.536 & 1.49 & 9.13 & 0.031 & \begin{tabular}{|l|}
0.144 \\
\end{tabular} & 0.103 & 0.01 & 0.035 & 0.062 \\
\hline SB4VS-03 & U22LM22 & 3 & 2 & 17 & 0.042 & 0.662 & \begin{tabular}{|l|}
0.033 \\
\end{tabular} & 0.062 & 0.02 & 0.104 & 0.033 & 0.585 & 1.69 & 11.1 & 0.028 & 0.160 & 0.12 & 0.011 & 0.029 & 0.063 \\
\hline LRM-01 & U26LM22 & 3 & 2 & 18 & $<0.010$ & 0.37 & $\begin{array}{l}<0.010 \\
\end{array}$ & 0.13 & 0.002 & 1.3 & $<0.010$ & 0.061 & 0.055 & 15.8 & 0.075 & 0.074 & $<0.100$ & 0.058 & $<0.010$ & 0.667 \\
\hline SB4VS-03 & U22LM12 & 3 & 2 & 19 & 0.043 & 0.663 & 0.033 & 0.063 & 0.02 & 0.106 & 0.034 & 0.594 & 1.7 & 11.3 & 0.028 & 0.174 & 0.121 & 0.011 & 0.03 & 0.068 \\
\hline SB4VS-09 & U06LM12 & 3 & 2 & 20 & 0.047 & 0.772 & \begin{tabular}{|l|}
0.036 \\
\end{tabular} & 0.057 & 0.026 & 0.127 & 0.035 & 0.701 & 1.96 & 10.5 & 0.037 & 0.206 & 0.141 & 0.012 & 0.104 & 0.077 \\
\hline LRM-01 & U26LM12 & 3 & 2 & 21 & $<0.010$ & 0.402 & $\begin{array}{l}<0.010 \\
\end{array}$ & 0.131 & 0.002 & 1.31 & $<0.010$ & 0.061 & 0.056 & 16 & 0.071 & 0.080 & $<0.100$ & 0.059 & $<0.010$ & 0.648 \\
\hline SB4VS-10 & U39LM22 & 3 & 2 & 22 & 0.049 & 0.795 & 0.04 & 0.06 & 0.024 & 0.135 & 0.038 & 0.575 & 1.76 & 10.3 & 0.037 & 0.171 & 0.125 & 0.011 & 0.045 & 0.075 \\
\hline SB4VS-23 & U19LM22 & 3 & 2 & 23 & 0.049 & 0.728 & 0.044 & 0.066 & 0.022 & 0.127 & 0.038 & 0.652 & 1.61 & 10.1 & 0.04 & 0.142 & 0.121 & 0.012 & 0.037 & 0.076 \\
\hline SB4VS-19 & U18LM22 & 3 & 2 & 24 & 0.032 & 0.557 & 0.028 & 0.045 & 0.016 & 0.088 & 0.024 & 0.536 & 1.44 & 8.92 & 0.022 & 0.154 & 0.103 & 0.01 & 0.03 & 0.046 \\
\hline SB4VS-21 & U01LM12 & 3 & 2 & 25 & 0.038 & 0.581 & 0.028 & 0.059 & 0.016 & 0.101 & 0.03 & 0.494 & 1.38 & 8.32 & 0.031 & 0.139 & $<0.100$ & $<0.010$ & 0.028 & 0.051 \\
\hline SB4VS-23 & U19LM12 & 3 & 2 & 26 & 0.05 & 0.743 & \begin{tabular}{|l|}
0.044 \\
\end{tabular} & 0.07 & 0.023 & 0.129 & 0.039 & 0.658 & 1.64 & 10.2 & 0.037 & \begin{tabular}{|l|}
0.164 \\
\end{tabular} & 0.124 & 0.012 & 0.037 & 0.077 \\
\hline Batch 1 & BCHLM323 & 3 & 2 & 27 & 0.131 & 0.86 & $\begin{array}{l}<0.010 \\
\end{array}$ & 0.071 & 0.319 & 3.17 & $<0.010$ & 0.84 & 1.35 & 7.43 & $<0.010$ & $\begin{array}{l}<0.100 \\
\end{array}$ & $<0.100$ & 0.388 & $<0.010$ & 0.068 \\
\hline U std & \begin{tabular}{|l|l} 
USTDLM323 \\
\end{tabular} & 3 & 2 & 28 & $<0.010$ & 0.909 & $\begin{array}{l}<0.010 \\
\end{array}$ & 0.167 & 0.006 & 2.77 & $<0.010$ & 0.697 & 2.17 & 9.4 & $<0.010$ & $<<0.100$ & $<0.100$ & 0.551 & $<0.010$ & $<0.010$ \\
\hline Batch 1 & BCHLM411 & 4 & 1 & 1 & 0.122 & 0.864 & $\begin{array}{l}<0.010 \\
\end{array}$ & 0.067 & 0.317 & 3.2 & $<0.010$ & 0.784 & 1.33 & 7.12 & $<0.010$ & $\begin{array}{l}<0.100 \\
\end{array}$ & $<0.100$ & 0.366 & $<0.010$ & 0.065 \\
\hline U std & \begin{tabular}{|l|l} 
USTDLM411 \\
\end{tabular} & 4 & 1 & 2 & $<0.010$ & 0.914 & $\begin{array}{l}<0.010 \\
\end{array}$ & 0.156 & 0.005 & 2.72 & $<0.010$ & 0.652 & 2.18 & 8.85 & $<0.010$ & $\begin{array}{l}<0.100 \\
\end{array}$ & $<0.100$ & 0.537 & $<0.010$ & $<0.010$ \\
\hline SB4VS-08 & U37LM11 & 4 & 1 & 3 & $\begin{array}{l}0.042 \\
\end{array}$ & 0.704 & 0.04 & 0.056 & 0.02 & 0.117 & 0.034 & 0.588 & 1.84 & 9.41 & 0.034 & \begin{tabular}{|l|}
0.163 \\
\end{tabular} & 0.128 & 0.011 & 0.034 & 0.069 \\
\hline SB4VS-22 & U23LM21 & 4 & 1 & 4 & \begin{tabular}{|l|}
0.049 \\
\end{tabular} & 0.628 & \begin{tabular}{|l|}
0.041 \\
\end{tabular} & 0.065 & 0.021 & 0.137 & 0.038 & 0.524 & 1.89 & 9.51 & 0.037 & \begin{tabular}{|l|}
0.148 \\
\end{tabular} & 0.123 & 0.01 & 0.036 & 0.08 \\
\hline SB4VS-29 & U43LM21 & 4 & 1 & 5 & 0.038 & 0.526 & 0.039 & 0.051 & 0.019 & 0.118 & 0.032 & 0.411 & 1.4 & 8.56 & 0.033 & 0.141 & 0.101 & 0.01 & 0.029 & 0.056 \\
\hline SB4VS-17 & U38LM11 & 4 & 1 & 6 & 0.031 & 0.615 & 0.021 & 0.044 & 0.018 & 0.107 & 0.026 & 0.452 & 1.55 & 8.52 & 0.023 & 0.142 & 0.097 & $<0.010$ & 0.026 & 0.048 \\
\hline LRM-03 & U34LM11 & 4 & 1 & 7 & $<0.010$ & 0.368 & \begin{tabular}{|l|}
$<0.010$ \\
\end{tabular} & 0.122 & 0.001 & 1.31 & $<0.010$ & 0.056 & 0.052 & 15.5 & 0.071 & 0.089 & $<0.100$ & 0.056 & $<0.010$ & 0.628 \\
\hline SB4VS-22 & U23LM11 & 4 & 1 & 8 & 0.047 & 0.623 & \begin{tabular}{|l|}
0.042 \\
\end{tabular} & 0.061 & 0.021 & 0.138 & 0.038 & 0.511 & 1.89 & 9.43 & 0.037 & \begin{tabular}{|l|}
0.154 \\
\end{tabular} & 0.121 & 0.01 & 0.035 & 0.078 \\
\hline SB4VS-02 & U15LM11 & 4 & 1 & 9 & 0.032 & 0.581 & 0.026 & 0.06 & 0.014 & $<0.100$ & 0.023 & 0.432 & 1.38 & 10.4 & 0.024 & 0.113 & 0.1 & $<0.010$ & 0.025 & 0.048 \\
\hline SB4VS-01 & U07LM21 & 4 & 1 & 10 & 0.037 & 0.596 & 0.026 & 0.05 & 0.017 & $<0.100$ & 0.027 & 0.488 & 1.47 & 10.3 & 0.026 & 0.137 & $<0.100$ & 0.011 & 0.024 & 0.051 \\
\hline LRM-03 & U34LM21 & 4 & 1 & 11 & $<0.010$ & 0.37 & $\begin{array}{l}<0.010 \\
\end{array}$ & 0.121 & 0.001 & 1.33 & $<0.010$ & 0.059 & 0.051 & 15.5 & 0.072 & 0.082 & $<0.100$ & 0.056 & $<0.010$ & 0.65 \\
\hline
\end{tabular}




\section{Table E2. Measured Elemental Concentrations (wt\%) for Samples Prepared Using Lithium Metaborate (continued)}

\begin{tabular}{|c|c|c|c|c|c|c|c|c|c|c|c|c|c|c|c|c|c|c|c|c|}
\hline Glass ID & Laboratory ID & Block & Sub-Block & $\begin{array}{c}\text { Analytical } \\
\text { Sequence }\end{array}$ & Ba & Ca & $\mathrm{Ce}$ & $\mathrm{Cr}$ & $\mathrm{Cu}$ & $\mathbf{K}$ & La & Mg & Mn & $\mathrm{Na}$ & $\mathbf{P b}$ & $\mathbf{S}$ & Th & $\mathbf{T i}$ & $\mathbf{Z n}$ & $\mathrm{Zr}$ \\
\hline SB4VS-29 & U43LM11 & 4 & 1 & 12 & 0.038 & 0.526 & 0.039 & 0.05 & 0.018 & 0.118 & 0.031 & 0.408 & 1.3 & 8.86 & 0.03 & 0.136 & 0.1 & 0.01 & 0.03 & 0.056 \\
\hline SB4VS-25 & U16LM11 & 4 & 1 & 13 & 0.032 & 0.571 & 0.017 & 0.05 & 0.015 & $<0.100$ & 0.024 & 0.588 & 1.61 & 9.56 & 0.025 & 0.158 & 0.113 & 0.01 & 0.024 & 0.049 \\
\hline Batch 1 & BCHLM412 & 4 & 1 & 14 & \begin{tabular}{|l|}
0.122 \\
\end{tabular} & 0.877 & \begin{tabular}{|l|}
$<0.010$ \\
\end{tabular} & 0.066 & 0.319 & 3.16 & $<0.010$ & 0.782 & 1.29 & 7.16 & $<0.010$ & \begin{tabular}{|l|}
$<0.100$ \\
\end{tabular} & $<0.100$ & 0.385 & 0.01 & 0.065 \\
\hline U std & \begin{tabular}{|l|} 
USTDLM412 \\
\end{tabular} & 4 & 1 & 15 & $<0.010$ & 0.914 & \begin{tabular}{|c|}
$<0.010$ \\
\end{tabular} & 0.154 & 0.005 & 2.74 & $<0.010$ & 0.64 & 2.12 & 8.9 & $<0.010$ & \begin{tabular}{|l|}
$<0.100$ \\
\end{tabular} & $<0.100$ & 0.529 & $<0.010$ & 0.002 \\
\hline SB4VS-33 & U30LM21 & 4 & 1 & 16 & \begin{tabular}{|l|}
0.024 \\
\end{tabular} & 0.849 & 0.022 & 0.033 & 0.014 & $<0.100$ & 0.02 & 0.582 & 1.73 & 8.33 & 0.016 & 0.180 & $<0.100$ & 0.013 & \begin{tabular}{|l|}
0.019 \\
\end{tabular} & 0.041 \\
\hline SB4VS-32 & U10LM21 & 4 & 1 & 17 & 0.053 & 0.877 & 0.053 & 0.06 & 0.024 & 0.163 & 0.041 & 0.433 & 1.55 & 10 & 0.039 & 0.225 & 0.114 & 0.01 & 0.041 & 0.083 \\
\hline SB4VS-32 & U10LM11 & 4 & 1 & 18 & \begin{tabular}{|l|}
0.054 \\
\end{tabular} & 0.853 & 0.053 & 0.062 & 0.024 & 0.153 & 0.042 & 0.446 & 1.54 & 9.88 & 0.037 & 0.207 & 0.117 & 0.011 & 0.04 & 0.085 \\
\hline SB4VS-02 & U15LM21 & 4 & 1 & 19 & 0.034 & 0.565 & 0.031 & 0.064 & 0.013 & $<0.100$ & 0.024 & 0.46 & 1.39 & 10.3 & 0.023 & 0.138 & 0.107 & 0.01 & 0.03 & 0.051 \\
\hline SB4VS-33 & U30LM11 & 4 & 1 & 20 & 0.023 & 0.858 & 0.022 & 0.033 & 0.013 & $<0.100$ & 0.02 & 0.563 & 1.72 & 8.22 & 0.015 & 0.187 & $<0.100$ & $<0.010$ & 0.026 & 0.04 \\
\hline SB4VS-25 & U16LM22 & 4 & 1 & 21 & 0.031 & 0.582 & 0.017 & 0.05 & 0.015 & $<<0.100$ & 0.024 & 0.574 & 1.69 & 9.52 & 0.023 & 0.165 & 0.109 & 0.01 & 0.024 & 0.048 \\
\hline SB4VS-08 & U37LM21 & 4 & 1 & 22 & 0.042 & 0.694 & 0.041 & 0.054 & 0.02 & 0.111 & 0.034 & 0.594 & 1.79 & 9.5 & 0.033 & 0.172 & 0.126 & 0.011 & 0.034 & 0.069 \\
\hline SB4VS-17 & U38LM21 & 4 & 1 & 23 & 0.03 & 0.601 & 0.02 & 0.041 & 0.017 & 0.108 & 0.024 & 0.418 & 1.42 & 8.35 & 0.021 & 0.126 & $<0.100$ & $<0.010$ & 0.024 & 0.045 \\
\hline $\begin{array}{l}\text { SB4VS-01 } \\
\end{array}$ & U07LM11 & 4 & 1 & 24 & 0.037 & 0.592 & 0.027 & 0.051 & 0.016 & $<0.100$ & 0.027 & 0.489 & 1.48 & 10.3 & 0.026 & 0.141 & $<0.100$ & 0.011 & 0.025 & 0.053 \\
\hline Batch 1 & BCHLM413 & 4 & 1 & 25 & \begin{tabular}{|l|}
0.118 \\
\end{tabular} & 0.871 & \begin{tabular}{|c|}
$<0.010$ \\
\end{tabular} & 0.065 & 0.317 & 3.2 & $<0.010$ & 0.763 & 1.31 & 7.3 & $<0.010$ & \begin{tabular}{|l|}
$<0.100$ \\
\end{tabular} & $<0.100$ & 0.371 & $<0.010$ & 0.065 \\
\hline U std & USTDLM413 & 4 & 1 & 26 & $<0.010$ & 0.912 & $<0.010$ & 0.155 & 0.005 & 2.78 & $<0.010$ & 0.643 & 2.13 & 9.13 & $<0.010$ & $<0.100$ & $<0.100$ & 0.525 & $<0.010$ & $<0.010$ \\
\hline Batch 1 & BCHLM421 & 4 & 2 & 1 & \begin{tabular}{|l|}
0.122 \\
\end{tabular} & 0.871 & \begin{tabular}{|l|}
$<0.010$ \\
\end{tabular} & 0.067 & 0.318 & 3.1 & $<0.010$ & 0.8 & 1.36 & 6.91 & $<0.010$ & \begin{tabular}{|l|}
$<0.100$ \\
\end{tabular} & $<0.100$ & 0.381 & $<0.010$ & 0.065 \\
\hline U std & \begin{tabular}{|l|} 
USTDLM421 \\
\end{tabular} & 4 & 2 & 2 & $<0.010$ & 0.911 & \begin{tabular}{|l|}
$<0.010$ \\
\end{tabular} & 0.16 & 0.006 & 2.73 & $<0.010$ & 0.677 & 2.17 & 8.79 & $<0.010$ & \begin{tabular}{|l|}
$<0.100$ \\
\end{tabular} & $<0.100$ & 0.546 & $<0.010$ & $<0.010$ \\
\hline LRM-03 & U34LM12 & 4 & 2 & 3 & $<0.010$ & 0.368 & \begin{tabular}{|l|}
$<0.010$ \\
\end{tabular} & 0.125 & 0.002 & 1.24 & $<0.010$ & 0.058 & 0.053 & 14.6 & 0.074 & \begin{tabular}{|l|}
0.089 \\
\end{tabular} & $<0.100$ & 0.058 & $<0.010$ & 0.637 \\
\hline SB4VS-32 & U10LM12 & 4 & 2 & 4 & \begin{tabular}{|l|}
0.054 \\
\end{tabular} & 0.848 & \begin{tabular}{|l|}
0.053 \\
\end{tabular} & 0.062 & 0.025 & 0.153 & 0.042 & 0.464 & 1.63 & 9.38 & 0.038 & 0.231 & 0.119 & 0.011 & 0.04 & 0.087 \\
\hline SB4VS-33 & U30LM22 & 4 & 2 & 5 & \begin{tabular}{|l|}
0.023 \\
\end{tabular} & 0.844 & 0.023 & 0.034 & 0.014 & $<0.100$ & 0.02 & 0.617 & 1.78 & 7.99 & 0.019 & 0.184 & $<0.100$ & 0.013 & 0.02 & 0.042 \\
\hline LRM-03 & U34LM22 & 4 & 2 & 6 & $<0.010$ & 0.363 & \begin{tabular}{|l|}
$<0.010$ \\
\end{tabular} & 0.126 & 0.002 & 1.27 & $<0.010$ & 0.061 & 0.053 & 15 & 0.076 & 0.090 & $<0.100$ & 0.057 & $<0.010$ & 0.658 \\
\hline SB4VS-17 & U38LM22 & 4 & 2 & 7 & \begin{tabular}{|l|}
0.029 \\
\end{tabular} & 0.597 & 0.021 & 0.041 & 0.018 & \begin{tabular}{|l|}
0.107 \\
\end{tabular} & 0.024 & 0.442 & 1.48 & 8 & 0.02 & $\begin{array}{ll}0.137 \\
\end{array}$ & $<0.100$ & $<0.010$ & 0.024 & 0.046 \\
\hline SB4VS-02 & U15LM22 & 4 & 2 & 8 & 0.034 & 0.563 & 0.032 & 0.067 & 0.014 & $\begin{array}{c}<0.100 \\
\end{array}$ & 0.023 & 0.488 & 1.41 & 9.94 & 0.026 & 0.136 & 0.109 & 0.01 & 0.031 & 0.052 \\
\hline SB4VS-02 & U15LM12 & 4 & 2 & 9 & 0.032 & 0.575 & 0.027 & 0.063 & 0.014 & $<0.100$ & 0.022 & 0.458 & 1.39 & 10 & 0.021 & 0.124 & 0.103 & $<0.010$ & 0.025 & 0.049 \\
\hline $\begin{array}{l}\text { SB4VS-01 } \\
\end{array}$ & U07LM22 & 4 & 2 & 10 & \begin{tabular}{|l|}
0.037 \\
\end{tabular} & 0.592 & \begin{tabular}{|l|}
0.027 \\
\end{tabular} & 0.052 & 0.017 & $<0.100$ & 0.027 & 0.514 & 1.54 & 10 & 0.024 & 0.129 & $<0.100$ & 0.011 & \begin{tabular}{|l|}
0.025 \\
\end{tabular} & 0.051 \\
\hline SB4VS-22 & U23LM12 & 4 & 2 & 11 & \begin{tabular}{|l|}
0.048 \\
\end{tabular} & 0.618 & 0.042 & 0.064 & 0.022 & 0.136 & 0.038 & 0.545 & 1.87 & 9.32 & 0.039 & 0.140 & 0.126 & 0.01 & 0.036 & 0.08 \\
\hline $\begin{array}{l}\text { SB4VS-01 } \\
\end{array}$ & U07LM12 & 4 & 2 & 12 & \begin{tabular}{|l|}
0.037 \\
\end{tabular} & 0.595 & \begin{tabular}{|l|}
0.027 \\
\end{tabular} & 0.053 & 0.017 & $<0.100$ & 0.027 & 0.513 & 1.53 & 10 & 0.028 & 0.154 & $<0.100$ & 0.011 & \begin{tabular}{|l|}
0.025 \\
\end{tabular} & 0.055 \\
\hline SB4VS-25 & U16LM22 & 4 & 2 & 13 & 0.031 & 0.583 & \begin{tabular}{|l|}
0.017 \\
\end{tabular} & 0.05 & 0.015 & $<<0.100$ & 0.023 & 0.595 & 1.73 & 9.17 & 0.024 & 0.150 & 0.113 & 0.01 & 0.024 & 0.049 \\
\hline Batch 1 & BCHLM 422 & 4 & 2 & 14 & 0.123 & 0.878 & $\begin{array}{l}<0.010 \\
\end{array}$ & 0.067 & 0.32 & 3.01 & $<0.010$ & 0.803 & 1.37 & 6.83 & $<0.010$ & \begin{tabular}{|l|}
$<0.100$ \\
\end{tabular} & $<0.100$ & 0.383 & $<0.010$ & 0.066 \\
\hline U std & \begin{tabular}{|l|} 
USTDLM422 \\
\end{tabular} & 4 & 2 & 15 & $<0.010$ & 0.916 & \begin{tabular}{|l|}
$<0.010$ \\
\end{tabular} & 0.16 & 0.006 & 2.7 & $<0.010$ & 0.675 & 2.18 & 8.83 & $<0.010$ & \begin{tabular}{|l|}
$<0.100$ \\
\end{tabular} & $<0.100$ & 0.54 & $<0.010$ & $<0.010$ \\
\hline $\begin{array}{l}\text { SB4VS-08 } \\
\end{array}$ & U37LM12 & 4 & 2 & 16 & \begin{tabular}{|l|}
0.042 \\
\end{tabular} & 0.706 & \begin{tabular}{|l|}
0.041 \\
\end{tabular} & 0.057 & 0.02 & 0.116 & 0.034 & 0.622 & 1.78 & 9.5 & 0.032 & \begin{tabular}{|l|}
0.176 \\
\end{tabular} & 0.13 & 0.011 & \begin{tabular}{|l|}
0.034 \\
\end{tabular} & 0.07 \\
\hline SB4VS-25 & U16LM12 & 4 & 2 & 17 & \begin{tabular}{|l|}
0.031 \\
\end{tabular} & 0.568 & \begin{tabular}{|l|}
0.017 \\
\end{tabular} & 0.052 & 0.016 & $\begin{array}{c}<0.100 \\
\end{array}$ & 0.024 & 0.619 & 1.69 & 9.26 & 0.023 & \begin{tabular}{|l|}
0.160 \\
\end{tabular} & 0.117 & 0.01 & 0.024 & 0.05 \\
\hline SB4VS-32 & U10LM22 & 4 & 2 & 18 & \begin{tabular}{|l|}
0.053 \\
\end{tabular} & 0.879 & 0.054 & 0.062 & 0.024 & 0.162 & 0.041 & 0.461 & 1.56 & 9.8 & 0.039 & \begin{tabular}{|l|}
0.217 \\
\end{tabular} & 0.118 & 0.011 & \begin{tabular}{|l|}
0.042 \\
\end{tabular} & 0.085 \\
\hline $\begin{array}{l}\text { SB4VS-08 } \\
\end{array}$ & $\begin{array}{l}\text { U37LM22 } \\
\end{array}$ & 4 & 2 & 19 & 0.042 & 0.695 & 0.042 & 0.056 & 0.02 & 0.111 & 0.034 & 0.631 & 1.79 & 9.39 & 0.035 & 0.176 & 0.134 & 0.011 & 0.035 & 0.071 \\
\hline SB4VS-29 & U43LM22 & 4 & 2 & 20 & 0.037 & 0.531 & 0.04 & 0.052 & 0.019 & 0.117 & 0.031 & 0.43 & 1.32 & 8.86 & 0.036 & \begin{tabular}{|l|}
0.135 \\
\end{tabular} & 0.103 & 0.01 & 0.029 & 0.057 \\
\hline SB4VS-22 & U23LM22 & 4 & 2 & 21 & \begin{tabular}{|l|}
0.049 \\
\end{tabular} & 0.63 & 0.042 & 0.067 & 0.022 & 0.137 & 0.038 & 0.545 & 1.87 & 9.44 & 0.038 & 0.154 & 0.128 & 0.01 & \begin{tabular}{|l|}
0.036 \\
\end{tabular} & 0.081 \\
\hline SB4VS-17 & U38LM12 & 4 & 2 & 22 & 0.031 & 0.625 & 0.021 & 0.045 & 0.018 & 0.108 & 0.026 & 0.476 & 1.56 & 8.52 & 0.023 & 0.139 & 0.1 & $<0.010$ & 0.026 & 0.049 \\
\hline SB4VS-33 & U30LM12 & 4 & 2 & 23 & 0.023 & 0.855 & 0.023 & 0.033 & 0.014 & $<0.100$ & 0.019 & 0.59 & 1.72 & 8.02 & 0.013 & 0.184 & $<0.100$ & $<0.010$ & 0.027 & 0.041 \\
\hline SB4VS-29 & U43LM12 & 4 & 2 & 24 & 0.037 & 0.525 & 0.04 & 0.052 & 0.019 & 0.116 & 0.032 & 0.431 & 1.34 & 8.64 & 0.033 & 0.139 & 0.104 & 0.01 & 0.03 & 0.056 \\
\hline Batch 1 & BCHLM423 & 4 & 2 & 25 & 0.123 & 0.917 & $<0.010$ & 0.067 & 0.318 & 3.06 & $<0.010$ & 0.811 & 1.36 & 6.99 & $<0.010$ & $<0.100$ & $<0.100$ & 0.385 & $<0.010$ & 0.065 \\
\hline U std & \begin{tabular}{|l|} 
USTDLM423 \\
\end{tabular} & 4 & 2 & 26 & $<0.010$ & 0.873 & \begin{tabular}{|l|}
$<0.010$ \\
\end{tabular} & 0.158 & 0.005 & 2.72 & $<0.010$ & 0.671 & 2.17 & 8.95 & $<0.010$ & \begin{tabular}{|c|c|c|c|c|}
$<0$ \\
\end{tabular} & $<0.100$ & $\begin{array}{l}0.547 \\
\end{array}$ & $\begin{array}{l}<0.010 \\
\end{array}$ & $<0.010$ \\
\hline
\end{tabular}


Table E3. Measured Elemental Concentrations (wt\%) for Samples Prepared Using Peroxide Fusion

\begin{tabular}{|c|c|c|c|c|c|c|c|c|c|c|c|}
\hline Glass ID & PSAL ID & Block & Sub-Block & $\begin{array}{l}\text { Analytical } \\
\text { Sequence }\end{array}$ & Al & B & $\mathrm{Fe}$ & $\mathbf{L i}$ & $\mathrm{Ni}$ & $\mathbf{S i}$ & $\mathbf{U}$ \\
\hline Batch 1 & BCHPF111 & 1 & 1 & 1 & 2.53 & 2.65 & 8.83 & 2.06 & 0.544 & 23 & $<0.100$ \\
\hline U std & USTDPF111 & 1 & 1 & 2 & 2.11 & 2.87 & 8.29 & 1.43 & 0.7 & 19.3 & 1.83 \\
\hline LRM-06 & U36PF21 & 1 & 1 & 3 & 5.49 & 2.55 & 0.954 & 0.139 & 0.096 & 24.5 & $<0.100$ \\
\hline SB4VS-02 & U15PF21 & 1 & 1 & 4 & 4.23 & 1.78 & 6.01 & 2.41 & 0.374 & 23 & 2.14 \\
\hline SB4VS-09 & U06PF11 & 1 & 1 & 5 & 5.97 & 2.4 & 7.54 & 2.02 & 0.448 & 19.1 & 2.75 \\
\hline LRM-02 & U33PF11 & 1 & 1 & 6 & 5.26 & 2.5 & 0.928 & 0.147 & 0.104 & 24.7 & $<0.100$ \\
\hline SB4VS-14 & U09PF21 & 1 & 1 & 7 & 4.77 & 2.76 & 6.21 & 2.31 & 0.357 & 21.6 & 2.31 \\
\hline LRM-06 & U36PF11 & 1 & 1 & 8 & 5.17 & 2.51 & 0.939 & 0.139 & 0.106 & 24.5 & $<0.100$ \\
\hline SB4VS-12 & U14PF21 & 1 & 1 & 9 & 5.29 & 2.62 & 6.16 & 2.21 & 0.43 & 20.7 & 2.3 \\
\hline SB4VS-16 & U11PF11 & 1 & 1 & 10 & 4.47 & 2.81 & 5.81 & 2.38 & 0.325 & 22 & 2.12 \\
\hline SB4VS-30 & U20PF11 & 1 & 1 & 11 & 3.99 & 2.8 & 5.76 & 2.38 & 0.386 & 21.8 & 1.92 \\
\hline SB4VS-09 & U06PF21 & 1 & 1 & 12 & 5.95 & 2.37 & 7.3 & 2 & 0.428 & 18.8 & 2.77 \\
\hline SB4VS-14 & U09PF11 & 1 & 1 & 13 & 4.71 & 2.77 & 6.29 & 2.3 & 0.362 & 21.6 & 2.31 \\
\hline Batch 1 & BCHPF112 & 1 & 1 & 14 & 2.54 & 2.47 & 8.62 & 2.06 & 0.511 & 22.7 & $<0.100$ \\
\hline U std & USTDPF112 & 1 & 1 & 15 & 2.14 & 2.99 & 8.26 & 1.43 & 0.728 & 19.6 & 1.91 \\
\hline LRM-04 & U08PF11 & 1 & 1 & 16 & 5.27 & 2.51 & 0.884 & 0.137 & 0.099 & 24.1 & $<0.100$ \\
\hline LRM-04 & U08PF21 & 1 & 1 & 17 & 5.42 & 2.53 & 0.89 & 0.14 & 0.103 & 24.6 & $<0.100$ \\
\hline SB4VS-30 & U20PF21 & 1 & 1 & 18 & 4.08 & 2.92 & 5.95 & 2.43 & 0.4 & 22.6 & 2.06 \\
\hline LRM-03 & U34PF21 & 1 & 1 & 19 & 5.25 & 2.5 & 0.91 & 0.137 & 0.098 & 24.6 & $<0.100$ \\
\hline SB4VS-02 & U15PF11 & 1 & 1 & 20 & 4.33 & 1.76 & 5.88 & 2.42 & 0.361 & 23 & 2.23 \\
\hline LRM-07 & U40PF11 & 1 & 1 & 21 & 5.35 & 2.5 & 0.918 & 0.137 & 0.098 & 24.9 & $<0.100$ \\
\hline LRM-02 & U33PF21 & 1 & 1 & 22 & 5.26 & 2.53 & 0.936 & 0.138 & 0.111 & 24.6 & $<0.100$ \\
\hline LRM-03 & U34PF11 & 1 & 1 & 23 & 5.31 & 2.48 & 0.887 & 0.137 & 0.091 & 24.7 & $<0.100$ \\
\hline LRM-07 & U40PF21 & 1 & 1 & 24 & 5.31 & 2.5 & 0.911 & 0.138 & 0.108 & 23.8 & $<0.100$ \\
\hline SB4VS-12 & U14PF11 & 1 & 1 & 25 & 5.4 & 2.69 & 6.35 & 2.25 & 0.456 & 21 & 2.42 \\
\hline SB4VS-16 & U11PF21 & 1 & 1 & 26 & 4.59 & 2.83 & 5.78 & 2.39 & 0.31 & 22.1 & 2.16 \\
\hline Batch 1 & BCHPF113 & 1 & 1 & 27 & 2.71 & 2.51 & 8.56 & 2.07 & 0.532 & 22.8 & $<0.100$ \\
\hline U std & USTDPF112 & 1 & 1 & 28 & 2.18 & 2.88 & 8.4 & 1.46 & 0.725 & 19.9 & 1.9 \\
\hline Batch 1 & BCHPF121 & 1 & 2 & 1 & 2.51 & 2.7 & 8.91 & 2.03 & 0.524 & 22.9 & $<0.100$ \\
\hline U std & USTDPF121 & 1 & 2 & 2 & 2.17 & 2.92 & 8.66 & 1.44 & 0.724 & 19.6 & 1.9 \\
\hline LRM-07 & U40PF22 & 1 & 2 & 3 & 5.32 & 2.54 & 0.947 & 0.139 & 0.081 & 23.6 & $<0.100$ \\
\hline LRM-04 & U08PF12 & 1 & 2 & 4 & 5.2 & 2.44 & 0.904 & 0.138 & 0.086 & 24.1 & $<0.100$ \\
\hline SB4VS-14 & U09PF22 & 1 & 2 & 5 & 4.71 & 2.75 & 6.49 & 2.3 & 0.351 & 21.8 & 2.27 \\
\hline LRM-02 & U33PF22 & 1 & 2 & 6 & 5.19 & 2.5 & 0.957 & 0.139 & 0.089 & 24.8 & $<0.100$ \\
\hline SB4VS-16 & U11PF12 & 1 & 2 & 7 & 4.49 & 2.8 & 6.07 & 2.37 & 0.324 & 22.3 & 2.16 \\
\hline SB4VS-16 & U11PF22 & 1 & 2 & 8 & 4.56 & 2.82 & 6.11 & 2.38 & 0.326 & 22.5 & 2.16 \\
\hline SB4VS-02 & U15PF12 & 1 & 2 & 9 & 4.32 & 1.73 & 6.09 & 2.43 & 0.362 & 23.4 & 2.21 \\
\hline SB4VS-02 & U15PF22 & 1 & 2 & 10 & 4.25 & 1.71 & 6.16 & 2.39 & 0.377 & 23.2 & 2.14 \\
\hline LRM-04 & U08PF22 & 1 & 2 & 11 & 5.4 & 2.46 & 0.93 & 0.141 & 0.089 & 25 & $<0.100$ \\
\hline SB4VS-30 & U20PF22 & 1 & 2 & 12 & 4.05 & 2.86 & 6.23 & 2.43 & 0.407 & 22.6 & 1.99 \\
\hline SB4VS-12 & U14PF12 & 1 & 2 & 13 & 5.4 & 2.66 & 6.59 & 2.25 & 0.448 & 21.5 & 2.41 \\
\hline Batch 1 & BCHPF122 & 1 & 2 & 14 & 2.54 & 2.45 & 8.96 & 2.05 & 0.541 & 23 & $<0.100$ \\
\hline U std & USTDPF122 & 1 & 2 & 15 & 2.16 & 2.79 & 8.55 & 1.44 & 0.714 & 19.8 & 1.86 \\
\hline LRM-03 & U34PF22 & 1 & 2 & 16 & 5.25 & 2.43 & 0.927 & 0.138 & 0.084 & 24.8 & $<0.100$ \\
\hline LRM-07 & U40PF12 & 1 & 2 & 17 & 5.36 & 2.48 & 0.939 & 0.138 & 0.101 & 25.3 & $<0.100$ \\
\hline SB4VS-09 & U06PF12 & 1 & 2 & 18 & 6 & 2.32 & 7.53 & 1.98 & 0.422 & 19.2 & 2.8 \\
\hline SB4VS-30 & U20PF12 & 1 & 2 & 19 & 3.97 & 2.77 & 6.01 & 2.34 & 0.372 & 22.2 & 1.92 \\
\hline LRM-02 & U33PF12 & 1 & 2 & 20 & 5.26 & 2.46 & 0.938 & 0.147 & 0.09 & 24.9 & $<0.100$ \\
\hline LRM-06 & U36PF22 & 1 & 2 & 21 & 5.68 & 2.46 & 0.94 & 0.139 & 0.094 & 24.5 & $<0.100$ \\
\hline SB4VS-09 & U06PF22 & 1 & 2 & 22 & 5.99 & 2.34 & 7.56 & 1.99 & 0.43 & 19.1 & 2.76 \\
\hline SB4VS-14 & U09PF12 & 1 & 2 & 23 & 4.72 & 2.74 & 6.52 & 2.29 & 0.349 & 21.8 & 2.33 \\
\hline SB4VS-12 & U14PF22 & 1 & 2 & 24 & 5.38 & 2.6 & 6.31 & 2.21 & 0.426 & 20.9 & 2.33 \\
\hline LRM-06 & U36PF12 & 1 & 2 & 25 & 5.22 & 2.48 & 0.967 & 0.139 & 0.096 & 24.8 & $<0.100$ \\
\hline LRM-03 & U34PF12 & 1 & 2 & 26 & 5.34 & 2.44 & 0.918 & 0.139 & 0.086 & 24.8 & $<0.100$ \\
\hline Batch 1 & BCHPF123 & 1 & 2 & 27 & 2.7 & 2.45 & 9.07 & 2.04 & 0.549 & 23 & $<0.100$ \\
\hline U std & USTDPF123 & 1 & 2 & 28 & 2.16 & 2.83 & 8.7 & 1.45 & 0.722 & 19.9 & 1.86 \\
\hline Batch 1 & BCHPF211 & 2 & 1 & 1 & 2.58 & 2.6 & 8.85 & 2.06 & 0.526 & 23.8 & $<0.100$ \\
\hline U std & USTDPF211 & 2 & 1 & 2 & 2.16 & 2.87 & 8.54 & 1.44 & 0.71 & 20.1 & 1.86 \\
\hline SB4VS-11 & U28PF11 & 2 & 1 & 3 & 5.73 & 2.6 & 6.69 & 2.16 & 0.453 & 21.3 & 2.64 \\
\hline SB4VS-25 & U16PF21 & 2 & 1 & 4 & 4.84 & 2.77 & 6.06 & 2.33 & 0.464 & 22.8 & 2.41 \\
\hline SB4VS-04 & U21PF21 & 2 & 1 & 5 & 5.76 & 1.49 & 7.92 & 2.08 & 0.494 & 21.5 & 2.77 \\
\hline SB4VS-35 & U41PF11 & 2 & 1 & 6 & 3.98 & 2.91 & 5.66 & 2.45 & 0.191 & 23.9 & 2.16 \\
\hline SB4VS-25 & U16PF11 & 2 & 1 & 7 & 4.82 & 2.76 & 6.02 & 2.31 & 0.454 & 22.6 & 2.42 \\
\hline SB4VS-24 & U12PF21 & 2 & 1 & 8 & 4.84 & 2.64 & 6.89 & 2.21 & 0.318 & 21.7 & 2.49 \\
\hline
\end{tabular}


Table E3. Measured Elemental Concentrations (wt\%) for Samples Prepared Using Peroxide Fusion (continued)

\begin{tabular}{|c|c|c|c|c|c|c|c|c|c|c|c|}
\hline Glass ID & PSAL ID & Block & Sub-Block & $\begin{array}{c}\text { Analytical } \\
\text { Sequence }\end{array}$ & Al & B & $\mathrm{Fe}$ & $\mathbf{L i}$ & $\mathbf{N i}$ & $\mathbf{S i}$ & $\mathbf{U}$ \\
\hline SB4VS-32 & U10PF21 & 2 & 1 & 9 & 4.63 & 2.51 & 6.53 & 2.18 & 0.485 & 21.1 & 2.11 \\
\hline SB4VS-28 & U35PF21 & 2 & 1 & 10 & 4.41 & 2.79 & 6.25 & 2.39 & 0.276 & 23.1 & 2.02 \\
\hline SB4VS-15 & U25PF21 & 2 & 1 & 11 & 4.75 & 2.65 & 6.49 & 2.28 & 0.318 & 22.3 & 2.27 \\
\hline SB4VS-07 & U27PF11 & 2 & 1 & 12 & 5.12 & 2.75 & 6.82 & 2.34 & 0.38 & 22.8 & 2.28 \\
\hline SB4VS-04 & U21PF11 & 2 & 1 & 13 & 5.79 & 1.44 & 7.5 & 2.1 & 0.472 & 21.2 & 2.61 \\
\hline Batch 1 & BCHPF212 & 2 & 1 & 14 & 2.58 & 2.46 & 9.01 & 2.06 & 0.537 & 24 & $<0.100$ \\
\hline U std & USTDPF212 & 2 & 1 & 15 & 2.17 & 2.89 & 8.68 & 1.43 & 0.728 & 20.9 & 1.88 \\
\hline SB4VS-31 & U17PF11 & 2 & 1 & 16 & 3.92 & 3.09 & 6.22 & 2.52 & 0.382 & 24.1 & 2.07 \\
\hline SB4VS-07 & U27PF21 & 2 & 1 & 17 & 5.44 & 2.8 & 6.61 & 2.33 & 0.392 & 23.5 & 2.28 \\
\hline SB4VS-27 & U05PF21 & 2 & 1 & 18 & 4.95 & 2.82 & 5.82 & 2.36 & 0.281 & 23.1 & 2.06 \\
\hline SB4VS-15 & U25PF11 & 2 & 1 & 19 & 4.87 & 2.75 & 6.68 & 2.34 & 0.331 & 22.6 & 2.29 \\
\hline SB4VS-32 & U10PF11 & 2 & 1 & 20 & 4.82 & 2.67 & 7.05 & 2.27 & 0.512 & 21.7 & 2.15 \\
\hline SB4VS-28 & U35PF11 & 2 & 1 & 21 & 4.4 & 2.9 & 6.74 & 2.41 & 0.299 & 23.7 & 2.09 \\
\hline SB4VS-35 & U41PF21 & 2 & 1 & 22 & 4.28 & 2.95 & 5.56 & 2.49 & 0.198 & 24.2 & 2.14 \\
\hline SB4VS-27 & U05PF11 & 2 & 1 & 23 & 4.82 & 2.79 & 5.58 & 2.33 & 0.277 & 22.8 & 2.03 \\
\hline SB4VS-24 & U12PF11 & 2 & 1 & 24 & 4.87 & 2.7 & 7.12 & 2.23 & 0.32 & 21.8 & 2.55 \\
\hline SB4VS-11 & U28PF21 & 2 & 1 & 25 & 5.71 & 2.61 & 6.81 & 2.15 & 0.464 & 21.4 & 2.6 \\
\hline SB4VS-31 & U17PF21 & 2 & 1 & 26 & 3.93 & 3.04 & 6.05 & 2.54 & 0.387 & 24.4 & 1.97 \\
\hline Batch 1 & BCHPF213 & 2 & 1 & 27 & 2.59 & 2.5 & 8.96 & 2.07 & 0.532 & 24.1 & $<0.100$ \\
\hline U std & USTDPF213 & 2 & 1 & 28 & 2.17 & 2.86 & 8.81 & 1.44 & 0.73 & 21.2 & 1.82 \\
\hline Batch 1 & BCHPF221 & 2 & 2 & 1 & 2.56 & 2.57 & 8.9 & 2.04 & 0.518 & 23.6 & $<0.100$ \\
\hline U std & USTDPF221 & 2 & 2 & 2 & 2.16 & 2.83 & 8.6 & 1.42 & 0.718 & 20.1 & 1.92 \\
\hline SB4VS-27 & U05PF12 & 2 & 2 & 3 & 4.73 & 2.69 & 5.42 & 2.28 & 0.273 & 22.2 & 2.06 \\
\hline SB4VS-31 & U17PF22 & 2 & 2 & 4 & 3.87 & 2.96 & 5.93 & 2.49 & 0.368 & 24 & 2.07 \\
\hline SB4VS-07 & U27PF22 & 2 & 2 & 5 & 5.38 & 2.69 & 6.46 & 2.3 & 0.373 & 23.1 & 2.31 \\
\hline SB4VS-07 & U27PF12 & 2 & 2 & 6 & 5.06 & 2.67 & 6.74 & 2.3 & 0.384 & 22.5 & 2.3 \\
\hline SB4VS-24 & U12PF12 & 2 & 2 & 7 & 4.82 & 2.59 & 6.98 & 2.2 & 0.319 & 21.3 & 2.57 \\
\hline SB4VS-35 & U41PF22 & 2 & 2 & 8 & 4.23 & 2.85 & 5.5 & 2.46 & 0.193 & 23.8 & 2.14 \\
\hline SB4VS-27 & U05PF22 & 2 & 2 & 9 & 4.93 & 2.73 & 5.75 & 2.35 & 0.274 & 22.8 & 2.09 \\
\hline SB4VS-28 & U35PF12 & 2 & 2 & 10 & 4.38 & 2.78 & 6.44 & 2.38 & 0.288 & 22.9 & 2.14 \\
\hline SB4VS-15 & U25PF12 & 2 & 2 & 11 & 4.84 & 2.59 & 6.24 & 2.29 & 0.313 & 21.8 & 2.31 \\
\hline SB4VS-04 & U21PF22 & 2 & 2 & 12 & 5.71 & 1.39 & 7.58 & 2.04 & 0.477 & 20.8 & 2.78 \\
\hline SB4VS-24 & U12PF22 & 2 & 2 & 13 & 4.79 & 2.54 & 6.76 & 2.19 & 0.308 & 21.4 & 2.51 \\
\hline Batch 1 & BCHPF222 & 2 & 2 & 14 & 2.55 & 2.38 & 8.79 & 2.03 & 0.511 & 23.5 & $<0.100$ \\
\hline U std & USTDPF222 & 2 & 2 & 15 & 2.15 & 2.8 & 8.44 & 1.41 & 0.678 & 20.2 & 1.91 \\
\hline SB4VS-25 & U16PF22 & 2 & 2 & 16 & 4.8 & 2.66 & 5.77 & 2.28 & 0.427 & 22.2 & 2.46 \\
\hline SB4VS-15 & U25PF22 & 2 & 2 & 17 & 4.69 & 2.56 & 6.27 & 2.24 & 0.303 & 21.6 & 2.26 \\
\hline SB4VS-31 & U17PF12 & 2 & 2 & 18 & 3.96 & 2.95 & 6.02 & 2.48 & 0.372 & 23.4 & 2.1 \\
\hline SB4VS-32 & U10PF22 & 2 & 2 & 19 & 4.62 & 2.45 & 6.48 & 2.16 & 0.482 & 21 & 2.14 \\
\hline SB4VS-04 & U21PF12 & 2 & 2 & 20 & 5.81 & 1.36 & 7.27 & 2.07 & 0.453 & 20.9 & 2.67 \\
\hline SB4VS-11 & U28PF12 & 2 & 2 & 21 & 5.71 & 2.48 & 6.64 & 2.14 & 0.446 & 20.9 & 2.62 \\
\hline SB4VS-11 & U28PF22 & 2 & 2 & 22 & 5.64 & 2.46 & 6.46 & 2.11 & 0.43 & 20.7 & 2.62 \\
\hline SB4VS-35 & U41PF12 & 2 & 2 & 23 & 3.98 & 2.78 & 5.34 & 2.41 & 0.176 & 23.3 & 2.16 \\
\hline SB4VS-32 & U10PF12 & 2 & 2 & 24 & 4.75 & 2.49 & 6.74 & 2.22 & 0.498 & 21.2 & 2.18 \\
\hline SB4VS-28 & U35PF22 & 2 & 2 & 25 & 4.35 & 2.66 & 6.12 & 2.36 & 0.266 & 22.5 & 2.03 \\
\hline SB4VS-25 & U16PF12 & 2 & 2 & 26 & 4.82 & 2.63 & 5.97 & 2.29 & 0.45 & 22.4 & 2.46 \\
\hline Batch 1 & BCHPF223 & 2 & 2 & 27 & 2.55 & 2.34 & 8.74 & 2.04 & 0.511 & 23.4 & $<0.100$ \\
\hline U std & USTDPF223 & 2 & 2 & 28 & 2.14 & 2.7 & 8.43 & 1.4 & 0.691 & 20.7 & 1.86 \\
\hline Batch 1 & BCHPF311 & 3 & 1 & 1 & 2.55 & 2.59 & 9.07 & 2.04 & 0.527 & 23.6 & $<0.100$ \\
\hline U std & USTDPF311 & 3 & 1 & 2 & 2.16 & 2.82 & 8.59 & 1.43 & 0.703 & 20.8 & 1.86 \\
\hline SB4VS-22 & U23PF11 & 3 & 1 & 3 & 6.09 & 2.6 & 6.83 & 2.19 & 0.348 & 21.6 & 2.52 \\
\hline SB4VS-08 & U37PF11 & 3 & 1 & 4 & 5.5 & 2.57 & 7.23 & 2.14 & 0.445 & 20.9 & 2.65 \\
\hline SB4VS-19 & U18PF21 & 3 & 1 & 5 & 4.31 & 2.88 & 5.6 & 2.46 & 0.363 & 23.5 & 2.08 \\
\hline SB4VS-10 & U39PF11 & 3 & 1 & 6 & 5.56 & 2.5 & 6.75 & 2.12 & 0.447 & 20.7 & 2.46 \\
\hline SB4VS-05 & U13PF11 & 3 & 1 & 7 & 4.06 & 3.06 & 5.23 & 2.56 & 0.305 & 25 & 1.89 \\
\hline SB4VS-05 & U13PF21 & 3 & 1 & 8 & 4.01 & 3.07 & 5.2 & 2.59 & 0.296 & 25 & 1.86 \\
\hline SB4VS-21 & U01PF21 & 3 & 1 & 9 & 4.47 & 2.96 & 5.21 & 2.55 & 0.31 & 24.8 & 1.99 \\
\hline SB4VS-13 & U32PF21 & 3 & 1 & 10 & 5.49 & 2.64 & 7.01 & 2.1 & 0.362 & 21.8 & 2.5 \\
\hline LRM-01 & U26PF21 & 3 & 1 & 11 & 5.36 & 2.46 & 0.966 & 0.123 & 0.091 & 24.9 & $<0.100$ \\
\hline SB4VS-08 & U37PF21 & 3 & 1 & 12 & 5.59 & 2.56 & 7.23 & 2.15 & 0.448 & 21.4 & 2.64 \\
\hline SB4VS-20 & U42PF21 & 3 & 1 & 13 & 4.17 & 2.97 & 5.62 & 2.54 & 0.342 & 24.8 & 2 \\
\hline Batch 1 & BCHPF312 & 3 & 1 & 14 & 2.6 & 2.44 & 8.97 & 2.04 & 0.532 & 23.8 & $<0.100$ \\
\hline U std & USTDPF312 & 3 & 1 & 15 & 2.16 & 2.82 & 8.61 & 1.42 & 0.726 & 20.2 & 1.88 \\
\hline SB4VS-19 & U18PF11 & 3 & 1 & 16 & 4.33 & 2.86 & 5.55 & 2.46 & 0.361 & 23.7 & 2.08 \\
\hline SB4VS-22 & U23PF21 & 3 & 1 & 17 & 6 & 2.53 & 6.64 & 2.13 & 0.344 & 20.9 & 2.5 \\
\hline
\end{tabular}


Table E3. Measured Elemental Concentrations (wt\%) for Samples Prepared Using Peroxide Fusion (continued)

\begin{tabular}{|c|c|c|c|c|c|c|c|c|c|c|c|}
\hline Glass ID & PSAL ID & Block & Sub-Block & $\begin{array}{c}\text { Analytical } \\
\text { Sequence }\end{array}$ & Al & B & $\mathrm{Fe}$ & $\mathbf{L i}$ & $\mathbf{N i}$ & $\mathbf{S i}$ & $\mathbf{U}$ \\
\hline SB4VS-33 & U30PF21 & 3 & 1 & 18 & 5.55 & 2.78 & 6.15 & 2.31 & 0.529 & 23 & 2.28 \\
\hline SB4VS-20 & U42PF11 & 3 & 1 & 19 & 4.16 & 2.95 & 5.51 & 2.51 & 0.345 & 24.2 & 2 \\
\hline SB4VS-13 & U32PF11 & 3 & 1 & 20 & 5.57 & 2.63 & 6.66 & 2.13 & 0.358 & 22 & 2.52 \\
\hline SB4VS-10 & U39PF21 & 3 & 1 & 21 & 5.67 & 2.52 & 7.22 & 2.16 & 0.504 & 20.8 & 2.5 \\
\hline LRM-05 & U03PF11 & 3 & 1 & 22 & 5.44 & 2.49 & 0.966 & 0.123 & 0.094 & 26.1 & $<0.100$ \\
\hline SB4VS-33 & U30PF11 & 3 & 1 & 23 & 5.46 & 2.75 & 6.08 & 2.29 & 0.532 & 22.8 & 2.25 \\
\hline LRM-01 & U26PF11 & 3 & 1 & 24 & 5.42 & 2.41 & 0.91 & 0.124 & 0.08 & 25.6 & $<0.100$ \\
\hline SB4VS-21 & U01PF11 & 3 & 1 & 25 & 4.33 & 2.78 & 4.75 & 2.48 & 0.263 & 23.6 & 1.91 \\
\hline LRM-05 & U03PF21 & 3 & 1 & 26 & 5.48 & 2.39 & 0.91 & 0.124 & 0.085 & 24.7 & $<0.100$ \\
\hline Batch 1 & BCHPF313 & 3 & 1 & 27 & 2.57 & 2.4 & 8.83 & 2.03 & 0.52 & 23.5 & $<0.100$ \\
\hline U std & USTDPF313 & 3 & 1 & 28 & 2.18 & 2.76 & 8.63 & 1.43 & 0.707 & 22.6 & 1.91 \\
\hline Batch 1 & BCHPF321 & 3 & 2 & 1 & 2.54 & 2.58 & 9.15 & 2.03 & 0.532 & 23.6 & $<0.100$ \\
\hline U std & USTDPF321 & 3 & 2 & 2 & 2.16 & 2.82 & 8.73 & 1.42 & 0.711 & 20.6 & 1.86 \\
\hline SB4VS-33 & U30PF22 & 3 & 2 & 3 & 5.51 & 2.8 & 6.17 & 2.32 & 0.516 & 23.1 & 2.22 \\
\hline SB4VS-10 & U39PF22 & 3 & 2 & 4 & 5.64 & 2.52 & 7.31 & 2.16 & 0.51 & 20.7 & 2.45 \\
\hline SB4VS-22 & U23PF12 & 3 & 2 & 5 & 6.01 & 2.52 & 6.75 & 2.18 & 0.327 & 21.3 & 2.45 \\
\hline SB4VS-33 & U30PF12 & 3 & 2 & 6 & 5.45 & 2.75 & 6.11 & 2.29 & 0.519 & 22.8 & 2.24 \\
\hline SB4VS-10 & U39PF12 & 3 & 2 & 7 & 5.65 & 2.43 & 6.9 & 2.16 & 0.468 & 21.1 & 2.46 \\
\hline SB4VS-08 & U37PF22 & 3 & 2 & 8 & 5.57 & 2.49 & 7.28 & 2.17 & 0.425 & 21.4 & 2.57 \\
\hline SB4VS-21 & U01PF22 & 3 & 2 & 9 & 4.48 & 2.89 & 5.14 & 2.54 & 0.291 & 24.4 & 1.99 \\
\hline SB4VS-19 & U18PF22 & 3 & 2 & 10 & 4.4 & 2.81 & 5.48 & 2.48 & 0.364 & 23.7 & 2.08 \\
\hline SB4VS-08 & U37PF12 & 3 & 2 & 11 & 5.57 & 2.5 & 7.1 & 2.14 & 0.428 & 21.1 & 2.65 \\
\hline SB4VS-21 & U01PF12 & 3 & 2 & 12 & 4.24 & 2.7 & 4.72 & 2.44 & 0.25 & 23.2 & 1.86 \\
\hline LRM-05 & U03PF12 & 3 & 2 & 13 & 5.38 & 2.42 & 0.957 & 0.107 & 0.078 & 25.7 & $<0.100$ \\
\hline Batch 1 & BCHPF322 & 3 & 2 & 14 & 2.56 & 2.32 & 8.69 & 2.01 & 0.506 & 23.2 & $<0.100$ \\
\hline U std & USTDPF322 & 3 & 2 & 15 & 2.15 & 2.77 & 8.49 & 1.4 & 0.692 & 20 & 1.88 \\
\hline LRM-01 & U26PF12 & 3 & 2 & 16 & 5.34 & 2.38 & 0.905 & 0.106 & 0.076 & 25 & $<0.100$ \\
\hline LRM-05 & U03PF22 & 3 & 2 & 17 & 5.46 & 2.36 & 0.92 & 0.107 & 0.075 & 24.6 & $<0.100$ \\
\hline SB4VS-13 & U32PF22 & 3 & 2 & 18 & 5.38 & 2.53 & 6.81 & 2.04 & 0.35 & 21.2 & 2.47 \\
\hline LRM-01 & U26PF22 & 3 & 2 & 19 & 5.26 & 2.41 & 0.953 & 0.107 & 0.081 & 24.5 & $<0.100$ \\
\hline SB4VS-05 & U13PF22 & 3 & 2 & 20 & 3.97 & 2.94 & 4.97 & 2.55 & 0.279 & 24.4 & 1.8 \\
\hline SB4VS-20 & U42PF12 & 3 & 2 & 21 & 4.17 & 2.9 & 5.38 & 2.51 & 0.326 & 24 & 2.01 \\
\hline SB4VS-20 & U42PF22 & 3 & 2 & 22 & 4.12 & 2.89 & 5.41 & 2.52 & 0.334 & 24.2 & 2 \\
\hline SB4VS-05 & U13PF12 & 3 & 2 & 23 & 4.02 & 2.96 & 5.1 & 2.53 & 0.286 & 24.4 & 1.83 \\
\hline SB4VS-19 & U18PF12 & 3 & 2 & 24 & 4.37 & 2.77 & 5.4 & 2.45 & 0.36 & 23.4 & 2.1 \\
\hline SB4VS-13 & U32PF12 & 3 & 2 & 25 & 5.6 & 2.58 & 6.52 & 2.11 & 0.347 & 21.9 & 2.54 \\
\hline SB4VS-22 & U23PF22 & 3 & 2 & 26 & 5.93 & 2.42 & 6.38 & 2.1 & 0.321 & 20.6 & 2.46 \\
\hline Batch 1 & BCHPF323 & 3 & 2 & 27 & 2.54 & 2.34 & 8.61 & 2.01 & 0.486 & 23.2 & $<0.100$ \\
\hline U std & USTDPF323 & 3 & 2 & 28 & 2.16 & 2.67 & 8.32 & 1.4 & 0.67 & 21.3 & 1.83 \\
\hline Batch 1 & BCHPF411 & 4 & 1 & 1 & 2.54 & 2.58 & 9.05 & 2.04 & 0.497 & 23.8 & $<0.100$ \\
\hline U std & USTDPF411 & 4 & 1 & 2 & 2.17 & 2.87 & 8.75 & 1.42 & 0.684 & 21.6 & 1.85 \\
\hline SB4VS-06 & U24PF21 & 4 & 1 & 3 & 4.53 & 2.93 & 5.82 & 2.45 & 0.309 & 23.8 & 2.07 \\
\hline SB4VS-17 & U38PF11 & 4 & 1 & 4 & 4.83 & 2.77 & 6.1 & 2.34 & 0.29 & 22.9 & 2.15 \\
\hline SB4VS-26 & U29PF11 & 4 & 1 & 5 & 4.63 & 2.75 & 6.39 & 2.32 & 0.282 & 23 & 2.42 \\
\hline SB4VS-01 & U07PF11 & 4 & 1 & 6 & 4.62 & 1.55 & 5.36 & 2.44 & 0.281 & 24.3 & 1.87 \\
\hline SB4VS-06 & U24PF11 & 4 & 1 & 7 & 4.47 & 2.9 & 6.02 & 2.42 & 0.323 & 24.1 & 2.09 \\
\hline SB4VS-26 & U29PF21 & 4 & 1 & 8 & 4.59 & 2.73 & 6.42 & 2.31 & 0.291 & 22.6 & 2.43 \\
\hline LRM-08 & U31PF21 & 4 & 1 & 9 & 5.32 & 2.42 & 0.898 & 0.091 & 0.057 & 24.6 & $<0.100$ \\
\hline SB4VS-18 & U02PF11 & 4 & 1 & 10 & 4.35 & 2.74 & 5.95 & 2.39 & 0.348 & 22.6 & 1.97 \\
\hline SB4VS-34 & U04PF11 & 4 & 1 & 11 & 5.22 & 2.76 & 6.41 & 2.38 & 0.165 & 22.8 & 2.27 \\
\hline SB4VS-01 & U07PF21 & 4 & 1 & 12 & 4.73 & 1.54 & 5.26 & 2.5 & 0.275 & 24.3 & 1.88 \\
\hline SB4VS-23 & U19PF11 & 4 & 1 & 13 & 5.13 & 2.57 & 6.31 & 2.2 & 0.447 & 21.8 & 2.31 \\
\hline Batch 1 & BCHPF412 & 4 & 1 & 14 & 2.56 & 2.39 & 8.8 & 2.01 & 0.495 & 23.5 & $<0.100$ \\
\hline U std & USTDPF412 & 4 & 1 & 15 & 2.19 & 2.82 & 8.41 & 1.4 & 0.659 & 20.5 & 1.92 \\
\hline SB4VS-17 & U38PF21 & 4 & 1 & 16 & 4.9 & 2.77 & 5.99 & 2.37 & 0.281 & 23.1 & 2.14 \\
\hline SB4VS-23 & U19PF21 & 4 & 1 & 17 & 5.08 & 2.6 & 6.43 & 2.2 & 0.449 & 21.8 & 2.28 \\
\hline SB4VS-29 & U43PF21 & 4 & 1 & 18 & 4.45 & 2.79 & 5.27 & 2.38 & 0.355 & 23.1 & 2.13 \\
\hline SB4VS-29 & U43PF11 & 4 & 1 & 19 & 4.46 & 2.81 & 5.26 & 2.4 & 0.356 & 23.1 & 2.12 \\
\hline SB4VS-34 & U04PF21 & 4 & 1 & 20 & 5.39 & 2.77 & 6.54 & 2.34 & 0.168 & 23.5 & 2.3 \\
\hline LRM-08 & U31PF11 & 4 & 1 & 21 & 5.33 & 2.37 & 0.862 & 0.092 & 0.05 & 25.5 & $<0.100$ \\
\hline SB4VS-03 & U22PF21 & 4 & 1 & 22 & 5.31 & 1.46 & 6.59 & 2.19 & 0.347 & 22.3 & 2.36 \\
\hline SB4VS-03 & U22PF11 & 4 & 1 & 23 & 5.21 & 1.47 & 6.93 & 2.19 & 0.378 & 22.2 & 2.48 \\
\hline SB4VS-18 & U02PF21 & 4 & 1 & 24 & 4.29 & 2.79 & 5.94 & 2.38 & 0.333 & 23.2 & 1.98 \\
\hline Batch 1 & BCHPF413 & 4 & 1 & 25 & 2.53 & 2.36 & 8.79 & 2.02 & 0.484 & 23.3 & $<0.100$ \\
\hline U std & USTDPF413 & 4 & 1 & 26 & 2.26 & 2.85 & 8.85 & 1.48 & 0.704 & 21.3 & 1.92 \\
\hline
\end{tabular}


Table E3. Measured Elemental Concentrations (wt\%) for Samples Prepared Using Peroxide Fusion (continued)

\begin{tabular}{|c|c|c|c|c|c|c|c|c|c|c|c|}
\hline Glass ID & PSAL ID & Block & Sub-Block & $\begin{array}{c}\text { Analytical } \\
\text { Sequence }\end{array}$ & Al & B & $\mathbf{F e}$ & $\mathbf{L i}$ & $\mathbf{N i}$ & $\mathbf{S i}$ & $\mathbf{U}$ \\
\hline Batch 1 & BCHPF421 & 4 & 2 & 1 & 2.59 & 2.6 & 9.05 & 2.06 & 0.546 & 23.8 & $<0.100$ \\
\hline U std & USTDPF421 & 4 & 2 & 2 & 2.21 & 2.86 & 8.63 & 1.44 & 0.735 & 21 & 1.88 \\
\hline SB4VS-06 & U24PF12 & 4 & 2 & 3 & 4.54 & 2.93 & 5.97 & 2.44 & 0.365 & 23.6 & 2.13 \\
\hline SB4VS-01 & U07PF12 & 4 & 2 & 4 & 4.66 & 1.54 & 5.2 & 2.45 & 0.316 & 24.1 & 1.91 \\
\hline SB4VS-01 & U07PF22 & 4 & 2 & 5 & 4.77 & 1.56 & 5.27 & 2.5 & 0.309 & 24.3 & 1.88 \\
\hline SB4VS-18 & U02PF12 & 4 & 2 & 6 & 4.38 & 2.77 & 6.05 & 2.42 & 0.393 & 22.6 & 1.95 \\
\hline SB4VS-29 & U43PF12 & 4 & 2 & 7 & 4.41 & 2.81 & 5.37 & 2.39 & 0.413 & 23 & 2.14 \\
\hline SB4VS-03 & U22PF22 & 4 & 2 & 8 & 5.38 & 1.48 & 6.77 & 2.22 & 0.412 & 22.4 & 2.39 \\
\hline SB4VS-06 & U24PF22 & 4 & 2 & 9 & 4.57 & 2.87 & 5.8 & 2.45 & 0.356 & 23.5 & 2.08 \\
\hline SB4VS-17 & U38PF22 & 4 & 2 & 10 & 5 & 2.78 & 6.02 & 2.39 & 0.34 & 23.2 & 2.18 \\
\hline SB4VS-34 & U04PF12 & 4 & 2 & 11 & 5.28 & 2.76 & 6.48 & 2.39 & 0.218 & 23.3 & 2.34 \\
\hline SB4VS-29 & U43PF22 & 4 & 2 & 12 & 4.46 & 2.8 & 5.44 & 2.38 & 0.416 & 23.1 & 2.14 \\
\hline SB4VS-17 & U38PF12 & 4 & 2 & 13 & 4.92 & 2.77 & 6.1 & 2.36 & 0.352 & 22.9 & 2.15 \\
\hline Batch 1 & BCHPF422 & 4 & 2 & 14 & 2.58 & 2.39 & 8.73 & 2.03 & 0.533 & 23.5 & $<0.100$ \\
\hline U std & USTDPF422 & 4 & 2 & 15 & 2.25 & 2.81 & 8.46 & 1.43 & 0.708 & 20.3 & 1.87 \\
\hline SB4VS-23 & U19PF12 & 4 & 2 & 16 & 5.15 & 2.62 & 6.37 & 2.22 & 0.488 & 21.6 & 2.36 \\
\hline LRM-08 & U31PF12 & 4 & 2 & 17 & 5.42 & 2.41 & 0.908 & 0.13 & 0.097 & 25.5 & $<0.100$ \\
\hline SB4VS-26 & U29PF12 & 4 & 2 & 18 & 4.64 & 2.68 & 6.11 & 2.29 & 0.319 & 22.4 & 2.49 \\
\hline SB4VS-23 & U19PF22 & 4 & 2 & 19 & 5.08 & 2.59 & 6.3 & 2.2 & 0.484 & 21.5 & 2.33 \\
\hline LRM-08 & U31PF22 & 4 & 2 & 20 & 5.37 & 2.41 & 0.933 & 0.129 & 0.105 & 24.6 & $<0.100$ \\
\hline SB4VS-03 & U22PF12 & 4 & 2 & 21 & 5.26 & 1.49 & 6.96 & 2.21 & 0.424 & 22.2 & 2.51 \\
\hline SB4VS-18 & U02PF22 & 4 & 2 & 22 & 4.41 & 2.81 & 5.89 & 2.43 & 0.359 & 23.5 & 2.09 \\
\hline SB4VS-34 & U04PF22 & 4 & 2 & 23 & 5.42 & 2.75 & 6.48 & 2.36 & 0.204 & 23.4 & 2.3 \\
\hline SB4VS-26 & U29PF22 & 4 & 2 & 24 & 4.67 & 2.72 & 6.32 & 2.32 & 0.33 & 22.5 & 2.47 \\
\hline Batch 1 & BCHPF423 & 4 & 2 & 25 & 2.58 & 2.39 & 8.79 & 2.04 & 0.516 & 23.3 & $<0.100$ \\
\hline U std & USTDPF423 & 4 & 2 & 26 & 2.14 & 2.68 & 8.13 & 1.4 & 0.685 & 19.5 & 1.86 \\
\hline
\end{tabular}


Table E4. Average Measured and Bias-Corrected Chemical Compositions Versus Targeted Compositions by Oxide by SB4 Variability Study Glass

(100-Batch 1; 200 -U std; 300 - LRM)

\begin{tabular}{|c|c|c|c|c|c|c|c|c|}
\hline Glass ID & Oxide & $\begin{array}{c}\text { Measured } \\
(\mathbf{w t} \%)\end{array}$ & $\begin{array}{c}\text { Measured } \\
\text { Bias-Corrected } \\
(\mathbf{w t} \%) \\
\end{array}$ & $\begin{array}{c}\text { Targeted } \\
(\mathbf{w t} \%)\end{array}$ & $\begin{array}{c}\text { Diff of } \\
\text { Measured } \\
(w t \%)\end{array}$ & $\begin{array}{c}\text { Diff. of } \\
\text { Meas BC } \\
(w t \%) \\
\end{array}$ & $\begin{array}{l}\text { \% Diff of } \\
\text { Measured }\end{array}$ & $\begin{array}{l}\% \text { Diff of } \\
\text { Meas BC }\end{array}$ \\
\hline SB4VS-01 & $\mathrm{Al}_{2} \mathrm{O}_{3}$ & 8.8710 & 8.9330 & 7.6310 & 1.2400 & 1.3020 & $16.2 \%$ & $17.1 \%$ \\
\hline SB4VS-01 & $\mathrm{B}_{2} \mathrm{O}_{3}$ & 4.9830 & 4.9090 & 5.4400 & -0.4570 & -0.5310 & $-8.4 \%$ & $-9.8 \%$ \\
\hline SB4VS-01 & $\mathrm{BaO}$ & 0.0410 & 0.0460 & 0.0400 & 0.0010 & 0.0060 & $2.5 \%$ & $15.0 \%$ \\
\hline SB4VS-01 & $\mathrm{CaO}$ & 0.8310 & 0.8240 & 0.7560 & 0.0750 & 0.0680 & $9.9 \%$ & $9.0 \%$ \\
\hline SB4VS-01 & $\mathrm{Ce}_{2} \mathrm{O}_{3}$ & 0.0310 & 0.0310 & 0.0480 & -0.0170 & -0.0170 & $-35.4 \%$ & $-35.4 \%$ \\
\hline SB4VS-01 & $\mathrm{Cr}_{2} \mathrm{O}_{3}$ & 0.0750 & 0.0830 & 0.0670 & 0.0080 & 0.0160 & $11.9 \%$ & $23.9 \%$ \\
\hline SB4VS-01 & $\mathrm{CuO}$ & 0.0210 & 0.0210 & 0.0190 & 0.0020 & 0.0020 & $10.5 \%$ & $10.5 \%$ \\
\hline SB4VS-01 & $\mathrm{Fe}_{2} \mathrm{O}_{3}$ & 7.5380 & 7.6330 & 8.4070 & -0.8690 & -0.7740 & $-10.3 \%$ & $-9.2 \%$ \\
\hline SB4VS-01 & $\mathrm{K}_{2} \mathrm{O}$ & 0.0600 & 0.0530 & 0.1060 & -0.0460 & -0.0530 & $-43.4 \%$ & $-50.0 \%$ \\
\hline SB4VS-01 & $\mathrm{La}_{2} \mathrm{O}_{3}$ & 0.0320 & 0.0320 & 0.0340 & -0.0020 & -0.0020 & $-5.9 \%$ & $-5.9 \%$ \\
\hline SB4VS-01 & $\mathrm{Li}_{2} \mathrm{O}$ & 5.3230 & 5.3860 & 5.4400 & -0.1170 & -0.0540 & $-2.2 \%$ & $-1.0 \%$ \\
\hline SB4VS-01 & $\mathrm{MgO}$ & 0.8310 & 0.8990 & 0.7970 & 0.0340 & 0.1020 & $4.3 \%$ & $12.8 \%$ \\
\hline SB4VS-01 & $\mathrm{MnO}$ & 1.9430 & 1.9430 & 1.7340 & 0.2090 & 0.2090 & $12.1 \%$ & $12.1 \%$ \\
\hline SB4VS-01 & $\mathrm{Na}_{2} \mathrm{O}$ & 13.6820 & 12.9600 & 12.9890 & 0.6930 & -0.0290 & $5.3 \%$ & $-0.2 \%$ \\
\hline SB4VS-01 & $\mathrm{NiO}$ & 0.3760 & 0.4330 & 0.4970 & -0.1210 & -0.0640 & $-24.3 \%$ & $-12.9 \%$ \\
\hline SB4VS-01 & $\mathrm{PbO}$ & 0.0280 & 0.0280 & 0.0290 & -0.0010 & -0.0010 & $-3.4 \%$ & $-3.4 \%$ \\
\hline SB4VS-01 & $\mathrm{SiO}_{2}$ & 51.8780 & 51.7490 & 52.9540 & -1.0760 & -1.2050 & $-2.0 \%$ & $-2.3 \%$ \\
\hline SB4VS-01 & $\mathrm{SO}_{4}{ }^{2-}$ & 0.4200 & 0.4200 & 0.4460 & -0.0260 & -0.0260 & $-5.8 \%$ & $-5.8 \%$ \\
\hline SB4VS-01 & $\mathrm{ThO}_{2}$ & 0.0570 & 0.0570 & 0.0200 & 0.0370 & 0.0370 & $185.0 \%$ & $185.0 \%$ \\
\hline SB4VS-01 & $\mathrm{TiO}_{2}$ & 0.0180 & 0.0200 & 0.0080 & 0.0100 & 0.0120 & $125.0 \%$ & $150.0 \%$ \\
\hline SB4VS-01 & $\mathrm{U}_{3} \mathrm{O}_{8}$ & 2.2230 & 2.4080 & 2.4310 & -0.2080 & -0.0230 & $-8.6 \%$ & $-0.9 \%$ \\
\hline SB4VS-01 & $\mathrm{ZnO}$ & 0.0310 & 0.0310 & 0.0310 & 0.0000 & 0.0000 & $0.0 \%$ & $0.0 \%$ \\
\hline SB4VS-01 & $\mathrm{ZrO}_{2}$ & 0.0710 & 0.0710 & 0.0750 & -0.0040 & -0.0040 & $-5.3 \%$ & $-5.3 \%$ \\
\hline SB4VS-01 & Sum & 99.3650 & 98.9700 & 99.9990 & -0.6340 & -1.0290 & $-0.6 \%$ & $-1.0 \%$ \\
\hline SB4VS-02 & $\mathrm{Al}_{2} \mathrm{O}_{3}$ & 8.0920 & 8.0690 & 8.5850 & -0.4930 & -0.5160 & $-5.7 \%$ & $-6.0 \%$ \\
\hline SB4VS-02 & $\mathrm{B}_{2} \mathrm{O}_{3}$ & 5.6190 & 5.3460 & 5.1200 & 0.4990 & 0.2260 & $9.7 \%$ & $4.4 \%$ \\
\hline SB4VS-02 & $\mathrm{BaO}$ & 0.0370 & 0.0410 & 0.0450 & -0.0080 & -0.0040 & $-17.8 \%$ & $-8.9 \%$ \\
\hline SB4VS-02 & $\mathrm{CaO}$ & 0.7990 & 0.7920 & 0.8500 & -0.0510 & -0.0580 & $-6.0 \%$ & $-6.8 \%$ \\
\hline SB4VS-02 & $\mathrm{Ce}_{2} \mathrm{O}_{3}$ & 0.0340 & 0.0340 & 0.0540 & -0.0200 & -0.0200 & $-37.0 \%$ & $-37.0 \%$ \\
\hline SB4VS-02 & $\mathrm{Cr}_{2} \mathrm{O}_{3}$ & 0.0930 & 0.1020 & 0.0750 & 0.0180 & 0.0270 & $24.0 \%$ & $36.0 \%$ \\
\hline SB4VS-02 & $\mathrm{CuO}$ & 0.0170 & 0.0170 & 0.0220 & -0.0050 & -0.0050 & $-22.7 \%$ & $-22.7 \%$ \\
\hline SB4VS-02 & $\mathrm{Fe}_{2} \mathrm{O}_{3}$ & 8.6280 & 8.7800 & 9.4580 & -0.8300 & -0.6780 & $-8.8 \%$ & $-7.2 \%$ \\
\hline SB4VS-02 & $\mathrm{K}_{2} \mathrm{O}$ & 0.0600 & 0.0530 & 0.1190 & -0.0590 & -0.0660 & $-49.6 \%$ & $-55.5 \%$ \\
\hline SB4VS-02 & $\mathrm{La}_{2} \mathrm{O}_{3}$ & 0.0270 & 0.0270 & 0.0380 & -0.0110 & -0.0110 & $-28.9 \%$ & $-28.9 \%$ \\
\hline SB4VS-02 & $\mathrm{Li}_{2} \mathrm{O}$ & 5.1940 & 5.2080 & 5.1200 & 0.0740 & 0.0880 & $1.4 \%$ & $1.7 \%$ \\
\hline SB4VS-02 & $\mathrm{MgO}$ & 0.7620 & 0.8250 & 0.8970 & -0.1350 & -0.0720 & $-15.1 \%$ & $-8.0 \%$ \\
\hline SB4VS-02 & $\mathrm{MnO}$ & 1.7980 & 1.7990 & 1.9510 & -0.1530 & -0.1520 & $-7.8 \%$ & $-7.8 \%$ \\
\hline SB4VS-02 & $\mathrm{Na}_{2} \mathrm{O}$ & 13.6960 & 12.9720 & 13.6120 & 0.0840 & -0.6400 & $0.6 \%$ & $-4.7 \%$ \\
\hline SB4VS-02 & $\mathrm{NiO}$ & 0.4690 & 0.5190 & 0.5590 & -0.0900 & -0.0400 & $-16.1 \%$ & $-7.2 \%$ \\
\hline SB4VS-02 & $\mathrm{PbO}$ & 0.0250 & 0.0250 & 0.0330 & -0.0080 & -0.0080 & $-24.2 \%$ & $-24.2 \%$ \\
\hline SB4VS-02 & $\mathrm{SiO}_{2}$ & 49.5250 & 50.7680 & 50.0730 & -0.5480 & 0.6950 & $-1.1 \%$ & $1.4 \%$ \\
\hline SB4VS-02 & $\mathrm{SO}_{4}^{2-}$ & 0.3830 & 0.3830 & 0.5010 & -0.1180 & -0.1180 & $-23.6 \%$ & $-23.6 \%$ \\
\hline SB4VS-02 & $\mathrm{ThO}_{2}$ & 0.1190 & 0.1190 & 0.0230 & 0.0960 & 0.0960 & $417.4 \%$ & $417.4 \%$ \\
\hline SB4VS-02 & $\mathrm{TiO}_{2}$ & 0.0130 & 0.0130 & 0.0090 & 0.0040 & 0.0040 & $44.4 \%$ & $44.4 \%$ \\
\hline SB4VS-02 & $\mathrm{U}_{3} \mathrm{O}_{8}$ & 2.5710 & 2.7950 & 2.7350 & -0.1640 & 0.0600 & $-6.0 \%$ & $2.2 \%$ \\
\hline SB4VS-02 & $\mathrm{ZnO}$ & 0.0350 & 0.0350 & 0.0350 & 0.0000 & 0.0000 & $0.0 \%$ & $0.0 \%$ \\
\hline SB4VS-02 & $\mathrm{ZrO}_{2}$ & 0.0680 & 0.0680 & 0.0840 & -0.0160 & -0.0160 & $-19.0 \%$ & $-19.0 \%$ \\
\hline SB4VS-02 & Sum & 98.0610 & 98.7900 & 99.9980 & -1.9370 & -1.2080 & $-1.9 \%$ & $-1.2 \%$ \\
\hline SB4VS-03 & $\mathrm{Al}_{2} \mathrm{O}_{3}$ & 9.9950 & 10.0650 & 9.5390 & 0.4560 & 0.5260 & $4.8 \%$ & $5.5 \%$ \\
\hline SB4VS-03 & $\mathrm{B}_{2} \mathrm{O}_{3}$ & 4.7490 & 4.6790 & 4.8000 & -0.0510 & -0.1210 & $-1.1 \%$ & $-2.5 \%$ \\
\hline SB4VS-03 & $\mathrm{BaO}$ & 0.0460 & 0.0490 & 0.0500 & -0.0040 & -0.0010 & $-8.0 \%$ & $-2.0 \%$ \\
\hline SB4VS-03 & $\mathrm{CaO}$ & 0.9340 & 0.9340 & 0.9440 & -0.0100 & -0.0100 & $-1.1 \%$ & $-1.1 \%$ \\
\hline SB4VS-03 & $\mathrm{Ce}_{2} \mathrm{O}_{3}$ & 0.0380 & 0.0380 & 0.0600 & -0.0220 & -0.0220 & $-36.7 \%$ & $-36.7 \%$ \\
\hline SB4VS-03 & $\mathrm{Cr}_{2} \mathrm{O}_{3}$ & 0.0910 & 0.0980 & 0.0840 & 0.0070 & 0.0140 & $8.3 \%$ & $16.7 \%$ \\
\hline SB4VS-03 & $\mathrm{CuO}$ & 0.0240 & 0.0240 & 0.0240 & 0.0000 & 0.0000 & $0.0 \%$ & $0.0 \%$ \\
\hline SB4VS-03 & $\mathrm{Fe}_{2} \mathrm{O}_{3}$ & 9.7400 & 9.8630 & 10.5090 & -0.7690 & -0.6460 & $-7.3 \%$ & $-6.1 \%$ \\
\hline SB4VS-03 & $\mathrm{K}_{2} \mathrm{O}$ & 0.1260 & 0.1130 & 0.1320 & -0.0060 & -0.0190 & $-4.5 \%$ & $-14.4 \%$ \\
\hline SB4VS-03 & $\mathrm{La}_{2} \mathrm{O}_{3}$ & 0.0380 & 0.0380 & 0.0430 & -0.0050 & -0.0050 & $-11.6 \%$ & $-11.6 \%$ \\
\hline SB4VS-03 & $\mathrm{Li}_{2} \mathrm{O}$ & 4.7420 & 4.7970 & 4.8000 & -0.0580 & -0.0030 & $-1.2 \%$ & $-0.1 \%$ \\
\hline SB4VS-03 & $\mathrm{MgO}$ & 0.9850 & 1.0330 & 0.9970 & -0.0120 & 0.0360 & $-1.2 \%$ & $3.6 \%$ \\
\hline SB4VS-03 & $\mathrm{MnO}$ & 2.2050 & 2.1560 & 2.1670 & 0.0380 & -0.0110 & $1.8 \%$ & $-0.5 \%$ \\
\hline SB4VS-03 & $\mathrm{Na}_{2} \mathrm{O}$ & 15.0980 & 14.0600 & 14.2360 & 0.8620 & -0.1760 & $6.1 \%$ & $-1.2 \%$ \\
\hline SB4VS-03 & $\mathrm{NiO}$ & 0.4970 & 0.5720 & 0.6210 & -0.1240 & -0.0490 & $-20.0 \%$ & $-7.9 \%$ \\
\hline
\end{tabular}


Table E4. Average Measured and Bias-Corrected Chemical Compositions Versus Targeted Compositions by Oxide by SB4 Variability Study Glass (continued)

(100 -Batch 1; 200 -U std; 300 - LRM)

\begin{tabular}{|c|c|c|c|c|c|c|c|c|}
\hline Glass ID & Oxide & $\begin{array}{c}\text { Measured } \\
\text { (wt\%) }\end{array}$ & $\begin{array}{c}\text { Measured } \\
\text { Bias-Corrected } \\
(\mathbf{w t} \%)\end{array}$ & $\begin{array}{c}\text { Targeted } \\
(w \mathrm{w} \%)\end{array}$ & $\begin{array}{c}\text { Diff of } \\
\text { Measured } \\
(\mathbf{w t} \%)\end{array}$ & $\begin{array}{c}\text { Diff. of } \\
\text { Meas BC } \\
(w t \%)\end{array}$ & $\begin{array}{l}\text { \% Diff of } \\
\text { Measured }\end{array}$ & $\begin{array}{l}\text { \% Diff of } \\
\text { Meas BC }\end{array}$ \\
\hline SB4VS-03 & $\mathrm{PbO}$ & 0.0300 & 0.0300 & 0.0360 & -0.0060 & -0.0060 & $-16.7 \%$ & $-16.7 \%$ \\
\hline SB4VS-03 & $\mathrm{SiO}_{2}$ & 47.6530 & 47.5350 & 47.1920 & 0.4610 & 0.3430 & $1.0 \%$ & $0.7 \%$ \\
\hline SB4VS-03 & $\mathrm{SO}_{4}{ }^{2-}$ & 0.4850 & 0.4850 & 0.5570 & -0.0720 & -0.0720 & $-12.9 \%$ & $-12.9 \%$ \\
\hline SB4VS-03 & $\mathrm{ThO}_{2}$ & 0.1430 & 0.1430 & 0.0250 & 0.1180 & 0.1180 & $472.0 \%$ & $472.0 \%$ \\
\hline SB4VS-03 & $\mathrm{TiO}_{2}$ & 0.0130 & 0.0140 & 0.0110 & 0.0020 & 0.0030 & $18.2 \%$ & $27.3 \%$ \\
\hline SB4VS-03 & $\mathrm{U}_{3} \mathrm{O}_{8}$ & 2.8710 & 3.1110 & 3.0390 & -0.1680 & 0.0720 & $-5.5 \%$ & $2.4 \%$ \\
\hline SB4VS-03 & $\mathrm{ZnO}$ & 0.0350 & 0.0350 & 0.0390 & -0.0040 & -0.0040 & $-10.3 \%$ & $-10.3 \%$ \\
\hline SB4VS-03 & $\mathrm{ZrO}_{2}$ & 0.0880 & 0.0880 & 0.0940 & -0.0060 & -0.0060 & $-6.4 \%$ & $-6.4 \%$ \\
\hline SB4VS-03 & Sum & 100.6260 & 99.9600 & 99.9990 & 0.6270 & -0.0390 & $0.6 \%$ & $0.0 \%$ \\
\hline SB4VS-04 & $\mathrm{Al}_{2} \mathrm{O}_{3}$ & 10.8980 & 10.9520 & 10.4930 & 0.4050 & 0.4590 & $3.9 \%$ & $4.4 \%$ \\
\hline SB4VS-04 & $\mathrm{B}_{2} \mathrm{O}_{3}$ & 4.5720 & 4.4610 & 4.4800 & 0.0920 & -0.0190 & $2.1 \%$ & $-0.4 \%$ \\
\hline SB4VS-04 & $\mathrm{BaO}$ & 0.0470 & 0.0530 & 0.0550 & -0.0080 & -0.0020 & $-14.5 \%$ & $-3.6 \%$ \\
\hline SB4VS-04 & $\mathrm{CaO}$ & 1.0530 & 1.0490 & 1.0390 & 0.0140 & 0.0100 & $1.3 \%$ & $1.0 \%$ \\
\hline SB4VS-04 & $\mathrm{Ce}_{2} \mathrm{O}_{3}$ & 0.0690 & 0.0690 & 0.0660 & 0.0030 & 0.0030 & $4.5 \%$ & $4.5 \%$ \\
\hline SB4VS-04 & $\mathrm{Cr}_{2} \mathrm{O}_{3}$ & 0.0790 & 0.0900 & 0.0920 & -0.0130 & -0.0020 & $-14.1 \%$ & $-2.2 \%$ \\
\hline SB4VS-04 & $\mathrm{CuO}$ & 0.0260 & 0.0260 & 0.0260 & 0.0000 & 0.0000 & $0.0 \%$ & $0.0 \%$ \\
\hline SB4VS-04 & $\mathrm{Fe}_{2} \mathrm{O}_{3}$ & 10.8190 & 10.9470 & 11.5600 & -0.7410 & -0.6130 & $-6.4 \%$ & $-5.3 \%$ \\
\hline SB4VS-04 & $\mathrm{K}_{2} \mathrm{O}$ & 0.1590 & 0.1420 & 0.1460 & 0.0130 & -0.0040 & $8.9 \%$ & $-2.7 \%$ \\
\hline SB4VS-04 & $\mathrm{La}_{2} \mathrm{O}_{3}$ & 0.0380 & 0.0380 & 0.0470 & -0.0090 & -0.0090 & $-19.1 \%$ & $-19.1 \%$ \\
\hline SB4VS-04 & $\mathrm{Li}_{2} \mathrm{O}$ & 4.4620 & 4.4780 & 4.4800 & -0.0180 & -0.0020 & $-0.4 \%$ & $0.0 \%$ \\
\hline SB4VS-04 & $\mathrm{MgO}$ & 1.0030 & 1.1090 & 1.0960 & -0.0930 & 0.0130 & $-8.5 \%$ & $1.2 \%$ \\
\hline SB4VS-04 & $\mathrm{MnO}$ & 2.4210 & 2.4730 & 2.3840 & 0.0370 & 0.0890 & $1.6 \%$ & $3.7 \%$ \\
\hline SB4VS-04 & $\mathrm{Na}_{2} \mathrm{O}$ & 15.4010 & 14.6550 & 14.8590 & 0.5420 & -0.2040 & $3.6 \%$ & $-1.4 \%$ \\
\hline SB4VS-04 & $\mathrm{NiO}$ & 0.6030 & 0.6810 & 0.6830 & -0.0800 & -0.0020 & $-11.7 \%$ & $-0.3 \%$ \\
\hline SB4VS-04 & $\mathrm{PbO}$ & 0.0320 & 0.0320 & 0.0400 & -0.0080 & -0.0080 & $-20.0 \%$ & $-20.0 \%$ \\
\hline SB4VS-04 & $\mathrm{SiO}_{2}$ & 45.1390 & 44.6470 & 44.3120 & 0.8270 & 0.3350 & $1.9 \%$ & $0.8 \%$ \\
\hline SB4VS-04 & $\mathrm{SO}_{4}{ }^{2-}$ & 0.5020 & 0.5020 & 0.6130 & -0.1110 & -0.1110 & $-18.1 \%$ & $-18.1 \%$ \\
\hline SB4VS-04 & $\mathrm{ThO}_{2}$ & 0.1500 & 0.1500 & 0.0280 & 0.1220 & 0.1220 & $435.7 \%$ & $435.7 \%$ \\
\hline SB4VS-04 & $\mathrm{TiO}_{2}$ & 0.0210 & 0.0220 & 0.0120 & 0.0090 & 0.0100 & $75.0 \%$ & $83.3 \%$ \\
\hline SB4VS-04 & $\mathrm{U}_{3} \mathrm{O}_{8}$ & 3.1930 & 3.4740 & 3.3430 & -0.1500 & 0.1310 & $-4.5 \%$ & $3.9 \%$ \\
\hline SB4VS-04 & $\mathrm{ZnO}$ & 0.0380 & 0.0380 & 0.0430 & -0.0050 & -0.0050 & $-11.6 \%$ & $-11.6 \%$ \\
\hline SB4VS-04 & $\mathrm{ZrO}_{2}$ & 0.0970 & 0.0970 & 0.1030 & -0.0060 & -0.0060 & $-5.8 \%$ & $-5.8 \%$ \\
\hline SB4VS-04 & Sum & 100.8220 & 100.1850 & 100.0000 & 0.8220 & 0.1850 & $0.8 \%$ & $0.2 \%$ \\
\hline SB4VS-05 & $\mathrm{Al}_{2} \mathrm{O}_{3}$ & 7.5860 & 7.6490 & 7.1540 & 0.4320 & 0.4950 & $6.0 \%$ & $6.9 \%$ \\
\hline SB4VS-05 & $\mathrm{B}_{2} \mathrm{O}_{3}$ & 9.6840 & 9.5650 & 9.8000 & -0.1160 & -0.2350 & $-1.2 \%$ & $-2.4 \%$ \\
\hline SB4VS-05 & $\mathrm{BaO}$ & 0.0320 & 0.0360 & 0.0370 & -0.0050 & -0.0010 & $-13.5 \%$ & $-2.7 \%$ \\
\hline SB4VS-05 & $\mathrm{CaO}$ & 0.7180 & 0.7280 & 0.7080 & 0.0100 & 0.0200 & $1.4 \%$ & $2.8 \%$ \\
\hline SB4VS-05 & $\mathrm{Ce}_{2} \mathrm{O}_{3}$ & 0.0340 & 0.0340 & 0.0450 & -0.0110 & -0.0110 & $-24.4 \%$ & $-24.4 \%$ \\
\hline SB4VS-05 & $\mathrm{Cr}_{2} \mathrm{O}_{3}$ & 0.0560 & 0.0640 & 0.0630 & -0.0070 & 0.0010 & $-11.1 \%$ & $1.6 \%$ \\
\hline SB4VS-05 & $\mathrm{CuO}$ & 0.0190 & 0.0200 & 0.0180 & 0.0010 & 0.0020 & $5.6 \%$ & $11.1 \%$ \\
\hline SB4VS-05 & $\mathrm{Fe}_{2} \mathrm{O}_{3}$ & 7.3270 & 7.4040 & 7.8820 & -0.5550 & -0.4780 & $-7.0 \%$ & $-6.1 \%$ \\
\hline SB4VS-05 & $\mathrm{K}_{2} \mathrm{O}$ & 0.0600 & 0.0530 & 0.0990 & -0.0390 & -0.0460 & $-39.4 \%$ & $-46.5 \%$ \\
\hline SB4VS-05 & $\mathrm{La}_{2} \mathrm{O}_{3}$ & 0.0270 & 0.0270 & 0.0320 & -0.0050 & -0.0050 & $-15.6 \%$ & $-15.6 \%$ \\
\hline SB4VS-05 & $\mathrm{Li}_{2} \mathrm{O}$ & 5.5060 & 5.5890 & 5.6000 & -0.0940 & -0.0110 & $-1.7 \%$ & $-0.2 \%$ \\
\hline SB4VS-05 & $\mathrm{MgO}$ & 0.6900 & 0.7690 & 0.7480 & -0.0580 & 0.0210 & $-7.8 \%$ & $2.8 \%$ \\
\hline SB4VS-05 & $\mathrm{MnO}$ & 1.6240 & 1.6220 & 1.6260 & -0.0020 & -0.0040 & $-0.1 \%$ & $-0.2 \%$ \\
\hline SB4VS-05 & $\mathrm{Na}_{2} \mathrm{O}$ & 10.3220 & 9.6500 & 9.8770 & 0.4450 & -0.2270 & $4.5 \%$ & $-2.3 \%$ \\
\hline SB4VS-05 & $\mathrm{NiO}$ & 0.3710 & 0.4230 & 0.4660 & -0.0950 & -0.0430 & $-20.4 \%$ & $-9.2 \%$ \\
\hline SB4VS-05 & $\mathrm{PbO}$ & 0.0270 & 0.0270 & 0.0270 & 0.0000 & 0.0000 & $0.0 \%$ & $0.0 \%$ \\
\hline SB4VS-05 & $\mathrm{SiO}_{2}$ & 52.8410 & 52.8200 & 52.9940 & -0.1530 & -0.1740 & $-0.3 \%$ & $-0.3 \%$ \\
\hline SB4VS-05 & $\mathrm{SO}_{4}{ }^{2-}$ & 0.3420 & 0.3420 & 0.4180 & -0.0760 & -0.0760 & $-18.2 \%$ & $-18.2 \%$ \\
\hline SB4VS-05 & $\mathrm{ThO}_{2}$ & 0.0570 & 0.0570 & 0.0190 & 0.0380 & 0.0380 & $200.0 \%$ & $200.0 \%$ \\
\hline SB4VS-05 & $\mathrm{TiO}_{2}$ & 0.0130 & 0.0140 & 0.0080 & 0.0050 & 0.0060 & $62.5 \%$ & $75.0 \%$ \\
\hline SB4VS-05 & $\mathrm{U}_{3} \mathrm{O}_{8}$ & 2.1760 & 2.3740 & 2.2790 & -0.1030 & 0.0950 & $-4.5 \%$ & $4.2 \%$ \\
\hline SB4VS-05 & $\mathrm{ZnO}$ & 0.0330 & 0.0330 & 0.0300 & 0.0030 & 0.0030 & $10.0 \%$ & $10.0 \%$ \\
\hline SB4VS-05 & $\mathrm{ZrO}_{2}$ & 0.0600 & 0.0600 & 0.0700 & -0.0100 & -0.0100 & $-14.3 \%$ & $-14.3 \%$ \\
\hline SB4VS-05 & Sum & 99.6050 & 99.3600 & 100.0000 & -0.3950 & -0.6400 & $-0.4 \%$ & $-0.6 \%$ \\
\hline SB4VS-06 & $\mathrm{Al}_{2} \mathrm{O}_{3}$ & 8.5550 & 8.6140 & 8.1080 & 0.4470 & 0.5060 & $5.5 \%$ & $6.2 \%$ \\
\hline SB4VS-06 & $\mathrm{B}_{2} \mathrm{O}_{3}$ & 9.3620 & 9.2230 & 9.2400 & 0.1220 & -0.0170 & $1.3 \%$ & $-0.2 \%$ \\
\hline SB4VS-06 & $\mathrm{BaO}$ & 0.0370 & 0.0400 & 0.0420 & -0.0050 & -0.0020 & $-11.9 \%$ & $-4.8 \%$ \\
\hline SB4VS-06 & $\mathrm{CaO}$ & 0.8350 & 0.8350 & 0.8030 & 0.0320 & 0.0320 & $4.0 \%$ & $4.0 \%$ \\
\hline SB4VS-06 & $\mathrm{Ce}_{2} \mathrm{O}_{3}$ & 0.0480 & 0.0480 & 0.0510 & -0.0030 & -0.0030 & $-5.9 \%$ & $-5.9 \%$ \\
\hline SB4VS-06 & $\mathrm{Cr}_{2} \mathrm{O}_{3}$ & 0.0790 & 0.0850 & 0.0710 & 0.0080 & 0.0140 & $11.3 \%$ & $19.7 \%$ \\
\hline SB4VS-06 & $\mathrm{CuO}$ & 0.0230 & 0.0240 & 0.0210 & 0.0020 & 0.0030 & $9.5 \%$ & $14.3 \%$ \\
\hline
\end{tabular}


Table E4. Average Measured and Bias-Corrected Chemical Compositions Versus Targeted Compositions by Oxide by SB4 Variability Study Glass (continued)

(100 -Batch 1; 200 -U std; 300 - LRM)

\begin{tabular}{|c|c|c|c|c|c|c|c|c|}
\hline Glass ID & Oxide & $\begin{array}{c}\text { Measured } \\
(w t \%)\end{array}$ & $\begin{array}{c}\text { Measured } \\
\text { Bias-Corrected } \\
(w \mathbf{w} \%) \\
\end{array}$ & $\begin{array}{c}\text { Targeted } \\
(\mathbf{w t} \%)\end{array}$ & $\begin{array}{c}\text { Diff of } \\
\text { Measured } \\
(w t \%) \\
\end{array}$ & $\begin{array}{c}\text { Diff. of } \\
\text { Meas BC } \\
(w t \%) \\
\end{array}$ & $\begin{array}{l}\text { \% Diff of } \\
\text { Measured }\end{array}$ & $\begin{array}{l}\% \text { Diff of } \\
\text { Meas BC }\end{array}$ \\
\hline SB4VS-06 & $\mathrm{Fe}_{2} \mathrm{O}_{3}$ & 8.4390 & 8.5450 & 8.9330 & -0.4940 & -0.3880 & $-5.5 \%$ & $-4.3 \%$ \\
\hline SB4VS-06 & $\mathrm{K}_{2} \mathrm{O}$ & 0.0760 & 0.0680 & 0.1130 & -0.0370 & -0.0450 & $-32.7 \%$ & $-39.8 \%$ \\
\hline SB4VS-06 & $\mathrm{La}_{2} \mathrm{O}_{3}$ & 0.0300 & 0.0300 & 0.0360 & -0.0060 & -0.0060 & $-16.7 \%$ & $-16.7 \%$ \\
\hline SB4VS-06 & $\mathrm{Li}_{2} \mathrm{O}$ & 5.2530 & 5.3150 & 5.2800 & -0.0270 & 0.0350 & $-0.5 \%$ & $0.7 \%$ \\
\hline SB4VS-06 & $\mathrm{MgO}$ & 0.7990 & 0.8380 & 0.8470 & -0.0480 & -0.0090 & $-5.7 \%$ & $-1.1 \%$ \\
\hline SB4VS-06 & $\mathrm{MnO}$ & 1.9050 & 1.8630 & 1.8420 & 0.0630 & 0.0210 & $3.4 \%$ & $1.1 \%$ \\
\hline SB4VS-06 & $\mathrm{Na}_{2} \mathrm{O}$ & 11.1820 & 10.4130 & 10.6600 & 0.5220 & -0.2470 & $4.9 \%$ & $-2.3 \%$ \\
\hline SB4VS-06 & $\mathrm{NiO}$ & 0.4300 & 0.4960 & 0.5280 & -0.0980 & -0.0320 & $-18.6 \%$ & $-6.1 \%$ \\
\hline SB4VS-06 & $\mathrm{PbO}$ & 0.0300 & 0.0300 & 0.0310 & -0.0010 & -0.0010 & $-3.2 \%$ & $-3.2 \%$ \\
\hline SB4VS-06 & $\mathrm{SiO}_{2}$ & 50.8080 & 50.6820 & 50.1940 & 0.6140 & 0.4880 & $1.2 \%$ & $1.0 \%$ \\
\hline SB4VS-06 & $\mathrm{SO}_{4}^{2-}$ & 0.4180 & 0.4180 & 0.4740 & -0.0560 & -0.0560 & $-11.8 \%$ & $-11.8 \%$ \\
\hline SB4VS-06 & $\mathrm{ThO}_{2}$ & 0.1040 & 0.1040 & 0.0210 & 0.0830 & 0.0830 & $395.2 \%$ & $395.2 \%$ \\
\hline SB4VS-06 & $\mathrm{TiO}_{2}$ & 0.0130 & 0.0130 & 0.0090 & 0.0040 & 0.0040 & $44.4 \%$ & $44.4 \%$ \\
\hline SB4VS-06 & $\mathrm{U}_{3} \mathrm{O}_{8}$ & 2.4670 & 2.6730 & 2.5830 & -0.1160 & 0.0900 & $-4.5 \%$ & $3.5 \%$ \\
\hline SB4VS-06 & $\mathrm{ZnO}$ & 0.0320 & 0.0320 & 0.0330 & -0.0010 & -0.0010 & $-3.0 \%$ & $-3.0 \%$ \\
\hline SB4VS-06 & $\mathrm{ZrO}_{2}$ & 0.0640 & 0.0640 & 0.0800 & -0.0160 & -0.0160 & $-20.0 \%$ & $-20.0 \%$ \\
\hline SB4VS-06 & Sum & 100.9910 & 100.4550 & 100.0000 & 0.9910 & 0.4550 & $1.0 \%$ & $0.5 \%$ \\
\hline SB4VS-07 & $\mathrm{Al}_{2} \mathrm{O}_{3}$ & 9.9200 & 9.9690 & 9.0620 & 0.8580 & 0.9070 & $9.5 \%$ & $10.0 \%$ \\
\hline SB4VS-07 & $\mathrm{B}_{2} \mathrm{O}_{3}$ & 8.7820 & 8.5710 & 8.6800 & 0.1020 & -0.1090 & $1.2 \%$ & $-1.3 \%$ \\
\hline SB4VS-07 & $\mathrm{BaO}$ & 0.0390 & 0.0440 & 0.0470 & -0.0080 & -0.0030 & $-17.0 \%$ & $-6.4 \%$ \\
\hline SB4VS-07 & $\mathrm{CaO}$ & 0.9230 & 0.9370 & 0.8970 & 0.0260 & 0.0400 & $2.9 \%$ & $4.5 \%$ \\
\hline SB4VS-07 & $\mathrm{Ce}_{2} \mathrm{O}_{3}$ & 0.0370 & 0.0370 & 0.0570 & -0.0200 & -0.0200 & $-35.1 \%$ & $-35.1 \%$ \\
\hline SB4VS-07 & $\mathrm{Cr}_{2} \mathrm{O}_{3}$ & 0.0570 & 0.0650 & 0.0790 & -0.0220 & -0.0140 & $-27.8 \%$ & $-17.7 \%$ \\
\hline SB4VS-07 & $\mathrm{CuO}$ & 0.0230 & 0.0240 & 0.0230 & 0.0000 & 0.0010 & $0.0 \%$ & $4.3 \%$ \\
\hline SB4VS-07 & $\mathrm{Fe}_{2} \mathrm{O}_{3}$ & 9.5180 & 9.6310 & 9.9840 & -0.4660 & -0.3530 & $-4.7 \%$ & $-3.5 \%$ \\
\hline SB4VS-07 & $\mathrm{K}_{2} \mathrm{O}$ & 0.1430 & 0.1250 & 0.1260 & 0.0170 & -0.0010 & $13.5 \%$ & $-0.8 \%$ \\
\hline SB4VS-07 & $\mathrm{La}_{2} \mathrm{O}_{3}$ & 0.0330 & 0.0330 & 0.0400 & -0.0070 & -0.0070 & $-17.5 \%$ & $-17.5 \%$ \\
\hline SB4VS-07 & $\mathrm{Li}_{2} \mathrm{O}$ & 4.9890 & 5.0070 & 4.9600 & 0.0290 & 0.0470 & $0.6 \%$ & $0.9 \%$ \\
\hline SB4VS-07 & $\mathrm{MgO}$ & 0.8130 & 0.9060 & 0.9470 & -0.1340 & -0.0410 & $-14.1 \%$ & $-4.3 \%$ \\
\hline SB4VS-07 & $\mathrm{MnO}$ & 2.0340 & 2.0310 & 2.0590 & -0.0250 & -0.0280 & $-1.2 \%$ & $-1.4 \%$ \\
\hline SB4VS-07 & $\mathrm{Na}_{2} \mathrm{O}$ & 11.6570 & 10.8990 & 11.4440 & 0.2130 & -0.5450 & $1.9 \%$ & $-4.8 \%$ \\
\hline SB4VS-07 & $\mathrm{NiO}$ & 0.4860 & 0.5490 & 0.5900 & -0.1040 & -0.0410 & $-17.6 \%$ & $-6.9 \%$ \\
\hline SB4VS-07 & $\mathrm{PbO}$ & 0.0290 & 0.0290 & 0.0350 & -0.0060 & -0.0060 & $-17.1 \%$ & $-17.1 \%$ \\
\hline SB4VS-07 & $\mathrm{SiO}_{2}$ & 49.1500 & 48.6160 & 47.3930 & 1.7570 & 1.2230 & $3.7 \%$ & $2.6 \%$ \\
\hline SB4VS-07 & $\mathrm{SO}_{4}{ }^{2-}$ & 0.4280 & 0.4280 & 0.5290 & -0.1010 & -0.1010 & $-19.1 \%$ & $-19.1 \%$ \\
\hline SB4VS-07 & $\mathrm{ThO}_{2}$ & 0.1030 & 0.1030 & 0.0240 & 0.0790 & 0.0790 & $329.2 \%$ & $329.2 \%$ \\
\hline SB4VS-07 & $\mathrm{TiO}_{2}$ & 0.0130 & 0.0140 & 0.0100 & 0.0030 & 0.0040 & $30.0 \%$ & $40.0 \%$ \\
\hline SB4VS-07 & $\mathrm{U}_{3} \mathrm{O}_{8}$ & 2.7030 & 2.9420 & 2.8870 & -0.1840 & 0.0550 & $-6.4 \%$ & $1.9 \%$ \\
\hline SB4VS-07 & $\mathrm{ZnO}$ & 0.0350 & 0.0350 & 0.0370 & -0.0020 & -0.0020 & $-5.4 \%$ & $-5.4 \%$ \\
\hline SB4VS-07 & $\mathrm{ZrO}_{2}$ & 0.0770 & 0.0770 & 0.0890 & -0.0120 & -0.0120 & $-13.5 \%$ & $-13.5 \%$ \\
\hline SB4VS-07 & Sum & 101.9940 & 101.0730 & 99.9990 & 1.9950 & 1.0740 & $2.0 \%$ & $1.1 \%$ \\
\hline SB4VS-08 & $\mathrm{Al}_{2} \mathrm{O}_{3}$ & 10.5010 & 10.5880 & 10.0160 & 0.4850 & 0.5720 & $4.8 \%$ & $5.7 \%$ \\
\hline SB4VS-08 & $\mathrm{B}_{2} \mathrm{O}_{3}$ & 8.1460 & 8.0470 & 8.1200 & 0.0260 & -0.0730 & $0.3 \%$ & $-0.9 \%$ \\
\hline SB4VS-08 & $\mathrm{BaO}$ & 0.0470 & 0.0520 & 0.0520 & -0.0050 & 0.0000 & $-9.6 \%$ & $0.0 \%$ \\
\hline SB4VS-08 & $\mathrm{CaO}$ & 0.9790 & 0.9710 & 0.9920 & -0.0130 & -0.0210 & $-1.3 \%$ & $-2.1 \%$ \\
\hline SB4VS-08 & $\mathrm{Ce}_{2} \mathrm{O}_{3}$ & 0.0480 & 0.0480 & 0.0630 & -0.0150 & -0.0150 & $-23.8 \%$ & $-23.8 \%$ \\
\hline SB4VS-08 & $\mathrm{Cr}_{2} \mathrm{O}_{3}$ & 0.0810 & 0.0900 & 0.0880 & -0.0070 & 0.0020 & $-8.0 \%$ & $2.3 \%$ \\
\hline SB4VS-08 & $\mathrm{CuO}$ & 0.0250 & 0.0250 & 0.0250 & 0.0000 & 0.0000 & $0.0 \%$ & $0.0 \%$ \\
\hline SB4VS-08 & $\mathrm{Fe}_{2} \mathrm{O}_{3}$ & 10.3080 & 10.4170 & 11.0350 & -0.7270 & -0.6180 & $-6.6 \%$ & $-5.6 \%$ \\
\hline SB4VS-08 & $\mathrm{K}_{2} \mathrm{O}$ & 0.1370 & 0.1210 & 0.1390 & -0.0020 & -0.0180 & $-1.4 \%$ & $-12.9 \%$ \\
\hline SB4VS-08 & $\mathrm{La}_{2} \mathrm{O}_{3}$ & 0.0400 & 0.0400 & 0.0450 & -0.0050 & -0.0050 & $-11.1 \%$ & $-11.1 \%$ \\
\hline SB4VS-08 & $\mathrm{Li}_{2} \mathrm{O}$ & 4.6290 & 4.6990 & 4.6400 & -0.0110 & 0.0590 & $-0.2 \%$ & $1.3 \%$ \\
\hline SB4VS-08 & $\mathrm{MgO}$ & 1.0090 & 1.0930 & 1.0470 & -0.0380 & 0.0460 & $-3.6 \%$ & $4.4 \%$ \\
\hline SB4VS-08 & $\mathrm{MnO}$ & 2.3240 & 2.3260 & 2.2760 & 0.0480 & 0.0500 & $2.1 \%$ & $2.2 \%$ \\
\hline SB4VS-08 & $\mathrm{Na}_{2} \mathrm{O}$ & 12.7390 & 12.0700 & 12.2280 & 0.5110 & -0.1580 & $4.2 \%$ & $-1.3 \%$ \\
\hline SB4VS-08 & $\mathrm{NiO}$ & 0.5550 & 0.6340 & 0.6520 & -0.0970 & -0.0180 & $-14.9 \%$ & $-2.8 \%$ \\
\hline SB4VS-08 & $\mathrm{PbO}$ & 0.0360 & 0.0360 & 0.0380 & -0.0020 & -0.0020 & $-5.3 \%$ & $-5.3 \%$ \\
\hline SB4VS-08 & $\mathrm{SiO}_{2}$ & 45.3530 & 45.3400 & 44.5920 & 0.7610 & 0.7480 & $1.7 \%$ & $1.7 \%$ \\
\hline SB4VS-08 & $\mathrm{SO}_{4}{ }^{2-}$ & 0.5150 & 0.5150 & 0.5850 & -0.0700 & -0.0700 & $-12.0 \%$ & $-12.0 \%$ \\
\hline SB4VS-08 & $\mathrm{ThO}_{2}$ & 0.1470 & 0.1470 & 0.0270 & 0.1200 & 0.1200 & $444.4 \%$ & $444.4 \%$ \\
\hline SB4VS-08 & $\mathrm{TiO}_{2}$ & 0.0180 & 0.0200 & 0.0110 & 0.0070 & 0.0090 & $63.6 \%$ & $81.8 \%$ \\
\hline SB4VS-08 & $\mathrm{U}_{3} \mathrm{O}_{8}$ & 3.0980 & 3.3810 & 3.1910 & -0.0930 & 0.1900 & $-2.9 \%$ & $6.0 \%$ \\
\hline SB4VS-08 & $\mathrm{ZnO}$ & 0.0430 & 0.0430 & 0.0410 & 0.0020 & 0.0020 & $4.9 \%$ & $4.9 \%$ \\
\hline SB4VS-08 & $\mathrm{ZrO}_{2}$ & 0.0940 & 0.0940 & 0.0980 & -0.0040 & -0.0040 & $-4.1 \%$ & $-4.1 \%$ \\
\hline
\end{tabular}


Table E4. Average Measured and Bias-Corrected Chemical Compositions Versus Targeted Compositions by Oxide by SB4 Variability Study Glass (continued)

(100 -Batch 1; 200 -U std; 300 - LRM)

\begin{tabular}{|c|c|c|c|c|c|c|c|c|}
\hline Glass ID & Oxide & $\begin{array}{c}\text { Measured } \\
\text { (wt\%) }\end{array}$ & $\begin{array}{c}\text { Measured } \\
\text { Bias-Corrected } \\
(\mathbf{w t} \%)\end{array}$ & $\begin{array}{c}\text { Targeted } \\
(w \mathrm{w} \%)\end{array}$ & $\begin{array}{c}\text { Diff of } \\
\text { Measured } \\
(\mathbf{w t} \%)\end{array}$ & $\begin{array}{c}\text { Diff. of } \\
\text { Meas BC } \\
(w t \%)\end{array}$ & $\begin{array}{l}\text { \% Diff of } \\
\text { Measured }\end{array}$ & $\begin{array}{l}\text { \% Diff of } \\
\text { Meas BC }\end{array}$ \\
\hline SB4VS-08 & Sum & 100.8740 & 100.7940 & 100.0010 & 0.8730 & 0.7930 & $0.9 \%$ & $0.8 \%$ \\
\hline SB4VS-09 & $\mathrm{Al}_{2} \mathrm{O}_{3}$ & 11.2940 & 11.2630 & 10.9700 & 0.3240 & 0.2930 & $3.0 \%$ & $2.7 \%$ \\
\hline SB4VS-09 & $\mathrm{B}_{2} \mathrm{O}_{3}$ & 7.5910 & 7.2230 & 7.5600 & 0.0310 & -0.3370 & $0.4 \%$ & $-4.5 \%$ \\
\hline SB4VS-09 & $\mathrm{BaO}$ & 0.0510 & 0.0550 & 0.0570 & -0.0060 & -0.0020 & $-10.5 \%$ & $-3.5 \%$ \\
\hline SB4VS-09 & $\mathrm{CaO}$ & 1.0850 & 1.0850 & 1.0860 & -0.0010 & -0.0010 & $-0.1 \%$ & $-0.1 \%$ \\
\hline SB4VS-09 & $\mathrm{Ce}_{2} \mathrm{O}_{3}$ & 0.0420 & 0.0420 & 0.0690 & -0.0270 & -0.0270 & $-39.1 \%$ & $-39.1 \%$ \\
\hline SB4VS-09 & $\mathrm{Cr}_{2} \mathrm{O}_{3}$ & 0.0830 & 0.0890 & 0.0960 & -0.0130 & -0.0070 & $-13.5 \%$ & $-7.3 \%$ \\
\hline SB4VS-09 & $\mathrm{CuO}$ & 0.0320 & 0.0320 & 0.0280 & 0.0040 & 0.0040 & $14.3 \%$ & $14.3 \%$ \\
\hline SB4VS-09 & $\mathrm{Fe}_{2} \mathrm{O}_{3}$ & 10.6980 & 10.8880 & 12.0860 & -1.3880 & -1.1980 & $-11.5 \%$ & $-9.9 \%$ \\
\hline SB4VS-09 & $\mathrm{K}_{2} \mathrm{O}$ & 0.1530 & 0.1360 & 0.1520 & 0.0010 & -0.0160 & $0.7 \%$ & $-10.5 \%$ \\
\hline SB4VS-09 & $\mathrm{La}_{2} \mathrm{O}_{3}$ & 0.0400 & 0.0400 & 0.0490 & -0.0090 & -0.0090 & $-18.4 \%$ & $-18.4 \%$ \\
\hline SB4VS-09 & $\mathrm{Li}_{2} \mathrm{O}$ & 4.3000 & 4.3120 & 4.3200 & -0.0200 & -0.0080 & $-0.5 \%$ & $-0.2 \%$ \\
\hline SB4VS-09 & $\mathrm{MgO}$ & 1.1380 & 1.1940 & 1.1460 & -0.0080 & 0.0480 & $-0.7 \%$ & $4.2 \%$ \\
\hline SB4VS-09 & $\mathrm{MnO}$ & 2.5180 & 2.4630 & 2.4930 & 0.0250 & -0.0300 & $1.0 \%$ & $-1.2 \%$ \\
\hline SB4VS-09 & $\mathrm{Na}_{2} \mathrm{O}$ & 13.7500 & 12.8050 & 13.0110 & 0.7390 & -0.2060 & $5.7 \%$ & $-1.6 \%$ \\
\hline SB4VS-09 & $\mathrm{NiO}$ & 0.5500 & 0.6080 & 0.7140 & -0.1640 & -0.1060 & $-23.0 \%$ & $-14.8 \%$ \\
\hline SB4VS-09 & $\mathrm{PbO}$ & 0.0380 & 0.0380 & 0.0420 & -0.0040 & -0.0040 & $-9.5 \%$ & $-9.5 \%$ \\
\hline SB4VS-09 & $\mathrm{SiO}_{2}$ & 40.7540 & 41.7770 & 41.7910 & -1.0370 & -0.0140 & $-2.5 \%$ & $0.0 \%$ \\
\hline SB4VS-09 & $\mathrm{SO}_{4}{ }^{2-}$ & 0.5830 & 0.5830 & 0.6410 & -0.0580 & -0.0580 & $-9.0 \%$ & $-9.0 \%$ \\
\hline SB4VS-09 & $\mathrm{ThO}_{2}$ & 0.1680 & 0.1680 & 0.0290 & 0.1390 & 0.1390 & $479.3 \%$ & $479.3 \%$ \\
\hline SB4VS-09 & $\mathrm{TiO}_{2}$ & 0.0180 & 0.0190 & 0.0120 & 0.0060 & 0.0070 & $50.0 \%$ & $58.3 \%$ \\
\hline SB4VS-09 & $\mathrm{U}_{3} \mathrm{O}_{8}$ & 3.2660 & 3.5510 & 3.4950 & -0.2290 & 0.0560 & $-6.6 \%$ & $1.6 \%$ \\
\hline SB4VS-09 & $\mathrm{ZnO}$ & 0.0860 & 0.0860 & 0.0450 & 0.0410 & 0.0410 & $91.1 \%$ & $91.1 \%$ \\
\hline SB4VS-09 & $\mathrm{ZrO}_{2}$ & 0.1040 & 0.1040 & 0.1080 & -0.0040 & -0.0040 & $-3.7 \%$ & $-3.7 \%$ \\
\hline SB4VS-09 & Sum & 98.3410 & 98.5590 & 100.0000 & -1.6590 & -1.4410 & $-1.7 \%$ & $-1.4 \%$ \\
\hline SB4VS-10 & $\mathrm{Al}_{2} \mathrm{O}_{3}$ & 10.6380 & 10.7260 & 10.0470 & 0.5910 & 0.6790 & $5.9 \%$ & $6.8 \%$ \\
\hline SB4VS-10 & $\mathrm{B}_{2} \mathrm{O}_{3}$ & 8.0260 & 7.9290 & 8.1200 & -0.0940 & -0.1910 & $-1.2 \%$ & $-2.4 \%$ \\
\hline SB4VS-10 & $\mathrm{BaO}$ & 0.0510 & 0.0550 & 0.0570 & -0.0060 & -0.0020 & $-10.5 \%$ & $-3.5 \%$ \\
\hline SB4VS-10 & $\mathrm{CaO}$ & 1.1240 & 1.1240 & 1.0460 & 0.0780 & 0.0780 & $7.5 \%$ & $7.5 \%$ \\
\hline SB4VS-10 & $\mathrm{Ce}_{2} \mathrm{O}_{3}$ & 0.0460 & 0.0460 & 0.0690 & -0.0230 & -0.0230 & $-33.3 \%$ & $-33.3 \%$ \\
\hline SB4VS-10 & $\mathrm{Cr}_{2} \mathrm{O}_{3}$ & 0.0850 & 0.0920 & 0.0950 & -0.0100 & -0.0030 & $-10.5 \%$ & $-3.2 \%$ \\
\hline SB4VS-10 & $\mathrm{CuO}$ & 0.0290 & 0.0290 & 0.0270 & 0.0020 & 0.0020 & $7.4 \%$ & $7.4 \%$ \\
\hline SB4VS-10 & $\mathrm{Fe}_{2} \mathrm{O}_{3}$ & 10.0720 & 10.1800 & 10.6040 & -0.5320 & -0.4240 & $-5.0 \%$ & $-4.0 \%$ \\
\hline SB4VS-10 & $\mathrm{K}_{2} \mathrm{O}$ & 0.1730 & 0.1540 & 0.1510 & 0.0220 & 0.0030 & $14.6 \%$ & $2.0 \%$ \\
\hline SB4VS-10 & $\mathrm{La}_{2} \mathrm{O}_{3}$ & 0.0410 & 0.0410 & 0.0490 & -0.0080 & -0.0080 & $-16.3 \%$ & $-16.3 \%$ \\
\hline SB4VS-10 & $\mathrm{Li}_{2} \mathrm{O}$ & 4.6290 & 4.6990 & 4.6400 & -0.0110 & 0.0590 & $-0.2 \%$ & $1.3 \%$ \\
\hline SB4VS-10 & $\mathrm{MgO}$ & 0.8990 & 0.9420 & 0.9920 & -0.0930 & -0.0500 & $-9.4 \%$ & $-5.0 \%$ \\
\hline SB4VS-10 & $\mathrm{MnO}$ & 2.2210 & 2.1730 & 2.2180 & 0.0030 & -0.0450 & $0.1 \%$ & $-2.0 \%$ \\
\hline SB4VS-10 & $\mathrm{Na}_{2} \mathrm{O}$ & 13.5070 & 12.5790 & 12.6680 & 0.8390 & -0.0890 & $6.6 \%$ & $-0.7 \%$ \\
\hline SB4VS-10 & $\mathrm{NiO}$ & 0.6140 & 0.7010 & 0.7060 & -0.0920 & -0.0050 & $-13.0 \%$ & $-0.7 \%$ \\
\hline SB4VS-10 & $\mathrm{PbO}$ & 0.0350 & 0.0350 & 0.0420 & -0.0070 & -0.0070 & $-16.7 \%$ & $-16.7 \%$ \\
\hline SB4VS-10 & $\mathrm{SiO}_{2}$ & 44.5510 & 44.5380 & 44.5360 & 0.0150 & 0.0020 & $0.0 \%$ & $0.0 \%$ \\
\hline SB4VS-10 & $\mathrm{SO}_{4}{ }^{2-}$ & 0.4960 & 0.4960 & 0.6110 & -0.1150 & -0.1150 & $-18.8 \%$ & $-18.8 \%$ \\
\hline SB4VS-10 & $\mathrm{ThO}_{2}$ & 0.1430 & 0.1430 & 0.0290 & 0.1140 & 0.1140 & $393.1 \%$ & $393.1 \%$ \\
\hline SB4VS-10 & $\mathrm{TiO}_{2}$ & 0.0130 & 0.0140 & 0.0120 & 0.0010 & 0.0020 & $8.3 \%$ & $16.7 \%$ \\
\hline SB4VS-10 & $\mathrm{U}_{3} \mathrm{O}_{8}$ & 2.9100 & 3.1750 & 3.1310 & -0.2210 & 0.0440 & $-7.1 \%$ & $1.4 \%$ \\
\hline SB4VS-10 & $\mathrm{ZnO}$ & 0.0490 & 0.0490 & 0.0450 & 0.0040 & 0.0040 & $8.9 \%$ & $8.9 \%$ \\
\hline SB4VS-10 & $\mathrm{ZrO}_{2}$ & 0.0960 & 0.0960 & 0.1070 & -0.0110 & -0.0110 & $-10.3 \%$ & $-10.3 \%$ \\
\hline SB4VS-10 & Sum & 100.4460 & 100.0130 & 100.0020 & 0.4440 & 0.0110 & $0.4 \%$ & $0.0 \%$ \\
\hline SB4VS-11 & $\mathrm{Al}_{2} \mathrm{O}_{3}$ & 10.7650 & 10.8190 & 10.4220 & 0.3430 & 0.3970 & $3.3 \%$ & $3.8 \%$ \\
\hline SB4VS-11 & $\mathrm{B}_{2} \mathrm{O}_{3}$ & 8.1700 & 7.9720 & 8.1200 & 0.0500 & -0.1480 & $0.6 \%$ & $-1.8 \%$ \\
\hline SB4VS-11 & $\mathrm{BaO}$ & 0.0420 & 0.0450 & 0.0480 & -0.0060 & -0.0030 & $-12.5 \%$ & $-6.3 \%$ \\
\hline SB4VS-11 & $\mathrm{CaO}$ & 0.9870 & 0.9870 & 0.9370 & 0.0500 & 0.0500 & $5.3 \%$ & $5.3 \%$ \\
\hline SB4VS-11 & $\mathrm{Ce}_{2} \mathrm{O}_{3}$ & 0.0240 & 0.0240 & 0.0580 & -0.0340 & -0.0340 & $-58.6 \%$ & $-58.6 \%$ \\
\hline SB4VS-11 & $\mathrm{Cr}_{2} \mathrm{O}_{3}$ & 0.0730 & 0.0790 & 0.0800 & -0.0070 & -0.0010 & $-8.8 \%$ & $-1.3 \%$ \\
\hline SB4VS-11 & $\mathrm{CuO}$ & 0.0240 & 0.0240 & 0.0230 & 0.0010 & 0.0010 & $4.3 \%$ & $4.3 \%$ \\
\hline SB4VS-11 & $\mathrm{Fe}_{2} \mathrm{O}_{3}$ & 9.5080 & 9.6200 & 10.6040 & -1.0960 & -0.9840 & $-10.3 \%$ & $-9.3 \%$ \\
\hline SB4VS-11 & $\mathrm{K}_{2} \mathrm{O}$ & 0.1420 & 0.1270 & 0.1270 & 0.0150 & 0.0000 & $11.8 \%$ & $0.0 \%$ \\
\hline SB4VS-11 & $\mathrm{La}_{2} \mathrm{O}_{3}$ & 0.0340 & 0.0340 & 0.0410 & -0.0070 & -0.0070 & $-17.1 \%$ & $-17.1 \%$ \\
\hline SB4VS-11 & $\mathrm{Li}_{2} \mathrm{O}$ & 4.6070 & 4.6230 & 4.6400 & -0.0330 & -0.0170 & $-0.7 \%$ & $-0.4 \%$ \\
\hline SB4VS-11 & $\mathrm{MgO}$ & 0.8970 & 0.9400 & 0.9920 & -0.0950 & -0.0520 & $-9.6 \%$ & $-5.2 \%$ \\
\hline SB4VS-11 & $\mathrm{MnO}$ & 2.3950 & 2.3430 & 2.3330 & 0.0620 & 0.0100 & $2.7 \%$ & $0.4 \%$ \\
\hline SB4VS-11 & $\mathrm{Na}_{2} \mathrm{O}$ & 12.9780 & 12.0860 & 12.3290 & 0.6490 & -0.2430 & $5.3 \%$ & $-2.0 \%$ \\
\hline SB4VS-11 & $\mathrm{NiO}$ & 0.5700 & 0.6440 & 0.7060 & -0.1360 & -0.0620 & $-19.3 \%$ & $-8.8 \%$ \\
\hline
\end{tabular}


Table E4. Average Measured and Bias-Corrected Chemical Compositions Versus Targeted Compositions by Oxide by SB4 Variability Study Glass (continued)

(100 -Batch 1; 200 -U std; 300 - LRM)

\begin{tabular}{|c|c|c|c|c|c|c|c|c|}
\hline Glass ID & Oxide & $\begin{array}{c}\text { Measured } \\
(w t \%)\end{array}$ & $\begin{array}{c}\text { Measured } \\
\text { Bias-Corrected } \\
(\mathbf{w t} \%)\end{array}$ & $\begin{array}{c}\text { Targeted } \\
(\mathbf{w t} \%)\end{array}$ & $\begin{array}{c}\text { Diff of } \\
\text { Measured } \\
(\mathbf{w t} \%)\end{array}$ & $\begin{array}{c}\text { Diff. of } \\
\text { Meas BC } \\
(w t \%)\end{array}$ & $\begin{array}{l}\text { \% Diff of } \\
\text { Measured }\end{array}$ & $\begin{array}{l}\text { \% Diff of } \\
\text { Meas BC }\end{array}$ \\
\hline SB4VS-11 & $\mathrm{PbO}$ & 0.0310 & 0.0310 & 0.0350 & -0.0040 & -0.0040 & $-11.4 \%$ & $-11.4 \%$ \\
\hline SB4VS-11 & $\mathrm{SiO}_{2}$ & 45.0860 & 44.5930 & 44.5360 & 0.5500 & 0.0570 & $1.2 \%$ & $0.1 \%$ \\
\hline SB4VS-11 & $\mathrm{SO}_{4}{ }^{2-}$ & 0.4620 & 0.4620 & 0.5590 & -0.0970 & -0.0970 & $-17.4 \%$ & $-17.4 \%$ \\
\hline SB4VS-11 & $\mathrm{ThO}_{2}$ & 0.1420 & 0.1420 & 0.0240 & 0.1180 & 0.1180 & $491.7 \%$ & $491.7 \%$ \\
\hline SB4VS-11 & $\mathrm{TiO}_{2}$ & 0.0100 & 0.0110 & 0.0100 & 0.0000 & 0.0010 & $0.0 \%$ & $10.0 \%$ \\
\hline SB4VS-11 & $\mathrm{U}_{3} \mathrm{O}_{8}$ & 3.0900 & 3.3620 & 3.2510 & -0.1610 & 0.1110 & $-5.0 \%$ & $3.4 \%$ \\
\hline SB4VS-11 & $\mathrm{ZnO}$ & 0.0400 & 0.0400 & 0.0380 & 0.0020 & 0.0020 & $5.3 \%$ & $5.3 \%$ \\
\hline SB4VS-11 & $\mathrm{ZrO}_{2}$ & 0.0810 & 0.0810 & 0.0900 & -0.0090 & -0.0090 & $-10.0 \%$ & $-10.0 \%$ \\
\hline SB4VS-11 & Sum & 100.1600 & 99.0910 & 100.0030 & 0.1570 & -0.9120 & $0.2 \%$ & $-0.9 \%$ \\
\hline SB4VS-12 & $\mathrm{Al}_{2} \mathrm{O}_{3}$ & 10.1420 & 10.1140 & 9.9260 & 0.2160 & 0.1880 & $2.2 \%$ & $1.9 \%$ \\
\hline SB4VS-12 & $\mathrm{B}_{2} \mathrm{O}_{3}$ & 8.5090 & 8.0960 & 8.4000 & 0.1090 & -0.3040 & $1.3 \%$ & $-3.6 \%$ \\
\hline SB4VS-12 & $\mathrm{BaO}$ & 0.0460 & 0.0520 & 0.0540 & -0.0080 & -0.0020 & $-14.8 \%$ & $-3.7 \%$ \\
\hline SB4VS-12 & $\mathrm{CaO}$ & 0.9000 & 0.9130 & 0.8920 & 0.0080 & 0.0210 & $0.9 \%$ & $2.4 \%$ \\
\hline SB4VS-12 & $\mathrm{Ce}_{2} \mathrm{O}_{3}$ & 0.0370 & 0.0370 & 0.0660 & -0.0290 & -0.0290 & $-43.9 \%$ & $-43.9 \%$ \\
\hline SB4VS-12 & $\mathrm{Cr}_{2} \mathrm{O}_{3}$ & 0.0780 & 0.0890 & 0.0910 & -0.0130 & -0.0020 & $-14.3 \%$ & $-2.2 \%$ \\
\hline SB4VS-12 & $\mathrm{CuO}$ & 0.0310 & 0.0310 & 0.0260 & 0.0050 & 0.0050 & $19.2 \%$ & $19.2 \%$ \\
\hline SB4VS-12 & $\mathrm{Fe}_{2} \mathrm{O}_{3}$ & 9.0820 & 9.2420 & 10.4080 & -1.3260 & -1.1660 & $-12.7 \%$ & $-11.2 \%$ \\
\hline SB4VS-12 & $\mathrm{K}_{2} \mathrm{O}$ & 0.1610 & 0.1410 & 0.1440 & 0.0170 & -0.0030 & $11.8 \%$ & $-2.1 \%$ \\
\hline SB4VS-12 & $\mathrm{La}_{2} \mathrm{O}_{3}$ & 0.0380 & 0.0380 & 0.0460 & -0.0080 & -0.0080 & $-17.4 \%$ & $-17.4 \%$ \\
\hline SB4VS-12 & $\mathrm{Li}_{2} \mathrm{O}$ & 4.8010 & 4.8140 & 4.8000 & 0.0010 & 0.0140 & $0.0 \%$ & $0.3 \%$ \\
\hline SB4VS-12 & $\mathrm{MgO}$ & 0.9180 & 1.0240 & 1.0490 & -0.1310 & -0.0250 & $-12.5 \%$ & $-2.4 \%$ \\
\hline SB4VS-12 & $\mathrm{MnO}$ & 2.2310 & 2.2280 & 2.2220 & 0.0090 & 0.0060 & $0.4 \%$ & $0.3 \%$ \\
\hline SB4VS-12 & $\mathrm{Na}_{2} \mathrm{O}$ & 11.8730 & 11.1000 & 11.4230 & 0.4500 & -0.3230 & $3.9 \%$ & $-2.8 \%$ \\
\hline SB4VS-12 & $\mathrm{NiO}$ & 0.5600 & 0.6190 & 0.6720 & -0.1120 & -0.0530 & $-16.7 \%$ & $-7.9 \%$ \\
\hline SB4VS-12 & $\mathrm{PbO}$ & 0.0340 & 0.0340 & 0.0400 & -0.0060 & -0.0060 & $-15.0 \%$ & $-15.0 \%$ \\
\hline SB4VS-12 & $\mathrm{SiO}_{2}$ & 44.9790 & 46.1070 & 46.0460 & -1.0670 & 0.0610 & $-2.3 \%$ & $0.1 \%$ \\
\hline SB4VS-12 & $\mathrm{SO}_{4}{ }^{2-}$ & 0.4550 & 0.4550 & 0.5320 & -0.0770 & -0.0770 & $-14.5 \%$ & $-14.5 \%$ \\
\hline SB4VS-12 & $\mathrm{ThO}_{2}$ & 0.1240 & 0.1240 & 0.0270 & 0.0970 & 0.0970 & $359.3 \%$ & $359.3 \%$ \\
\hline SB4VS-12 & $\mathrm{TiO}_{2}$ & 0.0130 & 0.0150 & 0.0110 & 0.0020 & 0.0040 & $18.2 \%$ & $36.4 \%$ \\
\hline SB4VS-12 & $\mathrm{U}_{3} \mathrm{O}_{8}$ & 2.7890 & 3.0320 & 2.9820 & -0.1930 & 0.0500 & $-6.5 \%$ & $1.7 \%$ \\
\hline SB4VS-12 & $\mathrm{ZnO}$ & 0.0440 & 0.0440 & 0.0430 & 0.0010 & 0.0010 & $2.3 \%$ & $2.3 \%$ \\
\hline SB4VS-12 & $\mathrm{ZrO}_{2}$ & 0.0800 & 0.0800 & 0.1020 & -0.0220 & -0.0220 & $-21.6 \%$ & $-21.6 \%$ \\
\hline SB4VS-12 & Sum & 97.9240 & 98.4310 & 100.0020 & -2.0780 & -1.5710 & $-2.1 \%$ & $-1.6 \%$ \\
\hline SB4VS-13 & $\mathrm{Al}_{2} \mathrm{O}_{3}$ & 10.4110 & 10.4970 & 9.9260 & 0.4850 & 0.5710 & $4.9 \%$ & $5.8 \%$ \\
\hline SB4VS-13 & $\mathrm{B}_{2} \mathrm{O}_{3}$ & 8.3560 & 8.2540 & 8.4000 & -0.0440 & -0.1460 & $-0.5 \%$ & $-1.7 \%$ \\
\hline SB4VS-13 & $\mathrm{BaO}$ & 0.0370 & 0.0420 & 0.0460 & -0.0090 & -0.0040 & $-19.6 \%$ & $-8.7 \%$ \\
\hline SB4VS-13 & $\mathrm{CaO}$ & 1.0590 & 1.0540 & 0.9960 & 0.0630 & 0.0580 & $6.3 \%$ & $5.8 \%$ \\
\hline SB4VS-13 & $\mathrm{Ce}_{2} \mathrm{O}_{3}$ & 0.0370 & 0.0370 & 0.0550 & -0.0180 & -0.0180 & $-32.7 \%$ & $-32.7 \%$ \\
\hline SB4VS-13 & $\mathrm{Cr}_{2} \mathrm{O}_{3}$ & 0.0660 & 0.0750 & 0.0760 & -0.0100 & -0.0010 & $-13.2 \%$ & $-1.3 \%$ \\
\hline SB4VS-13 & $\mathrm{CuO}$ & 0.0240 & 0.0240 & 0.0220 & 0.0020 & 0.0020 & $9.1 \%$ & $9.1 \%$ \\
\hline SB4VS-13 & $\mathrm{Fe}_{2} \mathrm{O}_{3}$ & 9.6500 & 9.7520 & 10.6110 & -0.9610 & -0.8590 & $-9.1 \%$ & $-8.1 \%$ \\
\hline SB4VS-13 & $\mathrm{K}_{2} \mathrm{O}$ & 0.0600 & 0.0540 & 0.1210 & -0.0610 & -0.0670 & $-50.4 \%$ & $-55.4 \%$ \\
\hline SB4VS-13 & $\mathrm{La}_{2} \mathrm{O}_{3}$ & 0.0300 & 0.0300 & 0.0390 & -0.0090 & -0.0090 & $-23.1 \%$ & $-23.1 \%$ \\
\hline SB4VS-13 & $\mathrm{Li}_{2} \mathrm{O}$ & 4.5100 & 4.5780 & 4.8000 & -0.2900 & -0.2220 & $-6.0 \%$ & $-4.6 \%$ \\
\hline SB4VS-13 & $\mathrm{MgO}$ & 0.9210 & 1.0170 & 1.0490 & -0.1280 & -0.0320 & $-12.2 \%$ & $-3.1 \%$ \\
\hline SB4VS-13 & $\mathrm{MnO}$ & 2.1080 & 2.1530 & 2.1120 & -0.0040 & 0.0410 & $-0.2 \%$ & $1.9 \%$ \\
\hline SB4VS-13 & $\mathrm{Na}_{2} \mathrm{O}$ & 12.1150 & 11.5280 & 11.4230 & 0.6920 & 0.1050 & $6.1 \%$ & $0.9 \%$ \\
\hline SB4VS-13 & $\mathrm{NiO}$ & 0.4510 & 0.5140 & 0.5700 & -0.1190 & -0.0560 & $-20.9 \%$ & $-9.8 \%$ \\
\hline SB4VS-13 & $\mathrm{PbO}$ & 0.0290 & 0.0290 & 0.0330 & -0.0040 & -0.0040 & $-12.1 \%$ & $-12.1 \%$ \\
\hline SB4VS-13 & $\mathrm{SiO}_{2}$ & 46.4760 & 46.4590 & 45.9390 & 0.5370 & 0.5200 & $1.2 \%$ & $1.1 \%$ \\
\hline SB4VS-13 & $\mathrm{SO}_{4}{ }^{2-}$ & 0.4220 & 0.4220 & 0.5320 & -0.1100 & -0.1100 & $-20.7 \%$ & $-20.7 \%$ \\
\hline SB4VS-13 & $\mathrm{ThO}_{2}$ & 0.1310 & 0.1310 & 0.0230 & 0.1080 & 0.1080 & $469.6 \%$ & $469.6 \%$ \\
\hline SB4VS-13 & $\mathrm{TiO}_{2}$ & 0.0080 & 0.0090 & 0.0100 & -0.0020 & -0.0010 & $-20.0 \%$ & $-10.0 \%$ \\
\hline SB4VS-13 & $\mathrm{U}_{3} \mathrm{O}_{8}$ & 2.9570 & 3.2260 & 3.0960 & -0.1390 & 0.1300 & $-4.5 \%$ & $4.2 \%$ \\
\hline SB4VS-13 & $\mathrm{ZnO}$ & 0.0340 & 0.0340 & 0.0360 & -0.0020 & -0.0020 & $-5.6 \%$ & $-5.6 \%$ \\
\hline SB4VS-13 & $\mathrm{ZrO}_{2}$ & 0.0650 & 0.0650 & 0.0850 & -0.0200 & -0.0200 & $-23.5 \%$ & $-23.5 \%$ \\
\hline SB4VS-13 & Sum & 99.9570 & 99.9840 & 100.0000 & -0.0430 & -0.0160 & $0.0 \%$ & $0.0 \%$ \\
\hline SB4VS-14 & $\mathrm{Al}_{2} \mathrm{O}_{3}$ & 8.9330 & 8.9080 & 8.7090 & 0.2240 & 0.1990 & $2.6 \%$ & $2.3 \%$ \\
\hline SB4VS-14 & $\mathrm{B}_{2} \mathrm{O}_{3}$ & 8.8710 & 8.4410 & 8.6800 & 0.1910 & -0.2390 & $2.2 \%$ & $-2.8 \%$ \\
\hline SB4VS-14 & $\mathrm{BaO}$ & 0.0330 & 0.0380 & 0.0430 & -0.0100 & -0.0050 & $-23.3 \%$ & $-11.6 \%$ \\
\hline SB4VS-14 & $\mathrm{CaO}$ & 0.9880 & 0.9830 & 0.9470 & 0.0410 & 0.0360 & $4.3 \%$ & $3.8 \%$ \\
\hline SB4VS-14 & $\mathrm{Ce}_{2} \mathrm{O}_{3}$ & 0.0360 & 0.0360 & 0.0520 & -0.0160 & -0.0160 & $-30.8 \%$ & $-30.8 \%$ \\
\hline SB4VS-14 & $\mathrm{Cr}_{2} \mathrm{O}_{3}$ & 0.0660 & 0.0750 & 0.0730 & -0.0070 & 0.0020 & $-9.6 \%$ & $2.7 \%$ \\
\hline SB4VS-14 & $\mathrm{CuO}$ & 0.0240 & 0.0240 & 0.0210 & 0.0030 & 0.0030 & $14.3 \%$ & $14.3 \%$ \\
\hline
\end{tabular}


Table E4. Average Measured and Bias-Corrected Chemical Compositions Versus Targeted Compositions by Oxide by SB4 Variability Study Glass (continued)

(100 -Batch 1; 200 -U std; 300 - LRM)

\begin{tabular}{|c|c|c|c|c|c|c|c|c|}
\hline Glass ID & Oxide & $\begin{array}{c}\text { Measured } \\
(\mathbf{w t} \%)\end{array}$ & $\begin{array}{c}\text { Measured } \\
\text { Bias-Corrected } \\
(w \mathbf{w} \%) \\
\end{array}$ & $\begin{array}{c}\text { Targeted } \\
(\mathbf{w t} \%)\end{array}$ & $\begin{array}{c}\text { Diff of } \\
\text { Measured } \\
(w t \%) \\
\end{array}$ & $\begin{array}{c}\text { Diff. of } \\
\text { Meas BC } \\
(w t \%) \\
\end{array}$ & $\begin{array}{l}\text { \% Diff of } \\
\text { Measured }\end{array}$ & $\begin{array}{l}\% \text { Diff of } \\
\text { Meas BC }\end{array}$ \\
\hline SB4VS-14 & $\mathrm{Fe}_{2} \mathrm{O}_{3}$ & 9.1180 & 9.2780 & 10.0130 & -0.8950 & -0.7350 & $-8.9 \%$ & $-7.3 \%$ \\
\hline SB4VS-14 & $\mathrm{K}_{2} \mathrm{O}$ & 0.0600 & 0.0540 & 0.1150 & -0.0550 & -0.0610 & $-47.8 \%$ & $-53.0 \%$ \\
\hline SB4VS-14 & $\mathrm{La}_{2} \mathrm{O}_{3}$ & 0.0270 & 0.0270 & 0.0370 & -0.0100 & -0.0100 & $-27.0 \%$ & $-27.0 \%$ \\
\hline SB4VS-14 & $\mathrm{Li}_{2} \mathrm{O}$ & 4.9520 & 4.9650 & 4.9600 & -0.0080 & 0.0050 & $-0.2 \%$ & $0.1 \%$ \\
\hline SB4VS-14 & $\mathrm{MgO}$ & 0.7910 & 0.8740 & 0.8970 & -0.1060 & -0.0230 & $-11.8 \%$ & $-2.6 \%$ \\
\hline SB4VS-14 & $\mathrm{MnO}$ & 2.0920 & 2.1370 & 2.1110 & -0.0190 & 0.0260 & $-0.9 \%$ & $1.2 \%$ \\
\hline SB4VS-14 & $\mathrm{Na}_{2} \mathrm{O}$ & 12.3910 & 11.7900 & 11.8430 & 0.5480 & -0.0530 & $4.6 \%$ & $-0.4 \%$ \\
\hline SB4VS-14 & $\mathrm{NiO}$ & 0.4510 & 0.4990 & 0.5410 & -0.0900 & -0.0420 & $-16.6 \%$ & $-7.8 \%$ \\
\hline SB4VS-14 & $\mathrm{PbO}$ & 0.0240 & 0.0240 & 0.0320 & -0.0080 & -0.0080 & $-25.0 \%$ & $-25.0 \%$ \\
\hline SB4VS-14 & $\mathrm{SiO}_{2}$ & 46.4230 & 47.5880 & 47.4430 & -1.0200 & 0.1450 & $-2.1 \%$ & $0.3 \%$ \\
\hline SB4VS-14 & $\mathrm{SO}_{4}^{2-}$ & 0.3900 & 0.3900 & 0.5050 & -0.1150 & -0.1150 & $-22.8 \%$ & $-22.8 \%$ \\
\hline SB4VS-14 & $\mathrm{ThO}_{2}$ & 0.1230 & 0.1230 & 0.0220 & 0.1010 & 0.1010 & $459.1 \%$ & $459.1 \%$ \\
\hline SB4VS-14 & $\mathrm{TiO}_{2}$ & 0.0080 & 0.0090 & 0.0090 & -0.0010 & 0.0000 & $-11.1 \%$ & $0.0 \%$ \\
\hline SB4VS-14 & $\mathrm{U}_{3} \mathrm{O}_{8}$ & 2.7180 & 2.9550 & 2.8330 & -0.1150 & 0.1220 & $-4.1 \%$ & $4.3 \%$ \\
\hline SB4VS-14 & $\mathrm{ZnO}$ & 0.0290 & 0.0290 & 0.0340 & -0.0050 & -0.0050 & $-14.7 \%$ & $-14.7 \%$ \\
\hline SB4VS-14 & $\mathrm{ZrO}_{2}$ & 0.0690 & 0.0690 & 0.0810 & -0.0120 & -0.0120 & $-14.8 \%$ & $-14.8 \%$ \\
\hline SB4VS-14 & Sum & 98.6170 & 99.3160 & 100.0010 & -1.3840 & -0.6850 & $-1.4 \%$ & $-0.7 \%$ \\
\hline SB4VS-15 & $\mathrm{Al}_{2} \mathrm{O}_{3}$ & 9.0460 & 9.0910 & 8.7090 & 0.3370 & 0.3820 & $3.9 \%$ & $4.4 \%$ \\
\hline SB4VS-15 & $\mathrm{B}_{2} \mathrm{O}_{3}$ & 8.4920 & 8.2870 & 8.6800 & -0.1880 & -0.3930 & $-2.2 \%$ & $-4.5 \%$ \\
\hline SB4VS-15 & $\mathrm{BaO}$ & 0.0430 & 0.0460 & 0.0510 & -0.0080 & -0.0050 & $-15.7 \%$ & $-9.8 \%$ \\
\hline SB4VS-15 & $\mathrm{CaO}$ & 0.8770 & 0.8770 & 0.8470 & 0.0300 & 0.0300 & $3.5 \%$ & $3.5 \%$ \\
\hline SB4VS-15 & $\mathrm{Ce}_{2} \mathrm{O}_{3}$ & 0.0440 & 0.0440 & 0.0620 & -0.0180 & -0.0180 & $-29.0 \%$ & $-29.0 \%$ \\
\hline SB4VS-15 & $\mathrm{Cr}_{2} \mathrm{O}_{3}$ & 0.0730 & 0.0790 & 0.0860 & -0.0130 & -0.0070 & $-15.1 \%$ & $-8.1 \%$ \\
\hline SB4VS-15 & $\mathrm{CuO}$ & 0.0240 & 0.0240 & 0.0250 & -0.0010 & -0.0010 & $-4.0 \%$ & $-4.0 \%$ \\
\hline SB4VS-15 & $\mathrm{Fe}_{2} \mathrm{O}_{3}$ & 9.1790 & 9.2860 & 10.3880 & -1.2090 & -1.1020 & $-11.6 \%$ & $-10.6 \%$ \\
\hline SB4VS-15 & $\mathrm{K}_{2} \mathrm{O}$ & 0.0600 & 0.0540 & 0.1370 & $\begin{array}{l}-0.0770 \\
\end{array}$ & -0.0830 & $-56.2 \%$ & $-60.6 \%$ \\
\hline SB4VS-15 & $\mathrm{La}_{2} \mathrm{O}_{3}$ & 0.0350 & 0.0350 & 0.0440 & -0.0090 & -0.0090 & $-20.5 \%$ & $-20.5 \%$ \\
\hline SB4VS-15 & $\mathrm{Li}_{2} \mathrm{O}$ & 4.9250 & 4.9420 & 4.9600 & -0.0350 & -0.0180 & $-0.7 \%$ & $-0.4 \%$ \\
\hline SB4VS-15 & $\mathrm{MgO}$ & 0.8090 & 0.8480 & 0.8970 & -0.0880 & -0.0490 & $-9.8 \%$ & $-5.5 \%$ \\
\hline SB4VS-15 & $\mathrm{MnO}$ & 2.1270 & 2.0810 & 2.1110 & 0.0160 & -0.0300 & $0.8 \%$ & $-1.4 \%$ \\
\hline SB4VS-15 & $\mathrm{Na}_{2} \mathrm{O}$ & 12.0650 & 11.2350 & 11.4150 & 0.6500 & -0.1800 & $5.7 \%$ & $-1.6 \%$ \\
\hline SB4VS-15 & $\mathrm{NiO}$ & 0.4020 & 0.4540 & 0.5410 & -0.1390 & -0.0870 & $-25.7 \%$ & $-16.1 \%$ \\
\hline SB4VS-15 & $\mathrm{PbO}$ & 0.0280 & 0.0280 & 0.0380 & -0.0100 & -0.0100 & $-26.3 \%$ & $-26.3 \%$ \\
\hline SB4VS-15 & $\mathrm{SiO}_{2}$ & 47.2250 & 46.7080 & 47.3420 & -0.1170 & -0.6340 & $-0.2 \%$ & $-1.3 \%$ \\
\hline SB4VS-15 & $\mathrm{SO}_{4}{ }^{2-}$ & 0.4310 & 0.4310 & 0.5530 & -0.1220 & -0.1220 & $-22.1 \%$ & $-22.1 \%$ \\
\hline SB4VS-15 & $\mathrm{ThO}_{2}$ & 0.1340 & 0.1340 & 0.0260 & 0.1080 & 0.1080 & $415.4 \%$ & $415.4 \%$ \\
\hline SB4VS-15 & $\mathrm{TiO}_{2}$ & 0.0130 & 0.0140 & 0.0110 & 0.0020 & 0.0030 & $18.2 \%$ & $27.3 \%$ \\
\hline SB4VS-15 & $\mathrm{U}_{3} \mathrm{O}_{8}$ & 2.6920 & 2.9290 & 2.9410 & -0.2490 & -0.0120 & $-8.5 \%$ & $-0.4 \%$ \\
\hline SB4VS-15 & $\mathrm{ZnO}$ & 0.0390 & 0.0390 & 0.0410 & -0.0020 & -0.0020 & $-4.9 \%$ & $-4.9 \%$ \\
\hline SB4VS-15 & $\mathrm{ZrO}_{2}$ & 0.0850 & 0.0850 & 0.0960 & -0.0110 & -0.0110 & $-11.5 \%$ & $-11.5 \%$ \\
\hline SB4VS-15 & Sum & 98.8480 & 97.7520 & 100.0010 & -1.1530 & -2.2490 & $-1.2 \%$ & $-2.2 \%$ \\
\hline SB4VS-16 & $\mathrm{Al}_{2} \mathrm{O}_{3}$ & 8.5550 & 8.5310 & 8.2500 & 0.3050 & 0.2810 & $3.7 \%$ & $3.4 \%$ \\
\hline SB4VS-16 & $\mathrm{B}_{2} \mathrm{O}_{3}$ & 9.0640 & 8.6250 & 8.9600 & 0.1040 & -0.3350 & $1.2 \%$ & $-3.7 \%$ \\
\hline SB4VS-16 & $\mathrm{BaO}$ & 0.0430 & 0.0460 & 0.0490 & -0.0060 & -0.0030 & $-12.2 \%$ & $-6.1 \%$ \\
\hline SB4VS-16 & $\mathrm{CaO}$ & 0.8770 & 0.8770 & 0.8030 & 0.0740 & 0.0740 & $9.2 \%$ & $9.2 \%$ \\
\hline SB4VS-16 & $\mathrm{Ce}_{2} \mathrm{O}_{3}$ & 0.0320 & 0.0320 & 0.0590 & -0.0270 & -0.0270 & $-45.8 \%$ & $-45.8 \%$ \\
\hline SB4VS-16 & $\mathrm{Cr}_{2} \mathrm{O}_{3}$ & 0.0770 & 0.0830 & 0.0820 & -0.0050 & 0.0010 & $-6.1 \%$ & $1.2 \%$ \\
\hline SB4VS-16 & $\mathrm{CuO}$ & 0.0260 & 0.0260 & 0.0240 & 0.0020 & 0.0020 & $8.3 \%$ & $8.3 \%$ \\
\hline SB4VS-16 & $\mathrm{Fe}_{2} \mathrm{O}_{3}$ & 8.4960 & 8.6440 & 9.5880 & -1.0920 & -0.9440 & $-11.4 \%$ & $-9.8 \%$ \\
\hline SB4VS-16 & $\mathrm{K}_{2} \mathrm{O}$ & 0.1460 & 0.1300 & 0.1290 & 0.0170 & 0.0010 & $13.2 \%$ & $0.8 \%$ \\
\hline SB4VS-16 & $\mathrm{La}_{2} \mathrm{O}_{3}$ & 0.0340 & 0.0340 & 0.0420 & -0.0080 & -0.0080 & $-19.0 \%$ & $-19.0 \%$ \\
\hline SB4VS-16 & $\mathrm{Li}_{2} \mathrm{O}$ & 5.1240 & 5.1380 & 5.1200 & 0.0040 & 0.0180 & $0.1 \%$ & $0.4 \%$ \\
\hline SB4VS-16 & $\mathrm{MgO}$ & 0.8680 & 0.9100 & 0.9440 & -0.0760 & -0.0340 & $-8.1 \%$ & $-3.6 \%$ \\
\hline SB4VS-16 & $\mathrm{MnO}$ & 1.9270 & 1.8850 & 1.9010 & 0.0260 & -0.0160 & $1.4 \%$ & $-0.8 \%$ \\
\hline SB4VS-16 & $\mathrm{Na}_{2} \mathrm{O}$ & 12.1960 & 11.3580 & 11.4300 & 0.7660 & -0.0720 & $6.7 \%$ & $-0.6 \%$ \\
\hline SB4VS-16 & $\mathrm{NiO}$ & 0.4090 & 0.4520 & 0.5130 & -0.1040 & -0.0610 & $-20.3 \%$ & $-11.9 \%$ \\
\hline SB4VS-16 & $\mathrm{PbO}$ & 0.0310 & 0.0310 & 0.0360 & -0.0050 & -0.0050 & $-13.9 \%$ & $-13.9 \%$ \\
\hline SB4VS-16 & $\mathrm{SiO}_{2}$ & 47.5460 & 48.7390 & 48.7450 & -1.1990 & -0.0060 & $-2.5 \%$ & $0.0 \%$ \\
\hline SB4VS-16 & $\mathrm{SO}_{4}{ }^{2-}$ & 0.4040 & 0.4040 & 0.4790 & -0.0750 & -0.0750 & $-15.7 \%$ & $-15.7 \%$ \\
\hline SB4VS-16 & $\mathrm{ThO}_{2}$ & 0.1210 & 0.1210 & 0.0250 & 0.0960 & 0.0960 & $384.0 \%$ & $384.0 \%$ \\
\hline SB4VS-16 & $\mathrm{TiO}_{2}$ & 0.0100 & 0.0110 & 0.0100 & 0.0000 & 0.0010 & $0.0 \%$ & $10.0 \%$ \\
\hline SB4VS-16 & $\mathrm{U}_{3} \mathrm{O}_{8}$ & 2.5350 & 2.7560 & 2.6840 & -0.1490 & 0.0720 & $-5.6 \%$ & $2.7 \%$ \\
\hline SB4VS-16 & $\mathrm{ZnO}$ & 0.0420 & 0.0420 & 0.0380 & 0.0040 & 0.0040 & $10.5 \%$ & $10.5 \%$ \\
\hline SB4VS-16 & $\mathrm{ZrO}_{2}$ & 0.0830 & 0.0830 & 0.0910 & -0.0080 & -0.0080 & $-8.8 \%$ & $-8.8 \%$ \\
\hline
\end{tabular}


Table E4. Average Measured and Bias-Corrected Chemical Compositions Versus Targeted Compositions by Oxide by SB4 Variability Study Glass (continued)

(100 -Batch 1; 200 -U std; 300 - LRM)

\begin{tabular}{|c|c|c|c|c|c|c|c|c|}
\hline Glass ID & Oxide & $\begin{array}{c}\text { Measured } \\
\text { (wt\%) }\end{array}$ & $\begin{array}{c}\text { Measured } \\
\text { Bias-Corrected } \\
(\mathbf{w t} \%)\end{array}$ & $\begin{array}{c}\text { Targeted } \\
(w \mathrm{w} \%)\end{array}$ & $\begin{array}{c}\text { Diff of } \\
\text { Measured } \\
(\mathbf{w t} \%)\end{array}$ & $\begin{array}{c}\text { Diff. of } \\
\text { Meas BC } \\
(w t \%)\end{array}$ & $\begin{array}{l}\text { \% Diff of } \\
\text { Measured }\end{array}$ & $\begin{array}{l}\text { \% Diff of } \\
\text { Meas BC }\end{array}$ \\
\hline SB4VS-16 & Sum & 98.6450 & 98.9570 & 100.0020 & -1.3570 & -1.0450 & $-1.4 \%$ & $-1.0 \%$ \\
\hline SB4VS-17 & $\mathrm{Al}_{2} \mathrm{O}_{3}$ & 9.2820 & 9.3460 & 8.9330 & 0.3490 & 0.4130 & $3.9 \%$ & $4.6 \%$ \\
\hline SB4VS-17 & $\mathrm{B}_{2} \mathrm{O}_{3}$ & 8.9270 & 8.7950 & 8.9600 & -0.0330 & -0.1650 & $-0.4 \%$ & $-1.8 \%$ \\
\hline SB4VS-17 & $\mathrm{BaO}$ & 0.0340 & 0.0380 & 0.0410 & -0.0070 & -0.0030 & $-17.1 \%$ & $-7.3 \%$ \\
\hline SB4VS-17 & $\mathrm{CaO}$ & 0.8530 & 0.8450 & 0.8030 & 0.0500 & 0.0420 & $6.2 \%$ & $5.2 \%$ \\
\hline SB4VS-17 & $\mathrm{Ce}_{2} \mathrm{O}_{3}$ & 0.0240 & 0.0240 & 0.0500 & -0.0260 & -0.0260 & $-52.0 \%$ & $-52.0 \%$ \\
\hline SB4VS-17 & $\mathrm{Cr}_{2} \mathrm{O}_{3}$ & 0.0620 & 0.0690 & 0.0690 & -0.0070 & 0.0000 & $-10.1 \%$ & $0.0 \%$ \\
\hline SB4VS-17 & $\mathrm{CuO}$ & 0.0220 & 0.0220 & 0.0200 & 0.0020 & 0.0020 & $10.0 \%$ & $10.0 \%$ \\
\hline SB4VS-17 & $\mathrm{Fe}_{2} \mathrm{O}_{3}$ & 8.6530 & 8.7620 & 9.7000 & -1.0470 & -0.9380 & $-10.8 \%$ & $-9.7 \%$ \\
\hline SB4VS-17 & $\mathrm{K}_{2} \mathrm{O}$ & 0.1290 & 0.1150 & 0.1090 & 0.0200 & 0.0060 & $18.3 \%$ & $5.5 \%$ \\
\hline SB4VS-17 & $\mathrm{La}_{2} \mathrm{O}_{3}$ & 0.0290 & 0.0290 & 0.0350 & -0.0060 & -0.0060 & $-17.1 \%$ & $-17.1 \%$ \\
\hline SB4VS-17 & $\mathrm{Li}_{2} \mathrm{O}$ & 5.0920 & 5.1510 & 5.1200 & -0.0280 & 0.0310 & $-0.5 \%$ & $0.6 \%$ \\
\hline SB4VS-17 & $\mathrm{MgO}$ & 0.7410 & 0.8020 & 0.8500 & -0.1090 & -0.0480 & $-12.8 \%$ & $-5.6 \%$ \\
\hline SB4VS-17 & $\mathrm{MnO}$ & 1.9400 & 1.9400 & 1.9010 & 0.0390 & 0.0390 & $2.1 \%$ & $2.1 \%$ \\
\hline SB4VS-17 & $\mathrm{Na}_{2} \mathrm{O}$ & 11.2520 & 10.6590 & 10.6810 & 0.5710 & -0.0220 & $5.3 \%$ & $-0.2 \%$ \\
\hline SB4VS-17 & $\mathrm{NiO}$ & 0.4020 & 0.4620 & 0.5130 & -0.1110 & -0.0510 & $-21.6 \%$ & $-9.9 \%$ \\
\hline SB4VS-17 & $\mathrm{PbO}$ & 0.0230 & 0.0230 & 0.0300 & -0.0070 & -0.0070 & $-23.3 \%$ & $-23.3 \%$ \\
\hline SB4VS-17 & $\mathrm{SiO}_{2}$ & 49.2570 & 49.1350 & 48.8410 & 0.4160 & 0.2940 & $0.9 \%$ & $0.6 \%$ \\
\hline SB4VS-17 & $\mathrm{SO}_{4}{ }^{2-}$ & 0.4070 & 0.4070 & 0.5240 & -0.1170 & -0.1170 & $-22.3 \%$ & $-22.3 \%$ \\
\hline SB4VS-17 & $\mathrm{ThO}_{2}$ & 0.0840 & 0.0840 & 0.0210 & 0.0630 & 0.0630 & $300.0 \%$ & $300.0 \%$ \\
\hline SB4VS-17 & $\mathrm{TiO}_{2}$ & 0.0080 & 0.0090 & 0.0090 & -0.0010 & 0.0000 & $-11.1 \%$ & $0.0 \%$ \\
\hline SB4VS-17 & $\mathrm{U}_{3} \mathrm{O}_{8}$ & 2.5410 & 2.7530 & 2.6840 & -0.1430 & 0.0690 & $-5.3 \%$ & $2.6 \%$ \\
\hline SB4VS-17 & $\mathrm{ZnO}$ & 0.0310 & 0.0310 & 0.0320 & -0.0010 & -0.0010 & $-3.1 \%$ & $-3.1 \%$ \\
\hline SB4VS-17 & $\mathrm{ZrO}_{2}$ & 0.0630 & 0.0630 & 0.0770 & -0.0140 & -0.0140 & $-18.2 \%$ & $-18.2 \%$ \\
\hline SB4VS-17 & Sum & 99.8610 & 99.5690 & 100.0030 & -0.1420 & -0.4340 & $-0.1 \%$ & $-0.4 \%$ \\
\hline SB4VS-18 & $\mathrm{Al}_{2} \mathrm{O}_{3}$ & 8.2330 & 8.2910 & 8.0360 & 0.1970 & 0.2550 & $2.5 \%$ & $3.2 \%$ \\
\hline SB4VS-18 & $\mathrm{B}_{2} \mathrm{O}_{3}$ & 8.9430 & 8.8110 & 9.2400 & -0.2970 & -0.4290 & $-3.2 \%$ & $-4.6 \%$ \\
\hline SB4VS-18 & $\mathrm{BaO}$ & 0.0320 & 0.0360 & 0.0390 & -0.0070 & -0.0030 & $-17.9 \%$ & $-7.7 \%$ \\
\hline SB4VS-18 & $\mathrm{CaO}$ & 0.8900 & 0.9030 & 0.8470 & 0.0430 & 0.0560 & $5.1 \%$ & $6.6 \%$ \\
\hline SB4VS-18 & $\mathrm{Ce}_{2} \mathrm{O}_{3}$ & 0.0180 & 0.0180 & 0.0470 & -0.0290 & -0.0290 & $-61.7 \%$ & $-61.7 \%$ \\
\hline SB4VS-18 & $\mathrm{Cr}_{2} \mathrm{O}_{3}$ & 0.0670 & 0.0760 & 0.0650 & 0.0020 & 0.0110 & $3.1 \%$ & $16.9 \%$ \\
\hline SB4VS-18 & $\mathrm{CuO}$ & 0.0230 & 0.0230 & 0.0190 & 0.0040 & 0.0040 & $21.1 \%$ & $21.1 \%$ \\
\hline SB4VS-18 & $\mathrm{Fe}_{2} \mathrm{O}_{3}$ & 8.5170 & 8.6250 & 9.2940 & -0.7770 & -0.6690 & $-8.4 \%$ & $-7.2 \%$ \\
\hline SB4VS-18 & $\mathrm{K}_{2} \mathrm{O}$ & 0.0750 & 0.0660 & 0.1030 & -0.0280 & -0.0370 & $-27.2 \%$ & $-35.9 \%$ \\
\hline SB4VS-18 & $\mathrm{La}_{2} \mathrm{O}_{3}$ & 0.0280 & 0.0280 & 0.0330 & -0.0050 & -0.0050 & $-15.2 \%$ & $-15.2 \%$ \\
\hline SB4VS-18 & $\mathrm{Li}_{2} \mathrm{O}$ & 5.1780 & 5.2380 & 5.2800 & -0.1020 & -0.0420 & $-1.9 \%$ & $-0.8 \%$ \\
\hline SB4VS-18 & $\mathrm{MgO}$ & 0.7970 & 0.8890 & 0.8920 & -0.0950 & -0.0030 & $-10.7 \%$ & $-0.3 \%$ \\
\hline SB4VS-18 & $\mathrm{MnO}$ & 1.9110 & 1.9090 & 1.8890 & 0.0220 & 0.0200 & $1.2 \%$ & $1.1 \%$ \\
\hline SB4VS-18 & $\mathrm{Na}_{2} \mathrm{O}$ & 10.8280 & 10.1240 & 10.3100 & 0.5180 & -0.1860 & $5.0 \%$ & $-1.8 \%$ \\
\hline SB4VS-18 & $\mathrm{NiO}$ & 0.4560 & 0.5250 & 0.5720 & -0.1160 & -0.0470 & $-20.3 \%$ & $-8.2 \%$ \\
\hline SB4VS-18 & $\mathrm{PbO}$ & 0.0280 & 0.0280 & 0.0280 & 0.0000 & 0.0000 & $0.0 \%$ & $0.0 \%$ \\
\hline SB4VS-18 & $\mathrm{SiO}_{2}$ & 49.1500 & 49.0280 & 50.1480 & -0.9980 & -1.1200 & $-2.0 \%$ & $-2.2 \%$ \\
\hline SB4VS-18 & $\mathrm{SO}_{4}{ }^{2-}$ & 0.3990 & 0.3990 & 0.4950 & -0.0960 & -0.0960 & $-19.4 \%$ & $-19.4 \%$ \\
\hline SB4VS-18 & $\mathrm{ThO}_{2}$ & 0.0710 & 0.0710 & 0.0200 & 0.0510 & 0.0510 & $255.0 \%$ & $255.0 \%$ \\
\hline SB4VS-18 & $\mathrm{TiO}_{2}$ & 0.0080 & 0.0090 & 0.0080 & 0.0000 & 0.0010 & $0.0 \%$ & $12.5 \%$ \\
\hline SB4VS-18 & $\mathrm{U}_{3} \mathrm{O}_{8}$ & 2.3550 & 2.5520 & 2.5350 & -0.1800 & 0.0170 & $-7.1 \%$ & $0.7 \%$ \\
\hline SB4VS-18 & $\mathrm{ZnO}$ & 0.0300 & 0.0300 & 0.0310 & -0.0010 & -0.0010 & $-3.2 \%$ & $-3.2 \%$ \\
\hline SB4VS-18 & $\mathrm{ZrO}_{2}$ & 0.0600 & 0.0600 & 0.0730 & -0.0130 & -0.0130 & $-17.8 \%$ & $-17.8 \%$ \\
\hline SB4VS-18 & Sum & 98.1000 & 97.7410 & 100.0040 & -1.9040 & -2.2630 & $-1.9 \%$ & $-2.3 \%$ \\
\hline SB4VS-19 & $\mathrm{Al}_{2} \mathrm{O}_{3}$ & 8.2240 & 8.2920 & 7.7920 & 0.4320 & 0.5000 & $5.5 \%$ & $6.4 \%$ \\
\hline SB4VS-19 & $\mathrm{B}_{2} \mathrm{O}_{3}$ & 9.1120 & 9.0010 & 9.2400 & -0.1280 & -0.2390 & $-1.4 \%$ & $-2.6 \%$ \\
\hline SB4VS-19 & $\mathrm{BaO}$ & 0.0330 & 0.0360 & 0.0390 & -0.0060 & -0.0030 & $-15.4 \%$ & $-7.7 \%$ \\
\hline SB4VS-19 & $\mathrm{CaO}$ & 0.8010 & 0.8010 & 0.7580 & 0.0430 & 0.0430 & $5.7 \%$ & $5.7 \%$ \\
\hline SB4VS-19 & $\mathrm{Ce}_{2} \mathrm{O}_{3}$ & 0.0320 & 0.0320 & 0.0470 & -0.0150 & -0.0150 & $-31.9 \%$ & $-31.9 \%$ \\
\hline SB4VS-19 & $\mathrm{Cr}_{2} \mathrm{O}_{3}$ & 0.0630 & 0.0680 & 0.0650 & -0.0020 & 0.0030 & $-3.1 \%$ & $4.6 \%$ \\
\hline SB4VS-19 & $\mathrm{CuO}$ & 0.0200 & 0.0200 & 0.0190 & 0.0010 & 0.0010 & $5.3 \%$ & $5.3 \%$ \\
\hline SB4VS-19 & $\mathrm{Fe}_{2} \mathrm{O}_{3}$ & 7.8740 & 7.9570 & 8.8250 & -0.9510 & -0.8680 & $-10.8 \%$ & $-9.8 \%$ \\
\hline SB4VS-19 & $\mathrm{K}_{2} \mathrm{O}$ & 0.0840 & 0.0750 & 0.1030 & -0.0190 & -0.0280 & $-18.4 \%$ & $-27.2 \%$ \\
\hline SB4VS-19 & $\mathrm{La}_{2} \mathrm{O}_{3}$ & 0.0260 & 0.0260 & 0.0330 & -0.0070 & -0.0070 & $-21.2 \%$ & $-21.2 \%$ \\
\hline SB4VS-19 & $\mathrm{Li}_{2} \mathrm{O}$ & 5.3020 & 5.3820 & 5.2800 & 0.0220 & 0.1020 & $0.4 \%$ & $1.9 \%$ \\
\hline SB4VS-19 & $\mathrm{MgO}$ & 0.8480 & 0.8890 & 0.8920 & -0.0440 & -0.0030 & $-4.9 \%$ & $-0.3 \%$ \\
\hline SB4VS-19 & $\mathrm{MnO}$ & 1.8430 & 1.8030 & 1.7960 & 0.0470 & 0.0070 & $2.6 \%$ & $0.4 \%$ \\
\hline SB4VS-19 & $\mathrm{Na}_{2} \mathrm{O}$ & 11.7380 & 10.9310 & 11.0170 & 0.7210 & -0.0860 & $6.5 \%$ & $-0.8 \%$ \\
\hline SB4VS-19 & $\mathrm{NiO}$ & 0.4610 & 0.5260 & 0.5720 & -0.1110 & -0.0460 & $-19.4 \%$ & $-8.0 \%$ \\
\hline
\end{tabular}


Table E4. Average Measured and Bias-Corrected Chemical Compositions Versus Targeted Compositions by Oxide by SB4 Variability Study Glass (continued)

(100 -Batch 1; 200 -U std; 300 - LRM)

\begin{tabular}{|c|c|c|c|c|c|c|c|c|}
\hline Glass ID & Oxide & $\begin{array}{c}\text { Measured } \\
(\mathbf{w t} \%)\end{array}$ & $\begin{array}{c}\text { Measured } \\
\text { Bias-Corrected } \\
(w \mathbf{w} \%) \\
\end{array}$ & $\begin{array}{c}\text { Targeted } \\
(\mathbf{w t} \%)\end{array}$ & $\begin{array}{c}\text { Diff of } \\
\text { Measured } \\
(w t \%) \\
\end{array}$ & $\begin{array}{c}\text { Diff. of } \\
\text { Meas BC } \\
(w t \%) \\
\end{array}$ & $\begin{array}{l}\text { \% Diff of } \\
\text { Measured }\end{array}$ & $\begin{array}{l}\% \text { Diff of } \\
\text { Meas BC }\end{array}$ \\
\hline SB4VS-19 & $\mathrm{PbO}$ & 0.0220 & 0.0220 & 0.0280 & -0.0060 & -0.0060 & $-21.4 \%$ & $-21.4 \%$ \\
\hline SB4VS-19 & $\mathrm{SiO}_{2}$ & 50.4340 & 50.4180 & 50.2390 & 0.1950 & 0.1790 & $0.4 \%$ & $0.4 \%$ \\
\hline SB4VS-19 & $\mathrm{SO}_{4}^{2-}$ & 0.4210 & 0.4210 & 0.4950 & -0.0740 & -0.0740 & $-14.9 \%$ & $-14.9 \%$ \\
\hline SB4VS-19 & $\mathrm{ThO}_{2}$ & 0.1060 & 0.1060 & 0.0200 & 0.0860 & 0.0860 & $430.0 \%$ & $430.0 \%$ \\
\hline SB4VS-19 & $\mathrm{TiO}_{2}$ & 0.0100 & 0.0110 & 0.0080 & 0.0020 & 0.0030 & $25.0 \%$ & $37.5 \%$ \\
\hline SB4VS-19 & $\mathrm{U}_{3} \mathrm{O}_{8}$ & 2.4590 & 2.6830 & 2.6320 & -0.1730 & 0.0510 & $-6.6 \%$ & $1.9 \%$ \\
\hline SB4VS-19 & $\mathrm{ZnO}$ & 0.0330 & 0.0330 & 0.0310 & 0.0020 & 0.0020 & $6.5 \%$ & $6.5 \%$ \\
\hline SB4VS-19 & $\mathrm{ZrO}_{2}$ & 0.0600 & 0.0600 & 0.0730 & -0.0130 & -0.0130 & $-17.8 \%$ & $-17.8 \%$ \\
\hline SB4VS-19 & Sum & 100.0050 & 99.5910 & 100.0040 & 0.0010 & -0.4130 & $0.0 \%$ & $-0.4 \%$ \\
\hline SB4VS-20 & $\mathrm{Al}_{2} \mathrm{O}_{3}$ & 7.8510 & 7.9160 & 7.5160 & 0.3350 & 0.4000 & $4.5 \%$ & $5.3 \%$ \\
\hline SB4VS-20 & $\mathrm{B}_{2} \mathrm{O}_{3}$ & 9.4260 & 9.3120 & 9.5200 & -0.0940 & -0.2080 & $-1.0 \%$ & $-2.2 \%$ \\
\hline SB4VS-20 & $\mathrm{BaO}$ & 0.0370 & 0.0420 & 0.0430 & -0.0060 & -0.0010 & $-14.0 \%$ & $-2.3 \%$ \\
\hline SB4VS-20 & $\mathrm{CaO}$ & 0.8030 & 0.8150 & 0.7970 & 0.0060 & 0.0180 & $0.8 \%$ & $2.3 \%$ \\
\hline SB4VS-20 & $\mathrm{Ce}_{2} \mathrm{O}_{3}$ & 0.0340 & 0.0340 & 0.0520 & -0.0180 & -0.0180 & $-34.6 \%$ & $-34.6 \%$ \\
\hline SB4VS-20 & $\mathrm{Cr}_{2} \mathrm{O}_{3}$ & 0.0670 & 0.0760 & 0.0730 & -0.0060 & 0.0030 & $-8.2 \%$ & $4.1 \%$ \\
\hline SB4VS-20 & $\mathrm{CuO}$ & 0.0220 & 0.0220 & 0.0210 & 0.0010 & 0.0010 & $4.8 \%$ & $4.8 \%$ \\
\hline SB4VS-20 & $\mathrm{Fe}_{2} \mathrm{O}_{3}$ & 7.8350 & 7.9170 & 8.7480 & -0.9130 & -0.8310 & $-10.4 \%$ & $-9.5 \%$ \\
\hline SB4VS-20 & $\mathrm{K}_{2} \mathrm{O}$ & 0.0910 & 0.0800 & 0.1150 & -0.0240 & -0.0350 & $-20.9 \%$ & $-30.4 \%$ \\
\hline SB4VS-20 & $\mathrm{La}_{2} \mathrm{O}_{3}$ & 0.0330 & 0.0330 & 0.0370 & -0.0040 & -0.0040 & $-10.8 \%$ & $-10.8 \%$ \\
\hline SB4VS-20 & $\mathrm{Li}_{2} \mathrm{O}$ & 5.4250 & 5.5070 & 5.4400 & -0.0150 & 0.0670 & $-0.3 \%$ & $1.2 \%$ \\
\hline SB4VS-20 & $\mathrm{MgO}$ & 0.6870 & 0.7650 & 0.7560 & -0.0690 & 0.0090 & $-9.1 \%$ & $1.2 \%$ \\
\hline SB4VS-20 & $\mathrm{MnO}$ & 1.6910 & 1.6890 & 1.6900 & 0.0010 & -0.0010 & $0.1 \%$ & $-0.1 \%$ \\
\hline SB4VS-20 & $\mathrm{Na}_{2} \mathrm{O}$ & 10.4370 & 9.7580 & 9.9390 & 0.4980 & -0.1810 & $5.0 \%$ & $-1.8 \%$ \\
\hline SB4VS-20 & $\mathrm{NiO}$ & 0.4290 & 0.4890 & 0.5380 & -0.1090 & -0.0490 & $-20.3 \%$ & $-9.1 \%$ \\
\hline SB4VS-20 & $\mathrm{PbO}$ & 0.0290 & 0.0290 & 0.0320 & -0.0030 & -0.0030 & $-9.4 \%$ & $-9.4 \%$ \\
\hline SB4VS-20 & $\mathrm{SiO}_{2}$ & 51.9850 & 51.9660 & 51.6370 & 0.3480 & 0.3290 & $0.7 \%$ & $0.6 \%$ \\
\hline SB4VS-20 & $\mathrm{SO}_{4}{ }^{2-}$ & 0.3340 & 0.3340 & 0.4260 & -0.0920 & -0.0920 & $-21.6 \%$ & $-21.6 \%$ \\
\hline SB4VS-20 & $\mathrm{ThO}_{2}$ & 0.0570 & 0.0570 & 0.0220 & 0.0350 & 0.0350 & $159.1 \%$ & $159.1 \%$ \\
\hline SB4VS-20 & $\mathrm{TiO}_{2}$ & 0.0130 & 0.0140 & 0.0090 & 0.0040 & 0.0050 & $44.4 \%$ & $55.6 \%$ \\
\hline SB4VS-20 & $\mathrm{U}_{3} \mathrm{O}_{8}$ & 2.3610 & 2.5770 & 2.4770 & -0.1160 & 0.1000 & $-4.7 \%$ & $4.0 \%$ \\
\hline SB4VS-20 & $\mathrm{ZnO}$ & 0.0320 & 0.0320 & 0.0340 & -0.0020 & -0.0020 & $-5.9 \%$ & $-5.9 \%$ \\
\hline SB4VS-20 & $\mathrm{ZrO}_{2}$ & 0.0630 & 0.0630 & 0.0810 & -0.0180 & -0.0180 & $-22.2 \%$ & $-22.2 \%$ \\
\hline SB4VS-20 & Sum & 99.7400 & 99.5260 & 100.0030 & -0.2630 & -0.4770 & $-0.3 \%$ & $-0.5 \%$ \\
\hline SB4VS-21 & $\mathrm{Al}_{2} \mathrm{O}_{3}$ & 8.2760 & 8.3440 & 7.9410 & 0.3350 & 0.4030 & $4.2 \%$ & $5.1 \%$ \\
\hline SB4VS-21 & $\mathrm{B}_{2} \mathrm{O}_{3}$ & 9.1200 & 9.0100 & 9.5200 & -0.4000 & -0.5100 & $-4.2 \%$ & $-5.4 \%$ \\
\hline SB4VS-21 & $\mathrm{BaO}$ & 0.0400 & 0.0430 & 0.0430 & -0.0030 & 0.0000 & $-7.0 \%$ & $0.0 \%$ \\
\hline SB4VS-21 & $\mathrm{CaO}$ & 0.8230 & 0.8230 & 0.7970 & 0.0260 & 0.0260 & $3.3 \%$ & $3.3 \%$ \\
\hline SB4VS-21 & $\mathrm{Ce}_{2} \mathrm{O}_{3}$ & 0.0320 & 0.0320 & 0.0520 & -0.0200 & -0.0200 & $-38.5 \%$ & $-38.5 \%$ \\
\hline SB4VS-21 & $\mathrm{Cr}_{2} \mathrm{O}_{3}$ & 0.0830 & 0.0890 & 0.0730 & 0.0100 & 0.0160 & $13.7 \%$ & $21.9 \%$ \\
\hline SB4VS-21 & $\mathrm{CuO}$ & 0.0190 & 0.0190 & 0.0210 & -0.0020 & -0.0020 & $-9.5 \%$ & $-9.5 \%$ \\
\hline SB4VS-21 & $\mathrm{Fe}_{2} \mathrm{O}_{3}$ & 7.0840 & 7.1590 & 8.0790 & -0.9950 & -0.9200 & $-12.3 \%$ & $-11.4 \%$ \\
\hline SB4VS-21 & $\mathrm{K}_{2} \mathrm{O}$ & 0.0910 & 0.0810 & 0.1150 & -0.0240 & -0.0340 & $-20.9 \%$ & $-29.6 \%$ \\
\hline SB4VS-21 & $\mathrm{La}_{2} \mathrm{O}_{3}$ & 0.0330 & 0.0330 & 0.0370 & -0.0040 & -0.0040 & $-10.8 \%$ & $-10.8 \%$ \\
\hline SB4VS-21 & $\mathrm{Li}_{2} \mathrm{O}$ & 5.3880 & 5.4690 & 5.4400 & -0.0520 & 0.0290 & $-1.0 \%$ & $0.5 \%$ \\
\hline SB4VS-21 & $\mathrm{MgO}$ & 0.8030 & 0.8420 & 0.8390 & -0.0360 & 0.0030 & $-4.3 \%$ & $0.4 \%$ \\
\hline SB4VS-21 & $\mathrm{MnO}$ & 1.7980 & 1.7590 & 1.7780 & 0.0200 & -0.0190 & $1.1 \%$ & $-1.1 \%$ \\
\hline SB4VS-21 & $\mathrm{Na}_{2} \mathrm{O}$ & 10.8480 & 10.1030 & 10.0530 & 0.7950 & 0.0500 & $7.9 \%$ & $0.5 \%$ \\
\hline SB4VS-21 & $\mathrm{NiO}$ & 0.3540 & 0.4040 & 0.4560 & -0.1020 & -0.0520 & $-22.4 \%$ & $-11.4 \%$ \\
\hline SB4VS-21 & $\mathrm{PbO}$ & 0.0290 & 0.0290 & 0.0320 & -0.0030 & -0.0030 & $-9.4 \%$ & $-9.4 \%$ \\
\hline SB4VS-21 & $\mathrm{SiO}_{2}$ & 51.3430 & 51.3240 & 51.6370 & -0.2940 & -0.3130 & $-0.6 \%$ & $-0.6 \%$ \\
\hline SB4VS-21 & $\mathrm{SO}_{4}^{2-}$ & 0.4020 & 0.4020 & 0.4660 & -0.0640 & -0.0640 & $-13.7 \%$ & $-13.7 \%$ \\
\hline SB4VS-21 & $\mathrm{ThO}_{2}$ & 0.0880 & 0.0880 & 0.0220 & 0.0660 & 0.0660 & $300.0 \%$ & $300.0 \%$ \\
\hline SB4VS-21 & $\mathrm{TiO}_{2}$ & 0.0080 & 0.0090 & 0.0090 & -0.0010 & 0.0000 & $-11.1 \%$ & $0.0 \%$ \\
\hline SB4VS-21 & $\mathrm{U}_{3} \mathrm{O}_{8}$ & 2.2850 & 2.4930 & 2.4770 & -0.1920 & 0.0160 & $-7.8 \%$ & $0.6 \%$ \\
\hline SB4VS-21 & $\mathrm{ZnO}$ & 0.0320 & 0.0320 & 0.0340 & -0.0020 & -0.0020 & $-5.9 \%$ & $-5.9 \%$ \\
\hline SB4VS-21 & $\mathrm{ZrO}_{2}$ & 0.0680 & 0.0680 & 0.0810 & -0.0130 & -0.0130 & $-16.0 \%$ & $-16.0 \%$ \\
\hline SB4VS-21 & Sum & 99.0490 & 98.6550 & 100.0020 & -0.9530 & -1.3470 & $-1.0 \%$ & $-1.3 \%$ \\
\hline SB4VS-22 & $\mathrm{Al}_{2} \mathrm{O}_{3}$ & 11.3510 & 11.4450 & 10.8200 & 0.5310 & 0.6250 & $4.9 \%$ & $5.8 \%$ \\
\hline SB4VS-22 & $\mathrm{B}_{2} \mathrm{O}_{3}$ & 8.1060 & 8.0070 & 8.1200 & -0.0140 & -0.1130 & $-0.2 \%$ & $-1.4 \%$ \\
\hline SB4VS-22 & $\mathrm{BaO}$ & 0.0540 & 0.0600 & 0.0610 & -0.0070 & -0.0010 & $-11.5 \%$ & $-1.6 \%$ \\
\hline SB4VS-22 & $\mathrm{CaO}$ & 0.8740 & 0.8670 & 0.8820 & -0.0080 & -0.0150 & $-0.9 \%$ & $-1.7 \%$ \\
\hline SB4VS-22 & $\mathrm{Ce}_{2} \mathrm{O}_{3}$ & 0.0490 & 0.0490 & 0.0740 & -0.0250 & -0.0250 & $-33.8 \%$ & $-33.8 \%$ \\
\hline SB4VS-22 & $\mathrm{Cr}_{2} \mathrm{O}_{3}$ & 0.0940 & 0.1030 & 0.1030 & -0.0090 & 0.0000 & $-8.7 \%$ & $0.0 \%$ \\
\hline SB4VS-22 & $\mathrm{CuO}$ & 0.0270 & 0.0270 & 0.0300 & -0.0030 & -0.0030 & $-10.0 \%$ & $-10.0 \%$ \\
\hline
\end{tabular}


Table E4. Average Measured and Bias-Corrected Chemical Compositions Versus Targeted Compositions by Oxide by SB4 Variability Study Glass (continued)

(100 -Batch 1; 200 -U std; 300 - LRM)

\begin{tabular}{|c|c|c|c|c|c|c|c|c|}
\hline Glass ID & Oxide & $\begin{array}{c}\text { Measured } \\
\text { (wt\%) }\end{array}$ & $\begin{array}{c}\text { Measured } \\
\text { Bias-Corrected } \\
(\mathbf{w t} \%)\end{array}$ & $\begin{array}{c}\text { Targeted } \\
(\mathbf{w t} \%)\end{array}$ & $\begin{array}{c}\text { Diff of } \\
\text { Measured } \\
(\mathbf{w t} \%)\end{array}$ & $\begin{array}{c}\text { Diff. of } \\
\text { Meas BC } \\
(w t \%)\end{array}$ & $\begin{array}{l}\text { \% Diff of } \\
\text { Measured }\end{array}$ & $\begin{array}{l}\text { \% Diff of } \\
\text { Meas BC }\end{array}$ \\
\hline SB4VS-22 & $\mathrm{Fe}_{2} \mathrm{O}_{3}$ & 9.5080 & 9.6070 & 10.1650 & -0.6570 & -0.5580 & $-6.5 \%$ & $-5.5 \%$ \\
\hline SB4VS-22 & $\mathrm{K}_{2} \mathrm{O}$ & 0.1650 & 0.1460 & 0.1630 & 0.0020 & -0.0170 & $1.2 \%$ & $-10.4 \%$ \\
\hline SB4VS-22 & $\mathrm{La}_{2} \mathrm{O}_{3}$ & 0.0450 & 0.0450 & 0.0520 & -0.0070 & -0.0070 & $-13.5 \%$ & $-13.5 \%$ \\
\hline SB4VS-22 & $\mathrm{Li}_{2} \mathrm{O}$ & 4.6290 & 4.6990 & 4.6400 & -0.0110 & 0.0590 & $-0.2 \%$ & $1.3 \%$ \\
\hline SB4VS-22 & $\mathrm{MgO}$ & 0.8810 & 0.9530 & 0.9370 & -0.0560 & 0.0160 & $-6.0 \%$ & $1.7 \%$ \\
\hline SB4VS-22 & $\mathrm{MnO}$ & 2.4270 & 2.4290 & 2.3910 & 0.0360 & 0.0380 & $1.5 \%$ & $1.6 \%$ \\
\hline SB4VS-22 & $\mathrm{Na}_{2} \mathrm{O}$ & 12.7050 & 12.0370 & 12.4590 & 0.2460 & -0.4220 & $2.0 \%$ & $-3.4 \%$ \\
\hline SB4VS-22 & $\mathrm{NiO}$ & 0.4260 & 0.4860 & 0.5440 & -0.1180 & -0.0580 & $-21.7 \%$ & $-10.7 \%$ \\
\hline SB4VS-22 & $\mathrm{PbO}$ & 0.0410 & 0.0410 & 0.0450 & -0.0040 & -0.0040 & $-8.9 \%$ & $-8.9 \%$ \\
\hline SB4VS-22 & $\mathrm{SiO}_{2}$ & 45.1390 & 45.1230 & 44.7040 & 0.4350 & 0.4190 & $1.0 \%$ & $0.9 \%$ \\
\hline SB4VS-22 & $\mathrm{SO}_{4}{ }^{2-}$ & 0.4460 & 0.4460 & 0.5330 & -0.0870 & -0.0870 & $-16.3 \%$ & $-16.3 \%$ \\
\hline SB4VS-22 & $\mathrm{ThO}_{2}$ & 0.1420 & 0.1420 & 0.0310 & 0.1110 & 0.1110 & $358.1 \%$ & $358.1 \%$ \\
\hline SB4VS-22 & $\mathrm{TiO}_{2}$ & 0.0170 & 0.0180 & 0.0130 & 0.0040 & 0.0050 & $30.8 \%$ & $38.5 \%$ \\
\hline SB4VS-22 & $\mathrm{U}_{3} \mathrm{O}_{8}$ & 2.9270 & 3.1940 & 3.0720 & -0.1450 & 0.1220 & $-4.7 \%$ & $4.0 \%$ \\
\hline SB4VS-22 & $\mathrm{ZnO}$ & 0.0450 & 0.0450 & 0.0480 & -0.0030 & -0.0030 & $-6.3 \%$ & $-6.3 \%$ \\
\hline SB4VS-22 & $\mathrm{ZrO}_{2}$ & 0.1080 & 0.1080 & 0.1150 & -0.0070 & -0.0070 & $-6.1 \%$ & $-6.1 \%$ \\
\hline SB4VS-22 & Sum & 100.2050 & 100.0750 & 100.0020 & 0.2030 & 0.0730 & $0.2 \%$ & $0.1 \%$ \\
\hline SB4VS-23 & $\mathrm{Al}_{2} \mathrm{O}_{3}$ & 9.6550 & 9.7230 & 9.2860 & 0.3690 & 0.4370 & $4.0 \%$ & $4.7 \%$ \\
\hline SB4VS-23 & $\mathrm{B}_{2} \mathrm{O}_{3}$ & 8.3560 & 8.2320 & 8.4000 & -0.0440 & -0.1680 & $-0.5 \%$ & $-2.0 \%$ \\
\hline SB4VS-23 & $\mathrm{BaO}$ & 0.0530 & 0.0570 & 0.0580 & -0.0050 & -0.0010 & $-8.6 \%$ & $-1.7 \%$ \\
\hline SB4VS-23 & $\mathrm{CaO}$ & 1.0360 & 1.0360 & 1.0480 & -0.0120 & -0.0120 & $-1.1 \%$ & $-1.1 \%$ \\
\hline SB4VS-23 & $\mathrm{Ce}_{2} \mathrm{O}_{3}$ & 0.0510 & 0.0510 & 0.0710 & -0.0200 & -0.0200 & $-28.2 \%$ & $-28.2 \%$ \\
\hline SB4VS-23 & $\mathrm{Cr}_{2} \mathrm{O}_{3}$ & 0.0990 & 0.1070 & 0.0980 & 0.0010 & 0.0090 & $1.0 \%$ & $9.2 \%$ \\
\hline SB4VS-23 & $\mathrm{CuO}$ & 0.0270 & 0.0270 & 0.0280 & -0.0010 & -0.0010 & $-3.6 \%$ & $-3.6 \%$ \\
\hline SB4VS-23 & $\mathrm{Fe}_{2} \mathrm{O}_{3}$ & 9.0820 & 9.1970 & 9.6810 & -0.5990 & -0.4840 & $-6.2 \%$ & $-5.0 \%$ \\
\hline SB4VS-23 & $\mathrm{K}_{2} \mathrm{O}$ & 0.1540 & 0.1370 & 0.1550 & -0.0010 & -0.0180 & $-0.6 \%$ & $-11.6 \%$ \\
\hline SB4VS-23 & $\mathrm{La}_{2} \mathrm{O}_{3}$ & 0.0440 & 0.0440 & 0.0500 & -0.0060 & -0.0060 & $-12.0 \%$ & $-12.0 \%$ \\
\hline SB4VS-23 & $\mathrm{Li}_{2} \mathrm{O}$ & 4.7470 & 4.8030 & 4.8000 & -0.0530 & 0.0030 & $-1.1 \%$ & $0.1 \%$ \\
\hline SB4VS-23 & $\mathrm{MgO}$ & 1.0800 & 1.1320 & 1.1010 & -0.0210 & 0.0310 & $-1.9 \%$ & $2.8 \%$ \\
\hline SB4VS-23 & $\mathrm{MnO}$ & 2.0820 & 2.0370 & 2.0580 & 0.0240 & -0.0210 & $1.2 \%$ & $-1.0 \%$ \\
\hline SB4VS-23 & $\mathrm{Na}_{2} \mathrm{O}$ & 13.4290 & 12.5070 & 12.6720 & 0.7570 & -0.1650 & $6.0 \%$ & $-1.3 \%$ \\
\hline SB4VS-23 & $\mathrm{NiO}$ & 0.5940 & 0.6850 & 0.7240 & -0.1300 & -0.0390 & $-18.0 \%$ & $-5.4 \%$ \\
\hline SB4VS-23 & $\mathrm{PbO}$ & 0.0400 & 0.0400 & 0.0430 & -0.0030 & -0.0030 & $-7.0 \%$ & $-7.0 \%$ \\
\hline SB4VS-23 & $\mathrm{SiO}_{2}$ & 46.3690 & 46.2540 & 46.0990 & 0.2700 & 0.1550 & $0.6 \%$ & $0.3 \%$ \\
\hline SB4VS-23 & $\mathrm{SO}_{4}{ }^{2-}$ & 0.4350 & 0.4350 & 0.5070 & -0.0720 & -0.0720 & $-14.2 \%$ & $-14.2 \%$ \\
\hline SB4VS-23 & $\mathrm{ThO}_{2}$ & 0.1430 & 0.1430 & 0.0300 & 0.1130 & 0.1130 & $376.7 \%$ & $376.7 \%$ \\
\hline SB4VS-23 & $\mathrm{TiO}_{2}$ & 0.0180 & 0.0190 & 0.0120 & 0.0060 & 0.0070 & $50.0 \%$ & $58.3 \%$ \\
\hline SB4VS-23 & $\mathrm{U}_{3} \mathrm{O}_{8}$ & 2.7360 & 2.9640 & 2.9250 & -0.1890 & 0.0390 & $-6.5 \%$ & $1.3 \%$ \\
\hline SB4VS-23 & $\mathrm{ZnO}$ & 0.0440 & 0.0440 & 0.0460 & -0.0020 & -0.0020 & $-4.3 \%$ & $-4.3 \%$ \\
\hline SB4VS-23 & $\mathrm{ZrO}_{2}$ & 0.1020 & 0.1020 & 0.1100 & -0.0080 & -0.0080 & $-7.3 \%$ & $-7.3 \%$ \\
\hline SB4VS-23 & Sum & 100.3780 & 99.7760 & 100.0020 & 0.3760 & -0.2260 & $0.4 \%$ & $-0.2 \%$ \\
\hline SB4VS-24 & $\mathrm{Al}_{2} \mathrm{O}_{3}$ & 9.1260 & 9.1720 & 8.7880 & 0.3380 & 0.3840 & $3.8 \%$ & $4.4 \%$ \\
\hline SB4VS-24 & $\mathrm{B}_{2} \mathrm{O}_{3}$ & 8.4280 & 8.2240 & 8.4000 & 0.0280 & -0.1760 & $0.3 \%$ & $-2.1 \%$ \\
\hline SB4VS-24 & $\mathrm{BaO}$ & 0.0340 & 0.0390 & 0.0410 & -0.0070 & -0.0020 & $-17.1 \%$ & $-4.9 \%$ \\
\hline SB4VS-24 & $\mathrm{CaO}$ & 1.0740 & 1.0690 & 1.0480 & 0.0260 & 0.0210 & $2.5 \%$ & $2.0 \%$ \\
\hline SB4VS-24 & $\mathrm{Ce}_{2} \mathrm{O}_{3}$ & 0.0370 & 0.0370 & 0.0500 & -0.0130 & -0.0130 & $-26.0 \%$ & $-26.0 \%$ \\
\hline SB4VS-24 & $\mathrm{Cr}_{2} \mathrm{O}_{3}$ & 0.0640 & 0.0720 & 0.0690 & -0.0050 & 0.0030 & $-7.2 \%$ & $4.3 \%$ \\
\hline SB4VS-24 & $\mathrm{CuO}$ & 0.0230 & 0.0230 & 0.0200 & 0.0030 & 0.0030 & $15.0 \%$ & $15.0 \%$ \\
\hline SB4VS-24 & $\mathrm{Fe}_{2} \mathrm{O}_{3}$ & 9.9190 & 10.0360 & 10.5710 & -0.6520 & -0.5350 & $-6.2 \%$ & $-5.1 \%$ \\
\hline SB4VS-24 & $\mathrm{K}_{2} \mathrm{O}$ & 0.0880 & 0.0780 & 0.1100 & -0.0220 & -0.0320 & $-20.0 \%$ & $-29.1 \%$ \\
\hline SB4VS-24 & $\mathrm{La}_{2} \mathrm{O}_{3}$ & 0.0260 & 0.0260 & 0.0350 & -0.0090 & -0.0090 & $-25.7 \%$ & $-25.7 \%$ \\
\hline SB4VS-24 & $\mathrm{Li}_{2} \mathrm{O}$ & 4.7530 & 4.7690 & 4.8000 & -0.0470 & -0.0310 & $-1.0 \%$ & $-0.6 \%$ \\
\hline SB4VS-24 & $\mathrm{MgO}$ & 0.7830 & 0.8650 & 0.8920 & -0.1090 & -0.0270 & $-12.2 \%$ & $-3.0 \%$ \\
\hline SB4VS-24 & $\mathrm{MnO}$ & 2.0430 & 2.0890 & 2.0580 & -0.0150 & 0.0310 & $-0.7 \%$ & $1.5 \%$ \\
\hline SB4VS-24 & $\mathrm{Na}_{2} \mathrm{O}$ & 13.1360 & 12.4980 & 12.6720 & 0.4640 & -0.1740 & $3.7 \%$ & $-1.4 \%$ \\
\hline SB4VS-24 & $\mathrm{NiO}$ & 0.4020 & 0.4550 & 0.5180 & -0.1160 & -0.0630 & $-22.4 \%$ & $-12.2 \%$ \\
\hline SB4VS-24 & $\mathrm{PbO}$ & 0.0250 & 0.0250 & 0.0300 & -0.0050 & -0.0050 & $-16.7 \%$ & $-16.7 \%$ \\
\hline SB4VS-24 & $\mathrm{SiO}_{2}$ & 46.1020 & 45.6000 & 46.0990 & 0.0030 & -0.4990 & $0.0 \%$ & $-1.1 \%$ \\
\hline SB4VS-24 & $\mathrm{SO}_{4}{ }^{2-}$ & 0.4010 & 0.4010 & 0.5070 & -0.1060 & -0.1060 & $-20.9 \%$ & $-20.9 \%$ \\
\hline SB4VS-24 & $\mathrm{ThO}_{2}$ & 0.1350 & 0.1350 & 0.0210 & 0.1140 & 0.1140 & $542.9 \%$ & $542.9 \%$ \\
\hline SB4VS-24 & $\mathrm{TiO}_{2}$ & 0.0080 & 0.0090 & 0.0090 & -0.0010 & 0.0000 & $-11.1 \%$ & $0.0 \%$ \\
\hline SB4VS-24 & $\mathrm{U}_{3} \mathrm{O}_{8}$ & 2.9830 & 3.2470 & 3.1530 & -0.1700 & 0.0940 & $-5.4 \%$ & $3.0 \%$ \\
\hline SB4VS-24 & $\mathrm{ZnO}$ & 0.0290 & 0.0290 & 0.0330 & -0.0040 & -0.0040 & $-12.1 \%$ & $-12.1 \%$ \\
\hline SB4VS-24 & $\mathrm{ZrO}_{2}$ & 0.0680 & 0.0680 & 0.0770 & -0.0090 & -0.0090 & $-11.7 \%$ & $-11.7 \%$ \\
\hline
\end{tabular}


Table E4. Average Measured and Bias-Corrected Chemical Compositions Versus Targeted Compositions by Oxide by SB4 Variability Study Glass (continued)

(100 -Batch 1; 200 -U std; 300 - LRM)

\begin{tabular}{|c|c|c|c|c|c|c|c|c|}
\hline Glass ID & Oxide & $\begin{array}{c}\text { Measured } \\
(w t \%)\end{array}$ & $\begin{array}{c}\text { Measured } \\
\text { Bias-Corrected } \\
(w \mathbf{w} \%) \\
\end{array}$ & $\begin{array}{c}\text { Targeted } \\
(\mathbf{w t} \%)\end{array}$ & $\begin{array}{c}\text { Diff of } \\
\text { Measured } \\
(w t \%) \\
\end{array}$ & $\begin{array}{c}\text { Diff. of } \\
\text { Meas BC } \\
(w t \%) \\
\end{array}$ & $\begin{array}{l}\text { \% Diff of } \\
\text { Measured }\end{array}$ & $\begin{array}{l}\% \text { Diff of } \\
\text { Meas BC }\end{array}$ \\
\hline SB4VS-24 & Sum & 99.6860 & 98.9650 & 100.0010 & -0.3150 & -1.0360 & $-0.3 \%$ & $-1.0 \%$ \\
\hline SB4VS-25 & $\mathrm{Al}_{2} \mathrm{O}_{3}$ & 9.1070 & 9.1530 & 8.6960 & 0.4110 & 0.4570 & $4.7 \%$ & $5.3 \%$ \\
\hline SB4VS-25 & $\mathrm{B}_{2} \mathrm{O}_{3}$ & 8.7100 & 8.4990 & 8.6800 & 0.0300 & -0.1810 & $0.3 \%$ & $-2.1 \%$ \\
\hline SB4VS-25 & $\mathrm{BaO}$ & 0.0350 & 0.0390 & 0.0390 & -0.0040 & 0.0000 & $-10.3 \%$ & $0.0 \%$ \\
\hline SB4VS-25 & $\mathrm{CaO}$ & 0.8060 & 0.7990 & 0.7980 & 0.0080 & 0.0010 & $1.0 \%$ & $0.1 \%$ \\
\hline SB4VS-25 & $\mathrm{Ce}_{2} \mathrm{O}_{3}$ & 0.0200 & 0.0200 & 0.0470 & -0.0270 & -0.0270 & $-57.4 \%$ & $-57.4 \%$ \\
\hline SB4VS-25 & $\mathrm{Cr}_{2} \mathrm{O}_{3}$ & 0.0740 & 0.0810 & 0.0660 & 0.0080 & 0.0150 & $12.1 \%$ & $22.7 \%$ \\
\hline SB4VS-25 & $\mathrm{CuO}$ & 0.0190 & 0.0190 & 0.0190 & 0.0000 & 0.0000 & $0.0 \%$ & $0.0 \%$ \\
\hline SB4VS-25 & $\mathrm{Fe}_{2} \mathrm{O}_{3}$ & 8.5140 & 8.6140 & 9.1970 & -0.6830 & -0.5830 & $-7.4 \%$ & $-6.3 \%$ \\
\hline SB4VS-25 & $\mathrm{K}_{2} \mathrm{O}$ & 0.0600 & 0.0530 & 0.1040 & -0.0440 & -0.0510 & $-42.3 \%$ & $-49.0 \%$ \\
\hline SB4VS-25 & $\mathrm{La}_{2} \mathrm{O}_{3}$ & 0.0280 & 0.0280 & 0.0340 & -0.0060 & -0.0060 & $-17.6 \%$ & $-17.6 \%$ \\
\hline SB4VS-25 & $\mathrm{Li}_{2} \mathrm{O}$ & 4.9570 & 4.9740 & 4.9600 & -0.0030 & 0.0140 & $-0.1 \%$ & $0.3 \%$ \\
\hline SB4VS-25 & $\mathrm{MgO}$ & 0.9850 & 1.0660 & 1.0460 & -0.0610 & 0.0200 & $-5.8 \%$ & $1.9 \%$ \\
\hline SB4VS-25 & $\mathrm{MnO}$ & 2.1690 & 2.1690 & 2.1630 & 0.0060 & 0.0060 & $0.3 \%$ & $0.3 \%$ \\
\hline SB4VS-25 & $\mathrm{Na}_{2} \mathrm{O}$ & 12.6410 & 11.9730 & 12.2380 & 0.4030 & -0.2650 & $3.3 \%$ & $-2.2 \%$ \\
\hline SB4VS-25 & $\mathrm{NiO}$ & 0.5710 & 0.6450 & 0.6870 & -0.1160 & -0.0420 & $-16.9 \%$ & $-6.1 \%$ \\
\hline SB4VS-25 & $\mathrm{PbO}$ & 0.0260 & 0.0260 & 0.0290 & -0.0030 & -0.0030 & $-10.3 \%$ & $-10.3 \%$ \\
\hline SB4VS-25 & $\mathrm{SiO}_{2}$ & 48.1340 & 47.6110 & 47.4940 & 0.6400 & 0.1170 & $1.3 \%$ & $0.2 \%$ \\
\hline SB4VS-25 & $\mathrm{SO}_{4}{ }^{2-}$ & 0.4740 & 0.4740 & 0.5770 & -0.1030 & -0.1030 & $-17.9 \%$ & $-17.9 \%$ \\
\hline SB4VS-25 & $\mathrm{ThO}_{2}$ & 0.1290 & 0.1290 & 0.0200 & 0.1090 & 0.1090 & $545.0 \%$ & $545.0 \%$ \\
\hline SB4VS-25 & $\mathrm{TiO}_{2}$ & 0.0170 & 0.0180 & 0.0080 & 0.0090 & 0.0100 & $112.5 \%$ & $125.0 \%$ \\
\hline SB4VS-25 & $\mathrm{U}_{3} \mathrm{O}_{8}$ & 2.8740 & 3.1280 & 2.9950 & -0.1210 & 0.1330 & $-4.0 \%$ & $4.4 \%$ \\
\hline SB4VS-25 & $\mathrm{ZnO}$ & 0.0300 & 0.0300 & 0.0310 & -0.0010 & -0.0010 & $-3.2 \%$ & $-3.2 \%$ \\
\hline SB4VS-25 & $\mathrm{ZrO}_{2}$ & 0.0660 & 0.0660 & 0.0740 & -0.0080 & -0.0080 & $-10.8 \%$ & $-10.8 \%$ \\
\hline SB4VS-25 & Sum & 100.4460 & 99.6140 & 100.0020 & 0.4440 & -0.3880 & $0.4 \%$ & $-0.4 \%$ \\
\hline SB4VS-26 & $\mathrm{Al}_{2} \mathrm{O}_{3}$ & 8.7530 & 8.8140 & 8.3480 & 0.4050 & 0.4660 & $4.9 \%$ & $5.6 \%$ \\
\hline SB4VS-26 & $\mathrm{B}_{2} \mathrm{O}_{3}$ & 8.7580 & 8.6290 & 8.6800 & 0.0780 & -0.0510 & $0.9 \%$ & $-0.6 \%$ \\
\hline SB4VS-26 & $\mathrm{BaO}$ & 0.0510 & 0.0580 & 0.0550 & -0.0040 & 0.0030 & $-7.3 \%$ & $5.5 \%$ \\
\hline SB4VS-26 & $\mathrm{CaO}$ & 0.9670 & 0.9810 & 0.9960 & -0.0290 & -0.0150 & $-2.9 \%$ & $-1.5 \%$ \\
\hline SB4VS-26 & $\mathrm{Ce}_{2} \mathrm{O}_{3}$ & 0.0570 & 0.0570 & 0.0670 & -0.0100 & -0.0100 & $-14.9 \%$ & $-14.9 \%$ \\
\hline SB4VS-26 & $\mathrm{Cr}_{2} \mathrm{O}_{3}$ & 0.0920 & 0.1050 & 0.0930 & -0.0010 & 0.0120 & $-1.1 \%$ & $12.9 \%$ \\
\hline SB4VS-26 & $\mathrm{CuO}$ & 0.0280 & 0.0290 & 0.0270 & 0.0010 & 0.0020 & $3.7 \%$ & $7.4 \%$ \\
\hline SB4VS-26 & $\mathrm{Fe}_{2} \mathrm{O}_{3}$ & 9.0210 & 9.1350 & 9.6440 & -0.6230 & -0.5090 & $-6.5 \%$ & $-5.3 \%$ \\
\hline SB4VS-26 & $\mathrm{K}_{2} \mathrm{O}$ & 0.1430 & 0.1260 & 0.1470 & -0.0040 & -0.0210 & $-2.7 \%$ & $-14.3 \%$ \\
\hline SB4VS-26 & $\mathrm{La}_{2} \mathrm{O}_{3}$ & 0.0350 & 0.0350 & 0.0470 & -0.0120 & -0.0120 & $-25.5 \%$ & $-25.5 \%$ \\
\hline SB4VS-26 & $\mathrm{Li}_{2} \mathrm{O}$ & 4.9730 & 5.0320 & 4.9600 & 0.0130 & 0.0720 & $0.3 \%$ & $1.5 \%$ \\
\hline SB4VS-26 & $\mathrm{MgO}$ & 0.9170 & 1.0230 & 1.0460 & -0.1290 & -0.0230 & $-12.3 \%$ & $-2.2 \%$ \\
\hline SB4VS-26 & $\mathrm{MnO}$ & 2.1340 & 2.1310 & 2.1630 & -0.0290 & -0.0320 & $-1.3 \%$ & $-1.5 \%$ \\
\hline SB4VS-26 & $\mathrm{Na}_{2} \mathrm{O}$ & 11.7850 & 11.0190 & 12.2380 & -0.4530 & -1.2190 & $-3.7 \%$ & $-10.0 \%$ \\
\hline SB4VS-26 & $\mathrm{NiO}$ & 0.3890 & 0.4480 & 0.4920 & -0.1030 & -0.0440 & $-20.9 \%$ & $-8.9 \%$ \\
\hline SB4VS-26 & $\mathrm{PbO}$ & 0.0380 & 0.0380 & 0.0410 & -0.0030 & -0.0030 & $-7.3 \%$ & $-7.3 \%$ \\
\hline SB4VS-26 & $\mathrm{SiO}_{2}$ & 48.4020 & 48.2820 & 47.2910 & 1.1110 & 0.9910 & $2.3 \%$ & $2.1 \%$ \\
\hline SB4VS-26 & $\mathrm{SO}_{4}{ }^{2-}$ & 0.3890 & 0.3890 & 0.4820 & -0.0930 & -0.0930 & $-19.3 \%$ & $-19.3 \%$ \\
\hline SB4VS-26 & $\mathrm{ThO}_{2}$ & 0.1330 & 0.1330 & 0.0280 & 0.1050 & 0.1050 & $375.0 \%$ & $375.0 \%$ \\
\hline SB4VS-26 & $\mathrm{TiO}_{2}$ & 0.0160 & 0.0170 & 0.0120 & 0.0040 & 0.0050 & $33.3 \%$ & $41.7 \%$ \\
\hline SB4VS-26 & $\mathrm{U}_{3} \mathrm{O}_{8}$ & 2.8920 & 3.1340 & 2.9950 & -0.1030 & 0.1390 & $-3.4 \%$ & $4.6 \%$ \\
\hline SB4VS-26 & $\mathrm{ZnO}$ & 0.0370 & 0.0370 & 0.0440 & -0.0070 & -0.0070 & $-15.9 \%$ & $-15.9 \%$ \\
\hline SB4VS-26 & $\mathrm{ZrO}_{2}$ & 0.0930 & 0.0930 & 0.1040 & -0.0110 & -0.0110 & $-10.6 \%$ & $-10.6 \%$ \\
\hline SB4VS-26 & Sum & 100.1030 & 99.7420 & 100.0000 & 0.1030 & -0.2580 & $0.1 \%$ & $-0.3 \%$ \\
\hline SB4VS-27 & $\mathrm{Al}_{2} \mathrm{O}_{3}$ & 9.1780 & 9.2240 & 8.8210 & 0.3570 & 0.4030 & $4.0 \%$ & $4.6 \%$ \\
\hline SB4VS-27 & $\mathrm{B}_{2} \mathrm{O}_{3}$ & 8.8790 & 8.6650 & 8.9600 & -0.0810 & -0.2950 & $-0.9 \%$ & $-3.3 \%$ \\
\hline SB4VS-27 & $\mathrm{BaO}$ & 0.0320 & 0.0360 & 0.0370 & -0.0050 & -0.0010 & $-13.5 \%$ & $-2.7 \%$ \\
\hline SB4VS-27 & $\mathrm{CaO}$ & 0.9490 & 0.9630 & 0.9440 & 0.0050 & 0.0190 & $0.5 \%$ & $2.0 \%$ \\
\hline SB4VS-27 & $\mathrm{Ce}_{2} \mathrm{O}_{3}$ & 0.0300 & 0.0300 & 0.0450 & -0.0150 & -0.0150 & $-33.3 \%$ & $-33.3 \%$ \\
\hline SB4VS-27 & $\mathrm{Cr}_{2} \mathrm{O}_{3}$ & 0.0650 & 0.0750 & 0.0620 & 0.0030 & 0.0130 & $4.8 \%$ & $21.0 \%$ \\
\hline SB4VS-27 & $\mathrm{CuO}$ & 0.0200 & 0.0200 & 0.0180 & 0.0020 & 0.0020 & $11.1 \%$ & $11.1 \%$ \\
\hline SB4VS-27 & $\mathrm{Fe}_{2} \mathrm{O}_{3}$ & 8.0670 & 8.1630 & 8.7130 & -0.6460 & -0.5500 & $-7.4 \%$ & $-6.3 \%$ \\
\hline SB4VS-27 & $\mathrm{K}_{2} \mathrm{O}$ & 0.0600 & 0.0530 & 0.0990 & -0.0390 & -0.0460 & $-39.4 \%$ & $-46.5 \%$ \\
\hline SB4VS-27 & $\mathrm{La}_{2} \mathrm{O}_{3}$ & 0.0250 & 0.0250 & 0.0320 & -0.0070 & -0.0070 & $-21.9 \%$ & $-21.9 \%$ \\
\hline SB4VS-27 & $\mathrm{Li}_{2} \mathrm{O}$ & 5.0160 & 5.0340 & 5.1200 & -0.1040 & -0.0860 & $-2.0 \%$ & $-1.7 \%$ \\
\hline SB4VS-27 & $\mathrm{MgO}$ & 0.7060 & 0.7870 & 0.8030 & -0.0970 & -0.0160 & $-12.1 \%$ & $-2.0 \%$ \\
\hline SB4VS-27 & $\mathrm{MnO}$ & 2.0240 & 2.0210 & 2.0490 & -0.0250 & -0.0280 & $-1.2 \%$ & $-1.4 \%$ \\
\hline SB4VS-27 & $\mathrm{Na}_{2} \mathrm{O}$ & 12.1050 & 11.3180 & 11.8040 & 0.3010 & -0.4860 & $2.5 \%$ & $-4.1 \%$ \\
\hline SB4VS-27 & $\mathrm{NiO}$ & 0.3520 & 0.3970 & 0.4660 & -0.1140 & -0.0690 & $-24.5 \%$ & $-14.8 \%$ \\
\hline
\end{tabular}


Table E4. Average Measured and Bias-Corrected Chemical Compositions Versus Targeted Compositions by Oxide by SB4 Variability Study Glass (continued)

(100 -Batch 1; 200 -U std; 300 - LRM)

\begin{tabular}{|c|c|c|c|c|c|c|c|c|}
\hline Glass ID & Oxide & $\begin{array}{c}\text { Measured } \\
(w t \%)\end{array}$ & $\begin{array}{c}\text { Measured } \\
\text { Bias-Corrected } \\
(\mathbf{w t} \%)\end{array}$ & $\begin{array}{c}\text { Targeted } \\
(\mathbf{w t} \%)\end{array}$ & $\begin{array}{c}\text { Diff of } \\
\text { Measured } \\
(\mathbf{w t} \%)\end{array}$ & $\begin{array}{c}\text { Diff. of } \\
\text { Meas BC } \\
(w t \%)\end{array}$ & $\begin{array}{l}\text { \% Diff of } \\
\text { Measured }\end{array}$ & $\begin{array}{l}\text { \% Diff of } \\
\text { Meas BC }\end{array}$ \\
\hline SB4VS-27 & $\mathrm{PbO}$ & 0.0260 & 0.0260 & 0.0270 & -0.0010 & -0.0010 & $-3.7 \%$ & $-3.7 \%$ \\
\hline SB4VS-27 & $\mathrm{SiO}_{2}$ & 48.6160 & 48.0860 & 48.6970 & -0.0810 & -0.6110 & $-0.2 \%$ & $-1.3 \%$ \\
\hline SB4VS-27 & $\mathrm{SO}_{4}{ }^{2-}$ & 0.4430 & 0.4430 & 0.5460 & -0.1030 & -0.1030 & $-18.9 \%$ & $-18.9 \%$ \\
\hline SB4VS-27 & $\mathrm{ThO}_{2}$ & 0.0570 & 0.0570 & 0.0190 & 0.0380 & 0.0380 & $200.0 \%$ & $200.0 \%$ \\
\hline SB4VS-27 & $\mathrm{TiO}_{2}$ & 0.0080 & 0.0090 & 0.0080 & 0.0000 & 0.0010 & $0.0 \%$ & $12.5 \%$ \\
\hline SB4VS-27 & $\mathrm{U}_{3} \mathrm{O}_{8}$ & 2.4290 & 2.6440 & 2.6330 & -0.2040 & 0.0110 & $-7.7 \%$ & $0.4 \%$ \\
\hline SB4VS-27 & $\mathrm{ZnO}$ & 0.0290 & 0.0290 & 0.0290 & 0.0000 & 0.0000 & $0.0 \%$ & $0.0 \%$ \\
\hline SB4VS-27 & $\mathrm{ZrO}_{2}$ & 0.0630 & 0.0630 & 0.0700 & -0.0070 & -0.0070 & $-10.0 \%$ & $-10.0 \%$ \\
\hline SB4VS-27 & Sum & 99.1790 & 98.1660 & 100.0020 & -0.8230 & -1.8360 & $-0.8 \%$ & $-1.8 \%$ \\
\hline SB4VS-28 & $\mathrm{Al}_{2} \mathrm{O}_{3}$ & 8.2850 & 8.3270 & 7.9090 & 0.3760 & 0.4180 & $4.8 \%$ & $5.3 \%$ \\
\hline SB4VS-28 & $\mathrm{B}_{2} \mathrm{O}_{3}$ & 8.9590 & 8.7430 & 8.9600 & -0.0010 & -0.2170 & $0.0 \%$ & $-2.4 \%$ \\
\hline SB4VS-28 & $\mathrm{BaO}$ & 0.0440 & 0.0500 & 0.0530 & -0.0090 & -0.0030 & $-17.0 \%$ & $-5.7 \%$ \\
\hline SB4VS-28 & $\mathrm{CaO}$ & 0.8010 & 0.7970 & 0.7560 & 0.0450 & 0.0410 & $6.0 \%$ & $5.4 \%$ \\
\hline SB4VS-28 & $\mathrm{Ce}_{2} \mathrm{O}_{3}$ & 0.0440 & 0.0440 & 0.0640 & -0.0200 & -0.0200 & $-31.3 \%$ & $-31.3 \%$ \\
\hline SB4VS-28 & $\mathrm{Cr}_{2} \mathrm{O}_{3}$ & 0.0730 & 0.0830 & 0.0880 & -0.0150 & -0.0050 & $-17.0 \%$ & $-5.7 \%$ \\
\hline SB4VS-28 & $\mathrm{CuO}$ & 0.0270 & 0.0270 & 0.0250 & 0.0020 & 0.0020 & $8.0 \%$ & $8.0 \%$ \\
\hline SB4VS-28 & $\mathrm{Fe}_{2} \mathrm{O}_{3}$ & 9.1320 & 9.2400 & 10.2170 & -1.0850 & -0.9770 & $-10.6 \%$ & $-9.6 \%$ \\
\hline SB4VS-28 & $\mathrm{K}_{2} \mathrm{O}$ & 0.1510 & 0.1340 & 0.1400 & 0.0110 & -0.0060 & $7.9 \%$ & $-4.3 \%$ \\
\hline SB4VS-28 & $\mathrm{La}_{2} \mathrm{O}_{3}$ & 0.0360 & 0.0360 & 0.0450 & -0.0090 & -0.0090 & $-20.0 \%$ & $-20.0 \%$ \\
\hline SB4VS-28 & $\mathrm{Li}_{2} \mathrm{O}$ & 5.1350 & 5.1530 & 5.1200 & 0.0150 & 0.0330 & $0.3 \%$ & $0.6 \%$ \\
\hline SB4VS-28 & $\mathrm{MgO}$ & 0.9020 & 0.9970 & 0.9910 & -0.0890 & 0.0060 & $-9.0 \%$ & $0.6 \%$ \\
\hline SB4VS-28 & $\mathrm{MnO}$ & 1.9430 & 1.9860 & 1.8520 & 0.0910 & 0.1340 & $4.9 \%$ & $7.2 \%$ \\
\hline SB4VS-28 & $\mathrm{Na}_{2} \mathrm{O}$ & 11.4070 & 10.8580 & 11.0310 & 0.3760 & -0.1730 & $3.4 \%$ & $-1.6 \%$ \\
\hline SB4VS-28 & $\mathrm{NiO}$ & 0.3590 & 0.4060 & 0.4660 & -0.1070 & -0.0600 & $-23.0 \%$ & $-12.9 \%$ \\
\hline SB4VS-28 & $\mathrm{PbO}$ & 0.0390 & 0.0390 & 0.0380 & 0.0010 & 0.0010 & $2.6 \%$ & $2.6 \%$ \\
\hline SB4VS-28 & $\mathrm{SiO}_{2}$ & 49.3110 & 48.7710 & 48.8890 & 0.4220 & -0.1180 & $0.9 \%$ & $-0.2 \%$ \\
\hline SB4VS-28 & $\mathrm{SO}_{4}{ }^{2-}$ & 0.4250 & 0.4250 & 0.5460 & -0.1210 & -0.1210 & $-22.2 \%$ & $-22.2 \%$ \\
\hline SB4VS-28 & $\mathrm{ThO}_{2}$ & 0.1230 & 0.1230 & 0.0270 & 0.0960 & 0.0960 & $355.6 \%$ & $355.6 \%$ \\
\hline SB4VS-28 & $\mathrm{TiO}_{2}$ & 0.0130 & 0.0130 & 0.0110 & 0.0020 & 0.0020 & $18.2 \%$ & $18.2 \%$ \\
\hline SB4VS-28 & $\mathrm{U}_{3} \mathrm{O}_{8}$ & 2.4410 & 2.6560 & 2.6330 & -0.1920 & 0.0230 & $-7.3 \%$ & $0.9 \%$ \\
\hline SB4VS-28 & $\mathrm{ZnO}$ & 0.0360 & 0.0360 & 0.0410 & -0.0050 & -0.0050 & $-12.2 \%$ & $-12.2 \%$ \\
\hline SB4VS-28 & $\mathrm{ZrO}_{2}$ & 0.0920 & 0.0920 & 0.0990 & -0.0070 & -0.0070 & $-7.1 \%$ & $-7.1 \%$ \\
\hline SB4VS-28 & Sum & 99.7770 & 99.0350 & 100.0010 & -0.2240 & -0.9660 & $-0.2 \%$ & $-1.0 \%$ \\
\hline SB4VS-29 & $\mathrm{Al}_{2} \mathrm{O}_{3}$ & 8.3990 & 8.4580 & 8.1510 & 0.2480 & 0.3070 & $3.0 \%$ & $3.8 \%$ \\
\hline SB4VS-29 & $\mathrm{B}_{2} \mathrm{O}_{3}$ & 9.0240 & 8.8900 & 9.2400 & -0.2160 & -0.3500 & $-2.3 \%$ & $-3.8 \%$ \\
\hline SB4VS-29 & $\mathrm{BaO}$ & 0.0420 & 0.0470 & 0.0500 & -0.0080 & -0.0030 & $-16.0 \%$ & $-6.0 \%$ \\
\hline SB4VS-29 & $\mathrm{CaO}$ & 0.7370 & 0.7310 & 0.7140 & 0.0230 & 0.0170 & $3.2 \%$ & $2.4 \%$ \\
\hline SB4VS-29 & $\mathrm{Ce}_{2} \mathrm{O}_{3}$ & 0.0460 & 0.0460 & 0.0600 & -0.0140 & -0.0140 & $-23.3 \%$ & $-23.3 \%$ \\
\hline SB4VS-29 & $\mathrm{Cr}_{2} \mathrm{O}_{3}$ & 0.0750 & 0.0820 & 0.0830 & -0.0080 & -0.0010 & $-9.6 \%$ & $-1.2 \%$ \\
\hline SB4VS-29 & $\mathrm{CuO}$ & 0.0230 & 0.0240 & 0.0240 & -0.0010 & 0.0000 & $-4.2 \%$ & $0.0 \%$ \\
\hline SB4VS-29 & $\mathrm{Fe}_{2} \mathrm{O}_{3}$ & 7.6270 & 7.7240 & 8.2290 & -0.6020 & -0.5050 & $-7.3 \%$ & $-6.1 \%$ \\
\hline SB4VS-29 & $\mathrm{K}_{2} \mathrm{O}$ & 0.1410 & 0.1250 & 0.1320 & 0.0090 & -0.0070 & $6.8 \%$ & $-5.3 \%$ \\
\hline SB4VS-29 & $\mathrm{La}_{2} \mathrm{O}_{3}$ & 0.0370 & 0.0370 & 0.0420 & -0.0050 & -0.0050 & $-11.9 \%$ & $-11.9 \%$ \\
\hline SB4VS-29 & $\mathrm{Li}_{2} \mathrm{O}$ & 5.1400 & 5.2010 & 5.2800 & -0.1400 & -0.0790 & $-2.7 \%$ & $-1.5 \%$ \\
\hline SB4VS-29 & $\mathrm{MgO}$ & 0.6960 & 0.7540 & 0.7580 & -0.0620 & -0.0040 & $-8.2 \%$ & $-0.5 \%$ \\
\hline SB4VS-29 & $\mathrm{MnO}$ & 1.7300 & 1.7310 & 1.7490 & -0.0190 & -0.0180 & $-1.1 \%$ & $-1.0 \%$ \\
\hline SB4VS-29 & $\mathrm{Na}_{2} \mathrm{O}$ & 11.7680 & 11.1510 & 11.3710 & 0.3970 & -0.2200 & $3.5 \%$ & $-1.9 \%$ \\
\hline SB4VS-29 & $\mathrm{NiO}$ & 0.4900 & 0.5640 & 0.6150 & -0.1250 & -0.0510 & $-20.3 \%$ & $-8.3 \%$ \\
\hline SB4VS-29 & $\mathrm{PbO}$ & 0.0360 & 0.0360 & 0.0360 & 0.0000 & 0.0000 & $0.0 \%$ & $0.0 \%$ \\
\hline SB4VS-29 & $\mathrm{SiO}_{2}$ & 49.3640 & 49.2420 & 50.1020 & -0.7380 & -0.8600 & $-1.5 \%$ & $-1.7 \%$ \\
\hline SB4VS-29 & $\mathrm{SO}_{4}{ }^{2-}$ & 0.4130 & 0.4130 & 0.5160 & -0.1030 & -0.1030 & $-20.0 \%$ & $-20.0 \%$ \\
\hline SB4VS-29 & $\mathrm{ThO}_{2}$ & 0.1160 & 0.1160 & 0.0250 & 0.0910 & 0.0910 & $364.0 \%$ & $364.0 \%$ \\
\hline SB4VS-29 & $\mathrm{TiO}_{2}$ & 0.0170 & 0.0180 & 0.0110 & 0.0060 & 0.0070 & $54.5 \%$ & $63.6 \%$ \\
\hline SB4VS-29 & $\mathrm{U}_{3} \mathrm{O}_{8}$ & 2.5150 & 2.7250 & 2.6800 & -0.1650 & 0.0450 & $-6.2 \%$ & $1.7 \%$ \\
\hline SB4VS-29 & $\mathrm{ZnO}$ & 0.0370 & 0.0370 & 0.0390 & -0.0020 & -0.0020 & $-5.1 \%$ & $-5.1 \%$ \\
\hline SB4VS-29 & $\mathrm{ZrO}_{2}$ & 0.0760 & 0.0760 & 0.0930 & -0.0170 & -0.0170 & $-18.3 \%$ & $-18.3 \%$ \\
\hline SB4VS-29 & Sum & 98.5490 & 98.2250 & 100.0000 & -1.4510 & -1.7750 & $-1.5 \%$ & $-1.8 \%$ \\
\hline SB4VS-30 & $\mathrm{Al}_{2} \mathrm{O}_{3}$ & 7.6010 & 7.5790 & 7.4700 & 0.1310 & 0.1090 & $1.8 \%$ & $1.5 \%$ \\
\hline SB4VS-30 & $\mathrm{B}_{2} \mathrm{O}_{3}$ & 9.1360 & 8.6930 & 9.2400 & -0.1040 & -0.5470 & $-1.1 \%$ & $-5.9 \%$ \\
\hline SB4VS-30 & $\mathrm{BaO}$ & 0.0290 & 0.0330 & 0.0350 & -0.0060 & -0.0020 & $-17.1 \%$ & $-5.7 \%$ \\
\hline SB4VS-30 & $\mathrm{CaO}$ & 0.7420 & 0.7390 & 0.7140 & 0.0280 & 0.0250 & $3.9 \%$ & $3.5 \%$ \\
\hline SB4VS-30 & $\mathrm{Ce}_{2} \mathrm{O}_{3}$ & 0.0320 & 0.0320 & 0.0420 & -0.0100 & -0.0100 & $-23.8 \%$ & $-23.8 \%$ \\
\hline SB4VS-30 & $\mathrm{Cr}_{2} \mathrm{O}_{3}$ & 0.0540 & 0.0620 & 0.0590 & -0.0050 & 0.0030 & $-8.5 \%$ & $5.1 \%$ \\
\hline SB4VS-30 & $\mathrm{CuO}$ & 0.0190 & 0.0190 & 0.0170 & 0.0020 & 0.0020 & $11.8 \%$ & $11.8 \%$ \\
\hline
\end{tabular}


Table E4. Average Measured and Bias-Corrected Chemical Compositions Versus Targeted Compositions by Oxide by SB4 Variability Study Glass (continued)

(100 -Batch 1; 200 -U std; 300 - LRM)

\begin{tabular}{|c|c|c|c|c|c|c|c|c|}
\hline Glass ID & Oxide & $\begin{array}{c}\text { Measured } \\
(\mathbf{w t} \%)\end{array}$ & $\begin{array}{c}\text { Measured } \\
\text { Bias-Corrected } \\
(w \mathbf{w} \%) \\
\end{array}$ & $\begin{array}{c}\text { Targeted } \\
(\mathbf{w t} \%)\end{array}$ & $\begin{array}{c}\text { Diff of } \\
\text { Measured } \\
(w t \%) \\
\end{array}$ & $\begin{array}{c}\text { Diff. of } \\
\text { Meas BC } \\
(w t \%) \\
\end{array}$ & $\begin{array}{l}\text { \% Diff of } \\
\text { Measured }\end{array}$ & $\begin{array}{l}\% \text { Diff of } \\
\text { Meas BC }\end{array}$ \\
\hline SB4VS-30 & $\mathrm{Fe}_{2} \mathrm{O}_{3}$ & 8.5600 & 8.7100 & 9.6500 & -1.0900 & -0.9400 & $-11.3 \%$ & $-9.7 \%$ \\
\hline SB4VS-30 & $\mathrm{K}_{2} \mathrm{O}$ & 0.0600 & 0.0540 & 0.0930 & -0.0330 & -0.0390 & $-35.5 \%$ & $-41.9 \%$ \\
\hline SB4VS-30 & $\mathrm{La}_{2} \mathrm{O}_{3}$ & 0.0420 & 0.0420 & 0.0300 & 0.0120 & 0.0120 & $40.0 \%$ & $40.0 \%$ \\
\hline SB4VS-30 & $\mathrm{Li}_{2} \mathrm{O}$ & 5.1560 & 5.1700 & 5.2800 & -0.1240 & -0.1100 & $-2.3 \%$ & $-2.1 \%$ \\
\hline SB4VS-30 & $\mathrm{MgO}$ & 0.6950 & 0.7680 & 0.7580 & -0.0630 & 0.0100 & $-8.3 \%$ & $1.3 \%$ \\
\hline SB4VS-30 & $\mathrm{MnO}$ & 2.0080 & 2.0500 & 1.9350 & 0.0730 & 0.1150 & $3.8 \%$ & $5.9 \%$ \\
\hline SB4VS-30 & $\mathrm{Na}_{2} \mathrm{O}$ & 11.1310 & 10.5930 & 10.8980 & 0.2330 & -0.3050 & $2.1 \%$ & $-2.8 \%$ \\
\hline SB4VS-30 & $\mathrm{NiO}$ & 0.4980 & 0.5510 & 0.6150 & -0.1170 & -0.0640 & $-19.0 \%$ & $-10.4 \%$ \\
\hline SB4VS-30 & $\mathrm{PbO}$ & 0.0200 & 0.0200 & 0.0260 & -0.0060 & -0.0060 & $-23.1 \%$ & $-23.1 \%$ \\
\hline SB4VS-30 & $\mathrm{SiO}_{2}$ & 47.7060 & 48.9040 & 50.1020 & -2.3960 & -1.1980 & $-4.8 \%$ & $-2.4 \%$ \\
\hline SB4VS-30 & $\mathrm{SO}_{4}^{2-}$ & 0.3490 & 0.3490 & 0.4310 & -0.0820 & -0.0820 & $-19.0 \%$ & $-19.0 \%$ \\
\hline SB4VS-30 & $\mathrm{ThO}_{2}$ & 0.0570 & 0.0570 & 0.0180 & 0.0390 & 0.0390 & $216.7 \%$ & $216.7 \%$ \\
\hline SB4VS-30 & $\mathrm{TiO}_{2}$ & 0.0080 & 0.0090 & 0.0070 & 0.0010 & 0.0020 & $14.3 \%$ & $28.6 \%$ \\
\hline SB4VS-30 & $\mathrm{U}_{3} \mathrm{O}_{8}$ & 2.3260 & 2.5290 & 2.4860 & -0.1600 & 0.0430 & $-6.4 \%$ & $1.7 \%$ \\
\hline SB4VS-30 & $\mathrm{ZnO}$ & 0.0240 & 0.0240 & 0.0280 & -0.0040 & -0.0040 & $-14.3 \%$ & $-14.3 \%$ \\
\hline SB4VS-30 & $\mathrm{ZrO}_{2}$ & 0.0550 & 0.0550 & 0.0660 & -0.0110 & -0.0110 & $-16.7 \%$ & $-16.7 \%$ \\
\hline SB4VS-30 & Sum & 96.3100 & 97.0430 & 100.0000 & -3.6900 & -2.9570 & $-3.7 \%$ & $-3.0 \%$ \\
\hline SB4VS-31 & $\mathrm{Al}_{2} \mathrm{O}_{3}$ & 7.4070 & 7.4440 & 7.0300 & 0.3770 & 0.4140 & $5.4 \%$ & $5.9 \%$ \\
\hline SB4VS-31 & $\mathrm{B}_{2} \mathrm{O}_{3}$ & 9.6920 & 9.4580 & 9.5200 & 0.1720 & -0.0620 & $1.8 \%$ & $-0.7 \%$ \\
\hline SB4VS-31 & $\mathrm{BaO}$ & 0.0380 & 0.0440 & 0.0470 & -0.0090 & -0.0030 & $-19.1 \%$ & $-6.4 \%$ \\
\hline SB4VS-31 & $\mathrm{CaO}$ & 0.8650 & 0.8770 & 0.8390 & 0.0260 & 0.0380 & $3.1 \%$ & $4.5 \%$ \\
\hline SB4VS-31 & $\mathrm{Ce}_{2} \mathrm{O}_{3}$ & 0.0380 & 0.0380 & 0.0570 & -0.0190 & -0.0190 & $-33.3 \%$ & $-33.3 \%$ \\
\hline SB4VS-31 & $\mathrm{Cr}_{2} \mathrm{O}_{3}$ & 0.0670 & 0.0770 & 0.0780 & -0.0110 & -0.0010 & $-14.1 \%$ & $-1.3 \%$ \\
\hline SB4VS-31 & $\mathrm{CuO}$ & 0.0230 & 0.0230 & 0.0230 & 0.0000 & 0.0000 & $0.0 \%$ & $0.0 \%$ \\
\hline SB4VS-31 & $\mathrm{Fe}_{2} \mathrm{O}_{3}$ & 8.6570 & 8.7590 & 9.0820 & -0.4250 & -0.3230 & $-4.7 \%$ & $-3.6 \%$ \\
\hline SB4VS-31 & $\mathrm{K}_{2} \mathrm{O}$ & 0.1330 & 0.1170 & 0.1240 & 0.0090 & -0.0070 & $7.3 \%$ & $-5.6 \%$ \\
\hline SB4VS-31 & $\mathrm{La}_{2} \mathrm{O}_{3}$ & 0.0260 & 0.0260 & 0.0400 & -0.0140 & -0.0140 & $-35.0 \%$ & $-35.0 \%$ \\
\hline SB4VS-31 & $\mathrm{Li}_{2} \mathrm{O}$ & 5.3980 & 5.4170 & 5.4400 & -0.0420 & -0.0230 & $-0.8 \%$ & $-0.4 \%$ \\
\hline SB4VS-31 & $\mathrm{MgO}$ & 0.6110 & 0.6810 & 0.7140 & -0.1030 & -0.0330 & $-14.4 \%$ & $-4.6 \%$ \\
\hline SB4VS-31 & $\mathrm{MnO}$ & 1.8010 & 1.7990 & 1.8210 & -0.0200 & -0.0220 & $-1.1 \%$ & $-1.2 \%$ \\
\hline SB4VS-31 & $\mathrm{Na}_{2} \mathrm{O}$ & 10.3260 & 9.6550 & 9.7280 & 0.5980 & -0.0730 & $6.1 \%$ & $-0.8 \%$ \\
\hline SB4VS-31 & $\mathrm{NiO}$ & 0.4800 & 0.5420 & 0.5790 & -0.0990 & -0.0370 & $-17.1 \%$ & $-6.4 \%$ \\
\hline SB4VS-31 & $\mathrm{PbO}$ & 0.0270 & 0.0270 & 0.0340 & -0.0070 & -0.0070 & $-20.6 \%$ & $-20.6 \%$ \\
\hline SB4VS-31 & $\mathrm{SiO}_{2}$ & 51.2900 & 50.7310 & 51.6790 & -0.3890 & -0.9480 & $-0.8 \%$ & $-1.8 \%$ \\
\hline SB4VS-31 & $\mathrm{SO}_{4}{ }^{2-}$ & 0.3860 & 0.3860 & 0.4850 & -0.0990 & -0.0990 & $-20.4 \%$ & $-20.4 \%$ \\
\hline SB4VS-31 & $\mathrm{ThO}_{2}$ & 0.0570 & 0.0570 & 0.0240 & 0.0330 & 0.0330 & $137.5 \%$ & $137.5 \%$ \\
\hline SB4VS-31 & $\mathrm{TiO}_{2}$ & 0.0080 & 0.0090 & 0.0100 & -0.0020 & -0.0010 & $-20.0 \%$ & $-10.0 \%$ \\
\hline SB4VS-31 & $\mathrm{U}_{3} \mathrm{O}_{8}$ & 2.4200 & 2.6340 & 2.5220 & -0.1020 & 0.1120 & $-4.0 \%$ & $4.4 \%$ \\
\hline SB4VS-31 & $\mathrm{ZnO}$ & 0.0340 & 0.0340 & 0.0370 & -0.0030 & -0.0030 & $-8.1 \%$ & $-8.1 \%$ \\
\hline SB4VS-31 & $\mathrm{ZrO}_{2}$ & 0.0800 & 0.0800 & 0.0880 & -0.0080 & -0.0080 & $-9.1 \%$ & $-9.1 \%$ \\
\hline SB4VS-31 & Sum & 99.8650 & 98.9140 & 100.0010 & -0.1360 & -1.0870 & $-0.1 \%$ & $-1.1 \%$ \\
\hline SB4VS-32 & $\mathrm{Al}_{2} \mathrm{O}_{3}$ & 8.8900 & 8.9340 & 8.4000 & 0.4900 & 0.5340 & $5.8 \%$ & $6.4 \%$ \\
\hline SB4VS-32 & $\mathrm{B}_{2} \mathrm{O}_{3}$ & 8.1460 & 7.9490 & 8.4000 & -0.2540 & -0.4510 & $-3.0 \%$ & $-5.4 \%$ \\
\hline SB4VS-32 & $\mathrm{BaO}$ & 0.0600 & 0.0660 & 0.0670 & -0.0070 & -0.0010 & $-10.4 \%$ & $-1.5 \%$ \\
\hline SB4VS-32 & $\mathrm{CaO}$ & 1.2090 & 1.1990 & 1.2000 & 0.0090 & -0.0010 & $0.8 \%$ & $-0.1 \%$ \\
\hline SB4VS-32 & $\mathrm{Ce}_{2} \mathrm{O}_{3}$ & 0.0620 & 0.0620 & 0.0810 & -0.0190 & -0.0190 & $-23.5 \%$ & $-23.5 \%$ \\
\hline SB4VS-32 & $\mathrm{Cr}_{2} \mathrm{O}_{3}$ & 0.0900 & 0.0990 & 0.1120 & -0.0220 & -0.0130 & $-19.6 \%$ & $-11.6 \%$ \\
\hline SB4VS-32 & $\mathrm{CuO}$ & 0.0300 & 0.0300 & 0.0320 & -0.0020 & -0.0020 & $-6.3 \%$ & $-6.3 \%$ \\
\hline SB4VS-32 & $\mathrm{Fe}_{2} \mathrm{O}_{3}$ & 9.5790 & 9.6920 & 10.8000 & -1.2210 & -1.1080 & $-11.3 \%$ & $-10.3 \%$ \\
\hline SB4VS-32 & $\mathrm{K}_{2} \mathrm{O}$ & 0.1900 & 0.1680 & 0.1770 & 0.0130 & -0.0090 & $7.3 \%$ & $-5.1 \%$ \\
\hline SB4VS-32 & $\mathrm{La}_{2} \mathrm{O}_{3}$ & 0.0490 & 0.0490 & 0.0570 & -0.0080 & -0.0080 & $-14.0 \%$ & $-14.0 \%$ \\
\hline SB4VS-32 & $\mathrm{Li}_{2} \mathrm{O}$ & 4.7530 & 4.7690 & 4.8000 & -0.0470 & -0.0310 & $-1.0 \%$ & $-0.6 \%$ \\
\hline SB4VS-32 & $\mathrm{MgO}$ & 0.7480 & 0.8090 & 0.8000 & -0.0520 & 0.0090 & $-6.5 \%$ & $1.1 \%$ \\
\hline SB4VS-32 & $\mathrm{MnO}$ & 2.0270 & 2.0270 & 2.0000 & 0.0270 & 0.0270 & $1.4 \%$ & $1.4 \%$ \\
\hline SB4VS-32 & $\mathrm{Na}_{2} \mathrm{O}$ & 13.1630 & 12.4680 & 12.8000 & 0.3630 & -0.3320 & $2.8 \%$ & $-2.6 \%$ \\
\hline SB4VS-32 & $\mathrm{NiO}$ & 0.6290 & 0.7110 & 0.8000 & -0.1710 & -0.0890 & $-21.4 \%$ & $-11.1 \%$ \\
\hline SB4VS-32 & $\mathrm{PbO}$ & 0.0410 & 0.0410 & 0.0490 & -0.0080 & -0.0080 & $-16.3 \%$ & $-16.3 \%$ \\
\hline SB4VS-32 & $\mathrm{SiO}_{2}$ & 45.4600 & 44.9660 & 45.6000 & -0.1400 & -0.6340 & $-0.3 \%$ & $-1.4 \%$ \\
\hline SB4VS-32 & $\mathrm{SO}_{4}{ }^{2-}$ & 0.6590 & 0.6590 & 0.8000 & -0.1410 & -0.1410 & $-17.6 \%$ & $-17.6 \%$ \\
\hline SB4VS-32 & $\mathrm{ThO}_{2}$ & 0.1330 & 0.1330 & 0.0340 & 0.0990 & 0.0990 & $291.2 \%$ & $291.2 \%$ \\
\hline SB4VS-32 & $\mathrm{TiO}_{2}$ & 0.0180 & 0.0190 & 0.0140 & 0.0040 & 0.0050 & $28.6 \%$ & $35.7 \%$ \\
\hline SB4VS-32 & $\mathrm{U}_{3} \mathrm{O}_{8}$ & 2.5290 & 2.7530 & 2.8000 & -0.2710 & -0.0470 & $-9.7 \%$ & $-1.7 \%$ \\
\hline SB4VS-32 & $\mathrm{ZnO}$ & 0.0510 & 0.0510 & 0.0530 & -0.0020 & -0.0020 & $-3.8 \%$ & $-3.8 \%$ \\
\hline SB4VS-32 & $\mathrm{ZrO}_{2}$ & 0.1150 & 0.1150 & 0.1250 & -0.0100 & -0.0100 & $-8.0 \%$ & $-8.0 \%$ \\
\hline
\end{tabular}


Table E4. Average Measured and Bias-Corrected Chemical Compositions Versus Targeted Compositions by Oxide by SB4 Variability Study Glass (continued)

(100 -Batch 1; 200 -U std; 300 - LRM)

\begin{tabular}{|c|c|c|c|c|c|c|c|c|}
\hline Glass ID & Oxide & $\begin{array}{c}\text { Measured } \\
(w t \%)\end{array}$ & $\begin{array}{c}\text { Measured } \\
\text { Bias-Corrected } \\
(w \mathbf{w} \%) \\
\end{array}$ & $\begin{array}{c}\text { Targeted } \\
(\mathbf{w t} \%)\end{array}$ & $\begin{array}{c}\text { Diff of } \\
\text { Measured } \\
(w t \%) \\
\end{array}$ & $\begin{array}{c}\text { Diff. of } \\
\text { Meas BC } \\
(w t \%) \\
\end{array}$ & $\begin{array}{l}\text { \% Diff of } \\
\text { Measured }\end{array}$ & $\begin{array}{l}\% \text { Diff of } \\
\text { Meas BC }\end{array}$ \\
\hline SB4VS-32 & Sum & 98.6320 & 97.7710 & 100.0010 & -1.3690 & -2.2300 & $-1.4 \%$ & $-2.2 \%$ \\
\hline SB4VS-33 & $\mathrm{Al}_{2} \mathrm{O}_{3}$ & 10.3780 & 10.4640 & 9.8800 & 0.4980 & 0.5840 & $5.0 \%$ & $5.9 \%$ \\
\hline SB4VS-33 & $\mathrm{B}_{2} \mathrm{O}_{3}$ & 8.9190 & 8.8120 & 8.6800 & 0.2390 & 0.1320 & $2.8 \%$ & $1.5 \%$ \\
\hline SB4VS-33 & $\mathrm{BaO}$ & 0.0260 & 0.0290 & 0.0320 & -0.0060 & -0.0030 & $-18.8 \%$ & $-9.4 \%$ \\
\hline SB4VS-33 & $\mathrm{CaO}$ & 1.1910 & 1.1810 & 1.1400 & 0.0510 & 0.0410 & $4.5 \%$ & $3.6 \%$ \\
\hline SB4VS-33 & $\mathrm{Ce}_{2} \mathrm{O}_{3}$ & 0.0260 & 0.0260 & 0.0380 & -0.0120 & -0.0120 & $-31.6 \%$ & $-31.6 \%$ \\
\hline SB4VS-33 & $\mathrm{Cr}_{2} \mathrm{O}_{3}$ & 0.0490 & 0.0530 & 0.0530 & -0.0040 & 0.0000 & $-7.5 \%$ & $0.0 \%$ \\
\hline SB4VS-33 & $\mathrm{CuO}$ & 0.0170 & 0.0170 & 0.0150 & 0.0020 & 0.0020 & $13.3 \%$ & $13.3 \%$ \\
\hline SB4VS-33 & $\mathrm{Fe}_{2} \mathrm{O}_{3}$ & 8.7600 & 8.8530 & 9.1200 & -0.3600 & -0.2670 & $-3.9 \%$ & $-2.9 \%$ \\
\hline SB4VS-33 & $\mathrm{K}_{2} \mathrm{O}$ & 0.0600 & 0.0530 & 0.0840 & -0.0240 & -0.0310 & $-28.6 \%$ & $-36.9 \%$ \\
\hline SB4VS-33 & $\mathrm{La}_{2} \mathrm{O}_{3}$ & 0.0230 & 0.0230 & 0.0270 & -0.0040 & -0.0040 & $-14.8 \%$ & $-14.8 \%$ \\
\hline SB4VS-33 & $\mathrm{Li}_{2} \mathrm{O}$ & 4.9570 & 5.0320 & 4.9600 & -0.0030 & 0.0720 & $-0.1 \%$ & $1.5 \%$ \\
\hline SB4VS-33 & $\mathrm{MgO}$ & 0.9750 & 1.0550 & 1.1400 & -0.1650 & -0.0850 & $-14.5 \%$ & $-7.5 \%$ \\
\hline SB4VS-33 & $\mathrm{MnO}$ & 2.2430 & 2.2440 & 2.2800 & -0.0370 & -0.0360 & $-1.6 \%$ & $-1.6 \%$ \\
\hline SB4VS-33 & $\mathrm{Na}_{2} \mathrm{O}$ & 10.9730 & 10.3930 & 10.4600 & 0.5130 & -0.0670 & $4.9 \%$ & $-0.6 \%$ \\
\hline SB4VS-33 & $\mathrm{NiO}$ & 0.6670 & 0.7610 & 0.7600 & -0.0930 & 0.0010 & $-12.2 \%$ & $0.1 \%$ \\
\hline SB4VS-33 & $\mathrm{PbO}$ & 0.0170 & 0.0170 & 0.0230 & -0.0060 & -0.0060 & $-26.1 \%$ & $-26.1 \%$ \\
\hline SB4VS-33 & $\mathrm{SiO}_{2}$ & 49.0430 & 49.0280 & 47.7800 & 1.2630 & 1.2480 & $2.6 \%$ & $2.6 \%$ \\
\hline SB4VS-33 & $\mathrm{SO}_{4}{ }^{2-}$ & 0.5500 & 0.5500 & 0.7600 & -0.2100 & -0.2100 & $-27.6 \%$ & $-27.6 \%$ \\
\hline SB4VS-33 & $\mathrm{ThO}_{2}$ & 0.0570 & 0.0570 & 0.0160 & 0.0410 & 0.0410 & $256.3 \%$ & $256.3 \%$ \\
\hline SB4VS-33 & $\mathrm{TiO}_{2}$ & 0.0150 & 0.0160 & 0.0070 & 0.0080 & 0.0090 & $114.3 \%$ & $128.6 \%$ \\
\hline SB4VS-33 & $\mathrm{U}_{3} \mathrm{O}_{8}$ & 2.6500 & 2.8920 & 2.6600 & -0.0100 & 0.2320 & $-0.4 \%$ & $8.7 \%$ \\
\hline SB4VS-33 & $\mathrm{ZnO}$ & 0.0290 & 0.0290 & 0.0250 & 0.0040 & 0.0040 & $16.0 \%$ & $16.0 \%$ \\
\hline SB4VS-33 & $\mathrm{ZrO}_{2}$ & 0.0550 & 0.0550 & 0.0600 & -0.0050 & -0.0050 & $-8.3 \%$ & $-8.3 \%$ \\
\hline SB4VS-33 & Sum & 101.6830 & 101.6430 & 100.0000 & 1.6830 & 1.6430 & $1.7 \%$ & $1.6 \%$ \\
\hline SB4VS-34 & $\mathrm{Al}_{2} \mathrm{O}_{3}$ & 10.0660 & 10.1360 & 9.3600 & 0.7060 & 0.7760 & $7.5 \%$ & $8.3 \%$ \\
\hline SB4VS-34 & $\mathrm{B}_{2} \mathrm{O}_{3}$ & 8.8870 & 8.7550 & 8.9600 & -0.0730 & -0.2050 & $-0.8 \%$ & $-2.3 \%$ \\
\hline SB4VS-34 & $\mathrm{BaO}$ & 0.0240 & 0.0270 & 0.0300 & -0.0060 & -0.0030 & $-20.0 \%$ & $-10.0 \%$ \\
\hline SB4VS-34 & $\mathrm{CaO}$ & 0.7400 & 0.7370 & 0.7200 & 0.0200 & 0.0170 & $2.8 \%$ & $2.4 \%$ \\
\hline SB4VS-34 & $\mathrm{Ce}_{2} \mathrm{O}_{3}$ & 0.0250 & 0.0250 & 0.0360 & -0.0110 & -0.0110 & $-30.6 \%$ & $-30.6 \%$ \\
\hline SB4VS-34 & $\mathrm{Cr}_{2} \mathrm{O}_{3}$ & 0.0540 & 0.0620 & 0.0500 & 0.0040 & 0.0120 & $8.0 \%$ & $24.0 \%$ \\
\hline SB4VS-34 & $\mathrm{CuO}$ & 0.0180 & 0.0180 & 0.0150 & 0.0030 & 0.0030 & $20.0 \%$ & $20.0 \%$ \\
\hline SB4VS-34 & $\mathrm{Fe}_{2} \mathrm{O}_{3}$ & 9.2610 & 9.3780 & 10.0800 & -0.8190 & -0.7020 & $-8.1 \%$ & $-7.0 \%$ \\
\hline SB4VS-34 & $\mathrm{K}_{2} \mathrm{O}$ & 0.0600 & 0.0540 & 0.0800 & -0.0200 & -0.0260 & $-25.0 \%$ & $-32.5 \%$ \\
\hline SB4VS-34 & $\mathrm{La}_{2} \mathrm{O}_{3}$ & 0.0210 & 0.0210 & 0.0260 & -0.0050 & -0.0050 & $-19.2 \%$ & $-19.2 \%$ \\
\hline SB4VS-34 & $\mathrm{Li}_{2} \mathrm{O}$ & 5.0970 & 5.1570 & 5.1200 & -0.0230 & 0.0370 & $-0.4 \%$ & $0.7 \%$ \\
\hline SB4VS-34 & $\mathrm{MgO}$ & 1.0070 & 1.1130 & 1.0800 & -0.0730 & 0.0330 & $-6.8 \%$ & $3.1 \%$ \\
\hline SB4VS-34 & $\mathrm{MnO}$ & 1.8560 & 1.8940 & 1.8000 & 0.0560 & 0.0940 & $3.1 \%$ & $5.2 \%$ \\
\hline SB4VS-34 & $\mathrm{Na}_{2} \mathrm{O}$ & 10.2990 & 9.8000 & 10.1200 & 0.1790 & -0.3200 & $1.8 \%$ & $-3.2 \%$ \\
\hline SB4VS-34 & $\mathrm{NiO}$ & 0.2400 & 0.2760 & 0.3600 & -0.1200 & -0.0840 & $-33.3 \%$ & $-23.3 \%$ \\
\hline SB4VS-34 & $\mathrm{PbO}$ & 0.0250 & 0.0250 & 0.0220 & 0.0030 & 0.0030 & $13.6 \%$ & $13.6 \%$ \\
\hline SB4VS-34 & $\mathrm{SiO}_{2}$ & 49.7390 & 49.6150 & 48.4400 & 1.2990 & 1.1750 & $2.7 \%$ & $2.4 \%$ \\
\hline SB4VS-34 & $\mathrm{SO}_{4}{ }^{2-}$ & 0.5430 & 0.5430 & 0.7200 & -0.1770 & -0.1770 & $-24.6 \%$ & $-24.6 \%$ \\
\hline SB4VS-34 & $\mathrm{ThO}_{2}$ & 0.1260 & 0.1260 & 0.0150 & 0.1110 & 0.1110 & $740.0 \%$ & $740.0 \%$ \\
\hline SB4VS-34 & $\mathrm{TiO}_{2}$ & 0.0080 & 0.0090 & 0.0060 & 0.0020 & 0.0030 & $33.3 \%$ & $50.0 \%$ \\
\hline SB4VS-34 & $\mathrm{U}_{3} \mathrm{O}_{8}$ & 2.7150 & 2.9420 & 2.8800 & -0.1650 & 0.0620 & $-5.7 \%$ & $2.2 \%$ \\
\hline SB4VS-34 & $\mathrm{ZnO}$ & 0.0210 & 0.0210 & 0.0240 & -0.0030 & -0.0030 & $-12.5 \%$ & $-12.5 \%$ \\
\hline SB4VS-34 & $\mathrm{ZrO}_{2}$ & 0.0560 & 0.0560 & 0.0560 & 0.0000 & 0.0000 & $0.0 \%$ & $0.0 \%$ \\
\hline SB4VS-34 & Sum & 100.8890 & 100.7910 & 100.0000 & 0.8890 & 0.7910 & $0.9 \%$ & $0.8 \%$ \\
\hline SB4VS-35 & $\mathrm{Al}_{2} \mathrm{O}_{3}$ & 7.7800 & 7.8190 & 7.1400 & 0.6400 & 0.6790 & $9.0 \%$ & $9.5 \%$ \\
\hline SB4VS-35 & $\mathrm{B}_{2} \mathrm{O}_{3}$ & 9.2490 & 9.0260 & 9.2400 & 0.0090 & -0.2140 & $0.1 \%$ & $-2.3 \%$ \\
\hline SB4VS-35 & $\mathrm{BaO}$ & 0.0450 & 0.0520 & 0.0570 & -0.0120 & -0.0050 & $-21.1 \%$ & $-8.8 \%$ \\
\hline SB4VS-35 & $\mathrm{CaO}$ & 0.7020 & 0.6990 & 0.6800 & 0.0220 & 0.0190 & $3.2 \%$ & $2.8 \%$ \\
\hline SB4VS-35 & $\mathrm{Ce}_{2} \mathrm{O}_{3}$ & 0.0490 & 0.0490 & 0.0690 & -0.0200 & -0.0200 & $-29.0 \%$ & $-29.0 \%$ \\
\hline SB4VS-35 & $\mathrm{Cr}_{2} \mathrm{O}_{3}$ & 0.0930 & 0.1060 & 0.0950 & -0.0020 & 0.0110 & $-2.1 \%$ & $11.6 \%$ \\
\hline SB4VS-35 & $\mathrm{CuO}$ & 0.0300 & 0.0300 & 0.0270 & 0.0030 & 0.0030 & $11.1 \%$ & $11.1 \%$ \\
\hline SB4VS-35 & $\mathrm{Fe}_{2} \mathrm{O}_{3}$ & 7.8850 & 7.9780 & 8.5000 & -0.6150 & -0.5220 & $-7.2 \%$ & $-6.1 \%$ \\
\hline SB4VS-35 & $\mathrm{K}_{2} \mathrm{O}$ & 0.1520 & 0.1350 & 0.1510 & 0.0010 & -0.0160 & $0.7 \%$ & $-10.6 \%$ \\
\hline SB4VS-35 & $\mathrm{La}_{2} \mathrm{O}_{3}$ & 0.0400 & 0.0400 & 0.0480 & -0.0080 & -0.0080 & $-16.7 \%$ & $-16.7 \%$ \\
\hline SB4VS-35 & $\mathrm{Li}_{2} \mathrm{O}$ & 5.2800 & 5.2990 & 5.2800 & 0.0000 & 0.0190 & $0.0 \%$ & $0.4 \%$ \\
\hline SB4VS-35 & $\mathrm{MgO}$ & 0.6360 & 0.7020 & 0.6800 & -0.0440 & 0.0220 & $-6.5 \%$ & $3.2 \%$ \\
\hline SB4VS-35 & $\mathrm{MnO}$ & 2.1530 & 2.1990 & 2.0400 & 0.1130 & 0.1590 & $5.5 \%$ & $7.8 \%$ \\
\hline SB4VS-35 & $\mathrm{Na}_{2} \mathrm{O}$ & 11.9030 & 11.3290 & 11.4800 & 0.4230 & -0.1510 & $3.7 \%$ & $-1.3 \%$ \\
\hline SB4VS-35 & $\mathrm{NiO}$ & 0.2410 & 0.2720 & 0.3400 & -0.0990 & -0.0680 & $-29.1 \%$ & $-20.0 \%$ \\
\hline
\end{tabular}


Table E4. Average Measured and Bias-Corrected Chemical Compositions Versus Targeted Compositions by Oxide by SB4 Variability Study Glass (continued)

(100 -Batch 1; 200 -U std; 300 - LRM)

\begin{tabular}{|c|c|c|c|c|c|c|c|c|}
\hline Glass ID & Oxide & $\begin{array}{c}\text { Measured } \\
(w t \%)\end{array}$ & $\begin{array}{c}\text { Measured } \\
\text { Bias-Corrected } \\
(\mathbf{w t} \%)\end{array}$ & $\begin{array}{c}\text { Targeted } \\
(\mathbf{w t} \%)\end{array}$ & $\begin{array}{c}\text { Diff of } \\
\text { Measured } \\
(\mathbf{w t} \%)\end{array}$ & $\begin{array}{c}\text { Diff. of } \\
\text { Meas BC } \\
(w t \%)\end{array}$ & $\begin{array}{l}\text { \% Diff of } \\
\text { Measured }\end{array}$ & $\begin{array}{l}\text { \% Diff of } \\
\text { Meas BC }\end{array}$ \\
\hline SB4VS-35 & $\mathrm{PbO}$ & 0.0370 & 0.0370 & 0.0420 & -0.0050 & -0.0050 & $-11.9 \%$ & $-11.9 \%$ \\
\hline SB4VS-35 & $\mathrm{SiO}_{2}$ & 50.9150 & 50.3610 & 50.5400 & 0.3750 & -0.1790 & $0.7 \%$ & $-0.4 \%$ \\
\hline SB4VS-35 & $\mathrm{SO}_{4}{ }^{2-}$ & 0.5060 & 0.5060 & 0.6800 & -0.1740 & -0.1740 & $-25.6 \%$ & $-25.6 \%$ \\
\hline SB4VS-35 & $\mathrm{ThO}_{2}$ & 0.1310 & 0.1310 & 0.0290 & 0.1020 & 0.1020 & $351.7 \%$ & $351.7 \%$ \\
\hline SB4VS-35 & $\mathrm{TiO}_{2}$ & 0.0190 & 0.0210 & 0.0120 & 0.0070 & 0.0090 & $58.3 \%$ & $75.0 \%$ \\
\hline SB4VS-35 & $\mathrm{U}_{3} \mathrm{O}_{8}$ & 2.5350 & 2.7590 & 2.7200 & -0.1850 & 0.0390 & $-6.8 \%$ & $1.4 \%$ \\
\hline SB4VS-35 & $\mathrm{ZnO}$ & 0.0390 & 0.0390 & 0.0450 & -0.0060 & -0.0060 & $-13.3 \%$ & $-13.3 \%$ \\
\hline SB4VS-35 & $\mathrm{ZrO}_{2}$ & 0.0980 & 0.0980 & 0.1060 & -0.0080 & -0.0080 & $-7.5 \%$ & $-7.5 \%$ \\
\hline SB4VS-35 & Sum & 100.5200 & 99.6870 & 100.0010 & 0.5190 & -0.3140 & $0.5 \%$ & $-0.3 \%$ \\
\hline Batch 1 & $\mathrm{Al}_{2} \mathrm{O}_{3}$ & 4.8560 & 4.8770 & 4.8770 & -0.0210 & 0.0000 & $-0.4 \%$ & $0.0 \%$ \\
\hline Batch 1 & $\mathrm{~B}_{2} \mathrm{O}_{3}$ & 7.9770 & 7.7770 & 7.7770 & 0.2000 & 0.0000 & $2.6 \%$ & $0.0 \%$ \\
\hline Batch 1 & $\mathrm{BaO}$ & 0.1350 & 0.1510 & 0.1510 & -0.0160 & 0.0000 & $-10.6 \%$ & $0.0 \%$ \\
\hline Batch 1 & $\mathrm{CaO}$ & 1.2200 & 1.2200 & 1.2200 & 0.0000 & 0.0000 & $0.0 \%$ & $0.0 \%$ \\
\hline Batch 1 & $\mathrm{Ce}_{2} \mathrm{O}_{3}$ & 0.0060 & 0.0060 & 0.0000 & 0.0060 & 0.0060 & & \\
\hline Batch 1 & $\mathrm{Cr}_{2} \mathrm{O}_{3}$ & 0.0960 & 0.1070 & 0.1070 & -0.0110 & 0.0000 & $-10.3 \%$ & $0.0 \%$ \\
\hline Batch 1 & $\mathrm{CuO}$ & 0.3980 & 0.3990 & 0.3990 & -0.0010 & 0.0000 & $-0.3 \%$ & $0.0 \%$ \\
\hline Batch 1 & $\mathrm{Fe}_{2} \mathrm{O}_{3}$ & 12.6730 & 12.8390 & 12.8390 & -0.1660 & 0.0000 & $-1.3 \%$ & $0.0 \%$ \\
\hline Batch 1 & $\mathrm{~K}_{2} \mathrm{O}$ & 3.7560 & 3.3270 & 3.3270 & 0.4290 & 0.0000 & $12.9 \%$ & $0.0 \%$ \\
\hline Batch 1 & $\mathrm{La}_{2} \mathrm{O}_{3}$ & 0.0060 & 0.0060 & 0.0000 & 0.0060 & 0.0060 & & \\
\hline Batch 1 & $\mathrm{Li}_{2} \mathrm{O}$ & 4.3930 & 4.4290 & 4.4290 & -0.0360 & 0.0000 & $-0.8 \%$ & $0.0 \%$ \\
\hline Batch 1 & $\mathrm{MgO}$ & 1.3050 & 1.4190 & 1.4190 & -0.1140 & 0.0000 & $-8.0 \%$ & $0.0 \%$ \\
\hline Batch 1 & $\mathrm{MnO}$ & 1.7270 & 1.7260 & 1.7260 & 0.0010 & 0.0000 & $0.1 \%$ & $0.0 \%$ \\
\hline Batch 1 & $\mathrm{Na}_{2} \mathrm{O}$ & 9.5660 & 9.0030 & 9.0030 & 0.5630 & 0.0000 & $6.3 \%$ & $0.0 \%$ \\
\hline Batch 1 & $\mathrm{NiO}$ & 0.6630 & 0.7510 & 0.7510 & -0.0880 & 0.0000 & $-11.7 \%$ & $0.0 \%$ \\
\hline Batch 1 & $\mathrm{PbO}$ & 0.0050 & 0.0050 & 0.0000 & 0.0050 & 0.0050 & & \\
\hline Batch 1 & $\mathrm{SiO}_{2}$ & 50.0860 & 50.2200 & 50.2200 & -0.1340 & 0.0000 & $-0.3 \%$ & $0.0 \%$ \\
\hline Batch 1 & $\mathrm{SO}_{4}{ }^{2-}$ & 0.1500 & 0.1500 & 0.0000 & 0.1500 & 0.1500 & & \\
\hline Batch 1 & $\mathrm{ThO}_{2}$ & 0.0570 & 0.0570 & 0.0000 & 0.0570 & 0.0570 & & \\
\hline Batch 1 & $\mathrm{TiO}_{2}$ & 0.6310 & 0.6770 & 0.6770 & -0.0460 & 0.0000 & $-6.8 \%$ & $0.0 \%$ \\
\hline Batch 1 & $\mathrm{U}_{3} \mathrm{O}_{8}$ & 0.0590 & 0.0640 & 0.0000 & 0.0590 & 0.0640 & & \\
\hline Batch 1 & $\mathrm{ZnO}$ & 0.0060 & 0.0060 & 0.0000 & 0.0060 & 0.0060 & & \\
\hline Batch 1 & $\mathrm{ZrO}_{2}$ & 0.0890 & 0.0890 & 0.0980 & -0.0090 & -0.0090 & $-9.2 \%$ & $-9.2 \%$ \\
\hline Batch 1 & Sum & 99.8600 & 99.3050 & 99.0200 & 0.8400 & 0.2850 & $0.8 \%$ & $0.3 \%$ \\
\hline U std & $\mathrm{Al}_{2} \mathrm{O}_{3}$ & 4.0990 & 4.1170 & 4.1000 & -0.0010 & 0.0170 & $0.0 \%$ & $0.4 \%$ \\
\hline U std & $\mathrm{B}_{2} \mathrm{O}_{3}$ & 9.0940 & 8.8660 & 9.2090 & -0.1150 & -0.3430 & $-1.2 \%$ & $-3.7 \%$ \\
\hline U std & $\mathrm{BaO}$ & 0.0060 & 0.0060 & 0.0000 & 0.0060 & 0.0060 & & \\
\hline U std & $\mathrm{CaO}$ & 1.2760 & 1.2770 & 1.3010 & -0.0250 & -0.0240 & $-1.9 \%$ & $-1.8 \%$ \\
\hline U std & $\mathrm{Ce}_{2} \mathrm{O}_{3}$ & 0.0060 & 0.0060 & 0.0000 & 0.0060 & 0.0060 & & \\
\hline U std & $\mathrm{Cr}_{2} \mathrm{O}_{3}$ & 0.2290 & 0.2550 & 0.0000 & 0.2290 & 0.2550 & & \\
\hline U std & $\mathrm{CuO}$ & 0.0070 & 0.0070 & 0.0000 & 0.0070 & 0.0070 & & \\
\hline U std & $\mathrm{Fe}_{2} \mathrm{O}_{3}$ & 12.2100 & 12.3700 & 13.1960 & -0.9860 & -0.8260 & $-7.5 \%$ & $-6.3 \%$ \\
\hline U std & $\mathrm{K}_{2} \mathrm{O}$ & 3.3010 & 2.9240 & 2.9990 & 0.3020 & -0.0750 & $10.1 \%$ & $-2.5 \%$ \\
\hline U std & $\mathrm{La}_{2} \mathrm{O}_{3}$ & 0.0060 & 0.0060 & 0.0000 & 0.0060 & 0.0060 & & \\
\hline U std & $\mathrm{Li}_{2} \mathrm{O}$ & 3.0730 & 3.0990 & 3.0570 & 0.0160 & 0.0420 & $0.5 \%$ & $1.4 \%$ \\
\hline U std & $\mathrm{MgO}$ & 1.0870 & 1.1810 & 1.2100 & -0.1230 & -0.0290 & $-10.2 \%$ & $-2.4 \%$ \\
\hline U std & $\mathrm{MnO}$ & 2.7800 & 2.7790 & 2.8920 & -0.1120 & -0.1130 & $-3.9 \%$ & $-3.9 \%$ \\
\hline U std & $\mathrm{Na}_{2} \mathrm{O}$ & 12.0260 & 11.3200 & 11.7950 & 0.2310 & -0.4750 & $2.0 \%$ & $-4.0 \%$ \\
\hline U std & $\mathrm{NiO}$ & 0.8990 & 1.0180 & 1.1200 & -0.2210 & -0.1020 & $-19.7 \%$ & $-9.1 \%$ \\
\hline U std & $\mathrm{PbO}$ & 0.0050 & 0.0050 & 0.0000 & 0.0050 & 0.0050 & & \\
\hline U std & $\mathrm{SiO}_{2}$ & 43.7670 & 43.8790 & 45.3530 & -1.5860 & -1.4740 & $-3.5 \%$ & $-3.3 \%$ \\
\hline U std & $\mathrm{SO}_{4}{ }^{2-}$ & 0.1500 & 0.1500 & 0.0000 & 0.1500 & 0.1500 & & \\
\hline U std & $\mathrm{ThO}_{2}$ & 0.0570 & 0.0570 & 0.0000 & 0.0570 & 0.0570 & & \\
\hline U std & $\mathrm{TiO}_{2}$ & 0.8960 & 0.9610 & 1.0490 & -0.1530 & -0.0880 & $-14.6 \%$ & $-8.4 \%$ \\
\hline U std & $\mathrm{U}_{3} \mathrm{O}_{8}$ & 2.2120 & 2.4060 & 2.4060 & -0.1940 & 0.0000 & $-8.1 \%$ & $0.0 \%$ \\
\hline U std & $\mathrm{ZnO}$ & 0.0060 & 0.0060 & 0.0000 & 0.0060 & 0.0060 & & \\
\hline U std & $\mathrm{ZrO}_{2}$ & 0.0060 & 0.0060 & 0.0000 & 0.0060 & 0.0060 & & \\
\hline U std & Sum & 97.1960 & 96.7000 & 99.6870 & -2.4910 & -2.9870 & $-2.5 \%$ & $-3.0 \%$ \\
\hline LRM & $\mathrm{Al}_{2} \mathrm{O}_{3}$ & 10.0910 & 10.1030 & 10.0000 & 0.0910 & 0.1030 & $0.9 \%$ & $1.0 \%$ \\
\hline LRM & $\mathrm{B}_{2} \mathrm{O}_{3}$ & 7.9220 & 7.6410 & 8.0000 & -0.0780 & -0.3590 & $-1.0 \%$ & $-4.5 \%$ \\
\hline LRM & $\mathrm{BaO}$ & 0.0060 & 0.0060 & 0.0050 & 0.0010 & 0.0010 & $20.0 \%$ & $20.0 \%$ \\
\hline LRM & $\mathrm{CaO}$ & 0.5380 & 0.5390 & 0.5000 & 0.0380 & 0.0390 & $7.6 \%$ & $7.8 \%$ \\
\hline LRM & $\mathrm{Ce}_{2} \mathrm{O}_{3}$ & 0.0060 & 0.0060 & 0.0000 & 0.0060 & 0.0060 & & \\
\hline LRM & $\mathrm{Cr}_{2} \mathrm{O}_{3}$ & 0.1790 & 0.2020 & 0.2000 & -0.0210 & 0.0020 & $-10.5 \%$ & $1.0 \%$ \\
\hline LRM & $\mathrm{CuO}$ & 0.0020 & 0.0020 & 0.0000 & 0.0020 & 0.0020 & & \\
\hline
\end{tabular}


Table E4. Average Measured and Bias-Corrected Chemical Compositions Versus Targeted Compositions by Oxide by SB4 Variability Study Glass (continued)

(100 -Batch 1; 200 -U std; 300 - LRM)

\begin{tabular}{|c|c|c|c|c|c|c|c|c|}
\hline Glass ID & Oxide & $\begin{array}{c}\text { Measured } \\
\quad(w t \%)\end{array}$ & $\begin{array}{c}\text { Measured } \\
\text { Bias-Corrected } \\
(w \mathbf{w} \%) \\
\end{array}$ & $\begin{array}{c}\text { Targeted } \\
(\mathbf{w t} \%)\end{array}$ & $\begin{array}{c}\text { Diff of } \\
\text { Measured } \\
(w t \%) \\
\end{array}$ & $\begin{array}{c}\text { Diff. of } \\
\text { Meas BC } \\
(w t \%) \\
\end{array}$ & $\begin{array}{l}\% \text { Diff of } \\
\text { Measured }\end{array}$ & $\begin{array}{l}\text { \% Diff of } \\
\text { Meas BC }\end{array}$ \\
\hline LRM & $\mathrm{Fe}_{2} \mathrm{O}_{3}$ & 1.3230 & 1.3430 & 1.0000 & 0.3230 & 0.3430 & $32.3 \%$ & $34.3 \%$ \\
\hline LRM & $\mathrm{K}_{2} \mathrm{O}$ & 1.5770 & 1.3960 & 1.5000 & 0.0770 & -0.1040 & $5.1 \%$ & $-6.9 \%$ \\
\hline LRM & $\mathrm{La}_{2} \mathrm{O}_{3}$ & 0.0060 & 0.0060 & 0.0000 & 0.0060 & 0.0060 & & \\
\hline LRM & $\mathrm{Li}_{2} \mathrm{O}$ & 0.2790 & 0.2810 & 0.1000 & 0.1790 & 0.1810 & $179.0 \%$ & $181.0 \%$ \\
\hline LRM & $\mathrm{MgO}$ & 0.0910 & 0.1000 & 0.1000 & -0.0090 & 0.0000 & $-9.0 \%$ & $0.0 \%$ \\
\hline LRM & $\mathrm{MnO}$ & 0.0660 & 0.0670 & 0.1000 & -0.0340 & -0.0330 & $-34.0 \%$ & $-33.0 \%$ \\
\hline LRM & $\mathrm{Na}_{2} \mathrm{O}$ & 20.8310 & 19.6250 & 20.0000 & 0.8310 & -0.3750 & $4.2 \%$ & $-1.9 \%$ \\
\hline LRM & $\mathrm{NiO}$ & 0.1140 & 0.1280 & 0.1000 & 0.0140 & 0.0280 & $14.0 \%$ & $28.0 \%$ \\
\hline LRM & $\mathrm{PbO}$ & 0.0760 & 0.0760 & 0.1000 & -0.0240 & -0.0240 & $-24.0 \%$ & $-24.0 \%$ \\
\hline LRM & $\mathrm{SiO}_{2}$ & 53.0080 & 53.8110 & 54.3700 & -1.3620 & -0.5590 & $-2.5 \%$ & $-1.0 \%$ \\
\hline LRM & $\mathrm{SO}_{4}^{2-}$ & 0.2300 & 0.2300 & 0.2400 & -0.0100 & -0.0100 & $-4.2 \%$ & $-4.2 \%$ \\
\hline LRM & $\mathrm{ThO}_{2}$ & 0.0570 & 0.0570 & 0.0000 & 0.0570 & 0.0570 & & \\
\hline LRM & $\mathrm{TiO}_{2}$ & 0.0930 & 0.1000 & 0.1000 & -0.0070 & 0.0000 & $-7.0 \%$ & $0.0 \%$ \\
\hline LRM & $\mathrm{U}_{3} \mathrm{O}_{8}$ & 0.0590 & 0.0640 & 0.0000 & 0.0590 & 0.0640 & & \\
\hline LRM & $\mathrm{ZnO}$ & 0.0080 & 0.0080 & 0.0000 & 0.0080 & 0.0080 & & \\
\hline LRM & $\mathrm{ZrO}_{2}$ & 0.8750 & 0.8750 & 1.0000 & -0.1250 & -0.1250 & $-12.5 \%$ & $-12.5 \%$ \\
\hline LRM & Sum & 97.437 & 96.667 & 97.415 & 0.0220 & -0.748 & $0.0 \%$ & $-0.8 \%$ \\
\hline
\end{tabular}




\section{Exhibit E1. Oxide Measurements in Analytical Sequence for Samples Prepared Using the LM Method}
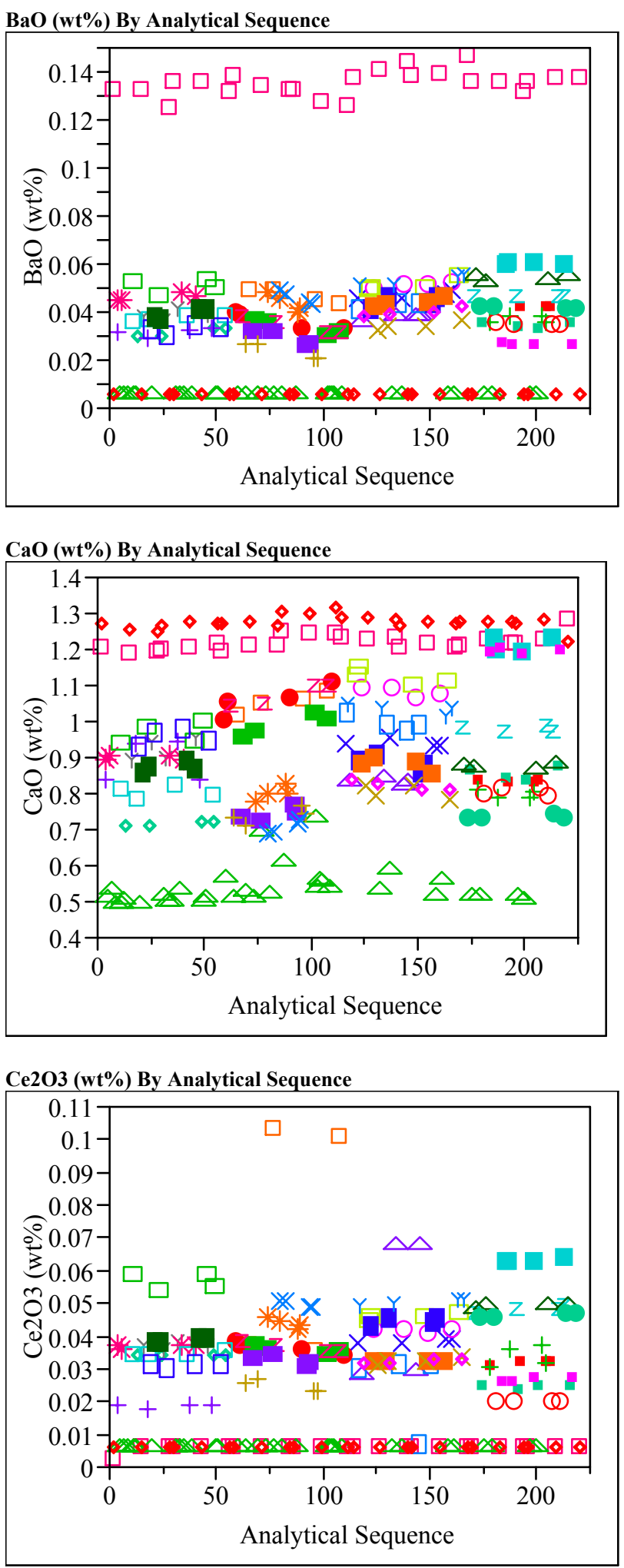

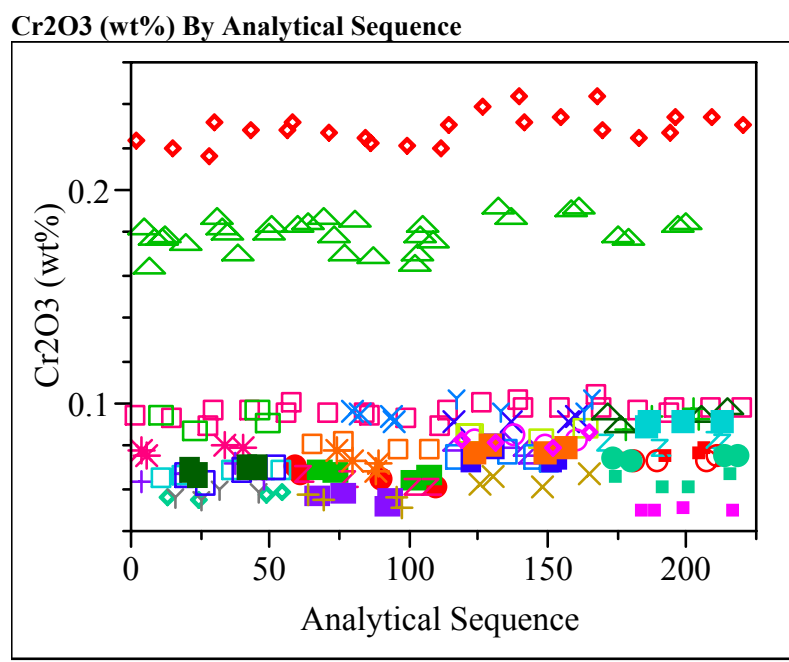

$\mathrm{CuO}(w \mathrm{t} \%)$ By Analytical Sequence

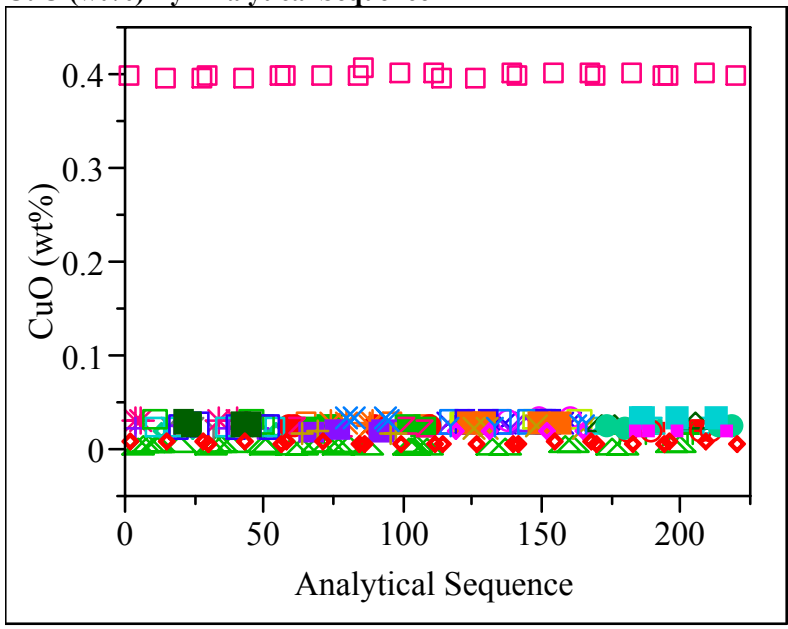

K2O (wt\%) By Analytical Sequence

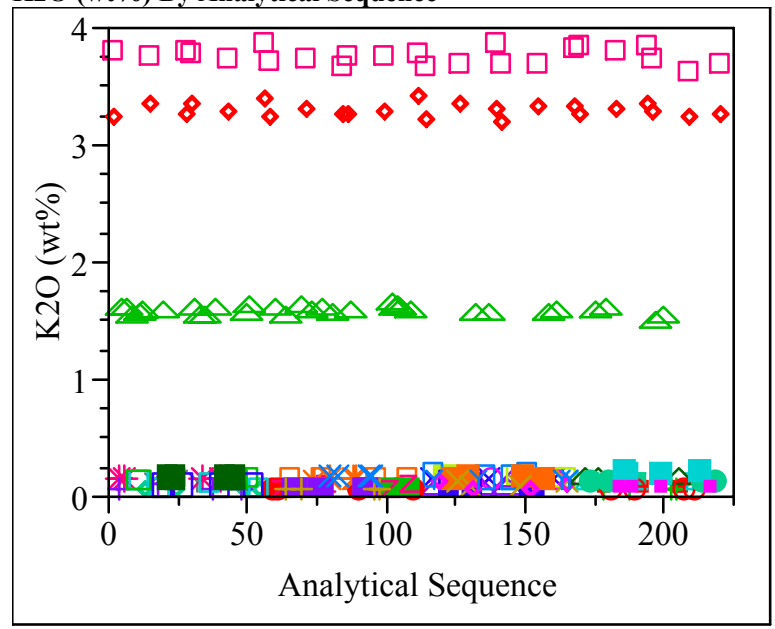




\section{Exhibit E1. Oxide Measurements in Analytical Sequence for Samples Prepared Using the LM Method (continued)}
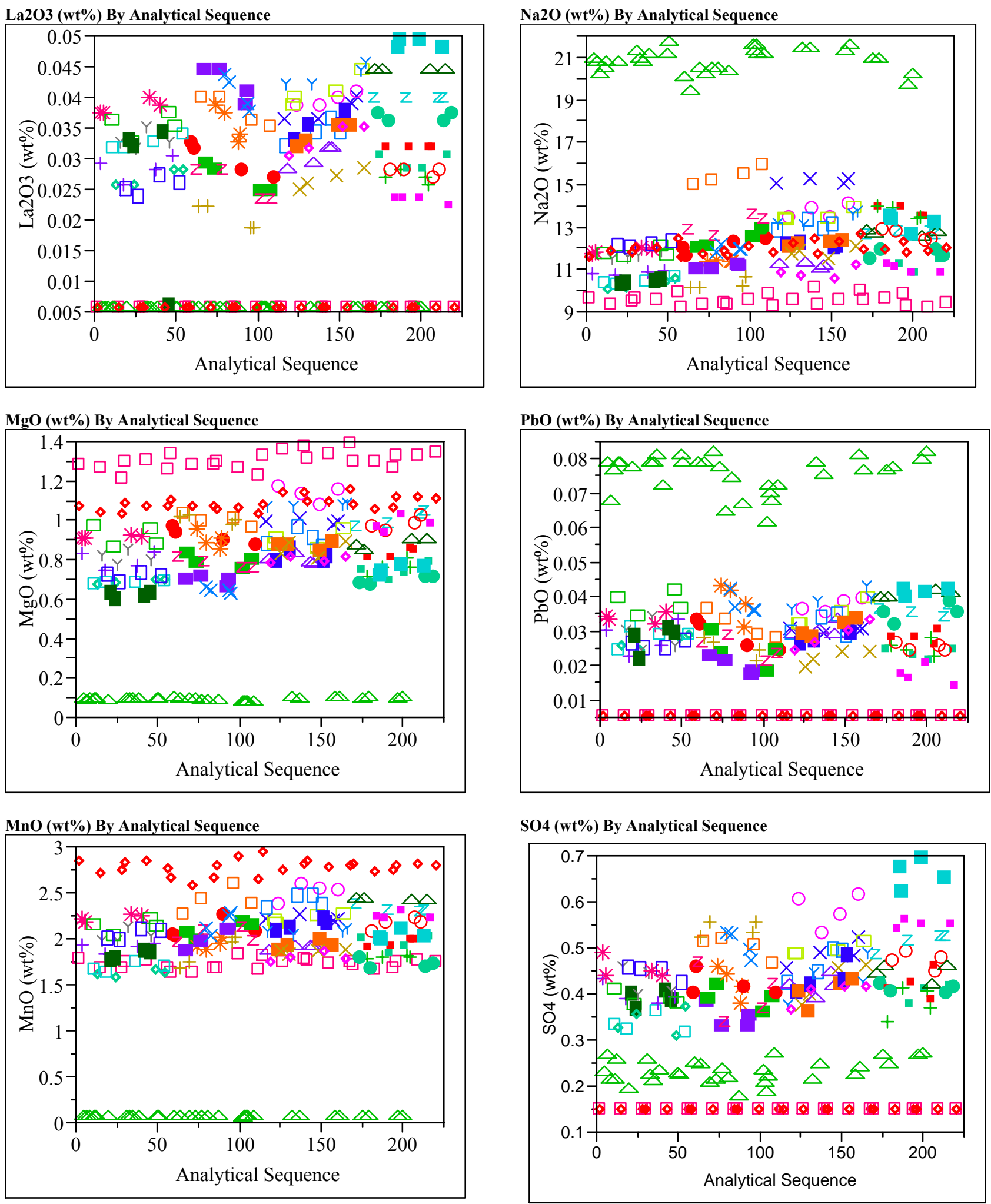


\section{Exhibit E1. Oxide Measurements in Analytical Sequence for Samples Prepared Using the LM Method (continued)}

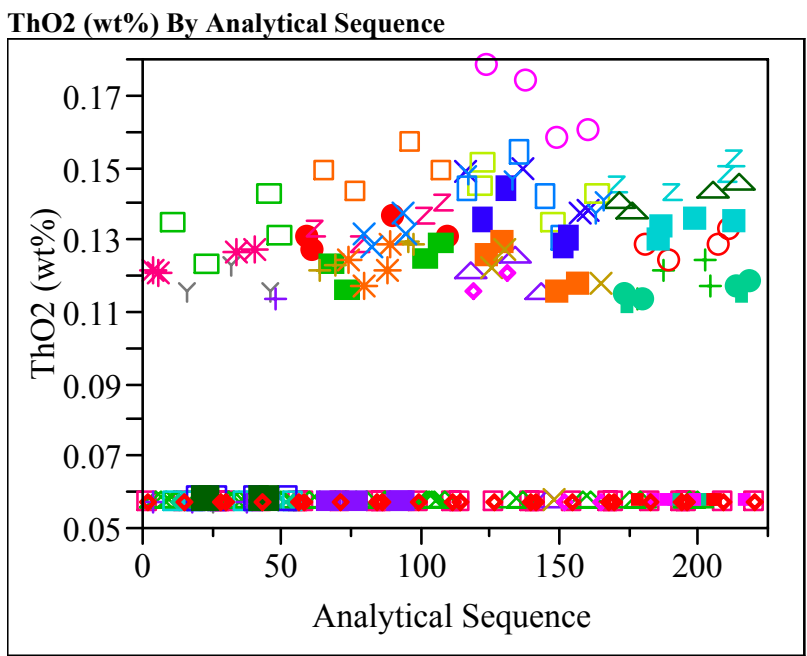

ZrO2 (wt\%) By Analytical Sequence

TiO2 (wt\%) By Analytical Sequence

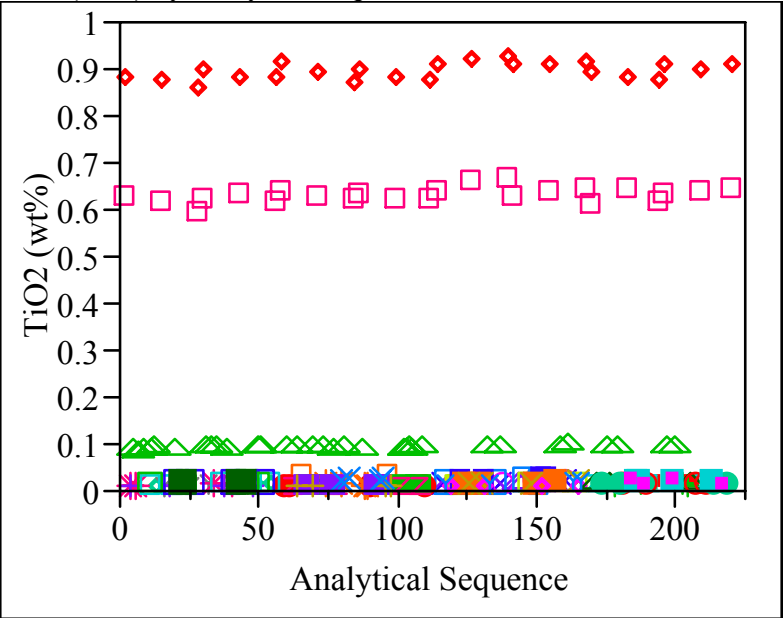

ZnO (wt\%) By Analytical Sequence
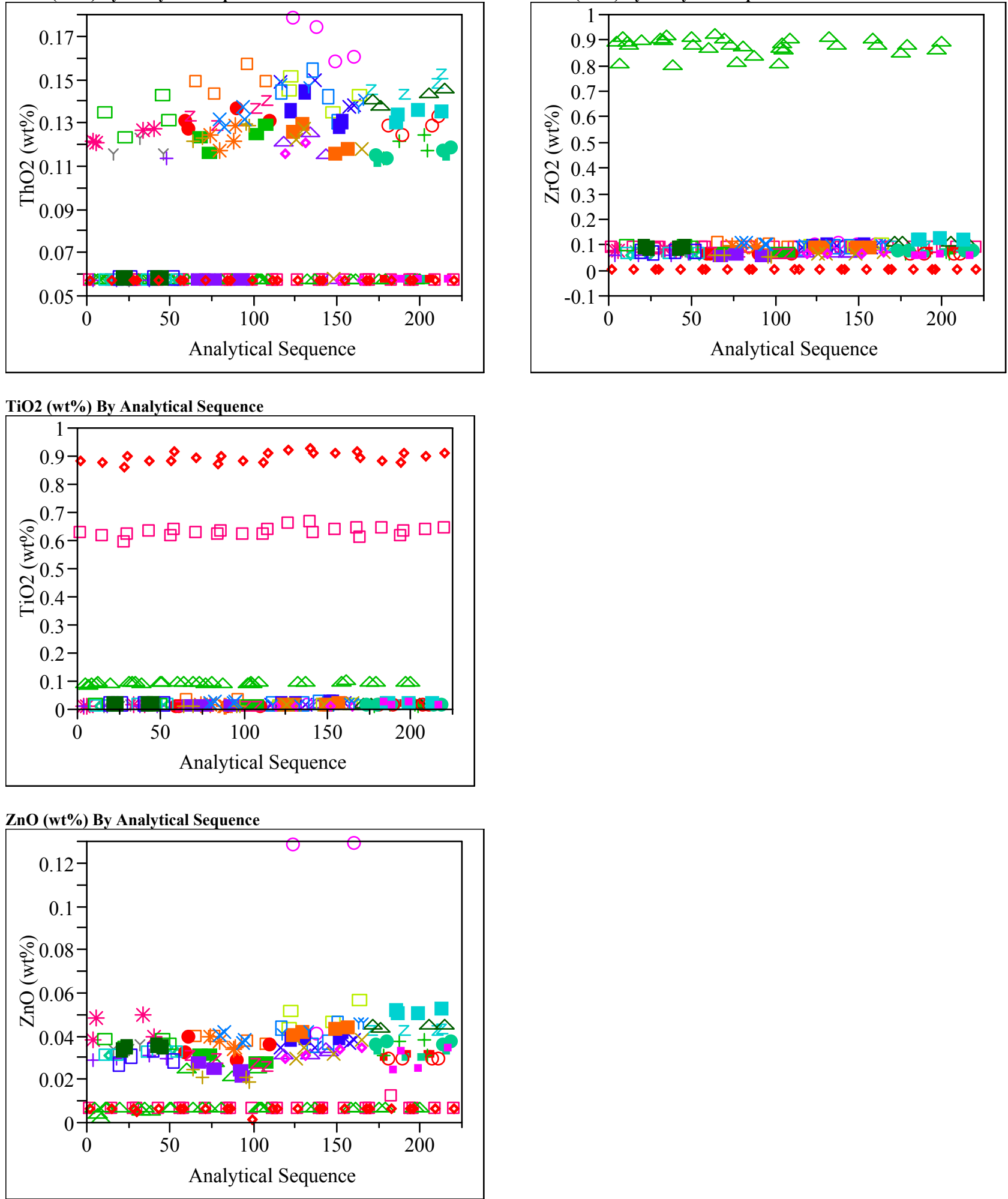
WSRC-STI-2006-00204

Revision 0

\section{Exhibit E2. Oxide Measurements in Analytical Sequence for Samples Prepared Using the PF Method}
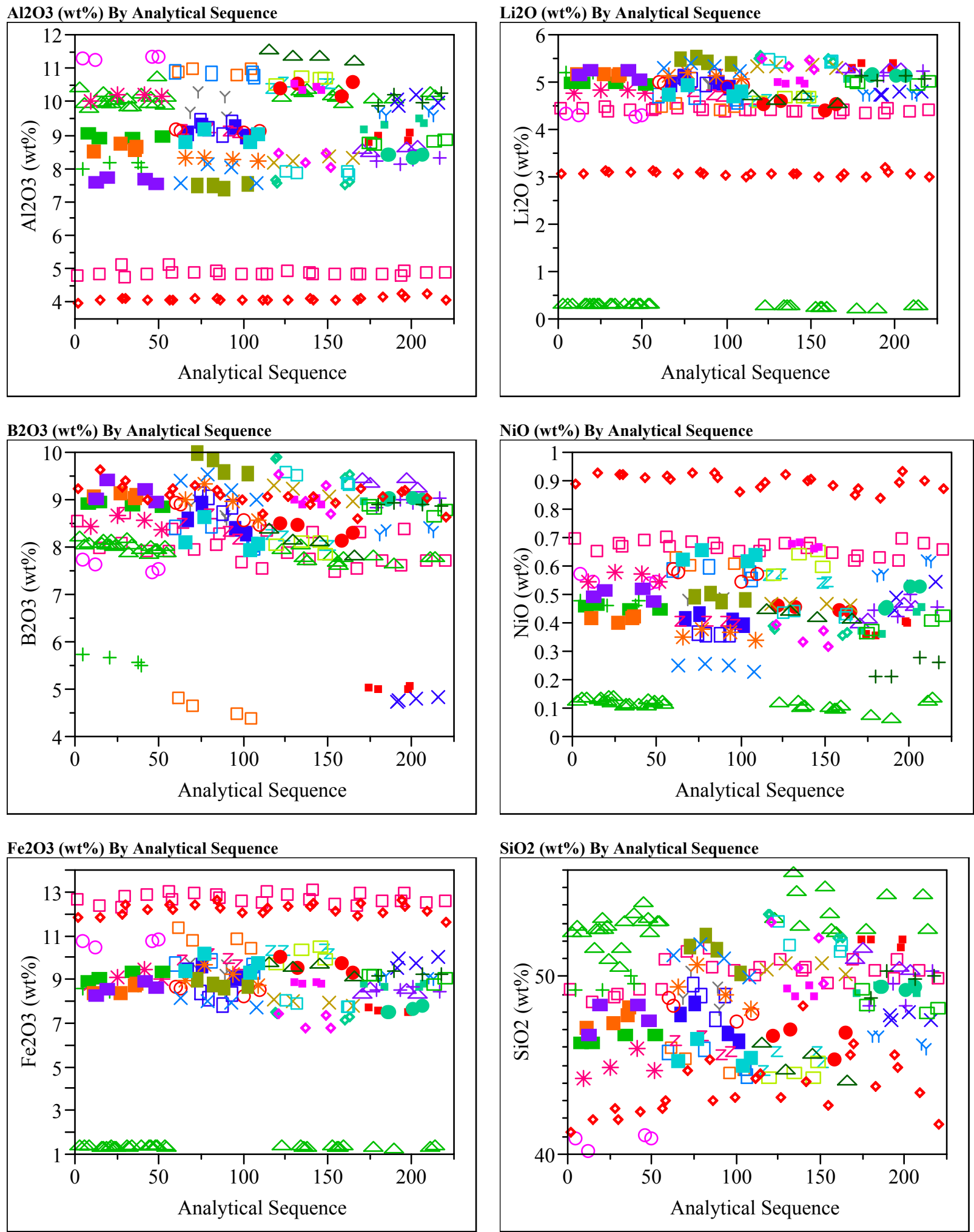
WSRC-STI-2006-00204

Revision 0

Exhibit E2. Oxide Measurements in Analytical Sequence for Samples Prepared Using the PF Method (continued)

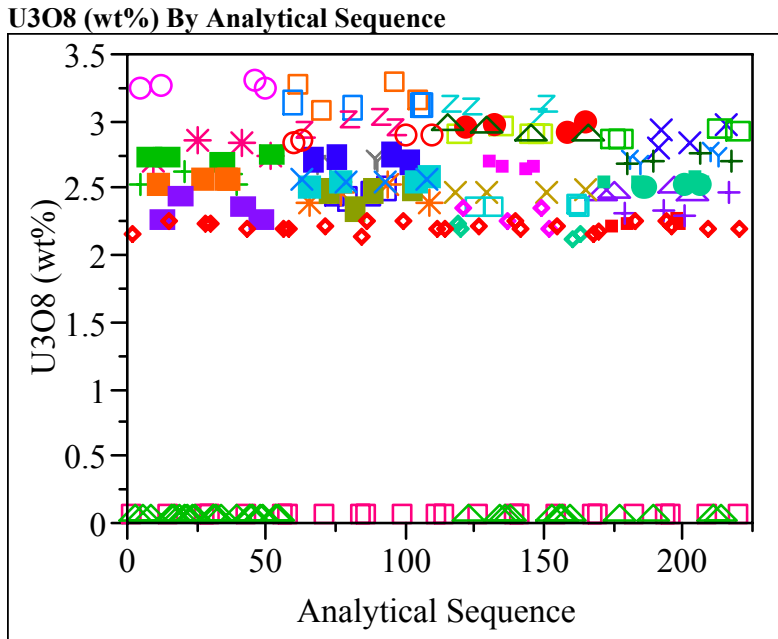




\section{Exhibit E3. PSAL Measurements by Analytical Block for Samples of the Standard Glasses Prepared Using the LM Method}

(Batch 1 - Glass \#100; U std - Glass \#200)

\section{Glass \#=100}

Oneway Analysis of BaO (wt\%) By Block/Sub-Block Study Reference Value: $0.151 \mathrm{wt} \%$

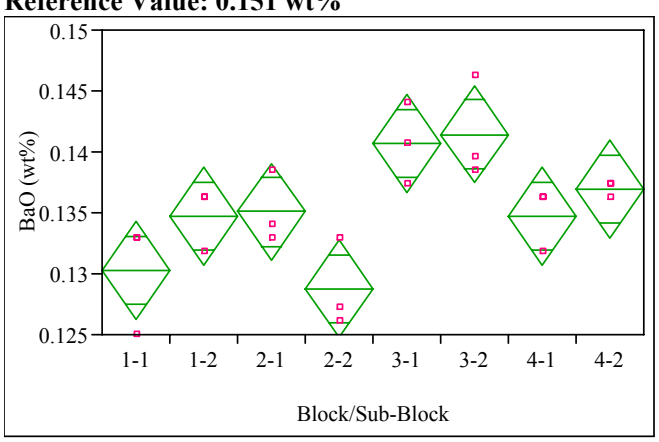

Oneway Anova
Summary of Fit

$\begin{array}{lr}\text { Rsquare } & 0.709376 \\ \text { Adj Rsquare } & 0.582228 \\ \text { Root Mean Square Error } & 0.003255 \\ \text { Mean of Response } & 0.135329 \\ \text { Observations (or Sum Wgts) } & 24\end{array}$

Analysis of Variance

Source DF Sum of Squares Mean Square F Ratio Prob $>$ F

$\begin{array}{lrrrrr}\text { Block/Sub-Block } & 7 & 0.00041381 & 0.000059 & 5.5791 & 0.002 \\ \text { Error } & 16 & 0.00016953 & 0.000011 & & \end{array}$

C. Total

0.00058334

Means for Oneway Anova

Level Number Mean Std Error Lower 95\% Upper 95\%

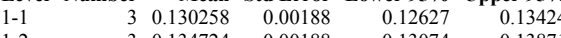

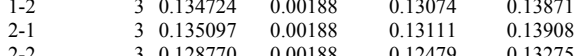

$\begin{array}{lllllll}2-2 & & 3 & 0.128770 & 0.00188 & 0.112479 & 0.13275 \\ 3-1 & & 3 & 0.140679 & 0.00188 & 0.13669 & 0.14466\end{array}$

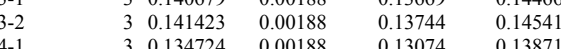

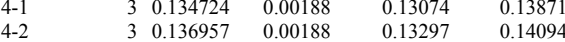

Std Error uses a pooled estimate of error variance
Glass \#=100

Oneway Analysis of $\mathrm{CaO}$ (wt\%) By Block/Sub-Block Study Reference Value: $1.220 \mathrm{wt} \%$

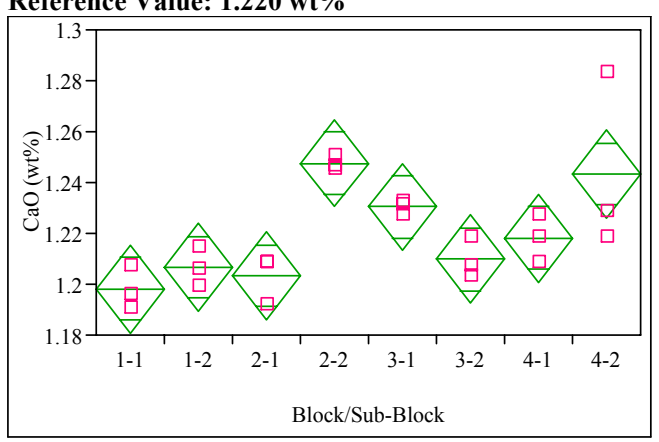

Oneway Anova
Summary of Fi

Rsquare
Adj Rsquare

$\begin{array}{lr}\text { Mean of Response } & 1.219694 \\ \text { Observations (or Sum Wgts) } & 24\end{array}$

Analysis of Variance

Source DF Sum of Squares Mean Square F Ratio Prob $>$ F

$\begin{array}{lrrrrr}\text { Block/Sub-Block } & 7 & 0.00737741 & 0.001054 & 5.2950 & 0.0028 \\ \text { Error } & 16 & 0.00318462 & 0.000199 & & \end{array}$

C. Total

0.01056204

Means for Oneway Anova

Level Number Mean Std Error Lower 95\% Upper 95\%

\begin{tabular}{|c|c|c|c|c|}
\hline $\begin{array}{ll}\text { Lev } \\
-1\end{array}$ & $\begin{array}{l}\text { Mean } \\
1.9818\end{array}$ & 0.00815 & 1180 & $\begin{array}{r}\text { er } \\
125 \% \\
12154\end{array}$ \\
\hline 3 & $\begin{array}{lll}3 & 1.20658\end{array}$ & 0.00815 & 1.1893 & 1.2238 \\
\hline $2-1$ & $\begin{array}{ll}3 & 1.20331\end{array}$ & 0.00815 & 1.1860 & 1.2206 \\
\hline-2 & 1.24762 & 0.00815 & 1.2304 & 1.2649 \\
\hline $3-1$ & 1.23036 & 0.00815 & 1.2131 & 1.2476 \\
\hline & 1.20984 & 0.00815 & 1.1926 & 1.2271 \\
\hline & 1.21824 & 0.00815 & 1.2010 & 1.2355 \\
\hline & 1.24342 & 0.00815 & 1.2262 & 1.2607 \\
\hline
\end{tabular}

Std Error uses a pooled estimate of error variance
Glass \#=100

Oneway Analysis of Ce2O3 (wt\%) By Block/Sub-Block Study Reference Value: $0.0 \mathrm{wt} \%$

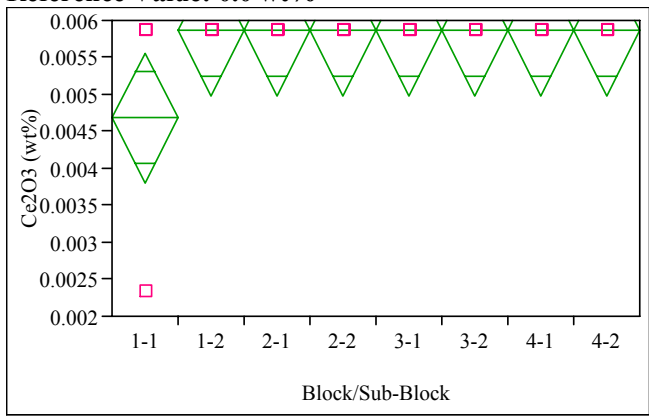

Oneway Anova

$\begin{array}{ll}\text { Rsquare } & 0.304348 \\ \text { Adj Rsquare } & -8.90-16\end{array}$

Root Mean Square Error $\quad \begin{array}{r}-8.900-16 \\ 0.00717\end{array}$

$\begin{array}{lr}\text { Mean of Response } & 0.00571 \\ \text { Observations (or Sum Wgts) } & 24\end{array}$

Analysis of Variance

$\begin{array}{lrrrrr}\text { Source } & \text { DF } & \text { Sum of Squares } & \text { Mean Square } & \text { F Ratio } & \text { Prob }>\text { F } \\ \text { Block/Sub-Block } & 7 & 0.00000360 & 5.1448 \mathrm{e}-7 & 1.0000 & 0.4663\end{array}$

$\begin{array}{lll}\text { C. Total } & 23 & 0.00000823 \\ & & 0.00001183\end{array}$

Means for Oneway Anova

Level Number Mean Std Error Lower 95\% Upper 95\%

$\begin{array}{llllll}1-1 & 3 & 0.004685 & 0.00041 & 0.00381 & 0.00556 \\ 1-2 & 3 & 0.0585 & 0.004 & 0.048 & 0.0673\end{array}$

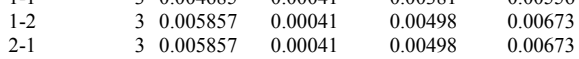

$\begin{array}{lllllll}2-2 & 3 & 0.005857 & 0.00041 & 0.00498 & 0.00673 \\ 3-1 & & 3 & 0.05857 & 0.00041 & 0.0498 & 0.0063\end{array}$

$\begin{array}{llllll}3-2 & 3 & 0.005857 & 0.00041 & 0.00498 & 0.00673 \\ 3-2 & 3 & 0.00498 & 0.00673\end{array}$

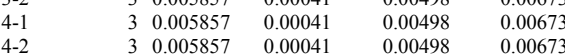

Std Error uses a pooled estimate of error variance 


\section{Exhibit E3. PSAL Measurements by Analytical Block for Samples of the Standard Glasses Prepared Using the LM Method (continued)}

(Batch 1 - Glass \#100; U std - Glass \#200)

Glass \#=100

Oneway Analysis of Cr2O3 (wt\%) By Block/Sub-Block Study Reference Value: $0.107 \mathrm{wt} \%$

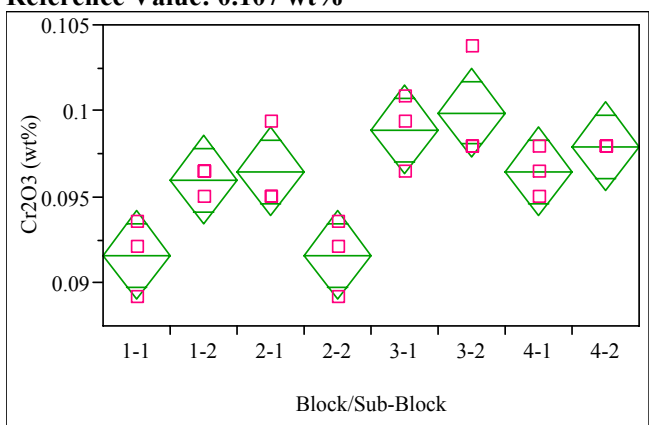

Oneway Anova
Summary of Fit

$\begin{array}{ll}\text { Rsquare } & 0.736495 \\ \text { Adj Rsquare } & 0.621212\end{array}$

0.621212
Root Mean Square Error $\quad 0.00211$

$\begin{array}{lr}\text { Mean of Response } & 0.0961 \\ \text { Observations (or Sum Wgts) } & 24\end{array}$

Analysis of Variance
Source DF Sum of Squares Mean Square F Ratio Prob $>$ F

$\begin{array}{lrrrrrr}\text { Source } & \text { DF } & \text { Sum of Squares } & \text { Mean Square } & \text { F Ratio } & \text { Prob }>\text { F } \\ \text { Block/Sub-Block } & 7 & 0.00019903 & 0.000028 & 6.3886 & 0.0011\end{array}$ $\begin{array}{lrrr}\text { Error } & 16 & 0.00007121 & 0.000028 \\ \text { C. Total } & 23 & 0.00027024 & \end{array}$

Means for Oneway Anova

Level Number Mean Std Error Lower 95\% Upper 95\%

$\begin{array}{llllll}1-1 & 3 & 0.091594 & 0.00122 & 0.08901 & 0.0948 \\ 1-2 & 3 & 0.095978 & 0.00122 & 0.09340 & 0.09856\end{array}$

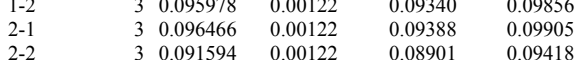

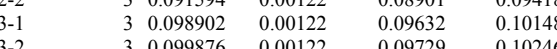

$\begin{array}{lllllll}3-2 & & 3 & 0.099876 & 0.00122 & 0.09729 & 0.10246 \\ 4-1 & & 3 & 0.096466 & 0.00122 & 0.09388 & 0.09905 \\ 4-2 & & 3 & 0.997927 & 0.00122 & 0.09535 & 0.10051\end{array}$

Std Error uses a pooled estimate of error variance
Glass \#=100

Oneway Analysis of $\mathrm{CuO}$ (wt\%) By Block/Sub-Block Study

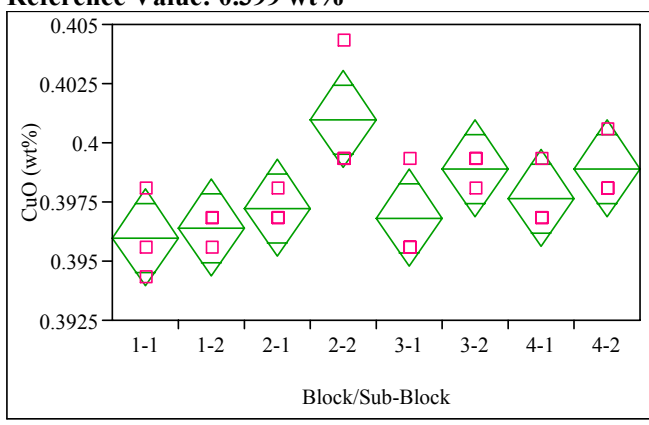

Oneway Anova

$\begin{array}{ll}\text { Rsquare } & 0.561224\end{array}$

Root Mean Square Error $\quad 0.001676$

$\begin{array}{lr}\text { Mean of Response } & 0.397864 \\ \text { Observations (or Sum Wgts) } & 24\end{array}$

Analysis of Variance

Source DF Sum of Squares Mean Square F Ratio Prob $>$ F

$\begin{array}{llllll}\text { Block/Sub-Block } & 7 & 0.00005746 & 8.2081 \mathrm{e}-6 & 2.9236 & 0.0358\end{array}$

$\begin{array}{llll}\text { Error } & 16 & 0.00004492 & 2.8075 \mathrm{e}-6 \\ \text { C. Total } & 23 & 0.00010238 & \end{array}$

Means for Oneway Anova

$\begin{array}{rrrrrr}\text { Level Number } & \text { Mean } & \text { Std Error } & \text { Lower 95\% } & \text { Upper 95\% } \\ 1-1 & 3 & 0.395986 & 0.00097 & 0.39394 & 0.39804\end{array}$

$\begin{array}{lllllll}2-2 & & 3 & 0.400993 & 0.00097 & 0.39894 & 0.40304 \\ 3-1 & & 3 & 0.396821 & 0.00097 & 0.39477 & 0.39887\end{array}$

$\begin{array}{llllll}3-1 & 3 & 0.396821 & 0.00097 & 0.09477 & 0.39887 \\ 3-2 & 3 & 0.398907 & 0.00097 & 0.39686 & 0.40096\end{array}$

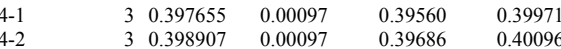

Std Error uses a pooled estimate of error variance Reference Value: 0.399 wt $\%$

Adj Rsquare $\quad 0.36926$

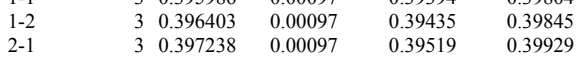

Glass \#=100

Oneway Analysis of K2O (wt\%) By Block/Sub-Block Study Reference Value: $3.327 \mathrm{wt} \%$

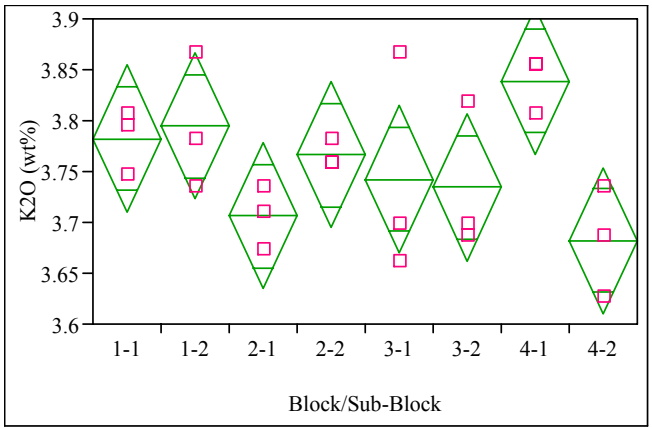

Oneway Anova
Summary of Fit

$\begin{array}{lr}\text { Rsquare } & 0.490168 \\ \text { Adj Rsquare } & 0.267116 \\ \text { Root Mean Square Error } & 0.058808 \\ \text { Mean of Response } & 3.755842 \\ \text { Observations (or Sum Wgts) } & 24\end{array}$

Analysis of Variance

Source DF Sum of Squares Mean Square F Ratio Prob $>$ F

$\begin{array}{lrrrrr}\text { Block/Sub-Block } & 7 & 0.05319953 & 0.007600 & 2.1976 & 0.0911\end{array}$

C. Total

0.10853333

Means for Oneway Anova

Level Number Mean Std Error Lower 95\% Upper 95\%

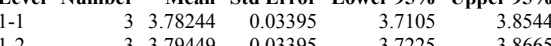

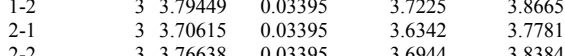

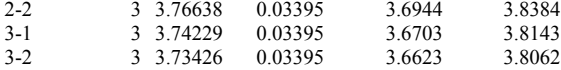

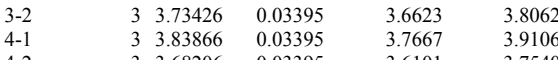

Std Error uses a pooled estimate of error variance 


\section{Exhibit E3. PSAL Measurements by Analytical Block for Samples of the Standard Glasses Prepared Using the LM Method (continued)}

(Batch 1 - Glass \#100; U std - Glass \#200)

Glass \#=100

Oneway Analysis of La2O3 (wt\%) By Block/Sub-Block Study Reference Value: $0.0 \mathrm{wt} \%$

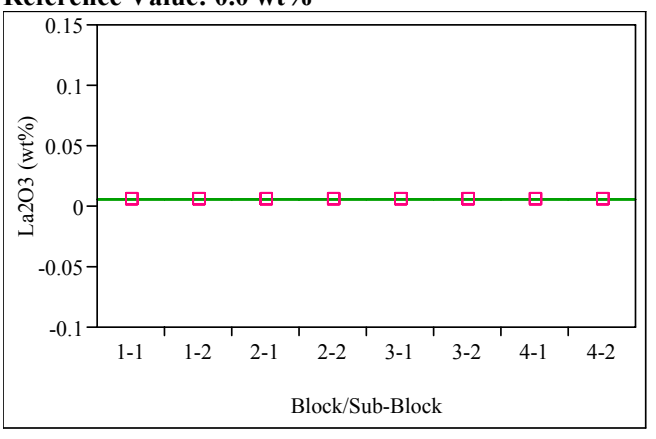

Oneway Anova
Summary of Fit

Rsquare

Adj Rsquare

$\begin{array}{lr}0 \\ \text { Mean of Response } & 0.005864\end{array}$

Observations (or Sum Wgts) $\quad 24$

Analysis of Variance
Source DF Sum of Squares Mean Square F Ratio Prob $>$ F

$\begin{array}{lcrr}\text { Source } & \text { DF } & \text { Sum of Squares } & \text { Mean Square } \\ \text { Block/Sub-Block } & 7 & 0 & 0 \\ \text { Error } & 16 & 0 & 0 \\ \text { C. } & 16 & 0 & \end{array}$

Error
C. Total

16
23

Means for Oneway Anova

$\begin{array}{lrrrrr}\text { Level } & \text { Number } & \text { Mean } & \text { Std Error } & \text { Lower 95\% } & \text { Upper 95\% } \\ 1-1 & 3 & 0.005864 & 0 & 0.00586 & 0.00586 \\ 1-2 & 3 & 0.005864 & 0 & 0.00586 & 0.00586 \\ 2-1 & 3 & 0.005864 & 0 & 0.05586 & 0.00586 \\ 2-2 & 3 & 0.005864 & 0 & 0.00586 & 0.00586 \\ 3-1 & 3 & 0.005864 & 0 & 0.00586 & 0.00586 \\ 3-2 & 3 & 0.005864 & 0 & 0.00586 & 0.00586 \\ 4-1 & 3 & 0.005864 & 0 & 0.00586 & 0.00586 \\ 4-2 & 3 & 0.005864 & 0 & 0.00586 & 0.00586\end{array}$

Std Error uses a pooled estimate of error variance
Glass \#=100

Oneway Analysis of $\mathrm{MgO}(\mathrm{wt} \%)$ By Block/Sub-Block Study Reference Value: $1.419 \mathrm{wt} \%$

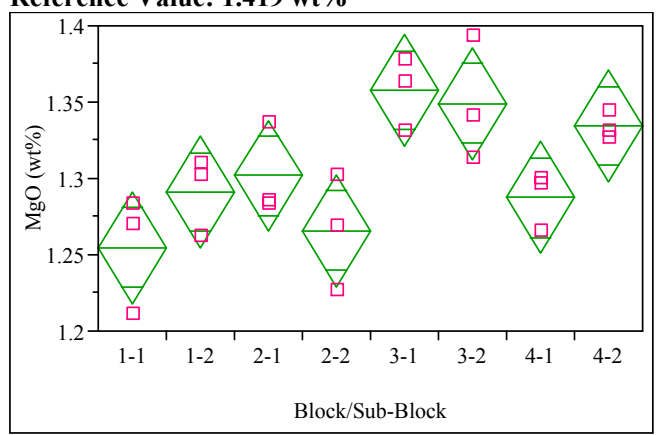

Oneway Anova
Summary of Fit

Rsquare
Adj Rsquare

Mean of Response 1.305289

Observations (or Sum Wgts) $\quad 24$

Analysis of Variance

Source DF Sum of Squares Mean Square F Ratio Prob $>$ F

$\begin{array}{lrrrrr}\text { Block/Sub-Block } & 7 & 0.03046943 & 0.004353 & 4.8847 & 0.004 \\ \text { Error } & 16 & 0.01425762 & 0.000891 & & \end{array}$

C. Total

0.01425762
0.04472705

Means for Oneway Anova

Level Number Mean Std Error Lower 95\% Upper 95\%

$\begin{array}{llllrr}1-1 & 3 & 1.25478 & 0.01723 & 1.2182 & 1.2913 \\ 1-2 & 3 & 1.29126 & 0.01723 & 1.2547 & 1.3278 \\ 2-1 & 3 & 1.30177 & 0.01723 & 1.2652 & 1.3383 \\ 2-2 & 3 & 1.26584 & 0.01723 & 1.2293 & 1.3024 \\ 3-1 & 3 & 1.35759 & 0.01723 & 1.3211 & 1.3941 \\ 3-2 & 3 & 1.34930 & 0.01723 & 1.3128 & 1.3858 \\ 4-1 & 3 & 1.28739 & 0.01723 & 1.2509 & 1.3239 \\ 4-2 & 3 & 1.33438 & 0.01723 & 1.2978 & 1.3709\end{array}$

Std Error uses a pooled estimate of error variance
Glass \#=100

Oneway Analysis of $\mathrm{MnO}(\mathrm{wt} \%)$ By Block/Sub-Block Study Reference Value: 1.726 wt $\%$

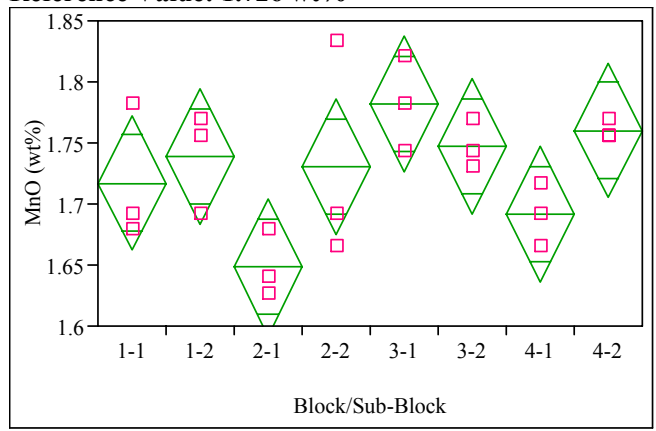

Oneway Anova

Summary of Fit

Rsquare
Adj Rsquare

0.527811 0.045269
1.72698 Observations (or Sum Wgts) $\quad \begin{aligned} 1.72698 \\ 24\end{aligned}$

Analysis of Variance

Source DF Sum of Squares Mean Square F Ratio Prob $>$ F $\begin{array}{lrrrrr}\text { Block/Sub-Block } & 7 & 0.03665056 & 0.005236 & 2.5550 & 0.0570\end{array}$ C. Total 0.06943877

Means for Oneway Anova

Level Number Mean Std Error Lower 95\% Upper 95\% $\begin{array}{llllll}1-1 & 3 & 1.71730 & 0.02614 & 1.6619 & 1.7727 \\ 1-2 & 3 & 1.73882 & 0.02614 & 1.6834 & 1.7942 \\ 2-1 & 3 & 1.64843 & 0.02614 & 1.5930 & 1.7038 \\ 2-2 & 3 & 1.73021 & 0.02614 & 1.6748 & 1.7856 \\ 3-1 & 3 & 1.78186 & 0.02614 & 1.7265 & 1.8373 \\ 3-2 & 3 & 1.77742 & 0.02614 & 1.6920 & 1.8028 \\ 4-1 & 3 & 1.69147 & 0.02614 & 1.6361 & 1.7469 \\ 4-2 & 3 & 1.76034 & 0.02614 & 1.7049 & 1.8157\end{array}$

Std Error uses a pooled estimate of error variance 


\section{Exhibit E3. PSAL Measurements by Analytical Block for Samples of the Standard Glasses Prepared Using the LM Method (continued)}

(Batch 1 - Glass \#100; U std - Glass \#200)

Glass \#=100

Oneway Analysis of Na2O (wt\%) By Block/Sub-Block Stud Reference Value: 9.003 wt $\%$

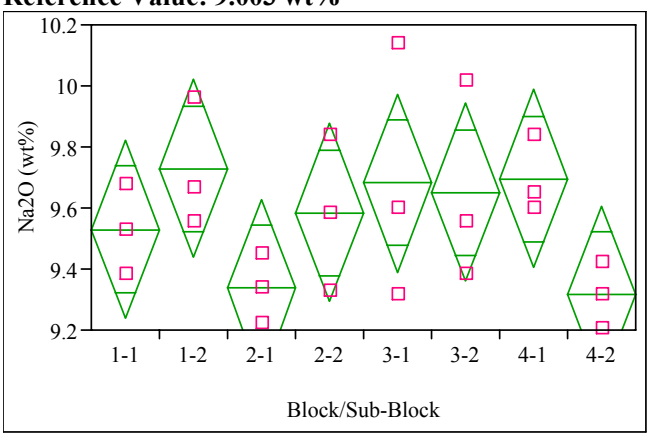

Oneway Anova
Summary of Fit

$\begin{array}{lr}\text { Rsquare } & 0.374919 \\ \text { Adj Rsquare } & 0.101445 \\ \text { Root Mean Square Error } & 0.238216 \\ \text { Mean of Response } & 9.565745 \\ \text { Observations (or Sum Wgts) } & 24\end{array}$

Analysis of Variance

Source $\quad$ DF Sum of Squares Mean Square F Ratio Prob $>$ F

$\begin{array}{lrrrrr}\text { Block/Sub-Block } & 7 & 0.5445785 & 0.077797 & 1.3710 & 0.2827 \\ \text { Error } & 16 & 0.9079463 & 0.056747 & & \end{array}$

C. Total

1.4525248

Means for Oneway Anova

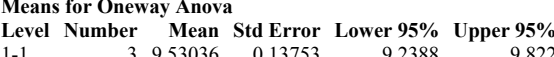

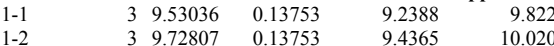

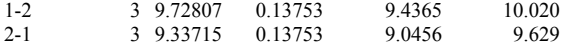

$\begin{array}{llllll}2-2 & 3 & 9.58428 & 0.13753 & 9.2927 & 9.876 \\ 3-1 & 3 & 9.68313 & 0.17753 & 9.3916 & 9.975\end{array}$

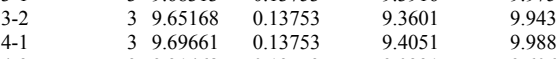

Std Error uses a pooled estimate of error variance
Glass \#=100

Oneway Analysis of PbO (wt\%) By Block/Sub-Block Study Reference Value: $0.0 \mathrm{wt} \%$

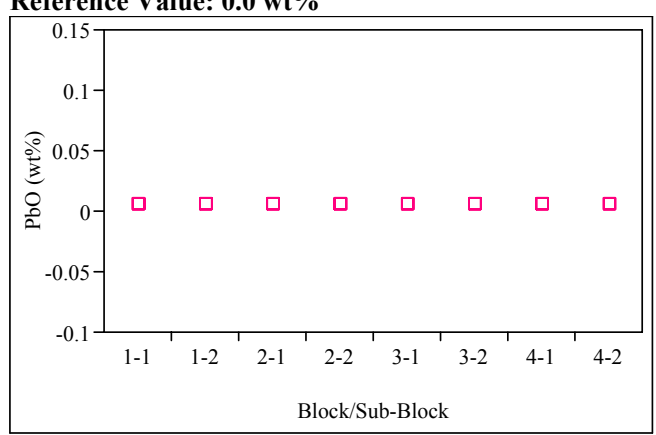

Oneway Anova

Summary of Fit

Rsquare
Adj Rsquare

Root Mean Square Error

Mean of Response

Observations (or Sum Wgts) $\quad \begin{array}{r}0.005386 \\ 24\end{array}$

Analysis of Variance

Source DF Sum of Squares Mean Square F Ratio Prob $>$ F $\begin{array}{llllll}\text { Block/Sub-Block } & 7 & 7.2222 \mathrm{e}-35 & 1.032 \mathrm{e}-35 & -3.0476 & 0.0000\end{array}$ C. Total $-5.417 \mathrm{e}-35$
$1.8056 \mathrm{e}-35$

Means for Oneway Anova

Level Number Mean Std Error Lower 95\% Upper 95\%

$\begin{array}{lrr}1-1 & 3 & 0.005386 \\ 1-2 & 3 & 0.005386\end{array}$

$\begin{array}{lll}2-1 & 3 & 0.005386 \\ 2-2 & 3 & 0.005386 \\ 3-1 & 3 & 0.05386\end{array}$

$\begin{array}{lll}3 & 0.005386\end{array}$

$\begin{array}{llll}3-2 & 3 & 0.005386 \\ 4-1 & 3 & 0.00586\end{array}$

30.005386

Std Error uses a pooled estimate of error variance
Glass \#=100

Oneway Analysis of SO4 (wt\%) By Block/Sub-Block Study Reference Value: $0.0 \mathrm{wt} \%$

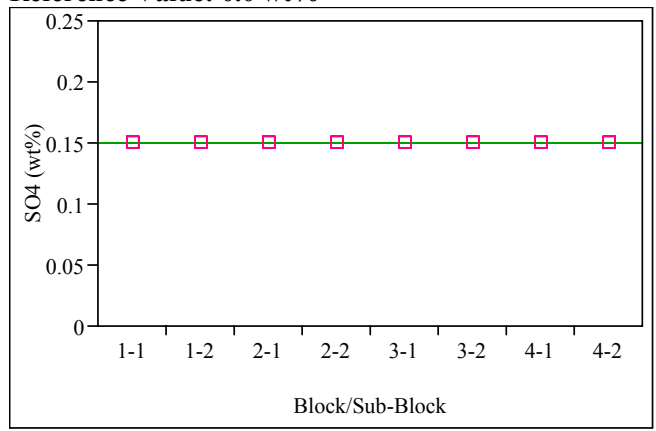

Oneway Anova

Summary of Fit

Rsquare
Adj Rsquare

Adj Rsquare

$\begin{array}{lr}\text { Root Mean Square Error } & 0 \\ \text { Mean of Response } & 0.149795\end{array}$

Observations (or Sum Wgts)

Analysis of Variance

Source DF Sum of Squares Mean Square F Ratio Prob $>$ F

$\begin{array}{lr}\text { Block/Sub-Block } & 7 \\ \text { Error } & 16 \\ \text { C. Total } & 23\end{array}$

Means for Oneway Anova

Level Number Mean Std Error Lower 95\% Upper 95\%

$\begin{array}{llllll}1-1 & 3 & 0.149795 & 0 & 0.14980 & 0.14980 \\ 1-2 & 3 & 0.147995 & 0 & 0.14980 & 0.14980 \\ 2-1 & 3 & 0.149795 & 0 & 0.14980 & 0.14980 \\ 2-2 & 3 & 0.149795 & 0 & 0.14980 & 0.14980 \\ 3-1 & 3 & 0.149795 & 0 & 0.14980 & 0.14980 \\ 3-2 & 3 & 0.149795 & 0 & 0.14980 & 0.14980 \\ 4-1 & 3 & 0.149795 & 0 & 0.14980 & 0.14980 \\ 4-2 & 3 & 0.149795 & 0 & 0.14980 & 0.14980\end{array}$

Std Error uses a pooled estimate of error variance 


\section{Exhibit E3. PSAL Measurements by Analytical Block for Samples of the Standard Glasses Prepared Using the LM Method (continued)}

(Batch 1 - Glass \#100; U std - Glass \#200)

Glass \#=100

Oneway Analysis of ThO2 (wt\%) By Block/Sub-Block Study Reference Value: $0.0 \mathrm{wt} \%$

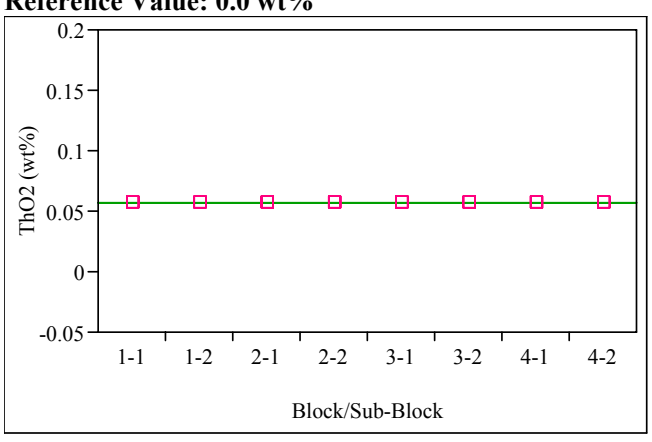

Oneway Anova

Summary of $F$

Rsquare
Adj Rsquare

Root Mean Square Error

$\begin{array}{lr}\text { Mean of Response } & 0.056895 \\ \text { Observations (or Sum Wgts) } & 24\end{array}$ Analysis of Variance
Source

$\begin{array}{ll}\text { Block/Sub-Block } & 7 \\ \text { Error } & 16 \\ \text { C. Total } & 23\end{array}$

Means for Oneway Anova

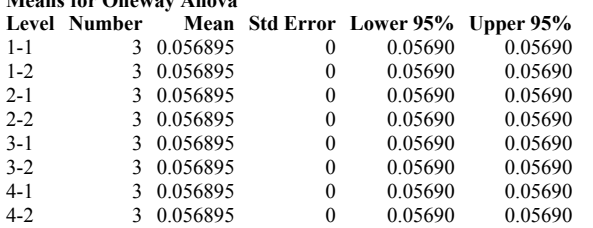

Std Error uses a pooled estimate of error variance
Glass \#=100

Oneway Analysis of TiO2 (wt\%) By Block/Sub-Block Study Reference Value: $0.677 \mathrm{wt} \%$

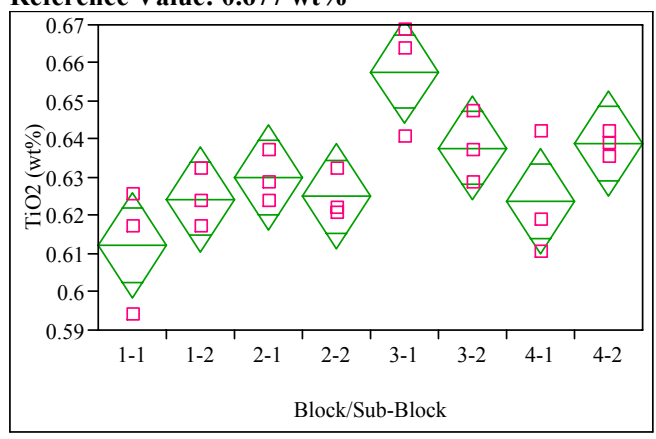

Oneway Anova
Summary of Fi

$\begin{array}{ll}\text { Rsquare } & 0.661334 \\ \text { Adj Rsquare } & 0.513168 \\ \text { Rot Mean Square Error } & 0.011215\end{array}$ Mean of Response $\quad 0.631199$

Observations (or Sum Wgts) $\quad 24$

Analysis of Variance

Source DF Sum of Squares Mean Square F Ratio Prob $>$ F $\begin{array}{lrrrrr}\text { Block/Sub-Block } & 7 & 0.00392989 & 0.000561 & 4.4635 & 0.0063 \\ \text { Error } & 16 & 0.00201248 & 0.000126 & & \end{array}$

C. Total 0.00594237

Means for Oneway Anova

Level Number Mean Std Error Lower 95\% Upper 95\%

$\begin{array}{llllll}1-1 & 3 & 0.612156 & 0.00648 & 0.59843 & 0.62588\end{array}$

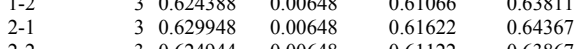

$\begin{array}{lllllll}2-2 & & 3 & 0.624944 & 0.00648 & 0.61122 & 0.63867 \\ 3-1 & & 3 & 0.657748 & 0.00648 & 0.64402 & 0.67147\end{array}$

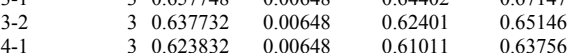

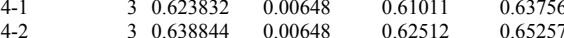

Std Error uses a pooled estimate of error variance
Glass \#=100

Oneway Analysis of $\mathrm{ZnO}(w t \%)$ By Block/Sub-Block Study Reference Value: $0.0 \mathrm{wt} \%$

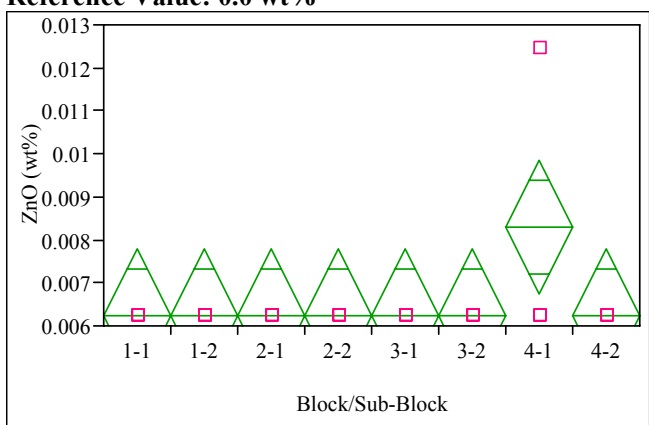

Oneway Anova

Summary of Fit

$\begin{array}{lr}\text { Rsquare } & 0.304348 \\ \text { Adj Rsquare } & 11116\end{array}$

Root Mean Square Error $\quad \begin{array}{rr}1.11 \mathrm{e}-16 \\ 0.00127\end{array}$ $\begin{array}{lr}\text { Mean of Response } & 0.006483 \\ \text { Observations (or Sum Wgts) } & 24\end{array}$

Analysis of Variance
Source DF Sum of Squares Mean Square F Ratio Prob $>$ F $\begin{array}{lrrrrrr}\text { Source } & \text { DF } & \text { Sum of Squares } & \text { Mean Square } & \text { F Ratio } & \text { Prob }>\text { F } \\ \text { Block/Sub-Block } & 7 & 0.00001130 & 1.6141 \mathrm{e}-6 & 1.0000 & 0.4663\end{array}$ $\begin{array}{lll}\text { Error } & 16 & 0.00002583\end{array}$ $1.6141 \mathrm{e}-6$

Means for Oneway Anova

Level Number Mean Std Error Lower 95\% Upper 95\%

$\begin{array}{lllllll}1-1 & 3 & & 0.006224 & 0.00073 & 0.00467 & 0.00778 \\ 1-2 & & 3 & 0.006224 & 0.00073 & 0.0467 & 0.00778\end{array}$

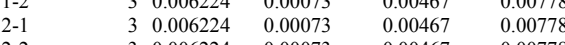

$\begin{array}{lllllll}2-2 & & 3 & 0.006224 & 0.00073 & 0.00467 & 0.00778 \\ 3-1 & & 3 & 0.006224 & 0.00073 & 0.00467 & 0.00778\end{array}$

$\begin{array}{lllllll}3-2 & & 3 & 0.006224 & 0.00073 & 0.00467 & 0.00778 \\ 4-1 & & 3 & 0.008299 & 0.00073 & 0.00674 & 0.00985 \\ 4-2 & & 3 & 0.006224 & 0.00073 & 0.00767 & 0.00778\end{array}$

Std Error uses a pooled estimate of error variance 


\section{Exhibit E3. PSAL Measurements by Analytical Block for Samples of the Standard Glasses Prepared Using the LM Method (continued)}

(Batch 1 - Glass \#100; U std - Glass \#200)

Glass \#=100

Oneway Analysis of ZrO2 (wt\%) By Block/Sub-Block Study Reference Value: 0.098 wt $\%$

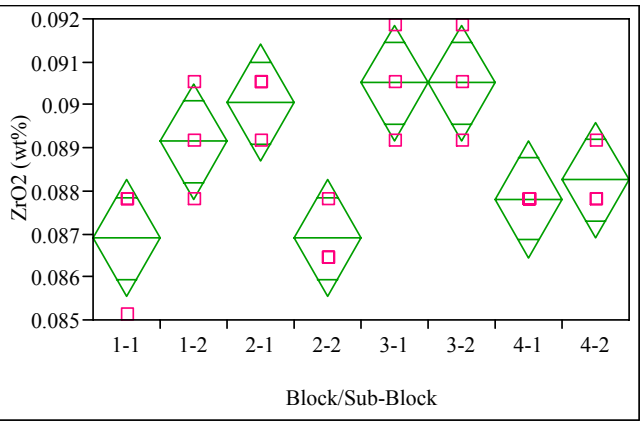

Oneway Anova

Summary of Fit

$\begin{array}{ll}\text { Rsquare } & 0.711387 \\ \text { Adj Rsquare } & 0.585118\end{array}$

Root Mean Square Error $\quad 0.001103$

$\begin{array}{lr}\text { Mean of Response } & 0.088759 \\ \text { Observations (or Sum Wgts) } & 24\end{array}$

Analysis of Variance
Source DF Sum of Squares Mean Square F Ratio Prob >

$\begin{array}{lrrrrr}\text { Source } & \text { DF } & \text { Sum of Squares } & \text { Mean Square } & \text { F Ratio } & \text { Prob }>\text { F } \\ \text { Block/Sub-Block } & 7 & 0.00004797 & 6.8533 \mathrm{e}-6 & 5.6339 & 0.0020\end{array}$

$\begin{array}{llll}\text { Error } & 16 & 0.00001946 & 1.2164 \mathrm{e}-6 \\ \text { C. Total } & 23 & 0.00006744 & \end{array}$

Means for Oneway Anova

Level Number Mean Std Error Lower 95\% Upper 95\%

$\begin{array}{llllll}1-1 & 3 & 0.086901 & 0.00064 & 0.08555 & 0.08825 \\ 1-2 & 3 & 0.089153 & 0.00064 & 0.08780 & 0.09050\end{array}$

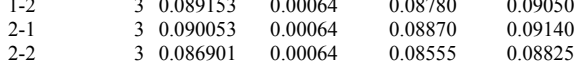

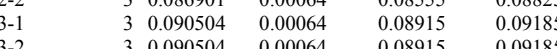

$\begin{array}{lllllll}3-2 & & 3 & 0.090504 & 0.00064 & 0.08915 & 0.09185 \\ 4-1 & & 3 & 0.087802 & 0.00064 & 0.08645 & 0.08915 \\ 4-2 & & 3 & 0.088252 & 0.00064 & 0.08690 & 0.08960\end{array}$

Std Error uses a pooled estimate of error variance
Glass \#=200

Oneway Analysis of BaO (wt\%) By Block/Sub-Block Study Reference Value: $0.0 \mathrm{wt} \%$

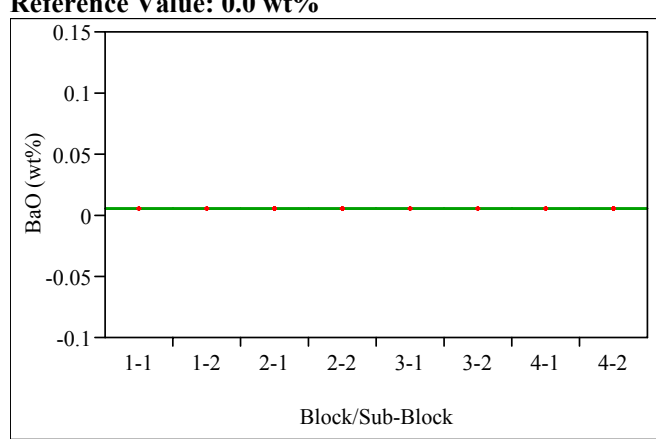

Oneway Anova
Summary of Fi

Rsquare

Adj Rsquare

Root Mean Square Erro

0.005583
Observations (or Sum Wgts)

Analysis of Variance

Source DF Sum of Squares Mean Square F Ratio Prob $>F$

\begin{tabular}{lr} 
Block/Sub-Block & 7 \\
Error & 16 \\
\hline C. & 23
\end{tabular}

Means for Oneway Anova

$\begin{array}{lrrrrr}\begin{array}{l}\text { Means for Oneway Anova } \\ \text { Level }\end{array} & \text { Number } & \text { Mean } & \text { Std Error } & \text { Lower 95\% } & \text { Upper 95\% } \\ 1-1 & 3 & 0.005583 & 0 & 0.00558 & 0.00558 \\ 1-2 & 3 & 0.005583 & 0 & 0.00558 & 0.00558 \\ 2-1 & 3 & 0.005583 & 0 & 0.00558 & 0.00558 \\ 2-2 & 3 & 0.005583 & 0 & 0.00558 & 0.05558 \\ 3-1 & 3 & 0.005583 & 0 & 0.00558 & 0.00558 \\ 3-2 & 3 & 0.005583 & 0 & 0.00558 & 0.00558 \\ 4-1 & 3 & 0.005583 & 0 & 0.00558 & 0.00558 \\ 4-2 & 3 & 0.005583 & 0 & 0.00558 & 0.00558\end{array}$

Std Error uses a pooled estimate of error variance
Glass \#=200

Oneway Analysis of $\mathrm{CaO}(w t \%)$ By Block/Sub-Block Study Reference Value: $1.301 \mathrm{wt} \%$

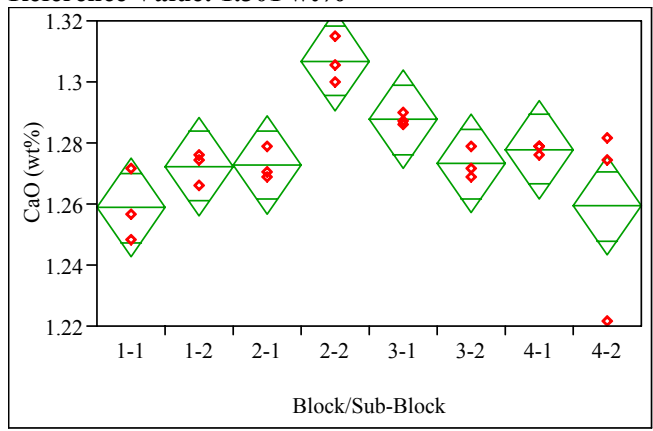

Oneway Anova
Summary of Fit

$\begin{array}{lr}\text { Rsquare } & 0.649128 \\ \text { Adj Rsquare } & 0.495621 \\ \text { Root Mean Square Error } & 0.013123 \\ \text { Mean of Response } & 1.276129 \\ \text { Observations (or Sum Wgts) } & 24\end{array}$

Analysis of Variance

Source DF Sum of Squares Mean Square F Ratio Prob $>$ F

$\begin{array}{lrrrrr}\text { Block/Sub-Block } & 7 & 0.00509727 & 0.000728 & 4.2287 & 0.008\end{array}$

C. Total

0.00785250

Means for Oneway Anova

Level Number Mean Std Error Lower 95\% Upper 95\%

\begin{tabular}{|c|c|c|c|c|}
\hline-1 & $\begin{array}{ll}3 & 1.25881\end{array}$ & 0.00758 & $\begin{array}{r}1.2428 \\
\end{array}$ & $\begin{array}{r}1.2749 \\
\end{array}$ \\
\hline & 1.27234 & 0.00758 & 1.2563 & 1.2884 \\
\hline & $\begin{array}{ll}3 & 1.27281\end{array}$ & 0.00758 & 1.2567 & 1.2889 \\
\hline & 31,30685 & 0.00758 & 1.2908 & 1.3229 \\
\hline & 31.28773 & 0.00758 & 1.2717 & 1.3038 \\
\hline & 1.27327 & 0.00758 & 1.2572 & 1.2893 \\
\hline & 1.27794 & 0.00758 & 1.2619 & 1.2940 \\
\hline $4-$ & 1.25928 & 0.00758 & 1.2432 & 1.2753 \\
\hline
\end{tabular}

Std Error uses a pooled estimate of error variance 


\section{Exhibit E3. PSAL Measurements by Analytical Block for Samples of the Standard Glasses Prepared Using the LM Method (continued)}

(Batch 1 - Glass \#100; U std - Glass \#200)

Glass \#=200

Oneway Analysis of Ce2O3 (wt\%) By Block/Sub-Block Study Reference Value: $0.0 \mathrm{wt} \%$

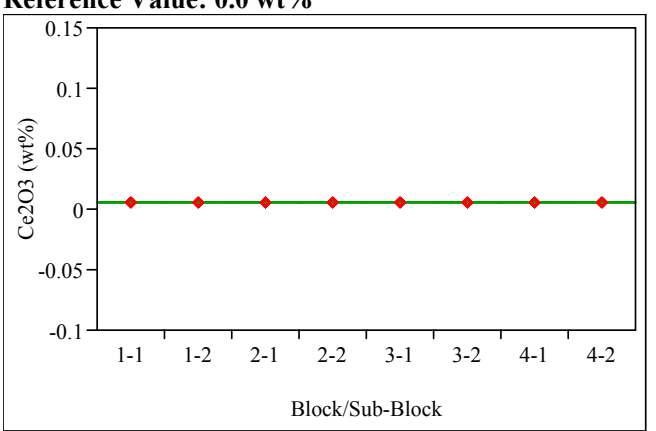

Oneway Anova
Summary of Fit

Rsquare

dj Rsquare

Root Mean Square Erior

$\begin{array}{lr} & 0.005857 \\ \text { Observations (or Sum Wgts) } & 24\end{array}$

Analysis of Variance
Source

$\begin{array}{lrll}\text { Block/Sub-Block } & 7 & 0 & 0 \\ \text { Error } & 16 & 0 & 0 \\ \text { C. Total } & 23 & 0\end{array}$

Means for Oneway Anova

$\begin{array}{lrrrrr}\text { Level Number } & \text { Mean } & \text { Std Error } & \text { Lower 95\% } & \text { Upper 95\% } \\ 1-1 & 3 & 0.005857 & 0 & 0.00586 & 0.00586 \\ 1-2 & 3 & 0.005857 & 0 & 0.00586 & 0.00586 \\ 2-1 & 3 & 0.005557 & 0 & 0.00586 & 0.00586 \\ 2-2 & 3 & 0.055857 & 0 & 0.05586 & 0.00586 \\ 3-1 & 3 & 0.005857 & 0 & 0.00586 & 0.00586 \\ 3-2 & 3 & 0.005857 & 0 & 0.00586 & 0.00586 \\ 4-1 & 3 & 0.005557 & 0 & 0.00586 & 0.00586 \\ 4-2 & 3 & 0.005857 & 0 & 0.00586 & 0.00586\end{array}$

Std Error uses a pooled estimate of error variance
Glass \#=200

Oneway Analysis of Cr2O3 (wt\%) By Block/Sub-Block Study Reference Value: $0.0 \mathrm{wt} \%$

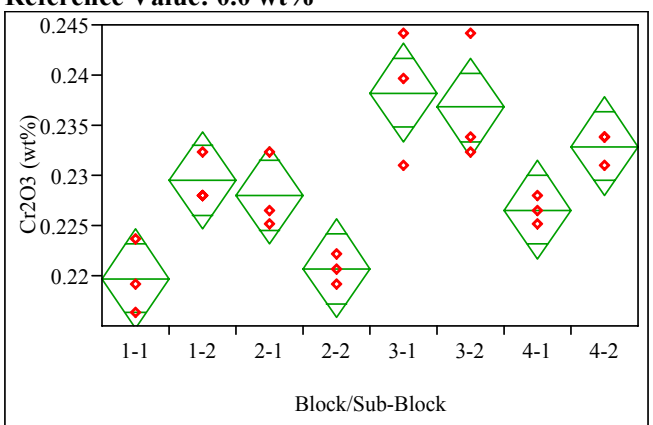

Oneway Anova

Summary of Fit

Rsquare
Adj Rsquare

\subsection{4}

Adj Rsquare $\quad 0.700604$

Root Mean Square Error $\quad 0.003992$

$\begin{array}{lr}\text { Mean of Response } & 0.229045 \\ \text { Observations (or Sum Wgts) } & 24\end{array}$

Analysis of Variance

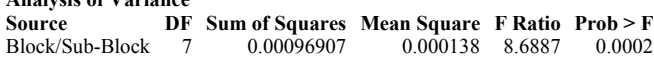
$\begin{array}{lll}\text { Error } & 16 & 0.00025493 \\ \text { C. Total } & 23 & 0.00122400\end{array}$ 0.000016

Means for Oneway Anova

\begin{tabular}{|c|c|c|c|c|}
\hline & & sta Err & & \\
\hline & 0.219727 & 0.00230 & 0.21484 & 0.22461 \\
\hline & 0.229471 & 0.00230 & 0.22459 & \\
\hline & 0.228010 & 0.00230 & 0.22312 & 0.23290 \\
\hline & 0.220 & 0.00230 & 0.2 & 59 \\
\hline & 0.238 & 0.00230 & 0.2 & 13 \\
\hline & 0.236779 & 0.00230 & 0.23189 & 0.24 \\
\hline & 0.2265 & 0.00230 & 0.22166 & 0.2 \\
\hline & (1) & 0.00230 & 0.22800 & \\
\hline
\end{tabular}

Std Error uses a pooled estimate of error variance
Glass \#=200

Oneway Analysis of $\mathrm{CuO}(\mathrm{wt} \%)$ By Block/Sub-Block Study Reference Value: $0.0 \mathrm{wt} \%$

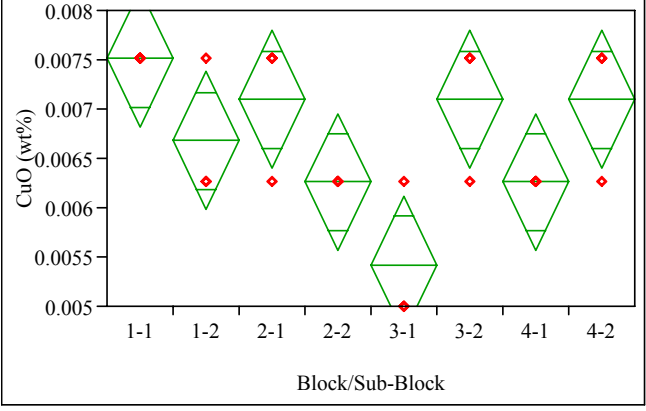

Oneway Anova

$\begin{array}{ll}\text { Rsquare } & 0.642857 \\ \text { Adj Rsquare } & 0.486607\end{array}$

Root Mean Square Error $\quad 0.000571$

$\begin{array}{lr}\text { Mean of Response } & 0.006676 \\ \text { Observations (or Sum Wgts) } & 24\end{array}$

Analysis of Variance

Source DF Sum of Squares Mean Square F Ratio Prob $>$ F

$\begin{array}{lllll} & & & \end{array}$

$\begin{array}{lll}\text { C. Total } & 16 & 0.00000522 \\ & 23 & 0.0000146\end{array}$

$3.2646 \mathrm{e}-7$

$\begin{array}{lllllr}\text { Means for Oneway Anova } & & & \\ \text { Level } & \text { Number } & \text { Mean } & \text { Std Error } & \text { Lower 95\% } & \text { Upper 95\% } \\ 1-1 & 3 & 0.007511 & 0.00033 & 0.00681 & 0.00821 \\ 1-2 & 3 & 0.006676 & 0.00033 & 0.00598 & 0.00738 \\ 2-1 & 3 & 0.007094 & 0.00033 & 0.00639 & 0.00779 \\ 2-2 & 3 & 0.006259 & 0.00033 & 0.00556 & 0.00696 \\ 3-1 & 3 & 0.005424 & 0.00033 & 0.00473 & 0.060612 \\ 3-2 & 3 & 0.007094 & 0.00033 & 0.00639 & 0.00779 \\ 4-1 & 3 & 0.006259 & 0.00033 & 0.00556 & 0.00696 \\ 4-2 & 3 & 0.007094 & 0.00033 & 0.00639 & 0.00779\end{array}$

Std Error uses a pooled estimate of error variance 
Exhibit E3. PSAL Measurements by Analytical Block for Samples of the Standard Glasses Prepared Using the LM Method (continued) (Batch 1 - Glass \#100; U std - Glass \#200)

Glass \#=200

Oneway Analysis of K2O (wt\%) By Block/Sub-Block Study Reference Value: 2.999 wt $\%$

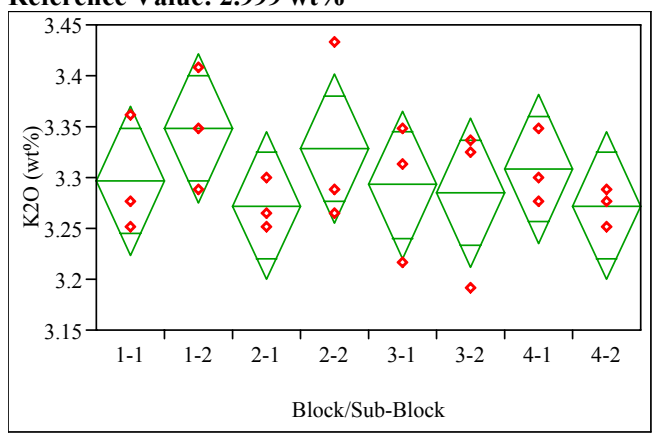

Oneway Anova
Summary of Fit

$\begin{array}{ll}\text { Rsquare } & 0.210667 \\ \text { Adj Rsquare } & -0.13467 \\ \text { Root Mean Square Error } & 0.059827 \\ \text { Mean of Response } & 3.300604\end{array}$

$\begin{array}{lr}\text { Mean of Response } & 3.300604 \\ \text { Observations (or Sum Wgts) } & 24\end{array}$

Analysis of Variance

Source DF Sum of Squares Mean Square F Ratio Prob $>$ F

$\begin{array}{lrllll}\text { Block/Sub-Block } & 7 & 0.01528451 & 0.002184 & 0.6100 & 0.7398 \\ \text { Error } & 16 & 0.05726855 & 0.003579 & & \end{array}$

C. Total

0.05726855
0.07255306

Means for Oneway Anova

Level Number Mean Std Error Lower 95\% Upper 95\%

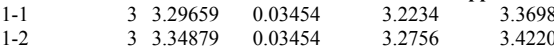

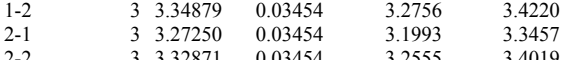

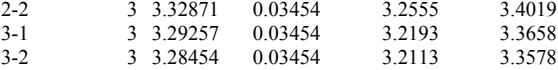

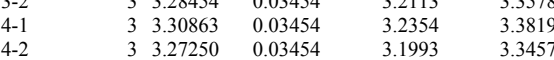

Std Error uses a pooled estimate of error variance
Glass \#=200

Oneway Analysis of La2O3 (wt\%) By Block/Sub-Block Study Reference Value: $0.0 \mathrm{wt} \%$

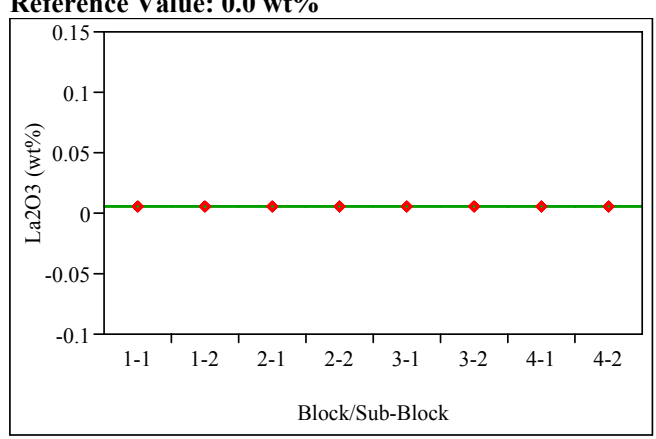

Oneway Anova

Summary of Fit

Rsquare
Adj Rsquare

Root Mean Square

Mean of Response $\quad 0.005864$

Observations (or Sum Wgts) $\quad 24$

Analysis of Variance
Source

$\begin{array}{lccr}\text { Source } & \text { DF } & \text { Sum of Squares } & \text { Mean Square } \\ \text { Block/Sub-Block } & 7 & 0 & 0 \\ \text { Error } & 16 & 0 & 0\end{array}$

Error
C. Total

F Ratio Prob $>$

Means for Oneway Anova

Level Number Mean Std Error Lower 95\% Upper 95\%

$\begin{array}{lllllll}1-1 & & 3 & 0.005864 & 0 & 0.00586 & 0.00586 \\ 1-2 & & 3 & 0.005864 & 0 & 0.0586 & 0.0586\end{array}$

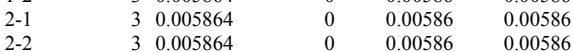

$\begin{array}{llllll}3-1 & 3 & 0.005864 & 0 & 0.00586 & 0.00586\end{array}$

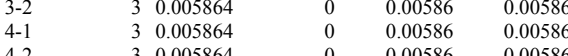

Std Error uses a pooled estimate of error variance
Glass \#=200

Oneway Analysis of $\mathrm{MgO}(\mathrm{wt} \%)$ By Block/Sub-Block Study Reference Value: $1.21 \mathrm{wt} \%$

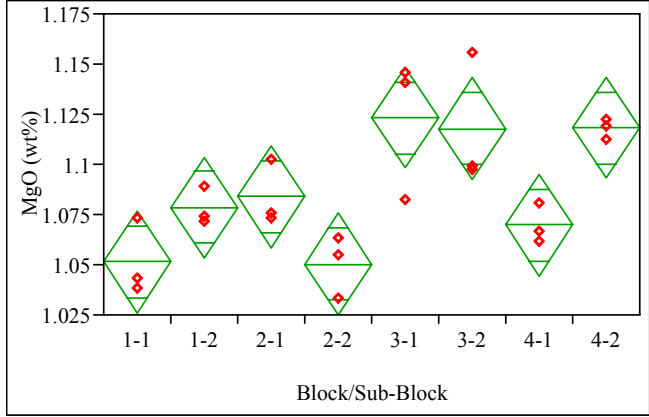

Oneway Anova

Summary of Fit

$\begin{array}{ll}\text { Rsquare } & 0.733003 \\ \text { Adj Rsquare } & 0.616192\end{array}$

Root Mean Square Error $\quad 0.020635$

$\begin{array}{lr}\text { Mean of Response } & 1.086601 \\ \text { Observations (or Sum Wgts) } & 24\end{array}$

Analysis of Variance
Source

$\begin{array}{lrrrrr}\text { Source } & \text { DF } & \text { Sum of Squares } & \text { Mean Square } & \text { F Ratio } & \text { Prob }>\text { F } \\ \text { Block/Sub-Block } & 7 & 0.01870293 & 0.002672 & 6.2751 & 0.0012\end{array}$

\begin{tabular}{lll} 
Error & 16 & 0.00681256 \\
\hline C. Tota & 23 & 0.525
\end{tabular} 0.000426

Means for Oneway Anova

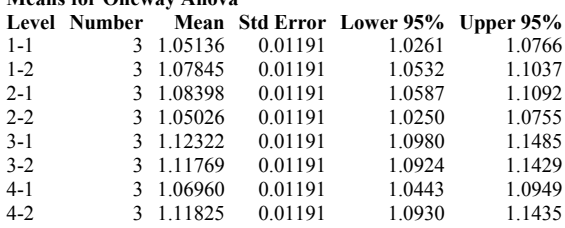

Std Error uses a pooled estimate of error variance 


\section{Exhibit E3. PSAL Measurements by Analytical Block for Samples of the Standard Glasses Prepared Using the LM Method (continued)}

(Batch 1 - Glass \#100; U std - Glass \#200)

Glass \#=200

Oneway Analysis of $\mathrm{MnO}(\mathrm{wt} \%)$ By Block/Sub-Block Study Reference Value: 2.892 wt $\%$

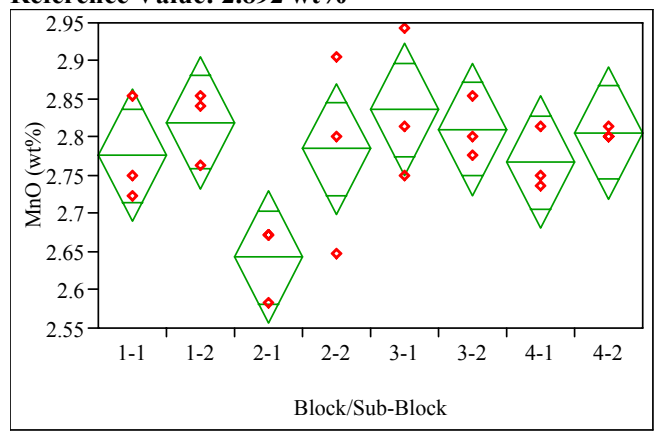

Oneway Anova
Summary of Fit

$\begin{array}{lr}\text { Rsquare } & 0.489286 \\ \text { Adj Rsquare } & 0.265848 \\ \text { Root Mean Square Error } & 0.070476 \\ \text { Mean of Response } & 2.780384 \\ \text { Observations (or Sum Wgts) } & 24\end{array}$

Analysis of Variance

Source DF Sum of Squares Mean Square F Ratio Prob $>$ F

$\begin{array}{lrllll}\text { Block/Sub-Block } & 7 & 0.07613535 & 0.010876 & 2.1898 & 0.092\end{array}$

C. Total

0.15560509

Means for Oneway Anova

Level Number Mean Std Error Lower 95\% Upper 95\%

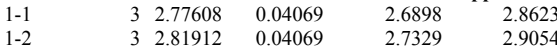

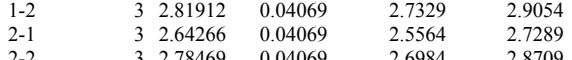

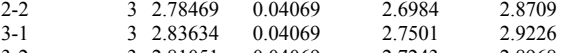

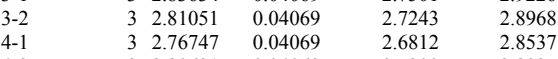

Std Error uses a pooled estimate of error variance
Glass \#=200

Oneway Analysis of Na2O (wt\%) By Block/Sub-Block Stud Reference Value: 11.795 wt $\%$

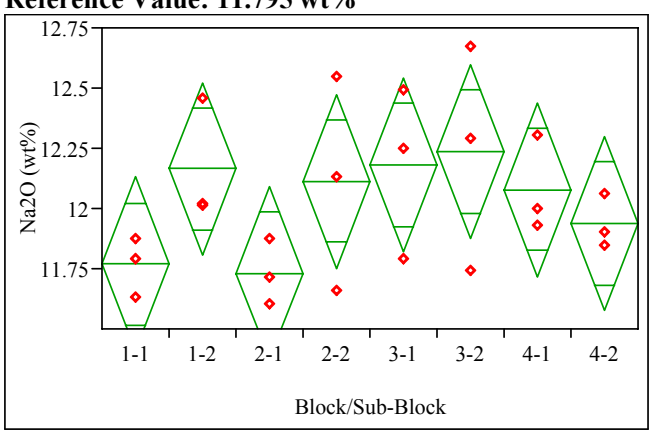

Oneway Anova

Summary of Fit

$\begin{array}{ll}\text { Rsquare } & 0.357719 \\ \text { Adj Rsquare } & 0.076721\end{array}$

Root Mean Square Error $\quad 0.294639$

$\begin{array}{lr}\text { Mean of Response } & 12.02641 \\ \text { Observations (or Sum Wgts) } & 24\end{array}$

Analysis of Variance

$\begin{array}{lrrrrrr}\text { Source } & \text { DF } & \text { Sum of Squares } & \text { Mean Square } & \text { F Ratio } & \text { Prob }>\text { F } \\ \text { Block/Sub-Block } & 7 & 0.7736017 & 0.110515 & 1.2730 & 0.3235\end{array}$

$\begin{array}{lll}\text { Error } & 16 & 1.3889943 \\ \text { C. Total } & 23 & 2.1625960\end{array}$ 0.086812

Means for Oneway Anova

Level Number Mean Std Error Lower 95\% Upper 95\%

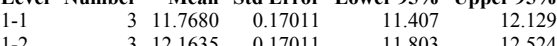

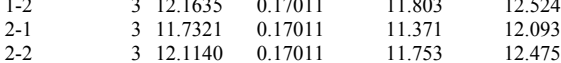

$\begin{array}{llll}3-1 & 3 & 12.1814 & 0.1701 \\ 3-2 & 3 & 12.2353 & 0.17001\end{array}$

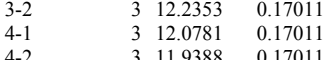

$\begin{array}{ll}11.875 & 12.596 \\ 11.717 & 12.439\end{array}$

Std Error uses a pooled estimate of error variance
Glass \#=200

Oneway Analysis of PbO (wt\%) By Block/Sub-Block Study Reference Value: $0.0 \mathbf{w t} \%$

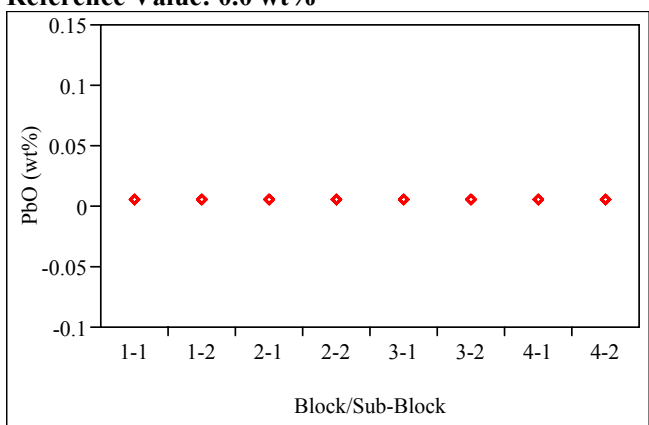

Oneway Anova

Summary of $\mathrm{F}$

Rsquare

$\quad 5.3125$

$\begin{array}{lr}\text { Mean of Response } & 0.005386 \\ \text { Observations (or Sum Wgts) } & 24\end{array}$

Analysis of Variance
Source DF Sum of Squares Mean Square F Ratio Prob $>$ F

$\begin{array}{lrrrrr}\text { Source } & \text { DF } & \text { Sum of Squares } & \text { Mean Square } & \text { F Ratio } & \text { Prob }>\text { F } \\ \text { Block/Sub-Block } & 7 & 7.2222 \mathrm{e}-35 & 1.032 \mathrm{e}-35 & -3.0476 & 0.0000\end{array}$

$\begin{array}{lrr}\text { Block } & 16 & -5.417 \mathrm{e}-35 \\ \text { Error } & 16 & 1.8056 \mathrm{e}-35 \\ \text { C. Total } & 23 & \end{array}$

Means for Oneway Anova

Teror

$\begin{array}{lrr}1-1 & 3 & 0.005386 \\ 1-2 & 3 & 0.005386 \\ 2-1 & 3 & 0.05386\end{array}$

$\begin{array}{lll}1-1 & & \\ 1-2 & 3 & 0.005386 \\ 2-2 & 3 & 0.005386 \\ 3-2 & 3 & 0.005386\end{array}$

$3 \begin{array}{ll}3 & 0.005386\end{array}$

$\begin{array}{lll}3-2 & 3 & 0.005386 \\ 4-1 & 3 & 0.005386 \\ 4-2 & 3 & 0.05386\end{array}$

Std Error uses a pooled estimate of error variance 


\section{Exhibit E3. PSAL Measurements by Analytical Block for Samples of the Standard Glasses Prepared Using the LM Method (continued)}

(Batch 1 - Glass \#100; U std - Glass \#200)

Glass \#=200

Oneway Analysis of SO4 (wt\%) By Block/Sub-Block Study Reference Value: $0.0 \mathrm{wt} \%$

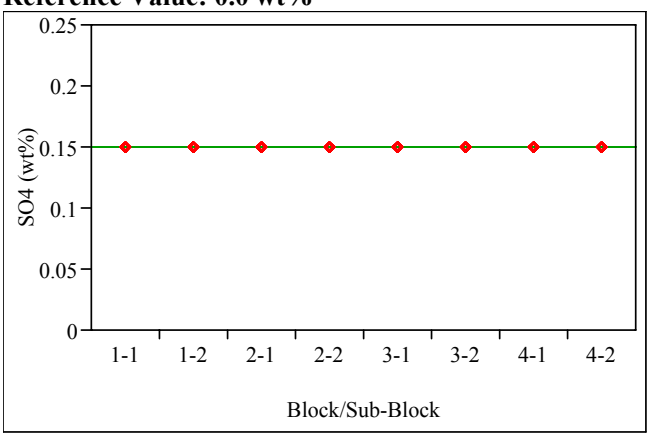

Oneway Anova
Summary of Fit

Rsquare
Adj Rsquare

Adj Rsquare

$\begin{array}{lr}\text { Root Mean Square Error } & 0 \\ \text { Mean of Response } & 0.149795 \\ \text { Observations (or Sum Wgts) } & 24\end{array}$

Analysis of Variance

Source DF Sum of Squares Mean Square F Ratio Prob $>$ F

\begin{tabular}{lr} 
Block/Sub-Block & 7 \\
Error & 16 \\
\hline C. Total & 23
\end{tabular}

Means for Oneway Anova

\begin{tabular}{lrrrrr}
\multicolumn{2}{l}{$\begin{array}{l}\text { Means for Oneway Anova } \\
\text { Level }\end{array}$} & $\begin{array}{c}\text { Number } \\
\text { Mean }\end{array}$ & Std Error & Lower 95\% & Upper 95\% \\
$1-1$ & 3 & 0.149795 & 0 & 0.14980 & 0.14980 \\
$1-2$ & 3 & 0.149795 & 0 & 0.14980 & 0.14980 \\
$2-1$ & 3 & 0.149795 & 0 & 0.14980 & 0.14980 \\
$2-2$ & 3 & 0.14995 & 0 & 0.14980 & 0.14980 \\
$3-1$ & 3 & 0.149795 & 0 & 0.14980 & 0.14980 \\
$3-2$ & 3 & 0.149795 & 0 & 0.14980 & 0.14980 \\
$4-1$ & 3 & 0.149795 & 0 & 0.14980 & 0.14980 \\
$4-2$ & 3 & 0.149795 & 0 & 0.14980 & 0.14980
\end{tabular}

Std Error uses a pooled estimate of error variance
Glass \#=200

Oneway Analysis of ThO2 (wt\%) By Block/Sub-Block Stud Reference Value: $0.0 \mathrm{wt} \%$

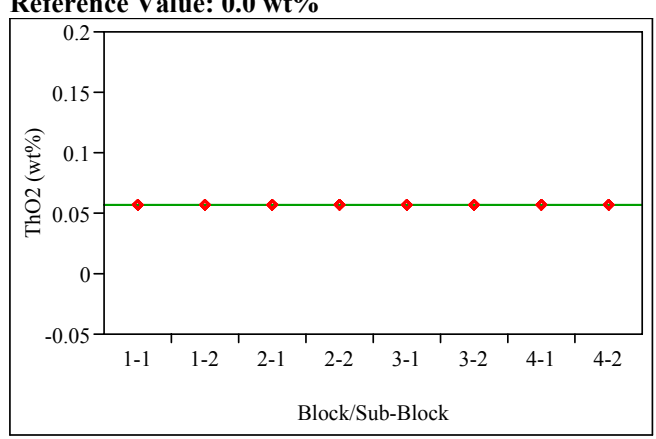

Oneway Anova

Summary of Fit

Rsquare
Adj Rsquare

Root Mean Square Enor

Mean of Response $\quad 0.056895$

Analysis of Variance
Source

$\begin{array}{lccr}\text { Source } & \text { DF } & \text { Sum of Squares } & \text { Mean Square } \\ \text { Block/Sub-Block } & 7 & 0 & 0 \\ \text { Error } & 16 & 0 & 0 \\ \text { C. Total } & 23 & 0 & \end{array}$

F Ratio Prob $>$

Means for Oneway Anova

Level Number Mean Std Error Lower 95\% Upper 95\%

$\begin{array}{lllllll}1-1 & & 3 & 0.056895 & 0 & 0.05690 & 0.05690 \\ 1-2 & & 3 & 0.056895 & 0 & 0.05690 & 0.05690\end{array}$

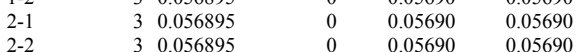

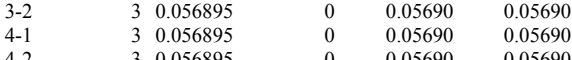

Std Error uses a pooled estimate of error variance
Observations (or Sum Wgts) $\quad 24$

$\begin{array}{llllll}3-1 & 3 & 0.056895 & 0 & 0.05690 & 0.05690\end{array}$
Glass \#=200

Oneway Analysis of TiO2 (wt\%) By Block/Sub-Block Study Reference Value: 1.049 wt $\%$

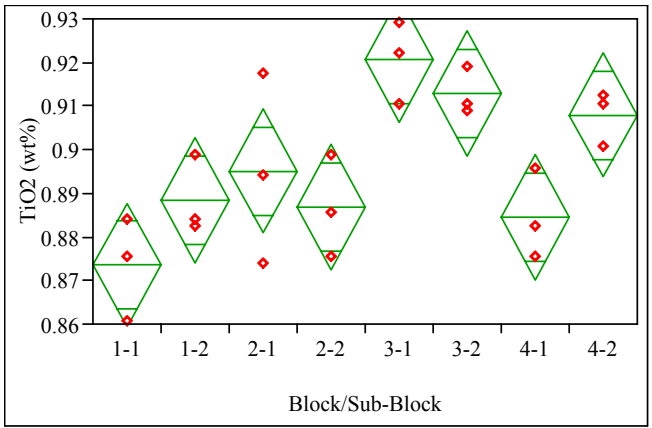

Oneway Anova

Summary of Fit

Rsquare
Adj Rsquare

Mean of Response

Observations (or Sum Wgts) $\quad 24$

Analysis of Variance

Source DF Sum of Squares Mean Square F Ratio Prob $>$ F $\begin{array}{lrrrrr}\text { Block/Sub-Block } & 7 & 0.00546058 & 0.000780 & 5.7172 & 0.0019 \\ \text { Error } & 16 & 0.00218312 & 0.000136 & & \end{array}$

C. Total

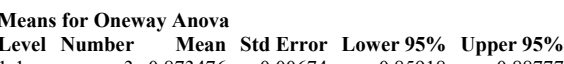

$\begin{array}{lllllll}1-1 & 3 & 0.873476 & 0.00674 & 0.85918 & 0.88777 \\ 1-2 & & 3 & 0.88848 & 0.00674 & 0.87419 & 0.9278\end{array}$

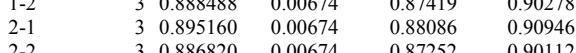

$\begin{array}{lllllll}2-2 & & 3 & 0.886820 & 0.00674 & 0.87252 & 0.90112 \\ 3-1 & & 3 & 0.920736 & 0.00674 & 0.90644 & 0.93503\end{array}$

$\begin{array}{llllll}3-2 & 3 & 0.912952 & 0.00674 & 0.89866 & 0.92725 \\ 4-1 & 3 & 0.884596 & 0.00674 & 0.87630 & 0.9289\end{array}$

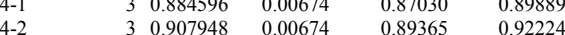

Std Error uses a pooled estimate of error variance 


\section{Exhibit E3. PSAL Measurements by Analytical Block for Samples of the Standard Glasses Prepared Using the LM Method (continued)}

(Batch 1 - Glass \#100; U std - Glass \#200)

Glass \#=200

Oneway Analysis of $\mathrm{ZnO}(\mathrm{wt} \%)$ By Block/Sub-Block Study Reference Value: $0.0 \mathrm{wt} \%$

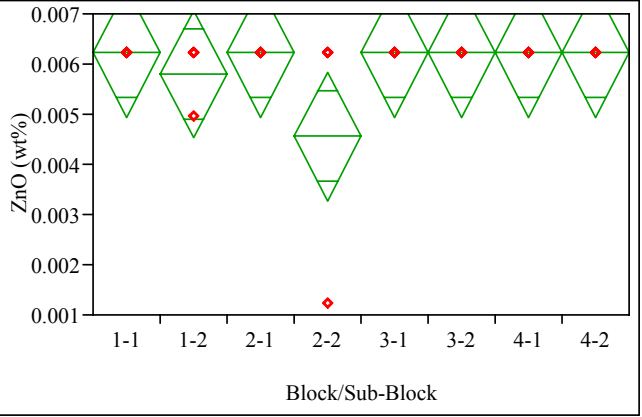

Oneway Anova

Summary of Fit

$\begin{array}{ll}\text { Rsquare } & 0.289817 \\ \text { Adj Rsquare } & -0.02089 \\ \text { Root Mean Square Error } & 0.001048\end{array}$

$\begin{array}{lr}\text { Mean of Response } & 0.005965 \\ \text { Observations (or Sum Wgts) } & 24\end{array}$

Analysis of Variance
Source

$\begin{array}{lrrrrr}\text { Source } & \text { DF } & \text { Sum of Squares } & \text { Mean Square } & \text { F Ratio } & \text { Prob }>\text { F } \\ \text { Block/Sub-Block } & 7 & 0.00000717 & 1.0238 \mathrm{e}-6 & 0.9328 & 0.5084\end{array}$

\begin{tabular}{lll} 
Error & 16 & 0.0000175 \\
\hline
\end{tabular}

$1.0976 \mathrm{e}-6$

Means for Oneway Anova

Level Number Mean Std Error Lower 95\% Upper 95\%

$\begin{array}{llllll}1-1 & 3 & 0.006224 & 0.00060 & 0.00494 & 0.0075 \\ 1-2 & 3 & 0.005809 & 0.0000 & 0.0453 & 0.0709\end{array}$

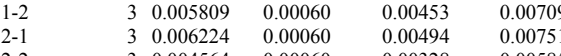

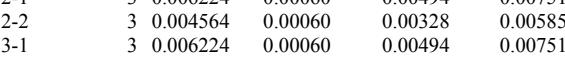

$\begin{array}{lllllll}3-2 & 3 & 0.006224 & 0.00060 & 0.00494 & 0.0075 \\ 4-1 & 3 & 0.006224 & 0.00060 & 0.00494 & 0.0075\end{array}$

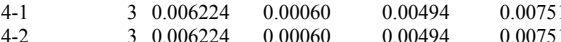

Std Error uses a pooled estimate of error variance
Glass \#=200

Oneway Analysis of ZrO2 (wt\%) By Block/Sub-Block Study Reference Value: $0.0 \mathrm{wt} \%$

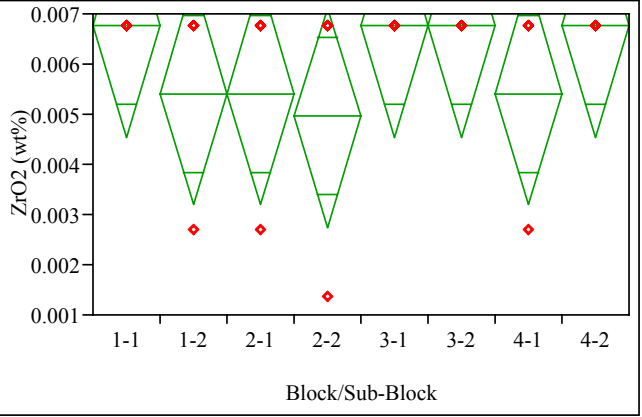

Oneway Anova

Summary of Fit

$\begin{array}{lr}\text { Rsquare } & 0.202781 \\ \text { Adj Rsquare } & -0.146\end{array}$

-0.146
Root Mean Square Error $\quad 0.001808$

$\begin{array}{lr}\text { Mean of Response } & 0.006022 \\ \text { Observations (or Sum Wgts) } & 24\end{array}$

Analysis of Variance
Source DF Sum of Squares Mean Square F Ratio Prob $>$ F

$\begin{array}{lrrrrr}\text { Source } & \text { DF } & \text { Sum of Squares } & \text { Mean Square } & \text { F Ratio } & \text { Prob }>\text { F } \\ \text { Block/Sub-Block } & 7 & 0.00001330 & 0.0000019 & 0.5814 & 0.7613\end{array}$

\begin{tabular}{lll} 
Error & 16 & 0.0000523 \\
\hline C. & 23 & 0.00053
\end{tabular}

$3.2692 \mathrm{e}-6$

Means for Oneway Anova

Level Number Mean Std Error Lower 95\% Upper 95\%

$\begin{array}{lllllll}1-1 & 3 & 0.006754 & 0.00104 & 0.00454 & 0.00897 \\ 1-2 & & 3 & 0.005403 & 0.00104 & 0.00319 & 0.00762\end{array}$

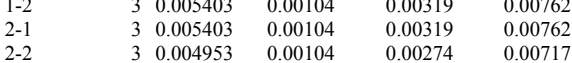

$\begin{array}{llllll}3-1 & 3 & 0.006754 & 0.00104 & 0.00454 & 0.00897\end{array}$

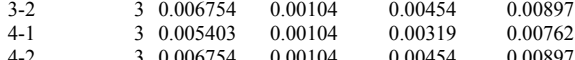

Std Error uses a pooled estimate of error variance 


\section{Exhibit E4: PSAL Measurements by Analytical Block for Samples of the} Standard Glasses Prepared Using the PF Method

(Batch 1 - Glass \#100; U std - Glass \#200)

Glass \#=100

Oneway Analysis of Al2O3 (wt\%) By Block/Sub-BIk Reference Value: $4.877 \mathrm{wt} \%$

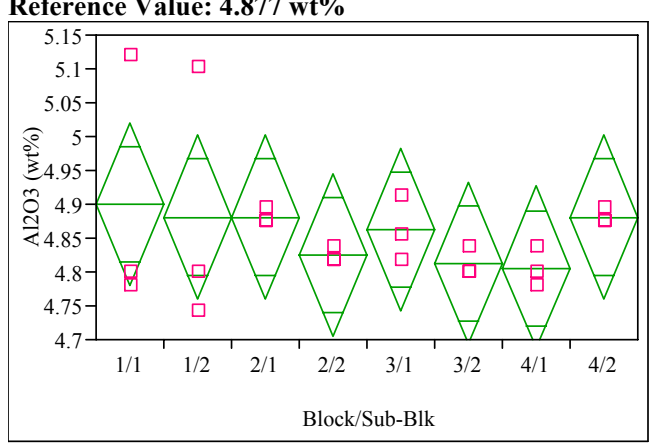

Oneway Anova
Summary of Fit

$\begin{array}{lr}\text { Rsquare } & 0.153048 \\ \text { Adj Rsquare } & -0.21749 \\ \text { Root Mean Square Error } & 0.098559 \\ \text { Mean of Response } & 4.856015 \\ \text { Observations (or Sum Wgts) } & 24\end{array}$

Analysis of Variance

Source DF Sum of Squares Mean Square F Ratio Prob $>$ F

$\begin{array}{lrrr}\text { Block/Sub-Blk } & 7 & 0.02808565 & 0.004012 \\ \text { Error } & 16 & 0.15542315 & 0.009714 \\ \text { C. Total } & 23 & 0.18350881 & \end{array}$

Means for Oneway Anova

Level Number Mean Std Error Lower 95\% Upper 95\%

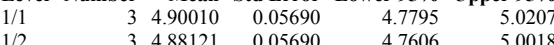

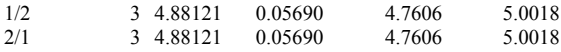

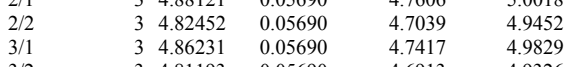

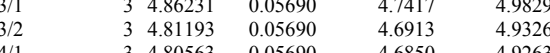

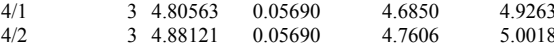

Std Error uses a pooled estimate of error variance

\section{Glass \#=100}

Oneway Analysis of B2O3 (wt\%) By Block/Sub-Blk Reference Value: $7.777 \mathrm{wt} \%$

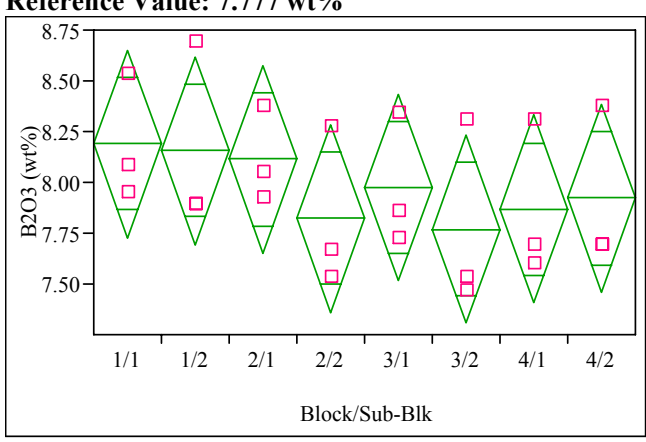

Oneway Anova

Summary of Fit

Rsquare

$\begin{array}{ll}\text { Adj Rsquare } & 0.18918 \\ \text { Root Mean Square Error } & -0.1655 \\ & 0.37751\end{array}$

$\begin{array}{lr}\text { Mean of Response } & 7.977302 \\ \text { Observations (or Sum Wgts) } & 24\end{array}$

Analysis of Variance

Source DF Sum of Squares Mean Square F Ratio Prob $>$ F

$\begin{array}{lrrr}\text { Block/Sub-Blk } & 7 & 0.5320387 & 0.076006 \\ \text { Error } & 16 & 2.2802151 & 0.142513 \\ \text { C. } & 23 & 28122538 & \end{array}$

Means for Oneway Anova

Level Number Mean Std Error Lower 95\% Upper 95\%

$\begin{array}{llllllll}1 / 1 & & 3 & 8.18928 & 0.21796 & 7.7272 & 8.6513 \\ 1 / 2 & & 3 & 8.15708 & 0.21796 & 7.6950 & 8.6191\end{array}$

$\begin{array}{llllll}1 / 2 & 3 & 8.15708 & 0.21796 & 7.6950 & 8.6191 \\ 2 / 1 & 3 & 8.11415 & 0.21796 & 7.6521 & 8.5762 \\ 2 / 2 & 3 & 7.82436 & 0.21796 & 7.3623 & 8.2864 \\ 3 & & 3.9746 & 0.2176 & 7.512 & 8.436\end{array}$

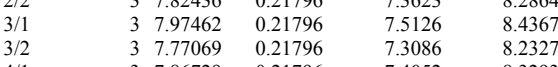

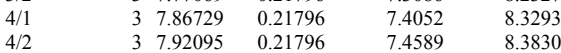

Std Error uses a pooled estimate of error variance

\section{Glass \#=100}

Oneway Analysis of Fe2O3 (wt\%) By Block/Sub-Blk Reference Value: 12.839 wt $\%$

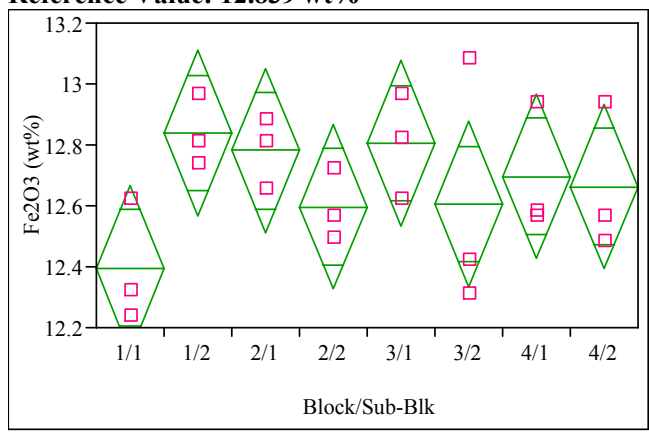

Oneway Anova
Summary of Fit

$\begin{array}{lr}\text { Rsquare } & 0.358571 \\ \text { Adj Rsquare } & 0.077946 \\ \text { Root Mean Square Error } & 0.220505 \\ \text { Mean of Response } & 12.6725 \\ \text { Observations (or Sum Wgts) } & 24\end{array}$

Observations (or Sum

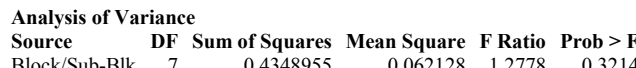

$\begin{array}{lrrr}\text { Block/Sub-Blk } & 7 & 0.4348955 & 0.062128 \\ \text { Error } & 16 & 0.7779624 & 0.048623\end{array}$

$\begin{array}{lll}\text { C. Total } & 23 & 1.2128579\end{array}$

Means for Oneway Anova
Level Number Mean Std Error Lower 95\% Upper 95\%

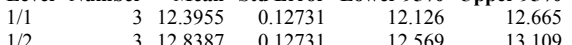

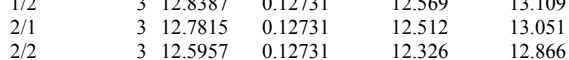

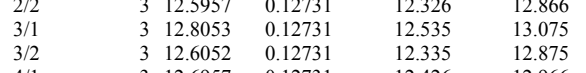

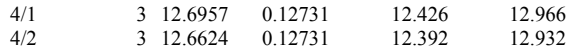

Std Error uses a pooled estimate of error variance 


\section{Exhibit E4: PSAL Measurements by Analytical Block for Samples of the}

Standard Glasses Prepared Using the PF Method (continued)

(Batch 1 - Glass \#100; U std - Glass \#200)

Glass \#=100

Oneway Analysis of Li2O (wt\%) By Block/Sub-Blk Reference Value: $4.429 \mathrm{wt} \%$

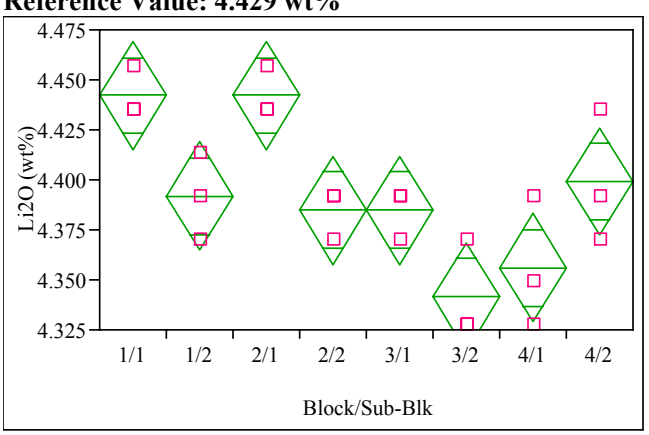

Oneway Anova
Summary of Fit

$\begin{array}{ll} & \\ \text { Rsquare } & 0.777654 \\ \text { Adj Rsquare } & 0.680378 \\ \text { Root Mean Square Error } & 0.021973 \\ \text { Mean of Response } & 4.392813\end{array}$

0.680378
Root Mean Square Error $\quad 0.021973$

$\begin{array}{lr}\text { Mean of Response } & 4.392813 \\ \text { Observations (or Sum Wgts) } & 24\end{array}$

Analysis of Variance
Source DF Sum of Squares Mean Square F Ratio Prob $>$ F

$\begin{array}{lrrrrr}\text { Source } & \text { DF } & \text { Sum of Squares } & \text { Mean Square } & \text { F Ratio } & \text { Prob }>\text { F F } \\ \text { Block/Sub-Blk } & 7 & 0.02701806 & 0.003860 & 7.9943 & 0.0003\end{array}$

$\begin{array}{llll}\text { Error } & 16 & 0.00772496 & 0.000483 \\ \text { C. Total } & 23 & 0.03474303 & \end{array}$

Means for Oneway Anova

$\begin{array}{lrrrrr}\text { Level } & \text { Number } & \text { Mean } & \text { Std Error } & \text { Lower 95\% } & \text { Upper 95\% } \\ 1 / 1 & 3 & 4.44215 & 0.01269 & 4.4153 & 4.4690 \\ 1 / 2 & 3 & 4.39192 & 0.01269 & 4.3650 & 4.4188 \\ 2 / 1 & 3 & 4.44215 & 0.01269 & 4.4153 & 4.4690 \\ 2 / 2 & 3 & 4.38474 & 0.01269 & 4.3578 & 4.4116 \\ 3 / 1 & 3 & 4.38474 & 0.01269 & 4.3578 & 4.4116 \\ 3 / 2 & 3 & 4.34168 & 0.01269 & 4.3148 & 4.3686 \\ 4 / 1 & 3 & 4.35603 & 0.01269 & 4.3291 & 4.3829 \\ 4 / 2 & 3 & 4.39909 & 0.01269 & 4.3722 & 4.4260\end{array}$

Std Error uses a pooled estimate of error variance

\section{Glass \#=100}

Oneway Analysis of NiO (wt\%) By Block/Sub-Blk

Reference Value: $0.751 \mathrm{wt} \%$

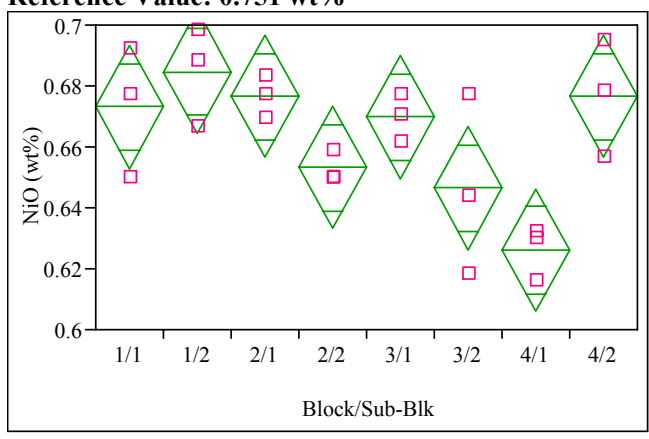

Oneway Anova

Summary of Fit

Rsquare

Adj Rsquare

Root Mean Square

Analysis of Variance

Source DF Sum of Squares Mean Square F Ratio Prob $>$ F

$\begin{array}{llllll}\text { BlockSSub-Blk } & 7 & 0.00814783 & 0.001164 & 4.3162 & 0.0073\end{array}$

$\begin{array}{lll}\text { Error } & 16 & 0.00431478 \\ \text { C. Total } & 23 & 0.01246261\end{array}$

$\begin{array}{llll}\text { Means for Oneway Anova } & & \\ \text { Level Number } & \text { Mean } & \text { Std Error Lower 95\% } & \text { Upper 95\% }\end{array}$

$\begin{array}{lllllll}1 / 1 & & 3 & 0.673153 & 0.00948 & 0.65305 & 0.69325 \\ 1 / 2 & & 3 & 0.684605 & 0.00948 & 0.6451 & 0.72470\end{array}$

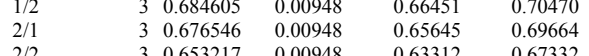

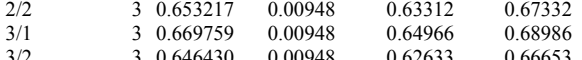

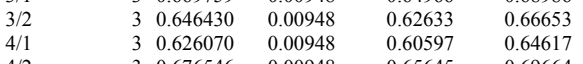

Std Eror ues a poled estimete of error varince

\section{Glass \#=100}

Oneway Analysis of $\mathrm{SiO} 2(\mathrm{wt} \%)$ By Block/Sub-BIk Reference Value: $50.22 \mathrm{wt} \%$

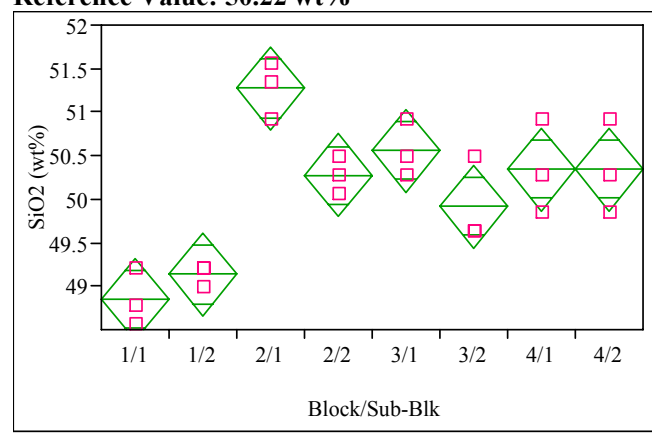

Oneway Anova
Summary of Fit

$\begin{array}{lr}\text { Rsquare } & 0.841664 \\ \text { Adj Rsquare } & 0.772391 \\ \text { Root Mean Square Error } & 0.388132 \\ \text { Mean of Response } & 50.08636 \\ \text { Observations (or Sum Wgts) } & 24\end{array}$

Analysis of Variance

Source DF Sum of Squares Mean Square F Ratio Prob $>F$

$\begin{array}{lrrrrr}\text { Block/Sub-Blk } & 7 & 12.812586 & 1.83037 & 12.1501 & <.0001\end{array}$

$\begin{array}{llr}\text { C. Total } & 23 & 15.410293 \\ \end{array}$

Means for Oneway Anova
Level Number Mean Std Error Lower 95\% Upper 95\%

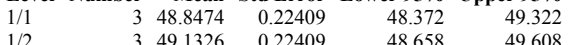

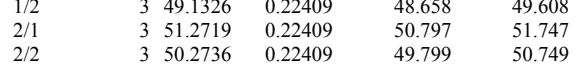

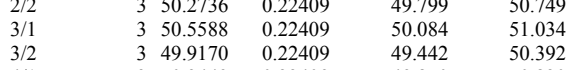

$\begin{array}{lllllll}4 / 1 & & 3 & 50.3449 & 0.22409 & 49.870 & 50.820 \\ 4 / 2 & & 3 & 503449 & 0.2409 & 49.870 & 50.820\end{array}$

Std Error uses a pooled estimate of error variance 


\section{Exhibit E4: PSAL Measurements by Analytical Block for Samples of the}

Standard Glasses Prepared Using the PF Method (continued)

(Batch 1 - Glass \#100; U std - Glass \#200)

Glass \#=100

Oneway Analysis of U3O8 (wt\%) By Block/Sub-Blk Reference Value: $0.0 \mathrm{wt} \%$

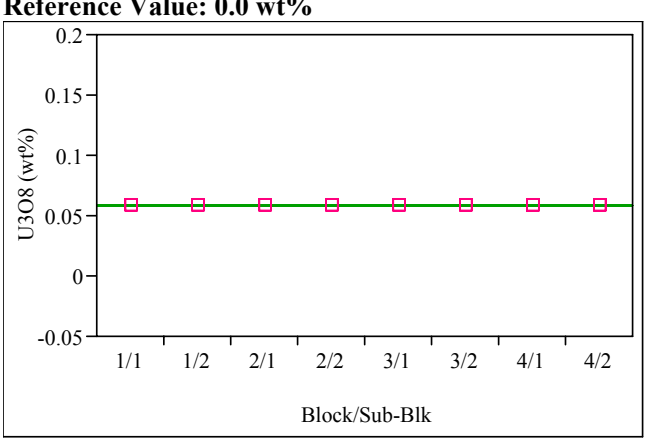

Oneway Anova

Rsquare

Adj Rsquare

Root Mean Square $\mathrm{E}$
Mean of Response

0.05896
Observations (or Sum Wgts)

Analysis of Variance

Source DF Sum of Squares Mean Square F Ratio Prob $>$ F \begin{tabular}{lrrr} 
Source & DF & Sum of Squares & Mean Square \\
Block/Sub-Blk & 7 & $4.6222 \mathrm{e}-33$ & $6.603 \mathrm{e}-34$ \\
\hline
\end{tabular}

$\begin{array}{llr}\text { Error } & 16 & 0 \\ \text { C. Total } & 23 & 4.6222 \mathrm{e}-33\end{array}$

Means for Oneway Anova

$\begin{array}{lrrrrr}\text { Level Number } & \text { Mean } & \text { Std Error } & \text { Lower 95\% } & \text { Upper 95\% } \\ 1 / 1 & 3 & 0.058960 & 0 & 0.05896 & 0.05896 \\ 1 / 2 & 3 & 0.058960 & 0 & 0.05896 & 0.05896 \\ 2 / 1 & 3 & 0.058960 & 0 & 0.05896 & 0.05896 \\ 2 / 2 & 3 & 0.058960 & 0 & 0.05896 & 0.05896 \\ 2 / 2 & 3 & 0.058960 & 0 & 0.05896 & 0.05896 \\ 3 / 1 & 3 & 0.058960 & 0 & 0.05896 & 0.05896 \\ 3 / 2 & 3 & 0.058960 & 0 & 0.05896 & 0.05896 \\ 4 / 1 & 3 & 0.058960 & 0 & 0.05896 & 0.05896\end{array}$

Std Error uses a pooled estimate of error variance

\section{Glass \#=200}

Oneway Analysis of Al2O3 (wt\%) By Block/Sub-Blk Reference Value: $4.1 \mathrm{wt} \%$

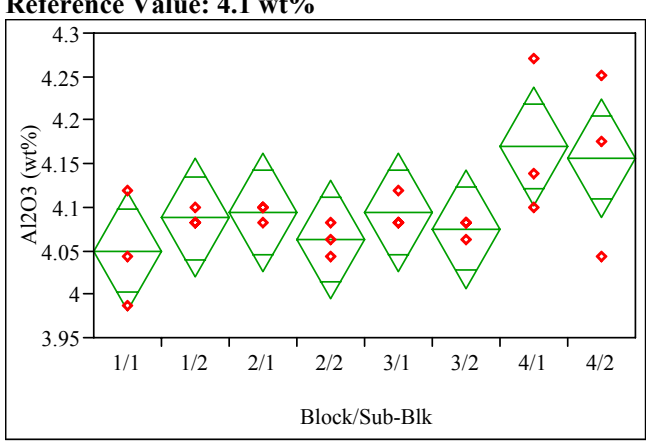

Oneway Anova

Summary of Fit

$\begin{array}{lr}\text { Rsquare } & 0.438644 \\ \text { Adj Rsquare } & 0.193051 \\ \text { Root Mean Square Error } & 0.055491 \\ \text { Mean of Response } & 4.09864 \\ \text { Observations (or Sum Wgts) } & 24\end{array}$

Observations (or Sum

Analysis of Variance

Source DF Sum of Squares Mean Square F Ratio Prob $>$ F

\begin{tabular}{lllll}
0.03849877 & 0.005500 & 1.7861 & 0.1593 \\
\hline
\end{tabular}

$\begin{array}{lll}\text { Error } & 16 & 0.04926890 \\ \text { C. Total } & 23 & 0.08776767\end{array}$

Means for Oneway Anova
Level Number Mean Std Error Lower 95\% Upper 95\%

$\begin{array}{llllll}1 / 1 & 3 & 4.04983 & 0.03204 & 3.9819 & 4.1177 \\ 1 / 2 & 3 & 4.08762 & 0.03204 & 4.0197 & 4.1555\end{array}$

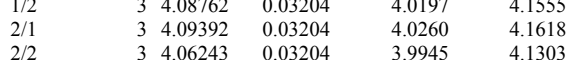

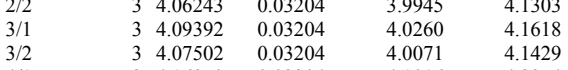

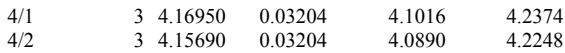

Std Error uses a pooled estimate of error variance

\section{Glass \#=200}

Oneway Analysis of B2O3 (wt\%) By Block/Sub-Blk Reference Value: 9.209 wt $\%$

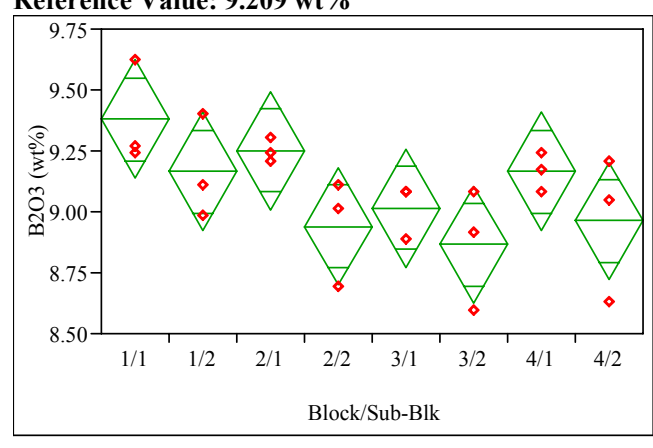

Oneway Anova
Summary of Fit

$\begin{array}{lr}\text { Rsquare } & 0.510791 \\ \text { Adj Rsquare } & 0.296763 \\ \text { Root Mean Square Error } & 0.197287 \\ \text { Mean of Response } & 9.093534 \\ \text { Observations (or Sum Wgts) } & 24\end{array}$

Observations (or Sum Walysis of Variane

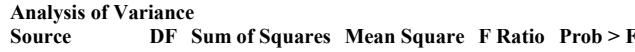

$\begin{array}{lrrrrrr}\text { Source } & \text { DF } & \text { Sum of Squares } & \text { Mean Square } & \text { F Ratio } & \text { Prob }>\text { F } \\ \text { Block/Sub-Blk } & 7 & 0.6502311 & 0.092890 & 2.3866 & 0.0709\end{array}$

$\begin{array}{lrrr}\text { Block/Sub-Blk } & 7 & 0.6502311 & 0.092890 \\ \text { Error } & 16 & 0.6227565 & 0.038922 \\ \text { C. Total } & 23 & 1.2729876\end{array}$

Means for Oneway Anova

Level Number Mean Std Error Lower 95\% Upper 95\%

$\begin{array}{llllll}1 / 1 & 3 & 9.38064 & 0.11390 & 9.1392 & 9.622 \\ 1 / 2 & 3 & 9.16598 & 0.11390 & 8.9245 & 9.4074\end{array}$

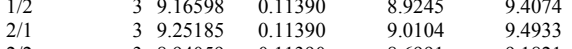

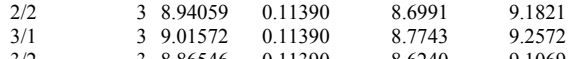

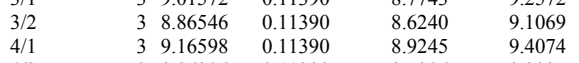

Std Error uses a pooled estimate of error variance 


\section{Exhibit E4: PSAL Measurements by Analytical Block for Samples of the}

Standard Glasses Prepared Using the PF Method (continued)

(Batch 1 - Glass \#100; U std - Glass \#200)

Glass \#=200

Oneway Analysis of Fe2O3 (wt\%) By Block/Sub-Blk Reference Value: $13.196 \mathrm{wt} \%$

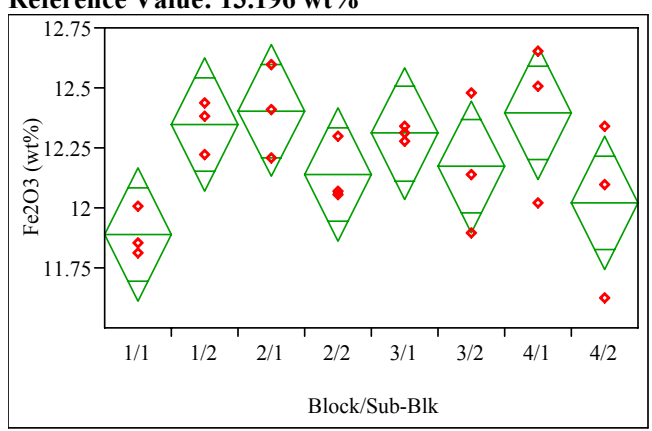

Oneway Anova

ummary of $F$

$\begin{array}{lr}\text { Rsquare } & 0.475777 \\ \text { Adj Rsquare } & 0.24643 \\ \text { Root Mean Square Error } & 0.225754 \\ \text { Mean of Response } & 12.20964\end{array}$

$\begin{array}{lr}\text { Mean of Response } & 12.20964 \\ \text { Observations (or Sum Wgts) } & 24\end{array}$

$\begin{array}{lrrrrr}\text { Analysis of Variance } & & & & \\ \text { Source } & \text { DF } & \text { Sum of Squares } & \text { Mean Square } & \text { F Ratio } & \text { Prob }>\text { F } \\ \text { Block/Sub-Blk } & 7 & 0.7400795 & 0.105726 & 2.0745 & 0.1075\end{array}$

$\begin{array}{llll}\text { Error } & 16 & 0.8154365 & 0.050965 \\ \text { C. Total } & 23 & 1.5555160 & \end{array}$

Means for Oneway Anova

\begin{tabular}{|c|c|c|c|c|c|}
\hline & & & & & \\
\hline & & Yean & Std Er & Lower 95\% & Upper $\mathbf{9 5 \%}$ \\
\hline $1 / 1$ & & 11.8903 & 0.13034 & 11.614 & 12.167 \\
\hline $1 / 2$ & 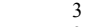 & 12.3478 & 0.13034 & 12.072 & 12.624 \\
\hline & 3 & $\begin{array}{l}12.4050 \\
12.1382\end{array}$ & $\begin{array}{l}0.13034 \\
0.13034\end{array}$ & $\begin{array}{l}12.129 \\
11.862\end{array}$ & $\begin{array}{l}12.681 \\
12.414\end{array}$ \\
\hline & 3 & 12.3097 & 0.13034 & 12.033 & 12.586 \\
\hline & & 12.1715 & 0.13034 & 11.895 & 12.448 \\
\hline & & 12.3955 & 0.13034 & 12.119 & 12.672 \\
\hline
\end{tabular}

Std Error uses a pooled estimate of error variance

\section{Glass \#=200}

Oneway Analysis of Li2O (wt\%) By Block/Sub-Blk

Reference Value: $3.057 \mathrm{wt} \%$

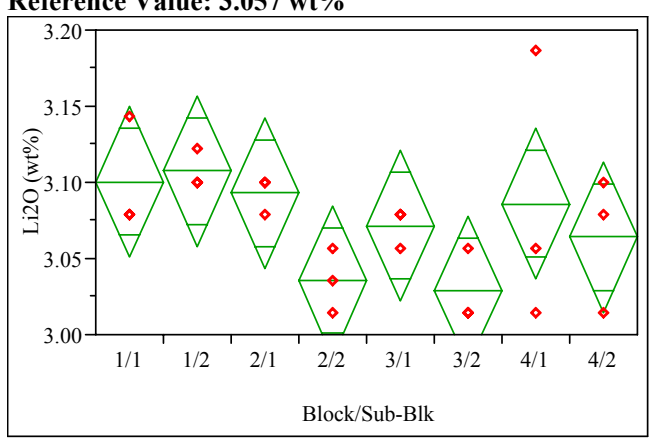

Oneway Anova

Summary of Fit

$\begin{array}{lr}\text { Rsquare } & 0.407407 \\ \text { Adj Rsquare } & 0.148148 \\ \text { Root Mean Square Error } & 0.040277 \\ \text { Mean of Response } & 3.073265 \\ \text { Observations (or Sum Wgts) } & 24\end{array}$

Observations (or S

Analysis of Variance

Source DF Sum of Squares Mean Square F Ratio Prob $>$ F

$\begin{array}{llll}0.01784467 & 0.002549 & 1.5714 & 0.2143\end{array}$

$\begin{array}{lll}\text { Error } & 16 & 0.02595588 \\ \text { C. Total } & 23 & 0.04380055\end{array}$ 0.001622

Means for Oneway Anova

Level Number Mean Std Error Lower 95\% Upper 95\%

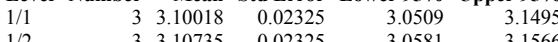

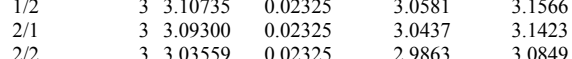

$\begin{array}{llllll}2 / 2 & 3 & 3.03559 & 0.02325 & 2.9863 & 3.0849 \\ 3 / 1 & 3 & 3.07147 & 0.02325 & 3.0222 & 3.1208 \\ 3 / 2 & 3 & 3.02841 & 0.02325 & 2.9791 & 3.0777\end{array}$

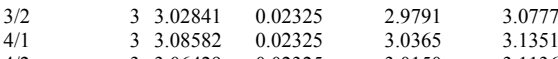

Std Error uses a pooled estimate of error variance

\section{Glass \#=200}

Oneway Analysis of NiO (wt\%) By Block/Sub-Blk Reference Value: 1.12 wt\%

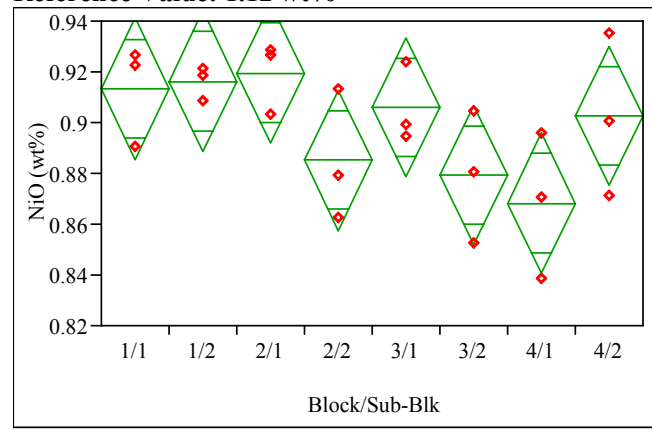

Oneway Anova

Summary of Fit

Rsquare

$\begin{array}{ll}\text { Adj Rsquare } & 0.480679 \\ \text { Root Mean Square } & 0.253476\end{array}$ Mean of Response $\quad \begin{array}{ll}0.022534 \\ 0.898809\end{array}$

Observations (or Sum Wgts)

Analysis of Variance

Source DF Sum of Squares Mean Square F Ratio Prob $>$ F

$\begin{array}{llll}\text { Block/Sub-Bk } & 7 & 0.00751983 & 0.001074 \\ \text { Error } & 16 & 0.00812435 & 0.000508 \\ \text { C. } & & & \end{array}$

$\begin{array}{lll}\text { C. Total } & 23 & 0.01564417\end{array}$

Means for Oneway Anova
Level Number Mean Std Error Lower 95\% Upper 95\%

$\begin{array}{lllllll}1 / 1 & & 3 & 0.913231 & 0.01301 & 0.88565 & 0.94081 \\ 1 / 2 & & 3 & 0.916200 & 0.01301 & 0.88862 & 0.94378\end{array}$

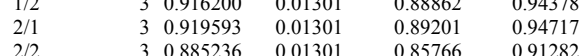

$\begin{array}{lllllll}2 / 2 & & 3 & 0.885236 & 0.01301 & 0.85766 & 0.91282 \\ 3 / 1 & & 3 & 0.906020 & 0.01301 & 0.87844 & 0.93360\end{array}$

$\begin{array}{lllllll}3 / 2 & 3 & 0.879298 & 0.01301 & 0.85172 & 0.90688 \\ 4 / 1 & & 3 & 0.868269 & 0.01301 & 0.8406 & 0.8985\end{array}$

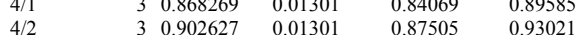

Std Error uses a pooled estimate of error variance 


\section{Exhibit E4: PSAL Measurements by Analytical Block for Samples of the} Standard Glasses Prepared Using the PF Method (continued)

(Batch 1 - Glass \#100; U std - Glass \#200)

Glass \#=200

Oneway Analysis of SiO2 (wt\%) By Block/Sub-Blk Reference Value: $\mathbf{4 5 . 3 5 3} \mathrm{wt} \%$

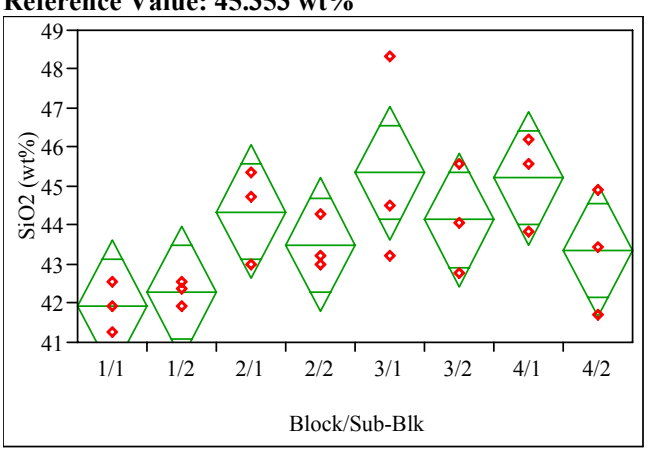

Oneway Anova

$\begin{array}{lr} & \\ \text { Rsquare } & 0.511403 \\ \text { Adj Rsquare } & 0.297642 \\ \text { Root Mean Square Error } & 1.396702 \\ \text { Mean of Response } & 43.76651 \\ \text { Observations (or Sum Wgts) } & 24\end{array}$

Analysis of Varianc

$\begin{array}{lrrrrr}\text { Source } & \text { DF } & \text { Sum of Squares } & \text { Mean Square } & \text { F Ratio } & \text { Prob }>\text { F F } \\ \text { Block/Sub-Blk } & 7 & 32.669328 & 4.66705 & 2.3924 & 0.0704\end{array}$

$\begin{array}{lll}\text { Error } & 16 & 31.2124 \\ \text { C. Tot } & 23 & 63.88177\end{array}$

Means for Oneway Anova

Level Number Mean Std Error Lower 95\% Upper 95\%

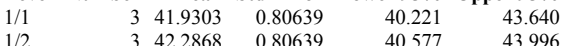

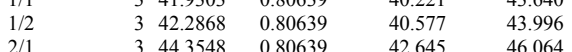

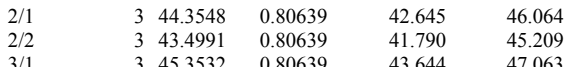

\begin{tabular}{lllll}
3 & 4.4 .1409 & 0.80639 & 43.644 & 47.063 \\
\hline & 0.431 & 45.850
\end{tabular}

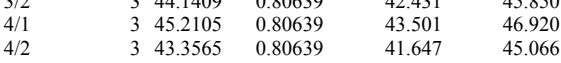

Std Error uses a pooled estimate of error variance
Glass \#=200

Oneway Analysis of U3O8 (wt\%) By Block/Sub-BIk

Reference Value: $2.406 \mathrm{wt} \%$

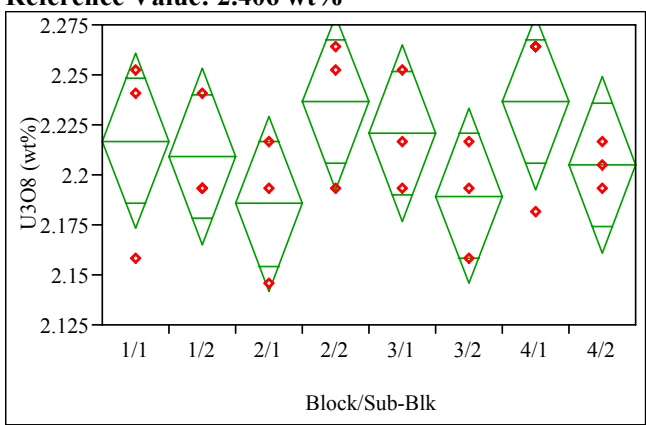

Oneway Anova

Summary of Fit

$\begin{array}{ll}\text { Rsquare } & 0.273174 \\ \text { Adj Rsquare } & -0.04481\end{array}$

Root Mean Square Error $\quad 0.03586$

$\begin{array}{lr}\text { Mean of Response } & 2.212474 \\ \text { Observations (or Sum Wgts) } & 24\end{array}$

$\begin{array}{lrrrrr}\begin{array}{l}\text { Source } \\ \text { Source }\end{array} & \text { Sum of Squares } & \text { Mean Square } & \text { F Ratio } & \text { Prob }>\text { F } \\ \text { Block/Sub-Blk } & 7 & 0.00773473 & 0.001105 & 0.8591 & 0.5575\end{array}$

$\begin{array}{lll}\text { Error } & 16 & 0.02057959 \\ \text { C. Total } & 23 & 0.02831431\end{array}$

Means for Oneway Anova

Level Number Mean Std Error Lower 95\% Upper 95\%

$\begin{array}{lllllll}1 / 1 & 3 & 2.21690 & 0.02071 & 2.1730 & 2.2608 \\ 1 / 2 & & 3 & 220903 & 0.02071 & 2.1651 & 2.2529\end{array}$

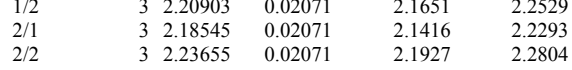

$\begin{array}{llll}3 / 1 & 3 & 2.22083 & 0.02071\end{array}$

\begin{tabular}{llllll}
$3 / 2$ & 3 & 2.18938 & 0.02071 & 2.1455 & 2.2333 \\
\hline
\end{tabular}

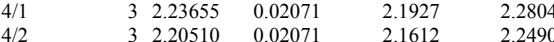

Std Error uses a pooled estimate of error variance 
Exhibit E5. Measured and Measured Bias-Corrected Oxide Weight Percents by Glass \# for the Glasses Prepared Using the LM Method

(100 - Batch 1; 200 - Ustd)
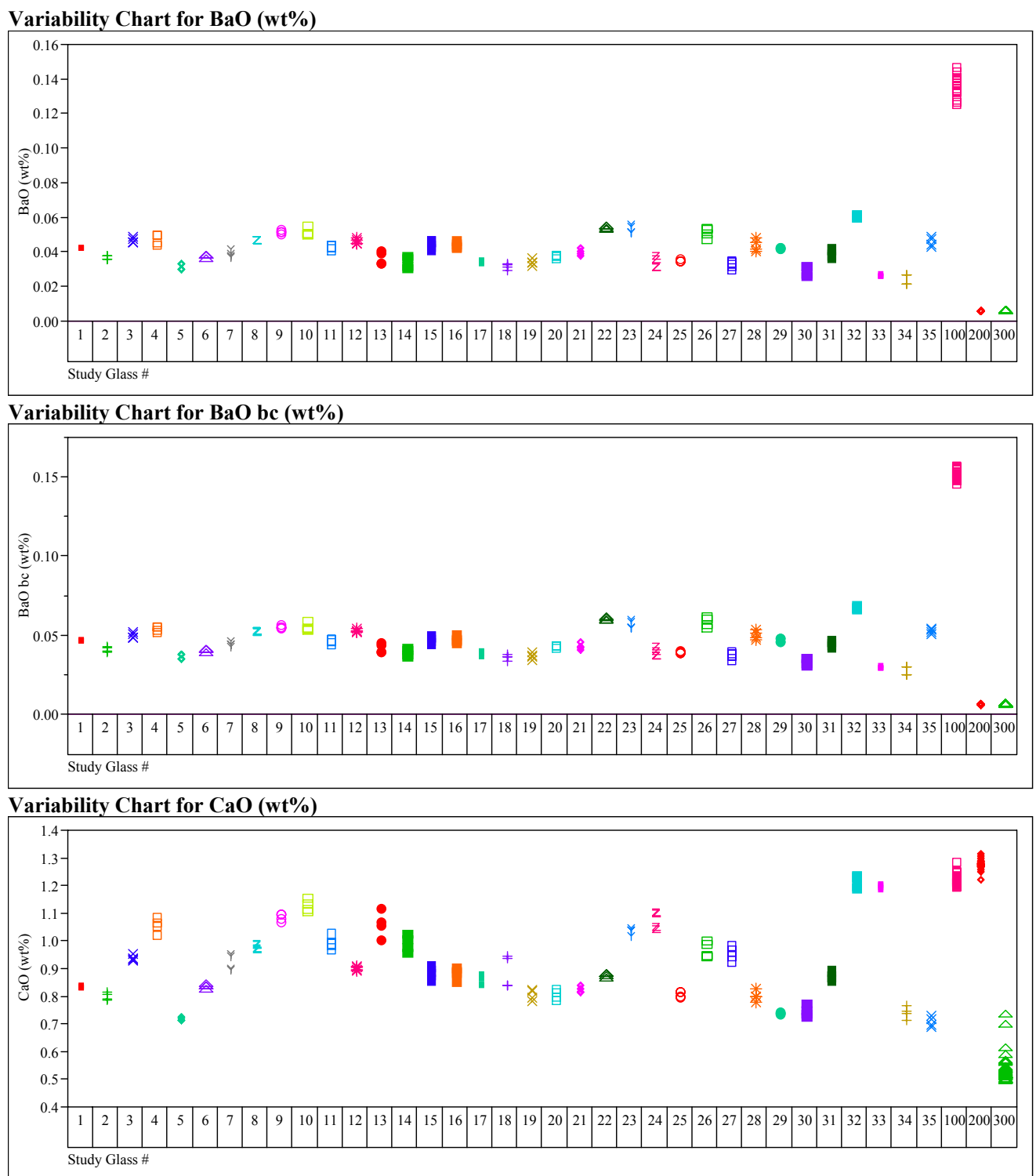

Variability Chart for $\mathrm{CaO}$ bc (wt\%)

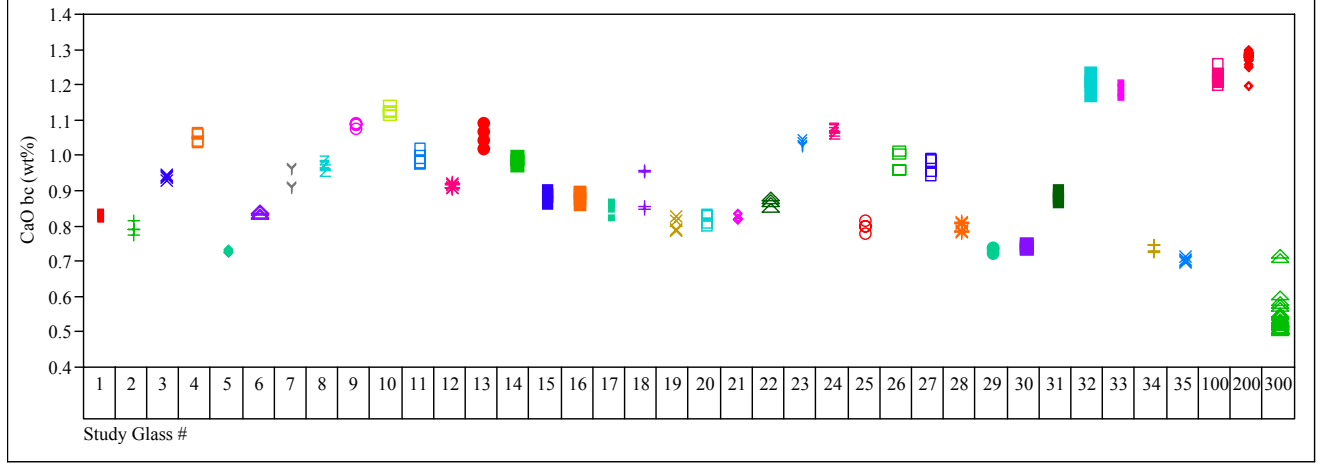


Exhibit E5. Measured and Measured Bias-Corrected Oxide Weight Percents by Glass \# for the Glasses Prepared Using the LM Method (continued)

(100 - Batch 1; 200 - Ustd)
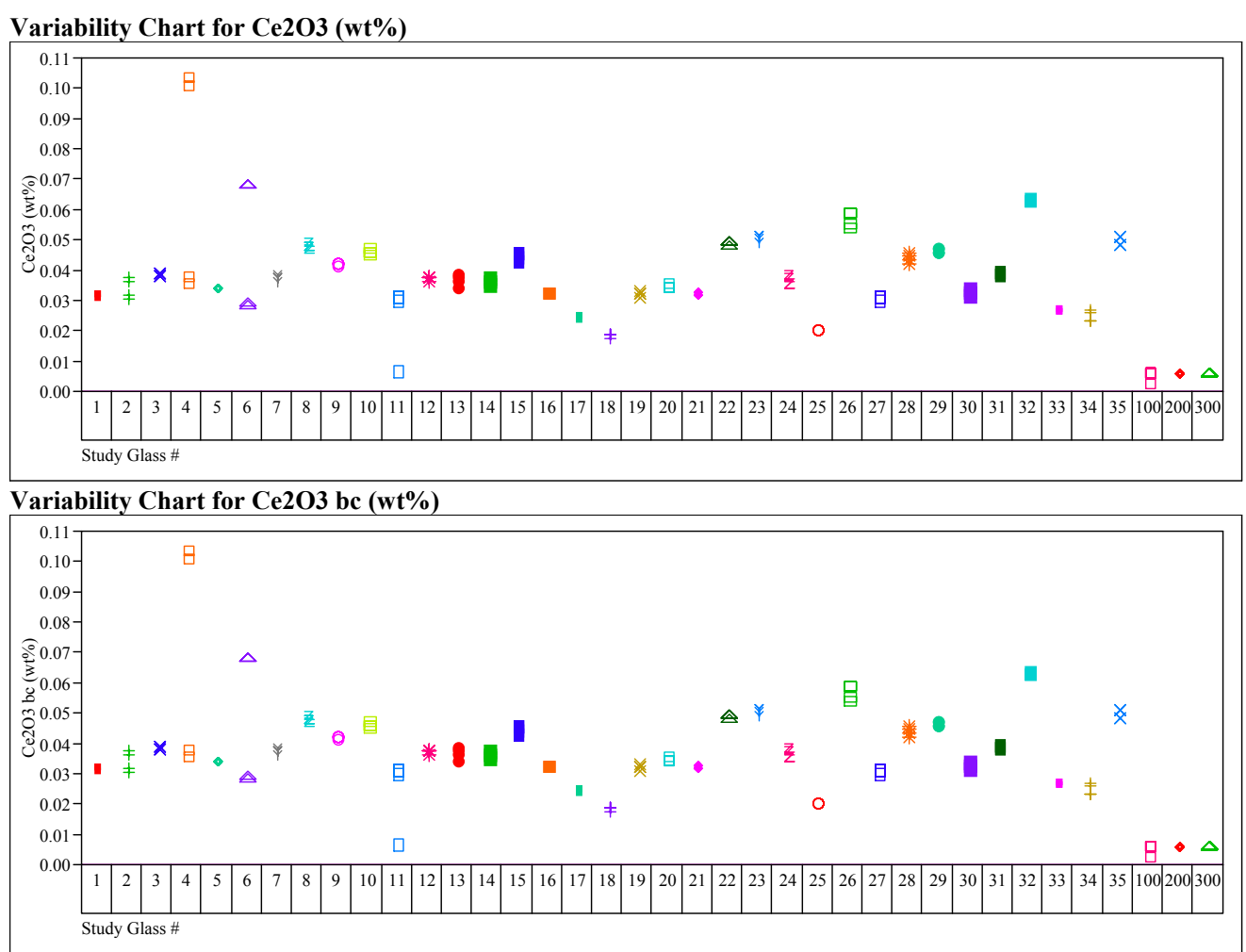

Variability Chart for Cr2O3 (wt\%)

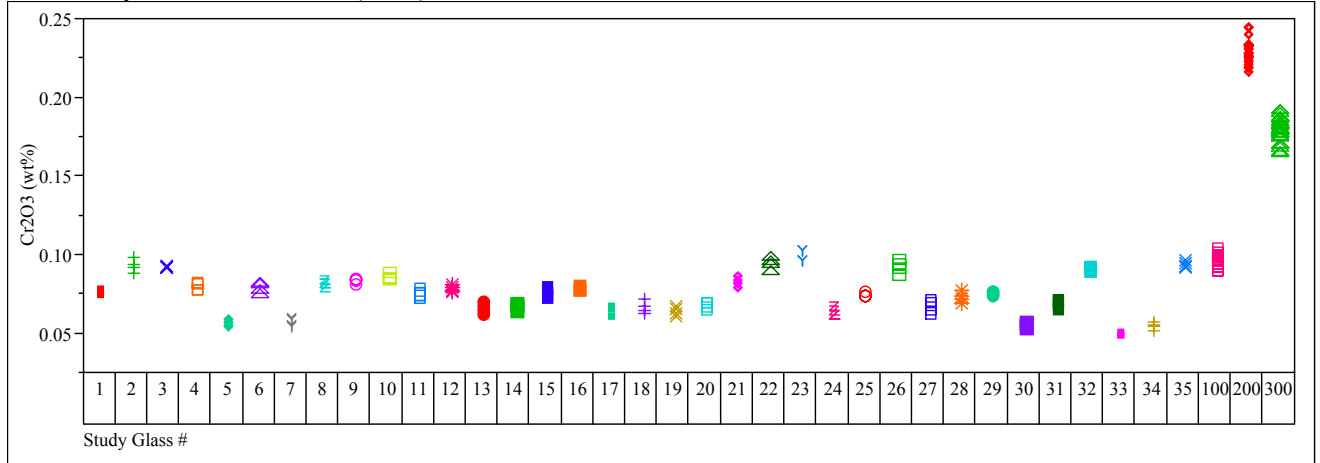

Variability Chart for Cr2O3 bc (wt\%)

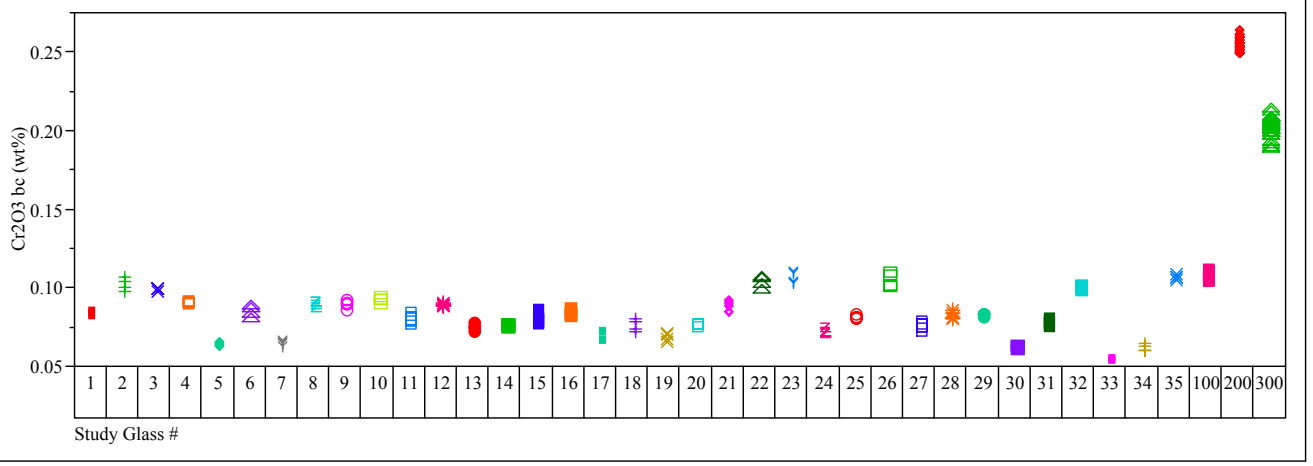


Exhibit E5. Measured and Measured Bias-Corrected Oxide Weight Percents by Glass \# for the Glasses Prepared Using the LM Method (continued)

(100 - Batch 1; 200 - Ustd)

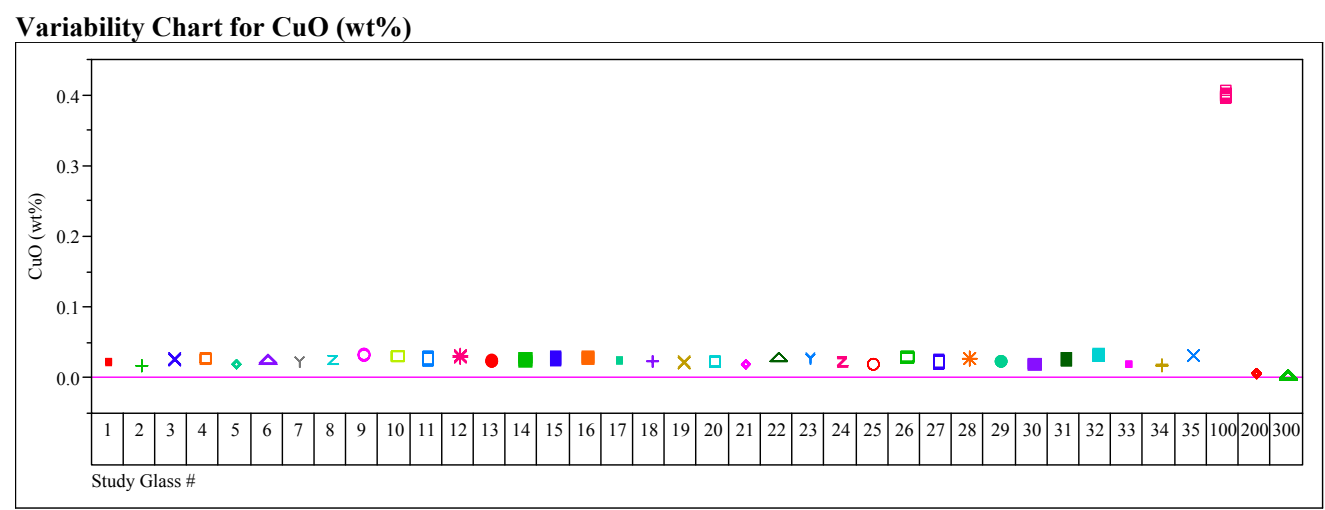

Variability Chart for $\mathrm{CuO}$ bc (wt\%)

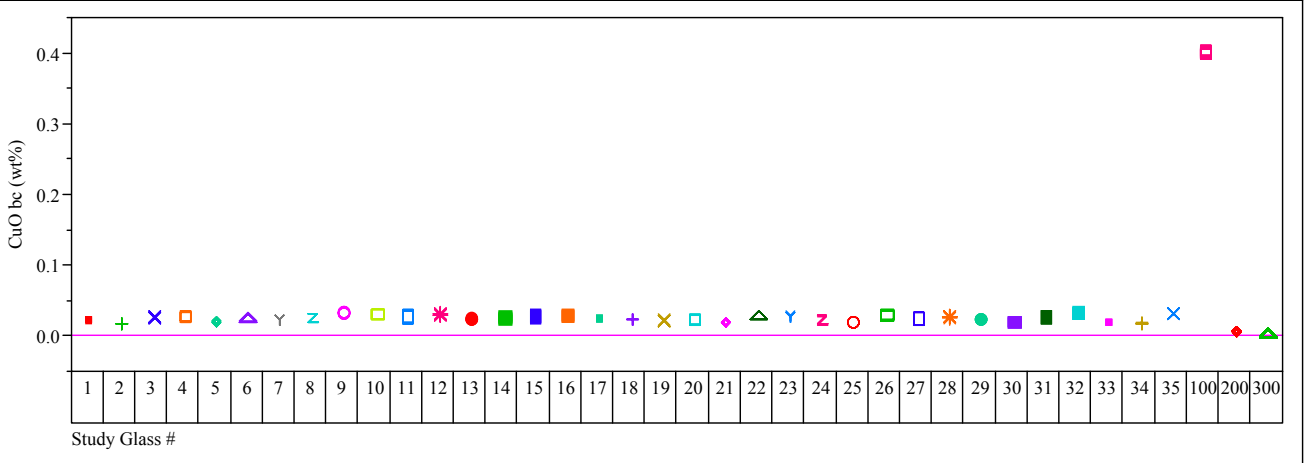

Variability Chart for K2O (wt\%)

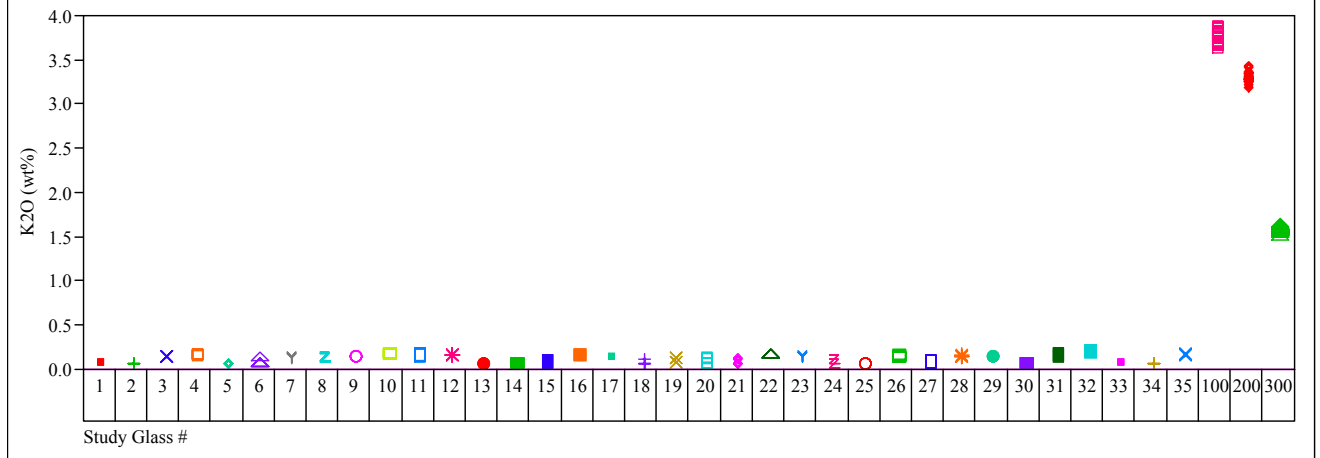

Variability Chart for K2O bc (wt\%)

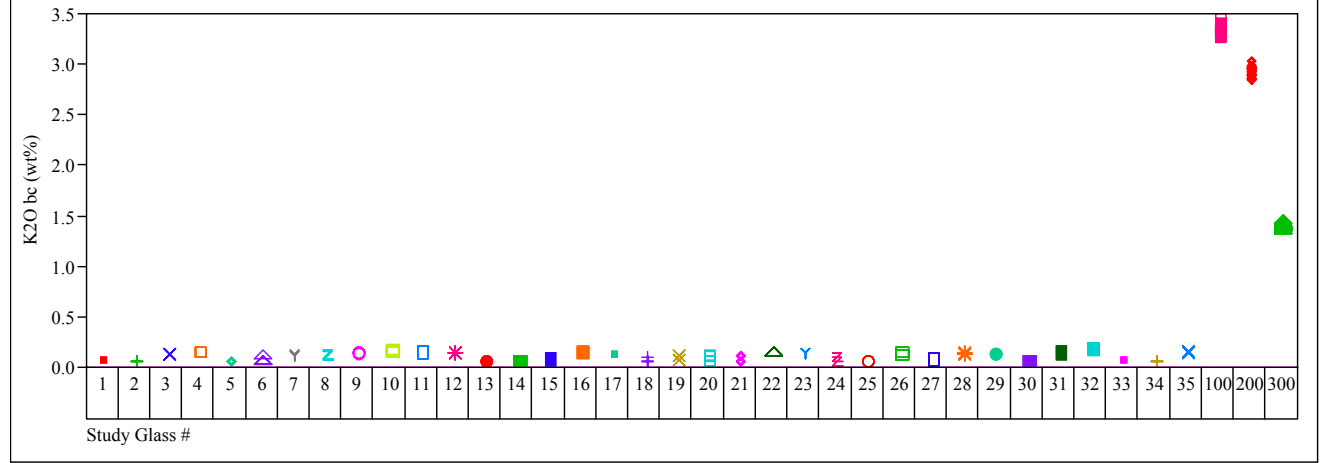


Exhibit E5. Measured and Measured Bias-Corrected Oxide Weight Percents by Glass \# for the Glasses Prepared Using the LM Method (continued)

(100 - Batch 1; 200 - Ustd)

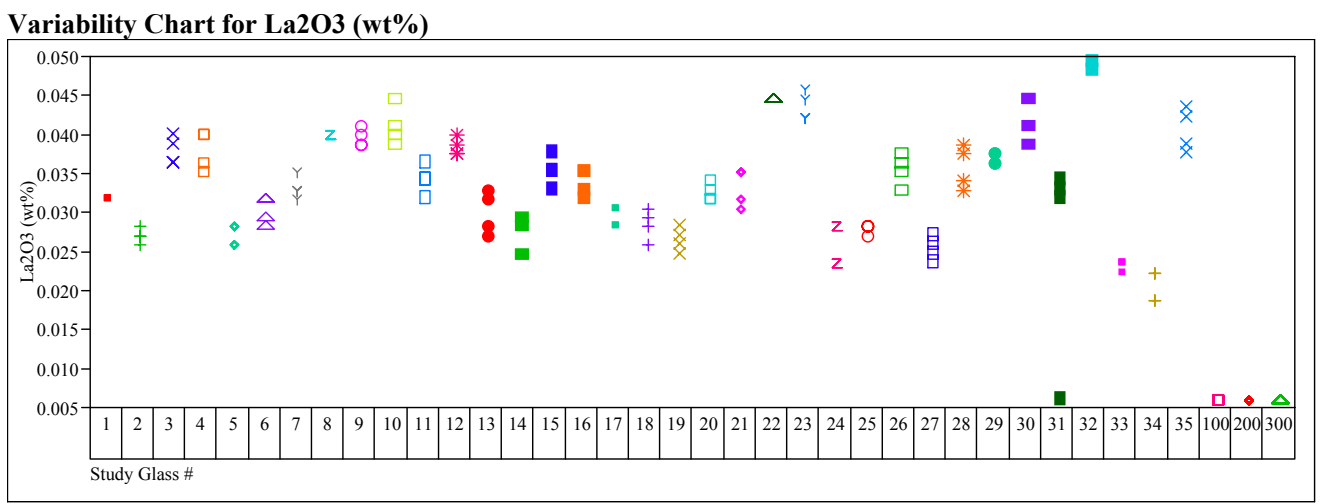

Variability Chart for La2O3 bc (wt\%)

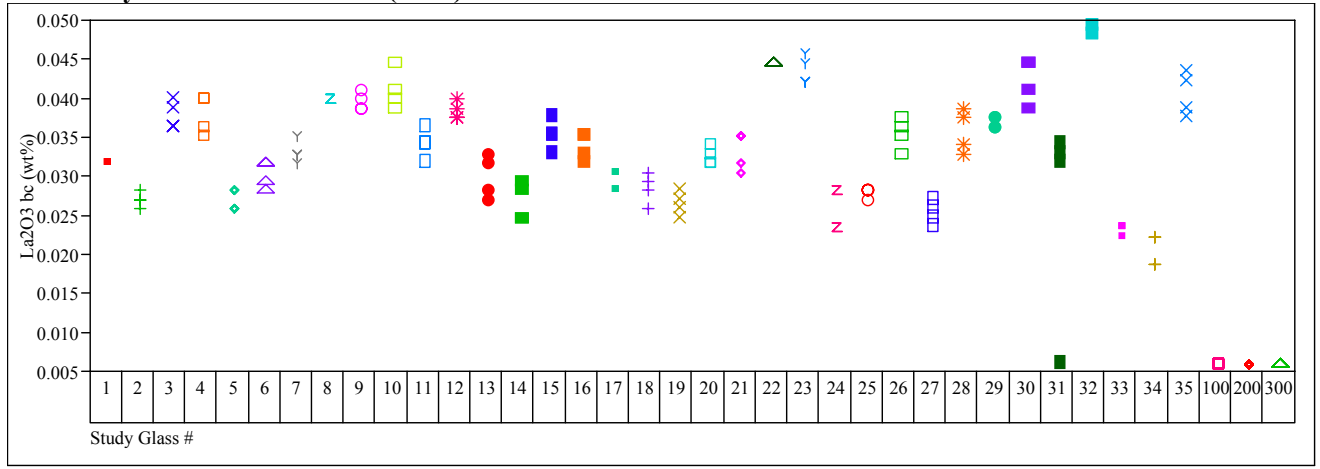

Variability Chart for $\mathrm{MgO}(\mathrm{wt} \%)$

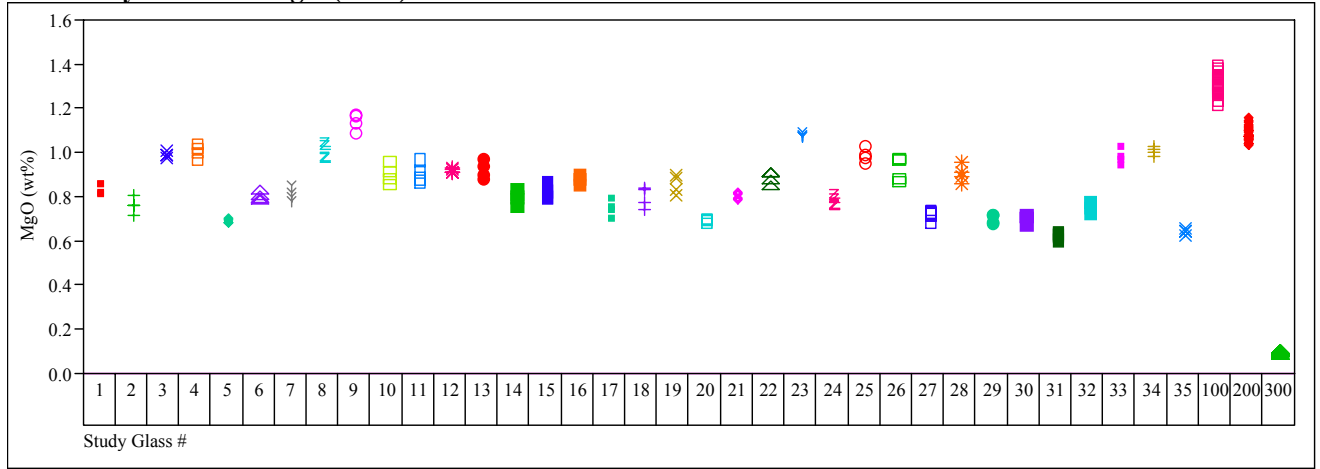

Variability Chart for MgO bc (wt\%)

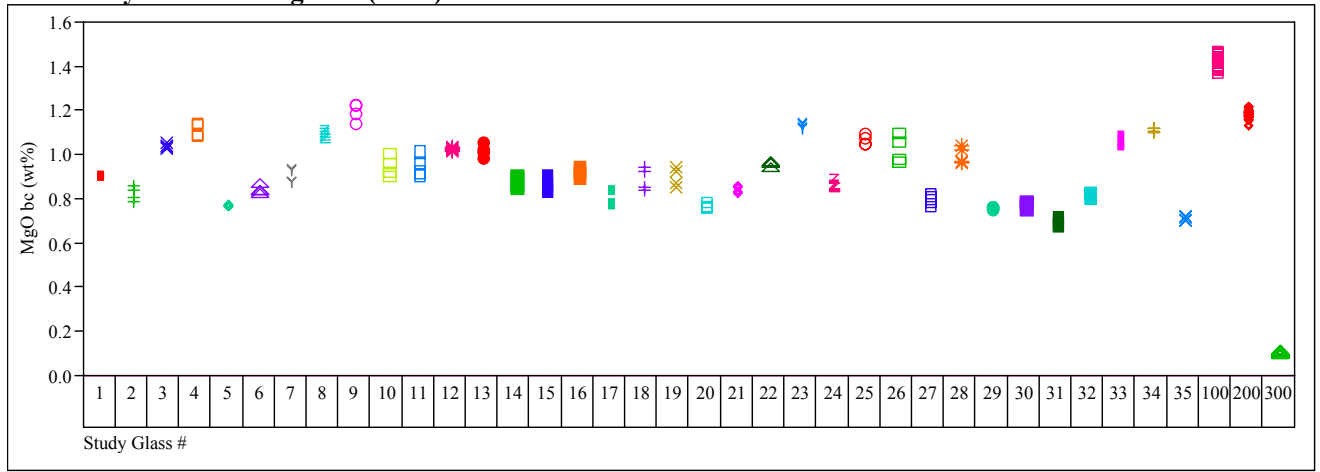


Exhibit E5. Measured and Measured Bias-Corrected Oxide Weight Percents by Glass \# for the Glasses Prepared Using the LM Method (continued)

(100 - Batch 1; 200 - Ustd)

Variability Chart for MnO (wt\%)

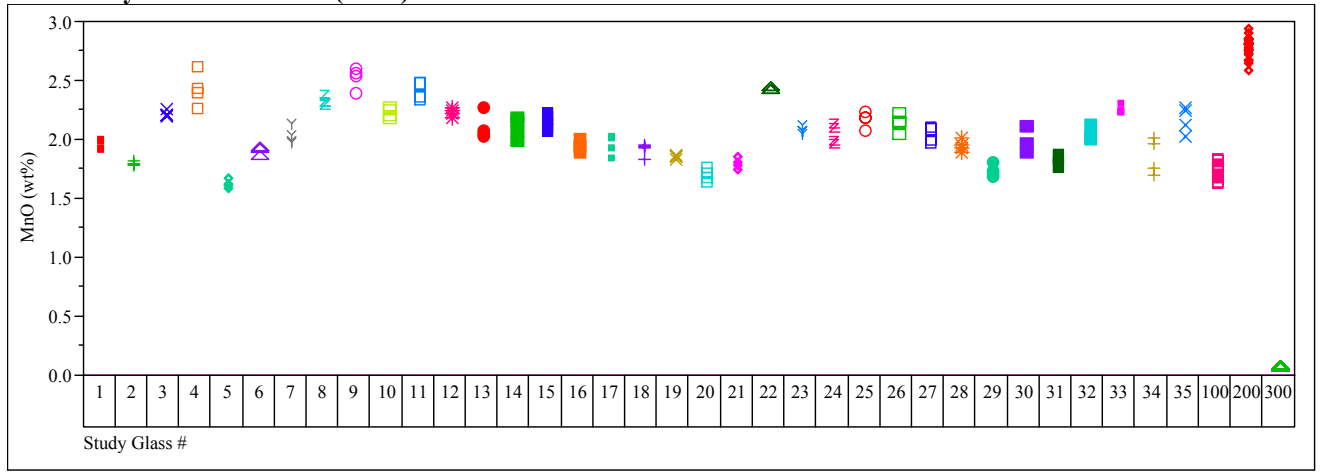

Variability Chart for MnO be (wt\%)

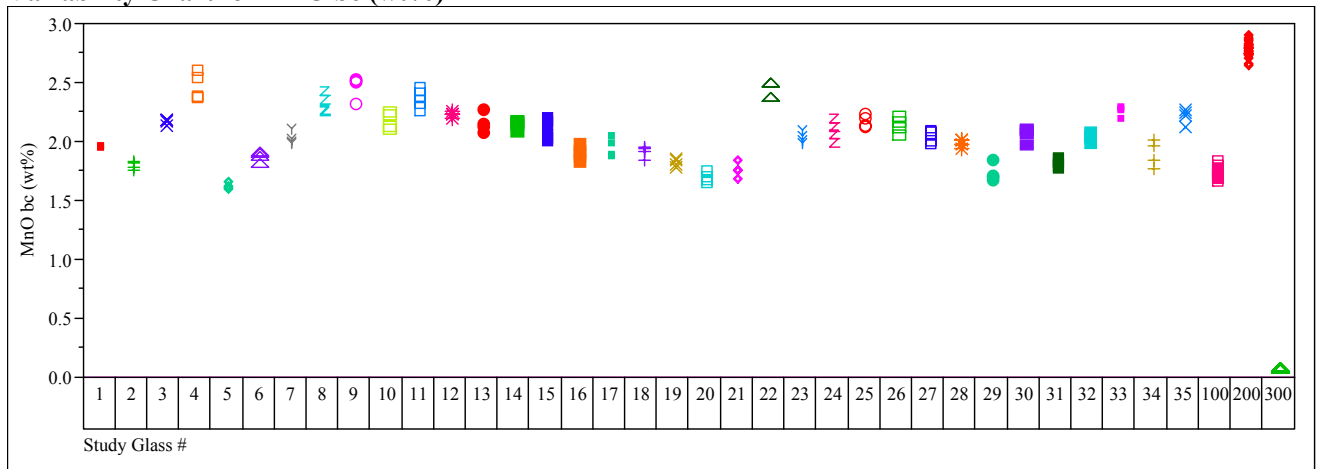

Variability Chart for Na2O (wt\%)

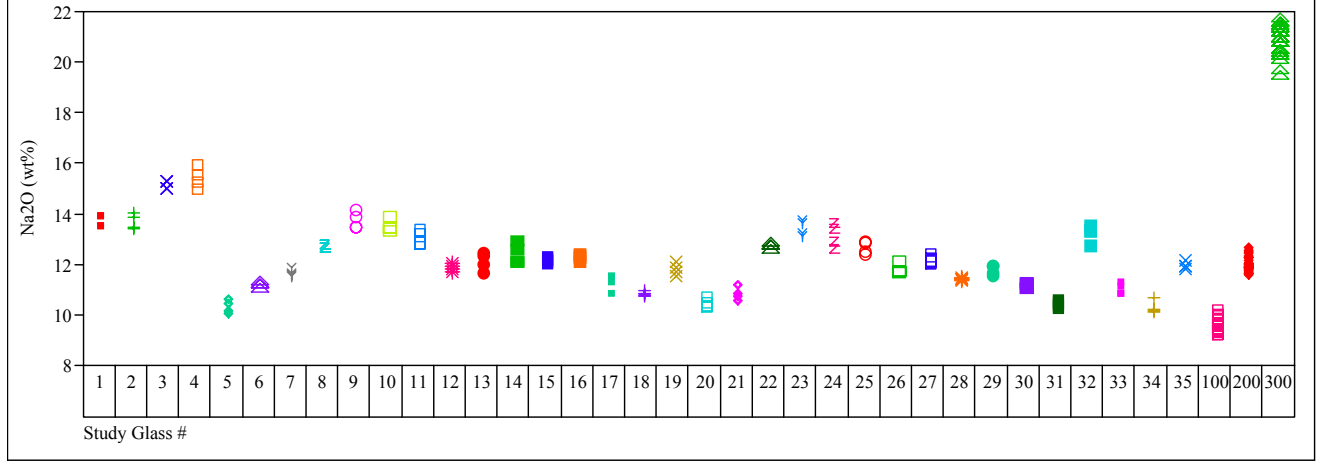

Variability Chart for Na2O bc (wt\%)

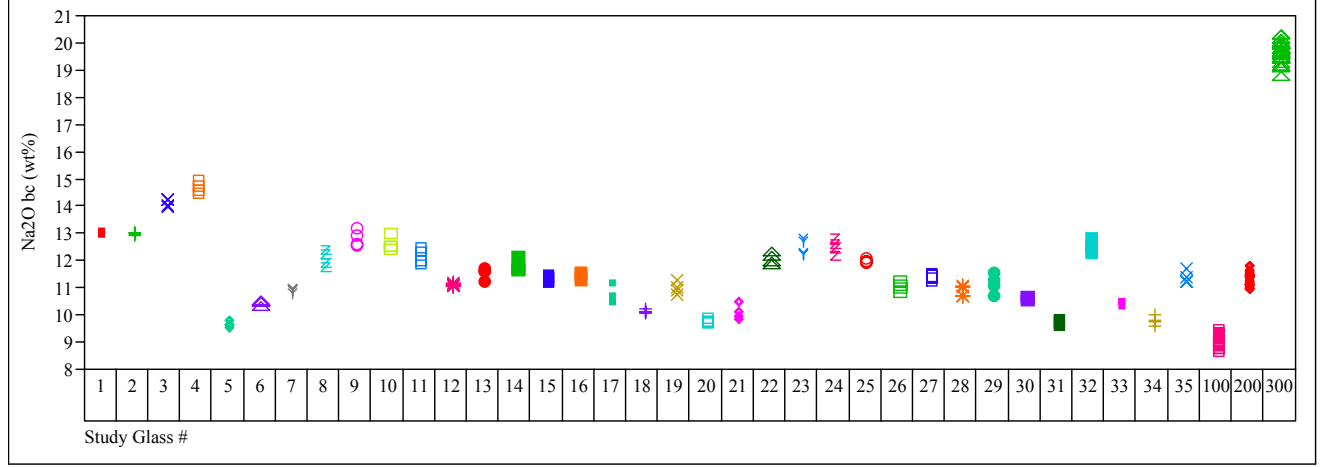


Exhibit E5. Measured and Measured Bias-Corrected Oxide Weight Percents by Glass \# for the Glasses Prepared Using the LM Method (continued)

(100 - Batch 1; 200 - Ustd)
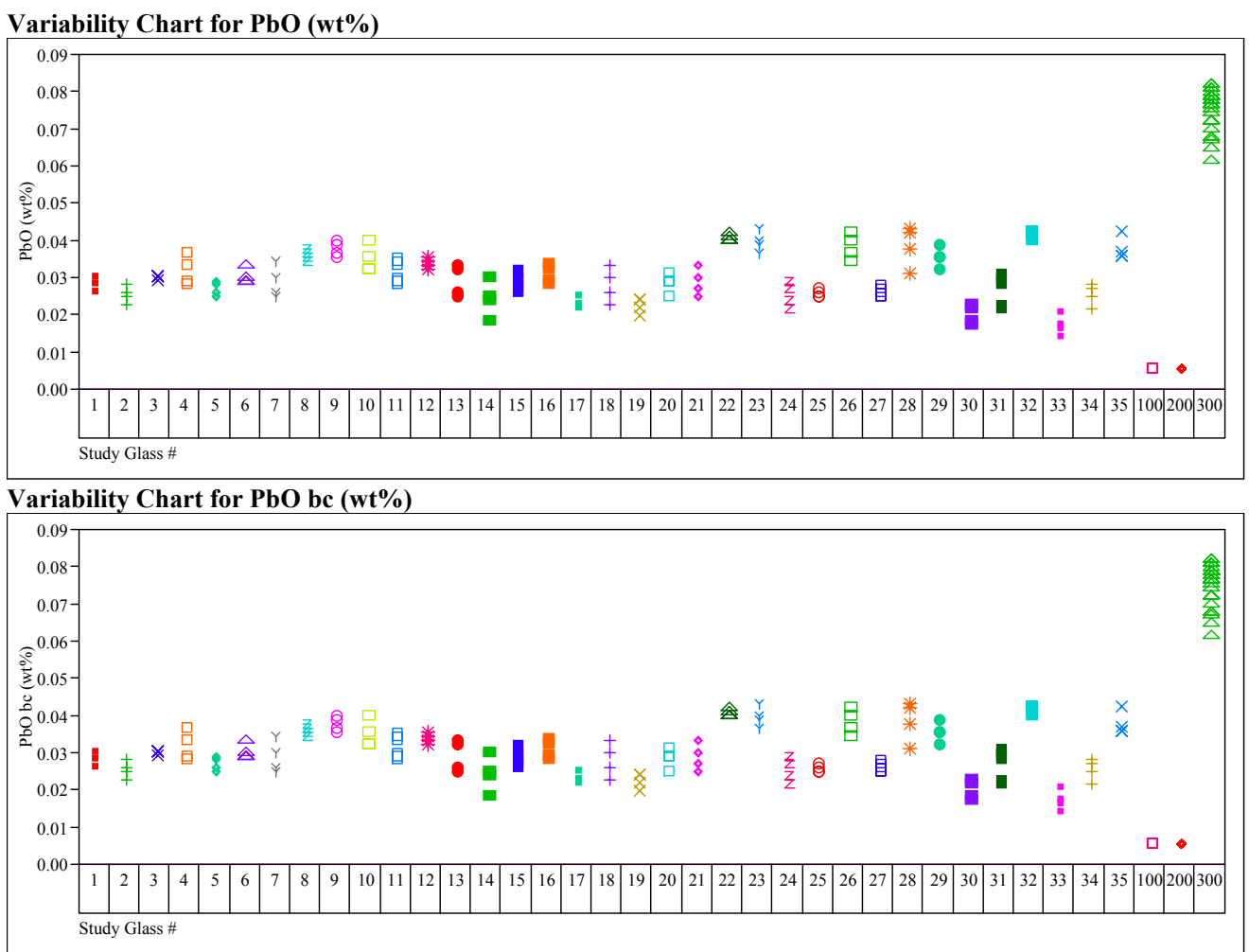

Variability Chart for SO4 (wt\%)
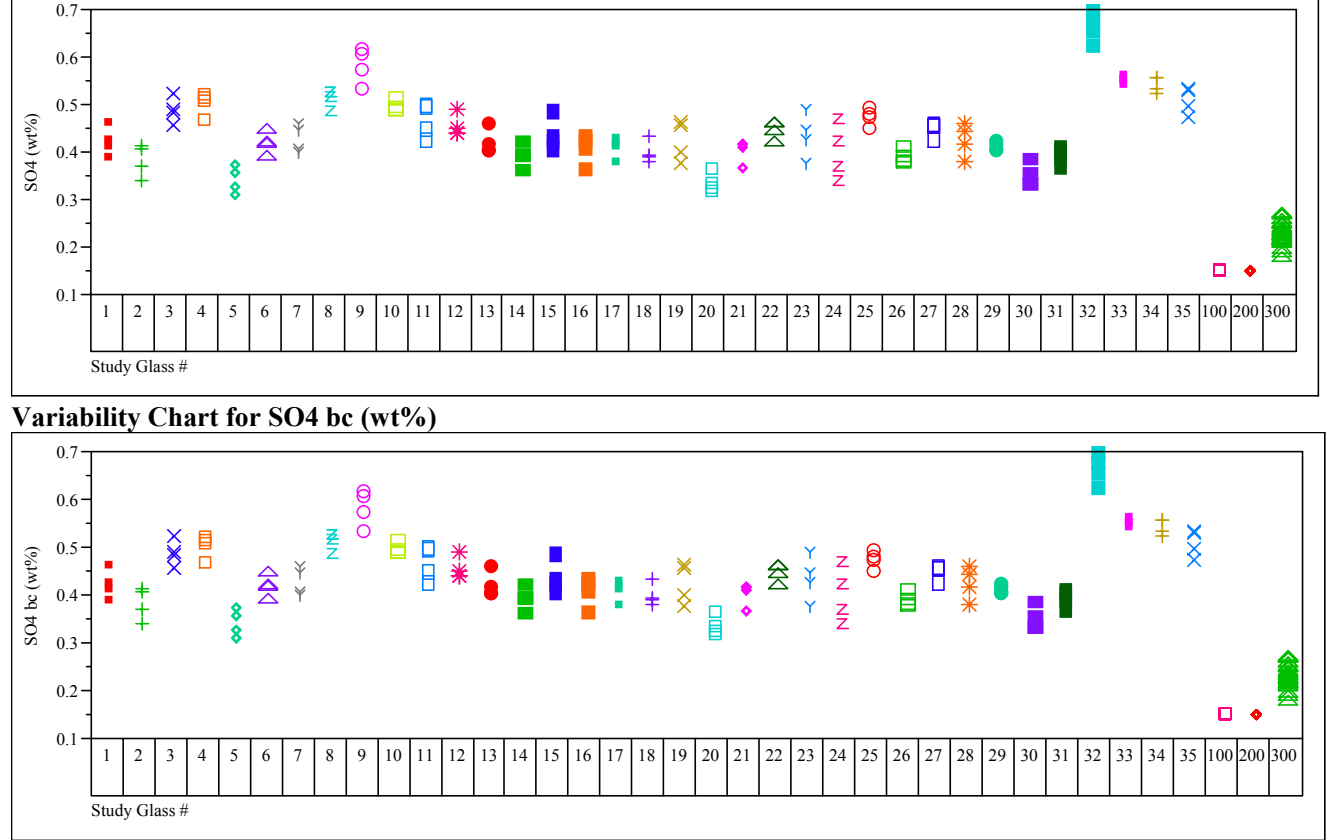
Exhibit E5. Measured and Measured Bias-Corrected Oxide Weight Percents by Glass \# for the Glasses Prepared Using the LM Method (continued)

(100 - Batch 1; 200 - Ustd)

Variability Chart for ThO2 (wt\%)

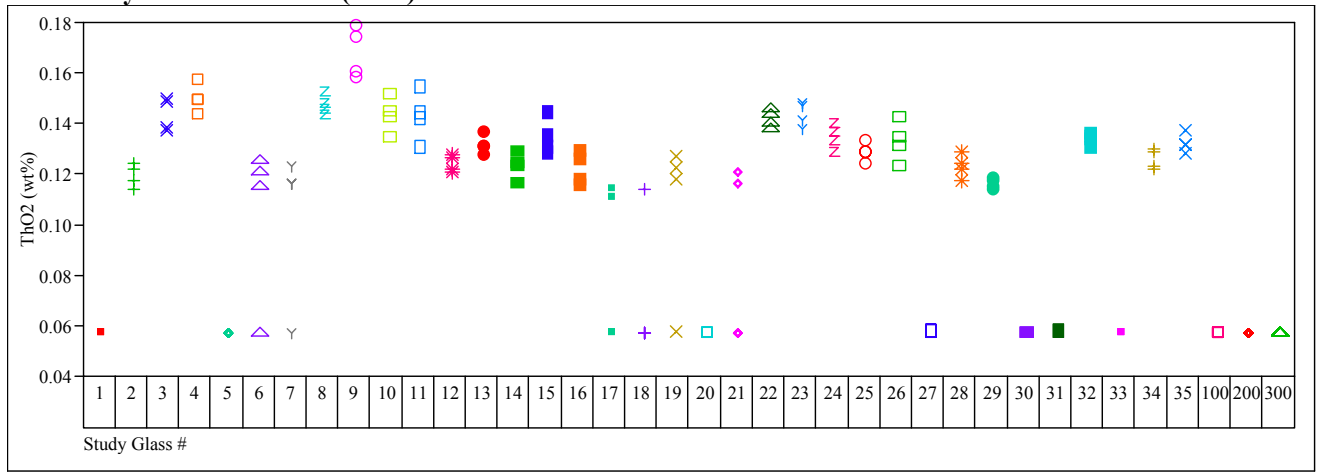

Variability Chart for ThO2 be (wt\%)

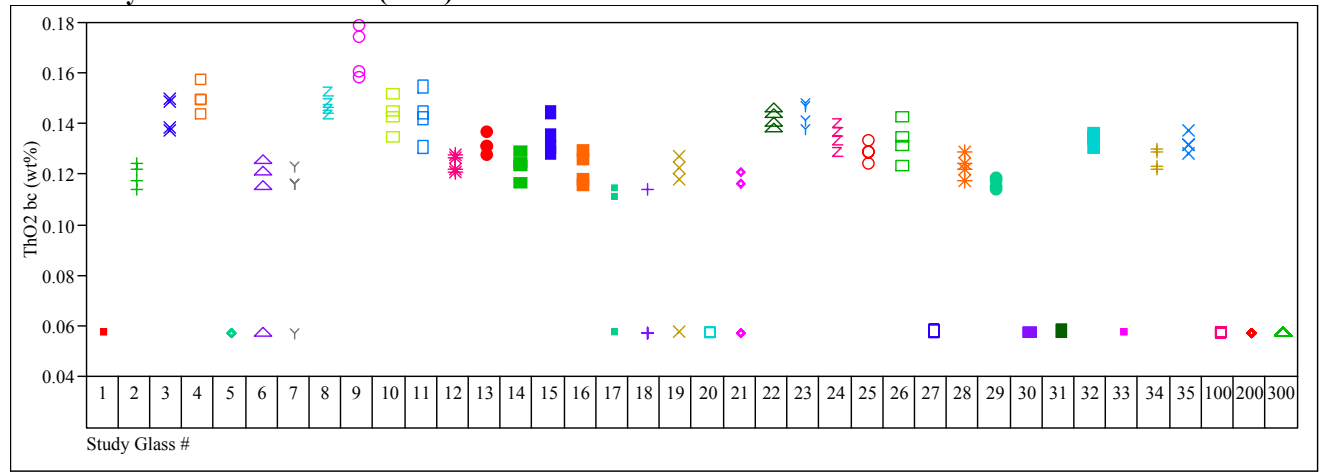

Variability Chart for TiO2 (wt\%)

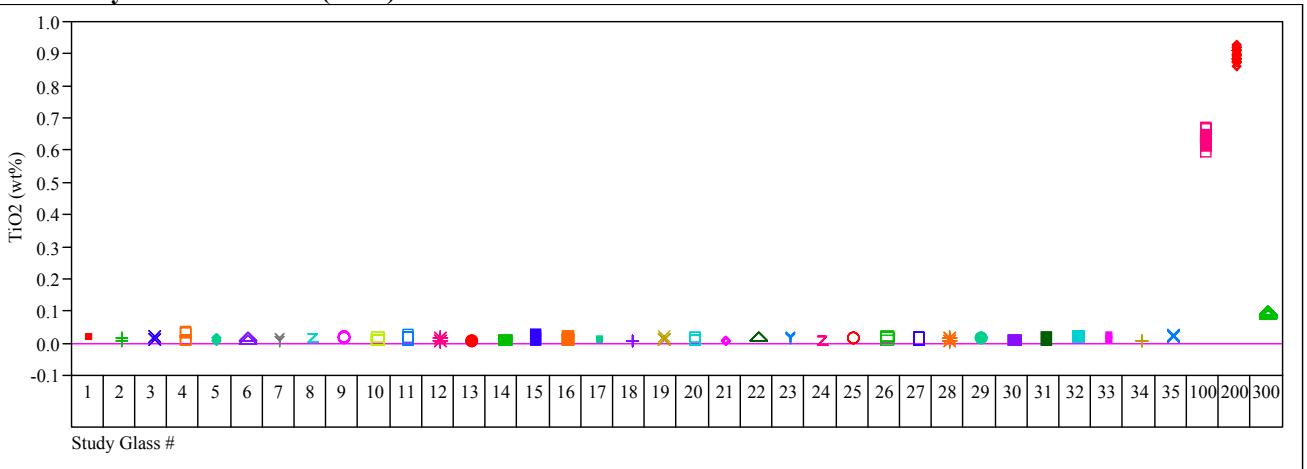

Variability Chart for TiO2 bc (wt\%)

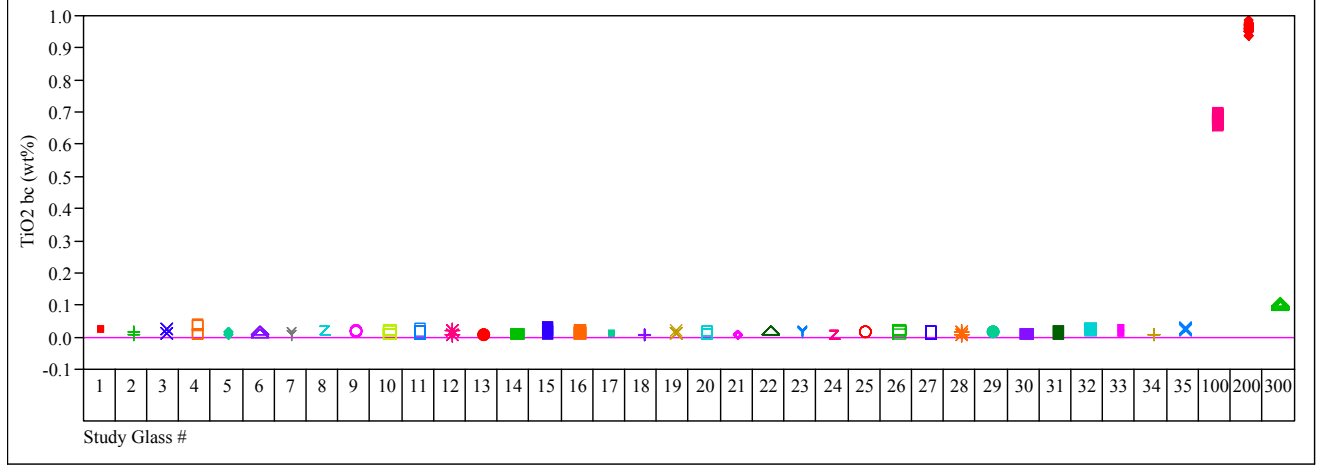


Exhibit E5. Measured and Measured Bias-Corrected Oxide Weight Percents by Glass \# for the Glasses Prepared Using the LM Method (continued)

(100 - Batch 1; 200 - Ustd)

Variability Chart for $\mathrm{ZnO}$ (wt\%)

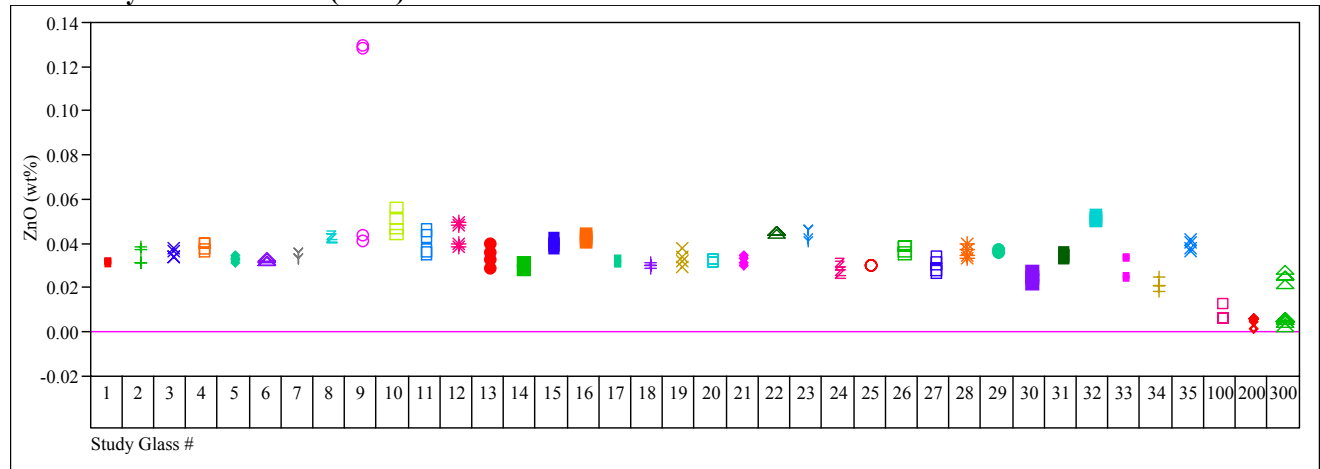

Variability Chart for $\mathrm{ZnO}$ be (wt\%)

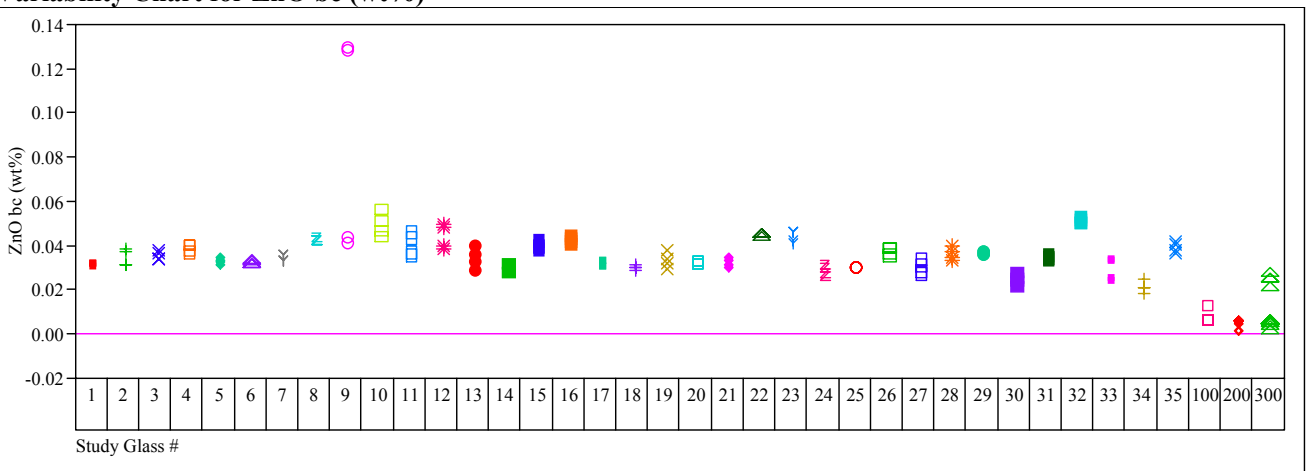

Variability Chart for ZrO2 (wt\%)

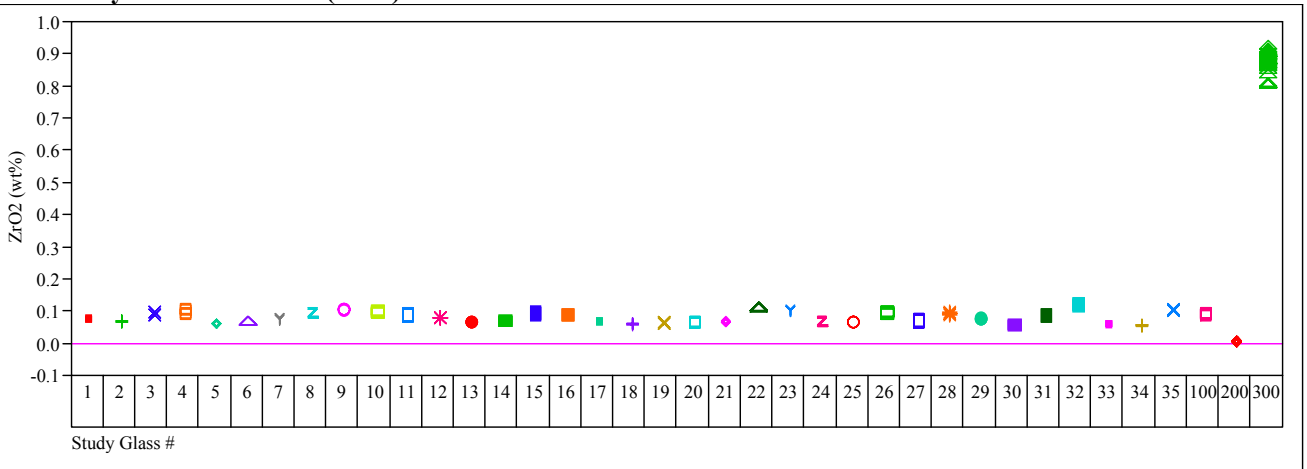

Variability Chart for ZrO2 be (wt\%)

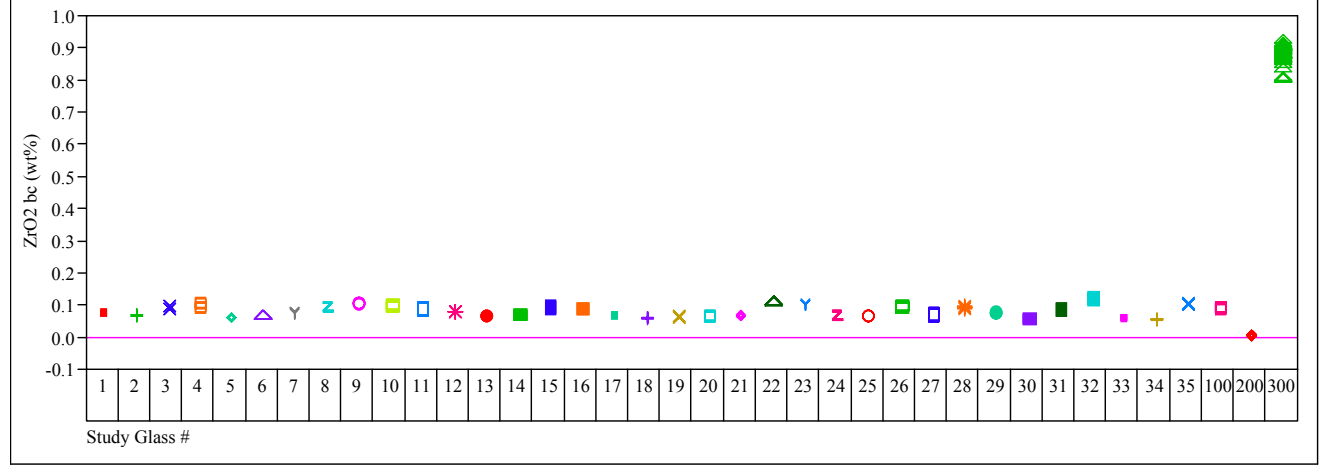


Exhibit E6. Measured and Measured Bias-Corrected Oxide Weight Percents by Glass \# for the Glasses Prepared Using the PF Method

$$
\text { (100 - Batch 1;200 - Ustd) }
$$

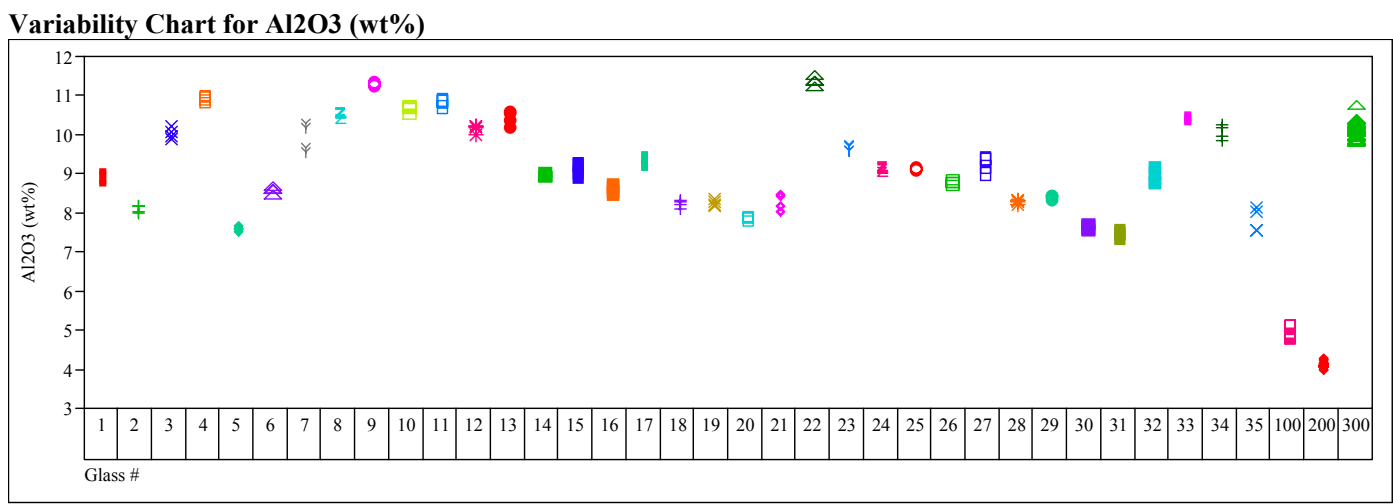

Variability Chart for $\mathrm{Al2O}$ bc (wt\%)

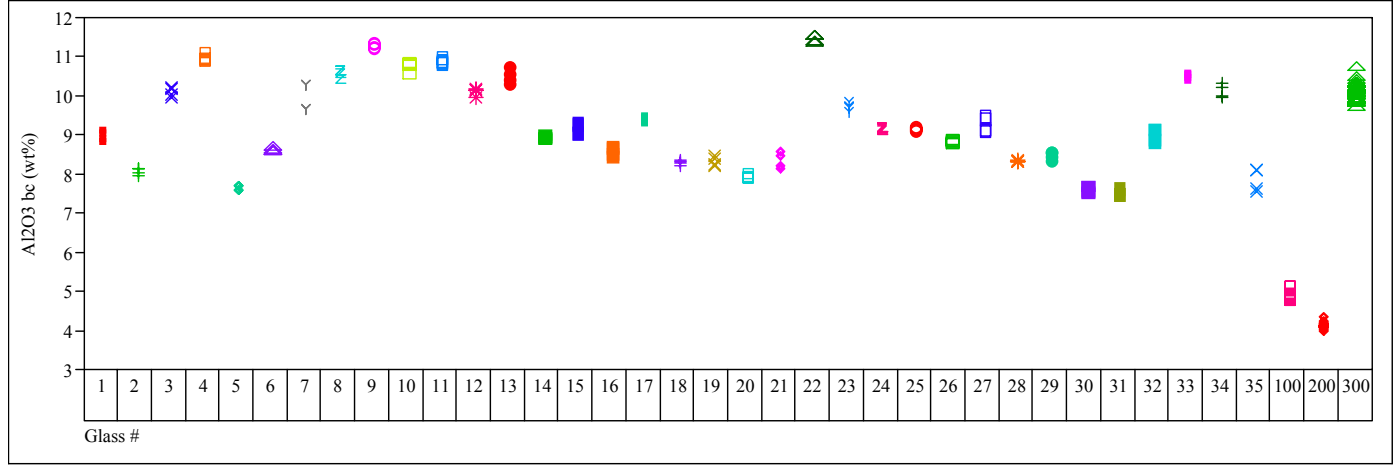

Variability Chart for B2O3 (wt\%)

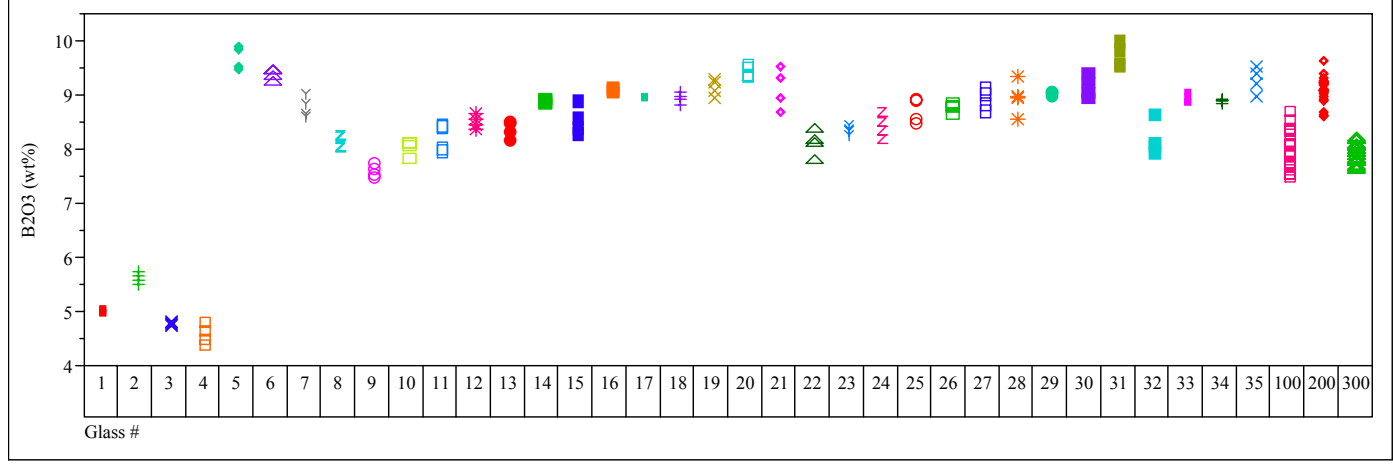


Exhibit E6. Measured and Measured Bias-Corrected Oxide Weight Percents by Glass \# for the Glasses Prepared Using the PF Method (continued)

(100 - Batch 1;200 - Ustd)

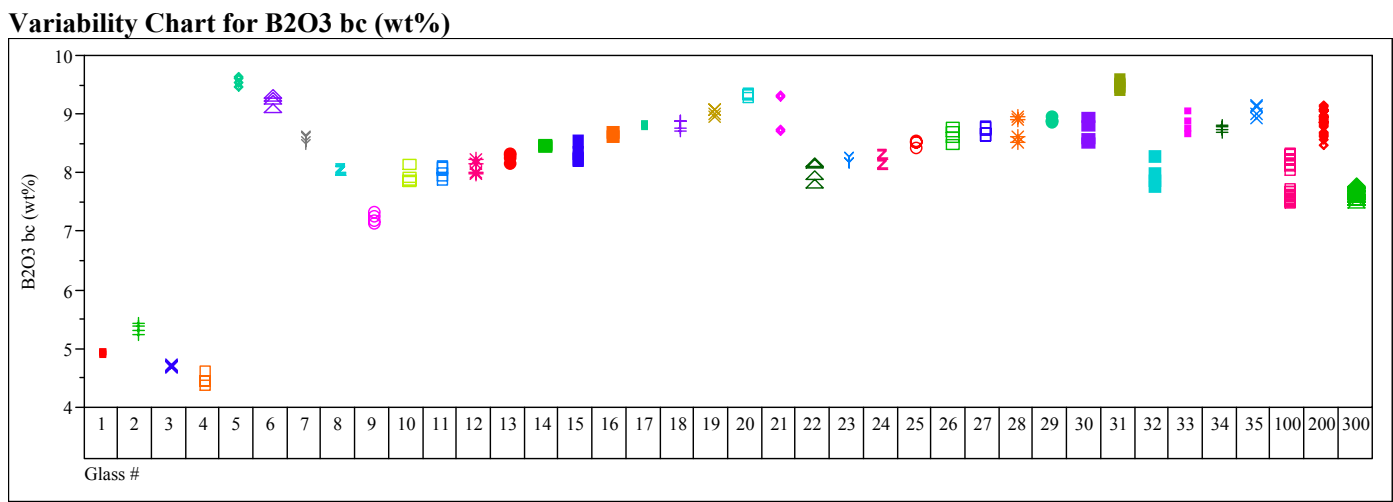

Variability Chart for Fe2O3 (wt\%)

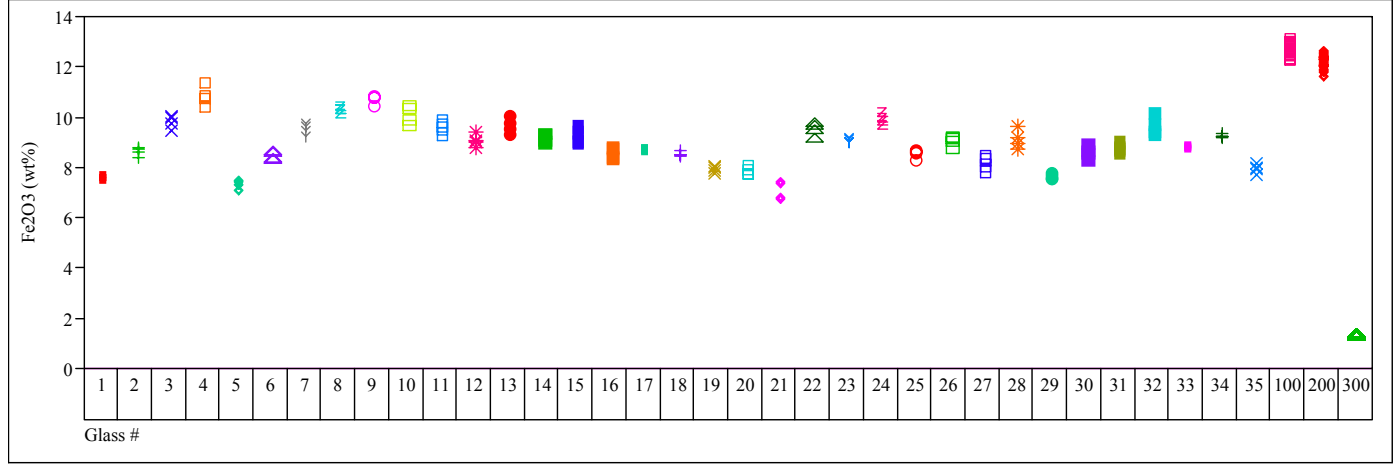

Variability Chart for Fe2O3 bc (wt\%)

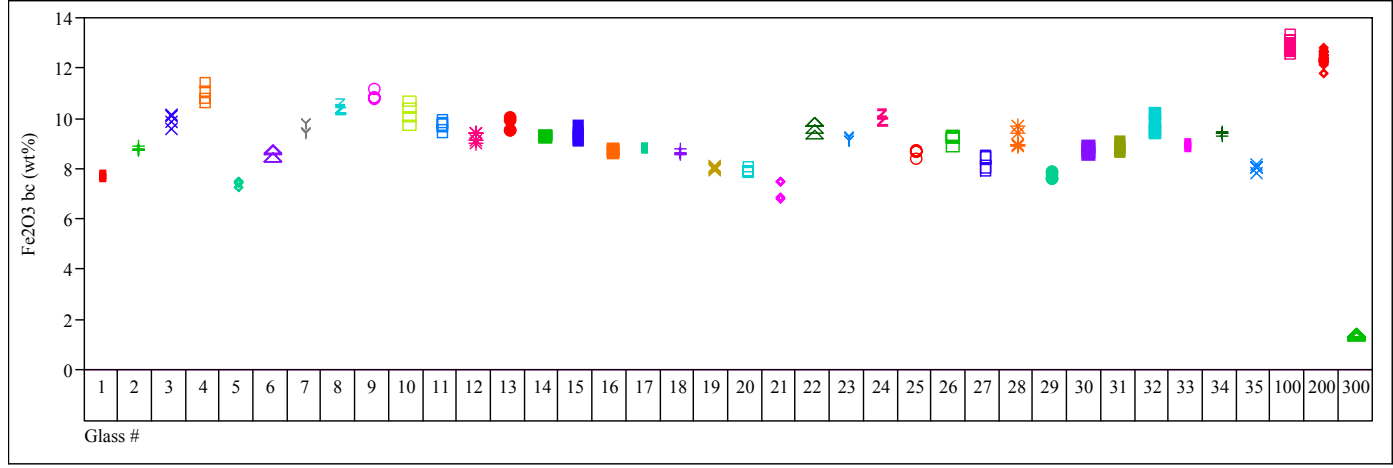


Exhibit E6. Measured and Measured Bias-Corrected Oxide Weight Percents by Glass \# for the Glasses Prepared Using the PF Method (continued)

(100 - Batch 1; 200 - Ustd)

Variability Chart for Li2O (wt\%)

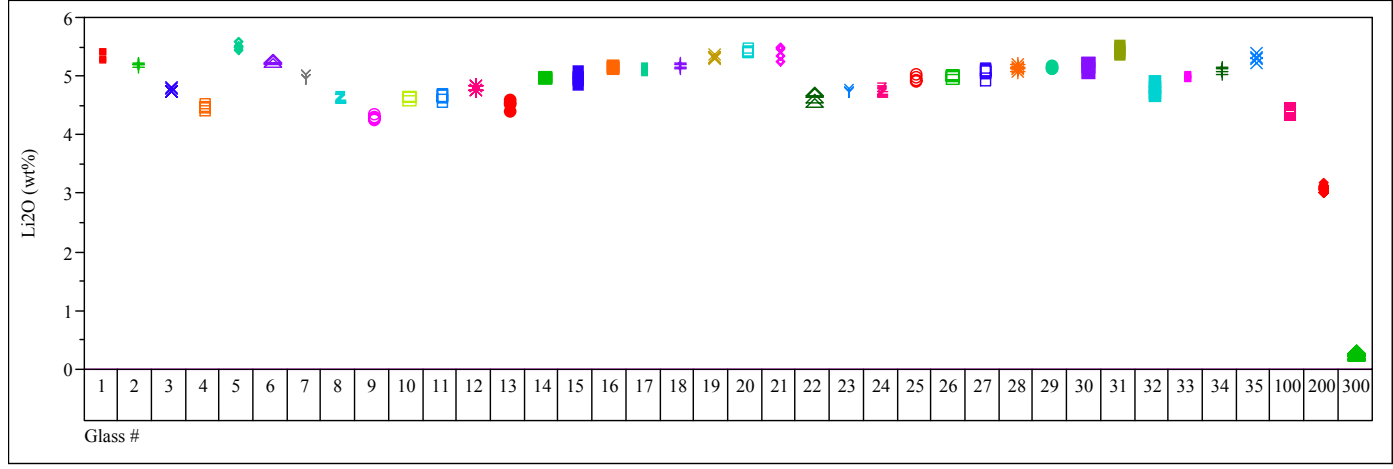

Variability Chart for Li2O be (wt\%)

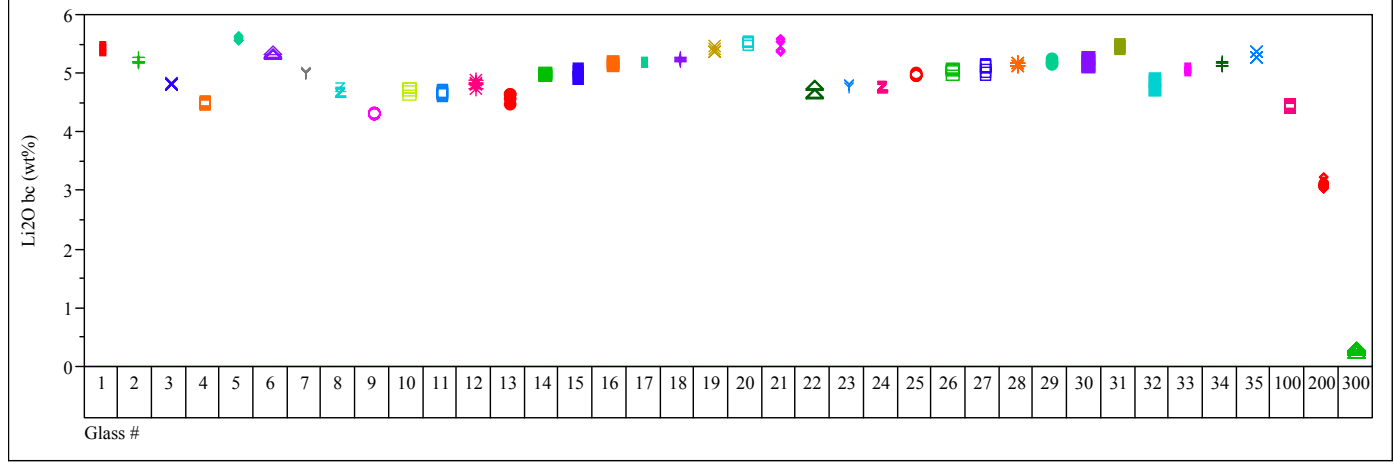

Variability Chart for NiO (wt\%)

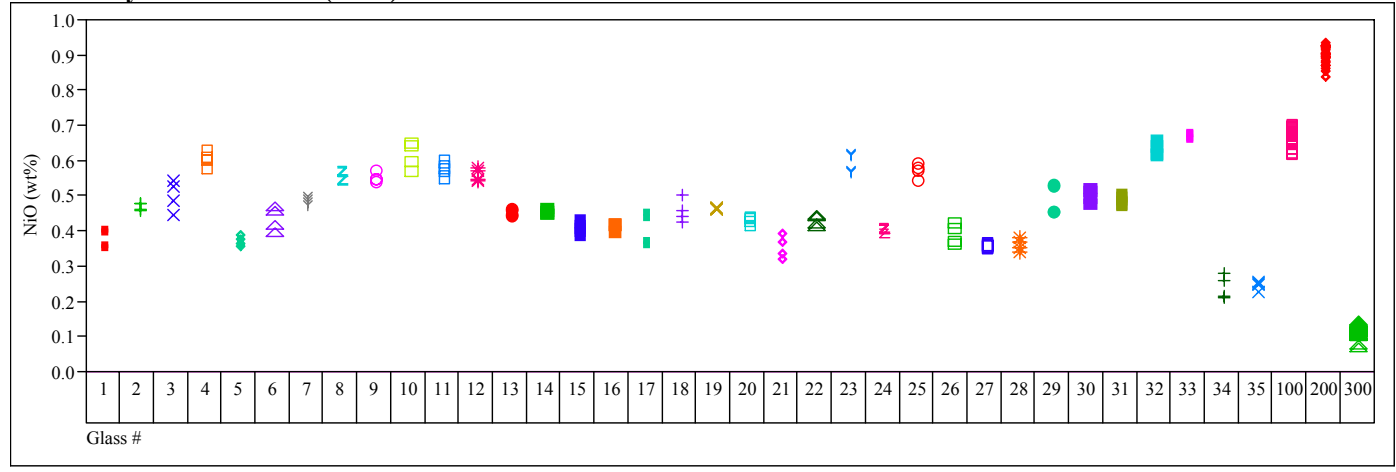


Exhibit E6. Measured and Measured Bias-Corrected Oxide Weight Percents by Glass \# for the Glasses Prepared Using the PF Method (continued)

(100 - Batch 1; 200 - Ustd)

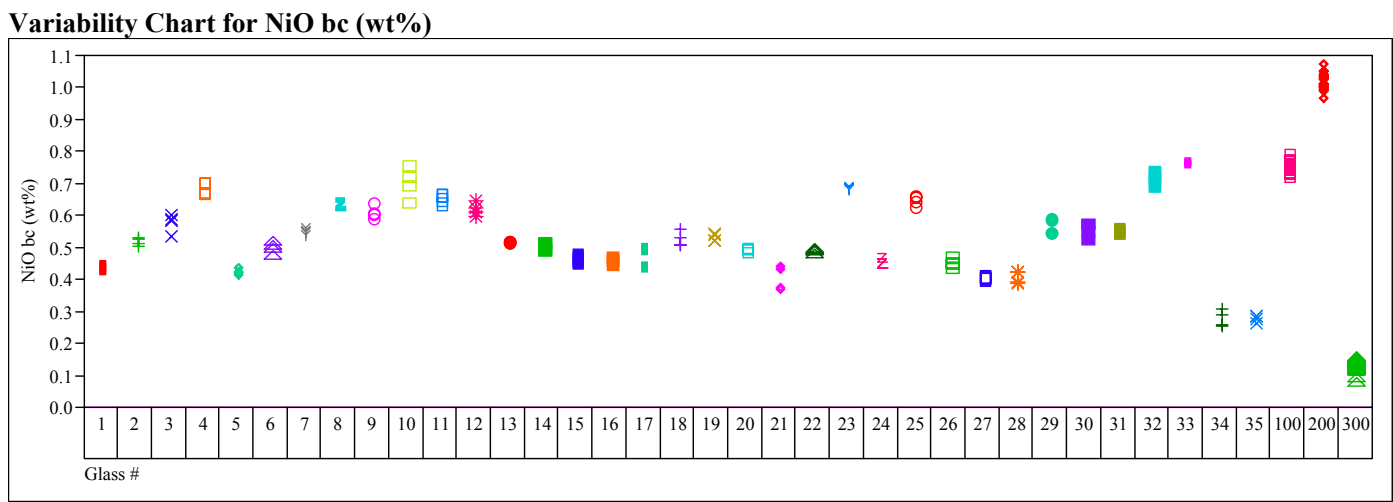

Variability Chart for $\mathrm{SiO} 2($ wt $\%)$

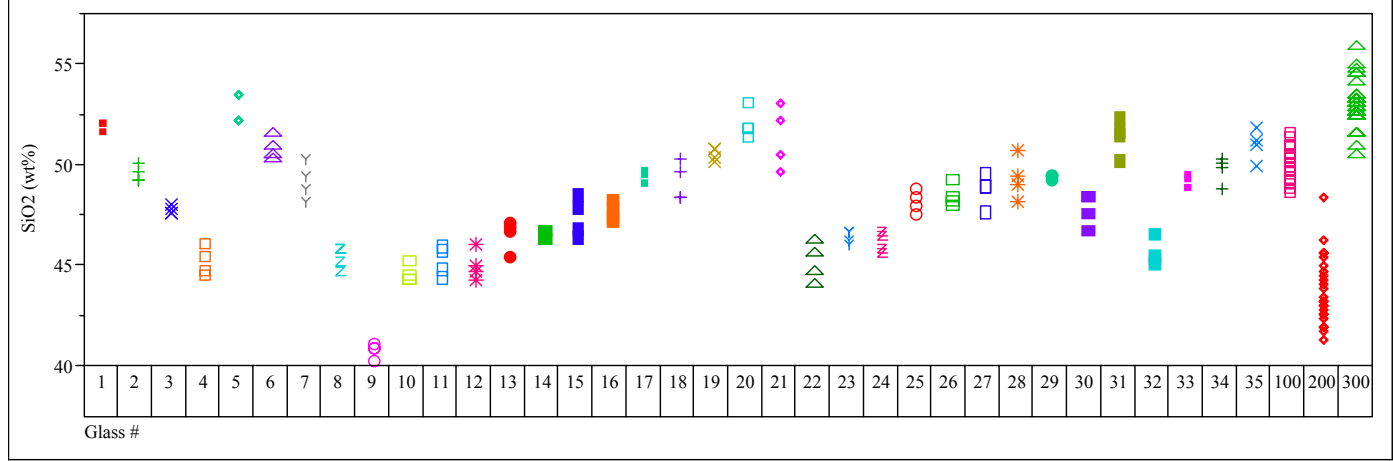

Variability Chart for SiO2 be (wt\%)

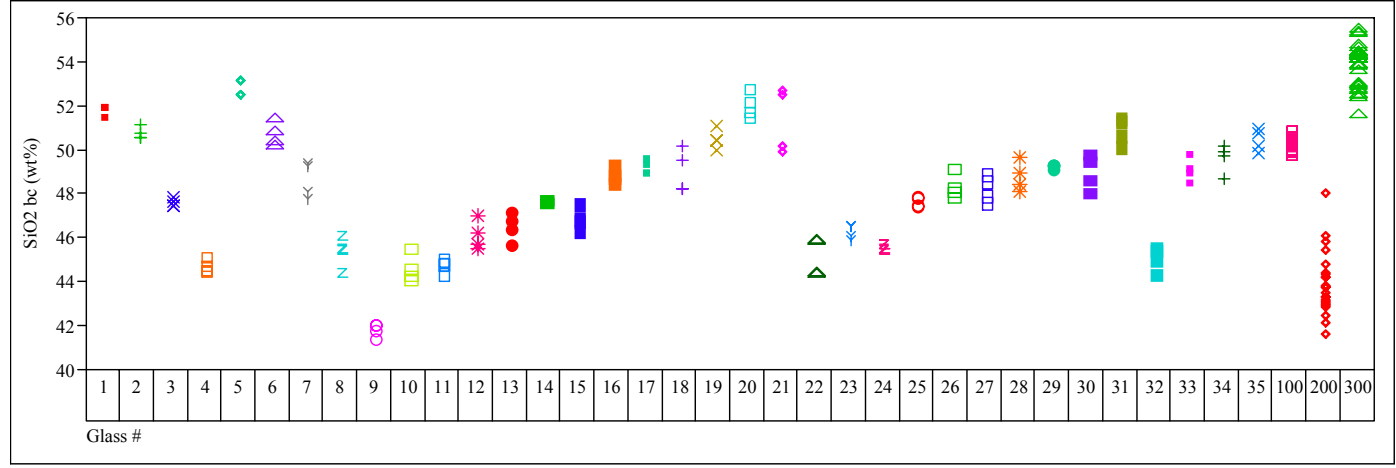


Exhibit E6. Measured and Measured Bias-Corrected Oxide Weight Percents by Glass \# for the Glasses Prepared Using the PF Method (continued)

(100 - Batch 1;200 - Ustd)

Variability Chart for U3O8 (wt\%)

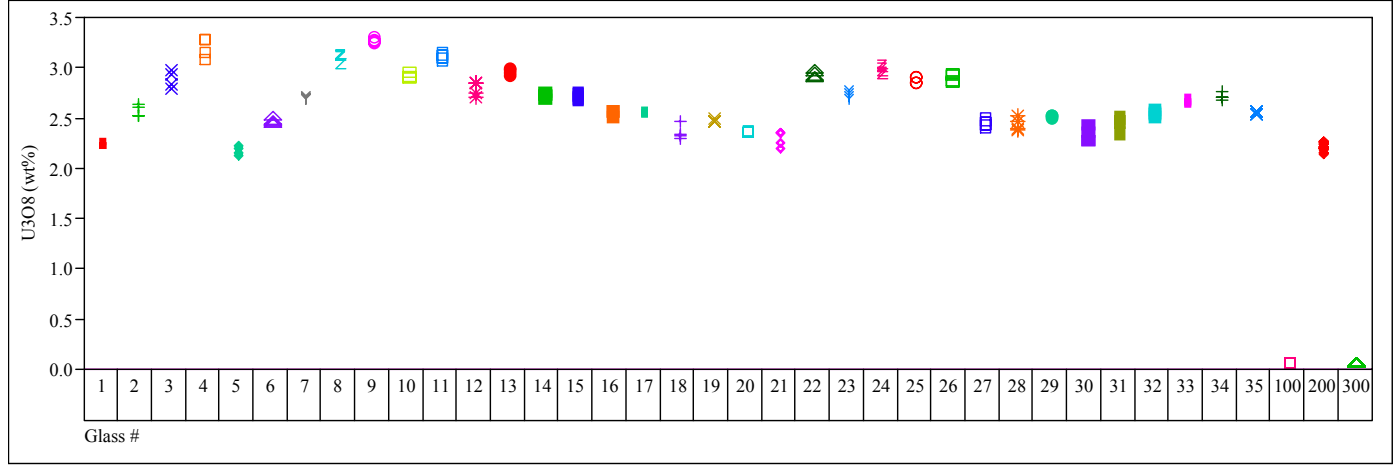

Variability Chart for U3O8 bc (wt\%)

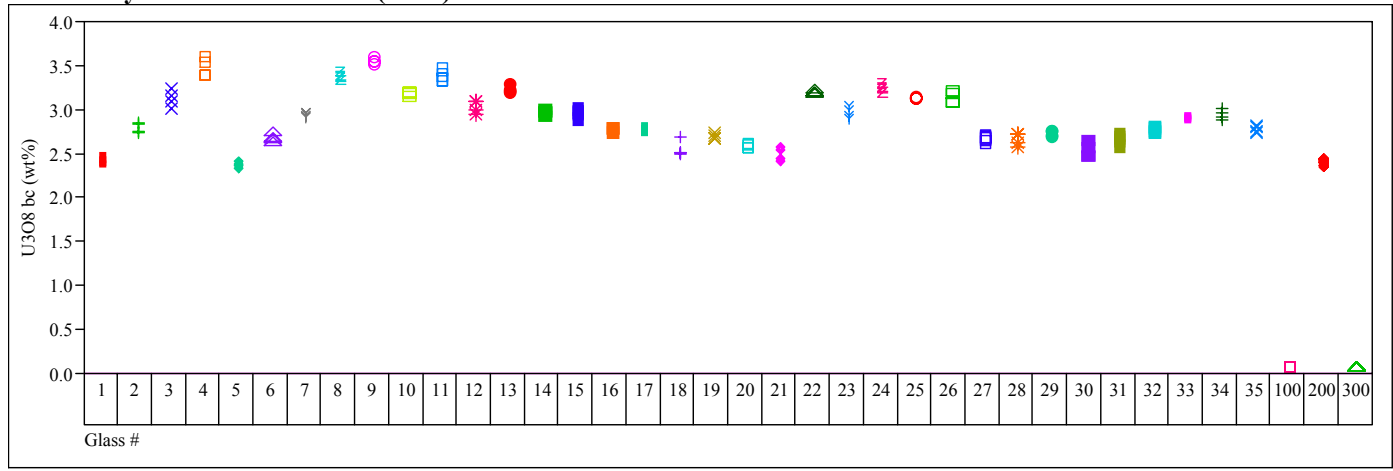




\section{Exhibit E7. Average Measured and Bias-Corrected (bc) Versus Targeted Compositions by Glass \# by Oxide}

(100 - Batch 1; 200 - Ustd)

\section{Plot for Al2O3 (wt\%)}

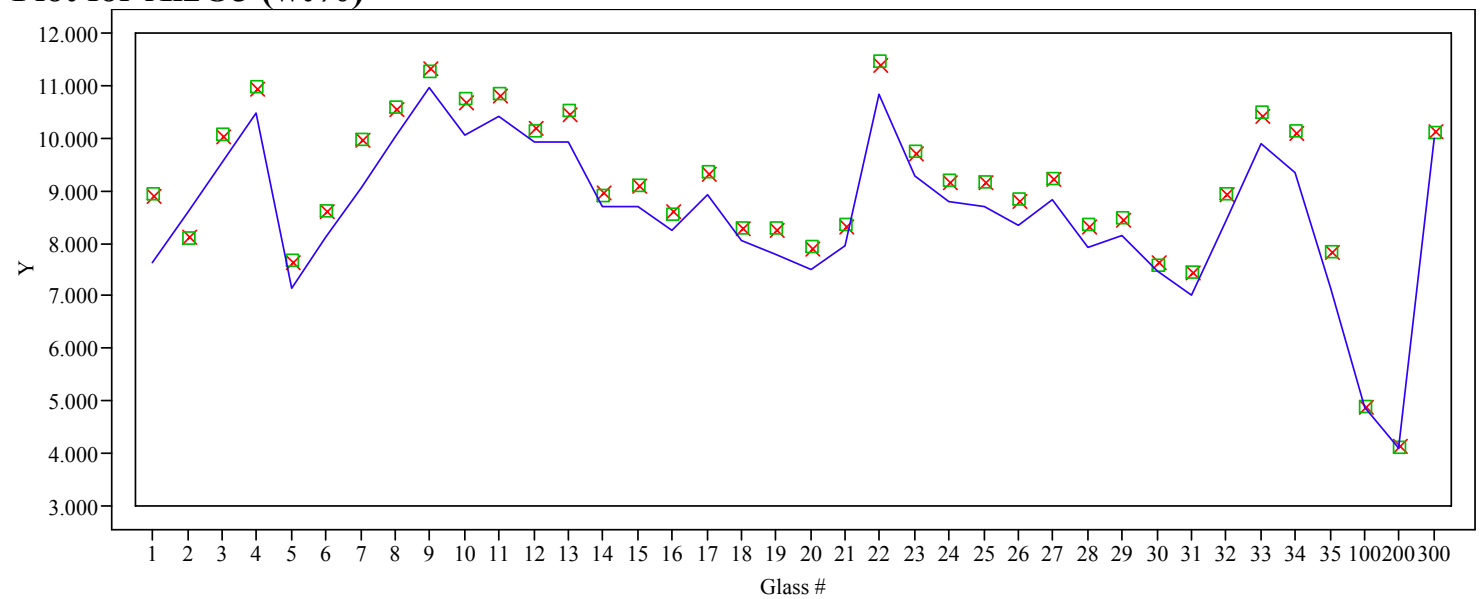

\section{Plot for B2O3 (wt\%)}

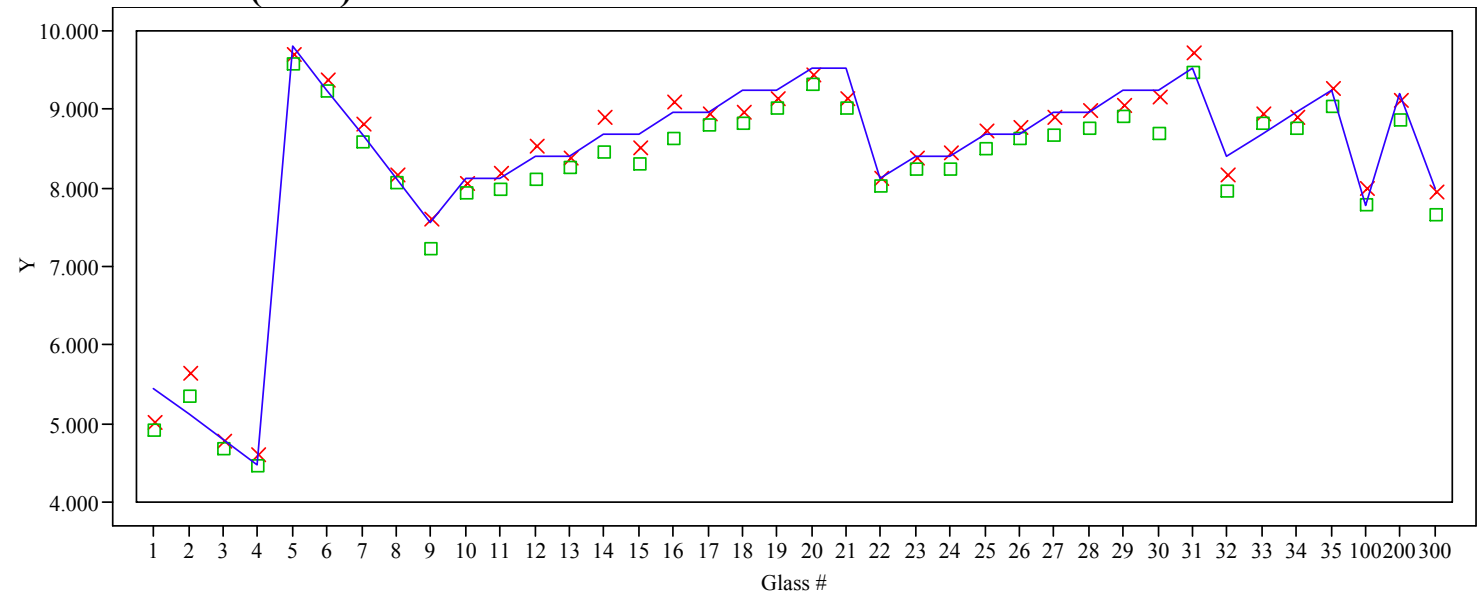

Plot for $\mathrm{BaO}(\mathrm{wt} \%)$

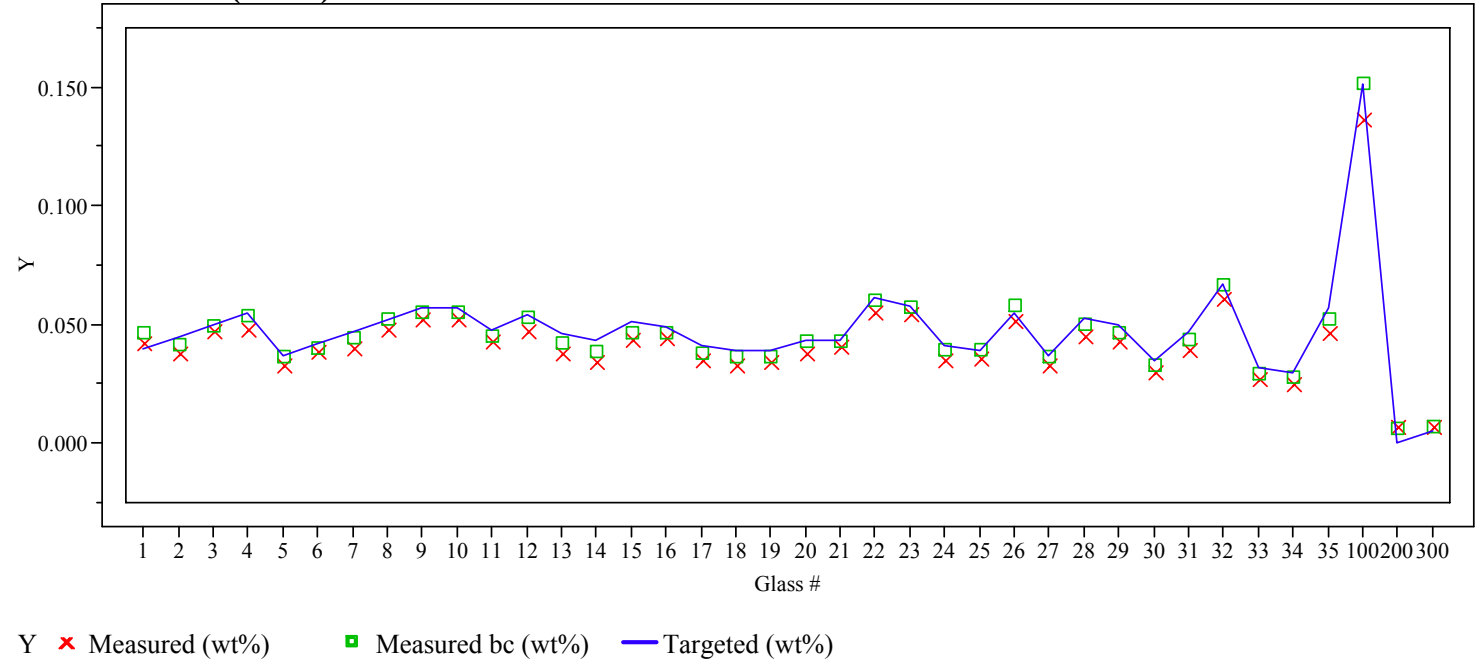




\section{Exhibit E7. Average Measured and Bias-Corrected (bc) Versus \\ Targeted Compositions by Glass \# by Oxide (continued)}

(100 - Batch 1; 200 - Ustd)

\section{Plot for $\mathrm{CaO}(\mathbf{w t} \%)$}

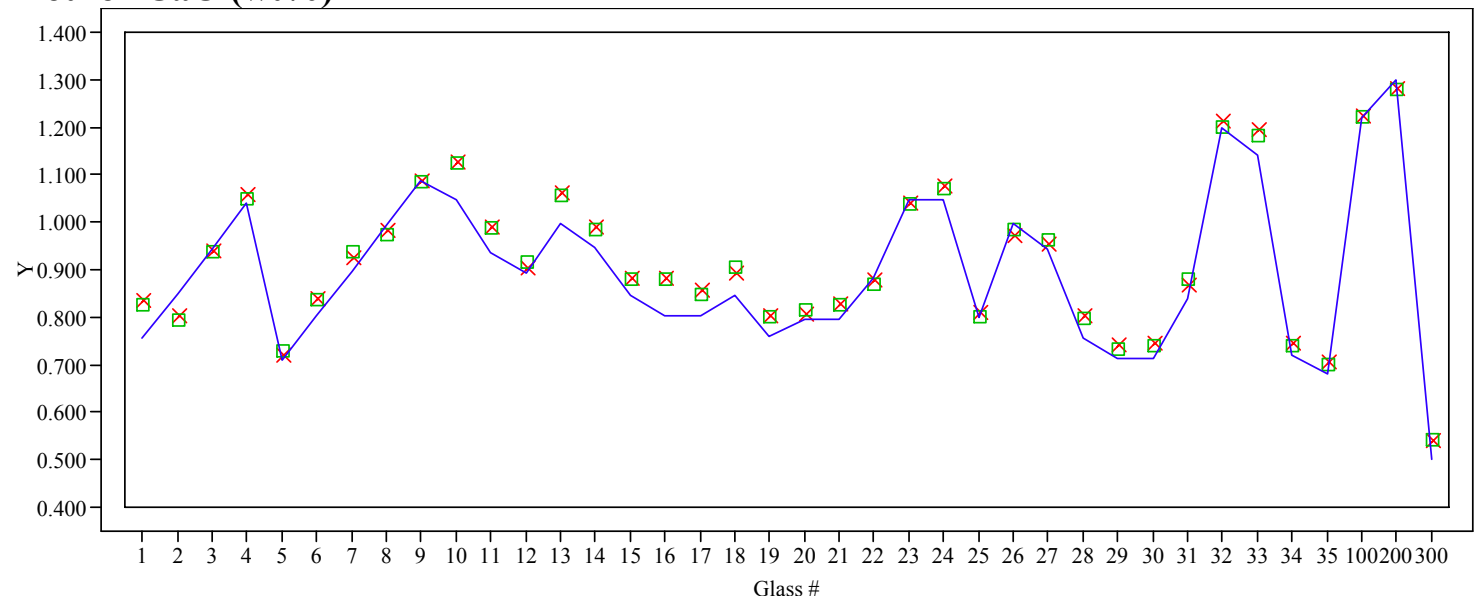

Plot for Ce2O3 (wt\%)

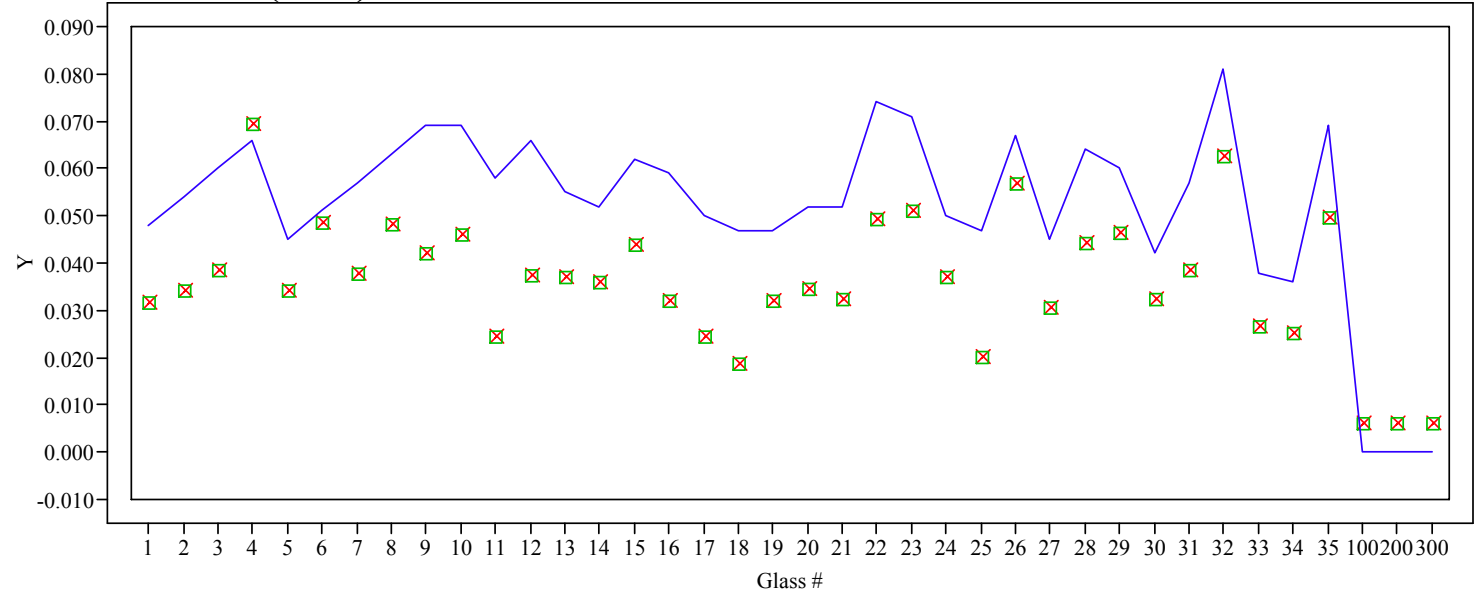

Plot for Cr2O3 (wt\%)

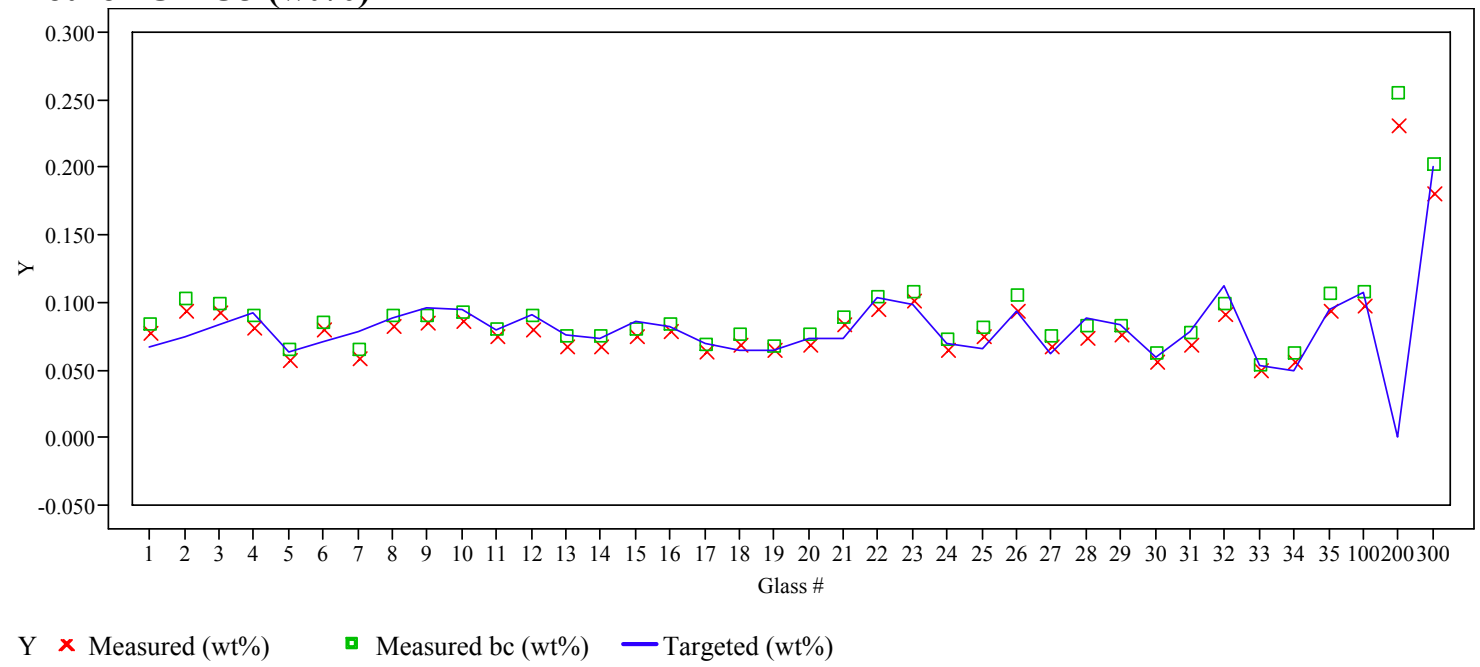




\section{Exhibit E7. Average Measured and Bias-Corrected (bc) Versus \\ Targeted Compositions by Glass \# by Oxide (continued)}

(100 - Batch 1; 200 - Ustd)

\section{Plot for $\mathrm{CuO}(\mathrm{wt} \%)$}

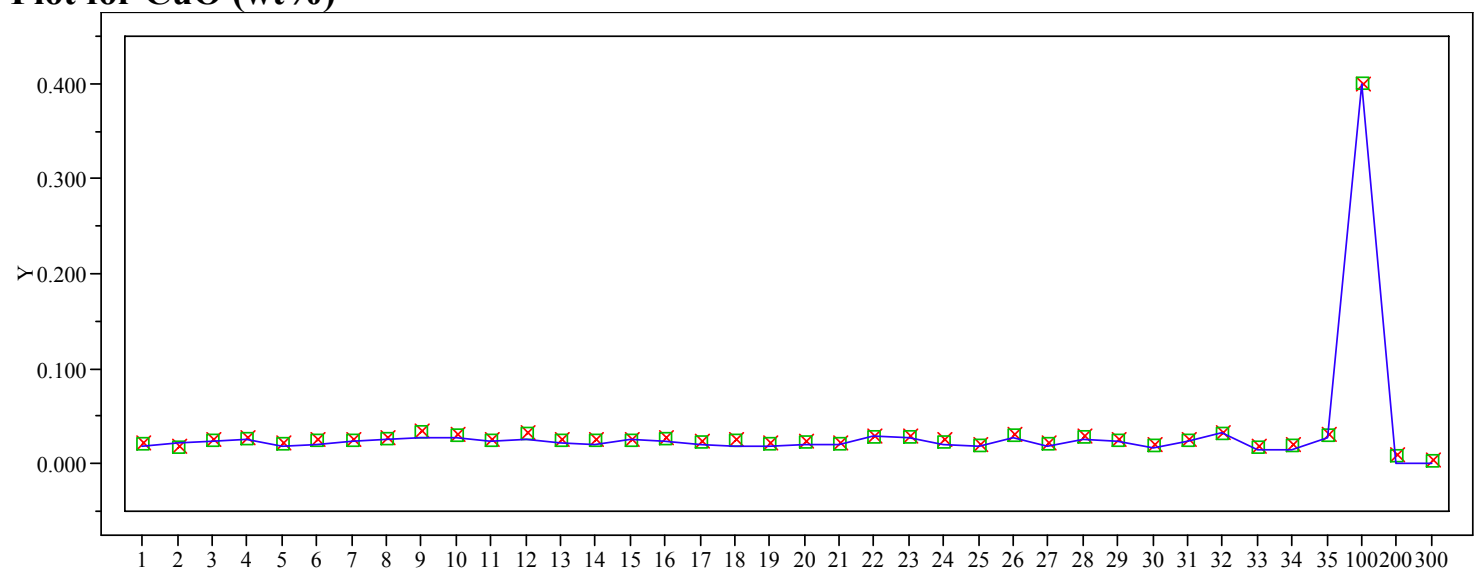
Glass \#

Plot for $\mathrm{Fe} 2 \mathrm{O} 3(\mathrm{wt} \%)$

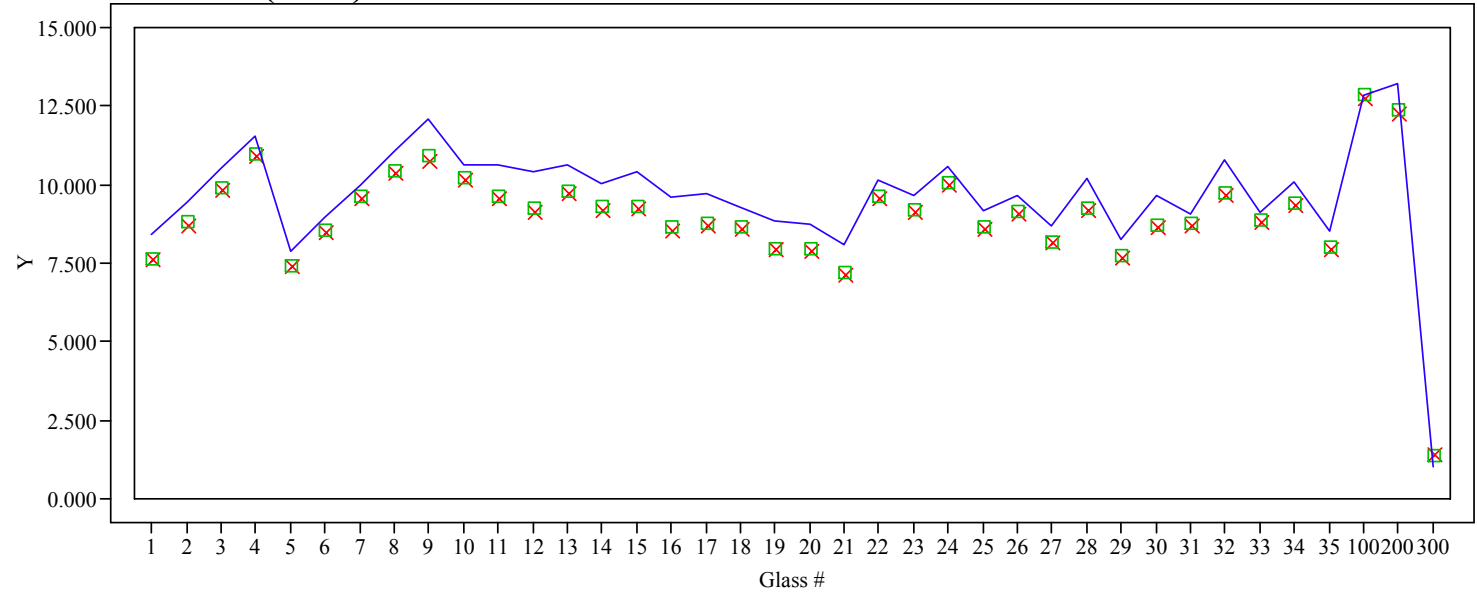

\section{Plot for K2O (wt\%)}

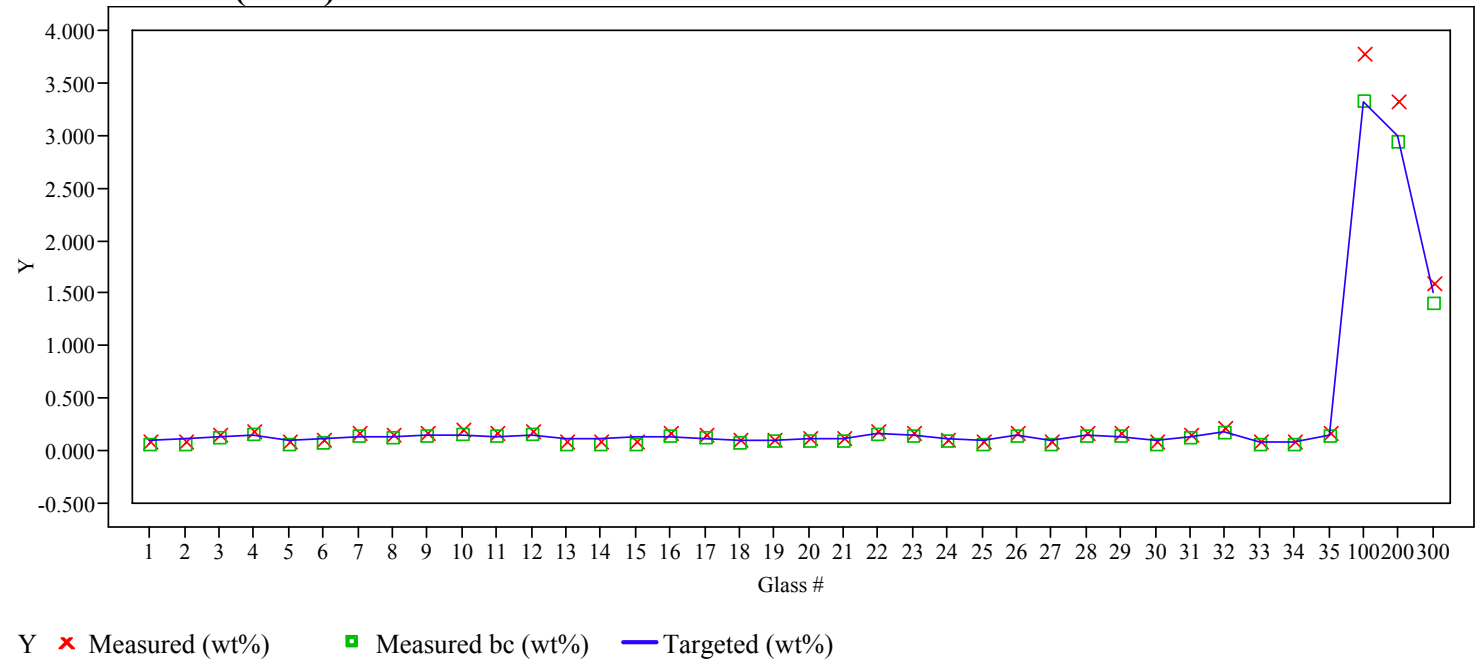




\section{Exhibit E7. Average Measured and Bias-Corrected (bc) Versus Targeted Compositions by Glass \# by Oxide (continued)}

(100 - Batch 1; 200 - Ustd)

\section{Plot for La2O3 (wt\%)}

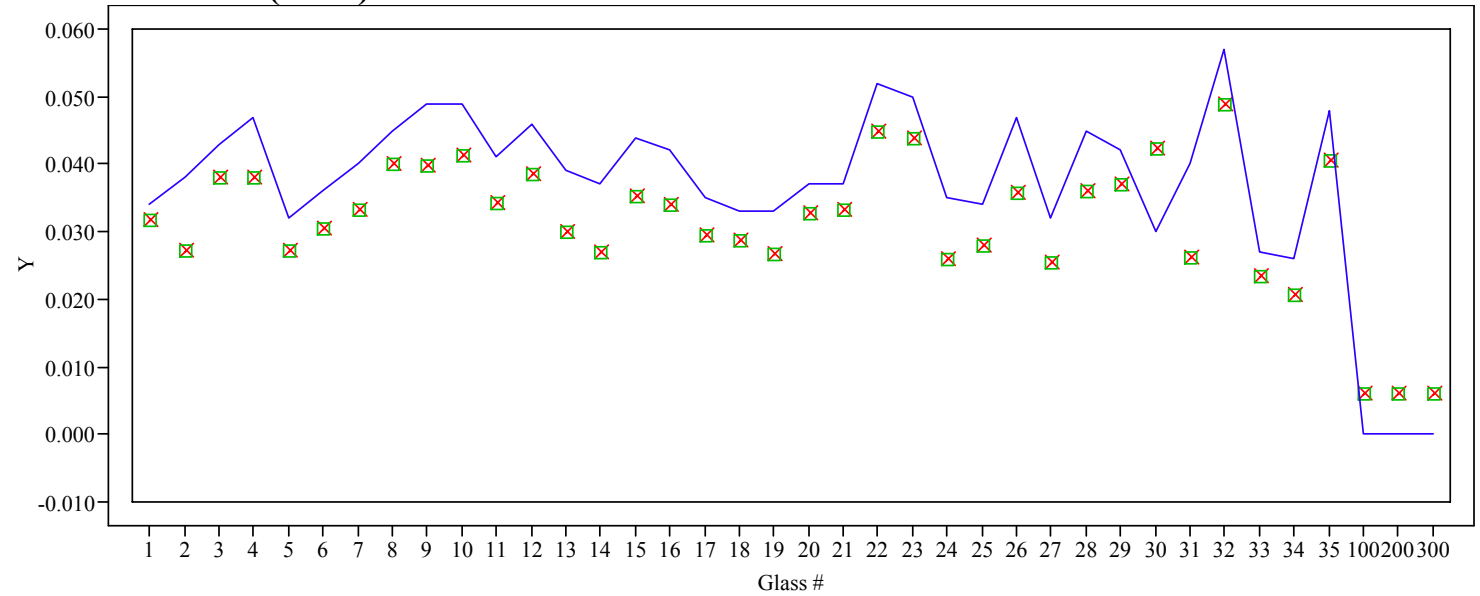

\section{Plot for Li2O (wt\%)}

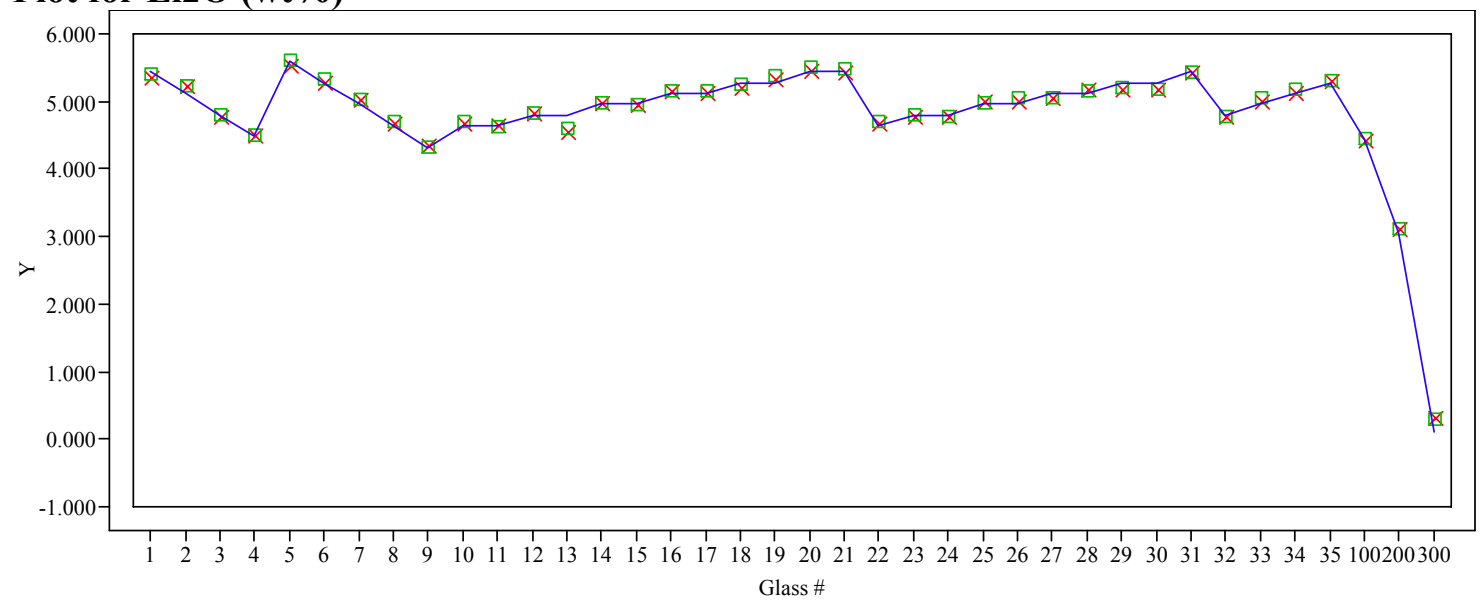

\section{Plot for MgO (wt\%)}

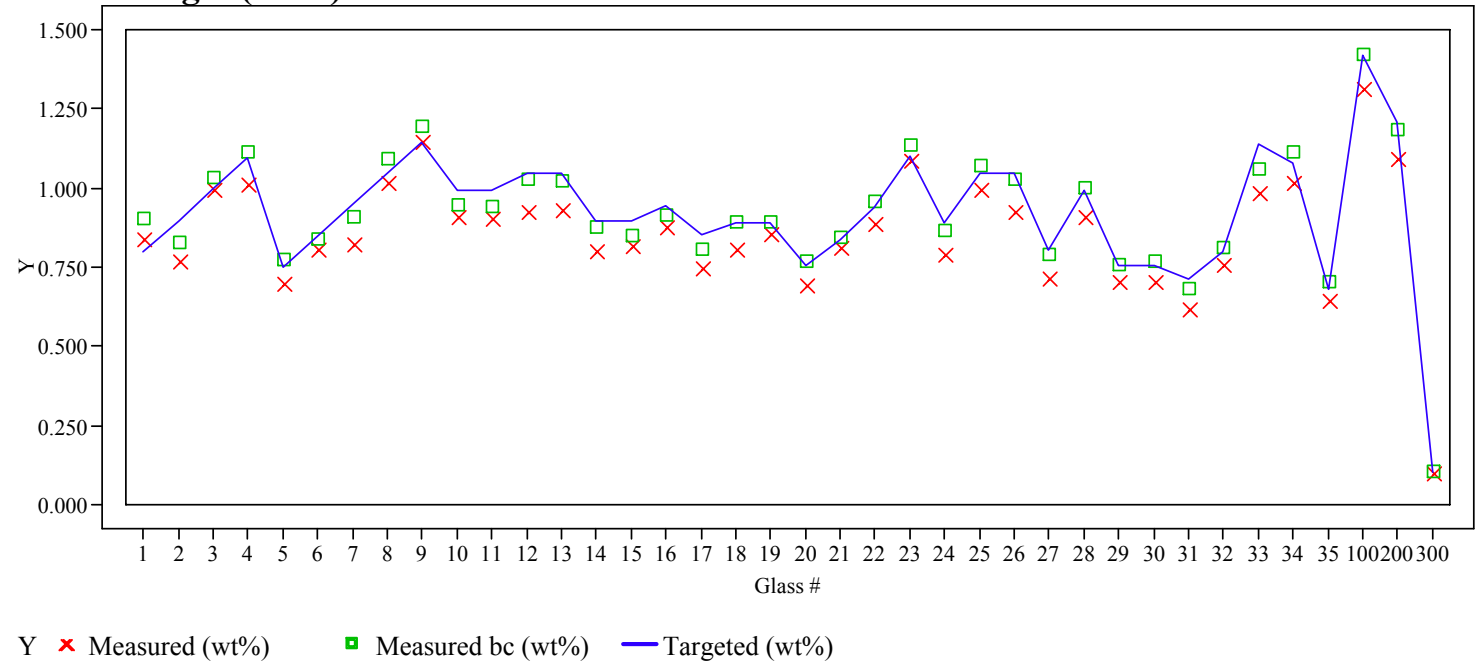




\section{Exhibit E7. Average Measured and Bias-Corrected (bc) Versus Targeted Compositions by Glass \# by Oxide (continued)}

(100 - Batch 1;200 - Ustd)

\section{Plot for MnO (wt\%)}

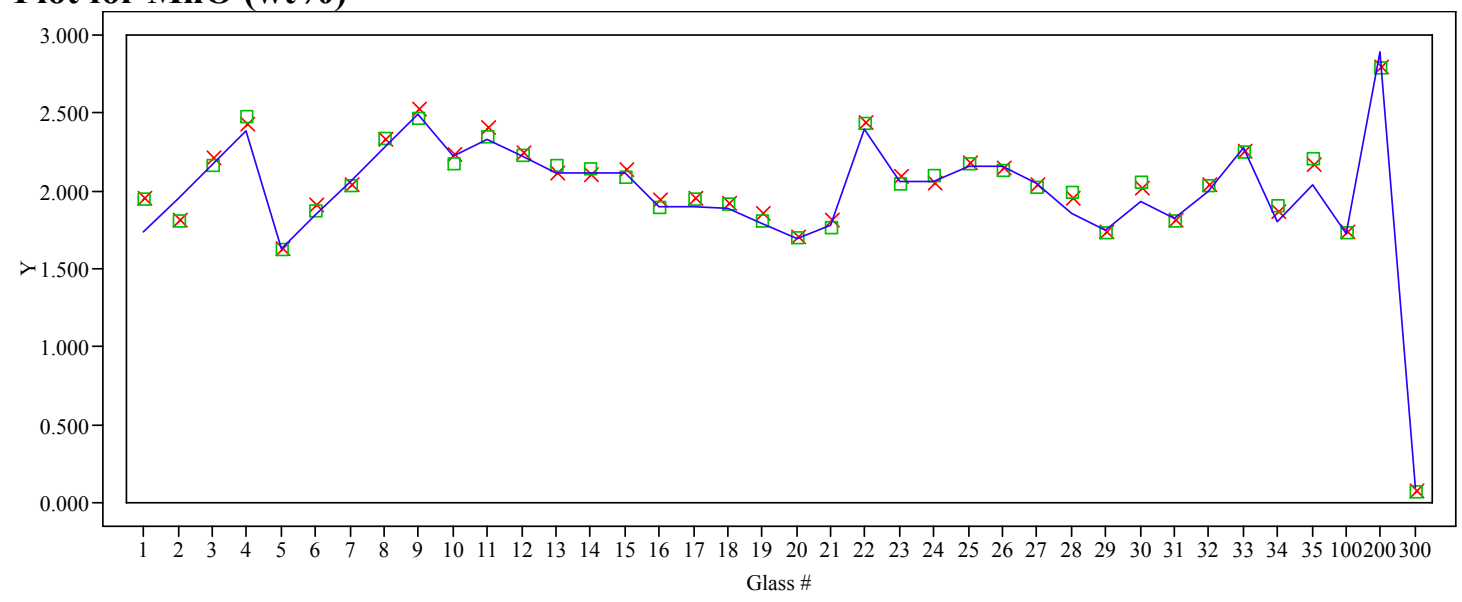

\section{Plot for Na2O (wt\%)}

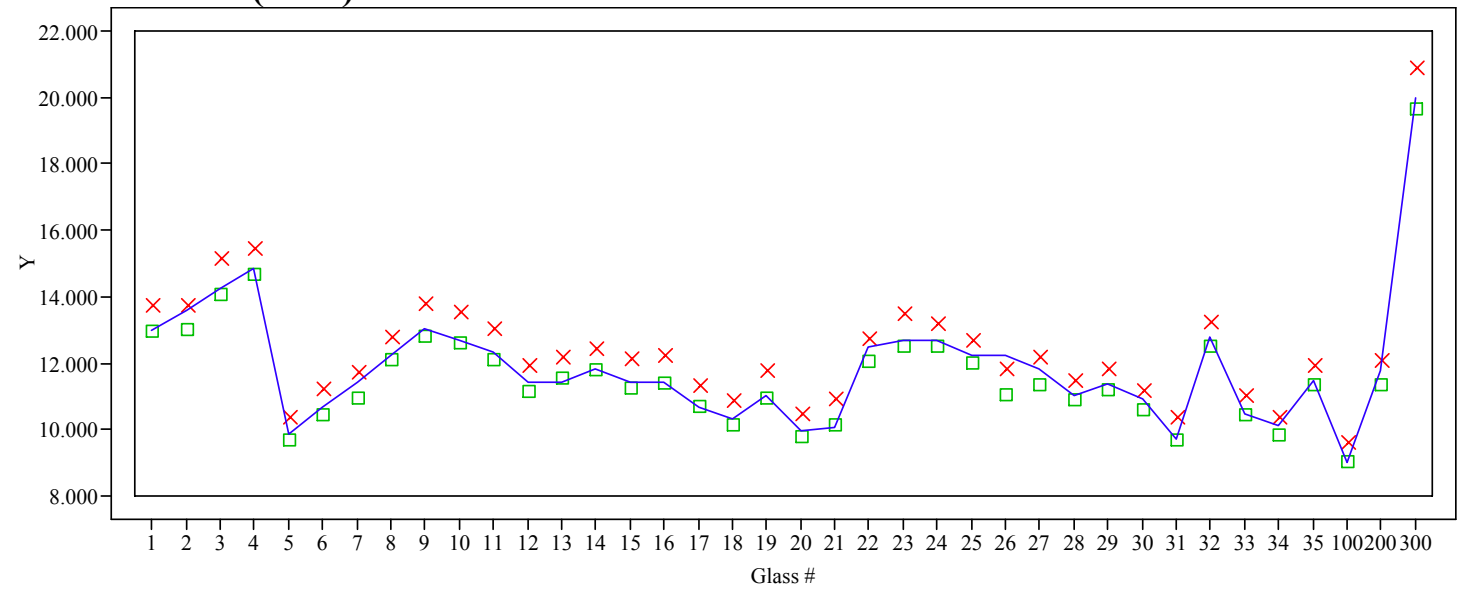

\section{Plot for NiO (wt\%)}

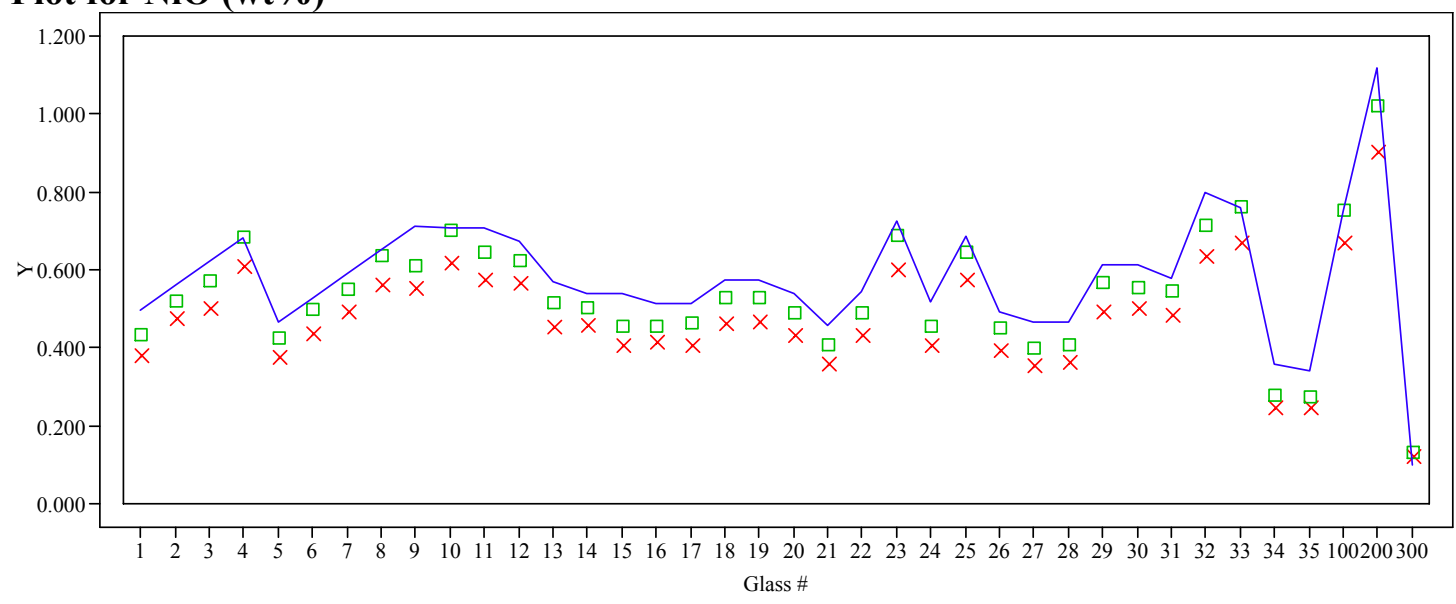

$\mathrm{Y} \times$ Measured $(\mathrm{wt} \%) \quad \square$ Measured bc $(\mathrm{wt} \%) \quad$ - Targeted (wt $\%)$ 


\section{Exhibit E7. Average Measured and Bias-Corrected (bc) Versus \\ Targeted Compositions by Glass \# by Oxide (continued)}

$(100-$ Batch 1; 200 - Ustd)

\section{Plot for $\mathrm{PbO}(\mathrm{wt} \%)$}

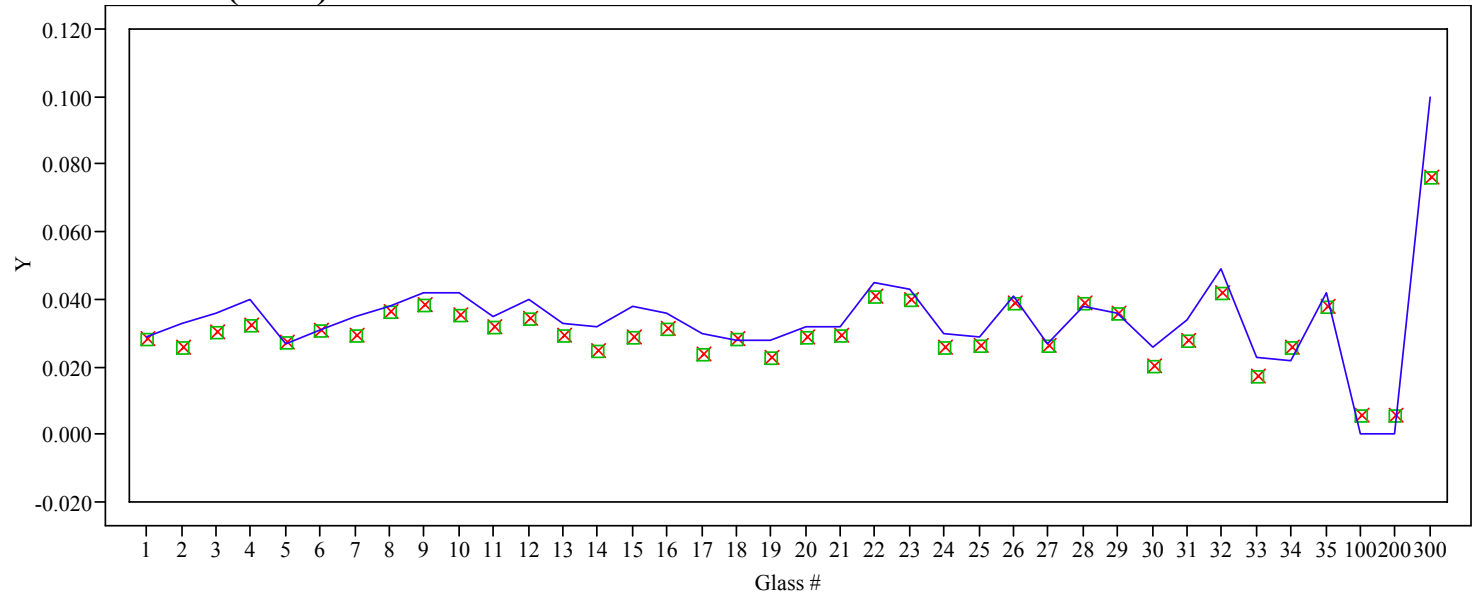

Plot for $\mathrm{SiO} 2(w t \%)$

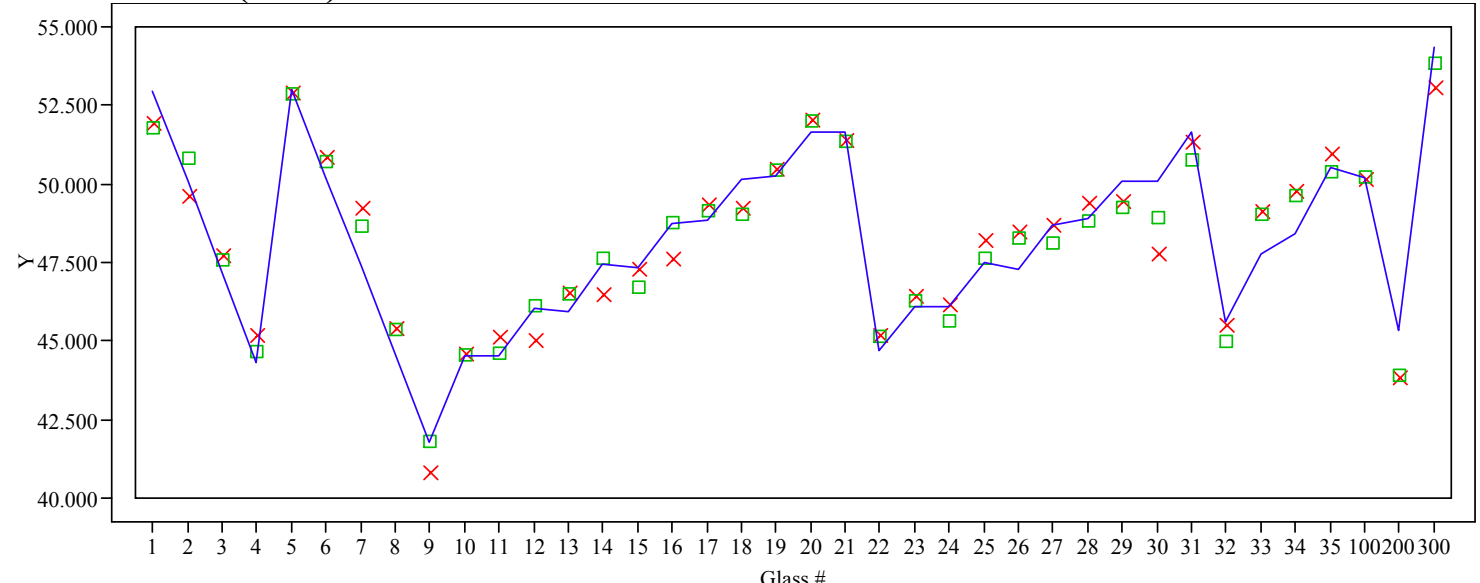

Plot for SO4 (wt\%)

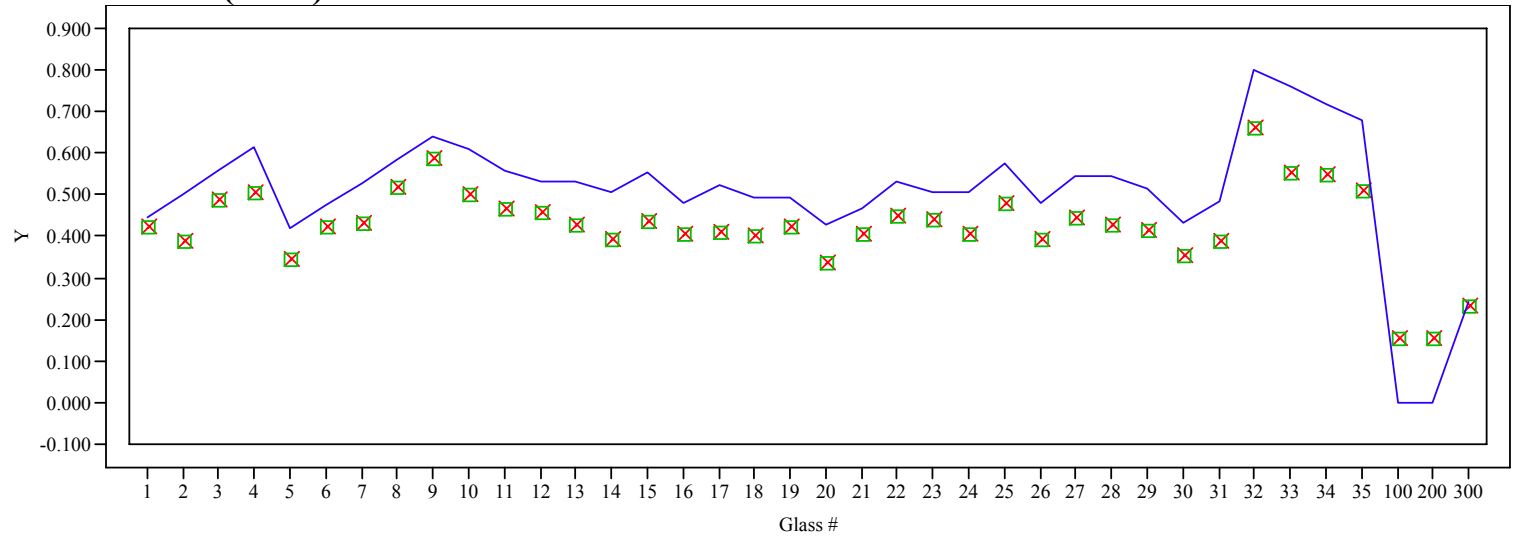

$\mathrm{Y} \times$ Measured $(\mathrm{wt} \%) \quad \square$ Measured bc (wt\%) - Targeted (wt\%) 


\section{Exhibit E7. Average Measured and Bias-Corrected (bc) Versus \\ Targeted Compositions by Glass \# by Oxide (continued)}

(100 - Batch 1; 200 - Ustd)

\section{Plot for ThO2 (wt\%)}

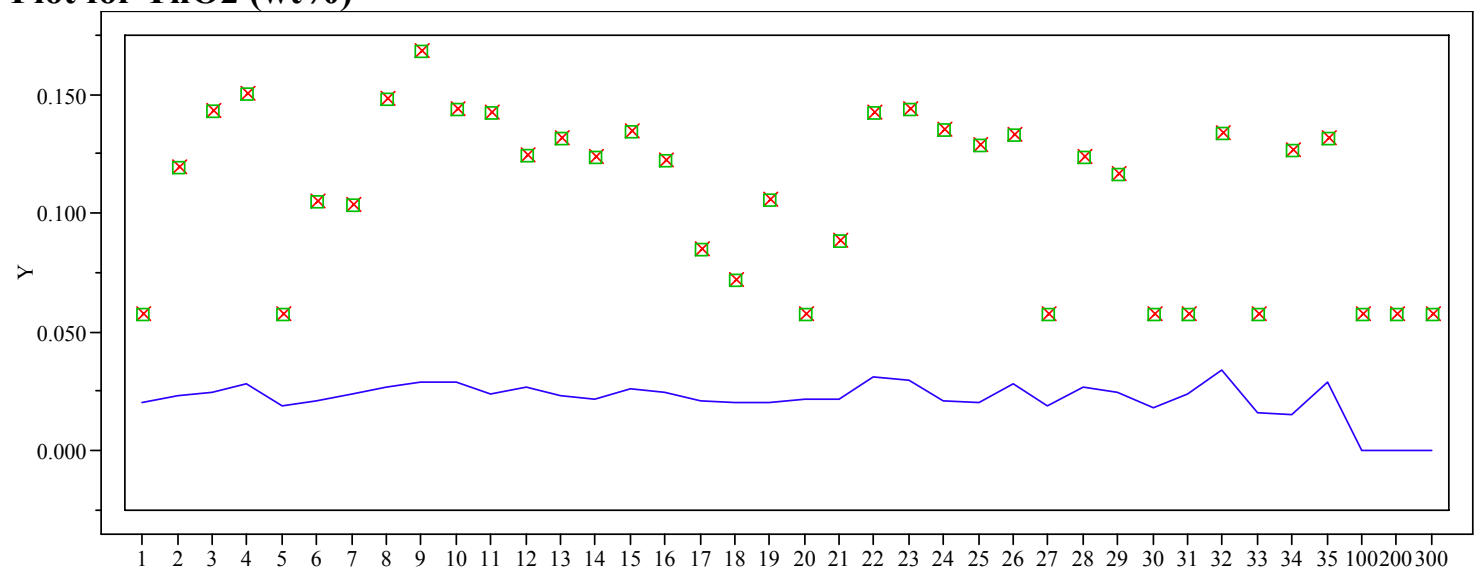
Glass \#

Plot for TiO2 (wt\%)

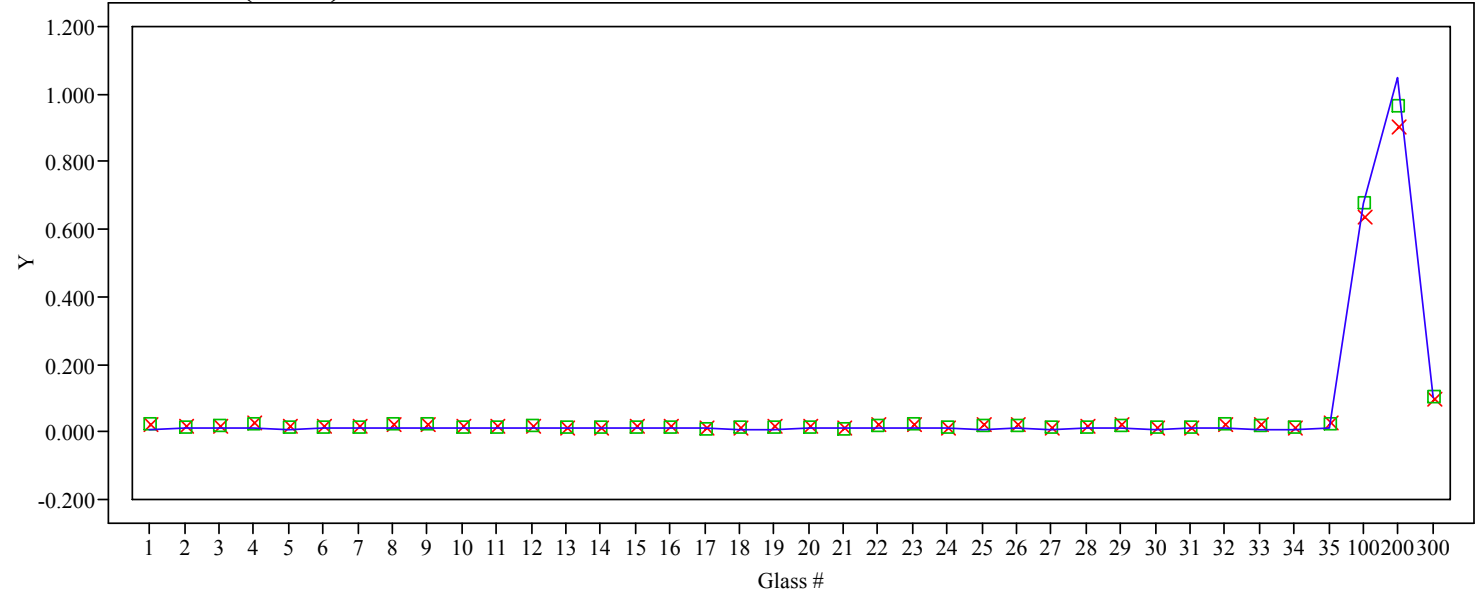

Plot for U3O8 (wt\%)

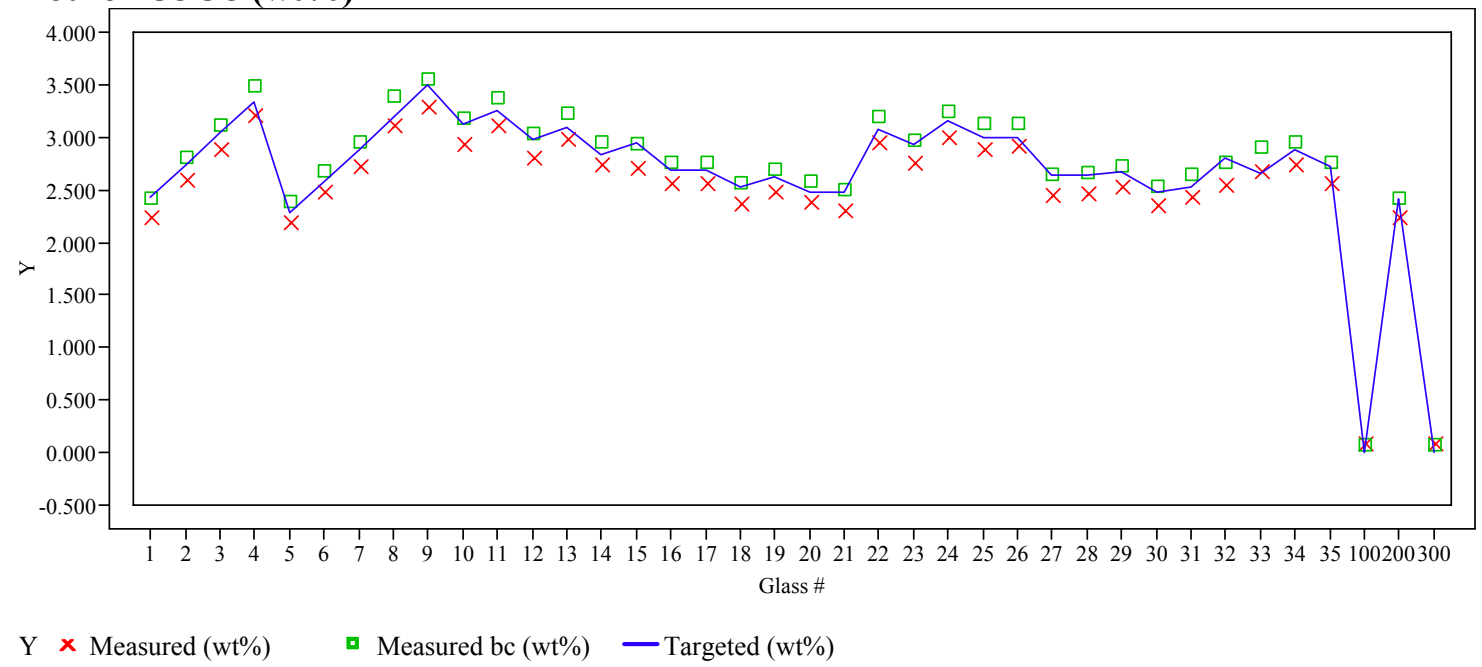




\section{Exhibit E7. Average Measured and Bias-Corrected (bc) Versus \\ Targeted Compositions by Glass \# by Oxide (continued)}

$(100-$ Batch $1 ; 200-$ Ustd $)$

\section{Plot for $\mathrm{ZnO}(\mathbf{w t} \%)$}

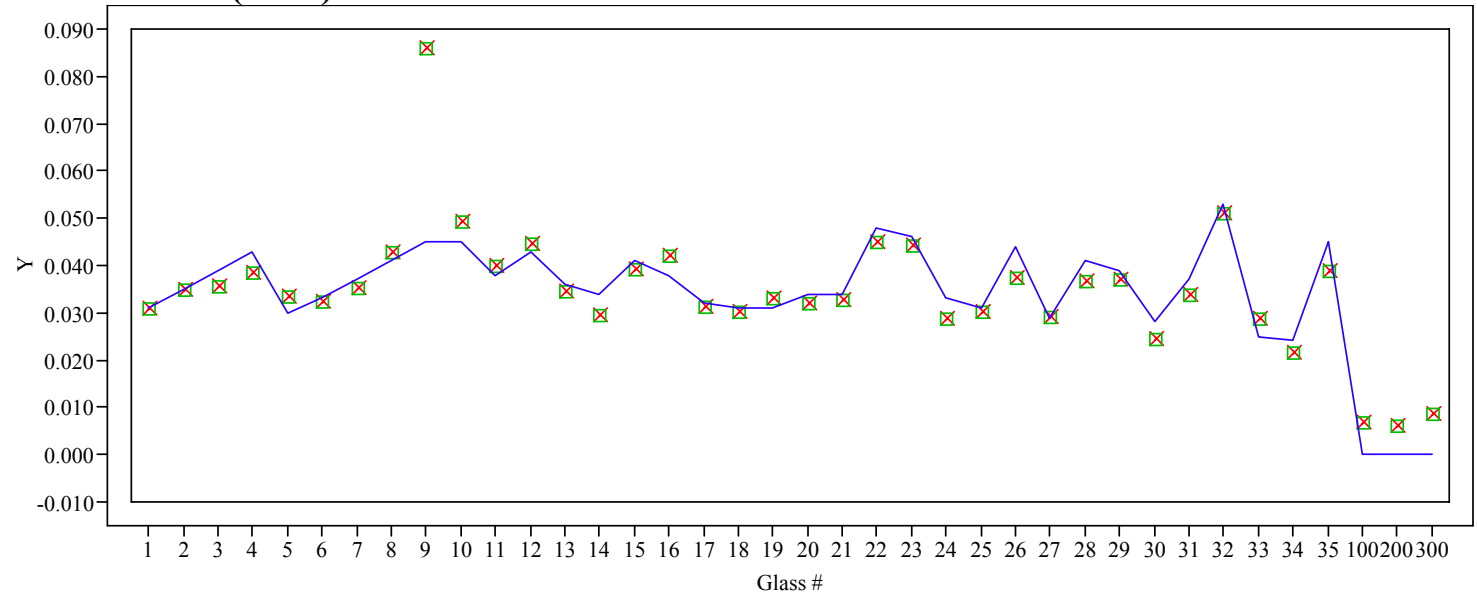

\section{Plot for $\mathrm{ZrO2}(\mathbf{w t} \%)$}

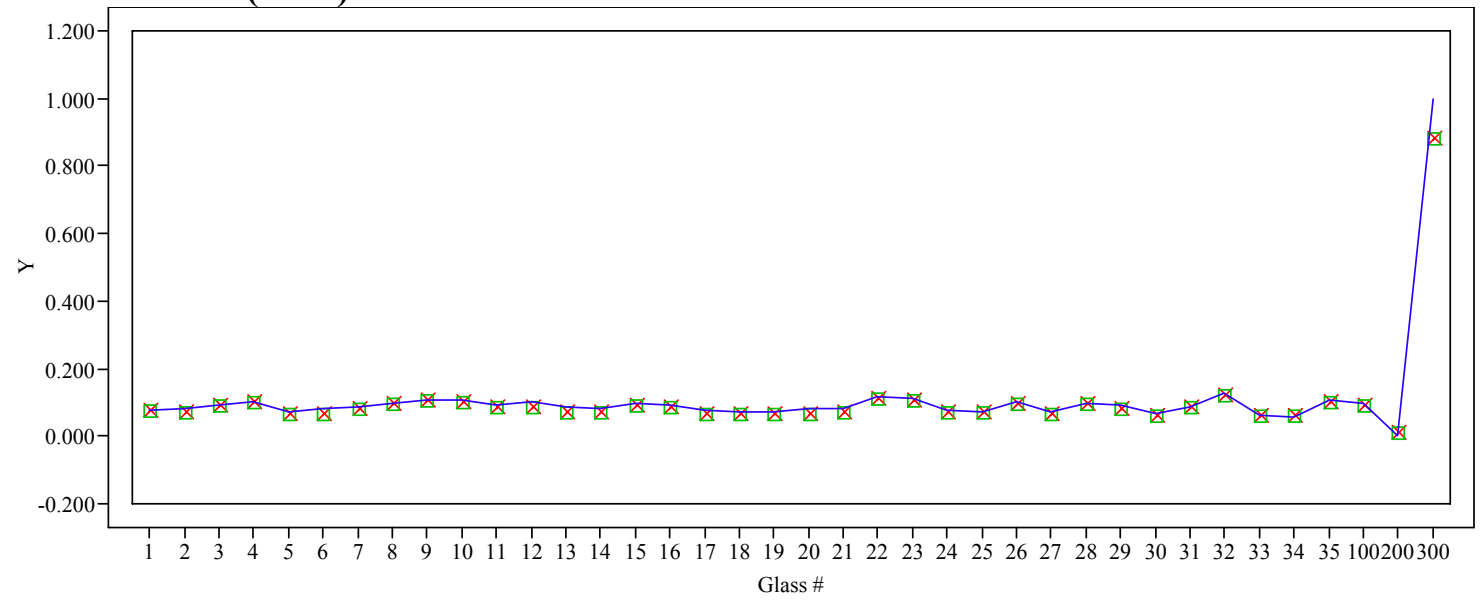

\section{Plot for Sum of Oxides}

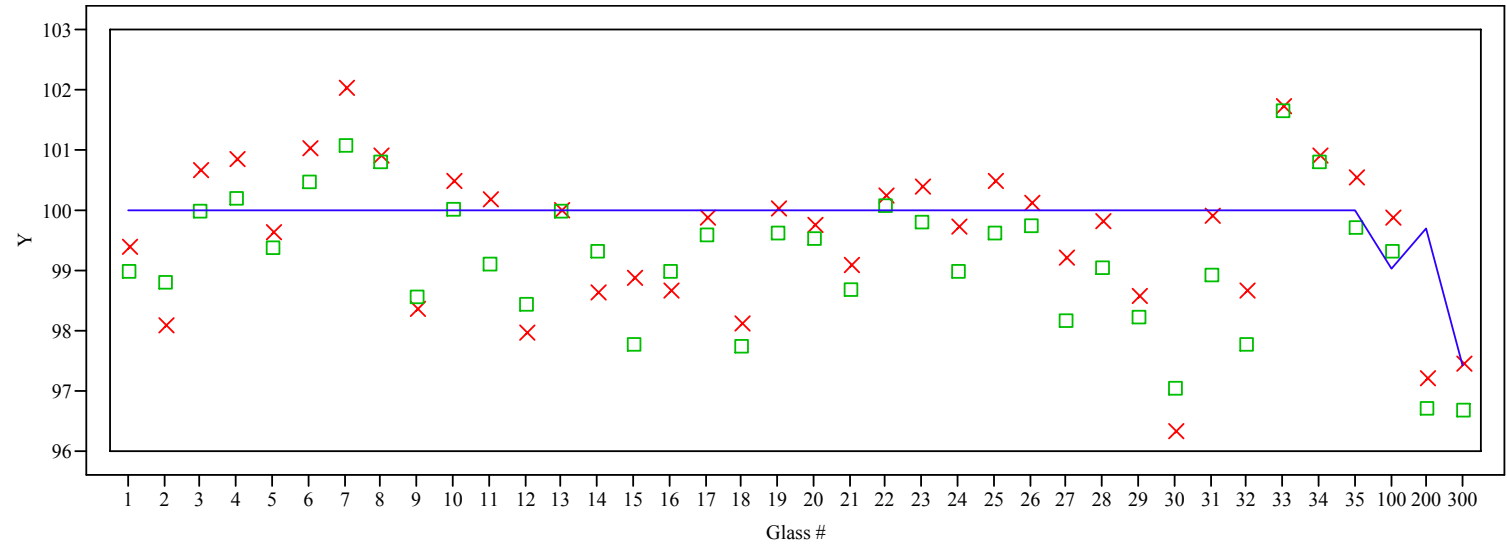

$\mathrm{Y} \times$ Measured $(\mathrm{wt} \%) \quad \square$ Measured bc (wt\%) - Targeted (wt \%) 


\section{Appendix F}

Tables and Exhibits Supporting the Analysis of the PCT Results for the SB4 Variability Study Glasses 
Table F1. Laboratory Measurements of the PCT Solutions for the Nepheline Study Glasses

\begin{tabular}{|c|c|c|c|c|c|c|c|c|c|c|c|c|c|}
\hline Set & Glass ID & $\begin{array}{c}\text { Heat } \\
\text { Treatment }\end{array}$ & $\begin{array}{c}\text { Laboratory } \\
\text { ID }\end{array}$ & Block & Seq & $\begin{array}{c}\mathbf{A l} \\
(\mathbf{p p m})\end{array}$ & $\begin{array}{c}\text { B } \\
(\mathrm{ppm})\end{array}$ & $\begin{array}{c}\mathbf{F e} \\
(\mathrm{ppm})\end{array}$ & $\begin{array}{c}\mathbf{L i} \\
(\mathbf{p p n})\end{array}$ & $\begin{array}{c}\mathrm{Na} \\
(\mathrm{ppm})\end{array}$ & $\begin{array}{c}\mathbf{S i} \\
(\mathbf{p p m})\end{array}$ & $\begin{array}{c}\text { Th } \\
(\mathbf{p p m})\end{array}$ & $\begin{array}{c}\mathbf{U} \\
\text { (ppm) }\end{array}$ \\
\hline 1 & Soln Std & & Soln Std & 1 & 1 & 3.85 & 22.0 & 3.98 & 9.76 & 82.9 & 49.1 & $<0.100$ & $<0.100$ \\
\hline 1 & SB4VS-06 & quenched & R38 & 1 & 2 & 10.4 & 11.2 & 3.57 & 10.3 & 26.3 & 61.3 & $<0.100$ & 2.02 \\
\hline 1 & SB4VS-06ccc & $\mathrm{ccc}$ & $\mathrm{R} 40$ & 1 & 3 & 10.6 & 11.1 & 3.26 & 10.1 & 27.6 & 61.7 & $<0.100$ & 2.30 \\
\hline 1 & SB4VS-01 & quenched & R29 & 1 & 4 & 12.8 & 6.53 & 6.30 & 11.7 & 50.8 & 74.7 & $<0.100$ & 2.58 \\
\hline 1 & SB4VS-01ccc & $\mathrm{ccc}$ & R08 & 1 & 5 & 13.0 & 6.33 & 5.70 & 11.9 & 48.7 & 74.7 & $<0.100$ & 2.50 \\
\hline 1 & blank & & R49 & 1 & 6 & $<0.100$ & $<0.100$ & $<0.100$ & $<0.500$ & $<0.100$ & $<0.100$ & $<0.100$ & $<0.100$ \\
\hline 1 & SB4VS-08 & quenched & R51 & 1 & 7 & 13.8 & 10.4 & 3.22 & 9.14 & 36.4 & 54.6 & $<0.100$ & 1.49 \\
\hline 1 & SB4VS-08ccc & $\mathrm{ccc}$ & R23 & 1 & 8 & 13.7 & 10.2 & 3.23 & 8.95 & 36.0 & 54.3 & $<0.100$ & 1.76 \\
\hline 1 & SB4VS-02 & quenched & $\mathrm{R} 46$ & 1 & 9 & 12.1 & 7.62 & 6.59 & 11.6 & 51.9 & 76.3 & $<0.100$ & 2.16 \\
\hline 1 & SB4VS-03 & quenched & R55 & 1 & 10 & 12.0 & 7.45 & 6.43 & 11.8 & 49.0 & 76.1 & $<0.100$ & 2.22 \\
\hline 1 & SB4VS-04 & quenched & R13 & 1 & 11 & 18.2 & 7.37 & 5.18 & 10.4 & 70.6 & 69.5 & $<0.100$ & 1.91 \\
\hline 1 & Soln Std & & Soln Std & 1 & 12 & 4.01 & 21.0 & 4.01 & 9.85 & 82.5 & 50.1 & $<0.100$ & $<0.100$ \\
\hline 1 & SB4VS-04ccc & $\mathrm{ccc}$ & R52 & 1 & 13 & 18.3 & 8.15 & 4.73 & 11.2 & 67.4 & 70.8 & $<0.100$ & 1.77 \\
\hline 1 & SB4VS-07 & quenched & R17 & 1 & 14 & 12.0 & 11.3 & 3.04 & 9.83 & 32.6 & 58.6 & $<0.100$ & 1.54 \\
\hline 1 & SB4VS-07ccc & $\mathrm{ccc}$ & $\mathrm{R} 43$ & 1 & 15 & 12.1 & 10.7 & 2.81 & 9.41 & 31.2 & 57.5 & $<0.100$ & 1.87 \\
\hline 1 & SB4VS-05 & quenched & R42 & 1 & 16 & 9.40 & 11.6 & 4.03 & 11.1 & 23.6 & 66.9 & $<0.100$ & 3.66 \\
\hline 1 & SB4VS-05 ccc & $\mathrm{ccc}$ & R19 & 1 & 17 & 10.9 & 12.0 & 6.53 & 11.6 & 24.0 & 69.2 & $<0.100$ & 3.04 \\
\hline 1 & EA & & R30 & 1 & 18 & $<0.100$ & 25.0 & $<0.100$ & 8.42 & 70.2 & 42.0 & $<0.100$ & $<0.100$ \\
\hline 1 & ARM-1 & & R05 & 1 & 19 & 3.16 & 11.1 & $<0.100$ & 8.44 & 22.9 & 37.1 & $<0.100$ & $<0.100$ \\
\hline 1 & SB4VS-09 & quenched & R22 & 1 & 20 & 16.4 & 11.0 & 3.04 & 8.86 & 45.0 & 53.3 & $<0.100$ & 1.76 \\
\hline 1 & SB4VS-09 $\mathrm{ccc}$ & $\operatorname{ccc}$ & R60 & 1 & 21 & 15.1 & 24.6 & 4.43 & 18.1 & 66.3 & 68.4 & $<0.100$ & 2.31 \\
\hline 1 & SB4VS-03 & quenched & R32 & 1 & 22 & 16.7 & 7.94 & 6.44 & 11.4 & 64.0 & 75.6 & $<0.100$ & 2.00 \\
\hline 1 & SB4VS-03ccc & $\mathrm{ccc}$ & R06 & 1 & 23 & 16.1 & 7.34 & 5.35 & 11.5 & 59.5 & 73.3 & $<0.100$ & 1.98 \\
\hline 1 & Soln Std & & Soln Std & 1 & 24 & 4.15 & 21.2 & 3.98 & 9.94 & 83.5 & 50.5 & $<0.100$ & $<0.100$ \\
\hline 1 & Soln Std & & Soln Std & 2 & 1 & 3.95 & 21.5 & 3.70 & 9.82 & 80.4 & 49.1 & $<0.100$ & $<0.100$ \\
\hline 1 & SB4VS-06 & quenched & R39 & 2 & 2 & 10.1 & 11.4 & 3.12 & 10.2 & 25.1 & 60.6 & $<0.100$ & 2.02 \\
\hline 1 & SB4VS-06ccc & $\mathrm{ccc}$ & R04 & 2 & 3 & 10.1 & 10.9 & 2.93 & 9.83 & 25.9 & 60.3 & $<0.100$ & 2.10 \\
\hline 1 & SB4VS-01 & quenched & $\mathrm{R} 45$ & 2 & 4 & 13.0 & 6.57 & 5.95 & 11.8 & 48.9 & 75.7 & $<0.100$ & 2.54 \\
\hline 1 & SB4VS-01ccc & $\mathrm{ccc}$ & $\mathrm{R} 21$ & 2 & 5 & 12.5 & 6.10 & 5.52 & 11.7 & 44.7 & 73.4 & $<0.100$ & 2.44 \\
\hline 1 & SB4VS-08 & quenched & R16 & 2 & 6 & 13.5 & 10.0 & 2.72 & 9.00 & 34.7 & 53.1 & $<0.100$ & 1.60 \\
\hline 1 & SB4VS-08ccc & $\mathrm{ccc}$ & R10 & 2 & 7 & 13.1 & 9.76 & 2.39 & 8.71 & 33.2 & 51.7 & $<0.100$ & 1.82 \\
\hline 1 & SB4VS-02 & quenched & R37 & 2 & 8 & 12.0 & 7.24 & 6.16 & 11.5 & 48.3 & 74.5 & $<0.100$ & 2.05 \\
\hline 1 & SB4VS-01 ccc & $\mathrm{ccc}$ & R57 & 2 & 9 & 11.7 & 7.17 & 5.64 & 11.7 & 45.2 & 74.8 & $<0.100$ & 2.06 \\
\hline 1 & SB4VS-04 & quenched & $\mathrm{R} 48$ & 2 & 10 & 18.1 & 7.01 & 4.23 & 10.3 & 66.8 & 67.4 & $<0.100$ & 1.84 \\
\hline 1 & SB4VS-04ccc & $\mathrm{ccc}$ & R36 & 2 & 11 & 18.4 & 7.50 & 4.65 & 11.3 & 65.5 & 71.1 & $<0.100$ & 1.81 \\
\hline 1 & Soln Std & & Soln Std & 2 & 12 & 4.05 & 21.0 & 3.71 & 9.95 & 79.8 & 49.9 & $<0.100$ & $<0.100$ \\
\hline 1 & SB4VS-07 & quenched & R62 & 2 & 13 & 12.1 & 11.3 & 2.76 & 9.94 & 31.0 & 58.7 & $<0.100$ & 1.70 \\
\hline 1 & SB4VS-07ccc & $\mathrm{ccc}$ & R47 & 2 & 14 & 11.9 & 10.6 & 2.46 & 9.38 & 30.6 & 57.4 & $<0.100$ & 1.94 \\
\hline 1 & SB4VS-05 & quenched & R12 & 2 & 15 & 9.06 & 11.2 & 3.52 & 10.9 & 23.4 & 64.5 & $<0.100$ & 3.45 \\
\hline
\end{tabular}


Table F1. Laboratory Measurements of the PCT Solutions for the Nepheline Study Glasses (continued)

\begin{tabular}{|c|c|c|c|c|c|c|c|c|c|c|c|c|c|}
\hline Set & Glass ID & $\begin{array}{c}\text { Heat } \\
\text { Treatment }\end{array}$ & $\begin{array}{c}\text { Laboratory } \\
\text { ID }\end{array}$ & Block & Seq & $\begin{array}{c}\text { Al } \\
(\mathbf{p p m})\end{array}$ & $\begin{array}{c}\text { B } \\
(\mathrm{ppm})\end{array}$ & $\begin{array}{c}\mathbf{F e} \\
(\mathrm{ppm})\end{array}$ & $\begin{array}{c}\mathbf{L i} \\
(\mathbf{p p m})\end{array}$ & $\begin{array}{c}\mathrm{Na} \\
(\mathrm{ppm})\end{array}$ & $\begin{array}{c}\mathbf{S i} \\
(\mathbf{p p m})\end{array}$ & $\begin{array}{c}\text { Th } \\
\text { (ppm) }\end{array}$ & $\begin{array}{c}\mathbf{U} \\
\text { (ppm) }\end{array}$ \\
\hline 1 & SB4VS-09ccc & $\mathrm{ccc}$ & R59 & 2 & 16 & 9.35 & 11.4 & 4.31 & 11.3 & 22.3 & 65.8 & $<0.100$ & 3.12 \\
\hline 1 & EA & & R20 & 2 & 17 & $<0.100$ & 27.0 & $<0.100$ & 8.96 & 72.6 & 44.0 & $<0.100$ & $<0.100$ \\
\hline 1 & ARM-1 & & R61 & 2 & 18 & 3.06 & 11.6 & $<0.100$ & 8.77 & 23.7 & 37.6 & $<0.100$ & $<0.100$ \\
\hline 1 & SB4VS-09 & quenched & R11 & 2 & 19 & 16.4 & 10.9 & 2.92 & 9.08 & 44.3 & 53.7 & $<0.100$ & 1.48 \\
\hline 1 & SB4VS-09ccc & $\mathrm{ccc}$ & R27 & 2 & 20 & 15.7 & 25.1 & 4.85 & 18.5 & 67.4 & 71.0 & $<0.100$ & 1.87 \\
\hline 1 & SB4VS-03 & quenched & R50 & 2 & 21 & 15.7 & 7.24 & 5.13 & 11.0 & 61.4 & 72.2 & $<0.100$ & 1.90 \\
\hline 1 & SB4VS-03 ccc & $\mathrm{ccc}$ & R01 & 2 & 22 & 15.6 & 7.06 & 4.90 & 11.4 & 57.2 & 72.4 & $<0.100$ & 2.00 \\
\hline 1 & Soln Std & & Soln Std & 2 & 23 & 4.05 & 21.1 & 3.76 & 10.0 & 81.8 & 50.4 & $<0.100$ & $<0.100$ \\
\hline 1 & Soln Std & & Soln Std & 3 & 1 & 4.01 & 21.4 & 3.60 & 9.83 & 81.6 & 48.8 & $<0.100$ & $<0.100$ \\
\hline 1 & SB4VS-06 & quenched & R24 & 3 & 2 & 10.5 & 11.8 & 3.26 & 10.5 & 26.9 & 62.0 & $<0.100$ & 1.99 \\
\hline 1 & SB4VS-06ccc & $\mathrm{ccc}$ & R33 & 3 & 3 & 10.2 & 11.0 & 2.87 & 9.84 & 25.8 & 60.0 & $<0.100$ & 2.30 \\
\hline 1 & blank & & R03 & 3 & 4 & $<0.100$ & $<0.100$ & $<0.100$ & $<0.500$ & $<0.100$ & $<0.100$ & $<0.100$ & $<0.100$ \\
\hline 1 & SB4VS-01 & quenched & R35 & 3 & 5 & 12.6 & 6.34 & 5.83 & 11.8 & 49.7 & 74.0 & $<0.100$ & 2.16 \\
\hline 1 & SB4VS-05ccc & $\mathrm{ccc}$ & R58 & 3 & 6 & 12.5 & 6.13 & 5.70 & 11.8 & 47.6 & 73.4 & $<0.100$ & 2.98 \\
\hline 1 & SB4VS-08 & quenched & R34 & 3 & 7 & 13.4 & 10.1 & 2.73 & 8.97 & 35.4 & 52.9 & $<0.100$ & 1.42 \\
\hline 1 & SB4VS-08ccc & $\mathrm{ccc}$ & R31 & 3 & 8 & 13.8 & 10.5 & 2.45 & 9.18 & 36.8 & 54.5 & $<0.100$ & 1.40 \\
\hline 1 & SB4VS-02 & quenched & R18 & 3 & 9 & 12.2 & 7.46 & 7.00 & 11.8 & 51.3 & 76.6 & $<0.100$ & 2.27 \\
\hline 1 & SB4VS-02ccc & $\mathrm{ccc}$ & R14 & 3 & 10 & 12.0 & 7.42 & 6.31 & 11.8 & 47.2 & 76.3 & $<0.100$ & 2.15 \\
\hline 1 & SB4VS-04 & quenched & R15 & 3 & 11 & 18.0 & 7.34 & 4.54 & 10.3 & 66.5 & 69.1 & $<0.100$ & 1.74 \\
\hline 1 & Soln Std & & Soln Std & 3 & 12 & 4.09 & 21.4 & 3.87 & 10.0 & 83.5 & 50.9 & $<0.100$ & $<0.100$ \\
\hline 1 & SB4VS-04ccc & $\mathrm{ccc}$ & R02 & 3 & 13 & 20.8 & 8.48 & 6.83 & 11.7 & 67.7 & 74.8 & $<0.100$ & 1.79 \\
\hline 1 & SB4VS-07 & quenched & R26 & 3 & 14 & 11.9 & 10.8 & 3.20 & 9.54 & 30.2 & 57.6 & $<0.100$ & 1.88 \\
\hline 1 & SB4VS-07ccc & $\mathrm{ccc}$ & R41 & 3 & 15 & 11.9 & 10.8 & 2.90 & 9.47 & 31.1 & 58.3 & $<0.100$ & 1.97 \\
\hline 1 & SB4VS-05 & quenched & R44 & 3 & 16 & 9.74 & 11.6 & 4.00 & 11.1 & 23.5 & 66.8 & $<0.100$ & 3.78 \\
\hline 1 & SB4VS-05ccc & $\mathrm{ccc}$ & R53 & 3 & 17 & 9.48 & 12.0 & 4.65 & 11.5 & 22.7 & 68.2 & $<0.100$ & 3.22 \\
\hline 1 & EA & & R25 & 3 & 18 & $<0.100$ & 37.1 & $<0.100$ & 10.7 & 94.4 & 52.1 & $<0.100$ & $<0.100$ \\
\hline 1 & ARM-1 & & R09 & 3 & 19 & 3.17 & 12.0 & $<0.100$ & 8.69 & 24.0 & 39.9 & $<0.100$ & $<0.100$ \\
\hline 1 & SB4VS-09 & quenched & R07 & 3 & 20 & 16.3 & 11.2 & 3.23 & 9.18 & 45.2 & 54.4 & $<0.100$ & 1.51 \\
\hline 1 & SB4VS-02ccc & $\mathrm{ccc}$ & R54 & 3 & 21 & 15.4 & 25.5 & 4.91 & 18.3 & 66.0 & 71.0 & $<0.100$ & 2.29 \\
\hline 1 & SB4VS-02ccc & $\mathrm{ccc}$ & R56 & 3 & 22 & 15.8 & 7.69 & 6.06 & 11.3 & 61.8 & 75.4 & $<0.100$ & 2.15 \\
\hline 1 & SB4VS-03ccc & $\mathrm{ccc}$ & R28 & 3 & 23 & 15.8 & 7.58 & 5.87 & 11.6 & 60.2 & 74.8 & $<0.100$ & 1.97 \\
\hline 1 & Soln Std & & Soln Std & 3 & 24 & 4.44 & 21.5 & 4.17 & 10.0 & 82.3 & 51.3 & $<0.100$ & $<0.100$ \\
\hline 2 & Soln Std & & Soln Std & 1 & 1 & 3.75 & 21.2 & 3.95 & 9.80 & 79.6 & 47.6 & $<0.100$ & $<0.100$ \\
\hline 2 & SB4VS-18ccc & $\mathrm{ccc}$ & S79 & 1 & 2 & 9.75 & 11.0 & 2.77 & 9.84 & 23.4 & 57.2 & $<0.100$ & 2.83 \\
\hline 2 & blank & & S26 & 1 & 3 & 0.656 & 0.351 & $<0.100$ & $<1.00$ & $<0.100$ & 0.287 & $<0.100$ & $<0.100$ \\
\hline 2 & SB4VS-19 & quenched & S51 & 1 & 4 & 9.24 & 11.2 & 3.01 & 10.4 & 27.0 & 58.9 & $<0.100$ & 2.32 \\
\hline 2 & SB4VS-21 & quenched & S29 & 1 & 5 & 9.42 & 10.3 & 2.87 & 10.1 & 20.4 & 57.0 & $<0.100$ & 2.51 \\
\hline 2 & SB4VS-12ccc & $\mathrm{ccc}$ & S80 & 1 & 6 & 12.6 & 10.4 & 2.31 & 9.49 & 30.1 & 53.6 & $<0.100$ & 1.56 \\
\hline 2 & EA & & S07 & 1 & 7 & $<0.100$ & 37.5 & $<0.100$ & 11.1 & 99.7 & 50.1 & $<0.100$ & $<0.100$ \\
\hline 2 & SB4VS-13 & quenched & S04 & 1 & 8 & 13.0 & 10.4 & 2.74 & 9.07 & 29.3 & 51.7 & $<0.100$ & 1.83 \\
\hline
\end{tabular}


Table F1. Laboratory Measurements of the PCT Solutions for the Nepheline Study Glasses (continued)

\begin{tabular}{|c|c|c|c|c|c|c|c|c|c|c|c|c|c|}
\hline Set & Glass ID & $\begin{array}{c}\text { Heat } \\
\text { Treatment }\end{array}$ & $\begin{array}{c}\text { Laboratory } \\
\text { ID }\end{array}$ & Block & Seq & $\begin{array}{c}\text { Al } \\
(\mathbf{p p m})\end{array}$ & $\begin{array}{c}\text { B } \\
(\mathbf{p p m})\end{array}$ & $\begin{array}{c}\mathbf{F e} \\
(\mathbf{p p m})\end{array}$ & $\begin{array}{c}\mathbf{L i} \\
(\mathbf{p p m})\end{array}$ & $\begin{array}{c}\mathrm{Na} \\
(\mathbf{p p m})\end{array}$ & $\begin{array}{c}\mathbf{S i} \\
(\mathbf{p p m})\end{array}$ & $\begin{array}{c}\text { Th } \\
\text { (ppm) }\end{array}$ & $\begin{array}{c}\mathbf{U} \\
\text { (ppm) }\end{array}$ \\
\hline 2 & Soln Std & & Soln Std & 1 & 9 & 3.79 & 20.4 & 4.06 & 9.81 & 81.4 & 47.7 & $<0.100$ & $<0.100$ \\
\hline 2 & SB4VS-11 & quenched & S20 & 1 & 10 & 14.2 & 11.0 & 2.56 & 9.41 & 36.9 & 53.0 & $<0.100$ & 1.61 \\
\hline 2 & SB4VS-21ccc & $\mathrm{ccc}$ & S01 & 1 & 11 & 9.47 & 10.5 & 2.46 & 9.98 & 21.8 & 57.5 & $<0.100$ & 2.71 \\
\hline 2 & SB4VS-18 & quenched & S56 & 1 & 12 & 9.78 & 10.8 & 2.53 & 10.3 & 23.4 & 57.2 & $<0.100$ & 2.04 \\
\hline 2 & SB4VS-11 ccc & $\mathrm{ccc}$ & S48 & 1 & 13 & 14.4 & 10.5 & 2.64 & 9.39 & 36.2 & 53.1 & $<0.100$ & 1.56 \\
\hline 2 & SB4VS-13ccc & $\mathrm{ccc}$ & S66 & 1 & 14 & 13.2 & 10.2 & 2.50 & 8.90 & 29.5 & 53.2 & $<0.100$ & 1.73 \\
\hline 2 & SB4VS-12 & quenched & S25 & 1 & 15 & 14.3 & 10.7 & 2.52 & 9.89 & 31.7 & 54.0 & $<0.100$ & 1.60 \\
\hline 2 & SB4VS-19ccc & $\operatorname{ccc}$ & S65 & 1 & 16 & 9.43 & 10.5 & 2.59 & 9.91 & 27.3 & 58.6 & $<0.100$ & 2.53 \\
\hline 2 & Soln Std & & Soln Std & 1 & 17 & 3.86 & 19.9 & 3.99 & 9.79 & 82.1 & 47.0 & $<0.100$ & $<0.100$ \\
\hline 2 & Soln Std & & Soln Std & 2 & 1 & 3.97 & 20.5 & 3.77 & 10.1 & 84.9 & 50.7 & $<0.100$ & $<0.100$ \\
\hline 2 & SB4VS-11 & quenched & S13 & 2 & 2 & 15.0 & 11.2 & 4.11 & 9.90 & 40.4 & 57.9 & $<0.100$ & 1.61 \\
\hline 2 & SB4VS-11ccc & $\mathrm{ccc}$ & S34 & 2 & 3 & 13.9 & 10.8 & 2.62 & 9.31 & 36.6 & 54.0 & $<0.100$ & 1.55 \\
\hline 2 & SB4VS-12ccc & $\mathrm{ccc}$ & S57 & 2 & 4 & 12.9 & 10.7 & 2.19 & 9.62 & 32.0 & 54.5 & $<0.100$ & 1.64 \\
\hline 2 & SB4VS-21 ccc & $\mathrm{ccc}$ & S45 & 2 & 5 & 9.35 & 10.2 & 2.78 & 9.88 & 22.6 & 58.6 & $<0.100$ & 2.62 \\
\hline 2 & SB4VS-18 & quenched & S53 & 2 & 6 & 9.72 & 10.8 & 2.77 & 10.5 & 24.7 & 58.5 & $<0.100$ & 2.16 \\
\hline 2 & SB4VS-12 & quenched & S54 & 2 & 7 & 13.7 & 11.0 & 3.05 & 10.1 & 33.7 & 56.4 & $<0.100$ & 1.67 \\
\hline 2 & SB4VS-21 & quenched & S16 & 2 & 8 & 9.49 & 10.6 & 2.51 & 10.5 & 22.8 & 58.1 & $<0.100$ & 2.51 \\
\hline 2 & Soln Std & & Soln Std & 2 & 9 & 3.88 & 20.6 & 3.71 & 9.94 & 85.7 & 47.8 & $<0.100$ & $<0.100$ \\
\hline 2 & SB4VS-19ccc & $\mathrm{ccc}$ & S50 & 2 & 10 & 9.72 & 11.0 & 2.75 & 10.1 & 28.3 & 61.2 & $<0.100$ & 2.59 \\
\hline 2 & SB4VS-13 & quenched & S69 & 2 & 11 & 13.2 & 10.7 & 2.44 & 9.55 & 32.6 & 55.5 & $<0.100$ & 1.74 \\
\hline 2 & EA & & $\mathrm{S} 30$ & 2 & 12 & 0.182 & 36.1 & 0.143 & 10.9 & 99.2 & 51.3 & $<0.100$ & $<0.100$ \\
\hline 2 & SB4VS-13ccc & $\mathrm{ccc}$ & S02 & 2 & 13 & 12.9 & 10.4 & 2.60 & 8.88 & 30.4 & 54.8 & $<0.100$ & 1.77 \\
\hline 2 & SB4VS-18ccc & $\mathrm{ccc}$ & S19 & 2 & 14 & 10.1 & 10.1 & 2.13 & 9.77 & 24.6 & 57.3 & $<0.100$ & 2.49 \\
\hline 2 & SB4VS-19 & quenched & S15 & 2 & 15 & 9.63 & 11.1 & 4.22 & 10.5 & 29.2 & 60.1 & $<0.100$ & 2.38 \\
\hline 2 & Soln Std & & Soln Std & 2 & 16 & 3.98 & 20.2 & 3.73 & 10.0 & 86.8 & 49.2 & $<0.100$ & $<0.100$ \\
\hline 2 & Soln Std & & Soln Std & 3 & 1 & 4.03 & 22.0 & 3.99 & 10.1 & 82.9 & 49.5 & $<0.100$ & $<0.100$ \\
\hline 2 & SB4VS-11 & quenched & S31 & 3 & 2 & 14.3 & 11.2 & 2.82 & 9.35 & 36.7 & 54.2 & $<0.100$ & 1.52 \\
\hline 2 & SB4VS-12ccc & $\mathrm{ccc}$ & S70 & 3 & 3 & 13.5 & 11.4 & 2.65 & 9.98 & 31.9 & 57.4 & $<0.100$ & 1.62 \\
\hline 2 & SB4VS-19ccc & $\mathrm{ccc}$ & S73 & 3 & 4 & 10.2 & 11.2 & 3.18 & 10.1 & 27.7 & 60.3 & $<0.100$ & 2.41 \\
\hline 2 & SB4VS-13 & quenched & S55 & 3 & 5 & 13.2 & 11.1 & 2.87 & 9.55 & 30.9 & 55.5 & $<0.100$ & 1.53 \\
\hline 2 & SB4VS-21 & quenched & S63 & 3 & 6 & 9.70 & 11.3 & 4.06 & 10.8 & 22.4 & 61.7 & $<0.100$ & 2.33 \\
\hline 2 & SB4VS-13ccc & $\mathrm{ccc}$ & S23 & 3 & 7 & 13.5 & 10.4 & 2.75 & 8.82 & 29.5 & 53.6 & $<0.100$ & 1.51 \\
\hline 2 & SB4VS-12 & quenched & S59 & 3 & 8 & 13.4 & 11.2 & 2.61 & 10.1 & 32.8 & 57.1 & $<0.100$ & 1.60 \\
\hline 2 & Soln Std & & Soln Std & 3 & 9 & 4.14 & 21.1 & 3.93 & 9.89 & 84.0 & 49.3 & $<0.100$ & $<0.100$ \\
\hline 2 & SB4VS-19 & quenched & S72 & 3 & 10 & 10.7 & 11.8 & 4.76 & 10.5 & 28.3 & 61.2 & $<0.100$ & 1.94 \\
\hline 2 & SB4VS-21ccc & $\mathrm{ccc}$ & S09 & 3 & 11 & 9.29 & 10.4 & 2.79 & 9.75 & 21.4 & 58.5 & $<0.100$ & 2.41 \\
\hline 2 & SB4VS-18ccc & $\mathrm{ccc}$ & S39 & 3 & 12 & 9.89 & 11.0 & 2.72 & 10.1 & 24.9 & 59.6 & $<0.100$ & 1.65 \\
\hline 2 & EA & & S68 & 3 & 13 & 1.31 & 37.5 & 1.12 & 10.9 & 101 & 51.9 & $<0.100$ & $<0.100$ \\
\hline 2 & SB4VS-11 ccc & $\mathrm{ccc}$ & S77 & 3 & 14 & 14.7 & 11.4 & 2.62 & 9.65 & 37.9 & 56.2 & $<0.100$ & 1.48 \\
\hline 2 & SB4VS-18 & quenched & S22 & 3 & 15 & 10.1 & 11.0 & 3.13 & 10.3 & 23.5 & 58.4 & $<0.100$ & 2.09 \\
\hline
\end{tabular}


Table F1. Laboratory Measurements of the PCT Solutions for the Nepheline Study Glasses (continued)

\begin{tabular}{|c|c|c|c|c|c|c|c|c|c|c|c|c|c|}
\hline Set & Glass ID & $\begin{array}{c}\text { Heat } \\
\text { Treatment }\end{array}$ & $\begin{array}{c}\text { Laboratory } \\
\text { ID }\end{array}$ & Block & Seq & $\begin{array}{c}\text { Al } \\
(\mathbf{p p m})\end{array}$ & $\begin{array}{c}\mathbf{B} \\
(\mathrm{ppm})\end{array}$ & $\begin{array}{c}\mathbf{F e} \\
(\mathrm{ppm})\end{array}$ & $\begin{array}{c}\mathbf{L i} \\
(\mathbf{p p m})\end{array}$ & $\begin{array}{c}\mathrm{Na} \\
(\mathrm{ppm})\end{array}$ & $\begin{array}{c}\mathbf{S i} \\
(\mathbf{p p m})\end{array}$ & $\begin{array}{c}\text { Th } \\
\text { (ppm) }\end{array}$ & $\begin{array}{c}\mathbf{U} \\
\text { (ppm) }\end{array}$ \\
\hline 2 & Soln Std & & Soln Std & 3 & 16 & 4.08 & 21.2 & 4.01 & 10.1 & 85.9 & 49.8 & $<0.100$ & $<0.100$ \\
\hline 2 & Soln Std & & Soln Std & 4 & 1 & 3.78 & 21.8 & 3.95 & 9.95 & 80.9 & 48.8 & $<0.100$ & $<0.100$ \\
\hline 2 & SB4VS-16ccc & $\mathrm{ccc}$ & S61 & 4 & 2 & 10.3 & 11.3 & 3.20 & 9.70 & 29.9 & 59.1 & $<0.100$ & 2.60 \\
\hline 2 & SB4VS-14ccc & $\mathrm{ccc}$ & S05 & 4 & 3 & 11.3 & 11.6 & 2.95 & 10.1 & 34.0 & 61.5 & $<0.100$ & 1.89 \\
\hline 2 & SB4VS-20ccc & $\mathrm{ccc}$ & S78 & 4 & 4 & 8.80 & 10.9 & 2.88 & 10.2 & 22.1 & 61.2 & $<0.100$ & 3.00 \\
\hline 2 & SB4VS-17ccc & $\mathrm{ccc}$ & S44 & 4 & 5 & 10.8 & 9.9 & 3.00 & 9.24 & 25.1 & 55.6 & $<0.100$ & 2.73 \\
\hline 2 & SB4VS-10 & quenched & S52 & 4 & 6 & 13.5 & 11.3 & 2.68 & 9.64 & 41.3 & 55.3 & $<0.100$ & 1.67 \\
\hline 2 & SB4VS-10ccc & $\mathrm{ccc}$ & $\mathrm{S} 10$ & 4 & 7 & 13.4 & 10.6 & 2.43 & 9.21 & 38.6 & 54.6 & $<0.100$ & 1.55 \\
\hline 2 & SB4VS-14 & quenched & S41 & 4 & 8 & 11.7 & 11.9 & 3.42 & 10.7 & 35.9 & 61.5 & $<0.100$ & 2.11 \\
\hline 2 & Soln Std & & Soln Std & 4 & 9 & 3.85 & 21.3 & 4.02 & 9.73 & 81.7 & 48.7 & $<0.100$ & $<0.100$ \\
\hline 2 & SB4VS-20 & quenched & S33 & 4 & 10 & 9.10 & 11.1 & 3.73 & 10.5 & 21.8 & 61.8 & $<0.100$ & 2.63 \\
\hline 2 & SB4VS-16 & quenched & S12 & 4 & 11 & 11.2 & 12.7 & 3.82 & 11.4 & 34.7 & 64.9 & $<0.100$ & 2.44 \\
\hline 2 & SB4VS-15ccc & $\mathrm{ccc}$ & S40 & 4 & 12 & 11.3 & 11.0 & 3.42 & 9.84 & 31.1 & 58.5 & $<0.100$ & 2.09 \\
\hline 2 & SB4VS-15 & quenched & S74 & 4 & 13 & 11.5 & 11.5 & 3.21 & 10.5 & 32.8 & 59.8 & $<0.100$ & 1.98 \\
\hline 2 & SB4VS-17 & quenched & S28 & 4 & 14 & 11.3 & 9.9 & 2.85 & 9.46 & 24.3 & 55.5 & $<0.100$ & 2.39 \\
\hline 2 & ARM-1 & & S37 & 4 & 15 & 2.66 & 10.5 & $<0.100$ & 7.90 & 20.7 & 34.9 & $<0.100$ & $<0.100$ \\
\hline 2 & Soln Std & & Soln Std & 4 & 16 & 3.86 & 20.5 & 4.11 & 9.76 & 83.0 & 48.7 & $<0.100$ & $<0.100$ \\
\hline 2 & Soln Std & & Soln Std & 5 & 1 & 3.94 & 21.2 & 3.94 & 9.80 & 80.8 & 48.0 & $<0.100$ & $<0.100$ \\
\hline 2 & SB4VS-10ccc & $\mathrm{ccc}$ & S03 & 5 & 2 & 13.8 & 11.0 & 2.22 & 9.04 & 37.6 & 52.9 & $<0.100$ & 1.42 \\
\hline 2 & SB4VS-20ccc & $\mathrm{ccc}$ & S06 & 5 & 3 & 9.79 & 10.9 & 5.48 & 10.3 & 22.9 & 61.5 & $<0.100$ & 2.96 \\
\hline 2 & SB4VS-17ccc & $\mathrm{ccc}$ & S38 & 5 & 4 & 11.1 & 10.0 & 3.45 & 9.28 & 24.6 & 55.5 & $<0.100$ & 2.55 \\
\hline 2 & SB4VS-10 & quenched & S24 & 5 & 5 & 13.5 & 11.1 & 2.44 & 9.47 & 40.7 & 54.1 & $<0.100$ & 1.47 \\
\hline 2 & SB4VS-14ccc & $\mathrm{ccc}$ & S64 & 5 & 6 & 11.6 & 10.8 & 2.68 & 9.67 & 32.7 & 56.8 & $<0.100$ & 1.76 \\
\hline 2 & SB4VS-14 & quenched & S60 & 5 & 7 & 11.3 & 11.6 & 2.95 & 10.4 & 34.9 & 59.5 & $<0.100$ & 1.87 \\
\hline 2 & SB4VS-20 & quenched & S42 & 5 & 8 & 8.88 & 10.4 & 3.45 & 10.3 & 21.8 & 58.4 & $<0.100$ & 2.52 \\
\hline 2 & Soln Std & & Soln Std & 5 & 9 & 4.14 & 20.4 & 3.83 & 9.68 & 81.2 & 47.7 & $<0.100$ & $<0.100$ \\
\hline 2 & SB4VS-15ccc & $\mathrm{ccc}$ & S36 & 5 & 10 & 11.9 & 11.4 & 3.17 & 10.1 & 31.3 & 58.7 & $<0.100$ & 1.92 \\
\hline 2 & SB4VS-17 & quenched & S58 & 5 & 11 & 11.1 & 9.9 & 3.09 & 9.50 & 25.1 & 54.8 & $<0.100$ & 2.20 \\
\hline 2 & SB4VS-15 & quenched & S27 & 5 & 12 & 11.9 & 11.4 & 3.46 & 10.5 & 33.0 & 59.6 & $<0.100$ & 1.83 \\
\hline 2 & SB4VS-16 ccc & $\mathrm{ccc}$ & S14 & 5 & 13 & 10.6 & 10.9 & 2.77 & 9.99 & 31.2 & 60.0 & $<0.100$ & 2.55 \\
\hline 2 & SB4VS-16 & quenched & S75 & 5 & 14 & 10.5 & 11.1 & 3.35 & 10.3 & 31.9 & 58.3 & $<0.100$ & 2.38 \\
\hline 2 & ARM-1 & & S67 & 5 & 15 & 2.85 & 9.9 & $<0.100$ & 7.92 & 21.1 & 35.1 & $<0.100$ & $<0.100$ \\
\hline 2 & Soln Std & & Soln Std & 5 & 16 & 4.17 & 20.5 & 3.91 & 9.71 & 82.0 & 48.1 & $<0.100$ & $<0.100$ \\
\hline 2 & Soln Std & & Soln Std & 6 & 1 & 3.97 & 21.4 & 4.20 & 10.0 & 80.1 & 46.7 & $<0.100$ & $<0.100$ \\
\hline 2 & SB4VS-17ccc & $\mathrm{ccc}$ & S11 & 6 & 2 & 11.0 & 10.5 & 3.44 & 9.48 & 24.4 & 54.8 & $<0.100$ & 2.38 \\
\hline 2 & SB4VS-15ccc & $\mathrm{ccc}$ & S46 & 6 & 3 & 11.9 & 12.0 & 3.27 & 10.7 & 32.4 & 60.4 & $<0.100$ & 2.13 \\
\hline 2 & SB4VS-20ccc & $\mathrm{ccc}$ & S32 & 6 & 4 & 8.91 & 10.8 & 4.52 & 10.3 & 21.8 & 58.2 & $<0.100$ & 3.11 \\
\hline 2 & SB4VS-14 & quenched & S62 & 6 & 5 & 11.3 & 11.8 & 3.03 & 10.7 & 34.9 & 58.6 & $<0.100$ & 2.00 \\
\hline 2 & SB4VS-10ccc & $\mathrm{ccc}$ & S08 & 6 & 6 & 14.0 & 10.5 & 2.57 & 9.38 & 38.6 & 51.8 & $<0.100$ & 1.51 \\
\hline 2 & SB4VS-10 & quenched & S47 & 6 & 7 & 13.3 & 11.1 & 2.33 & 9.75 & 40.9 & 52.5 & $<0.100$ & 1.59 \\
\hline
\end{tabular}


Table F1. Laboratory Measurements of the PCT Solutions for the Nepheline Study Glasses (continued)

\begin{tabular}{|c|c|c|c|c|c|c|c|c|c|c|c|c|c|}
\hline Set & Glass ID & $\begin{array}{c}\text { Heat } \\
\text { Treatment }\end{array}$ & $\begin{array}{c}\text { Laboratory } \\
\text { ID }\end{array}$ & Block & Seq & $\begin{array}{c}\text { Al } \\
(\mathbf{p p m})\end{array}$ & $\begin{array}{c}\text { B } \\
(\mathrm{ppm})\end{array}$ & $\begin{array}{c}\mathbf{F e} \\
(\mathrm{ppm})\end{array}$ & $\begin{array}{c}\mathbf{L i} \\
(\mathbf{p p m})\end{array}$ & $\begin{array}{c}\mathrm{Na} \\
(\mathrm{ppm})\end{array}$ & $\begin{array}{c}\mathbf{S i} \\
(\mathbf{p p m})\end{array}$ & $\begin{array}{c}\text { Th } \\
\text { (ppm) }\end{array}$ & $\begin{array}{c}\mathbf{U} \\
\text { (ppm) }\end{array}$ \\
\hline 2 & SB4VS-14ccc & $\mathrm{ccc}$ & S17 & 6 & 8 & 11.1 & 11.0 & 4.51 & 10.1 & 33.4 & 57.2 & $<0.100$ & 1.82 \\
\hline 2 & Soln Std & & Soln Std & 6 & 9 & 4.11 & 20.4 & 3.98 & 9.99 & 80.4 & 46.0 & $<0.100$ & $<0.100$ \\
\hline 2 & SB4VS-16ccc & $\mathrm{ccc}$ & S35 & 6 & 10 & 9.69 & 10.6 & 2.96 & 9.34 & 28.2 & 54.8 & $<0.100$ & 2.43 \\
\hline 2 & SB4VS-16 & quenched & S18 & 6 & 11 & 10.5 & 11.4 & 2.78 & 10.5 & 31.0 & 57.5 & $<0.100$ & 2.51 \\
\hline 2 & SB4VS-20 & quenched & S71 & 6 & 12 & 8.98 & 11.1 & 3.11 & 10.9 & 22.3 & 58.8 & $<0.100$ & 2.55 \\
\hline 2 & blank & & S21 & 6 & 13 & $<0.100$ & $<0.100$ & $<0.100$ & $<1.00$ & $<0.100$ & $<0.100$ & $<0.100$ & $<0.100$ \\
\hline 2 & SB4VS-15 & quenched & S49 & 6 & 14 & 11.5 & 11.1 & 3.40 & 10.5 & 31.8 & 57.1 & $<0.100$ & 1.89 \\
\hline 2 & SB4VS-17 & quenched & S43 & 6 & 15 & 11.0 & 10.0 & 3.04 & 9.96 & 24.7 & 53.5 & $<0.100$ & 2.43 \\
\hline 2 & ARM-1 & & S76 & 6 & 16 & 3.02 & 10.4 & 0.24 & 8.34 & 21.9 & 33.2 & $<0.100$ & $<0.100$ \\
\hline 2 & Soln Std & & Soln Std & 6 & 17 & 4.15 & 20.2 & 4.04 & 10.0 & 81.8 & 45.6 & $<0.100$ & $<0.100$ \\
\hline 3 & Soln Std & & Soln Std & 1 & 1 & 3.92 & 21.2 & 3.84 & 9.68 & 81.2 & 49.9 & $<0.100$ & $<0.100$ \\
\hline 3 & SB4VS-24 & quenched & T48 & 1 & 2 & 11.6 & 11.6 & 2.94 & 9.59 & 39.8 & 58.9 & $<0.100$ & 1.66 \\
\hline 3 & SB4VS-30 & quenched & T01 & 1 & 3 & 9.20 & 11.5 & 3.64 & 10.5 & 27.6 & 61.9 & $<0.100$ & 3.08 \\
\hline 3 & EA & & $\mathrm{T} 77$ & 1 & 4 & $<0.100$ & 37.5 & $<0.100$ & 11.1 & 98.2 & 53.7 & $<0.100$ & $<0.100$ \\
\hline 3 & SB4VS-33ccc & $\mathrm{ccc}$ & T37 & 1 & 5 & 11.3 & 10.4 & 1.72 & 9.17 & 24.1 & 53.6 & $<0.100$ & 1.22 \\
\hline 3 & SB4VS-27 & quenched & T26 & 1 & 6 & 11.0 & 11.1 & 2.59 & 9.85 & 31.5 & 58.8 & $<0.100$ & 1.79 \\
\hline 3 & SB4VS-30ccc & $\mathrm{ccc}$ & T81 & 1 & 7 & 9.45 & 11.7 & 3.74 & 10.6 & 29.0 & 64.5 & $<0.100$ & 2.79 \\
\hline 3 & SB4VS-32ccc & $\mathrm{ccc}$ & T89 & 1 & 8 & 10.7 & 12.0 & 2.60 & 10.1 & 42.9 & 59.4 & $<0.100$ & 1.62 \\
\hline 3 & SB4VS-28 & quenched & T88 & 1 & 9 & 9.85 & 11.4 & 2.96 & 10.3 & 29.0 & 60.5 & $<0.100$ & 2.13 \\
\hline 3 & Soln Std & & Soln Std & 1 & 10 & 3.89 & 20.5 & 3.87 & 9.73 & 81.9 & 49.7 & $<0.100$ & $<0.100$ \\
\hline 3 & SB4VS-25ccc & $\mathrm{ccc}$ & $\mathrm{T} 71$ & 1 & 11 & 10.9 & 12.0 & 2.49 & 9.69 & 35.0 & 58.5 & $<0.100$ & 1.72 \\
\hline 3 & SB4VS-24ccc & $\mathrm{ccc}$ & T16 & 1 & 12 & 12.0 & 11.6 & 3.68 & 9.74 & 39.6 & 60.9 & $<0.100$ & 2.00 \\
\hline 3 & SB4VS-28ccc & $\mathrm{ccc}$ & T82 & 1 & 13 & 9.38 & 10.6 & 2.75 & 9.40 & 27.3 & 57.3 & $<0.100$ & 2.50 \\
\hline 3 & SB4VS-27ccc & $\mathrm{ccc}$ & T76 & 1 & 14 & 11.3 & 11.0 & 2.53 & 9.69 & 31.8 & 59.6 & $<0.100$ & 1.77 \\
\hline 3 & SB4VS-32 & quenched & T09 & 1 & 15 & 10.7 & 11.7 & 2.95 & 9.81 & 42.9 & 58.6 & $<0.100$ & 1.69 \\
\hline 3 & SB4VS-33 & quenched & T31 & 1 & 16 & 11.8 & 10.5 & 2.06 & 9.92 & 24.7 & 55.4 & $<0.100$ & 1.53 \\
\hline 3 & SB4VS-25 & quenched & T52 & 1 & 17 & 10.9 & 11.3 & 2.56 & 9.68 & 35.3 & 59.0 & $<0.100$ & 1.67 \\
\hline 3 & blank & & T14 & 1 & 18 & $<0.100$ & 0.154 & $<0.100$ & $<1.00$ & $<0.100$ & $<0.100$ & $<0.100$ & $<0.100$ \\
\hline 3 & Soln Std & & Soln Std & 1 & 19 & 3.92 & 20.6 & 3.97 & 9.72 & 82.5 & 50.1 & $<0.100$ & $<0.100$ \\
\hline 3 & Soln Std & & Soln Std & 2 & 1 & 3.86 & 21.0 & 3.50 & 9.71 & 81.9 & 49.6 & $<0.100$ & $<0.100$ \\
\hline 3 & SB4VS-25 & quenched & T87 & 2 & 2 & 10.8 & 11.4 & 1.99 & 9.38 & 34.8 & 57.1 & $<0.100$ & 1.39 \\
\hline 3 & EA & & T66 & 2 & 3 & $<0.100$ & 36.3 & $<0.100$ & 10.6 & 95.5 & 51.4 & $<0.100$ & $<0.100$ \\
\hline 3 & SB4VS-30 & quenched & $\mathrm{T} 84$ & 2 & 4 & 9.32 & 12.1 & 3.44 & 10.6 & 27.8 & 62.7 & $<0.100$ & 2.90 \\
\hline 3 & SB4VS-28 & quenched & $\mathrm{T} 03$ & 2 & 5 & 9.61 & 11.2 & 2.31 & 9.90 & 27.6 & 59.3 & $<0.100$ & 2.29 \\
\hline 3 & SB4VS-25ccc & $\mathrm{ccc}$ & $\mathrm{T} 30$ & 2 & 6 & 11.0 & 11.4 & 2.08 & 9.74 & 35.5 & 59.3 & $<0.100$ & 1.50 \\
\hline 3 & SB4VS-30 ccc & $\mathrm{ccc}$ & T24 & 2 & 7 & 9.38 & 11.6 & 3.33 & 10.5 & 28.6 & 63.9 & $<0.100$ & 3.01 \\
\hline 3 & SB4VS-24ccc & $\mathrm{ccc}$ & T57 & 2 & 8 & 11.0 & 10.6 & 2.30 & 9.07 & 36.5 & 56.0 & $<0.100$ & 1.34 \\
\hline 3 & SB4VS-33ccc & ccc & T92 & 2 & 9 & 11.2 & 9.81 & 1.24 & 8.95 & 23.6 & 52.7 & $<0.100$ & 1.22 \\
\hline 3 & Soln Std & & Soln Std & 2 & 10 & 3.79 & 20.6 & 3.62 & 9.64 & 80.6 & 49.8 & $<0.100$ & $<0.100$ \\
\hline 3 & SB4VS-32ccc & $\mathrm{ccc}$ & T17 & 2 & 11 & 10.7 & 12.7 & 2.11 & 10.1 & 43.2 & 58.9 & $<0.100$ & 1.59 \\
\hline
\end{tabular}


Table F1. Laboratory Measurements of the PCT Solutions for the Nepheline Study Glasses (continued)

\begin{tabular}{|c|c|c|c|c|c|c|c|c|c|c|c|c|c|}
\hline Set & Glass ID & $\begin{array}{c}\text { Heat } \\
\text { Treatment }\end{array}$ & $\begin{array}{c}\text { Laboratory } \\
\text { ID }\end{array}$ & Block & Seq & $\begin{array}{c}\text { Al } \\
(\mathbf{p p m})\end{array}$ & $\begin{array}{c}\mathbf{B} \\
(\mathrm{ppm})\end{array}$ & $\begin{array}{c}\mathbf{F e} \\
(\mathrm{ppm})\end{array}$ & $\begin{array}{c}\mathbf{L i} \\
(\mathbf{p p m})\end{array}$ & $\begin{array}{c}\mathrm{Na} \\
(\mathrm{ppm})\end{array}$ & $\begin{array}{c}\mathbf{S i} \\
(\mathbf{p p m})\end{array}$ & $\begin{array}{c}\text { Th } \\
\text { (ppm) }\end{array}$ & $\begin{array}{c}\mathbf{U} \\
\text { (ppm) }\end{array}$ \\
\hline 3 & SB4VS-24 & quenched & $\mathrm{T} 72$ & 2 & 12 & 11.2 & 11.3 & 2.27 & 9.35 & 47.9 & 57.1 & $<0.100$ & 1.41 \\
\hline 3 & SB4VS-32 & quenched & T04 & 2 & 13 & 10.3 & 11.6 & 2.53 & 9.54 & 41.9 & 56.9 & $<0.100$ & 1.50 \\
\hline 3 & SB4VS-28ccc & $\mathrm{ccc}$ & T41 & 2 & 14 & 9.42 & 10.8 & 2.47 & 9.48 & 26.6 & 58.3 & $<0.100$ & 2.19 \\
\hline 3 & SB4VS-27ccc & $\mathrm{ccc}$ & T02 & 2 & 15 & 10.5 & 10.2 & 2.34 & 8.96 & 29.6 & 56.4 & $<0.100$ & 1.87 \\
\hline 3 & SB4VS-27 & quenched & T49 & 2 & 16 & 11.0 & 10.9 & 2.39 & 9.78 & 31.4 & 59.0 & $<0.100$ & 1.68 \\
\hline 3 & SB4VS-33 & quenched & T38 & 2 & 17 & 11.4 & 10.3 & 1.52 & 9.74 & 24.1 & 54.3 & $<0.100$ & 1.28 \\
\hline 3 & Soln Std & & Soln Std & 2 & 18 & 3.83 & 20.7 & 3.49 & 9.62 & 81.6 & 49.5 & $<0.100$ & $<0.100$ \\
\hline 3 & Soln Std & & Soln Std & 3 & 1 & 3.83 & 21.1 & 4.00 & 9.67 & 81.8 & 49.4 & $<0.100$ & $<0.100$ \\
\hline 3 & SB4VS-25ccc & $\mathrm{ccc}$ & T34 & 3 & 2 & 11.1 & 11.9 & 2.48 & 9.93 & 36.1 & 59.8 & $<0.100$ & 1.58 \\
\hline 3 & SB4VS-24ccc & $\mathrm{ccc}$ & T64 & 3 & 3 & 11.6 & 11.4 & 2.94 & 9.53 & 38.1 & 58.9 & $<0.100$ & 1.55 \\
\hline 3 & SB4VS-30 ccc & $\mathrm{ccc}$ & T32 & 3 & 4 & 9.27 & 11.6 & 3.83 & 10.4 & 28.2 & 63.5 & $<0.100$ & 2.21 \\
\hline 3 & SB4VS-30 & quenched & T62 & 3 & 5 & 9.54 & 11.9 & 3.88 & 10.9 & 29.0 & 64.2 & $<0.100$ & 3.00 \\
\hline 3 & SB4VS-28 & quenched & T20 & 3 & 6 & 9.71 & 10.7 & 3.27 & 9.68 & 27.3 & 57.2 & $<0.100$ & 1.86 \\
\hline 3 & SB4VS-33 & quenched & $\mathrm{T} 40$ & 3 & 7 & 11.4 & 10.3 & 1.92 & 9.76 & 23.9 & 53.6 & $<0.100$ & 1.28 \\
\hline 3 & SB4VS-27 & quenched & T28 & 3 & 8 & 11.2 & 11.1 & 2.67 & 9.99 & 32.4 & 59.6 & $<0.100$ & 1.80 \\
\hline 3 & EA & & T12 & 3 & 9 & $<0.100$ & 35.8 & $<0.100$ & 10.4 & 95.6 & 50.2 & $<0.100$ & $<0.100$ \\
\hline 3 & Soln Std & & Soln Std & 3 & 10 & 3.85 & 20.5 & 3.83 & 9.67 & 83.2 & 48.9 & $<0.100$ & $<0.100$ \\
\hline 3 & SB4VS-28ccc & $\mathrm{ccc}$ & T46 & 3 & 11 & 9.77 & 11.2 & 2.69 & 9.72 & 28.7 & 59.1 & $<0.100$ & 2.82 \\
\hline 3 & SB4VS-24 & quenched & T39 & 3 & 12 & 11.4 & 11.3 & 2.88 & 9.49 & 39.8 & 57.3 & $<0.100$ & 1.44 \\
\hline 3 & SB4VS-32ccc & $\mathrm{ccc}$ & $\mathrm{T} 23$ & 3 & 13 & 10.7 & 11.9 & 2.50 & 9.98 & 42.8 & 59.0 & $<0.100$ & 1.54 \\
\hline 3 & SB4VS-27ccc & $\operatorname{ccc}$ & T42 & 3 & 14 & 11.0 & 10.4 & 2.41 & 9.36 & 31.0 & 57.1 & $<0.100$ & 1.74 \\
\hline 3 & SB4VS-32 & quenched & $\mathrm{T} 22$ & 3 & 15 & 10.6 & 11.8 & 2.41 & 9.94 & 43.8 & 58.0 & $<0.100$ & 1.56 \\
\hline 3 & SB4VS-33ccc & $\mathrm{ccc}$ & $\mathrm{T} 53$ & 3 & 16 & 11.7 & 9.88 & 1.68 & 9.18 & 25.6 & 53.2 & $<0.100$ & 1.33 \\
\hline 3 & SB4VS-25 & quenched & T59 & 3 & 17 & 10.7 & 10.7 & 2.32 & 9.35 & 35.7 & 56.3 & $<0.100$ & 1.59 \\
\hline 3 & Soln Std & & Soln Std & 3 & 18 & 3.85 & 19.9 & 3.69 & 9.52 & 84.2 & 48.1 & $<0.100$ & $<0.100$ \\
\hline 3 & Soln Std & & Soln Std & 4 & 1 & 3.79 & 20.4 & 3.74 & 9.77 & 81.1 & 50.0 & $<0.100$ & $<0.100$ \\
\hline 3 & SB4VS-23ccc & $\mathrm{ccc}$ & T05 & 4 & 2 & 11.7 & 11.1 & 2.11 & 9.55 & 42.1 & 56.4 & $<0.100$ & 1.39 \\
\hline 3 & SB4VS-34ccc & $\mathrm{ccc}$ & T21 & 4 & 3 & 12.4 & 10.8 & 2.93 & 10.2 & 23.7 & 59.0 & $<0.100$ & 1.98 \\
\hline 3 & SB4VS-35 & quenched & T11 & 4 & 4 & 9.20 & 12.2 & 3.55 & 11.0 & 32.5 & 64.7 & $<0.100$ & 2.57 \\
\hline 3 & SB4VS-34 & quenched & T61 & 4 & 5 & 12.4 & 10.8 & 3.32 & 10.6 & 22.5 & 59.2 & $<0.100$ & 1.87 \\
\hline 3 & SB4VS-31 ccc & $\mathrm{ccc}$ & T55 & 4 & 6 & 8.31 & 11.0 & 2.75 & 10.5 & 22.2 & 61.8 & $<0.100$ & 2.97 \\
\hline 3 & SB4VS-29 & quenched & T18 & 4 & 7 & 10.2 & 10.9 & 3.18 & 10.3 & 29.4 & 60.4 & $<0.100$ & 2.02 \\
\hline 3 & SB4VS-26ccc & $\mathrm{ccc}$ & T29 & 4 & 8 & 10.2 & 10.8 & 1.97 & 9.68 & 33.5 & 57.7 & $<0.100$ & 1.41 \\
\hline 3 & SB4VS-22ccc & $\mathrm{ccc}$ & $\mathrm{T} 35$ & 4 & 9 & 14.4 & 9.77 & 2.58 & 8.70 & 35.0 & 52.5 & $<0.100$ & 1.64 \\
\hline 3 & Soln Std & & Soln Std & 4 & 10 & 3.90 & 19.9 & 3.67 & 9.74 & 83.1 & 48.8 & $<0.100$ & $<0.100$ \\
\hline 3 & SB4VS-26 & quenched & T85 & 4 & 11 & 10.5 & 11.3 & 2.13 & 9.67 & 34.5 & 56.2 & $<0.100$ & 1.65 \\
\hline 3 & SB4VS-23 & quenched & T47 & 4 & 12 & 11.6 & 10.7 & 1.81 & 9.18 & 40.0 & 53.8 & $<0.100$ & 1.34 \\
\hline 3 & SB4VS-22 & quenched & T15 & 4 & 13 & 14.2 & 9.52 & 1.99 & 8.50 & 34.8 & 50.3 & $<0.100$ & 1.39 \\
\hline 3 & SB4VS-31 & quenched & T65 & 4 & 14 & 8.27 & 10.9 & 2.88 & 10.7 & 21.5 & 60.5 & $<0.100$ & 3.04 \\
\hline 3 & SB4VS-29ccc & $\mathrm{ccc}$ & T13 & 4 & 15 & 10.1 & 10.7 & 2.99 & 10.0 & 29.8 & 59.6 & $<0.100$ & 1.90 \\
\hline
\end{tabular}


Table F1. Laboratory Measurements of the PCT Solutions for the Nepheline Study Glasses (continued)

\begin{tabular}{|c|c|c|c|c|c|c|c|c|c|c|c|c|c|}
\hline Set & Glass ID & $\begin{array}{c}\text { Heat } \\
\text { Treatment }\end{array}$ & $\begin{array}{c}\text { Laboratory } \\
\text { ID }\end{array}$ & Block & Seq & $\begin{array}{c}\mathbf{A l} \\
(\mathbf{p p m})\end{array}$ & $\begin{array}{c}\text { B } \\
(\mathbf{p p m})\end{array}$ & $\begin{array}{c}\mathbf{F e} \\
(\mathbf{p p m})\end{array}$ & $\begin{array}{c}\mathbf{L i} \\
(\mathbf{p p m})\end{array}$ & $\begin{array}{c}\mathbf{N a} \\
(\mathbf{p p m})\end{array}$ & $\begin{array}{c}\mathbf{S i} \\
(\mathbf{p p m})\end{array}$ & $\begin{array}{c}\text { Th } \\
(\mathbf{p p m})\end{array}$ & $\begin{array}{c}\mathbf{U} \\
\text { (ppm) }\end{array}$ \\
\hline 3 & SB4VS-35 ccc & $\mathrm{ccc}$ & $\mathrm{T} 70$ & 4 & 16 & 8.95 & 11.7 & 3.26 & 10.7 & 32.5 & 63.0 & $<0.100$ & 2.43 \\
\hline 3 & ARM-1 & & T91 & 4 & 17 & 2.82 & 11.0 & $<0.100$ & 8.42 & 22.8 & 36.4 & $<0.100$ & $<0.100$ \\
\hline 3 & Soln Std & & Soln Std & 4 & 18 & 4.01 & 20.0 & 3.61 & 9.75 & 84.2 & 48.4 & $<0.100$ & $<0.100$ \\
\hline 3 & Soln Std & & Soln Std & 5 & 1 & 4.01 & 21.0 & 3.69 & 9.79 & 82.2 & 50.0 & $<0.100$ & $<0.100$ \\
\hline 3 & SB4VS-31 & quenched & T67 & 5 & 2 & 8.39 & 11.6 & 3.03 & 11.1 & 21.3 & 66.6 & $<0.100$ & 3.23 \\
\hline 3 & SB4VS-29ccc & $\mathrm{ccc}$ & T79 & 5 & 3 & 10.2 & 11.3 & 3.08 & 10.1 & 29.3 & 62.2 & $<0.100$ & 2.11 \\
\hline 3 & SB4VS-22ccc & $\mathrm{ccc}$ & T36 & 5 & 4 & 14.7 & 10.3 & 2.21 & 9.05 & 35.5 & 54.3 & $<0.100$ & 1.71 \\
\hline 3 & SB4VS-26ccc & $\mathrm{ccc}$ & T07 & 5 & 5 & 10.4 & 11.1 & 2.05 & 9.69 & 33.2 & 59.3 & $<0.100$ & 1.68 \\
\hline 3 & SB4VS-31 ccc & $\mathrm{ccc}$ & T60 & 5 & 6 & 8.41 & 11.4 & 2.77 & 10.6 & 22.1 & 63.4 & $<0.100$ & 3.09 \\
\hline 3 & SB4VS-22 & quenched & $\mathrm{T} 69$ & 5 & 7 & 14.3 & 10.1 & 2.06 & 8.69 & 34.7 & 53.0 & $<0.100$ & 1.66 \\
\hline 3 & SB4VS-29 & quenched & T63 & 5 & 8 & 10.2 & 11.3 & 3.38 & 10.4 & 29.1 & 61.4 & $<0.100$ & 2.12 \\
\hline 3 & SB4VS-35ccc & $\mathrm{ccc}$ & $\mathrm{T} 43$ & 5 & 9 & 8.79 & 11.5 & 3.36 & 10.2 & 30.8 & 62.0 & $<0.100$ & 2.67 \\
\hline 3 & Soln Std & & Soln Std & 5 & 10 & 4.04 & 20.7 & 3.82 & 9.84 & 82.5 & 50.7 & $<0.100$ & $<0.100$ \\
\hline 3 & SB4VS-35 & quenched & T27 & 5 & 11 & 9.38 & 12.9 & 3.65 & 11.1 & 32.8 & 65.9 & $<0.100$ & 2.90 \\
\hline 3 & SB4VS-23 & quenched & T08 & 5 & 12 & 11.7 & 11.0 & 2.57 & 8.99 & 38.5 & 56.4 & $<0.100$ & 1.85 \\
\hline 3 & ARM-1 & & T83 & 5 & 13 & 2.96 & 11.2 & $<0.100$ & 8.37 & 22.2 & 37.2 & $<0.100$ & $<0.100$ \\
\hline 3 & SB4VS-34ccc & $\mathrm{ccc}$ & T06 & 5 & 14 & 12.6 & 11.1 & 3.12 & 10.3 & 23.6 & 60.6 & $<0.100$ & 2.26 \\
\hline 3 & SB4VS-26 & quenched & T19 & 5 & 15 & 10.5 & 11.4 & 2.18 & 10.0 & 34.5 & 59.7 & $<0.100$ & 1.67 \\
\hline 3 & SB4VS-23ccc & $\mathrm{ccc}$ & $\mathrm{T} 75$ & 5 & 16 & 11.8 & 11.2 & 2.22 & 9.58 & 39.0 & 57.8 & $<0.100$ & 1.50 \\
\hline 3 & SB4VS-34 & quenched & $\mathrm{T} 25$ & 5 & 17 & 13.2 & 11.8 & 3.47 & 11.3 & 23.9 & 64.6 & $<0.100$ & 2.13 \\
\hline 3 & Soln Std & & Soln Std & 5 & 18 & 3.99 & 20.8 & 3.96 & 10.0 & 83.4 & 53.1 & $<0.100$ & $<0.100$ \\
\hline 3 & Soln Std & & Soln Std & 6 & 1 & 3.84 & 20.9 & 3.84 & 9.70 & 83.0 & 49.8 & $<0.100$ & $<0.100$ \\
\hline 3 & SB4VS-22 & quenched & T50 & 6 & 2 & 14.0 & 9.88 & 2.54 & 8.22 & 34.1 & 51.5 & $<0.100$ & 1.73 \\
\hline 3 & SB4VS-31 & quenched & T56 & 6 & 3 & 8.11 & 10.8 & 3.25 & 10.2 & 20.9 & 60.2 & $<0.100$ & 2.50 \\
\hline 3 & SB4VS-22ccc & $\mathrm{ccc}$ & T44 & 6 & 4 & 14.3 & 10.1 & 2.34 & 8.78 & 34.9 & 53.1 & $<0.100$ & 1.60 \\
\hline 3 & ARM-1 & & T74 & 6 & 5 & 2.73 & 10.9 & $<0.100$ & 8.10 & 21.5 & 37.0 & $<0.100$ & $<0.100$ \\
\hline 3 & SB4VS-35 & quenched & T51 & 6 & 6 & 8.99 & 12.0 & 3.54 & 10.7 & 31.9 & 63.3 & $<0.100$ & 2.67 \\
\hline 3 & SB4VS-29 & quenched & T58 & 6 & 7 & 10.2 & 11.2 & 3.48 & 10.3 & 29.6 & 60.7 & $<0.100$ & 2.18 \\
\hline 3 & SB4VS-34ccc & $\mathrm{ccc}$ & T33 & 6 & 8 & 12.4 & 11.0 & 3.36 & 10.2 & 23.5 & 60.2 & $<0.100$ & 2.00 \\
\hline 3 & blank & & T90 & 6 & 9 & $<0.100$ & $<0.100$ & $<0.100$ & $<1.00$ & $<0.100$ & $<0.100$ & $<0.100$ & $<0.100$ \\
\hline 3 & Soln Std & & Soln Std & 6 & 10 & 3.83 & 20.3 & 3.87 & 9.62 & 82.1 & 50.1 & $<0.100$ & $<0.100$ \\
\hline 3 & SB4VS-34 & quenched & $\mathrm{T} 80$ & 6 & 11 & 12.6 & 11.7 & 3.38 & 10.8 & 22.6 & 61.8 & $<0.100$ & 2.12 \\
\hline 3 & SB4VS-23ccc & $\mathrm{ccc}$ & $\mathrm{T} 10$ & 6 & 12 & 11.6 & 11.1 & 2.19 & 9.38 & 38.9 & 56.5 & $<0.100$ & 1.41 \\
\hline 3 & SB4VS-29ccc & $\mathrm{ccc}$ & $\mathrm{T} 73$ & 6 & 13 & 10.2 & 11.1 & 3.18 & 9.97 & 29.2 & 60.9 & $<0.100$ & 2.06 \\
\hline 3 & SB4VS-23 & quenched & T54 & 6 & 14 & 11.7 & 11.1 & 2.06 & 9.31 & 39.7 & 56.9 & $<0.100$ & 1.42 \\
\hline 3 & SB4VS-26ccc & $\mathrm{ccc}$ & T45 & 6 & 15 & 10.2 & 11.0 & 2.06 & 9.51 & 33.5 & 58.2 & $<0.100$ & 1.75 \\
\hline 3 & SB4VS-31ccc & $\mathrm{ccc}$ & $\mathrm{T} 78$ & 6 & 16 & 8.44 & 11.3 & 2.86 & 10.5 & 23.0 & 62.9 & $<0.100$ & 2.82 \\
\hline 3 & SB4VS-26 & quenched & T86 & 6 & 17 & 10.2 & 11.0 & 2.45 & 9.63 & 33.6 & 57.9 & $<0.100$ & 1.67 \\
\hline 3 & SB4VS-35ccc & $\mathrm{ccc}$ & T68 & 6 & 18 & 9.31 & 12.1 & 3.55 & 10.7 & 32.8 & 66.5 & $<0.100$ & 2.85 \\
\hline 3 & Soln Std & & Soln Std & 6 & 19 & 3.81 & 20.9 & 4.16 & 9.87 & 84.0 & 52.8 & $<0.100$ & $<0.100$ \\
\hline
\end{tabular}


Table F2. PSAL Measurements of the PCT Solutions for the Study Glasses After Appropriate Adjustments

\begin{tabular}{|c|c|c|c|c|c|c|c|c|c|c|c|c|c|}
\hline Set & Glass ID & $\begin{array}{c}\text { Heat } \\
\text { Treatment }\end{array}$ & Laboratory ID & Block & Seq & Al (ppm) & B (ppm) & $\mathrm{Fe}(p p m)$ & $\mathbf{L i}(\mathbf{p p m})$ & Na (ppm) & Si (ppm) & Th (ppm) & $\mathrm{U}$ (ppm) \\
\hline 1 & Soln Std & & Soln Std & 1 & 1 & 3.85 & 22 & 3.98 & 9.76 & 82.9 & 49.1 & 0.05 & 0.05 \\
\hline 1 & SB4VS-06 & quenched & R38 & 1 & 2 & 17.33368 & 18.66704 & 5.950119 & 17.16701 & 43.83421 & 102.16871 & 0.083335 & 3.366734 \\
\hline 1 & SB4VS-06ccc & $\mathrm{ccc}$ & R40 & 1 & 3 & 17.66702 & 18.50037 & 5.433442 & 16.83367 & 46.00092 & 102.83539 & 0.083335 & 3.83341 \\
\hline 1 & SB4VS-01 & quenched & R29 & 1 & 4 & 21.33376 & 10.883551 & 10.50021 & 19.50039 & 84.66836 & 124.50249 & 0.083335 & 4.300086 \\
\hline 1 & SB4VS-01ccc & ccc & R08 & 1 & 5 & 21.6671 & 10.550211 & 9.50019 & 19.83373 & 81.16829 & 124.50249 & 0.083335 & 4.16675 \\
\hline 1 & blank & & R49 & 1 & 6 & 0.083335 & 0.083335 & 0.083335 & 0.416675 & 0.083335 & 0.083335 & 0.083335 & 0.083335 \\
\hline 1 & SB4VS-08 & quenched & R51 & 1 & 7 & 23.00046 & 17.33368 & 5.366774 & 15.233638 & 60.66788 & 91.00182 & 0.083335 & 2.483383 \\
\hline 1 & SB4VS-08ccc & $\mathrm{ccc}$ & R23 & 1 & 8 & 22.83379 & 17.00034 & 5.383441 & 14.916965 & 60.0012 & 90.50181 & 0.083335 & 2.933392 \\
\hline 1 & SB4VS-02 & quenched & R46 & 1 & 9 & 20.16707 & 12.700254 & 10.983553 & 19.33372 & 86.50173 & 127.16921 & 0.083335 & 3.600072 \\
\hline 1 & SB4VS-03 & quenched & R55 & 1 & 10 & 20.0004 & 12.416915 & 10.716881 & 19.66706 & 81.6683 & 126.83587 & 0.083335 & 3.700074 \\
\hline 1 & SB4VS-04 & quenched & R13 & 1 & 11 & 30.33394 & 12.283579 & 8.633506 & 17.33368 & 117.66902 & 115.83565 & 0.083335 & 3.183397 \\
\hline 1 & Soln Std & & Soln Std & 1 & 12 & 4.01 & 21 & 4.01 & 9.85 & 82.5 & 50.1 & 0.05 & 0.05 \\
\hline 1 & SB4VS-04ccc & $\mathrm{ccc}$ & R52 & 1 & 13 & 30.50061 & 13.583605 & 7.883491 & 18.66704 & 112.33558 & 118.00236 & 0.083335 & 2.950059 \\
\hline 1 & SB4VS-07 & quenched & R17 & 1 & 14 & 20.0004 & 18.83371 & 5.066768 & 16.383661 & 54.33442 & 97.66862 & 0.083335 & 2.566718 \\
\hline 1 & SB4VS-07ccc & $\mathrm{ccc}$ & $\mathrm{R} 43$ & 1 & 15 & 20.16707 & 59 & 4.683427 & 647 & 52.0 & 95.8 & 0.083335 & 3.116729 \\
\hline 1 & SB4VS-05 & quenched & R42 & 1 & 16 & 15 . & 19.33372 & 6.716801 & 18.50037 & 39.33412 & 111.50223 & 0.083335 & 6.100122 \\
\hline 1 & SB4VS-05ccc & $\mathrm{ccc}$ & R19 & 1 & 17 & 18.16703 & 20.0004 & 10.883551 & 19.33372 & 40.0008 & 115.33564 & 0.083335 & 5.066768 \\
\hline 1 & EA & & R30 & 1 & 18 & 0.833335 & 416.6675 & 0.833335 & 140.33361 & 1170.00234 & 700.0014 & 0.833335 & 0.833335 \\
\hline 1 & ARM-1 & & R05 & 1 & 19 & 5.266772 & 18.50037 & 0.083335 & 14.066948 & 38.16743 & 61.83457 & 0.083335 & 0.083335 \\
\hline 1 & SB4VS-09 & quenched & R22 & 1 & 20 & 27.33388 & 18.3337 & 5.066768 & 14.766962 & 75.0015 & 88.83511 & 0.083335 & 2.933392 \\
\hline 1 & SB4VS-09ccc & $\mathrm{ccc}$ & R60 & 1 & 21 & 25.16717 & 41.00082 & 7.383481 & 30.16727 & 110.50221 & 114.00228 & 0.083335 & 3.850077 \\
\hline 1 & SB4VS-03 & quenched & R32 & 1 & 22 & 27.83389 & 13.233598 & 10.733548 & 19.00038 & 106.6688 & 126.00252 & 0.083335 & 3.3334 \\
\hline 1 & SB4VS-03ccc & $\mathrm{ccc}$ & R06 & 1 & 23 & 26.83387 & 12.233578 & 8.916845 & 19.16705 & 99.16865 & 122.16911 & 0.083335 & 3.300066 \\
\hline 1 & $\mathrm{aStd}$ & & oln Std & 1 & 24 & 4.15 & 21.2 & 3.9 & 9.94 & 83.5 & 50.5 & 0.05 & 0.05 \\
\hline 1 & & & Soln Std & 2 & 1 & 3.95 & 21.5 & 3 & 9.82 & 80. & 49.1 & 0.05 & 0.05 \\
\hline 1 & SB4VS-06 & quenched & R39 & 2 & 2 & 16.83367 & 19.00038 & 5.200104 & 17.00034 & 41.83417 & 101.00202 & 0.083335 & 3.366734 \\
\hline 1 & SB4VS-06ccc & $\mathrm{ccc}$ & R04 & 2 & 3 & 16.83367 & 18.16703 & 4.883431 & 16.383661 & 43.16753 & 100.50201 & 0.083335 & 3.50007 \\
\hline 1 & SB4VS-01 & quenched & R45 & 2 & 4 & 21.6671 & 10.950219 & 9.916865 & 19.66706 & 81.50163 & 126.16919 & 0.083335 & 4.233418 \\
\hline 1 & SB4VS-01ccc & $\mathrm{ccc}$ & R21 & 2 & 5 & 20.83375 & 10.16687 & 9.200184 & 19.50039 & 74.50149 & 122.33578 & 0.083335 & 4.066748 \\
\hline
\end{tabular}


Table F2. PSAL Measurements of the PCT Solutions for the Study Glasses After Appropriate Adjustments (continued)

\begin{tabular}{|c|c|c|c|c|c|c|c|c|c|c|c|c|c|}
\hline Set & Glass ID & $\begin{array}{c}\text { Heat } \\
\text { Treatment }\end{array}$ & Laboratory ID & Block & Seq & Al (ppm) & B (ppm) & $\mathrm{Fe}(\mathrm{ppm})$ & Li (ppm) & Na (ppm) & Si (ppm) & Th (ppm) & $\mathbf{U}(\mathbf{p p m})$ \\
\hline 1 & SB4VS-08 & quenched & R16 & 2 & 6 & 22.50045 & 16.667 & 4.533424 & 15.0003 & 57.83449 & 88.50177 & 0.083335 & 2.66672 \\
\hline 1 & SB4VS-08ccc & ccc & R10 & 2 & 7 & 21.83377 & 16.266992 & 3.983413 & 14.516957 & 55.33444 & 86.16839 & 0.083335 & 3.033394 \\
\hline 1 & SB4VS-02 & quenched & R37 & 2 & 8 & 20.0004 & 12.066908 & 10.266872 & 19.16705 & 80.50161 & 124.16915 & 0.083335 & 3.416735 \\
\hline 1 & SB4VS-01ccc & ccc & $\bar{R} 57$ & 2 & 9 & 19.50039 & 11.950239 & 9.400188 & 19.50039 & 75.33484 & 124.66916 & 0.083335 & 3.433402 \\
\hline 1 & SB4VS-04 & quenched & R48 & 2 & \begin{tabular}{|l|}
10 \\
\end{tabular} & 30.16727 & 11.683567 & 7.050141 & 17.16701 & 111.33556 & 112.33558 & 0.083335 & 3.066728 \\
\hline 1 & SB4VS-04ccc & $\mathrm{ccc}$ & R36 & 2 & 11 & 30.66728 & 12.50025 & 7.750155 & 18.83371 & 109.16885 & 118.50237 & 0.083335 & 3.016727 \\
\hline 1 & Soln Std & & Soln Std & 2 & 12 & 4.05 & 21 & 3.71 & 9.95 & 79.8 & 49.9 & 0.05 & 0.05 \\
\hline 1 & SB4VS-07 & quenched & R62 & 2 & 13 & 20.16707 & 18.83371 & 4.600092 & 16.566998 & 51.6677 & 97.83529 & 0.083335 & 2.83339 \\
\hline 1 & SB4VS-07ccc & ccc & R47 & 2 & 14 & 19.83373 & 17.66702 & 4.100082 & 15.633646 & 51.00102 & 95.66858 & 0.083335 & 3.233398 \\
\hline 1 & SB4VS-05 & quenched & R12 & 2 & 15 & 15.100302 & 18.66704 & 5.866784 & 18.16703 & 39.00078 & 107.50215 & 0.083335 & 5.750115 \\
\hline 1 & SB4VS-09ccc & $\mathrm{ccc}$ & R59 & 2 & 16 & 15.583645 & 19.00038 & 7.183477 & 18.83371 & 37.16741 & 109.66886 & 0.083335 & 5.200104 \\
\hline 1 & $\overline{E A}$ & & R20 & 2 & 17 & 0.833335 & 450.0009 & 0.833335 & 149.33363 & 1210.00242 & 733.3348 & 0.833335 & 0.833335 \\
\hline 1 & ARM-1 & & R61 & 2 & 18 & 5.100102 & 19.33372 & 0.083335 & 14.616959 & 39.50079 & 62.66792 & 0.083335 & 0.083335 \\
\hline 1 & SB4VS-09 & quenched & R11 & 2 & 19 & 27.33388 & 18.16703 & 4.866764 & 15.133636 & 73.83481 & 89.50179 & 0.083335 & 2.466716 \\
\hline 1 & SB4VS-09ccc & $\overline{c c c}$ & R27 & 2 & 20 & 26.16719 & 41.83417 & 8.083495 & 30.83395 & 112.33558 & 118.3357 & 0.083335 & 3.116729 \\
\hline 1 & SB4VS-03 & quenched & R50 & 2 & 21 & 26.16719 & 12.066908 & 8.550171 & 18.3337 & 102.33538 & 120.33574 & 0.083335 & 3.16673 \\
\hline 1 & SB4VS-03ccc & $\mathrm{ccc}$ & R01 & 2 & 22 & 26.00052 & 11.766902 & 8.16683 & 19.00038 & 95.33524 & 120.66908 & 0.083335 & 3.3334 \\
\hline 1 & Soln Std & & Soln Std & 2 & 23 & 4.05 & 21.1 & 3.76 & 10 & 81.8 & 50.4 & 0.05 & 0.05 \\
\hline 1 & Soln Std & & Soln Std & 3 & 1 & 4.01 & 21.4 & 3.6 & 9.83 & 81.6 & 48.8 & 0.05 & 0.05 \\
\hline 1 & SB4VS-06 & quenched & R24 & 3 & 2 & 17.50035 & 19.66706 & 5.433442 & 17.50035 & 44.83423 & 103.3354 & 0.083335 & 3.316733 \\
\hline 1 & SB4VS-06ccc & $\mathrm{ccc}$ & R33 & 3 & 3 & 17.00034 & 18.3337 & 4.783429 & 16.400328 & 43.00086 & 100.002 & 0.083335 & 3.83341 \\
\hline 1 & blank & & R03 & 3 & 4 & 0.083335 & 0.083335 & 0.083335 & 0.416675 & 0.083335 & 0.083335 & 0.083335 & 0.083335 \\
\hline 1 & SB4VS-01 & quenched & R35 & 3 & 5 & 21.00042 & 10.566878 & 9.716861 & 19.66706 & 82.83499 & 123.3358 & 0.083335 & 3.600072 \\
\hline 1 & SB4VS-05ccc & ccc & R58 & 3 & 6 & 20.83375 & 10.216871 & 9.50019 & 19.66706 & 79.33492 & 122.33578 & 0.083335 & 4.966766 \\
\hline 1 & SB4VS-08 & quenched & R34 & 3 & 7 & 22.33378 & 16.83367 & 4.550091 & 14.950299 & 59.00118 & 88.16843 & 0.083335 & 2.366714 \\
\hline 1 & SB4VS-08ccc & ccc & R31 & 3 & 8 & 23.00046 & 17.50035 & 4.083415 & 15.300306 & 61.33456 & 90.83515 & 0.083335 & 2.33338 \\
\hline 1 & SB4VS-02 & quenched & R18 & 3 & 9 & 20.33374 & 12.433582 & 11.6669 & 19.66706 & 85.50171 & 127.66922 & 0.083335 & 3.783409 \\
\hline 1 & SB4VS-02ccc & $\mathrm{ccc}$ & R14 & 3 & 10 & 20.0004 & 12.366914 & 10.516877 & 19.66706 & 78.66824 & 127.16921 & 0.083335 & 3.583405 \\
\hline 1 & SB4VS-04 & quenched & R15 & 3 & 11 & 30.0006 & 12.233578 & 7.566818 & 17.16701 & 110.83555 & 115.16897 & 0.083335 & 2.900058 \\
\hline 1 & Soln Std & & Soln Std & 3 & 12 & 4.09 & 21.4 & 3.87 & 10 & 83.5 & 50.9 & 0.05 & 0.05 \\
\hline 1 & SB4VS-04ccc & $\mathrm{ccc}$ & R02 & 3 & 13 & 34.66736 & 14.133616 & 11.383561 & 19.50039 & 112.83559 & 124.66916 & 0.083335 & 2.983393 \\
\hline 1 & SB4VS-07 & quenched & R26 & 3 & \begin{tabular}{|l|}
14 \\
\end{tabular} & 19.83373 & 18.00036 & 5.33344 & 15.900318 & 50.33434 & 96.00192 & 0.083335 & 3.133396 \\
\hline
\end{tabular}


Table F2. PSAL Measurements of the PCT Solutions for the Study Glasses After Appropriate Adjustments (continued)

\begin{tabular}{|c|c|c|c|c|c|c|c|c|c|c|c|c|c|}
\hline Set & Glass ID & $\begin{array}{c}\text { Heat } \\
\text { Treatment }\end{array}$ & Laboratory ID & Block & Seq & Al (ppm) & B (ppm) & $\mathrm{Fe}(\mathrm{ppm})$ & Li (ppm) & $\mathrm{Na}(\mathrm{ppm})$ & Si (ppm) & Th (ppm) & $\mathbf{U}(\mathbf{p p m})$ \\
\hline 1 & SB4VS-07ccc & ccc & R41 & 3 & 15 & 19.83373 & 18.00036 & 4.83343 & 15.783649 & 51.83437 & 97.16861 & 0.083335 & 3.283399 \\
\hline 1 & SB4VS-05 & quenched & R44 & 3 & \begin{tabular}{|l|}
16 \\
\end{tabular} & 16.233658 & 19.33372 & 6.6668 & 18.50037 & 39.16745 & 111.33556 & 0.083335 & 6.300126 \\
\hline 1 & SB4VS-05ccc & $\mathrm{ccc}$ & R53 & 3 & 17 & 15.800316 & 20.0004 & 7.750155 & 19.16705 & 37.83409 & 113.66894 & 0.083335 & 5.366774 \\
\hline 1 & $\overline{\mathrm{EA}}$ & & $\mathrm{R} 25$ & 3 & 18 & 0.833335 & 618.33457 & 0.833335 & 178.33369 & 1573.33648 & \begin{tabular}{|l|}
868.33507 \\
\end{tabular} & 0.833335 & 0.833335 \\
\hline 1 & ARM-1 & & R09 & 3 & 19 & 5.283439 & 20.0004 & 0.083335 & 14.483623 & 40.0008 & 66.50133 & 0.083335 & 0.083335 \\
\hline 1 & SB4VS-09 & quenched & R07 & 3 & 20 & 27.16721 & 18.66704 & 5.383441 & 15.300306 & 75.33484 & 90.66848 & 0.083335 & 2.516717 \\
\hline 1 & SB4VS-02ccc & $\mathrm{ccc}$ & R54 & 3 & 21 & 25.66718 & 42.50085 & 8.183497 & 30.50061 & 110.0022 & 118.3357 & 0.083335 & 3.816743 \\
\hline 1 & SB4VS-02ccc & $\overline{c c c}$ & R56 & 3 & 22 & 26.33386 & 12.816923 & 10.100202 & 18.83371 & 103.00206 & 125.66918 & 0.083335 & 3.583405 \\
\hline 1 & SB4VS-03ccc & $\mathrm{ccc}$ & R28 & 3 & 23 & 26.33386 & 12.633586 & 9.783529 & 19.33372 & 100.33534 & 124.66916 & 0.083335 & 3.283399 \\
\hline 1 & Soln Std & & Soln Std & 3 & 24 & 4.44 & 21.5 & 4.17 & 10 & 82.3 & 51.3 & 0.05 & 0.05 \\
\hline 2 & Soln Std & & Soln Std & 1 & 1 & 3.75 & 21.2 & 3.95 & 9.8 & 79.6 & 47.6 & 0.05 & 0.05 \\
\hline 2 & SB4VS-18ccc & $\mathrm{ccc}$ & S79 & 1 & 2 & 16.250325 & 18.3337 & 4.616759 & 16.400328 & 39.00078 & 95.33524 & 0.083335 & 4.716761 \\
\hline 2 & blank & & S26 & 1 & 3 & 1.0933552 & 0.5850117 & 0.083335 & 0.83335 & 0.083335 & \begin{tabular}{|l|}
0.4783429 \\
\end{tabular} & 0.083335 & 0.083335 \\
\hline 2 & SB4VS-19 & quenched & S51 & 1 & 4 & 15.400308 & 18.66704 & 5.016767 & 17.33368 & 45.0009 & 98.16863 & 0.083335 & 3.866744 \\
\hline 2 & -21 & quenched & S29 & 1 & 5 & 15.700314 & 17.1 & 4.783 & 16.83367 & 34.00068 & 95.0019 & 0.083335 & 4.183417 \\
\hline 2 & SB4VS-12ccc & $\mathrm{cc}$ & S80 & 1 & 6 & 21. & 17 & 977 & 15.816983 & 767 & 12 & 335 & 2.600052 \\
\hline 2 & $\overline{E A}$ & & S07 & 1 & 7 & 0.833335 & 625.00125 & 0.833335 & 185.00037 & 1661.66999 & 835.00167 & 0.833335 & 0.833335 \\
\hline 2 & SB4VS-13 & quenched & S04 & 1 & 8 & 21.6671 & 17.33368 & 4.566758 & 15.116969 & 48.83431 & \begin{tabular}{|l|}
86.16839 \\
\end{tabular} & 0.083335 & 3.050061 \\
\hline 2 & Soln Std & & Soln Std & 1 & 9 & 3.79 & 20.4 & 4.06 & 9.81 & 81.4 & 47.7 & 0.05 & 0.05 \\
\hline 2 & SB4VS-11 & quenched & S20 & 1 & 10 & 23.66714 & 18.3337 & 4.266752 & 15.683647 & 61.50123 & 88.3351 & 0.083335 & 2.683387 \\
\hline 2 & SB4VS-21ccc & $\mathrm{ccc}$ & S01 & 1 & 11 & 15.783649 & 17.50035 & 4.100082 & 16.633666 & 36.33406 & 95.83525 & 0.083335 & 4.516757 \\
\hline 2 & SB4VS-18 & quenched & S56 & 1 & 12 & 16.300326 & 18.00036 & 4.216751 & 17.16701 & 39.00078 & 95.33524 & 0.083335 & 3.400068 \\
\hline 2 & SB4VS-11ccc & $\mathrm{ccc}$ & S48 & 1 & 13 & 24.00048 & 17.50035 & 4.400088 & 15.650313 & 60.33454 & 88.50177 & 0.083335 & 2.600052 \\
\hline 2 & SB4VS-13ccc & $\mathrm{ccc}$ & S66 & 1 & 14 & 22.00044 & 17.00034 & 4.16675 & 14.83363 & 49.16765 & 88.66844 & 0.083335 & 2.883391 \\
\hline 2 & SB4VS-12 & quenched & S25 & 1 & 15 & 23.83381 & 17.83369 & 4.200084 & 16.483663 & 52.83439 & 90.0018 & 0.083335 & 2.66672 \\
\hline 2 & SB4VS-19ccc & $\mathrm{ccc}$ & S65 & 1 & 16 & 15.716981 & 17.50035 & 4.316753 & 16.516997 & 45.50091 & 97.66862 & 0.083335 & 4.216751 \\
\hline 2 & Soln Std & & Soln Std & 1 & 17 & 3.86 & 19.9 & 3.99 & 9.79 & 82.1 & 47 & 0.05 & 0.05 \\
\hline 2 & Soln Std & & Soln Std & 2 & 1 & 3.97 & 20.5 & 3.77 & 10.1 & 84.9 & 50.7 & 0.05 & 0.05 \\
\hline 2 & SB4VS-11 & quenched & $\mathrm{S} 13$ & 2 & 2 & 25.0005 & 18.66704 & 6.850137 & 16.50033 & 67.33468 & 96.50193 & 0.083335 & 2.683387 \\
\hline 2 & SB4VS-11ccc & ccc & S34 & 2 & 3 & 23.16713 & 18.00036 & 4.366754 & 15.516977 & 61.00122 & 90.0018 & 0.083335 & 2.583385 \\
\hline 2 & SB4VS-12ccc & $\mathrm{ccc}$ & S57 & 2 & 4 & 21.50043 & 17.83369 & 3.650073 & 16.033654 & 53.3344 & 90.83515 & 0.083335 & 2.733388 \\
\hline 2 & SB4VS-21ccc & $\overline{\mathrm{ccc}}$ & S45 & 2 & 5 & 15.583645 & 17.00034 & 4.633426 & 16.466996 & 37.66742 & 97.66862 & 0.083335 & 4.366754 \\
\hline
\end{tabular}


Table F2. PSAL Measurements of the PCT Solutions for the Study Glasses After Appropriate Adjustments (continued)

\begin{tabular}{|c|c|c|c|c|c|c|c|c|c|c|c|c|c|}
\hline Set & Glass ID & $\begin{array}{c}\text { Heat } \\
\text { Treatment }\end{array}$ & Laboratory ID & Block & Seq & Al (ppm) & B (ppm) & $\mathrm{Fe}(\mathrm{ppm})$ & Li (ppm) & Na (ppm) & Si (ppm) & Th (ppm) & $\mathbf{U}(\mathbf{p p m})$ \\
\hline 2 & SB4VS-18 & quenched & S53 & 2 & 6 & 16.200324 & 18.00036 & 4.616759 & 17.50035 & 41.16749 & 97.50195 & 0.083335 & 3.600072 \\
\hline 2 & SB4VS-12 & quenched & S54 & 2 & 7 & 22.83379 & 18.3337 & \begin{tabular}{|l|}
5.083435 \\
\end{tabular} & 16.83367 & 56.16779 & 94.00188 & 0.083335 & 2.783389 \\
\hline 2 & SB4VS-21 & quenched & S16 & 2 & 8 & 15.816983 & 17.66702 & 4.183417 & 17.50035 & 38.00076 & 96.83527 & 0.083335 & 4.183417 \\
\hline 2 & Soln Std & & Soln Std & 2 & 9 & 3.88 & 20.6 & 3.71 & 9.94 & 85.7 & 47.8 & 0.05 & 0.05 \\
\hline 2 & SB4VS-19ccc & $\mathrm{ccc}$ & S50 & 2 & 10 & 16.200324 & 18.3337 & 4.583425 & 16.83367 & 47.16761 & 102.00204 & 0.083335 & 4.316753 \\
\hline 2 & SB4VS-13 & quenched & S69 & 2 & 11 & 22.00044 & 17.83369 & 4.066748 & 15.916985 & 54.33442 & 92.50185 & 0.083335 & 2.900058 \\
\hline 2 & EA & & S30 & 2 & 12 & 3.0333394 & 601.66787 & 2.3833381 & 181.66703 & 1653.33664 & 855.00171 & 0.833335 & 0.833335 \\
\hline 2 & SB4VS-13ccc & $\mathrm{ccc}$ & S02 & 2 & 13 & 21.50043 & 17.33368 & 4.33342 & 14.800296 & 50.66768 & 91.33516 & 0.083335 & 2.950059 \\
\hline 2 & SB4VS-18ccc & $\mathrm{ccc}$ & S19 & 2 & 14 & 16.83367 & 16.83367 & 3.550071 & 16.283659 & 41.00082 & 95.50191 & 0.083335 & 4.150083 \\
\hline 2 & SB4VS-19 & quenched & S15 & 2 & 15 & 16.050321 & 18.50037 & 7.033474 & 17.50035 & 48.66764 & 100.16867 & 0.083335 & 3.966746 \\
\hline 2 & Soln Std & & Soln Std & 2 & 16 & 3.98 & 20.2 & 3.73 & 10 & 86.8 & 49.2 & 0.05 & 0.05 \\
\hline 2 & Soln Std & & Soln Std & 3 & 1 & 4.03 & 22 & 3.99 & 10.1 & 82.9 & 49.5 & 0.05 & 0.05 \\
\hline 2 & SB4VS-11 & quenched & S31 & 3 & 2 & 23.83381 & 18.66704 & 4.700094 & 15.583645 & 61.16789 & 90.33514 & 0.083335 & 2.533384 \\
\hline 2 & SB4VS-12ccc & $\overline{\mathrm{ccc}}$ & S70 & 3 & 3 & 22.50045 & 19.00038 & 4.416755 & 16.633666 & 53.16773 & 95.66858 & 0.083335 & 2.700054 \\
\hline 2 & SB4VS-19ccc & ccc & S73 & 3 & 4 & 17.00034 & 18.66704 & 5.300106 & 16.83367 & 46.16759 & 100.50201 & 0.083335 & 4.016747 \\
\hline 2 & SB4VS-13 & quenched & S55 & 3 & 5 & 22.00044 & 18.50037 & 4.783429 & 15.916985 & 51.50103 & 92.50185 & 0.083335 & 2.550051 \\
\hline 2 & SB4VS-21 & quenched & S63 & 3 & 6 & 16.16699 & 18.83371 & 6.766802 & 18.00036 & 37.33408 & 102.83539 & 0.083335 & 3.883411 \\
\hline 2 & SB4VS-13ccc & $\mathrm{ccc}$ & S23 & 3 & 7 & 22.50045 & 17.33368 & 4.583425 & 14.700294 & 49.16765 & 89.33512 & 0.083335 & 2.516717 \\
\hline 2 & SB4VS-12 & quenched & S59 & 3 & 8 & 22.33378 & 18.66704 & 4.350087 & 16.83367 & 54.66776 & 95.16857 & 0.083335 & 2.66672 \\
\hline 2 & Soln Std & & Soln Std & 3 & 9 & 4.14 & 21.1 & 3.93 & 9.89 & 84 & 49.3 & 0.05 & 0.05 \\
\hline 2 & SB4VS-19 & quenched & S72 & 3 & 10 & 17.83369 & 19.66706 & 7.933492 & 17.50035 & 47.16761 & 102.00204 & 0.083335 & 3.233398 \\
\hline 2 & SB4VS-21ccc & ccc & S09 & 3 & 11 & 15.483643 & 17.33368 & 4.650093 & 16.250325 & 35.66738 & 97.50195 & 0.083335 & 4.016747 \\
\hline 2 & SB4VS-18ccc & ccc & S39 & 3 & 12 & 16.483663 & 18.3337 & 4.533424 & 16.83367 & 41.50083 & 99.33532 & 0.083335 & 2.750055 \\
\hline 2 & $\overline{\mathrm{EA}}$ & & S68 & 3 & 13 & 21.833377 & 625.00125 & 18.666704 & 181.66703 & 1683.3367 & 865.00173 & 0.833335 & 0.833335 \\
\hline 2 & SB4VS-11ccc & ccc & S77 & 3 & 14 & 24.50049 & 19.00038 & 4.366754 & 16.083655 & 63.16793 & 93.66854 & 0.083335 & 2.466716 \\
\hline 2 & SB4VS-18 & quenched & S22 & 3 & 15 & 16.83367 & 18.3337 & 5.216771 & 17.16701 & 39.16745 & 97.33528 & 0.083335 & 3.483403 \\
\hline 2 & Soln Std & & Soln Std & 3 & 16 & 4.08 & 21.2 & 4.01 & 10.1 & 85.9 & 49.8 & 0.05 & 0.05 \\
\hline 2 & Soln Std & & Soln Std & 4 & 1 & 3.78 & 21.8 & 3.95 & 9.95 & 80.9 & 48.8 & 0.05 & 0.05 \\
\hline 2 & SB4VS-16ccc & $\mathrm{ccc}$ & S61 & 4 & 2 & 17.16701 & 18.83371 & 5.33344 & 16.16699 & 49.83433 & 98.50197 & 0.083335 & 4.33342 \\
\hline 2 & SB4VS-14ccc & ccc & S05 & 4 & 3 & 18.83371 & 19.33372 & 4.916765 & 16.83367 & 56.6678 & 102.50205 & 0.083335 & 3.150063 \\
\hline 2 & SB4VS-20ccc & ccc & S78 & 4 & 4 & 14.66696 & 18.16703 & 4.800096 & 17.00034 & 36.83407 & 102.00204 & 0.083335 & 5.0001 \\
\hline 2 & SB4VS-17ccc & $\mathrm{ccc}$ & S44 & 4 & 5 & 18.00036 & 16.50033 & 5.0001 & 15.400308 & 41.83417 & 92.66852 & 0.083335 & \begin{tabular}{|l|}
4.550091 \\
\end{tabular} \\
\hline
\end{tabular}


Table F2. PSAL Measurements of the PCT Solutions for the Study Glasses After Appropriate Adjustments (continued)

\begin{tabular}{|c|c|c|c|c|c|c|c|c|c|c|c|c|c|}
\hline Set & Glass ID & $\begin{array}{c}\text { Heat } \\
\text { Treatment }\end{array}$ & Laboratory ID & Block & Seq & Al (ppm) & B (ppm) & $\mathrm{Fe}(\mathrm{ppm})$ & $\mathbf{L i}$ (ppm) & $\mathrm{Na}$ (ppm) & Si (ppm) & Th (ppm) & $\mathbf{U}$ (ppm) \\
\hline 2 & SB4VS-10 & quenched & S52 & 4 & 6 & 22.50045 & 18.83371 & 4.466756 & 16.066988 & 68.83471 & 92.16851 & 0.083335 & 2.783389 \\
\hline 2 & SB4VS-10ccc & $\operatorname{ccc}$ & S10 & 4 & 7 & 22.33378 & 17.66702 & 4.050081 & 15.350307 & 64.33462 & 91.00182 & 0.083335 & 2.583385 \\
\hline 2 & SB4VS-14 & quenched & S41 & 4 & 8 & 19.50039 & 19.83373 & 5.700114 & 17.83369 & 59.83453 & 102.50205 & 0.083335 & 3.516737 \\
\hline 2 & Soln Std & & Soln Std & 4 & 9 & 3.85 & 21.3 & 4.02 & 9.73 & 81.7 & 48.7 & 0.05 & 0.05 \\
\hline 2 & SB4VS-20 & quenched & S33 & 4 & 10 & 15.16697 & 18.50037 & 6.216791 & 17.50035 & 36.33406 & 103.00206 & 0.083335 & 4.383421 \\
\hline 2 & SB4VS-16 & quenched & S12 & 4 & 11 & 18.66704 & 21.16709 & 6.366794 & 19.00038 & 57.83449 & 108.16883 & 0.083335 & 4.066748 \\
\hline 2 & SB4VS-15ccc & $\mathrm{ccc}$ & S40 & 4 & 12 & 18.83371 & 18.3337 & 5.700114 & 16.400328 & 51.83437 & 97.50195 & 0.083335 & 3.483403 \\
\hline 2 & SB4VS-15 & quenched & S74 & 4 & 13 & 19.16705 & 19.16705 & 5.350107 & 17.50035 & 54.66776 & 99.66866 & 0.083335 & 3.300066 \\
\hline 2 & SB4VS-17 & quenched & S28 & 4 & 14 & 18.83371 & 16.50033 & 4.750095 & 15.766982 & 40.50081 & 92.50185 & 0.083335 & 3.983413 \\
\hline 2 & ARM-1 & & S37 & 4 & 15 & 4.433422 & 17.50035 & 0.083335 & 13.16693 & 34.50069 & 58.16783 & 0.083335 & 0.083335 \\
\hline 2 & Soln Std & & Soln Std & 4 & 16 & 3.86 & 20.5 & 4.11 & 9.76 & 83 & 48.7 & 0.05 & 0.05 \\
\hline 2 & Soln Std & & Soln Std & 5 & 1 & 3.94 & 21.2 & 3.94 & 9.8 & 80.8 & 48 & 0.05 & 0.05 \\
\hline 2 & SB4VS-10ccc & $\mathrm{ccc}$ & S03 & 5 & 2 & 23.00046 & 18.3337 & 3.700074 & 15.066968 & 62.66792 & 88.16843 & 0.083335 & 2.366714 \\
\hline 2 & SB4VS-20ccc & $\mathrm{ccc}$ & S06 & 5 & 3 & 16.316993 & 18.16703 & 9.133516 & 17.16701 & 38.16743 & 102.50205 & 0.083335 & 4.933432 \\
\hline 2 & SB4VS-17ccc & $\overline{c c c}$ & S38 & 5 & 4 & 18.50037 & 16.667 & 5.750115 & 15.466976 & 41.00082 & 92.50185 & 0.083335 & 4.250085 \\
\hline 2 & $\overline{\text { SB4 }}$ & quenche & S24 & 5 & 5 & 22.50045 & 18.5 & 4.0 & 15.7 & 69 & 90. & 335 & 2.450049 \\
\hline 2 & SB4VS-14ccc & $\mathrm{ccc}$ & S64 & 5 & 6 & 19.33372 & 18.00036 & 4.466756 & 16.116989 & 54.50109 & 94.66856 & 0.083335 & 2.933392 \\
\hline 2 & SB4VS-14 & quenched & S60 & 5 & 7 & 18.83371 & 19.33372 & 4.916765 & 17.33368 & 58.16783 & 99.16865 & 0.083335 & 3.116729 \\
\hline 2 & SB4VS-20 & quenched & S42 & 5 & 8 & 14.800296 & 17.33368 & 5.750115 & 17.16701 & 36.33406 & 97.33528 & 0.083335 & 4.200084 \\
\hline 2 & Soln Std & & Soln Std & 5 & 9 & 4.14 & 20.4 & 3.83 & 9.68 & 81.2 & 47.7 & 0.05 & 0.05 \\
\hline 2 & SB4VS-15ccc & ccc & S36 & 5 & 10 & 19.83373 & 19.00038 & 5.283439 & 16.83367 & 52.16771 & 97.83529 & 0.083335 & 3.200064 \\
\hline 2 & SB4VS-17 & quenched & S58 & 5 & 11 & 18.50037 & 16.50033 & 5.150103 & 15.83365 & 41.83417 & 91.33516 & 0.083335 & 3.66674 \\
\hline 2 & SB4VS-15 & quenched & S27 & 5 & 12 & 19.83373 & 19.00038 & 5.766782 & 17.50035 & 55.0011 & 99.33532 & 0.083335 & 3.050061 \\
\hline 2 & SB4VS-16ccc & $\mathrm{ccc}$ & S14 & 5 & 13 & 17.66702 & 18.16703 & 4.616759 & 16.650333 & 52.00104 & 100.002 & 0.083335 & 4.250085 \\
\hline 2 & SB4VS-16 & quenched & S75 & 5 & 14 & 17.50035 & 18.50037 & 5.583445 & 17.16701 & 53.16773 & 97.16861 & 0.083335 & 3.966746 \\
\hline 2 & $4 \mathrm{PM} 1$ & & S67 & 5 & 15 & 4.750095 & 16.50033 & 0.083335 & 13.200264 & 35.16737 & 58.50117 & 0.083335 & 0.083335 \\
\hline 2 & & & oln Std & 5 & 16 & 4. & 20 & 3. & 9.71 & 8 & 48 & 0.05 & 0.05 \\
\hline 2 & & & Soln Std & 6 & 1 & & & 4 & 10 & 80 & 46.7 & 0.05 & 0.05 \\
\hline 2 & SB4VS-17ccc & $\mathrm{ccc}$ & S11 & 6 & 2 & 18.3337 & 17.50035 & 5.733448 & 15.800316 & 40.66748 & 91.33516 & 0.083335 & 3.966746 \\
\hline 2 & SB4VS-15ccc & $\mathrm{ccc}$ & S46 & 6 & 3 & 19.83373 & 20.0004 & 5.450109 & 17.83369 & 54.00108 & 100.66868 & 0.083335 & 3.550071 \\
\hline 2 & SB4VS-20ccc & $\mathrm{ccc}$ & S32 & 6 & 4 & 14.850297 & 18.00036 & 7.533484 & 17.16701 & 36.33406 & 97.00194 & 0.083335 & 5.183437 \\
\hline 2 & SB4VS-14 & quenched & S62 & 6 & 5 & 18.83371 & 19.66706 & 5.050101 & 17.83369 & 58.16783 & 97.66862 & 0.083335 & 3.3334 \\
\hline 2 & SB4VS-10ccc & $\mathrm{ccc}$ & S08 & 6 & 6 & 23.3338 & 17.50035 & 4.283419 & 15.633646 & 64.33462 & 86.33506 & 0.083335 & 2.516717 \\
\hline
\end{tabular}


Table F2. PSAL Measurements of the PCT Solutions for the Study Glasses After Appropriate Adjustments (continued)

\begin{tabular}{|c|c|c|c|c|c|c|c|c|c|c|c|c|c|}
\hline Set & Glass ID & $\begin{array}{c}\text { Heat } \\
\text { Treatment }\end{array}$ & Laboratory ID & Block & Seq & $\mathbf{A l}(\mathbf{p p m})$ & B (ppm) & $\mathrm{Fe}(\mathrm{ppm})$ & Li (ppm) & $\mathrm{Na}$ (ppm) & Si (ppm) & Th (ppm) & $\mathbf{U}(\mathbf{p p m})$ \\
\hline 2 & SB4VS-10 & quenched & S47 & 6 & 7 & 22.16711 & 18.50037 & 3.883411 & 16.250325 & 68.16803 & 87.50175 & 0.083335 & 2.650053 \\
\hline 2 & SB4VS-14ccc & ccc & S17 & 6 & 8 & 18.50037 & 18.3337 & 7.516817 & 16.83367 & 55.66778 & 95.33524 & 0.083335 & 3.033394 \\
\hline 2 & Soln Std & & Soln Std & 6 & 9 & 4.11 & 20.4 & 3.98 & 9.99 & 80.4 & 46 & 0.05 & 0.05 \\
\hline 2 & SB4VS-16ccc & $\mathrm{ccc}$ & S35 & 6 & 10 & 16.150323 & 17.66702 & 4.933432 & 15.566978 & 47.00094 & 91.33516 & 0.083335 & 4.050081 \\
\hline 2 & SB4VS-16 & quenched & S18 & 6 & 11 & 17.50035 & 19.00038 & 4.633426 & 17.50035 & 51.6677 & 95.83525 & 0.083335 & 4.183417 \\
\hline 2 & SB4VS-20 & quenched & S71 & 6 & 12 & 14.966966 & 18.50037 & 5.183437 & 18.16703 & 37.16741 & 98.00196 & 0.083335 & 4.250085 \\
\hline 2 & blank & & S21 & 6 & 13 & 0.083335 & 0.083335 & 0.083335 & 0.83335 & 0.083335 & 0.083335 & 0.083335 & 0.083335 \\
\hline 2 & SB4VS-15 & quenched & S49 & 6 & 14 & 19.16705 & 18.50037 & 5.66678 & 17.50035 & 53.00106 & 95.16857 & 0.083335 & 3.150063 \\
\hline 2 & SB4VS-17 & quenched & S43 & 6 & 15 & 18.3337 & 16.667 & 5.066768 & 16.600332 & 41.16749 & 89.16845 & 0.083335 & 4.050081 \\
\hline 2 & ARM-1 & & S76 & 6 & 16 & 5.033434 & 17.33368 & 0.400008 & 13.900278 & 36.50073 & 55.33444 & 0.083335 & 0.083335 \\
\hline 2 & Soln Std & & Soln Std & 6 & 17 & 4.15 & 20.2 & 4.04 & 10 & 81.8 & 45.6 & 0.05 & 0.05 \\
\hline 3 & Soln Std & & Soln Std & 1 & 1 & 3.92 & 21.2 & 3.84 & 9.68 & 81.2 & 49.9 & 0.05 & 0.05 \\
\hline 3 & SB4VS-24 & quenched & T48 & 1 & 2 & 19.33372 & 19.33372 & 4.900098 & 15.983653 & 66.33466 & 98.16863 & 0.083335 & 2.766722 \\
\hline 3 & SB4VS-30 & quenched & T01 & 1 & 3 & 15.33364 & 19.16705 & 6.066788 & 17.50035 & 46.00092 & 103.16873 & 0.083335 & 5.133436 \\
\hline 3 & EA & & T77 & 1 & 4 & 0.833335 & 625.00125 & 0.833335 & 185.00037 & 1636.66994 & 895.00179 & 0.833335 & 0.833335 \\
\hline 3 & SB4VS-33ccc & ccc & T37 & 1 & 5 & 18.83371 & 17.33368 & 2.866724 & 15.283639 & 40.16747 & 89.33512 & 0.083335 & 2.033374 \\
\hline 3 & SB4VS-27 & quenched & T26 & 1 & 6 & 18.3337 & 18.50037 & 4.316753 & 16.416995 & 52.50105 & 98.00196 & 0.083335 & 2.983393 \\
\hline 3 & SB4VS-30ccc & $\mathrm{ccc}$ & T81 & 1 & 7 & 15.750315 & 19.50039 & 6.233458 & 17.66702 & 48.3343 & 107.50215 & 0.083335 & 4.650093 \\
\hline 3 & SB4VS-32ccc & $\mathrm{ccc}$ & T89 & 1 & 8 & 17.83369 & 20.0004 & 4.33342 & 16.83367 & 71.50143 & 99.00198 & 0.083335 & 2.700054 \\
\hline 3 & SB4VS-28 & quenched & T88 & 1 & 9 & 16.416995 & 19.00038 & 4.933432 & 17.16701 & 48.3343 & 100.83535 & 0.083335 & 3.550071 \\
\hline 3 & Soln Std & & Soln Std & 1 & 10 & 3.89 & 20.5 & 3.87 & 9.73 & 81.9 & 49.7 & 0.05 & 0.05 \\
\hline 3 & SB4VS-25ccc & $\mathrm{ccc}$ & $\mathrm{T} 71$ & 1 & 11 & 18.16703 & 20.0004 & 4.150083 & 16.150323 & 58.3345 & 97.50195 & 0.083335 & 2.866724 \\
\hline 3 & SB4VS-24ccc & ccc & T16 & 1 & 12 & 20.0004 & 19.33372 & 6.133456 & 16.233658 & 66.00132 & 101.50203 & 0.083335 & 3.3334 \\
\hline 3 & SB4VS-28ccc & ccc & $\mathrm{T} 82$ & 1 & 13 & 15.633646 & 17.66702 & 4.583425 & 15.66698 & 45.50091 & 95.50191 & 0.083335 & 4.16675 \\
\hline 3 & SB4VS-27ccc & $\mathrm{ccc}$ & T76 & 1 & 14 & 18.83371 & 18.3337 & 4.216751 & 16.150323 & 53.00106 & 99.33532 & 0.083335 & 2.950059 \\
\hline 3 & SB4VS-32 & quenched & T09 & 1 & 15 & 17.83369 & 19.50039 & 4.916765 & 16.350327 & 71.50143 & 97.66862 & 0.083335 & 2.816723 \\
\hline 3 & SB4VS-33 & quenched & T31 & 1 & 16 & 19.66706 & 17.50035 & 3.433402 & 16.533664 & 41.16749 & 92.33518 & 0.083335 & 2.550051 \\
\hline 3 & SB4VS-25 & quenched & T52 & 1 & 17 & 18.16703 & 18.83371 & 4.266752 & 16.133656 & 58.83451 & 98.3353 & 0.083335 & 2.783389 \\
\hline 3 & blank & & T14 & 1 & 18 & 0.083335 & 0.2566718 & 0.083335 & 0.83335 & 0.083335 & 0.083335 & 0.083335 & 0.083335 \\
\hline 3 & Soln Std & & Soln Std & 1 & 19 & 3.92 & 20.6 & 3.97 & 9.72 & 82.5 & 50.1 & 0.05 & 0.05 \\
\hline 3 & Soln Std & & Soln Std & 2 & 1 & 3.86 & 21 & 3.5 & 9.71 & 81.9 & 49.6 & 0.05 & 0.05 \\
\hline 3 & SB4VS-25 & quenched & T87 & 2 & 2 & 18.00036 & 19.00038 & 3.316733 & 15.633646 & 58.00116 & 95.16857 & 0.083335 & 2.316713 \\
\hline
\end{tabular}


Table F2. PSAL Measurements of the PCT Solutions for the Study Glasses After Appropriate Adjustments (continued)

\begin{tabular}{|c|c|c|c|c|c|c|c|c|c|c|c|c|c|}
\hline Set & Glass ID & $\begin{array}{c}\text { Heat } \\
\text { Treatment }\end{array}$ & Laboratory ID & Block & Seq & Al (ppm) & B (ppm) & $\mathrm{Fe}(\mathrm{ppm})$ & Li (ppm) & Na (ppm) & $\mathrm{Si}(\mathbf{p p m})$ & Th (ppm) & $\mathbf{U}(\mathbf{p p m})$ \\
\hline 3 & EA & & T66 & 2 & 3 & 0.833335 & 605.00121 & 0.833335 & 176.66702 & 1591.66985 & 856.66838 & 0.833335 & 0.833335 \\
\hline 3 & SB4VS-30 & quenched & T84 & 2 & 4 & 15.533644 & \begin{tabular}{|l|}
20.16707 \\
\end{tabular} & 5.733448 & 17.66702 & 46.33426 & \begin{tabular}{|l|l|}
104.50209 \\
\end{tabular} & 0.083335 & \begin{tabular}{|l}
4.83343 \\
\end{tabular} \\
\hline 3 & SB4VS-28 & quenched & T03 & 2 & 5 & 16.016987 & 18.66704 & 3.850077 & 16.50033 & 46.00092 & \begin{tabular}{|c|}
98.83531 \\
\end{tabular} & 0.083335 & \begin{tabular}{|l|}
3.816743 \\
\end{tabular} \\
\hline 3 & SB4VS-25ccc & ccc & T30 & 2 & 6 & 18.3337 & 19.00038 & 3.466736 & 16.233658 & 59.16785 & 98.83531 & 0.083335 & 2.50005 \\
\hline 3 & SB4VS-30ccc & ccc & $\mathrm{T} 24$ & 2 & 7 & 15.633646 & 19.33372 & 5.550111 & 17.50035 & 47.66762 & 106.50213 & 0.083335 & 5.016767 \\
\hline 3 & SB4VS-24ccc & ccc & T57 & 2 & 8 & 18.3337 & 17.66702 & 3.83341 & 15.116969 & 60.83455 & 93.3352 & 0.083335 & 2.233378 \\
\hline 3 & SB4VS-33ccc & ccc & T92 & 2 & 9 & 18.66704 & 16.350327 & 2.066708 & 14.916965 & 39.33412 & 87.83509 & 0.083335 & 2.033374 \\
\hline 3 & Soln Std & & Soln Std & 2 & 10 & 3.79 & 20.6 & 3.62 & 9.64 & 80.6 & 49.8 & 0.05 & 0.05 \\
\hline 3 & SB4VS-32ccc & $\mathrm{ccc}$ & T17 & 2 & 11 & 17.83369 & 21.16709 & 3.516737 & 16.83367 & 72.00144 & 98.16863 & 0.083335 & 2.650053 \\
\hline 3 & SB4VS-24 & quenched & $\mathrm{T} 72$ & 2 & 12 & 18.66704 & 18.83371 & 3.783409 & 15.583645 & 79.83493 & 95.16857 & 0.083335 & 2.350047 \\
\hline 3 & SB4VS-32 & quenched & T04 & 2 & \begin{tabular}{|l|}
13 \\
\end{tabular} & 17.16701 & \begin{tabular}{|l|}
19.33372 \\
\end{tabular} & 4.216751 & 15.900318 & 69.83473 & \begin{tabular}{|c|}
94.83523 \\
\end{tabular} & 0.083335 & \begin{tabular}{|l|}
2.50005 \\
\end{tabular} \\
\hline 3 & SB4VS-28ccc & ccc & T41 & 2 & 14 & 15.700314 & 18.00036 & 4.116749 & 15.800316 & 44.33422 & 97.16861 & 0.083335 & 3.650073 \\
\hline 3 & SB4VS-27ccc & ccc & T02 & 2 & 15 & 17.50035 & 17.00034 & 3.900078 & 14.933632 & 49.33432 & 94.00188 & 0.083335 & 3.116729 \\
\hline 3 & SB4VS-27 & quenched & T49 & 2 & 16 & 18.3337 & 18.16703 & 3.983413 & 16.300326 & 52.33438 & 98.3353 & 0.083335 & 2.800056 \\
\hline 3 & SB4VS-33 & quenched & T38 & 2 & 17 & 19.00038 & 17.16701 & 2.533384 & 16.233658 & 40.16747 & 90.50181 & 0.083335 & 2.133376 \\
\hline 3 & Soln Std & & Soln Std & 2 & 18 & 3.83 & 20.7 & 3.49 & 9.62 & 81.6 & 49.5 & 0.05 & 0.05 \\
\hline 3 & Soln Std & & Soln Std & 3 & 1 & 3.83 & 21.1 & 4 & 9.67 & 81.8 & 49.4 & 0.05 & 0.05 \\
\hline 3 & SB4VS-25ccc & $\mathrm{ccc}$ & T34 & 3 & 2 & 18.50037 & 19.83373 & 4.133416 & 16.550331 & 60.16787 & 99.66866 & 0.083335 & 2.633386 \\
\hline 3 & SB4VS-24ccc & ccc & T64 & 3 & 3 & 19.33372 & 19.00038 & 4.900098 & 15.883651 & 63.50127 & 98.16863 & 0.083335 & 2.583385 \\
\hline 3 & SB4VS-30ccc & $\overline{c c c}$ & T32 & 3 & 4 & 15.450309 & 19.33372 & 6.383461 & 17.33368 & 47.00094 & 105.83545 & 0.083335 & 3.683407 \\
\hline 3 & SB4VS-30 & quenched & T62 & 3 & 5 & 15.900318 & 19.83373 & 6.466796 & 18.16703 & 48.3343 & 107.00214 & 0.083335 & 5.0001 \\
\hline 3 & SB4VS-28 & quenched & T20 & 3 & 6 & 16.183657 & 17.83369 & 5.450109 & 16.133656 & 45.50091 & 95.33524 & 0.083335 & 3.100062 \\
\hline 3 & SB4VS-33 & quenched & $\mathrm{T} 40$ & 3 & 7 & 19.00038 & \begin{tabular}{|l|}
17.16701 \\
\end{tabular} & 3.200064 & 16.266992 & 39.83413 & 89.33512 & 0.083335 & 2.133376 \\
\hline 3 & SB4VS-27 & quenched & $\mathrm{T} 28$ & 3 & 8 & 18.66704 & 18.50037 & 4.450089 & 16.650333 & 54.00108 & 99.33532 & 0.083335 & 3.00006 \\
\hline 3 & $\overline{E A}$ & & T12 & 3 & 9 & 0.833335 & 596.66786 & 0.833335 & 173.33368 & 1593.33652 & 836.66834 & 0.833335 & 0.833335 \\
\hline 3 & Soln Std & & Soln Std & 3 & 10 & 3.85 & 20.5 & 3.83 & 9.67 & 83.2 & 48.9 & 0.05 & 0.05 \\
\hline 3 & SB4VS-28ccc & ccc & T46 & 3 & 11 & 16.283659 & 18.66704 & 4.483423 & 16.200324 & 47.83429 & 98.50197 & 0.083335 & 4.700094 \\
\hline 3 & SB4VS-24 & quenched & T39 & 3 & 12 & 19.00038 & 18.83371 & 4.800096 & 15.816983 & 66.33466 & 95.50191 & 0.083335 & 2.400048 \\
\hline 3 & SB4VS-32ccc & ccc & $\mathrm{T} 23$ & 3 & 13 & 17.83369 & 19.83373 & 4.16675 & 16.633666 & 71.33476 & 98.3353 & 0.083335 & 2.566718 \\
\hline 3 & SB4VS-27ccc & $\mathrm{ccc}$ & T42 & 3 & 14 & 18.3337 & 17.33368 & 4.016747 & 15.600312 & 51.6677 & 95.16857 & 0.083335 & 2.900058 \\
\hline 3 & SB4VS-32 & quenched & $\mathrm{T} 22$ & 3 & 15 & 17.66702 & 19.66706 & 4.016747 & 16.566998 & 73.00146 & 96.6686 & 0.083335 & 2.600052 \\
\hline
\end{tabular}


Table F2. PSAL Measurements of the PCT Solutions for the Study Glasses After Appropriate Adjustments (continued)

\begin{tabular}{|c|c|c|c|c|c|c|c|c|c|c|c|c|c|}
\hline Set & Glass ID & $\begin{array}{c}\text { Heat } \\
\text { Treatment }\end{array}$ & Laboratory ID & Block & Seq & $\mathbf{A l}(\mathbf{p p m})$ & B (ppm) & $\mathrm{Fe}(\mathrm{ppm})$ & Li (ppm) & $\mathrm{Na}(\mathrm{ppm})$ & Si (ppm) & Th (ppm) & $\mathbf{U}(\mathbf{p p m})$ \\
\hline 3 & SB4VS-33ccc & $\mathrm{ccc}$ & T53 & 3 & 16 & 19.50039 & 16.466996 & 2.800056 & 15.300306 & 42.66752 & 88.66844 & 0.083335 & 2.216711 \\
\hline 3 & SB4VS-25 & quenched & T59 & 3 & 17 & 17.83369 & 17.83369 & 3.866744 & 15.583645 & 59.50119 & 93.83521 & 0.083335 & 2.650053 \\
\hline 3 & Soln Std & & Soln Std & 3 & 18 & 3.85 & 19.9 & 3.69 & 9.52 & 84.2 & 48.1 & 0.05 & 0.05 \\
\hline 3 & Soln Std & & Soln Std & 4 & 1 & 3.79 & 20.4 & 3.74 & 9.77 & 81.1 & 50 & 0.05 & 0.05 \\
\hline 3 & SB4VS-23ccc & ccc & T05 & 4 & 2 & 19.50039 & 18.50037 & 3.516737 & 15.916985 & 70.16807 & 94.00188 & 0.083335 & 2.316713 \\
\hline 3 & SB4VS-34ccc & $\operatorname{ccc}$ & $\mathrm{T} 21$ & 4 & 3 & 20.66708 & 18.00036 & 4.883431 & 17.00034 & 39.50079 & 98.3353 & 0.083335 & 3.300066 \\
\hline 3 & SB4VS-35 & quenched & T11 & 4 & 4 & 15.33364 & 20.33374 & 5.916785 & 18.3337 & 54.16775 & 107.83549 & 0.083335 & 4.283419 \\
\hline 3 & SB4VS-34 & quenched & T61 & 4 & 5 & 20.66708 & 18.00036 & 5.533444 & 17.66702 & 37.50075 & 98.66864 & 0.083335 & 3.116729 \\
\hline 3 & SB4VS-31ccc & ccc & T55 & 4 & 6 & 13.850277 & 18.3337 & 4.583425 & 17.50035 & 37.00074 & 103.00206 & 0.083335 & 4.950099 \\
\hline 3 & SB4VS-29 & quenched & T18 & 4 & 7 & 17.00034 & 18.16703 & 5.300106 & 17.16701 & 49.00098 & 100.66868 & 0.083335 & 3.366734 \\
\hline 3 & SB4VS-26ccc & ccc & T29 & 4 & 8 & 17.00034 & 18.00036 & 3.283399 & 16.133656 & 55.83445 & 96.16859 & 0.083335 & 2.350047 \\
\hline 3 & SB4VS-22ccc & $\operatorname{ccc}$ & T35 & 4 & 9 & 24.00048 & 16.283659 & 4.300086 & 14.50029 & 58.3345 & 87.50175 & 0.083335 & 2.733388 \\
\hline 3 & Soln Std & & Soln Std & 4 & 10 & 3.9 & 19.9 & 3.67 & 9.74 & 83.1 & 48.8 & 0.05 & 0.05 \\
\hline 3 & SB4VS-26 & quenched & $\mathrm{T} 85$ & 4 & 11 & 17.50035 & 18.83371 & 3.550071 & 16.116989 & 57.50115 & 93.66854 & 0.083335 & 2.750055 \\
\hline 3 & SB4VS-23 & quenched & T47 & 4 & 12 & 19.33372 & 17.83369 & 3.016727 & 15.300306 & 66.668 & 89.66846 & 0.083335 & 2.233378 \\
\hline 3 & SB4VS-22 & quenched & $\mathrm{T} 15$ & 4 & 13 & 23.66714 & 15.866984 & 3.316733 & 14.16695 & 58.00116 & 83.83501 & 0.083335 & 2.316713 \\
\hline 3 & SB4VS-31 & quenched & T65 & 4 & 14 & 13.783609 & 18.16703 & 4.800096 & 17.83369 & 35.83405 & 100.83535 & 0.083335 & 5.066768 \\
\hline 3 & SB4VS-29ccc & ccc & $\mathrm{T} 13$ & 4 & 15 & 16.83367 & 17.83369 & 4.983433 & 16.667 & 49.66766 & 99.33532 & 0.083335 & 3.16673 \\
\hline 3 & SB4VS-35ccc & $\overline{\operatorname{ccc}}$ & $\mathrm{T} 70$ & 4 & 16 & 14.916965 & 19.50039 & 5.433442 & 17.83369 & 54.16775 & 105.0021 & 0.083335 & 4.050081 \\
\hline 3 & ARM-1 & & T91 & 4 & 17 & 4.700094 & 18.3337 & 0.083335 & 14.033614 & 38.00076 & 60.66788 & 0.083335 & 0.083335 \\
\hline 3 & Soln Std & & Soln Std & 4 & 18 & 4.01 & 20 & 3.61 & 9.75 & 84.2 & 48.4 & 0.05 & 0.05 \\
\hline 3 & Soln Std & & Soln Std & 5 & 1 & 4.01 & 21 & 3.69 & 9.79 & 82.2 & 50 & 0.05 & 0.05 \\
\hline 3 & SB4VS-31 & quenched & T67 & 5 & 2 & 13.983613 & 19.33372 & 5.050101 & 18.50037 & 35.50071 & 111.00222 & 0.083335 & 5.383441 \\
\hline 3 & SB4VS-29ccc & ccc & T79 & 5 & 3 & 17.00034 & 18.83371 & 5.133436 & 16.83367 & 48.83431 & 103.66874 & 0.083335 & 3.516737 \\
\hline 3 & SB4VS-22ccc & ccc & T36 & 5 & 4 & 24.50049 & 17.16701 & 3.683407 & 15.083635 & 59.16785 & 90.50181 & 0.083335 & 2.850057 \\
\hline 3 & SB4VS-26ccc & $\overline{c c c}$ & T07 & 5 & 5 & 17.33368 & 18.50037 & 3.416735 & 16.150323 & 55.33444 & 98.83531 & 0.083335 & 2.800056 \\
\hline 3 & SB4VS-31ccc & ccc & T60 & 5 & 6 & 14.016947 & 19.00038 & 4.616759 & 17.66702 & 36.83407 & 105.66878 & 0.083335 & 5.150103 \\
\hline 3 & SB4VS-22 & quenched & T69 & 5 & 7 & 23.83381 & 16.83367 & 3.433402 & 14.483623 & 57.83449 & 88.3351 & 0.083335 & 2.766722 \\
\hline 3 & SB4VS-29 & quenched & T63 & 5 & 8 & 17.00034 & 18.83371 & 5.633446 & 17.33368 & 48.50097 & 102.33538 & 0.083335 & 3.533404 \\
\hline 3 & SB4VS-35ccc & ccc & T43 & 5 & 9 & 14.650293 & 19.16705 & 5.600112 & 17.00034 & 51.33436 & 103.3354 & 0.083335 & 4.450089 \\
\hline
\end{tabular}


Table F2. PSAL Measurements of the PCT Solutions for the Study Glasses After Appropriate Adjustments (continued)

\begin{tabular}{|c|c|c|c|c|c|c|c|c|c|c|c|c|c|}
\hline Set & Glass ID & $\begin{array}{c}\text { Heat } \\
\text { Treatment }\end{array}$ & Laboratory ID & Block & Seq & Al (ppm) & B (ppm) & $\mathrm{Fe}(\mathrm{ppm})$ & Li (ppm) & Na (ppm) & $\mathrm{Si}(\mathrm{ppm})$ & Th (ppm) & $\mathbf{U}$ (ppm) \\
\hline 3 & Soln Std & & Soln Std & 5 & 10 & 4.04 & 20.7 & 3.82 & 9.84 & 82.5 & 50.7 & 0.05 & 0.05 \\
\hline 3 & SB4VS-35 & quenched & $\mathrm{T} 27$ & 5 & 11 & 15.633646 & 21.50043 & 6.083455 & 18.50037 & 54.66776 & 109.83553 & 0.083335 & 4.83343 \\
\hline 3 & SB4VS-23 & quenched & T08 & 5 & 12 & 19.50039 & 18.3337 & 4.283419 & 14.983633 & 64.16795 & 94.00188 & 0.083335 & 3.083395 \\
\hline 3 & ARM-1 & & $\mathrm{T} 83$ & 5 & 13 & 4.933432 & 18.66704 & 0.083335 & 13.950279 & 37.00074 & 62.00124 & 0.083335 & 0.083335 \\
\hline 3 & SB4VS-34ccc & $\mathrm{ccc}$ & T06 & 5 & 14 & 21.00042 & 18.50037 & 5.200104 & 17.16701 & 39.33412 & 101.00202 & 0.083335 & 3.766742 \\
\hline 3 & SB4VS-26 & quenched & T19 & 5 & 15 & 17.50035 & 19.00038 & 3.633406 & 16.667 & 57.50115 & 99.50199 & 0.083335 & 2.783389 \\
\hline 3 & SB4VS-23ccc & $\mathrm{ccc}$ & $\mathrm{T} 75$ & 5 & 16 & 19.66706 & 18.66704 & 3.700074 & 15.966986 & 65.0013 & 96.33526 & 0.083335 & 2.50005 \\
\hline 3 & SB4VS-34 & quenched & $\mathrm{T} 25$ & 5 & 17 & 22.00044 & 19.66706 & 5.783449 & 18.83371 & 39.83413 & 107.66882 & 0.083335 & 3.550071 \\
\hline 3 & Soln Std & & Soln Std & 5 & 18 & 3.99 & 20.8 & 3.96 & 10 & 83.4 & 53.1 & 0.05 & 0.05 \\
\hline 3 & Soln Std & & Soln Std & 6 & 1 & 3.84 & 20.9 & 3.84 & 9.7 & 83 & 49.8 & 0.05 & 0.05 \\
\hline 3 & SB4VS-22 & quenched & T50 & 6 & 2 & 23.3338 & 16.466996 & 4.233418 & 13.700274 & 56.83447 & 85.83505 & 0.083335 & 2.883391 \\
\hline 3 & SB4VS-31 & quenched & T56 & 6 & 3 & 13.516937 & 18.00036 & 5.416775 & 17.00034 & 34.83403 & 100.33534 & 0.083335 & 4.16675 \\
\hline 3 & SB4VS-22ccc & $\mathrm{ccc}$ & T44 & 6 & 4 & 23.83381 & 16.83367 & 3.900078 & 14.633626 & 58.16783 & 88.50177 & 0.083335 & 2.66672 \\
\hline 3 & ARM-1 & & $\mathrm{T} 74$ & 6 & 5 & 4.550091 & 18.16703 & 0.083335 & 13.50027 & 35.83405 & 61.6679 & 0.083335 & 0.083335 \\
\hline 3 & SB4VS-35 & quenched & T51 & 6 & 6 & 14.983633 & 20.0004 & 5.900118 & 17.83369 & 53.16773 & 105.50211 & 0.083335 & 4.450089 \\
\hline 3 & SB4VS-29 & quenched & T58 & 6 & 7 & 17.00034 & 18.66704 & 5.800116 & 17.16701 & 49.33432 & 101.16869 & 0.083335 & 3.633406 \\
\hline 3 & SB4VS-34ccc & $\mathrm{ccc}$ & T33 & 6 & 8 & 20.66708 & 18.3337 & 5.600112 & 17.00034 & 39.16745 & 100.33534 & 0.083335 & 3.3334 \\
\hline 3 & blank & & T90 & 6 & 9 & 0.083335 & 0.083335 & 0.083335 & 0.83335 & 0.083335 & 0.083335 & 0.083335 & 0.083335 \\
\hline 3 & Soln Std & & Soln Std & 6 & 10 & 3.83 & 20.3 & 3.87 & 9.62 & 82.1 & 50.1 & 0.05 & 0.05 \\
\hline 3 & SB4VS-34 & quenched & $\mathrm{T} 80$ & 6 & 11 & 21.00042 & 19.50039 & 5.633446 & 18.00036 & 37.66742 & 103.00206 & 0.083335 & 3.533404 \\
\hline 3 & SB4VS-23ccc & $\mathrm{ccc}$ & $\mathrm{T} 10$ & 6 & 12 & 19.33372 & 18.50037 & 3.650073 & 15.633646 & 64.83463 & 94.16855 & 0.083335 & 2.350047 \\
\hline 3 & SB4VS-29ccc & $\mathrm{ccc}$ & $\mathrm{T} 73$ & 6 & 13 & 17.00034 & 18.50037 & 5.300106 & 16.616999 & 48.66764 & 101.50203 & 0.083335 & 3.433402 \\
\hline 3 & SB4VS-23 & quenched & T54 & 6 & 14 & 19.50039 & 18.50037 & 3.433402 & 15.516977 & 66.16799 & 94.83523 & 0.083335 & 2.366714 \\
\hline 3 & SB4VS-26ccc & $\mathrm{ccc}$ & T45 & 6 & 15 & 17.00034 & 18.3337 & 3.433402 & 15.850317 & 55.83445 & 97.00194 & 0.083335 & 2.916725 \\
\hline 3 & SB4VS-31ccc & $\mathrm{ccc}$ & T78 & 6 & 16 & 14.066948 & 18.83371 & 4.766762 & 17.50035 & 38.3341 & 104.83543 & 0.083335 & 4.700094 \\
\hline 3 & SB4VS-26 & quenched & T86 & 6 & 17 & 17.00034 & 18.3337 & 4.083415 & 16.050321 & 56.00112 & 96.50193 & 0.083335 & 2.783389 \\
\hline 3 & SB4VS-35ccc & $\mathrm{ccc}$ & T68 & 6 & 18 & 15.516977 & 20.16707 & 5.916785 & 17.83369 & 54.66776 & 110.83555 & 0.083335 & \begin{tabular}{|l|}
4.750095 \\
\end{tabular} \\
\hline 3 & Soln Std & & Soln Std & 6 & 19 & 3.81 & 20.9 & 4.16 & 9.87 & 84 & 52.8 & 0.05 & 0.05 \\
\hline
\end{tabular}


Exhibit F1. Laboratory PCT Measurements in Analytical Sequence for Study Glasses, EA, ARM, Blanks, and Solution Standards
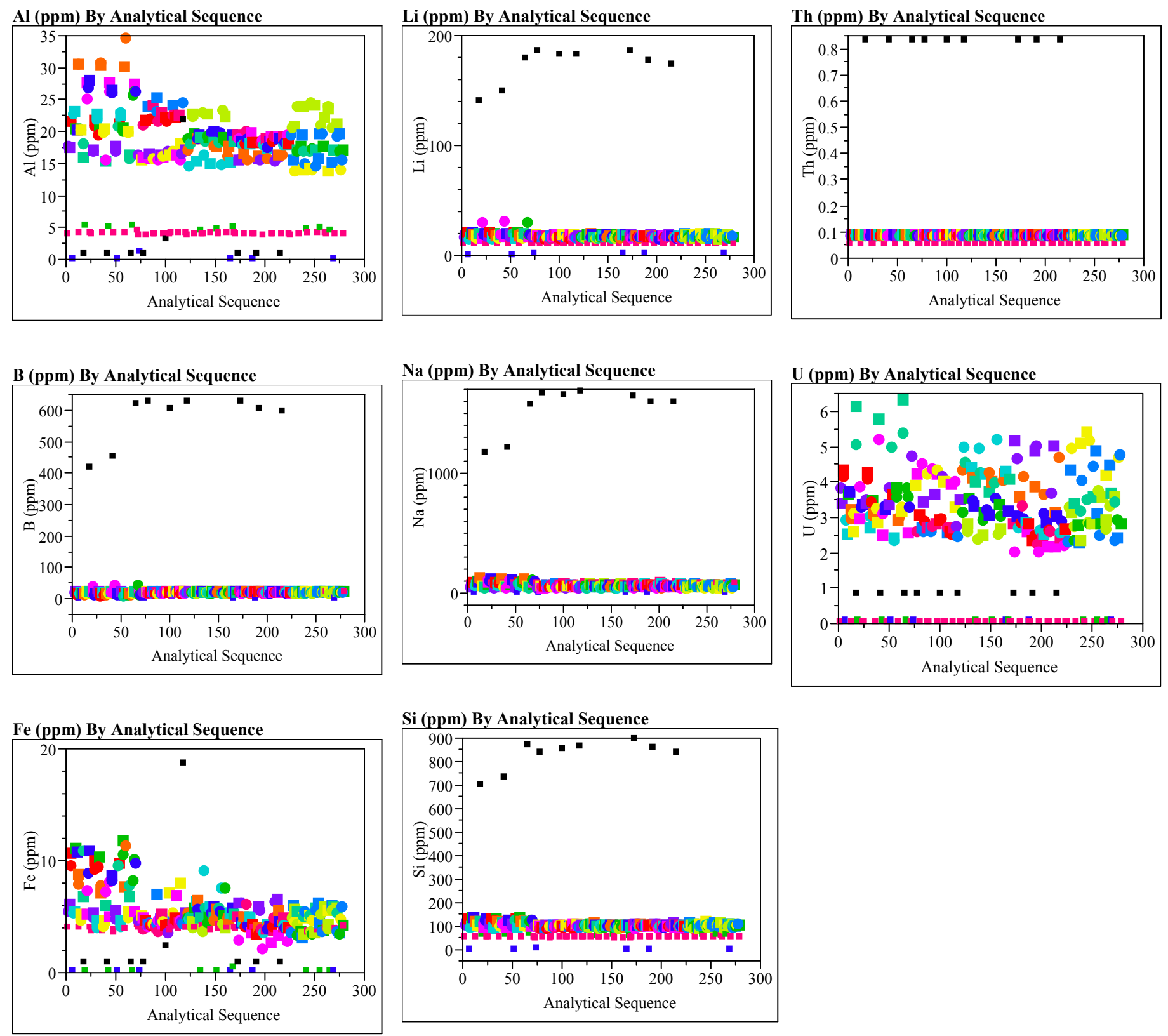
Exhibit F2. Laboratory PCT Measurements in Analytical Sequence for Study Glasses

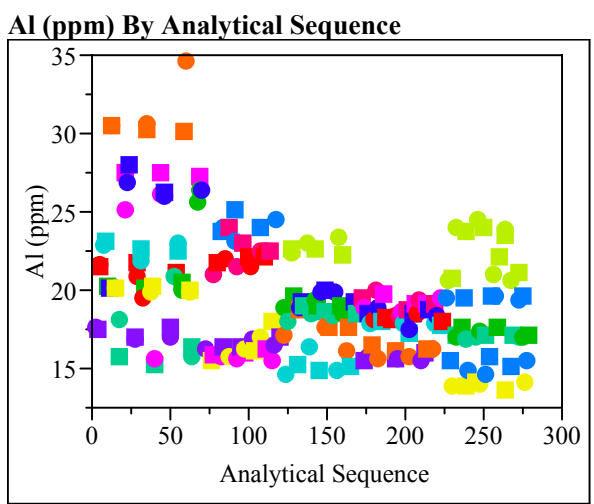

Li (ppm) By Analytical Sequence

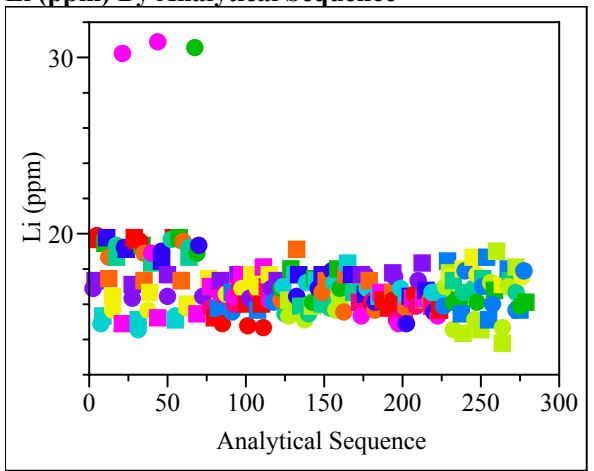

B (ppm) By Analytical Sequence

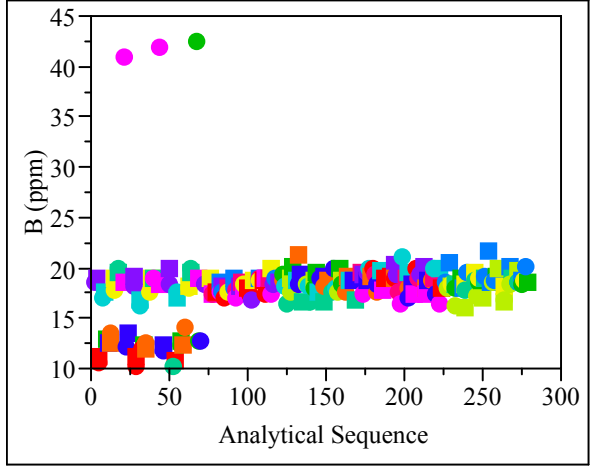

Fe (ppm) By Analytical Sequence

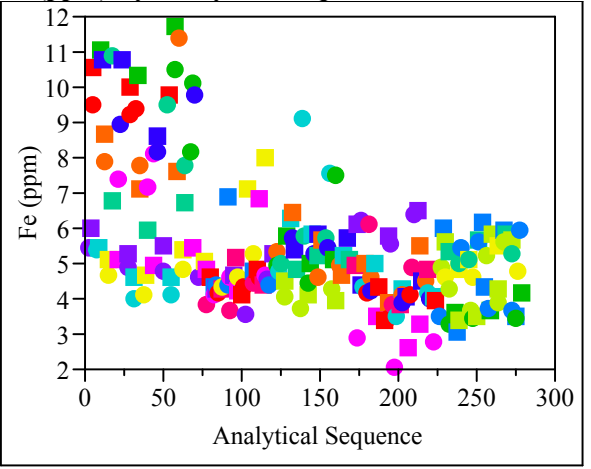

Na (ppm) By Analytical Sequence

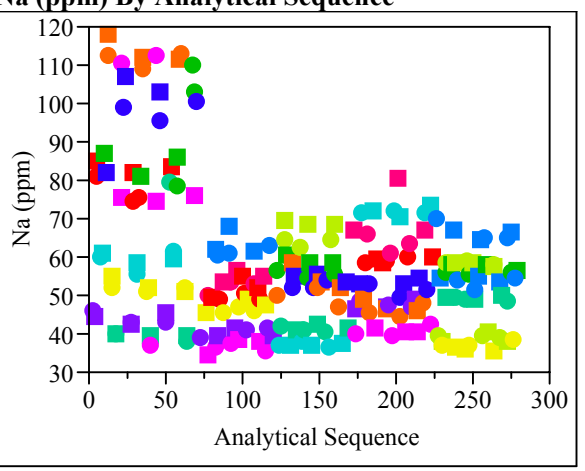

Si (ppm) By Analytical Sequence

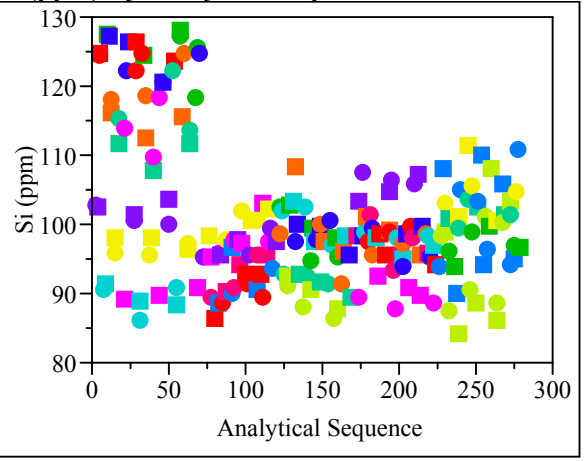

Th (ppm) By Analytical Sequence

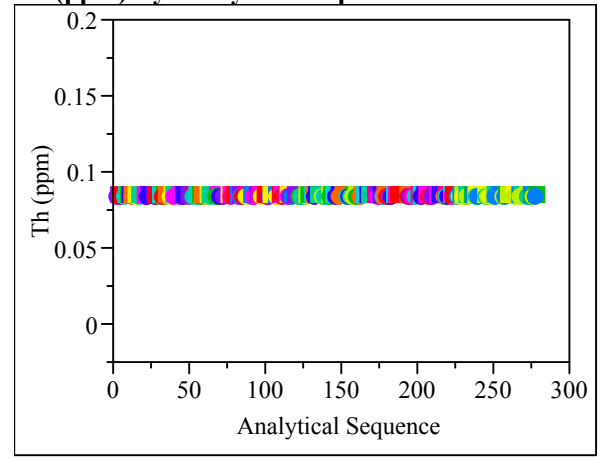

U (ppm) By Analytical Sequence

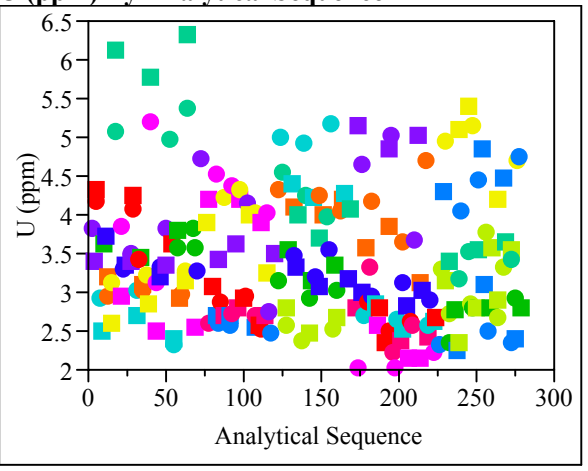




\section{Exhibit F3. Measurements of the Multi-Element Solution Standard by Set and ICP Block}

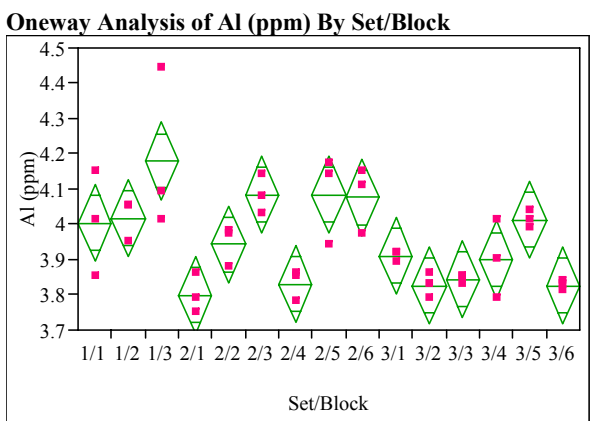

Oneway Anova

Summary of Fit

Rsquare

$\begin{array}{ll} & 0.698265 \\ \text { Adj Rsquare } & 0.557455\end{array}$

Root Mean Square Error $\quad 0.092532$

Mean of Response 3.955778

Observations (or Sum Wgts) $\quad 45$

$\begin{array}{lrrrrr}\begin{array}{l}\text { Analysis of Variance } \\ \text { Source }\end{array} & \text { DF } & \begin{array}{r}\text { Sum of } \\ \text { Squares }\end{array} & \begin{array}{r}\text { Mean } \\ \text { Square }\end{array} & \begin{array}{r}\text { Ratio } \\ \text { Prob > }\end{array} \\ \text { Set/Block } & 14 & 0.59443111 & 0.042459 & 4.9589 & 0.0001 \\ \text { Error } & 30 & 0.25686667 & 0.008562 & & \\ \text { C. Total } & 44 & 0.85129778 & & & \end{array}$

C. Total $\quad 44 \quad 0.85129778$

Means for Oneway Anova

\begin{tabular}{lrrrrr}
\multicolumn{1}{l}{ Level } & Number & Mean & Std Error & Lower $95 \%$ & Upper 95\% \\
$1 / 1$ & 3 & 4.00333 & 0.05342 & 3.8942 & 4.1124 \\
$1 / 2$ & 3 & 4.01667 & 0.05342 & 3.9076 & 4.1258 \\
$1 / 3$ & 3 & 4.18000 & 0.05342 & 4.0709 & 4.2891 \\
$2 / 1$ & 3 & 3.80000 & 0.05342 & 3.6909 & 3.9091 \\
$2 / 2$ & 3 & 3.94333 & 0.05342 & 3.8342 & 4.0524 \\
$2 / 3$ & 3 & 4.08333 & 0.05342 & 3.9742 & 4.1924 \\
$2 / 4$ & 3 & 3.83000 & 0.05342 & 3.7209 & 3.9391 \\
$2 / 5$ & 3 & 4.08333 & 0.05342 & 3.9742 & 4.1924 \\
$2 / 6$ & 3 & 4.07667 & 0.05342 & 3.9676 & 4.1858 \\
$3 / 1$ & 3 & 3.91000 & 0.05342 & 3.8009 & 4.0191 \\
$3 / 2$ & 3 & 3.82667 & 0.05342 & 3.7176 & 3.9358 \\
$3 / 3$ & 3 & 3.84333 & 0.05342 & 3.7342 & 3.9524 \\
$3 / 4$ & 3 & 3.90000 & 0.05342 & 3.7909 & 4.0091 \\
$3 / 5$ & 3 & 4.01333 & 0.05342 & 3.9042 & 4.1224 \\
$3 / 6$ & 3 & 3.82667 & 0.05342 & 3.7176 & 3.9358
\end{tabular}

Std Error uses a pooled estimate of error variance

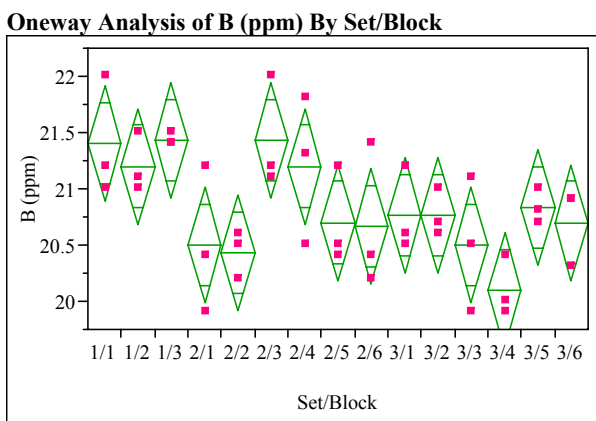

Oneway Anova

Summary of Fit

$\begin{array}{lr}\text { Rsquare } & 0.546574 \\ \text { Adj Rsquare } & 0.334976 \\ \text { Root Mean Square Error } & 0.436908 \\ \text { Mean of Response } & 20.84222 \\ \text { Observations (or Sum Wgts) } & 45\end{array}$

\section{Analysis of Variance}

$\begin{array}{lrrrrr}\text { Source } & \text { DF } & \begin{array}{r}\text { Sum of } \\ \text { Squares }\end{array} & \begin{array}{r}\text { Mean } \\ \text { Square }\end{array} & \begin{array}{r}\text { Fatio } \\ \text { Prob }>\end{array} \\ \text { Set/Block } & 14 & 6.903111 & 0.493079 & 2.5831 & 0.0143 \\ \text { Error } & 30 & 5.726667 & 0.190889 & & \\ \text { C. Total } & 44 & 12.629778 & & & \end{array}$

C. Total 44

5.726677

\begin{tabular}{|c|c|c|c|c|c|}
\hline Level & Number & Mean & Std Error & Lower 95\% & Upper $95 \%$ \\
\hline $1 / 1$ & & 21.4000 & 0.25225 & 20.885 & 21.915 \\
\hline $1 / 2$ & 3 & 21.2000 & 0.25225 & 20.685 & 21.715 \\
\hline$/ 3$ & 3 & 21.4333 & 0.25225 & 20.918 & 48 \\
\hline$/ 1$ & 3 & 20.5000 & 0.25225 & 19.985 & 21.015 \\
\hline $2 / 2$ & 3 & 20.4333 & 0.25225 & 9.918 & \\
\hline $2 / 3$ & 3 & 21.4333 & 0.25225 & 20.918 & 48 \\
\hline 2/4 & 3 & 21.2000 & 0.25225 & 20.685 & 21.715 \\
\hline $2 / 5$ & 3 & 20.7000 & 0.25225 & 20.185 & 21.215 \\
\hline $2 / 6$ & f & 20.6667 & 0.25225 & 52 & 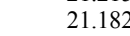 \\
\hline $3 / 1$ & 3 & 20.7667 & 0.25225 & 20.252 & 21.282 \\
\hline 12 & & 20.7667 & 0.25225 & 20.252 & 18 \\
\hline $3 / 3$ & 3 & 20.5000 & 0.25225 & 19.985 & \\
\hline $3 / 4$ & & 20.1000 & 0.25225 & 19.585 & \\
\hline $3 / 5$ & 3 & 20.8333 & 0.25225 & 20.318 & 21.3 \\
\hline & & & & & \\
\hline
\end{tabular}

Std Error uses a pooled estimate of error variance

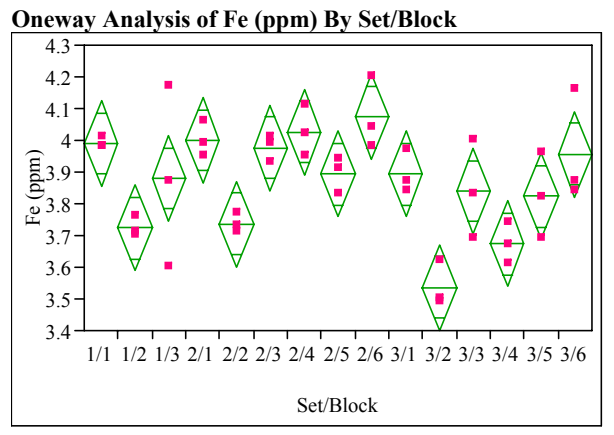

\section{Oneway Anova}

Summary of Fit

$\begin{array}{lr}\text { Rsquare } & 0.700229 \\ \text { Adj Rsquare } & 0.560336 \\ \text { Root Mean Square Error } & 0.115085 \\ \text { Mean of Response } & 3.868222 \\ \text { Observations (or Sum Wgts) } & 45\end{array}$

Analysis of Variance

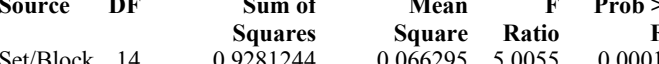
$\begin{array}{llllll}\text { Set/Block } & 14 & 0.9281244 & 0.066295 & 5.0055 & 0.000\end{array}$ $\begin{array}{lll}\text { Error } & 30 & 0.3973333 \\ \text { C. Total } & 44 & 1.3254578\end{array}$

Means for Oneway Anova

Level Number Mean Std Error Lower 95\% Upper 95\% $\begin{array}{llllll}1 / 1 & 3 & 3.99000 & 0.06644 & 3.8543 & 4.1257 \\ 1 / 2 & 3 & 3.72333 & 0.06644 & 3.5876 & 3.8590\end{array}$

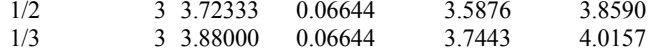
$\begin{array}{llllll}2 / 1 & 3 & 4.00000 & 0.06644 & 3.8643 & 4.1357\end{array}$

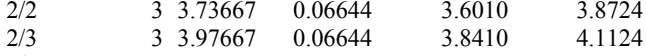

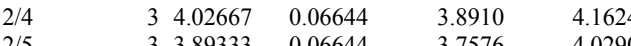
$\begin{array}{llllll}2 / 5 & 3 & 3.89333 & 0.06644 & 3.7576 & 4.0290 \\ 2 / 6 & 3 & 4.07333 & 0.06644 & 3.9376 & 4.290\end{array}$ $\begin{array}{llllll}3 / 1 & 3 & 3.89333 & 0.06644 & 3.7576 & 4.0290\end{array}$ $\begin{array}{llllll}3 / 2 & 3 & 3.53667 & 0.06644 & 3.4010 & 3.6724 \\ 3 / 3 & 3 & 3.84000 & 0.06644 & 3.7043 & 3.9757 \\ 3 / 4 & 3 & 3.67333 & 0.06644 & 3.5376 & 3.8090\end{array}$ $\begin{array}{llllll}3 / 4 & 3 & 3.67333 & 0.06644 & 3.5376 & 3.8090\end{array}$

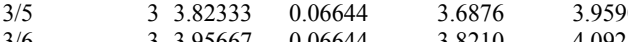
Std Error uses a pooled estimate of error variance 
Exhibit F3. Measurements of the Multi-Element Solution Standard by Set and ICP Block (continued)

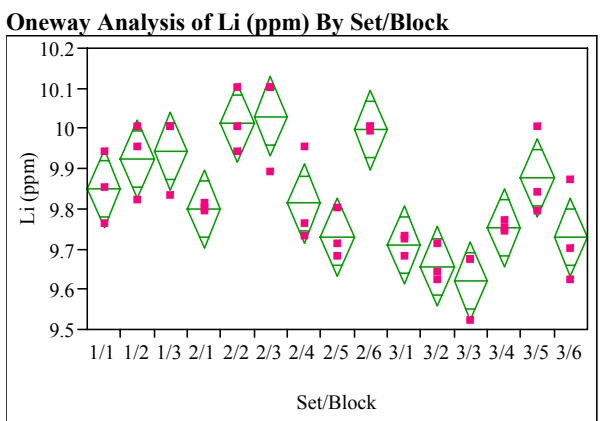

Oneway Anova

Summary of Fit

Rsquare

Adj Rsquare $\quad 0.670336$

0.083613

9.829778

Analysis of Variance

$\begin{array}{lcrrrr}\text { Source } & \text { DF } & \begin{array}{r}\text { Sum of } \\ \text { Squares }\end{array} & \begin{array}{r}\text { Mean } \\ \text { Square }\end{array} & \begin{array}{r}\text { Fatio } \\ \text { Prob }>\end{array} \\ \text { Set/Block } & 14 & 0.72336444 & 0.051669 & 7.3907 & <.0001 \\ \text { Error } & 30 & 0.20973333 & 0.006991 & & \\ \text { C. Total } & 44 & 0.93309778 & & & \end{array}$

C. Total $\quad 44 \quad 0.93309778$

Means for Oneway Anova

Level Number Mean Std Error Lower 95\% Upper 95\%

$\begin{array}{lrrrrr}1 / 1 & 3 & 9.8500 & 0.04827 & 9.7514 & 9.949 \\ 1 / 2 & 3 & 9.9233 & 0.04827 & 9.8247 & 10.022 \\ 1 / 3 & 3 & 9.9433 & 0.04827 & 9.8447 & 10.042 \\ 2 / 1 & 3 & 9.8000 & 0.04827 & 9.7014 & 9.899 \\ 2 / 2 & 3 & 10.0133 & 0.04827 & 9.9147 & 10.112 \\ 2 / 3 & 3 & 10.0300 & 0.04827 & 9.9314 & 10.129 \\ 2 / 4 & 3 & 9.8133 & 0.04827 & 9.7147 & 9.912 \\ 2 / 5 & 3 & 9.7300 & 0.04827 & 9.6314 & 9.829 \\ 2 / 6 & 3 & 9.9967 & 0.04827 & 9.8981 & 10.095 \\ 3 / 1 & 3 & 9.7100 & 0.04827 & 9.6114 & 9.809 \\ 3 / 2 & 3 & 9.6567 & 0.04827 & 9.5581 & 9.755 \\ 3 / 3 & 3 & 9.6200 & 0.04827 & 9.5214 & 9.719 \\ 3 / 4 & 3 & 9.7533 & 0.04827 & 9.6547 & 9.852 \\ 3 / 5 & 3 & 9.8767 & 0.04827 & 9.7781 & 9.975 \\ 3 / 6 & 3 & 9.7300 & 0.04827 & 9.6314 & 9.829\end{array}$

Std Error uses a pooled estimate of error variance

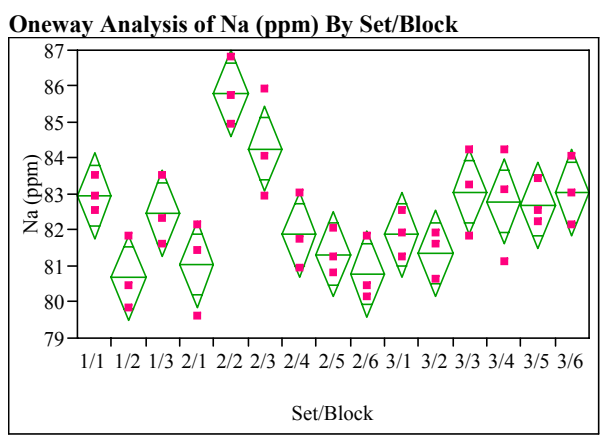

\section{Oneway Anova}

Summary of Fit

$\begin{array}{lr}\text { Rsquare } & 0.721185 \\ \text { Adj Rsquare } & 0.591071 \\ \text { Root Mean Square Error } & 1.017513 \\ \text { Mean of Response } & 82.4 \\ \text { Observations (or Sum Wgts) } & 45\end{array}$

$\begin{array}{lrrrrr}\begin{array}{l}\text { Analysis of Variance } \\ \text { Source }\end{array} & \text { DF } & \begin{array}{r}\text { Sum of } \\ \text { Squares }\end{array} & \begin{array}{r}\text { Mean } \\ \text { Square }\end{array} & \begin{array}{r}\text { Fatio } \\ \text { Prob > }\end{array} \\ & & 80.34000 & 5.73857 & 5.5427 & <.0001 \\ \text { Set/Block } & 14 & 31.06000 & 1.03533 & & \\ \text { Error } & 30 & 111.40000 & & & \\ \text { C. Total } & 44 & & & & \end{array}$

\section{Means for Oneway Anova}

Level Number Mean Std Error Lower 95\% Upper 95\%

$\begin{array}{rrrrrr}1 / 1 & 3 & 82.9667 & 0.58746 & 81.767 & 84.166\end{array}$

$\begin{array}{llllll}1 / 2 & 3 & 80.6667 & 0.58746 & 79.467 & 81.866 \\ 1 / 3 & 3 & 82.467 & 0.58746 & 81.267 & 83.666\end{array}$

$\begin{array}{llllll}1 / 3 & 3 & 82.4667 & 0.58746 & 81.267 & 83.666 \\ 2 / 1 & 3 & 81.0333 & 0.58746 & 79.834 & 82.233\end{array}$

$\begin{array}{llllrr}1 / 3 & 3 & 81.0333 & 0.58746 & 79.834 & 82.233 \\ 2 / 2 & 3 & 85.8000 & 0.58746 & 84.600 & 87.000\end{array}$

$\begin{array}{llllll}2 / 3 & 3 & 84.2667 & 0.58746 & 83.067 & 85.466\end{array}$

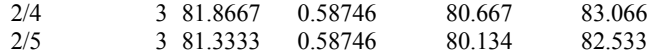

$\begin{array}{llllll}2 / 5 & 3 & 81.3333 & 0.58746 & 80.134 & 82.533 \\ 2 / 6 & 3 & 80.7667 & 0.58746 & 79.567 & 81.966\end{array}$

$\begin{array}{llllll}3 / 1 & 3 & 81.8667 & 0.58746 & 80.667 & 83.066\end{array}$

$\begin{array}{llllll}3 / 2 & 3 & 81.3667 & 0.58746 & 80.167 & 82.566\end{array}$

$\begin{array}{llllll}3 / 3 & 3 & 83.0667 & 0.58746 & 81.867 & 84.266 \\ 3 / 4 & 3 & 82.8000 & 0.58746 & 81.600 & 84.000\end{array}$

$\begin{array}{llllll}3 / 5 & 3 & 82.7000 & 0.58746 & 81.500 & 83.900 \\ 3 / 6 & 3 & 83.0333 & 0.58746 & 81.834 & 84.233\end{array}$

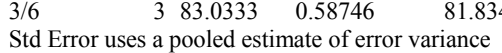

Oneway Analysis of Si (ppm) By Set/Block

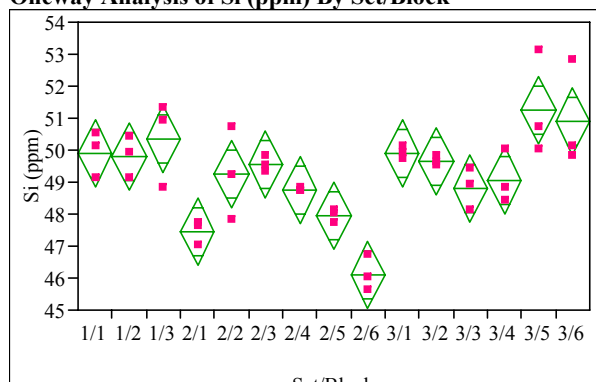

Set/Block

\section{Oneway Anova}

Summary of Fit

Rsquare

Adj Rsquare $\quad 0.75637$

Root Mean Square Error $\quad 0.893682$

$\begin{array}{lr}\text { Mean of Response } & 49.23778 \\ \text { Observations (or Sum Wgts) } & 45\end{array}$

Analysis of Variance

Source DF

$\begin{array}{lrrrrr}\text { Source } & \text { DF } & \begin{array}{r}\text { Sum of } \\ \text { Squares }\end{array} & \begin{array}{r}\text { Mean } \\ \text { Square }\end{array} & \begin{array}{r}\text { Ratio } \\ \text { Pqrob }>\end{array} \\ \text { Set/Block } & 14 & 74.385778 & 5.31327 & 6.6527 & <.0001\end{array}$

$\begin{array}{lll}\text { Crror } & 30 & 23.960000 \\ \text { C. Total } & 44 & 98.345778\end{array}$

$5.31327 \quad 6.6527<.0001$
0.7867

Means for Oneway Anova

Level Number Mean Std Error Lower 95\% Upper 95\%

$\begin{array}{llllrr}1 / 1 & 3 & 49.9000 & 0.51597 & 48.846 & 50.954\end{array}$

$\begin{array}{llllll}1 / 2 & 3 & 49.8000 & 0.51597 & 48.746 & 50.854 \\ 1 / 3 & 3 & 50.3333 & 0.51597 & 49.280 & 51.387\end{array}$

$\begin{array}{llllll}1 / 3 & 3 & 50.3333 & 0.51597 & 49.280 & 51.387 \\ 2 / 1 & 3 & 47.4333 & 0.51597 & 46.380 & 48.487\end{array}$

$\begin{array}{llllll}2 / 2 & 3 & 49.2333 & 0.51597 & 48.180 & 50.287 \\ 2 / 3 & 3 & 49.5333 & 0.51597 & 48.480 & 50.587\end{array}$

$\begin{array}{llllll}2 / 3 & 3 & 49.5333 & 0.51597 & 48.480 & 50.587 \\ 2 / 4 & 3 & 48.7333 & 0.51597 & 47.680 & 49.787\end{array}$

$\begin{array}{llllll}2 / 5 & 3 & 47.9333 & 0.51597 & 46.880 & 48.987\end{array}$

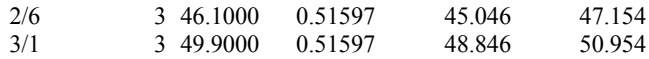

$\begin{array}{llllll}3 / 2 & 3 & 49.6333 & 0.51597 & 48.580 & 50.687 \\ 3 / 3 & 3 & 48.8000 & 0.51597 & 47.746 & 49.854\end{array}$

$\begin{array}{llllll}3 / 3 & 3 & 48.8000 & 0.51597 & 47.746 & 49.854 \\ 3 / 4 & 3 & 49.0667 & 0.51597 & 48.013 & 50.120\end{array}$

$\begin{array}{llllll}3 / 5 & 3 & 51.2667 & 0.51597 & 50.213 & 52.320 \\ 3 / 6 & 3 & 50.9000 & 0.51597 & 49.846 & 51.95\end{array}$

Std Error uses a pooled estimate of error variance 
Exhibit F3. Measurements of the Multi-Element Solution Standard by Set and ICP Block (continued)

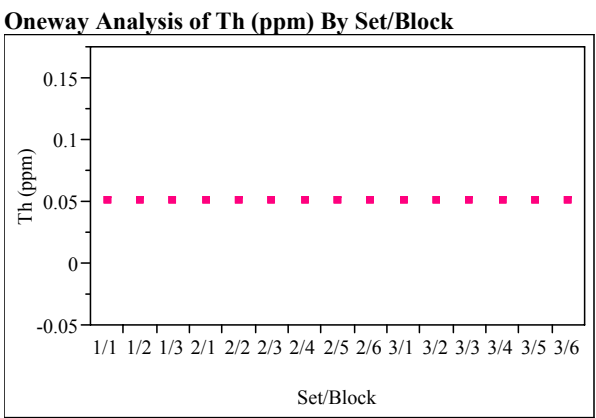

\section{Oneway Anova}

Summary of Fit

\begin{tabular}{|c|c|c|c|c|}
\hline \multicolumn{2}{|l|}{ Rsquare } & \\
\hline \multicolumn{2}{|c|}{ Adj Rsquare } & & & \\
\hline \multicolumn{5}{|c|}{ Root Mean Square Error } \\
\hline & \multicolumn{3}{|c|}{.05} \\
\hline \multicolumn{2}{|c|}{ Observations (or Sum Wgts) } & \multicolumn{3}{|l|}{45} \\
\hline \multicolumn{5}{|c|}{ Analysis of Variance } \\
\hline Source DF & $\begin{array}{r}\text { Sum of } \\
\text { Squares }\end{array}$ & $\begin{array}{r}\text { Mean } \\
\text { Square }\end{array}$ & $\begin{array}{r}\mathbf{F} \\
\text { Ratio }\end{array}$ & $\begin{array}{r}\text { Prob }> \\
F\end{array}$ \\
\hline Set/Block 14 & $1.95 \mathrm{e}-32$ & $1.393 \mathrm{e}-33$ & -3.8571 & 0.0000 \\
\hline Error & $-1.083 \mathrm{e}-32$ & $-3.61 e-34$ & & \\
\hline C. Total 44 & $8.6667 \mathrm{e}-33$ & & & \\
\hline
\end{tabular}

\section{Total $\begin{array}{ll}30 & -1.06670-33 \\ & \end{array}$}

Level Number Mean Std Error Lower 95\% Upper 95\%

$\begin{array}{lrrr}1 / 1 & 3 & 0.050000\end{array}$

$\begin{array}{lll}1 / 1 & 3 & 0.050000 \\ 1 / 2 & 3 & 0.050000\end{array}$

$\begin{array}{lll}1 / 3 & 3 & 0.050000\end{array}$

$2 / 1 \quad 3 \quad 30.050000$

$2 / 3 \quad 30.050000$

$\begin{array}{lll}2 / 4 & 3 & 0.050000 \\ 2 / 5 & 3 & 0.050000\end{array}$

$2 / 6 \quad 30.050000$

$3 / 1 \quad 3 \quad 0.050000$

$3 / 3 \quad 30.050000$

$\begin{array}{lll}3 / 4 & 3 & 0.050000 \\ 3 / 5 & 3 & 0.050000\end{array}$

$3 / 6 \quad 3 \quad 0.050000$

Std Error uses a pooled estimate of error variance

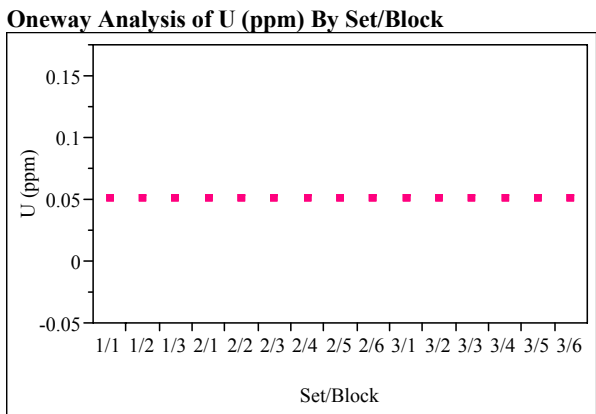

\section{Oneway Anova}

Summary of Fit

$\begin{array}{lr}\text { Rsquare } & 2.25 \\ \text { Adj Rsquare } & 2.833333 \\ \text { Root Mean Square Error } & \\ \text { Mean of Response } & 0.05 \\ \text { Observations (or Sum Wgts) } & 45\end{array}$

$\begin{array}{lrrrrr}\begin{array}{l}\text { Analysis of Variance } \\ \text { Source }\end{array} & \text { DF } & \begin{array}{r}\text { Sum of } \\ \text { Squares }\end{array} & \begin{array}{r}\text { Mean } \\ \text { Square }\end{array} & \begin{array}{r}\text { F } \\ \text { Ratio }\end{array} & \begin{array}{r}\text { Prob > } \\ \text { F }\end{array} \\ \text { Set/Block } & 14 & 1.95 \mathrm{e}-32 & 1.393 \mathrm{e}-33 & -3.8571 & 0.0000 \\ \text { Error } & 30 & -1.083 \mathrm{e}-32 & -3.61 \mathrm{e}-34 & & \\ \text { C. Total } & 44 & 8.6667 \mathrm{e}-33 & & & \end{array}$

C. Total $44 \quad 8.6667 \mathrm{e}-33$

Means for Oneway Anova
Level Number Mean Std Error Lower 95\% Upper 95\%

$\begin{array}{lll}1 / 1 & 3 & 0.050000 \\ 1 / 2 & 3 & 0.050000\end{array}$

$\begin{array}{lll}1 / 3 & 3 & 0.050000 \\ 1 / 3 & 3 & 0.050000\end{array}$

$\begin{array}{llll}2 / 1 & 3 & 0.050000 \\ 2 / 2 & 3 & 0.050000\end{array}$

$2 / 3 \quad \begin{array}{llll}3 & 0.050000 \\ 2 / 4 & 3 & 0.050000\end{array}$

$2 / 4 \quad 3 \quad 30.050000$

$\begin{array}{llll}2 / 6 & 3 & 0.050000\end{array}$

$\begin{array}{lll}3 & 0.050000 \\ 3 & 0.050000\end{array}$

30.050000

$\begin{array}{lll}3 & 0.050000\end{array}$

30.050000

30.050000

$3 / 6 \quad 30.050000$

Std Error uses a pooled estimate of error variance 
Exhibit F4. Laboratory PCT Measurements by Glass Number for Study Glasses and Standards

(100 - Solution Standard; 101 - EA; 102 - ARM; 103 - Blanks)

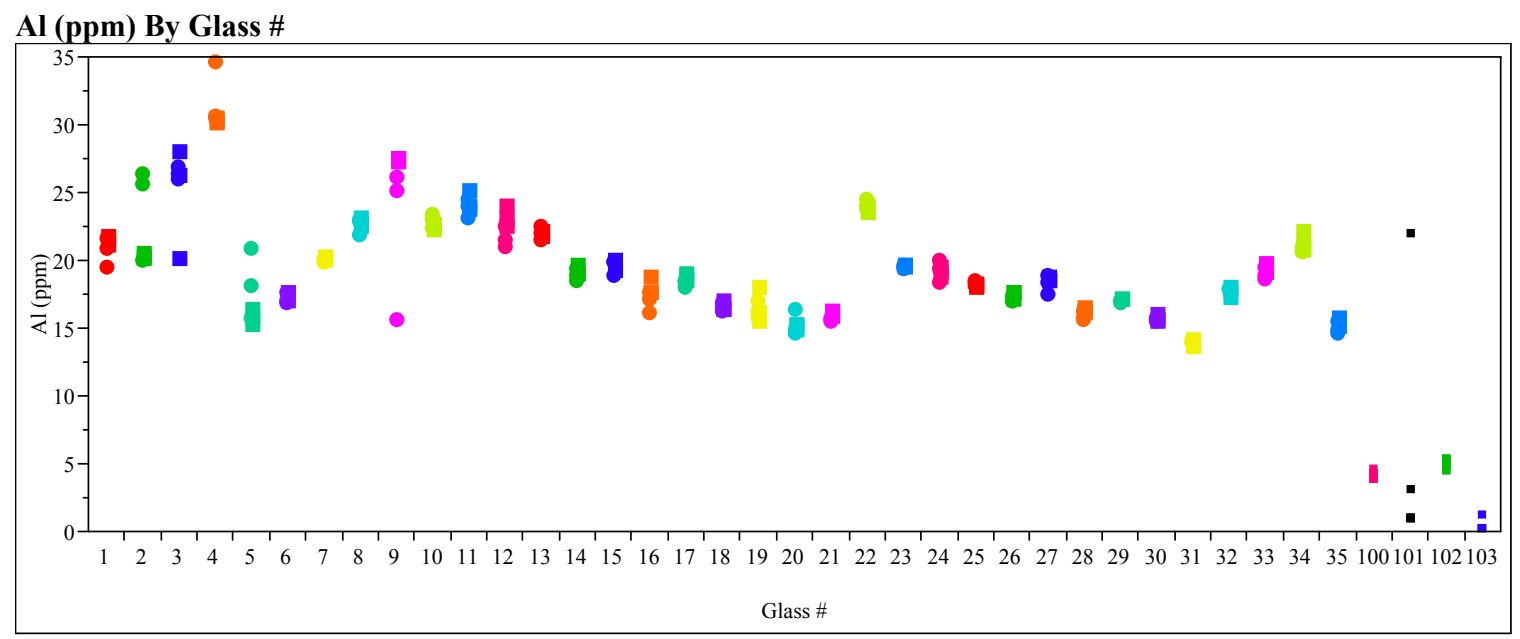

B (ppm) By Glass \#

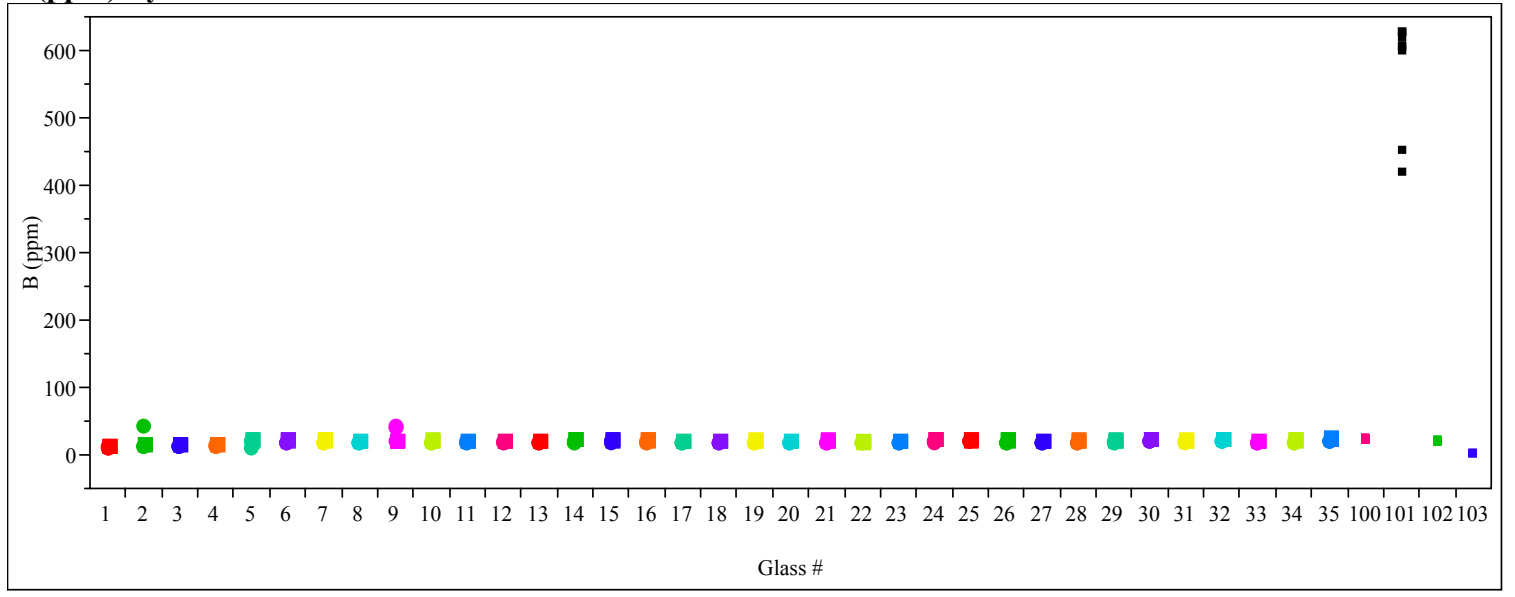

Fe (ppm) By Glass \#

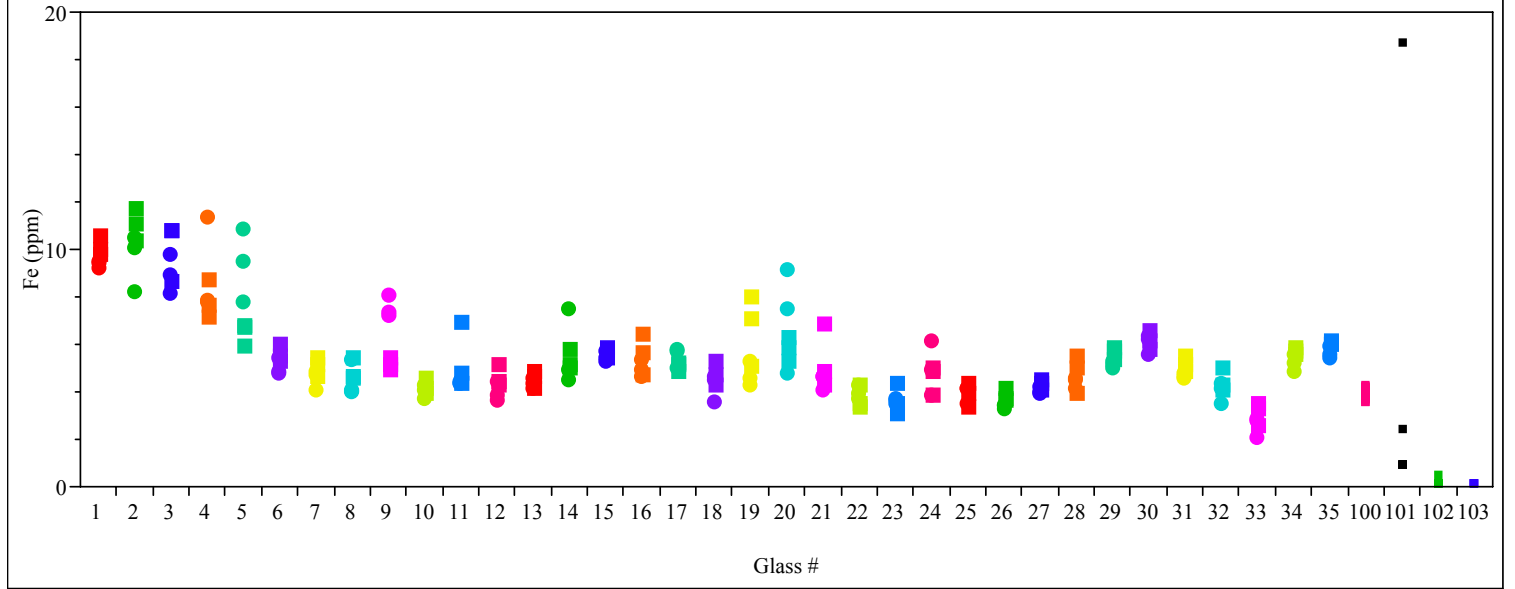


Exhibit F4. Laboratory PCT Measurements by Glass Number for Study Glasses and Standards (continued)

(100 - Solution Standard; 101 - EA; 102 - ARM; 103 - Blanks)

Li (ppm) By Glass \#

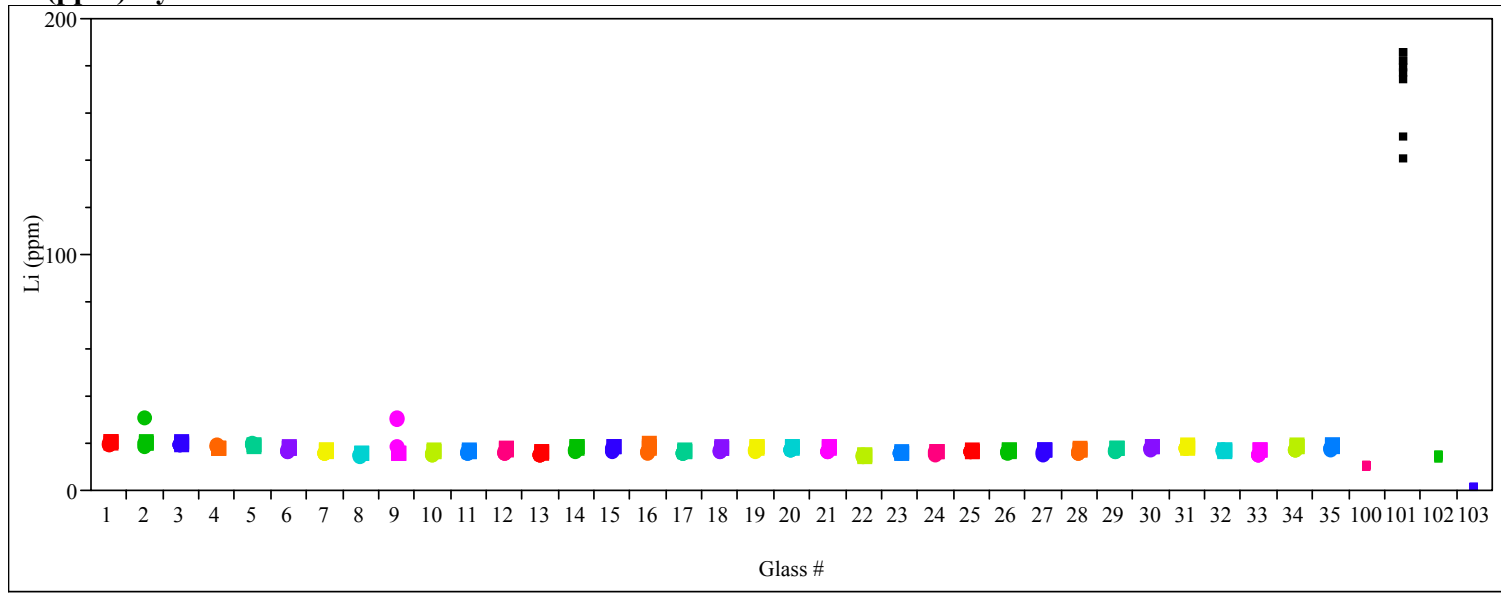

Na (ppm) By Glass \#

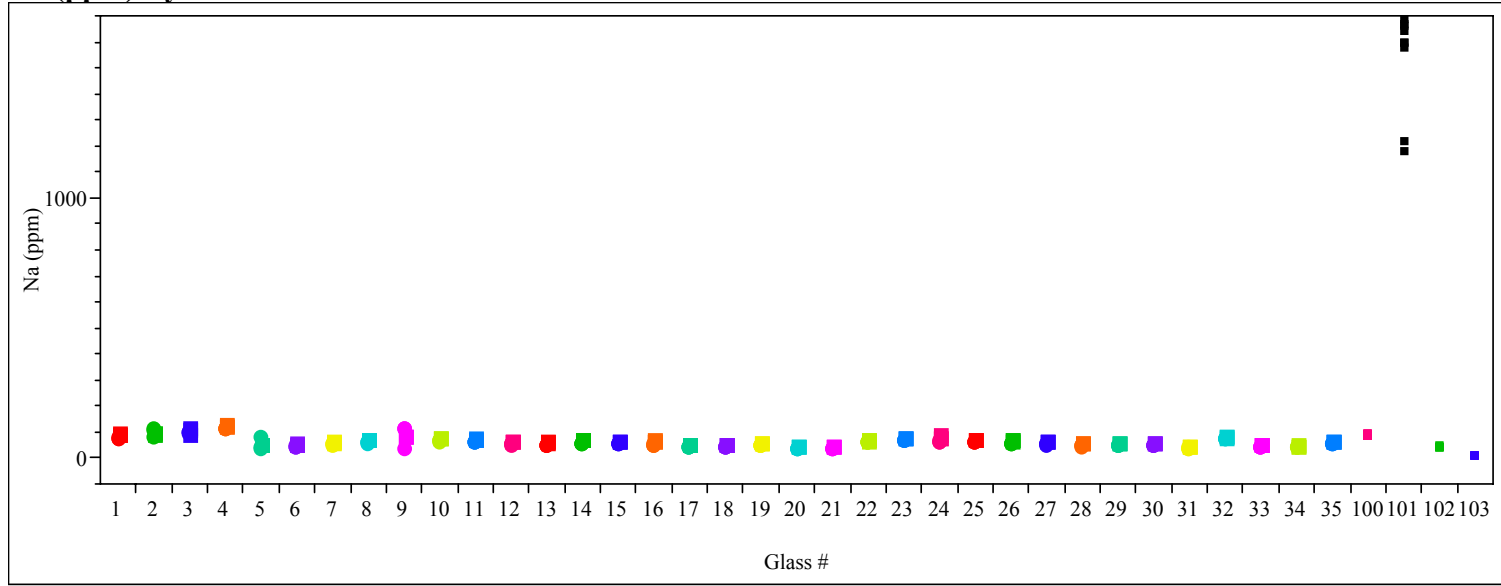

Si (ppm) By Glass \#

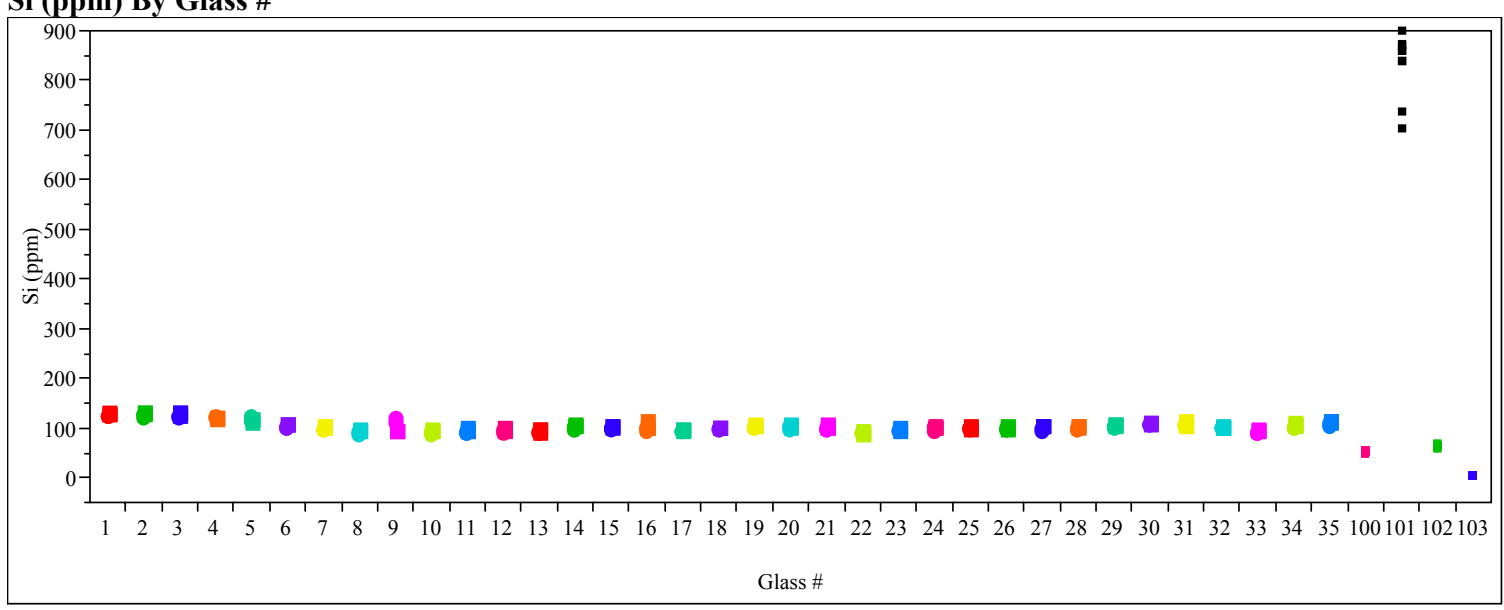


Exhibit F4. Laboratory PCT Measurements by Glass Number for Study Glasses and Standards (continued)

(100 - Solution Standard; 101 - EA; 102 - ARM; 103 - Blanks)

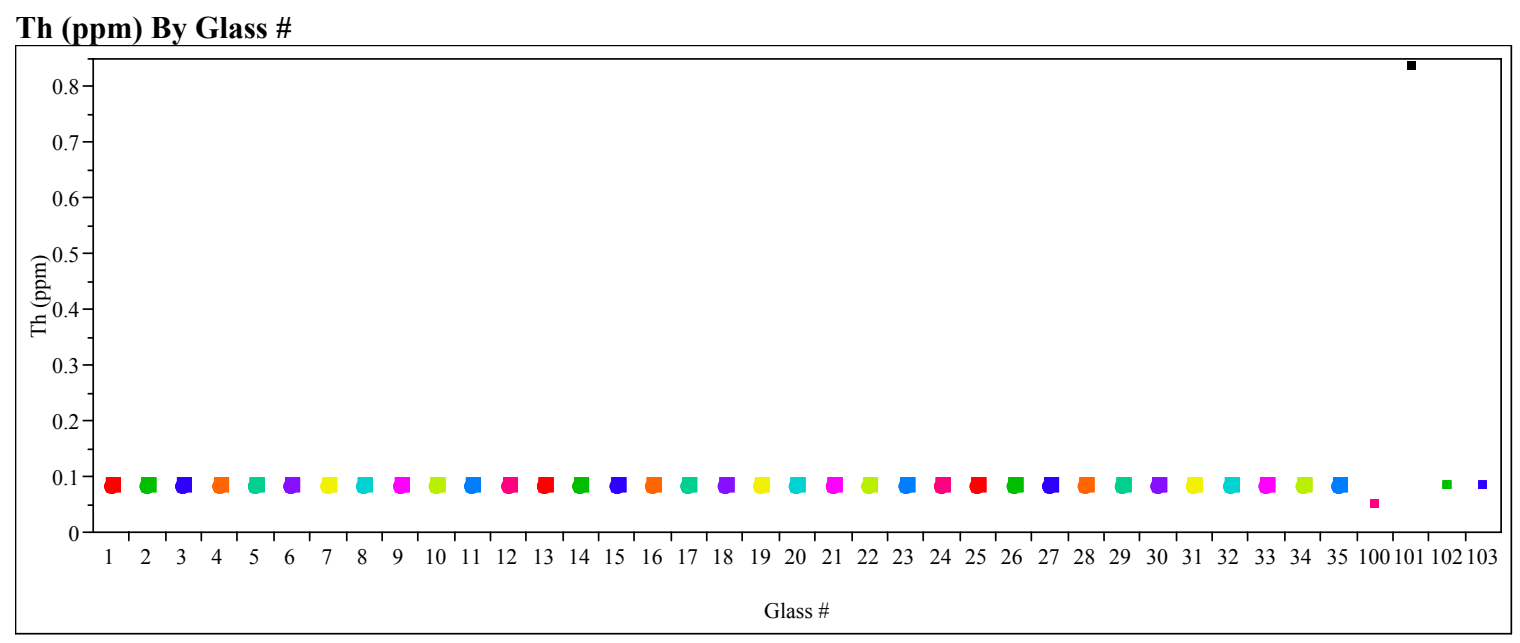

U (ppm) By Glass \#

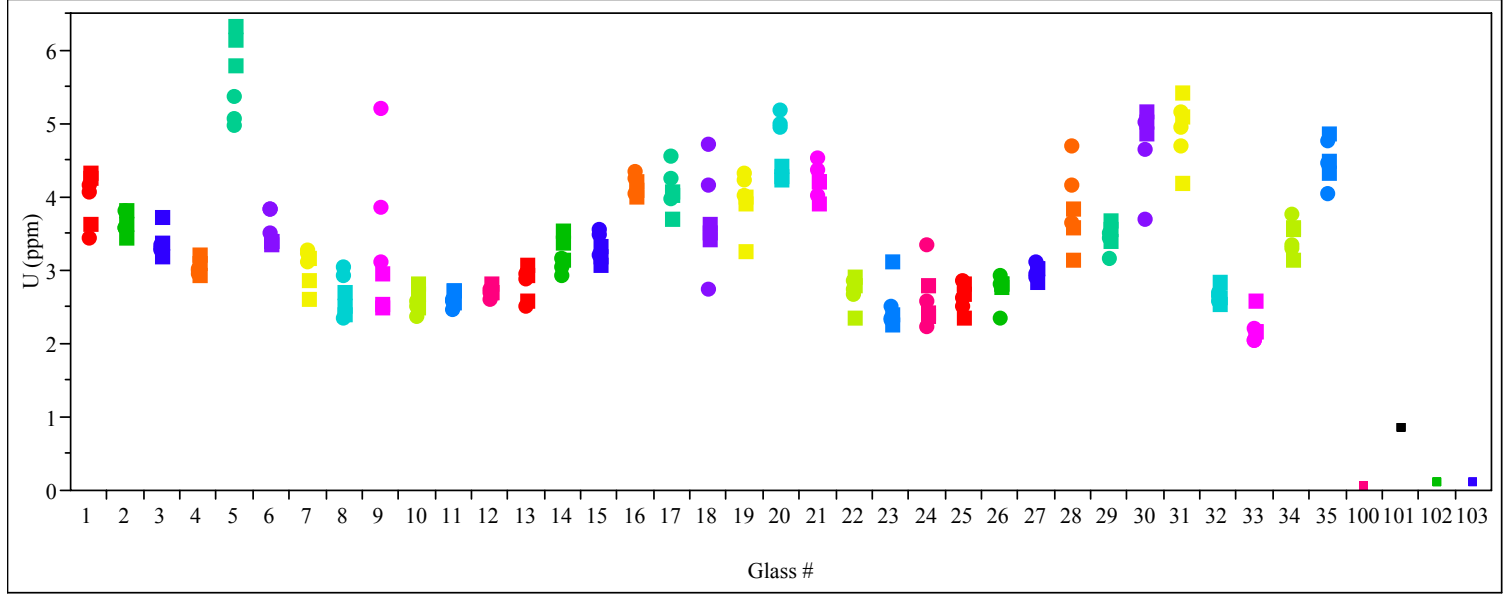




\section{Exhibit F5. Laboratory PCT Measurements by Glass Number for Study Glasses}

Variability Chart for Al (ppm)

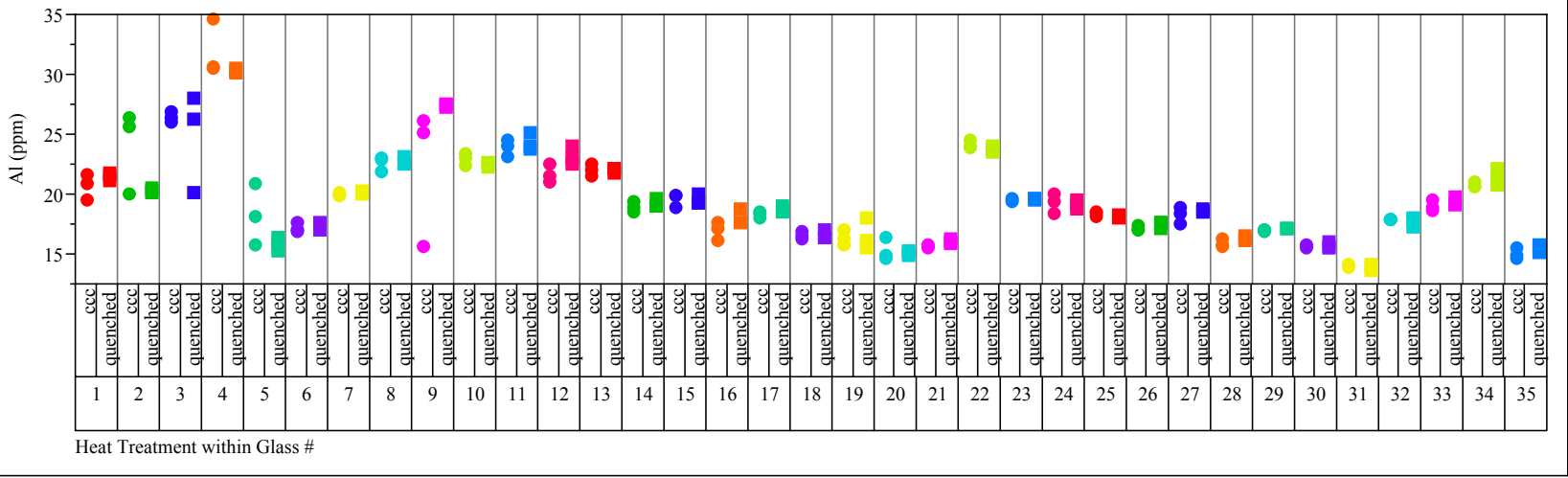

\section{Variability Chart for B (ppm)}

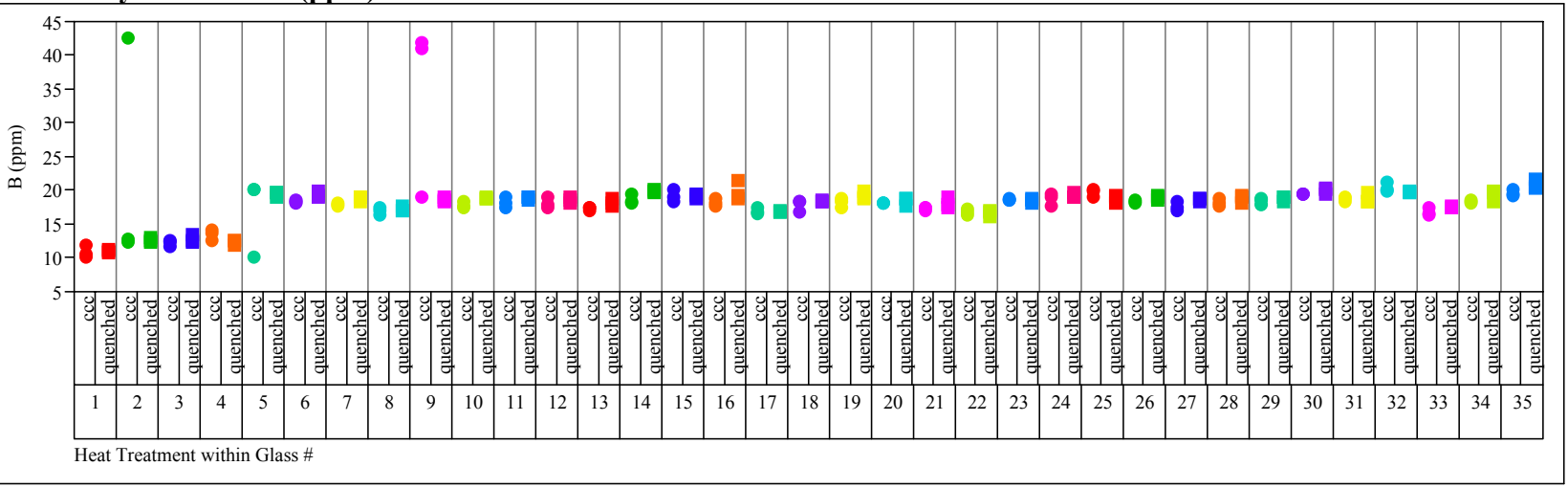

\section{Variability Chart for Fe (ppm)}

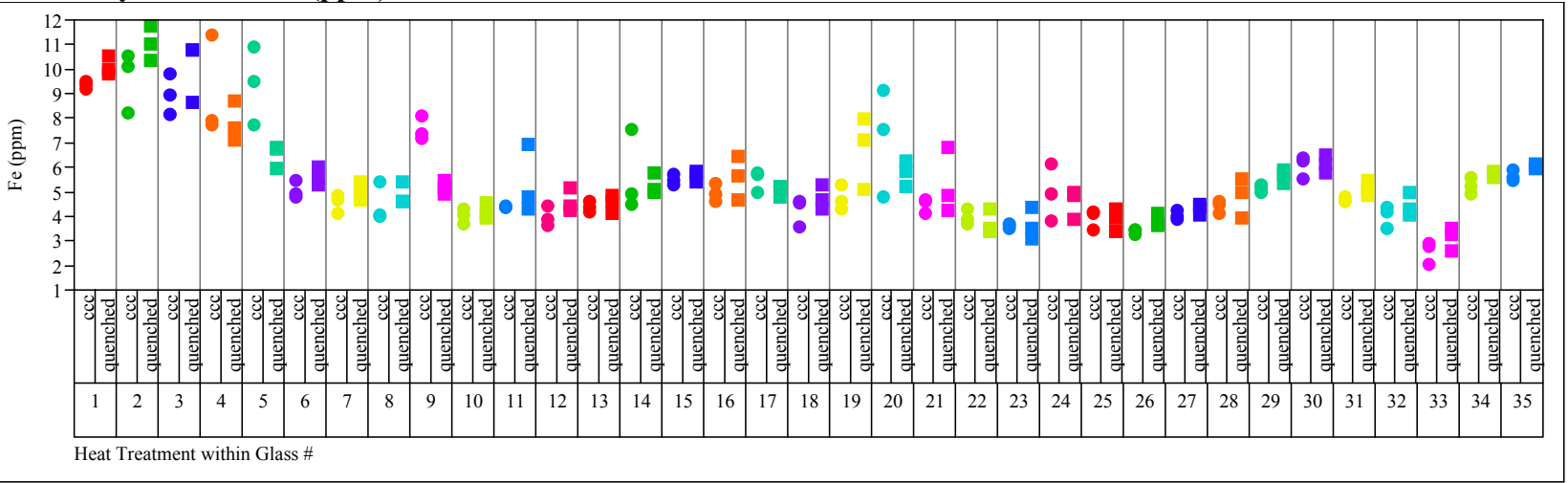




\section{Exhibit F5. Laboratory PCT Measurements by Glass Number for Study Glasses (continued)}

Variability Chart for Li (ppm)

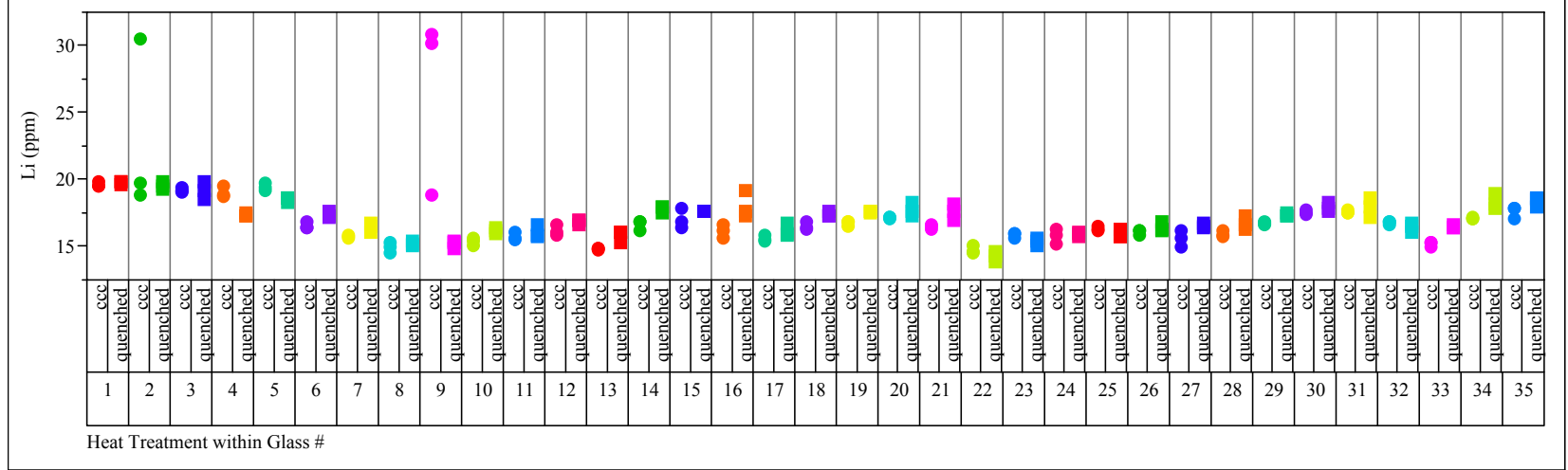

Variability Chart for Na (ppm)

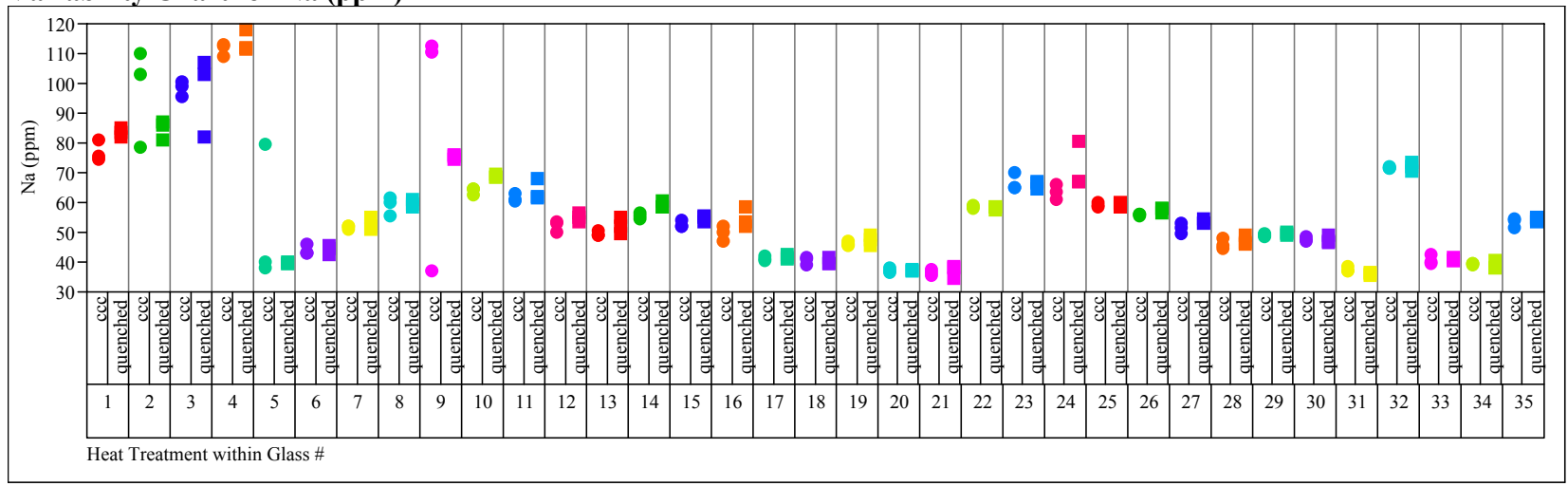

Variability Chart for Si (ppm)

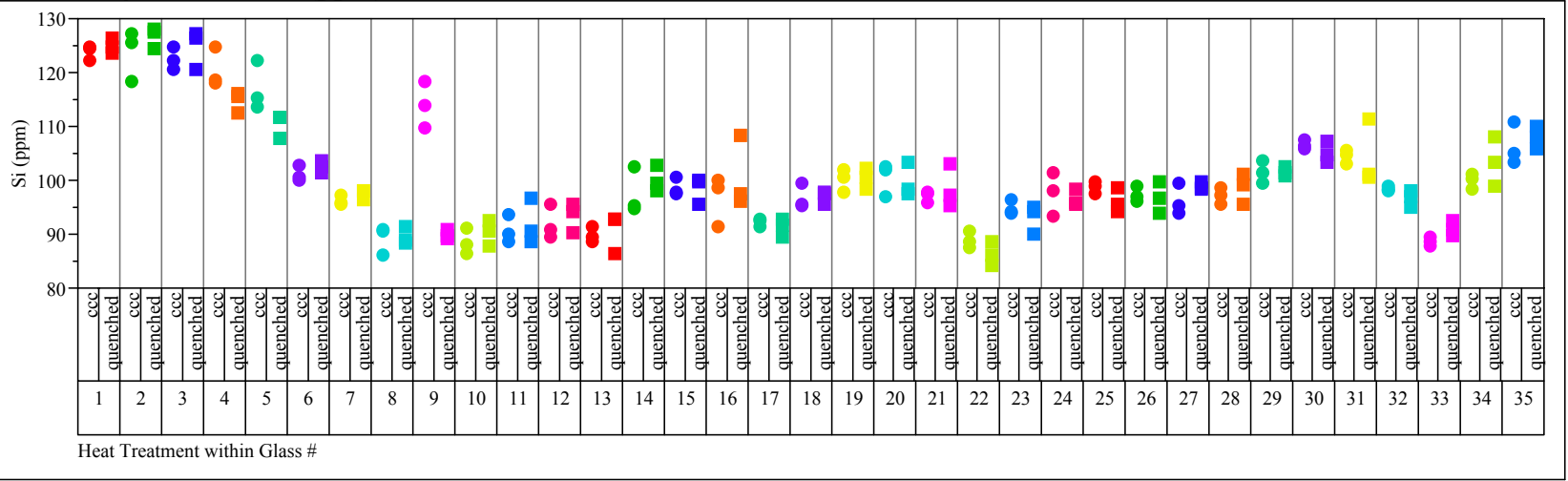




\section{Exhibit F5. Laboratory PCT Measurements by Glass Number for Study Glasses (continued)}

Variability Chart for Th (ppm)

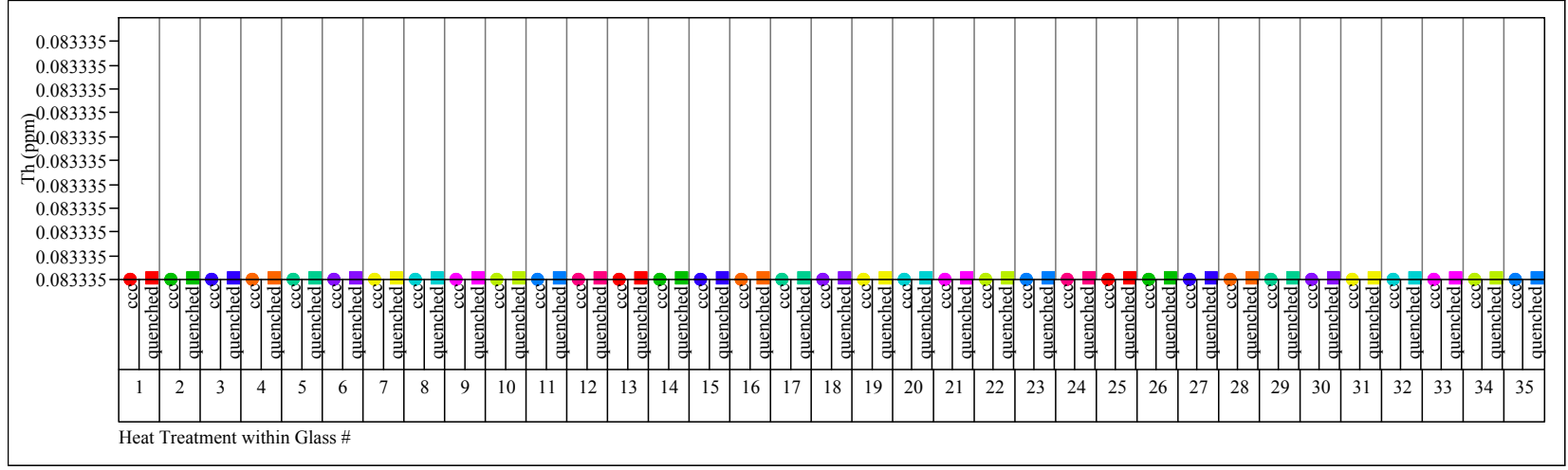

Variability Chart for U (ppm)

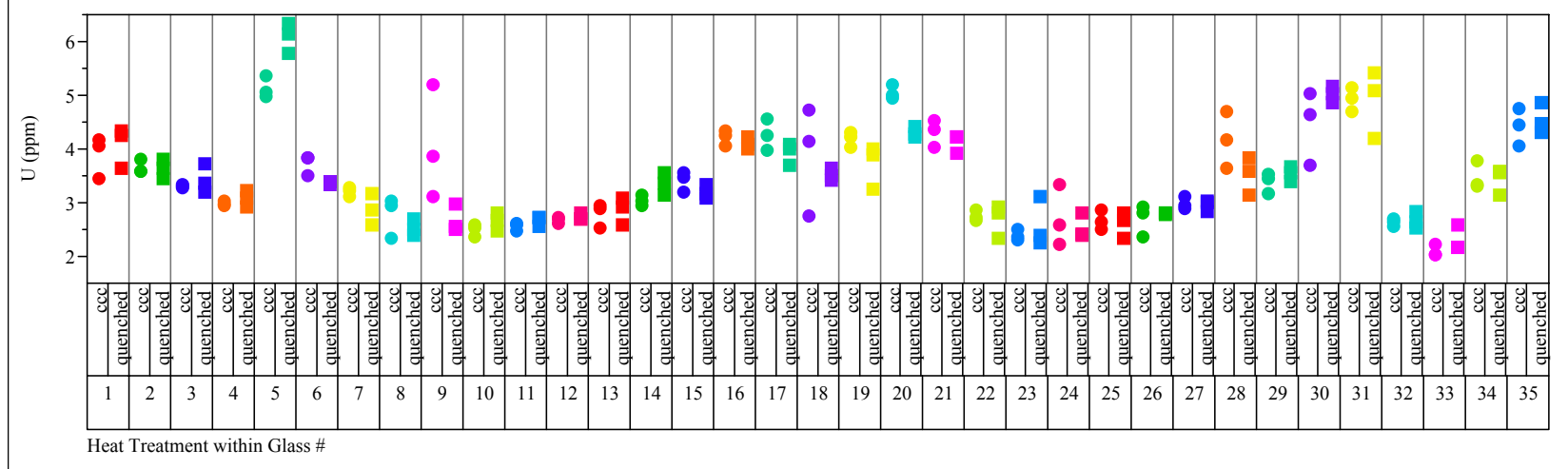




\section{Exhibit F6. Correlations and Scatter Plots of Normalized PCTs Over All Compositional Views and Heat Treatments}

\section{Correlations}

$\log$ NL[B $(g / L)]$

$\log \mathrm{NL}[\mathrm{Li}(\mathrm{g} / \mathrm{L})]$

$\log \mathrm{NL}[\mathrm{Na}(\mathrm{g} / \mathrm{L})]$

$\log \mathrm{NL}[\mathrm{Si}(\mathrm{g} / \mathrm{L})]$

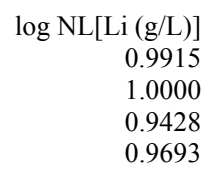

1.0000

0.9428

0.9693

$\log \mathrm{NL}[\mathrm{Si}(\mathrm{g} / \mathrm{L})]$
0.9655
0.9693
0.9534
1.0000

\section{Scatterplot Matrix}

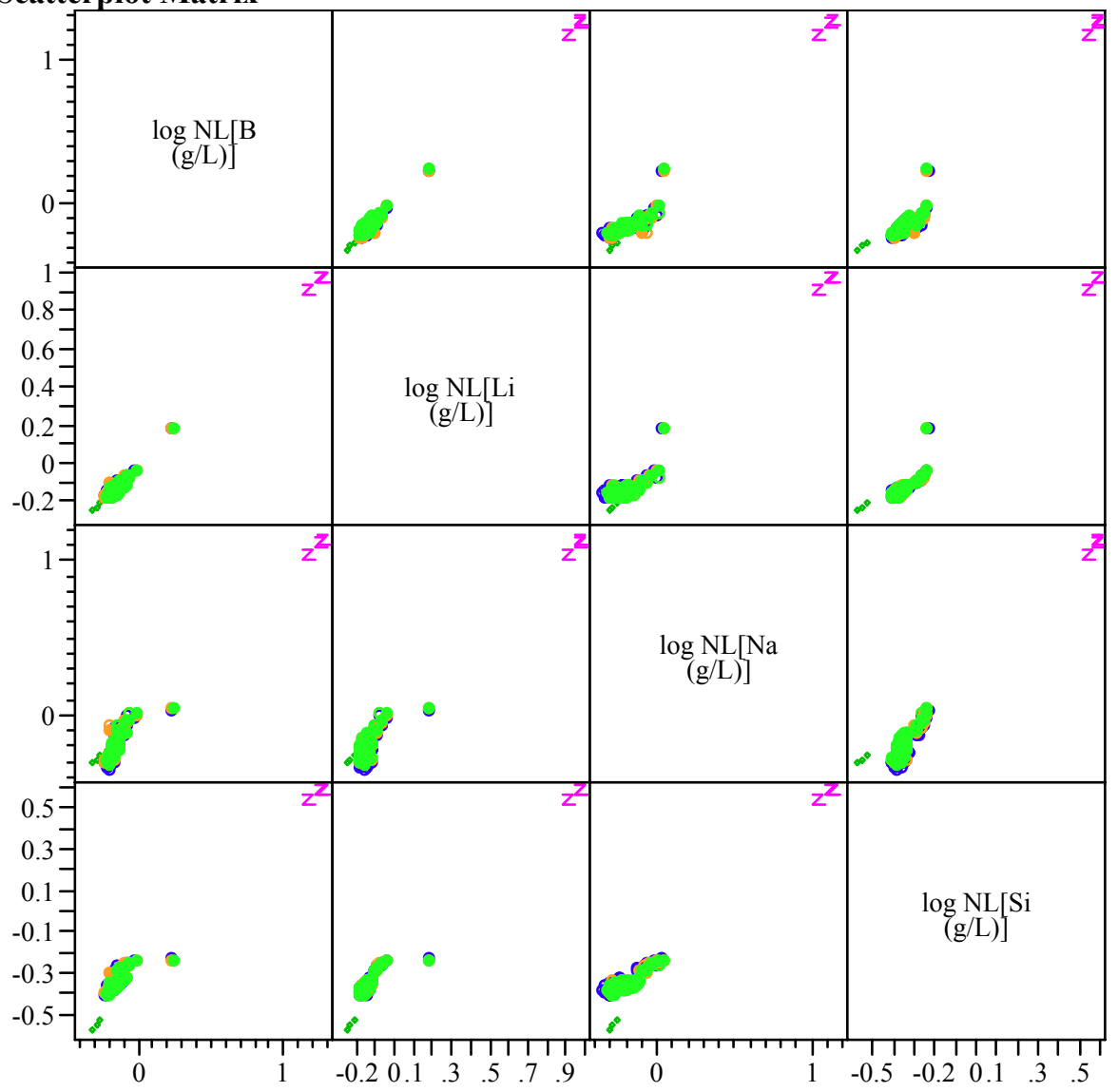




\section{Exhibit F7. Heat Treatment Effect on $\log (\mathrm{ppm})$ PCT Response}

t Test: quenched-ccc

Assuming unequal variances $\log [$ B ppm] By Heat Treatment Glass \#=1

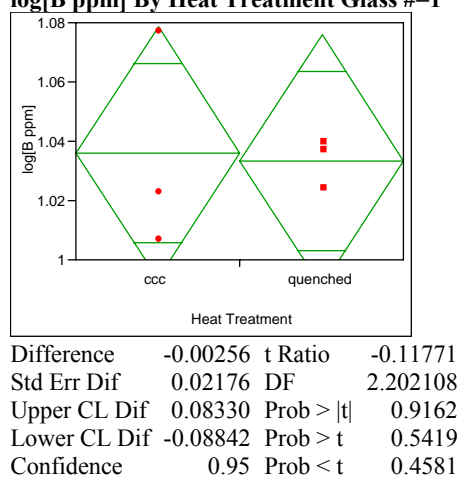

$\log [\mathrm{Li}$ ppm] By Heat Treatment Glass \#=1

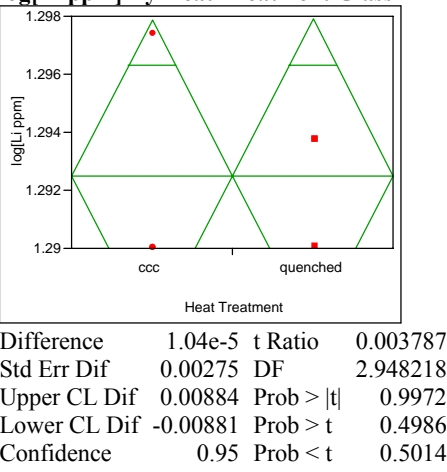

$\log [\mathrm{Na}$ ppm] By Heat Treatment Glass \#=1

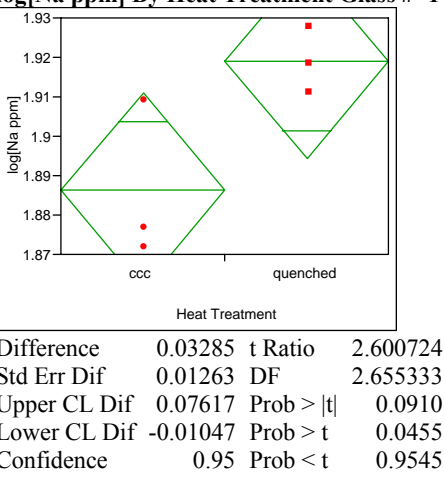

$\log [$ Si ppm] By Heat Treatment Glass \#=1

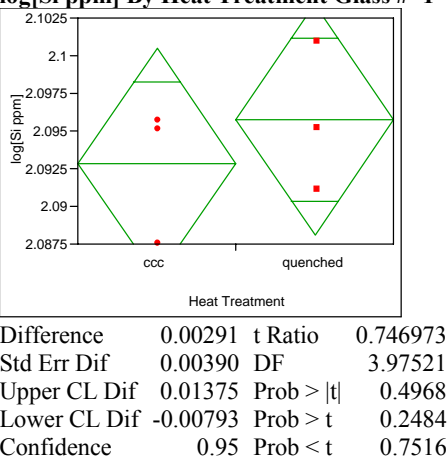

t Test: quenched-ccc

Assuming unequal variances $\log [$ B ppm] By Heat Treatment Glass \#=2

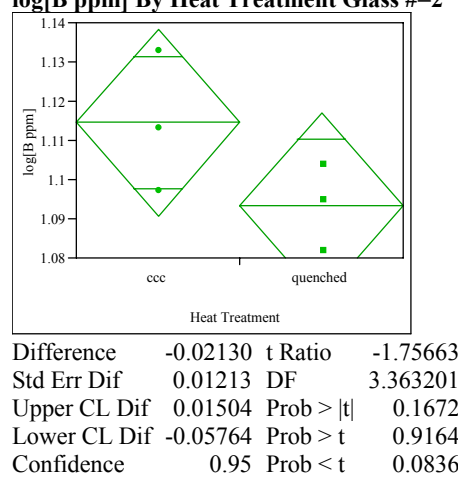

$\log [\mathrm{Li} \mathrm{ppm}]$ By Heat Treatment Glass \#=2

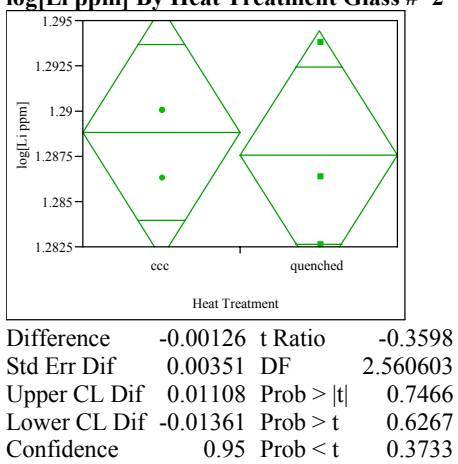

$\log [\mathrm{Na}$ ppm] By Heat Treatment Glass \#=2

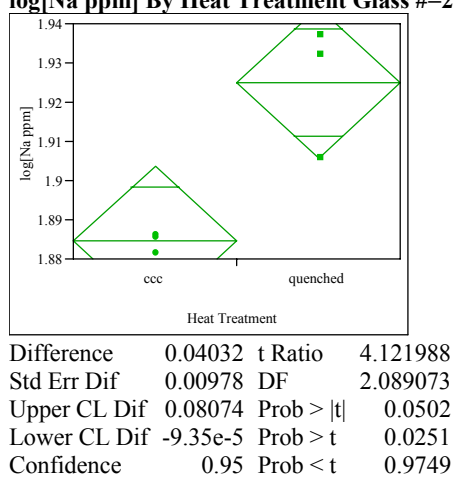

$\log [\mathrm{Si}$ ppm] By Heat Treatment Glass \#=2

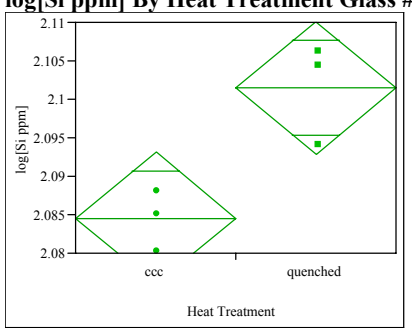

Difference $\quad 0.016921$ t Ratio 3.848792 Std Err Dif $\quad 0.004396$ DF 3.269891 Upper CL Dif 0.030281 Prob $>|t| \quad 0.0265$ Lower CL Dif 0.003561 Prob $>$ t 0.0133

Confidence $\quad 0.95$ Prob $<\mathrm{t} \quad 0.9867$ t Test: quenched-ccc

Assuming unequal variances $\log [$ B ppm] By Heat Treatment Glass \#=3

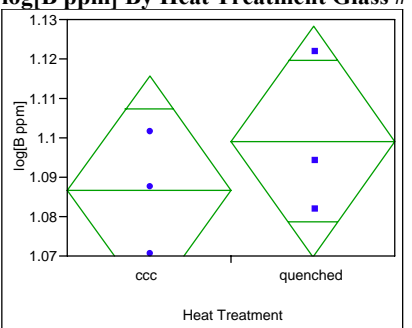

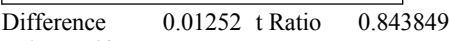
Std Err Dif $\quad 0.01483$ DF $\quad 3.716801$

Upper CL Dif 0.05496 Prob $>|t| \quad 0.4496$ Lower CL Dif -0.02993 Prob $>\mathrm{t} \quad 0.2248$ Confidence $\quad 0.95$ Prob $<\mathrm{t} \quad 0.7752$

$\log [\mathrm{Li}$ ppm] By Heat Treatment Glass \#=3

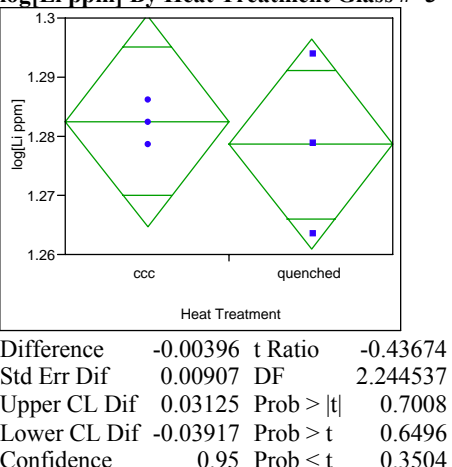

$\begin{array}{lrl}\text { Confidence } & 0.95 \text { Prob }<\mathrm{t} & 0.3504\end{array}$

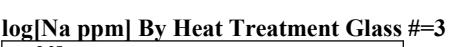

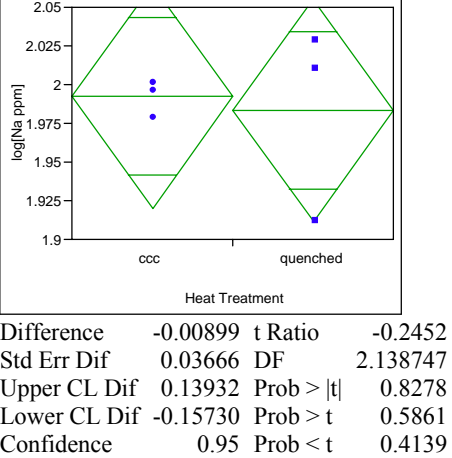

$\log [$ Si ppm] By Heat Treatment Glass \#=3

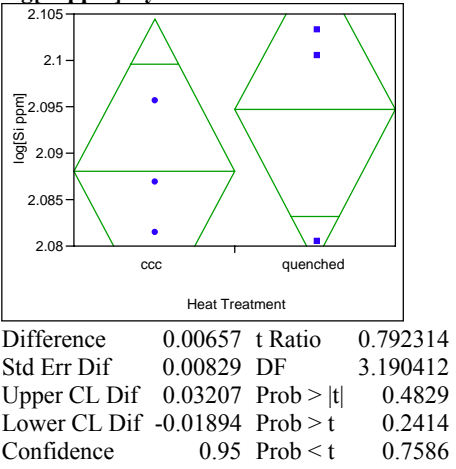




\section{Exhibit F7. Heat Treatment Effect on $\log (\mathrm{ppm})$ PCT Response (continued)}

t Test: quenched-ccc

Assuming unequal variances $\log [$ B ppm] By Heat Treatment Glass \# $=4$

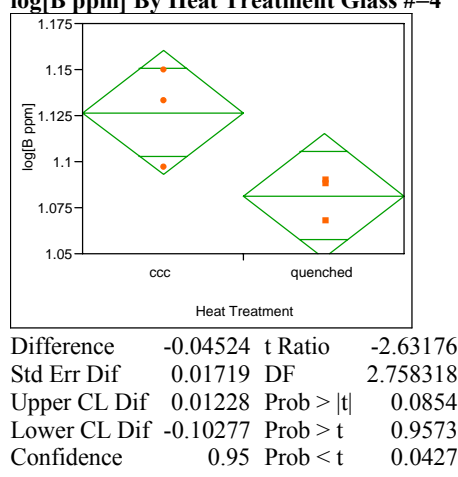

$\log [\mathrm{Li} \mathrm{ppm}]$ By Heat Treatment Glass \#=4

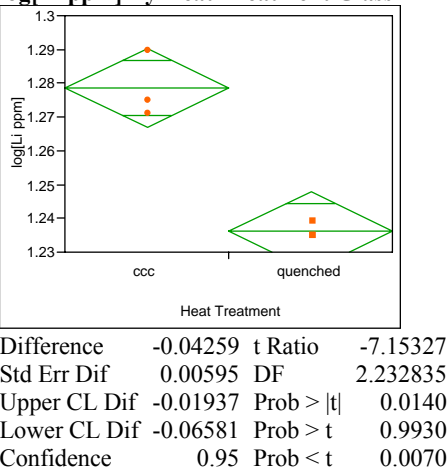

$\log [\mathrm{Na}$ ppm] By Heat Treatment Glass \#=4

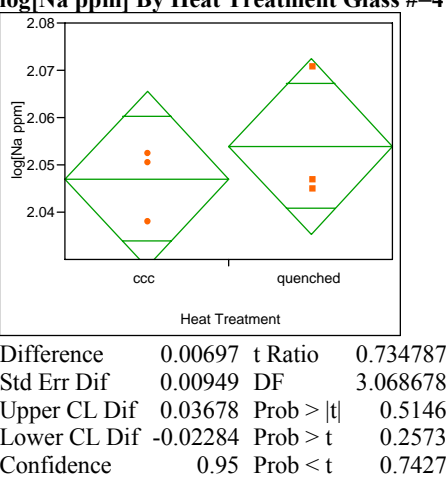

$\log [$ Si ppm] By Heat Treatment Glass \#=4

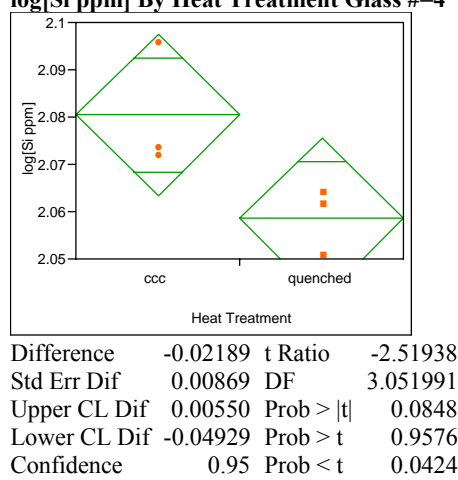

t Test: quenched-ccc

Assuming unequal variances $\log [$ B ppm] By Heat Treatment Glass \#=5

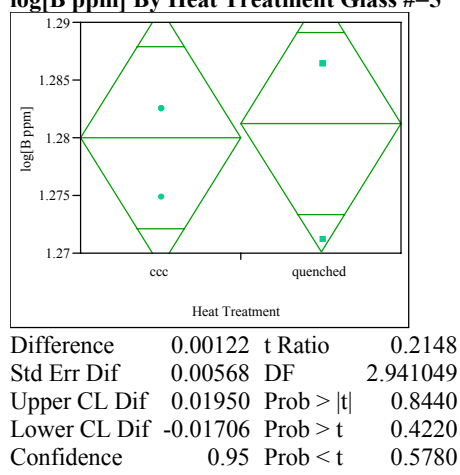

$\log [\mathrm{Li}$ ppm] By Heat Treatment Glass \#=5

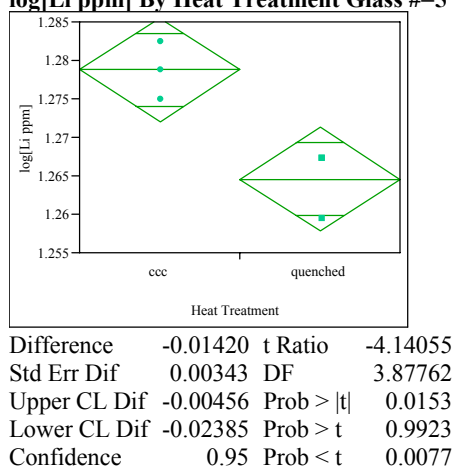

$\log [\mathrm{Na}$ ppm] By Heat Treatment Glass \#=5

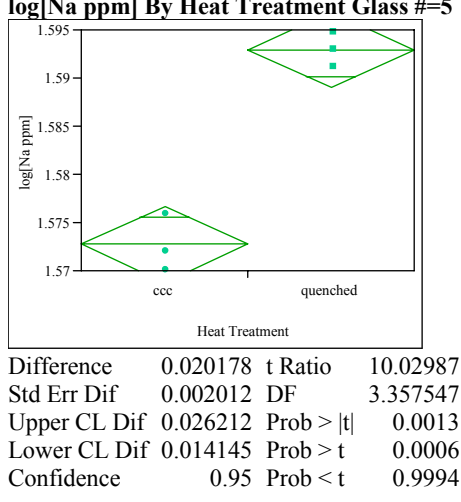

$\log [\mathrm{Si}$ ppm] By Heat Treatment Glass \#=5

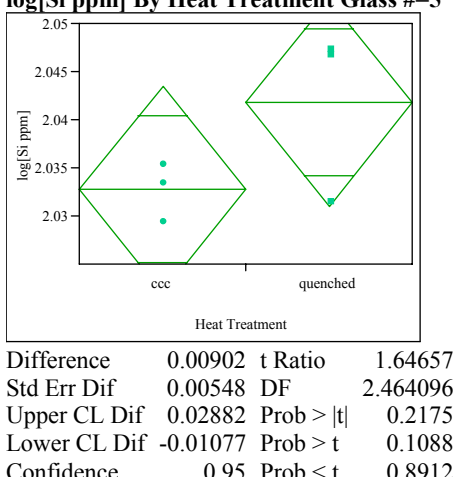

t Test: quenched-ccc

Assuming unequal variances $\log [$ B ppm] By Heat Treatment Glass \#=6

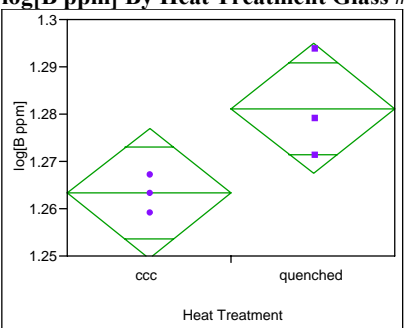

\begin{tabular}{lll}
\hline Difference & 0.01795 t Ratio & 2.55249
\end{tabular} Std Err Dif $\quad 0.00703$ DF 2.463011

Upper CL Dif 0.04337 Prob $>|t| \quad 0.1019$ Lower CL Dif -0.00746 Prob $>t \quad 0.0510$ $\begin{array}{lll}\text { Confidence } & 0.95 \text { Prob }<\mathrm{t} \quad 0.9490\end{array}$

$\log [\mathrm{Li}$ ppm] By Heat Treatment Glass \#=6

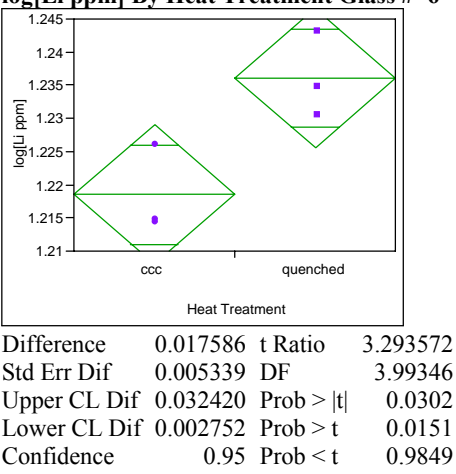

$\log [$ Na ppm] By Heat Treatment Glass \#=6

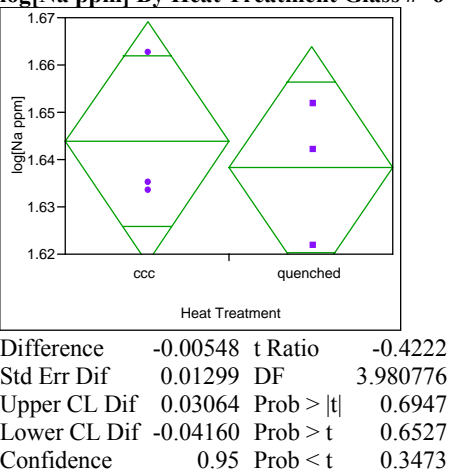

$\log [$ Si ppm] By Heat Treatment Glass \#=6

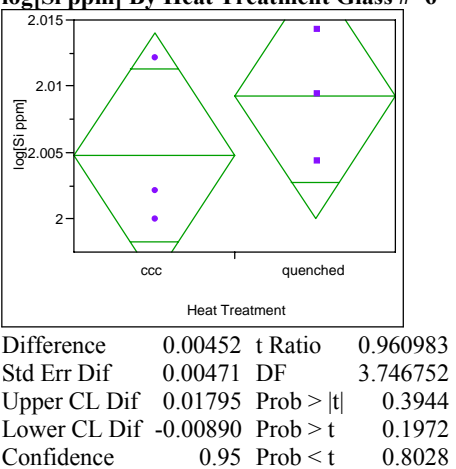




\section{Exhibit F7. Heat Treatment Effect on $\log (\mathrm{ppm})$ PCT Response (continued)}

t Test: quenched-ccc

Assuming unequal variances $\log [$ B ppm] By Heat Treatment Glass \#=7

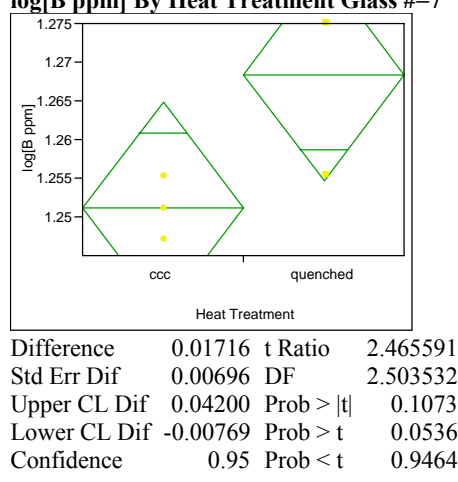

$\log [\mathrm{Li}$ ppm] By Heat Treatment Glass \#=7

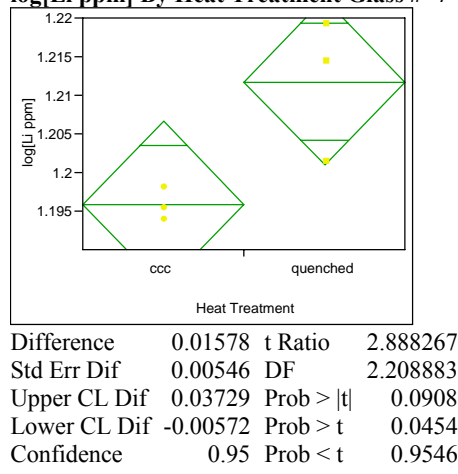

$\log [\mathrm{Na}$ ppm] By Heat Treatment Glass \#=7

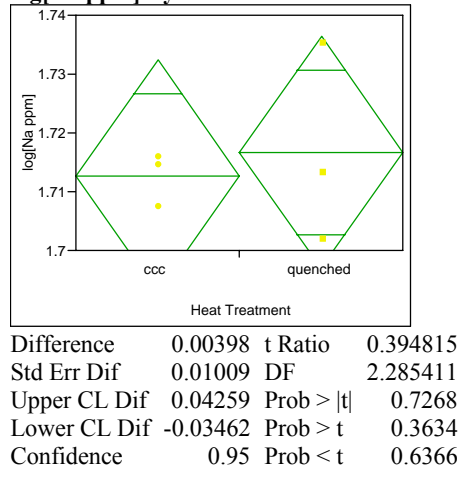

$\log [$ Si ppm] By Heat Treatment Glass \#=7

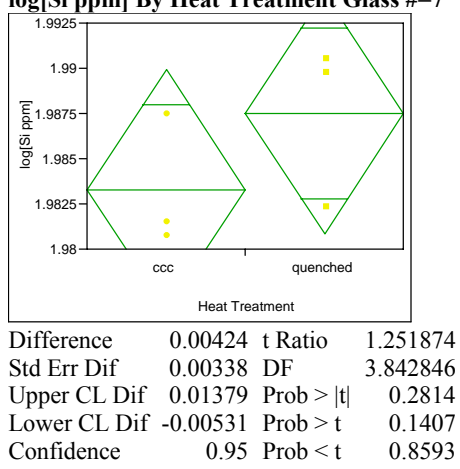

t Test: quenched-ccc

Assuming unequal variances $\log [$ B ppm] By Heat Treatment Glass \#=8

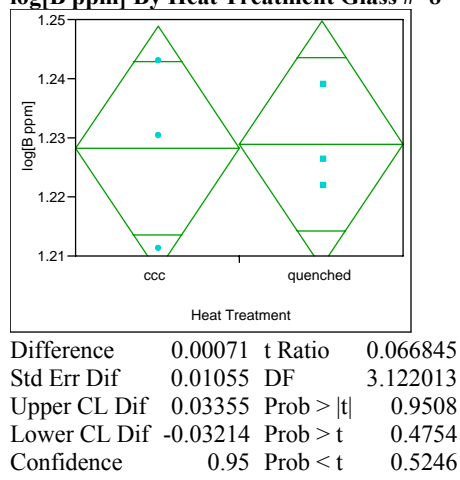

$\log [\mathrm{Li}$ ppm $]$ By Heat Treatment Glass \#=8

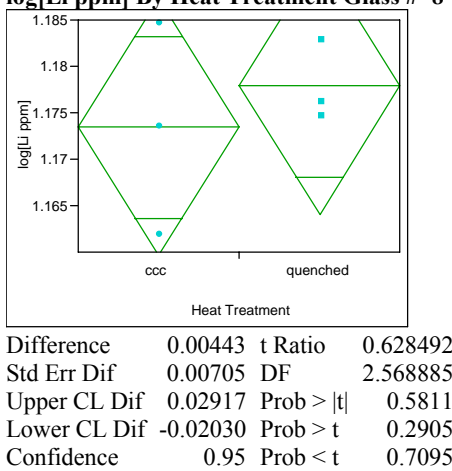

$\log [$ Na ppm] By Heat Treatment Glass \# $=8$

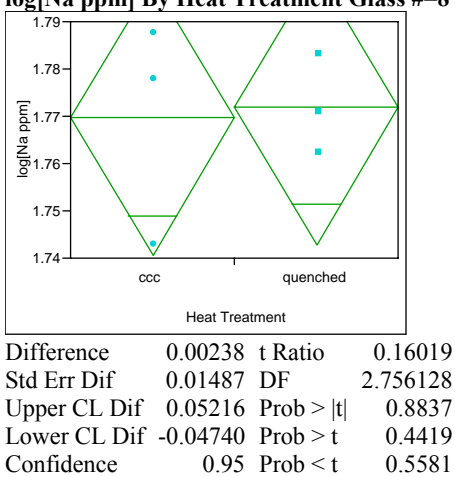

$\log [$ Si ppm $]$ By Heat Treatment Glass \#=8

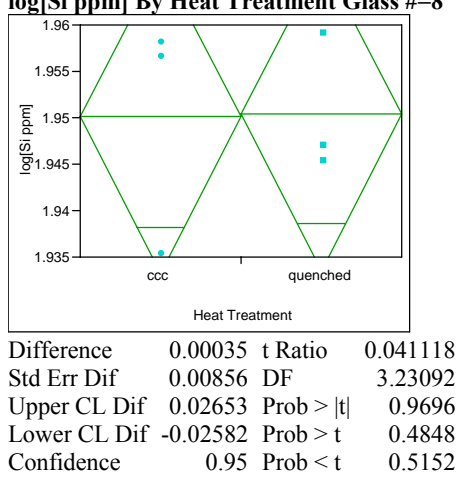

t Test: quenched-ccc

Assuming unequal variances $\log [$ B ppm] By Heat Treatment Glass \#=9

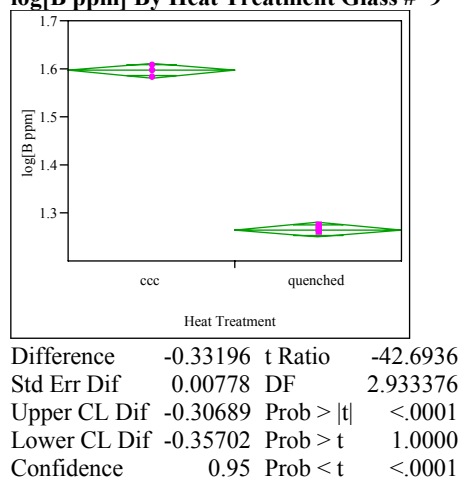

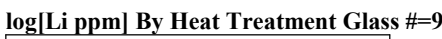

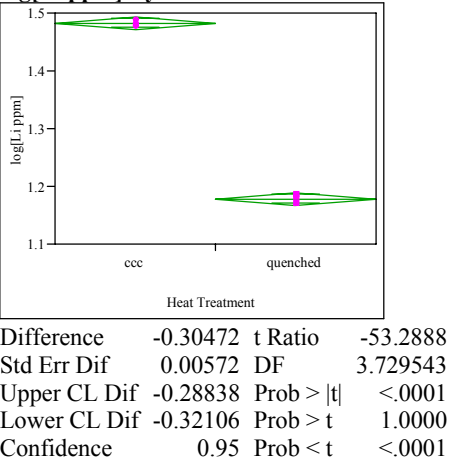

$\log [$ Na ppm] By Heat Treatment Glass \#=9

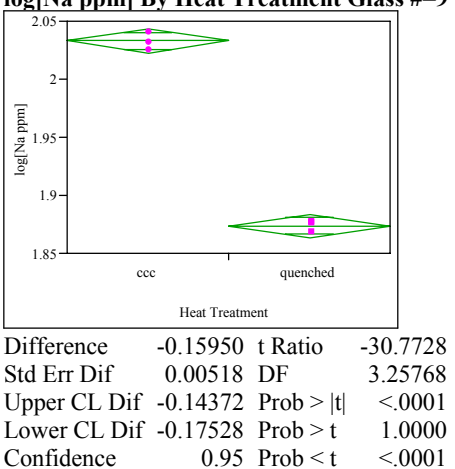

$\log [$ Si ppm] By Heat Treatment Glass \#=9

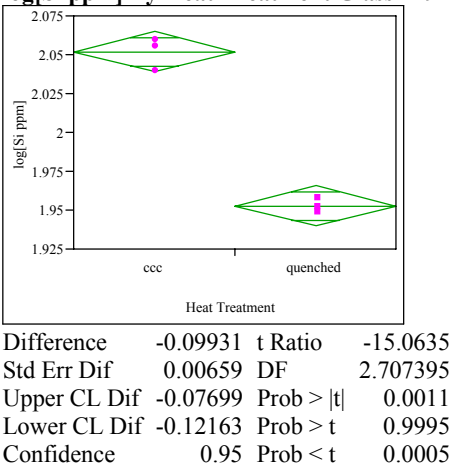




\section{Exhibit F7. Heat Treatment Effect on $\log (\mathrm{ppm})$ PCT Response (continued)}

t Test: quenched-ccc

Assuming unequal variances $\log [$ B ppm] By Heat Treatment Glass \#=10

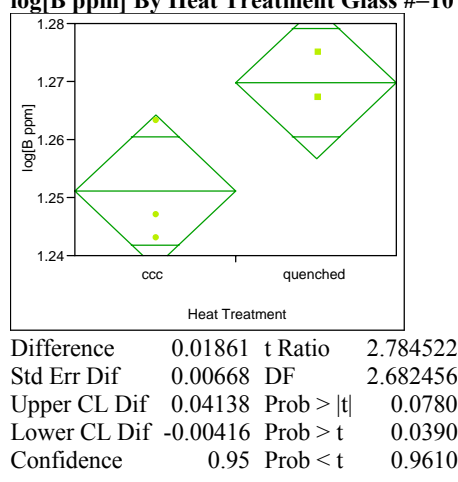

$\log [\mathrm{Li}$ ppm] By Heat Treatment Glass \#=10

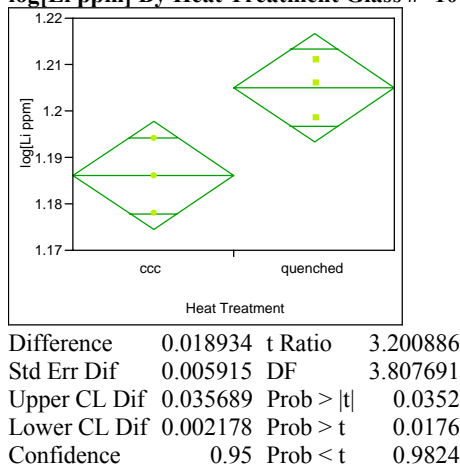

$\log [$ Na ppm] By Heat Treatment Glass \#=10

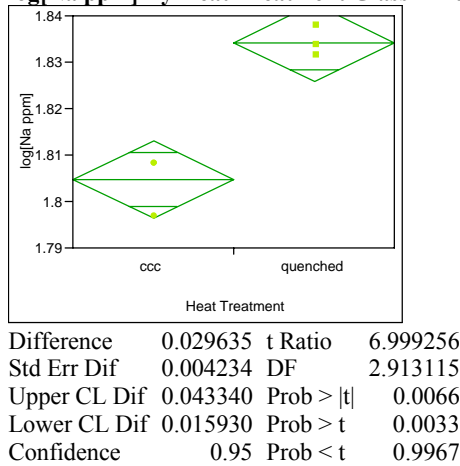

$\log [$ Si ppm] By Heat Treatment Glass \#=10

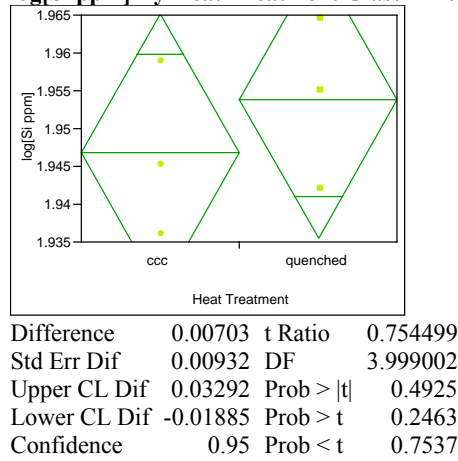

t Test: quenched-ccc

Assuming unequal variances $\log [$ B ppm] By Heat Treatment Glass \#=11

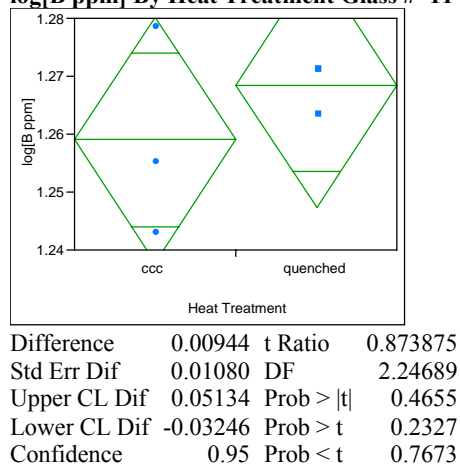

$\log [\mathrm{Li} \mathrm{ppm}]$ By Heat Treatment Glass \#=11

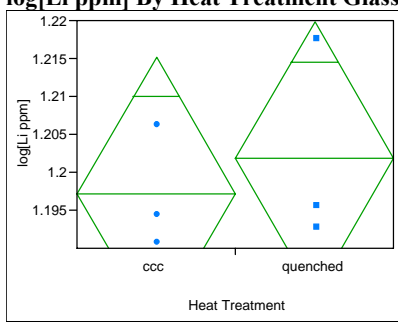

Difference $\quad 0.00463$ t Ratio 0.506134 Std Err Dif $\quad 0.00915$ DF $\quad 3.268861$ Upper CL Dif 0.03244 Prob $>|t| 0.6449$ Lower CL Dif -0.02318 Prob $>t \quad 0.3225$ Confidence $\quad 0.95$ Prob $<\mathrm{t} \quad 0.6775$

$\log [\mathrm{Na}$ ppm] By Heat Treatment Glass \#=11

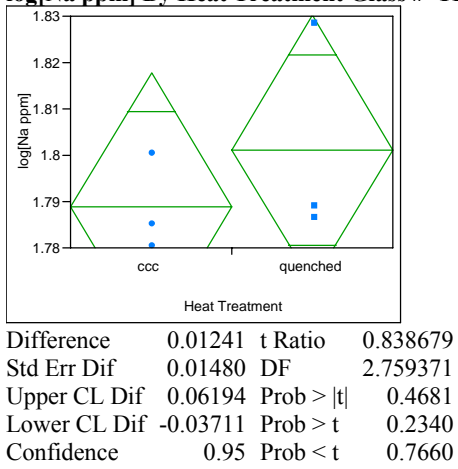

$\log [\mathrm{Si}$ ppm] By Heat Treatment Glass \#=11

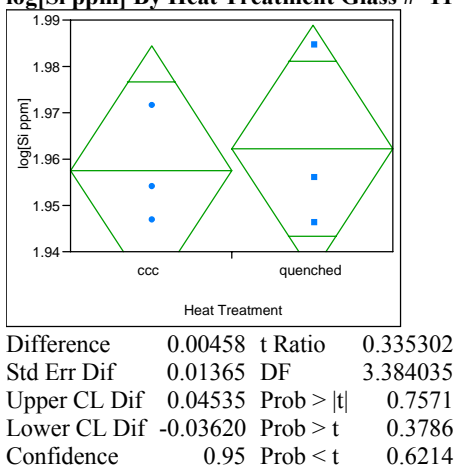

t Test: quenched-ccc

Assuming unequal variances $\log [$ B ppm] By Heat Treatment Glass \#=12

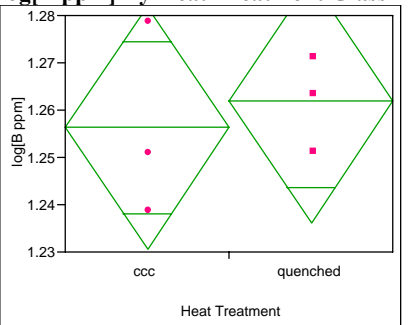

Difference $\quad 0.00556$ t Ratio 0.423583 Std Err Dif $\quad 0.01312$ DF 2.906264

Upper CL Dif 0.04808 Prob $>|t| \quad 0.7013$ Lower CL Dif -0.03697 Prob $>t \quad 0.3506$ $\begin{array}{lll}\text { Confidence } & 0.95 \text { Prob }<\mathrm{t} \quad 0.6494\end{array}$

$\log [\mathrm{Li}$ ppm] By Heat Treatment Glass \#=12

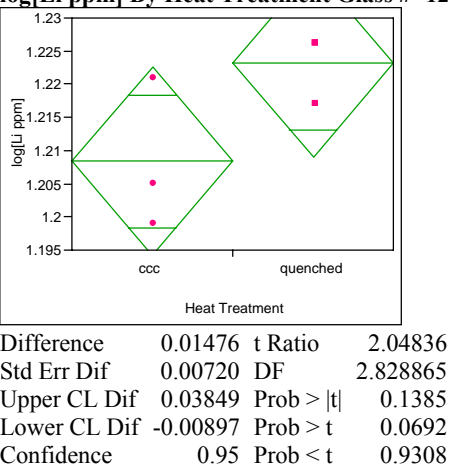

$\log [$ Na ppm] By Heat Treatment Glass \#=12

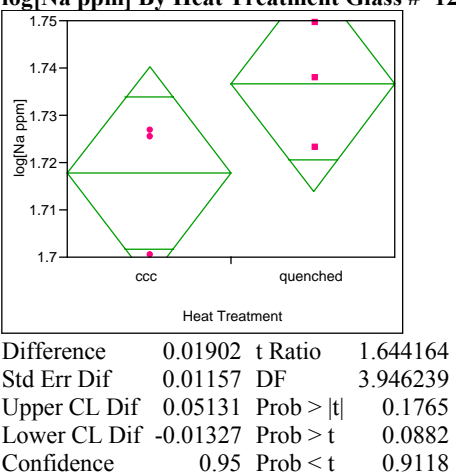

$\log [$ Si ppm] By Heat Treatment Glass \#=12

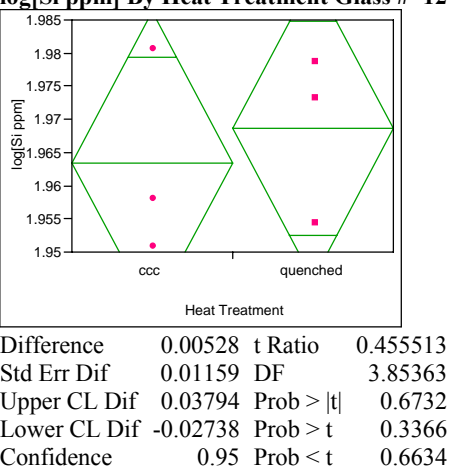




\section{Exhibit F7. Heat Treatment Effect on $\log (\mathrm{ppm})$ PCT Response (continued)}

t Test: quenched-ccc

Assuming unequal variances $\log [$ B ppm] By Heat Treatment Glass \#=13

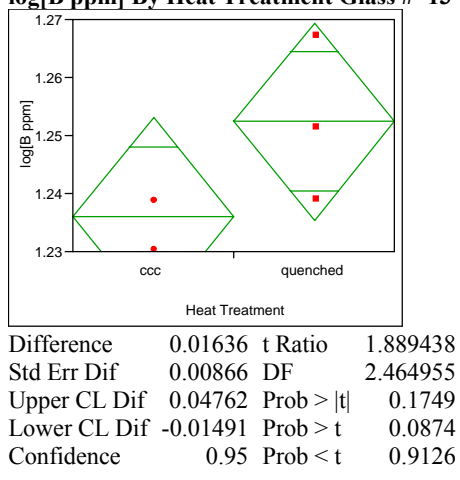

$\log [\mathrm{Li}$ ppm] By Heat Treatment Glass \#=13

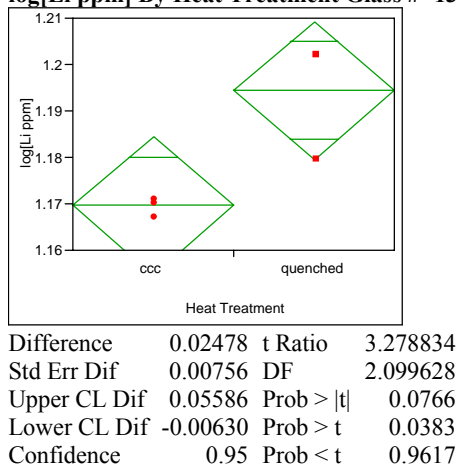

$\log [$ Na ppm] By Heat Treatment Glass \#=13

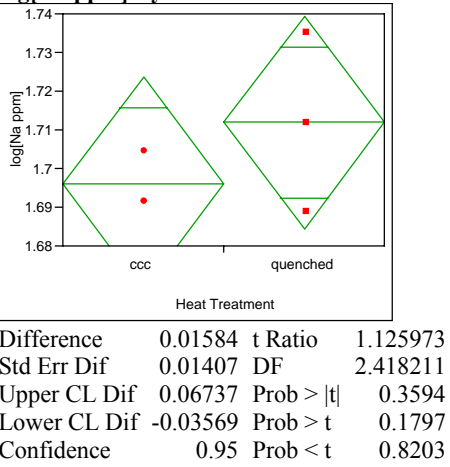

$\log [$ Si ppm] By Heat Treatment Glass \#=13

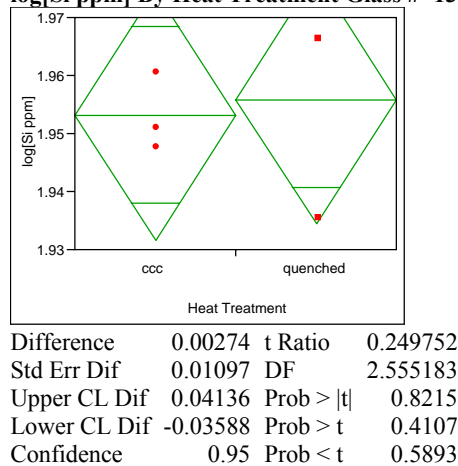

t Test: quenched-ccc

Assuming unequal variances $\log [$ B ppm] By Heat Treatment Glass \#=14

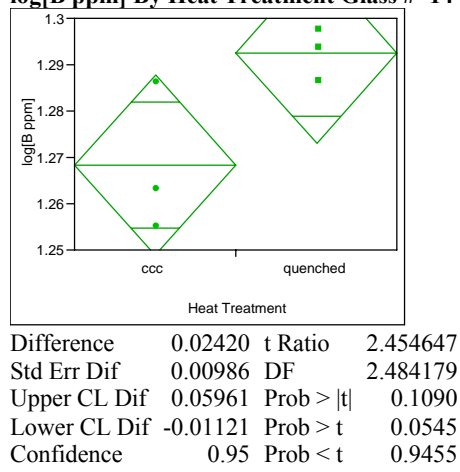

$\log [\mathrm{Li} \mathrm{ppm}]$ By Heat Treatment Glass \#=14

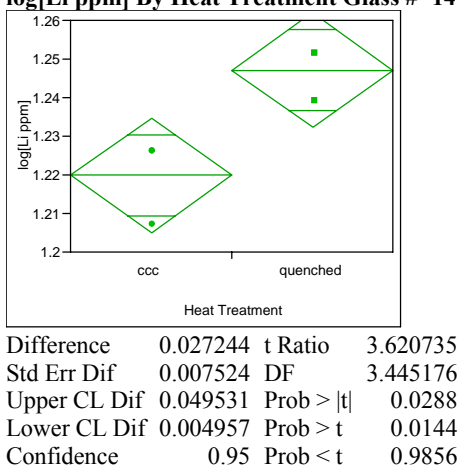

$\log [$ Na ppm] By Heat Treatment Glass \#=14

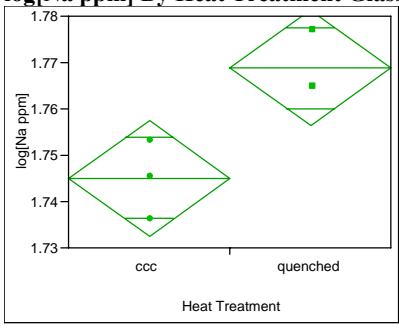

Difference $\quad 0.023657$ t Ratio 3.709447 Std Err Dif $\quad 0.006378$ DF $\quad 3.877714$ Upper CL Dif 0.041587 Prob $>|\mathrm{t}| \quad 0.0218$ Lower CL Dif 0.005728 Prob $>$ t 0.0109

Confidence $\quad 0.95$ Prob $<\mathrm{t} \quad 0.989$
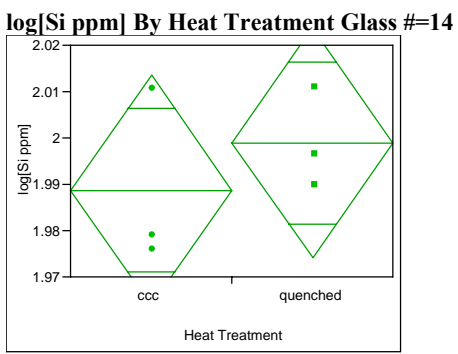

Difference $\quad 0.01022$ t Ratio 0.807902

Std Err Dif $\quad 0.01265$ DF 3.14551

Upper CL Dif 0.04946 Prob $>|t| \quad 0.4758$

Lower CL Dif -0.02901 Prob $>t \quad 0.2379$

Confidence $\quad 0.95$ Prob $<t \quad 0.7621$ t Test: quenched-ccc

Assuming unequal variances $\log [$ B ppm] By Heat Treatment Glass \#=15

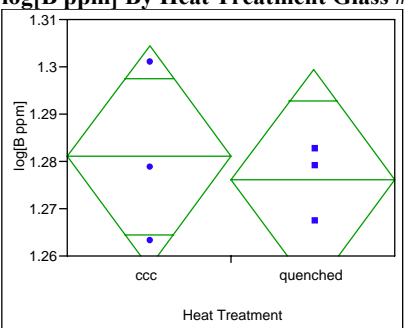

Difference $\quad-0.00485$ t Ratio $\quad-0.40759$ Std Err Dif $\quad 0.01190$ DF $\quad 2.689413$

Upper CL Dif 0.03562 Prob $>|t| 0.7138$

Lower CL Dif -0.04533 Prob $>\mathrm{t} \quad 0.6431$

$\begin{array}{lll}\text { Confidence } & 0.95 \text { Prob }<\mathrm{t} & 0.3569\end{array}$

$\log [\mathrm{Li}$ ppm] By Heat Treatment Glass \#=15

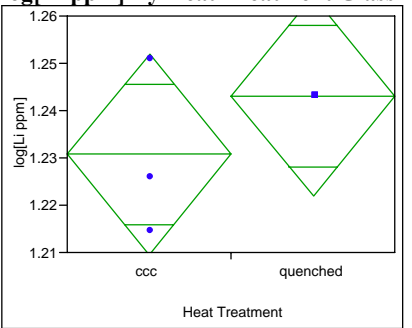

Difference $\quad 0.01229$ t Ratio 1.143068 Std Err Dif $\quad 0.01075$ DF

Upper CL Dif 0.05855 Prob $>|t| \quad 0.3714$

Lower CL Dif -0.03397 Prob $>t \quad 0.1857$

Confidence $\quad 0.95$ Prob $<\mathrm{t} \quad 0.8143$

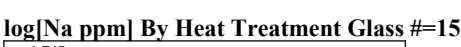

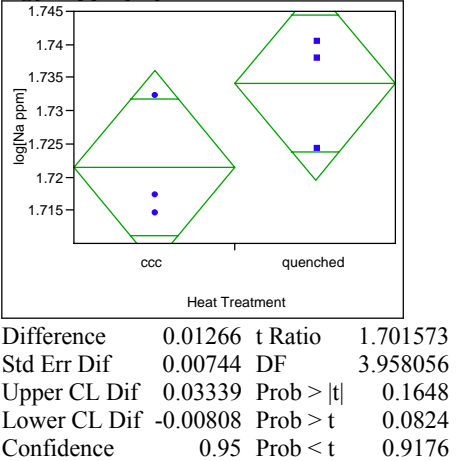

$\log [$ Si ppm] By Heat Treatment Glass \#=15

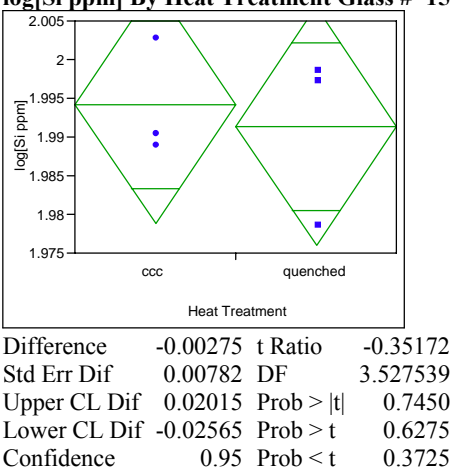




\section{Exhibit F7. Heat Treatment Effect on $\log (\mathrm{ppm})$ PCT Response (continued)}

t Test: quenched-ccc

Assuming unequal variances $\log [\mathrm{B}$ ppm $]$ By Heat Treatment Glass \#=16

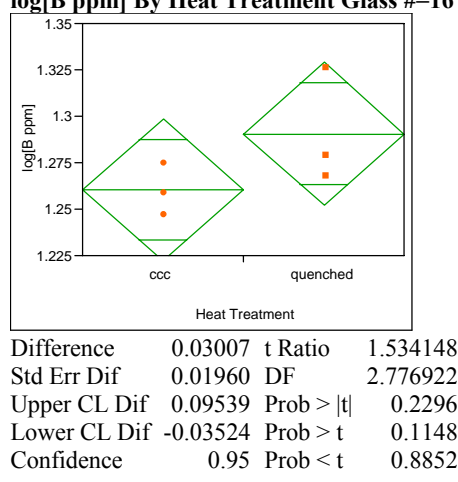

$\log [\mathrm{Li}$ ppm] By Heat Treatment Glass \#=16

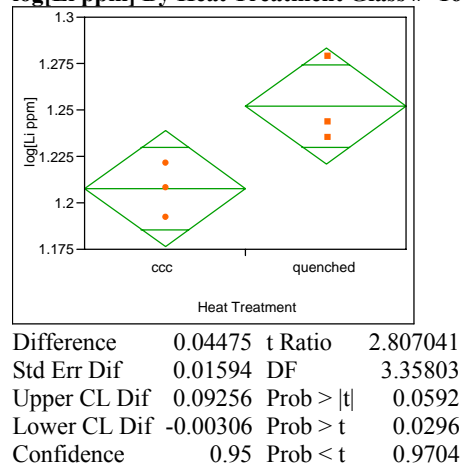

$\log [$ Na ppm] By Heat Treatment Glass \#=16

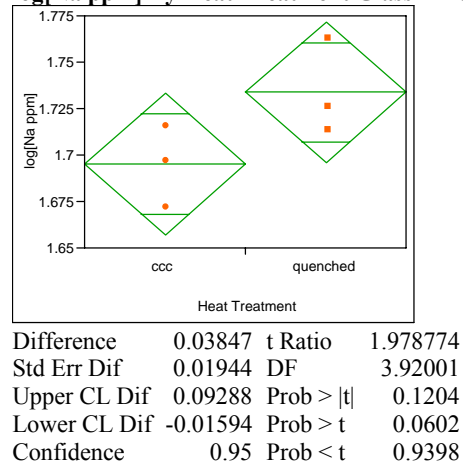

$\log [\mathrm{Si}$ ppm] By Heat Treatment Glass \#=16

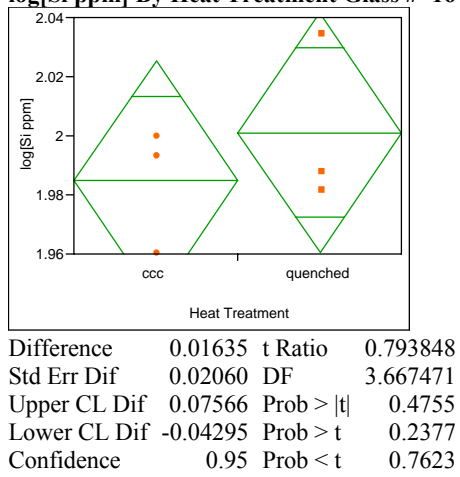

t Test: quenched-ccc

Assuming unequal variances $\log [$ B ppm] By Heat Treatment Glass \#=17

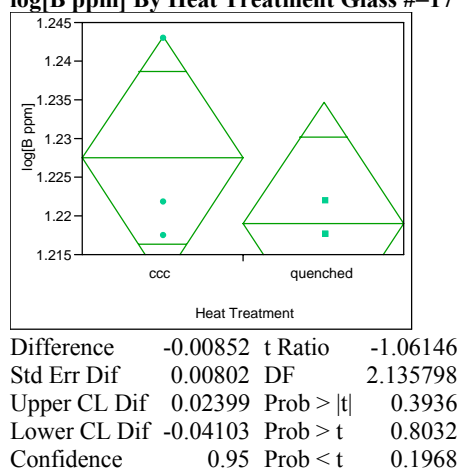

$\log [\mathrm{Li}$ ppm] By Heat Treatment Glass \#=17

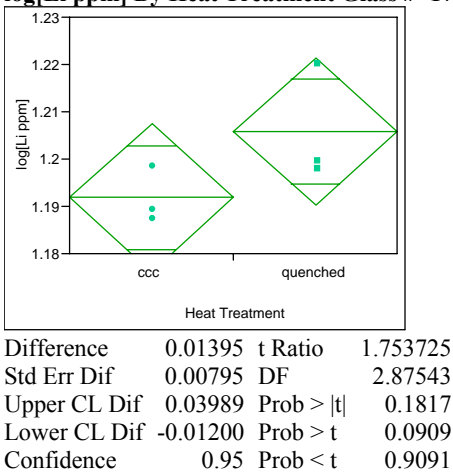

$\log [$ Na ppm] By Heat Treatment Glass \#=17

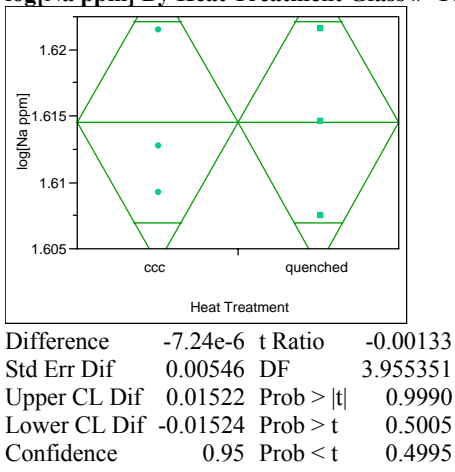

$\log [$ Si ppm] By Heat Treatment Glass \#=17

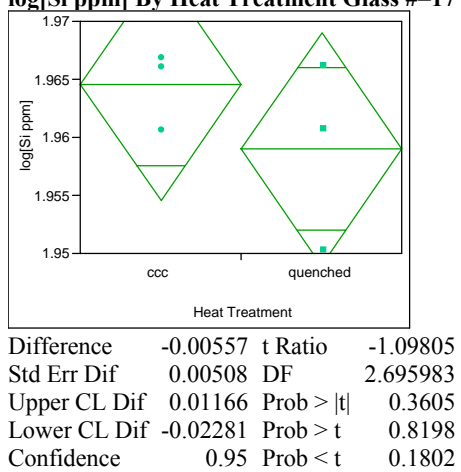

t Test: quenched-ccc

Assuming unequal variances $\log [$ B ppm] By Heat Treatment Glass \#=18

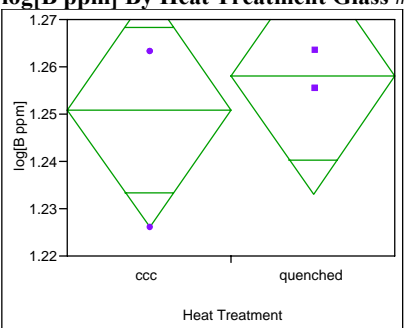

Difference $\quad 0.00704$ t Ratio 0.557344 Std Err Dif $\quad 0.01264$ DF 2.184441

Upper CL Dif 0.05726 Prob $>|t| 0.6291$ Lower CL Dif -0.04317 Prob $>\mathrm{t} \quad 0.3146$ $\begin{array}{lll}\text { Confidence } & 0.95 \text { Prob }<\mathrm{t} \quad 0.6854\end{array}$

$\log [\mathrm{Li}$ ppm] By Heat Treatment Glass \#=18

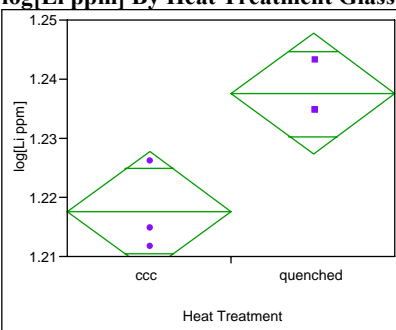

Difference $\quad 0.019884$ t Ratio 3.828516

Std Err Dif $\quad 0.005194$ DF $\quad 3.387233$

Upper CL Dif 0.035394 Prob $>|t| \quad 0.0253$

Lower CL Dif 0.004375 Prob $>t \quad 0.0126$

Confidence $\quad 0.95$ Prob $<\mathrm{t} \quad 0.9874$

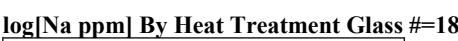

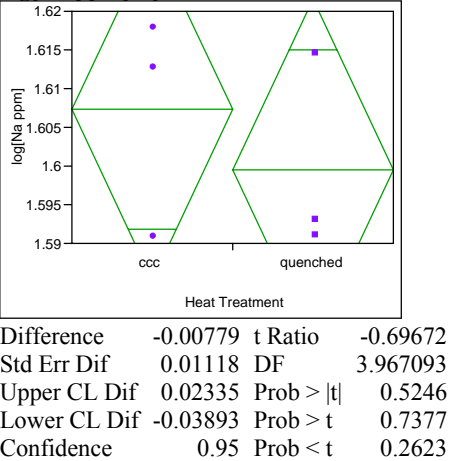

$\log [$ Si ppm] By Heat Treatment Glass \#=18

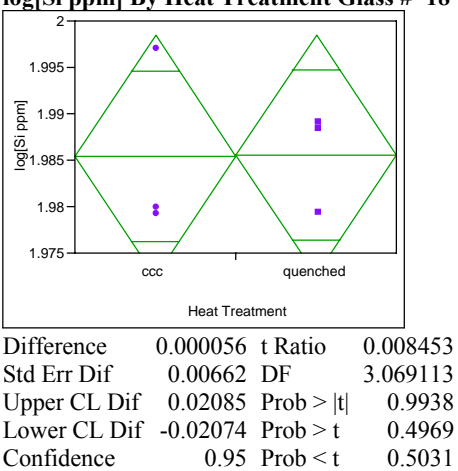




\section{Exhibit F7. Heat Treatment Effect on $\log (\mathrm{ppm})$ PCT Response (continued)}

t Test: quenched-ccc

Assuming unequal variances

$\log [\mathrm{B}$ ppm $]$ By Heat Treatment Glass \#=19

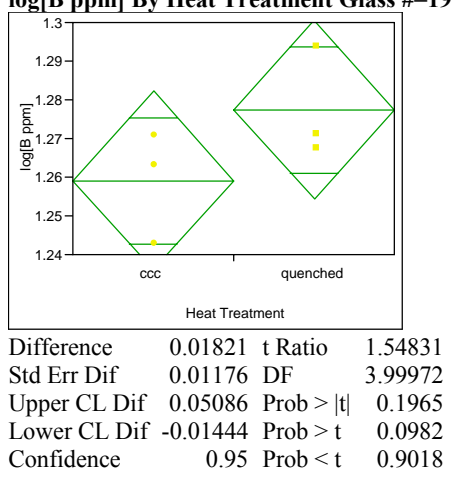

$\log [\mathrm{Li}$ ppm] By Heat Treatment Glass \#=19

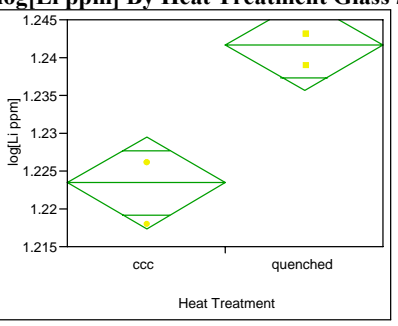

Difference $\quad 0.018232$ t Ratio 5.92223 Std Err Dif $\quad 0.003079$ DF 2.954118 Upper CL Dif 0.028116 Prob $>|t| \quad 0.0100$ Lower CL Dif 0.008348 Prob $>\mathrm{t} \quad 0.0050$ Confidence $\quad 0.95$ Prob $<\mathrm{t} \quad 0.9950$

$\log [$ Na ppm] By Heat Treatment Glass \#=19

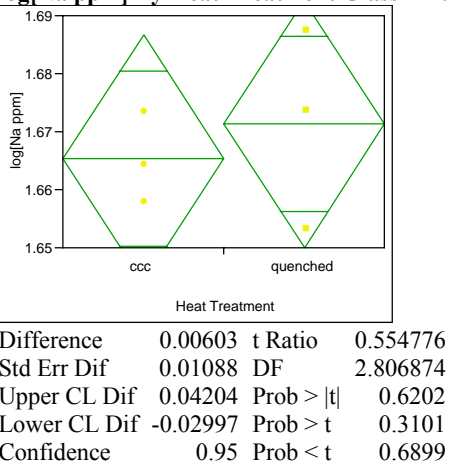

$\log [$ Si ppm] By Heat Treatment Glass \#=19

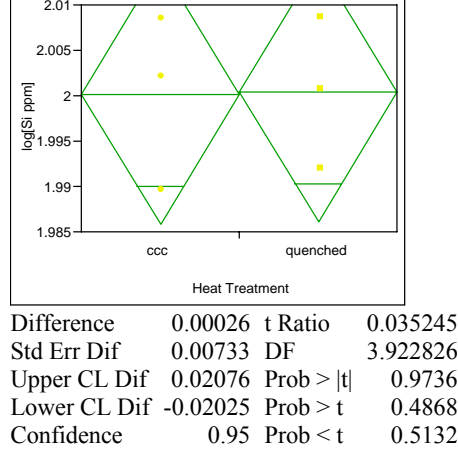

t Test: quenched-ccc

Assuming unequal variances $\log [$ B ppm] By Heat Treatment Glass \#=20

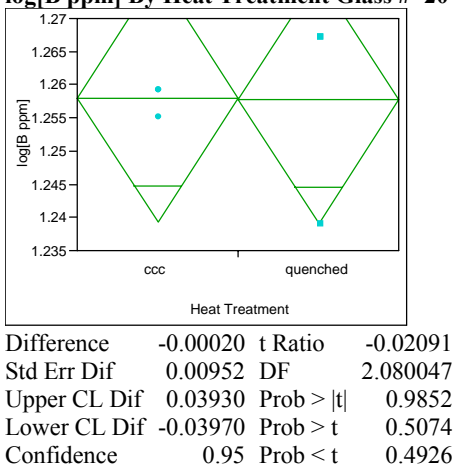

$\log [\mathrm{Li}$ ppm] By Heat Treatment Glass \#=20

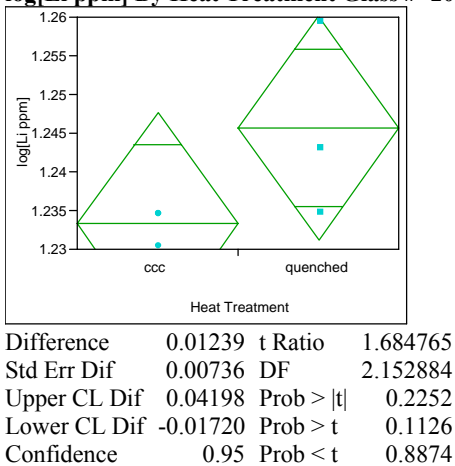

$\log [$ Na ppm] By Heat Treatment Glass \#=20

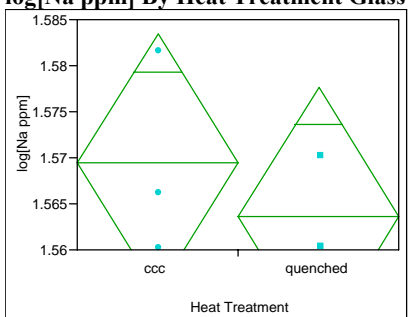

Difference $\quad-0.00582$ t Ratio $\quad-0.81227$ Std Err Dif $\quad 0.00717$ DF 2.991877 Upper CL Dif 0.01702 Prob $>|t| \quad 0.4763$ Lower CL Dif -0.02867 Prob $>$ t 0.7619 Confidence $\quad 0.95$ Prob $<\mathrm{t} \quad 0.2381$

$\log [$ Si ppm $]$ By Heat Treatment Glass \#=20

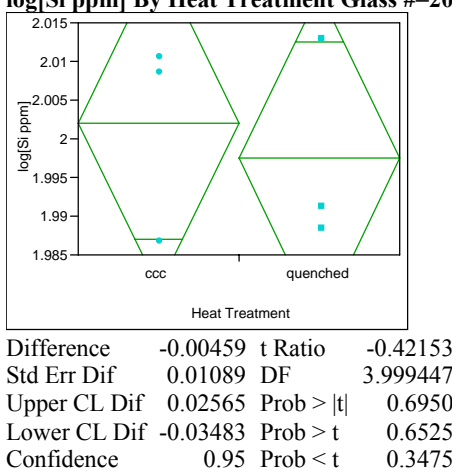

t Test: quenched-ccc

Assuming unequal variances $\log [$ B ppm] By Heat Treatment Glass \#=21

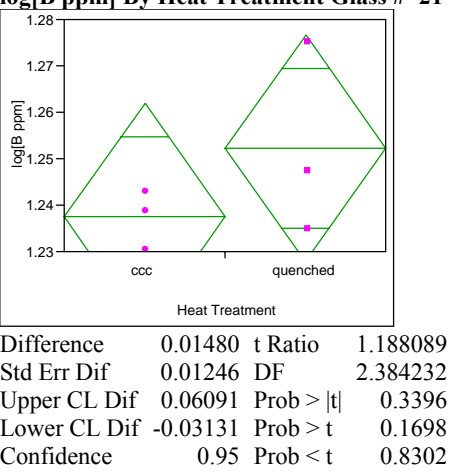

$\log [\mathrm{Li}$ ppm] By Heat Treatment Glass \#=21

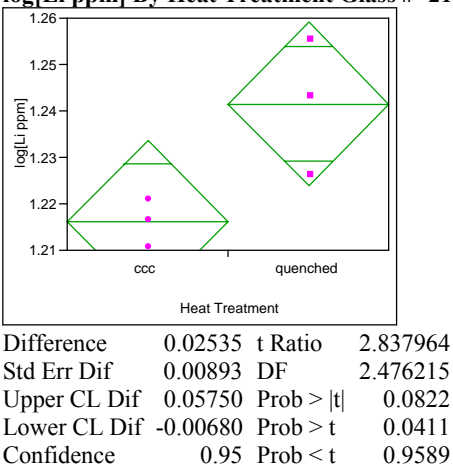

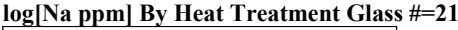

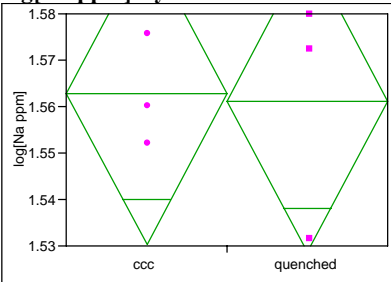

Heat Treatment

Difference $\quad-0.00172$ t Ratio $\quad-0.10422$ Std Err Dif $\quad 0.01652$ DF 2.823748 Upper CL Dif 0.05276 Prob $>|t| \quad 0.9240$ Lower CL Dif -0.05621 Prob $>t \quad 0.5380$ Confidence $\quad 0.95$ Prob $<\mathrm{t} \quad 0.4620$

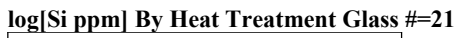

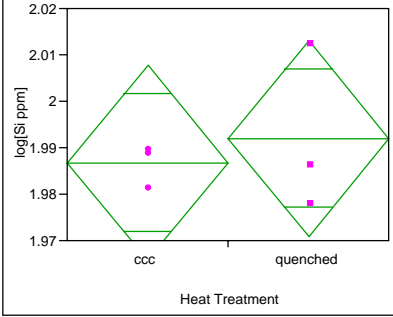

Difference $\quad 0.00520$ t Ratio 0.486657

Std Err Dif $\quad 0.01070$ DF 2.256041

Upper CL Dif 0.04656 Prob $>|t| \quad 0.6697$ Lower CL Dif -0.03615 Prob $>t \quad 0.3349$

Confidence $\quad 0.95$ Prob $<\mathrm{t} \quad 0.6651$ 


\section{Exhibit F7. Heat Treatment Effect on $\log (\mathrm{ppm})$ PCT Response (continued)}

t Test: quenched-ccc

Assuming unequal variances $\log [\mathrm{B}$ ppm] By Heat Treatment Glass \#=22

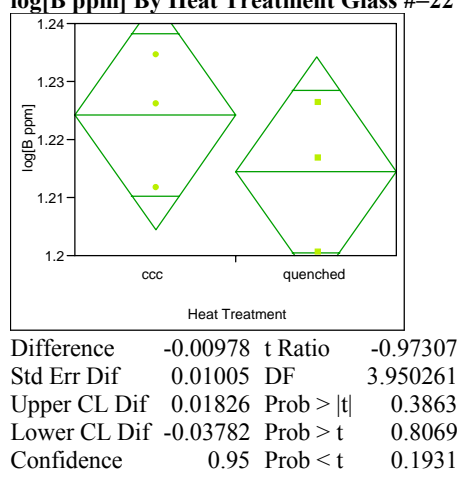

$\log [\mathrm{Li} \mathrm{ppm]} \mathrm{By} \mathrm{Heat} \mathrm{Treatment} \mathrm{Glass} \mathrm{\# =22}$

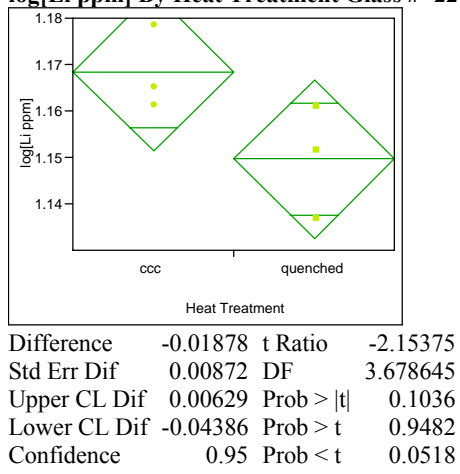

$\log [\mathrm{Na}$ ppm] By Heat Treatment Glass \#=22

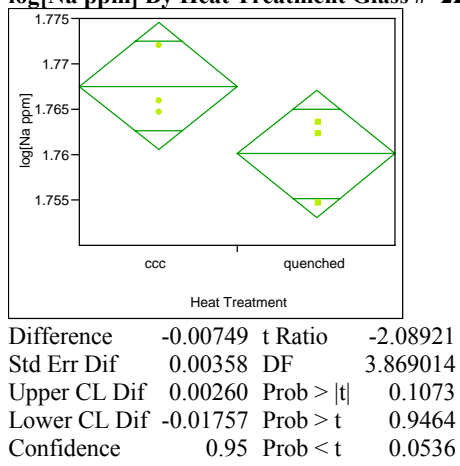

$\log [\mathrm{Si}$ ppm] By Heat Treatment Glass \#=22

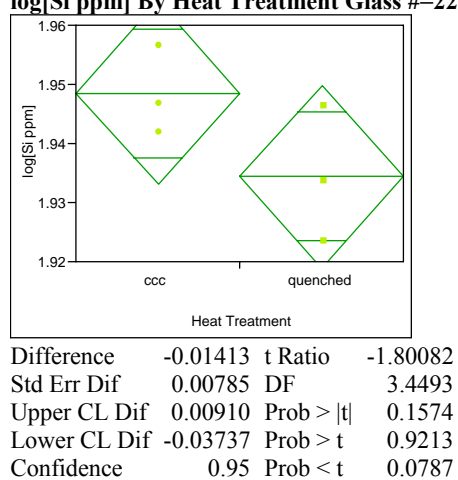

t Test: quenched-ccc

Assuming unequal variances $\log [$ B ppm] By Heat Treatment Glass \#=23

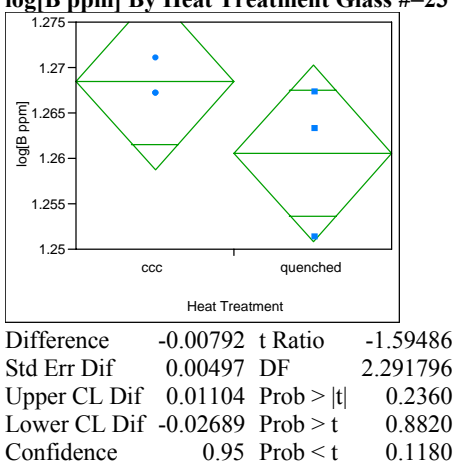

$\log [\mathrm{Li} \mathrm{ppm}]$ By Heat Treatment Glass \#=23

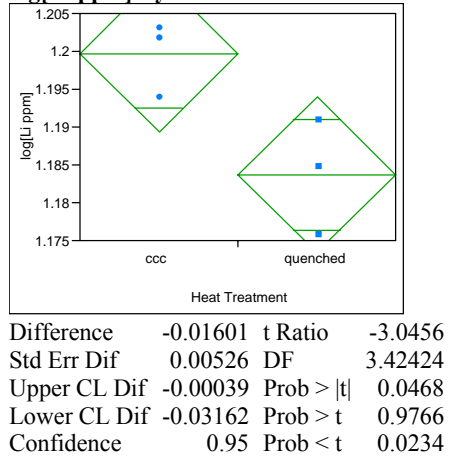

$\log [$ Na ppm] By Heat Treatment Glass \#=23

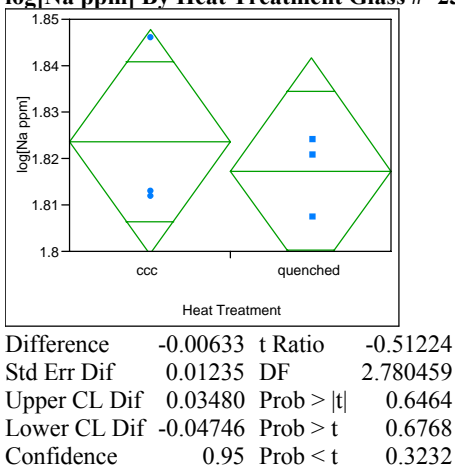

$\log [\mathrm{Si}$ ppm] By Heat Treatment Glass \#=23

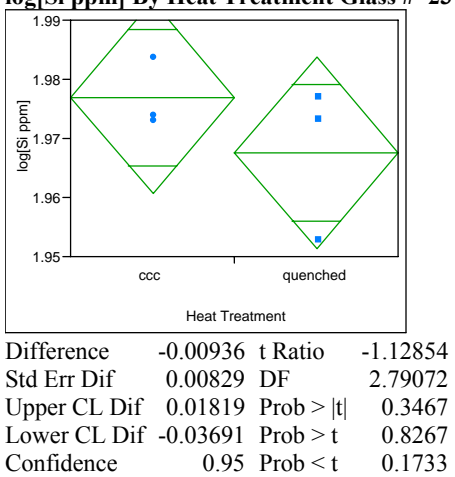

t Test: quenched-ccc

Assuming unequal variances Treatment Glass \#=24

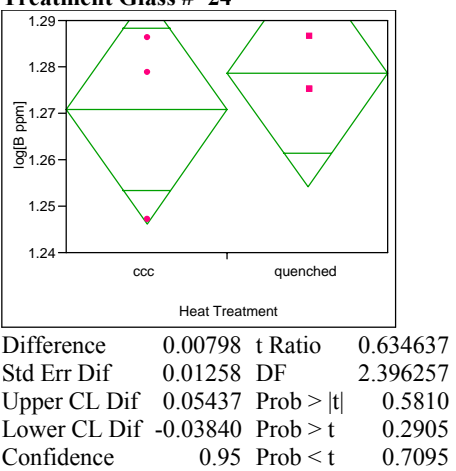

$\log [\mathrm{Li}$ ppm] By Heat Treatment Glass \#=24

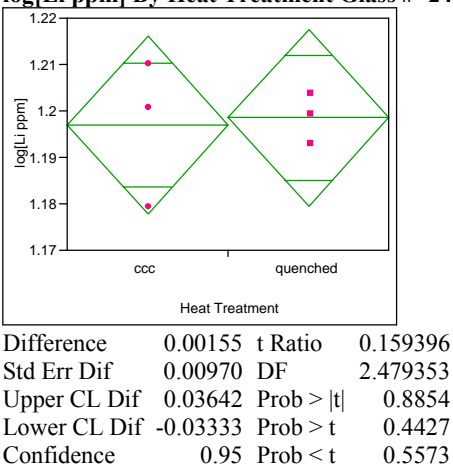

$\log [\mathrm{Na}$ ppm] By Heat Treatment Glass \#=24

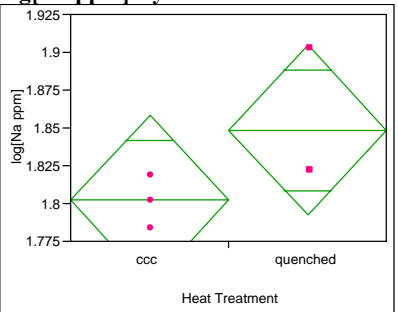

Difference $\quad 0.04640$ t Ratio 1.616566 Std Err Dif $\quad 0.02870$ DF 2.569411 Upper CL Dif 0.14703 Prob $>|\mathrm{t}| \quad 0.2193$ Lower CL Dif -0.05424 Prob $>t \quad 0.1096$ Confidence $\quad 0.95$ Prob $<\mathrm{t} \quad 0.8904$

$\underline{\log [S i}$ ppm] By Heat Treatment Glass \#=24

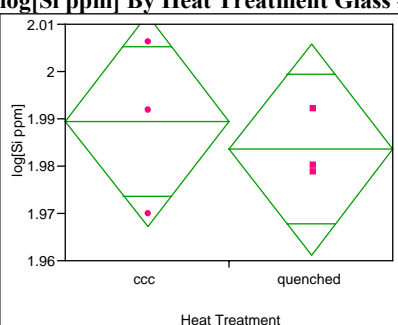

Difference $\quad-0.00600$ t Ratio $\quad-0.52607$

Std Err Dif $\quad 0.01141$ DF 2.631617

Upper CL Dif 0.03337 Prob $>|t| \quad 0.6399$

Lower CL Dif -0.04538 Prob $>\mathrm{t} \quad 0.6800$

Confidence $\quad 0.95$ Prob $<t \quad 0.3200$ 


\section{Exhibit F7. Heat Treatment Effect on $\log (\mathrm{ppm})$ PCT Response (continued)}

t Test: quenched-ccc

Assuming unequal variances $\log [\mathrm{B}$ ppm $]$ By Heat Treatment Glass \#=25

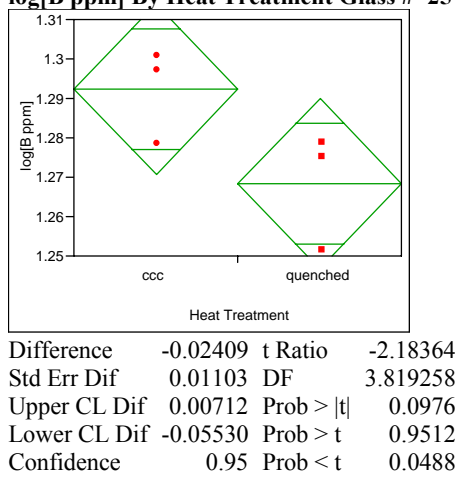

$\log [\mathrm{Li}$ ppm] By Heat Treatment Glass \#=25

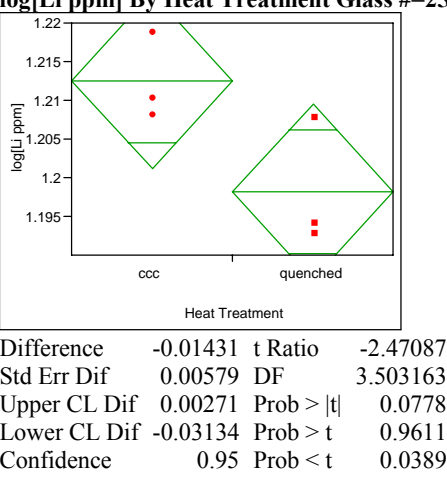

$\log [$ Na ppm] By Heat Treatment Glass \#=25

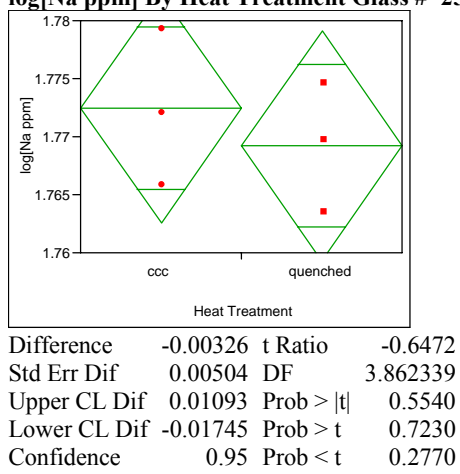

$\log [$ Si ppm] By Heat Treatment Glass \#=25

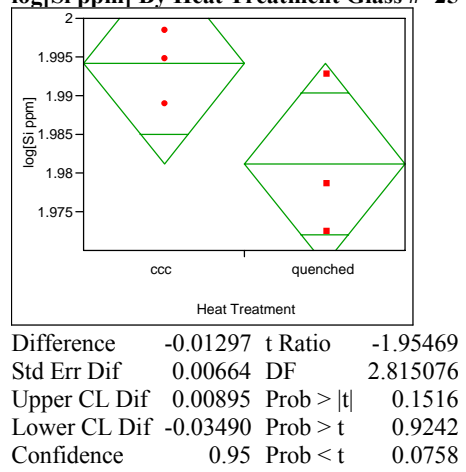

t Test: quenched-ccc

Assuming unequal variances $\log [$ B ppm] By Heat Treatment Glass \#=26

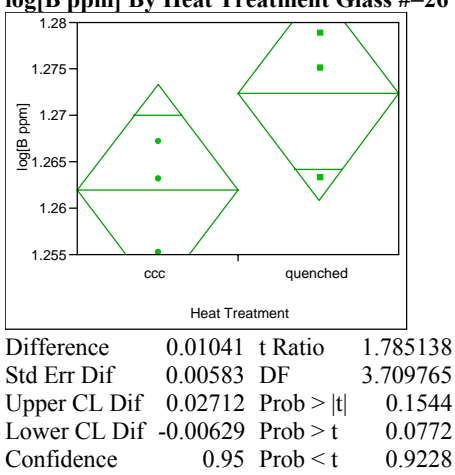

$\log [\mathrm{Li}$ ppm] By Heat Treatment Glass \#=26

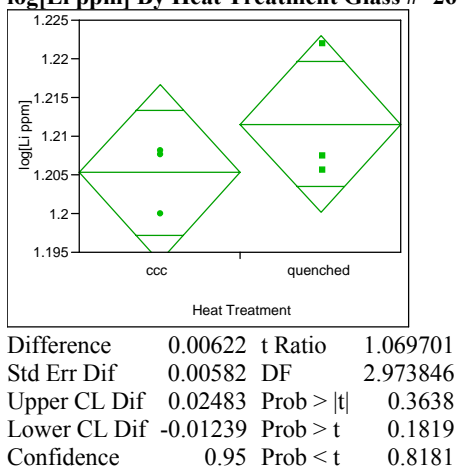

$\log [\mathrm{Na}$ ppm] By Heat Treatment Glass \#=26

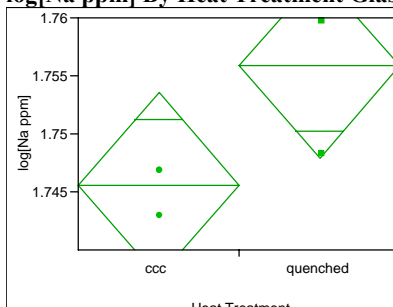

Difference $\quad 0.01025$ t Ratio 2.535778 Std Err Dif $\quad 0.00404$ DF 2.457119 Upper CL Dif 0.02488 Prob $>|t| \quad 0.1035$ Lower CL Dif -0.00438 Prob $>t \quad 0.0517$ Confidence $\quad 0.95$ Prob $<\mathrm{t} \quad 0.9483$

$\log [\mathrm{Si}$ ppm] By Heat Treatment Glass \#=26

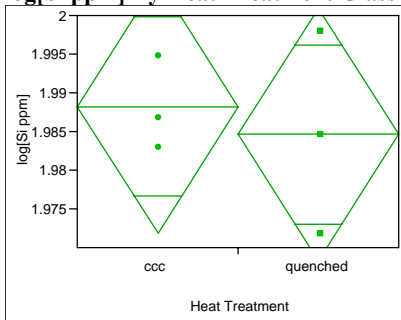

Difference $\quad-0.00359$ t Ratio $\quad-0.42989$ Std Err Dif $\quad 0.00835$ DF $\quad 2.819439$ Upper CL Dif 0.02396 Prob $>|t| \quad 0.6980$ Lower CL Dif -0.03114 Prob $>\mathrm{t} \quad 0.6510$ Confidence $\quad 0.95$ Prob $<\mathrm{t} \quad 0.3490$ t Test: quenched-ccc

Assuming unequal variances $\log [$ B ppm] By Heat Treatment Glass \#=27

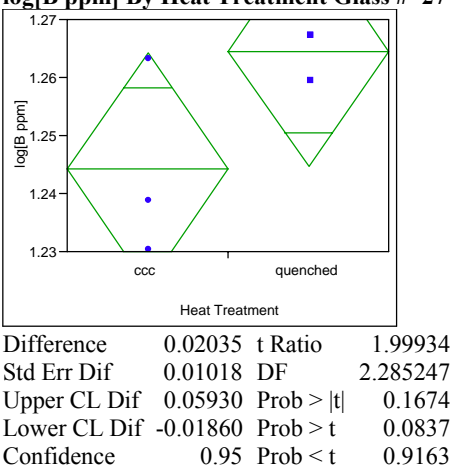

$\log [\mathrm{Li}$ ppm] By Heat Treatment Glass \#=27

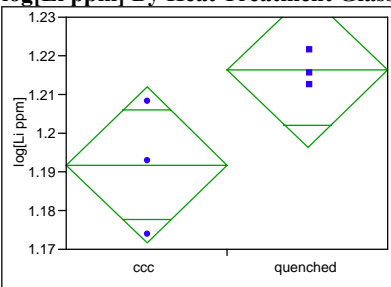

Heat Treatment

Difference $\quad 0.02448$ t Ratio 2.397936 Std Err Dif $\quad 0.01021$ DF 2.301808 Upper CL Dif 0.06332 Prob $>|t| \quad 0.1221$

Lower CL Dif -0.01436 Prob $>t \quad 0.0610$ Confidence $\quad 0.95$ Prob $<\mathrm{t} \quad 0.9390$

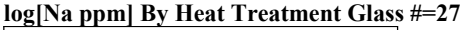

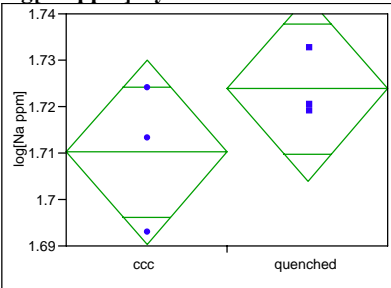

Heat Treatment

Difference $\quad 0.01357$ t Ratio 1.345057 Std Err Dif $\quad 0.01009$ DF 2.85817 Upper CL Dif 0.04659 Prob $>|t| \quad 0.2754$ Lower CL Dif -0.01945 Prob $>t \quad 0.1377$ Confidence $\quad 0.95$ Prob $<\mathrm{t} \quad 0.8623$

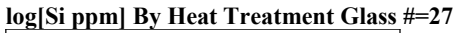

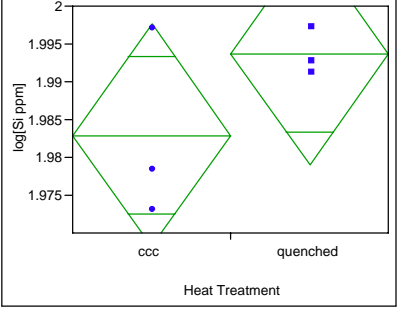

Difference $\quad 0.01077$ t Ratio 1.441254 Std Err Dif $\quad 0.00747$ DF 2.234808 Upper CL Dif 0.03990 Prob $>|t| \quad 0.2738$ Lower CL Dif -0.01835 Prob $>t \quad 0.1369$ $\begin{array}{lll}\text { Confidence } & 0.95 \text { Prob }<\mathrm{t} \quad 0.8631\end{array}$ 


\section{Exhibit F7. Heat Treatment Effect on $\log (\mathrm{ppm})$ PCT Response (continued)}

t Test: quenched-ccc

Assuming unequal variances $\log [$ B ppm] By Heat Treatment Glass \#=28

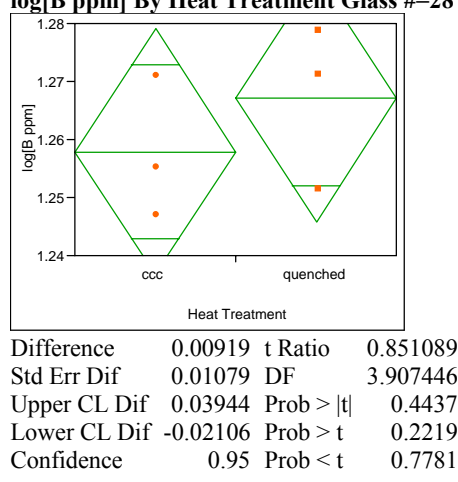

$\log [\mathrm{Li}$ ppm] By Heat Treatment Glass \#=28

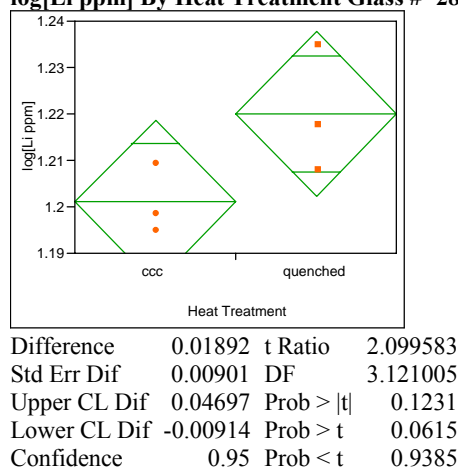

$\log [$ Na ppm] By Heat Treatment Glass \#=28

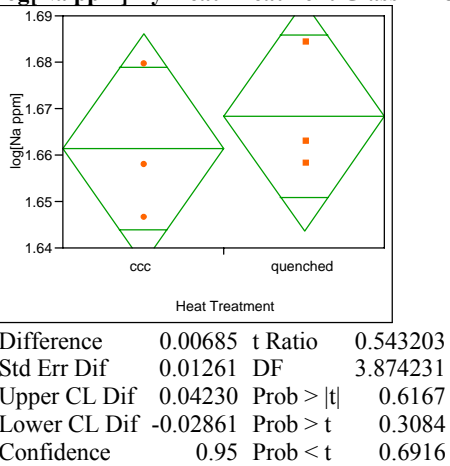

$\log [$ Si ppm] By Heat Treatment Glass \#=28

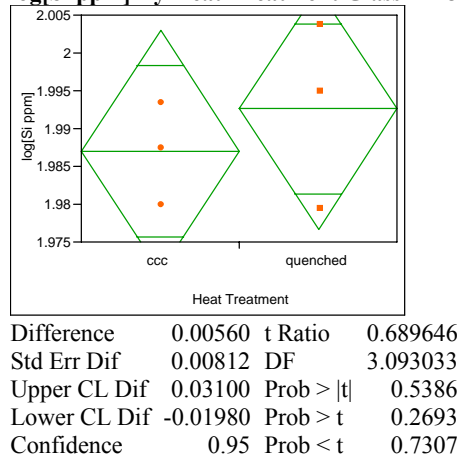

t Test: quenched-ccc

Assuming unequal variances $\log [$ B ppm] By Heat Treatment Glass \#=29

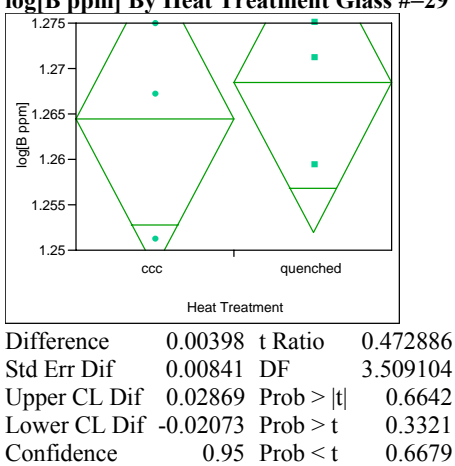

$\log [\mathrm{Li} \mathrm{ppm}]$ By Heat Treatment Glass \#=29

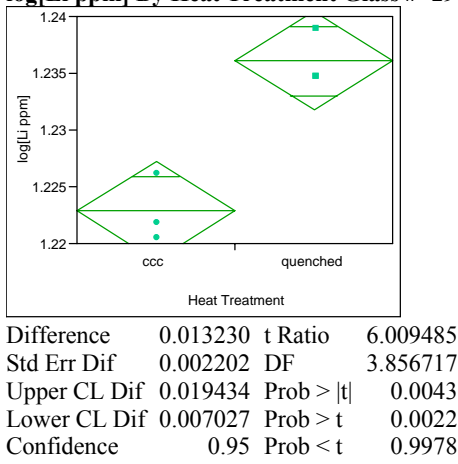

$\log [\mathrm{Na}$ ppm] By Heat Treatment Glass \#=29

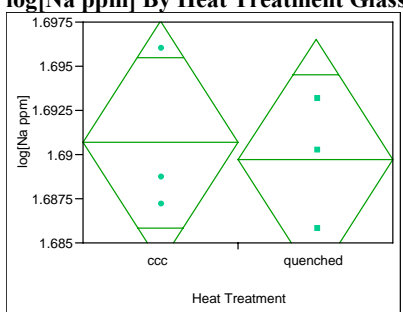

Difference $\quad-0.00098$ t Ratio $\quad-0.28142$ Std Err Dif $\quad 0.00348$ DF $\quad 3.79163$

Upper CL Dif 0.00889 Prob $>|\mathrm{t}| \quad 0.7931$

Lower CL Dif -0.01084 Prob $>t \quad 0.6035$

Confidence $\quad 0.95$ Prob $<\mathrm{t} \quad 0.3965$

$\log [\mathrm{Si}$ ppm] By Heat Treatment Glass \#=29

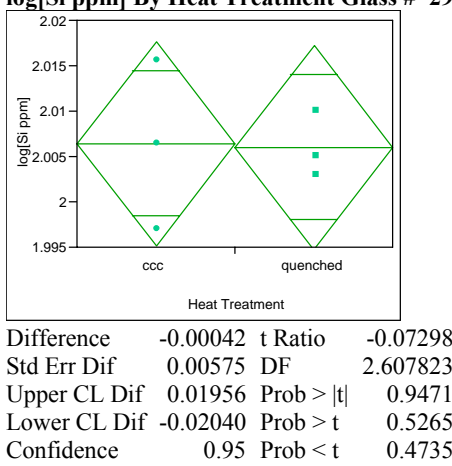

t Test: quenched-ccc

Assuming unequal variances $\log [$ B ppm] By Heat Treatment Glass \#=30

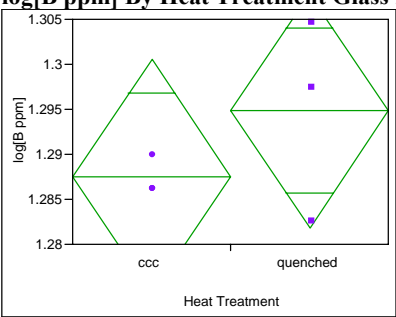

Difference $\quad 0.00731$ t Ratio 1.104352 Std Err Dif $\quad 0.00662$ DF $\quad 2.145946$ Upper CL Dif 0.03401 Prob $>|t| \quad 0.3778$ Lower CL Dif -0.01939 Prob $>t \quad 0.1889$

Confidence $\quad 0.95$ Prob $<\mathrm{t} \quad 0.8111$

$\log [\mathrm{Li} \mathrm{ppm}]$ By Heat Treatment Glass \#=30

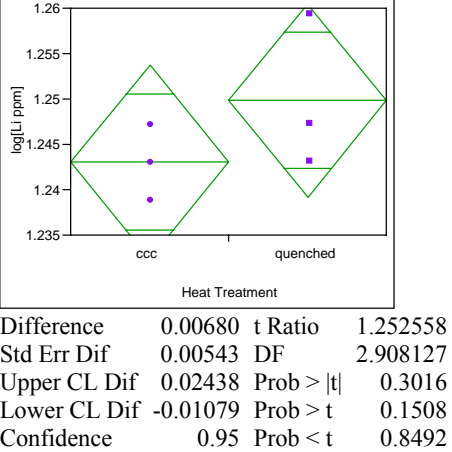

$\log [\mathrm{Na}$ ppm] By Heat Treatment Glass \#=30

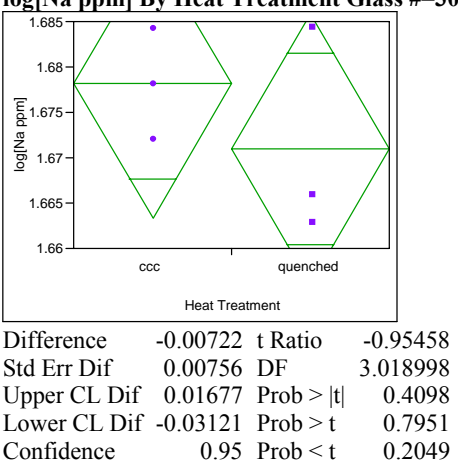

$\log [\mathrm{Si}$ ppm] By Heat Treatment Glass \#=30

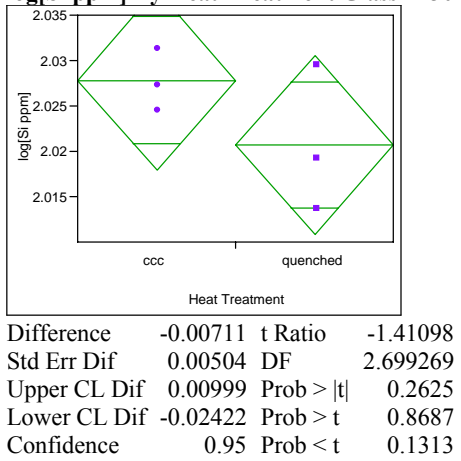




\section{Exhibit F7. Heat Treatment Effect on $\log (\mathrm{ppm})$ PCT Response (continued)}

t Test: quenched-ccc

Assuming unequal variances $\log [$ B ppm] By Heat Treatment Glass \#=31

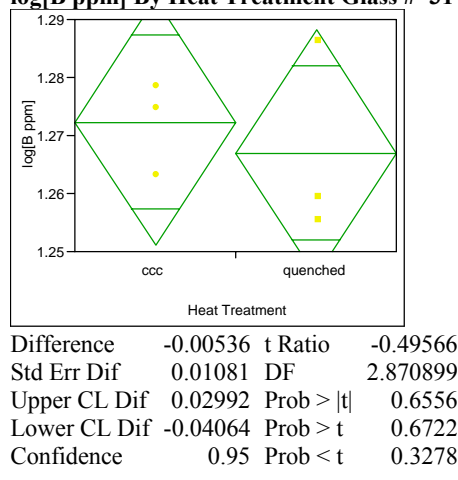

$\log [\mathrm{Li}$ ppm] By Heat Treatment Glass \#=31

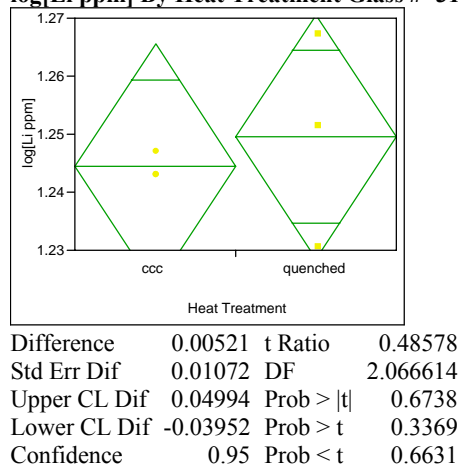

$\log [\mathrm{Na}$ ppm] By Heat Treatment Glass \#=31

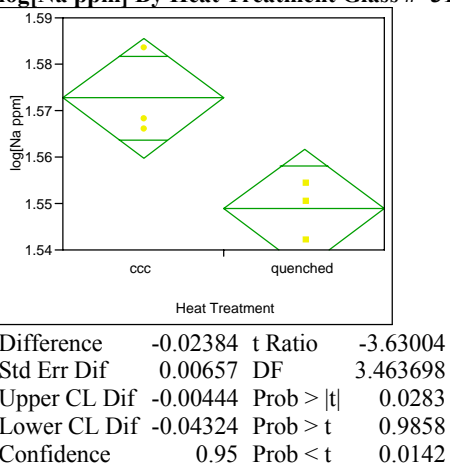

$\log [$ Si ppm] By Heat Treatment Glass \#=31

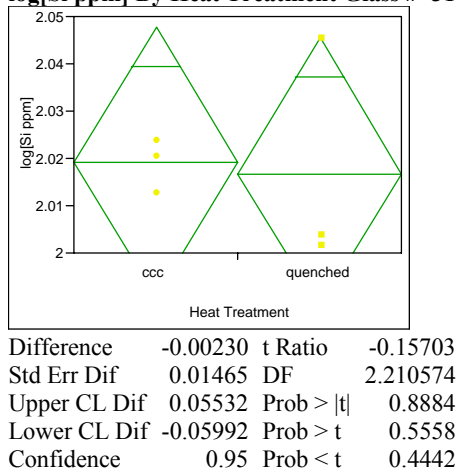

t Test: quenched-ccc

Assuming unequal variances $\log [$ B ppm] By Heat Treatment Glass \#=32

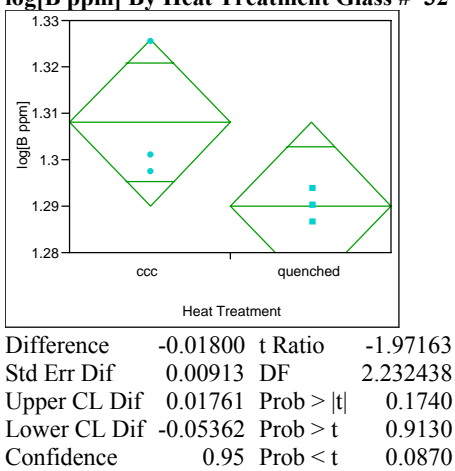

$\log [\mathrm{Li}$ ppm] By Heat Treatment Glass \#=32

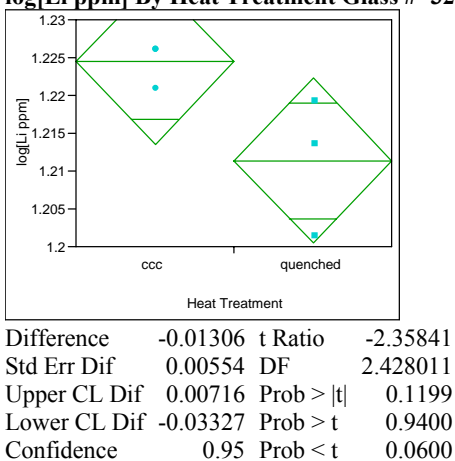

$\log [\mathrm{Na}$ ppm] By Heat Treatment Glass \#=32

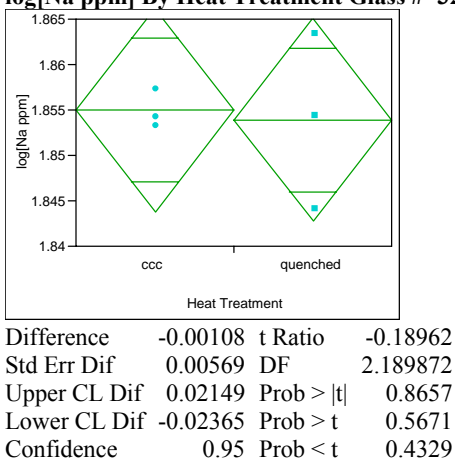

$\log [\mathrm{Si}$ ppm] By Heat Treatment Glass \#=32

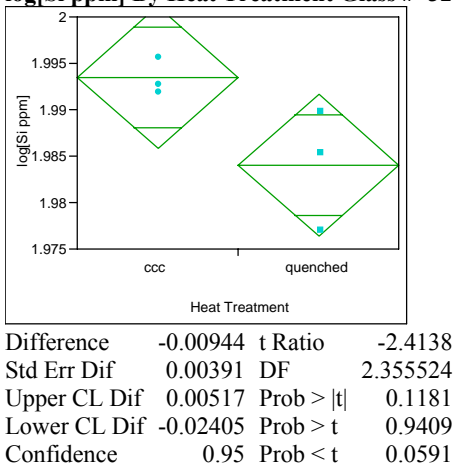

t Test: quenched-ccc

Assuming unequal variances $\log [$ B ppm] By Heat Treatment Glass \#=33

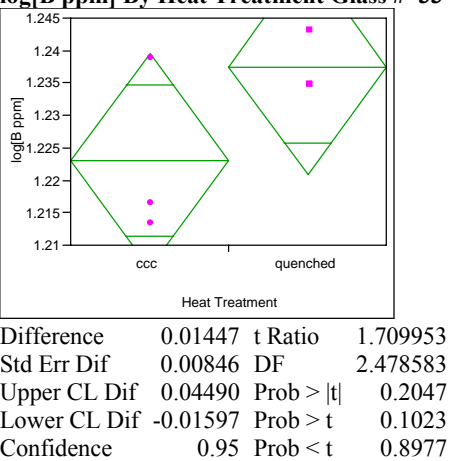

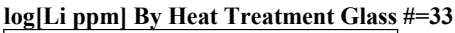

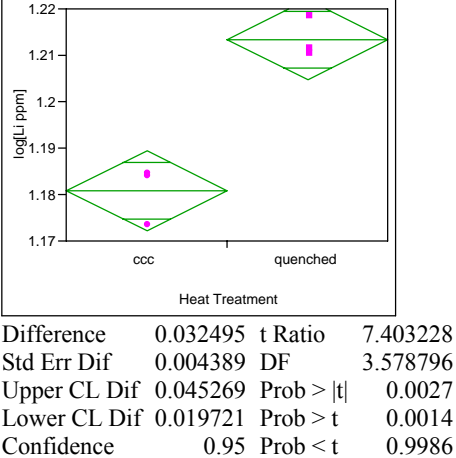

$\log [$ Na ppm] By Heat Treatment Glass \#=33

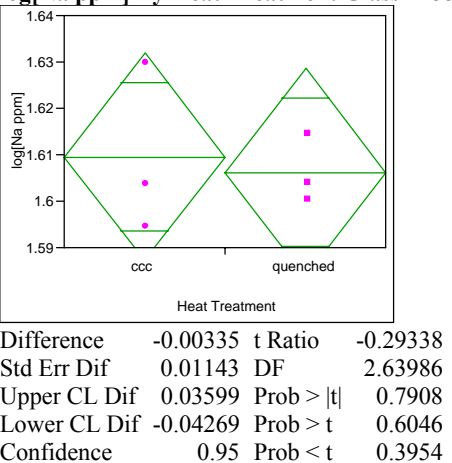

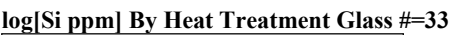

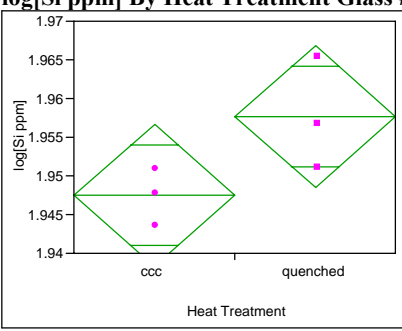

Difference $\quad 0.01020$ t Ratio 2.176828 Std Err Dif $\quad 0.00468$ DF 2.974174

Upper CL Dif 0.02518 Prob $>|\mathrm{t}| \quad 0.1185$ Lower CL Dif -0.00478 Prob $>t \quad 0.0592$ $\begin{array}{lll}\text { Confidence } & 0.95 \text { Prob }<\mathrm{t} \quad 0.9408\end{array}$ 


\section{Exhibit F7. Heat Treatment Effect on $\log (\mathrm{ppm})$ PCT Response (continued)}

t Test: quenched-ccc

Assuming unequal variances

$\log [$ B ppm $]$ By Heat Treatment Glass \#=34

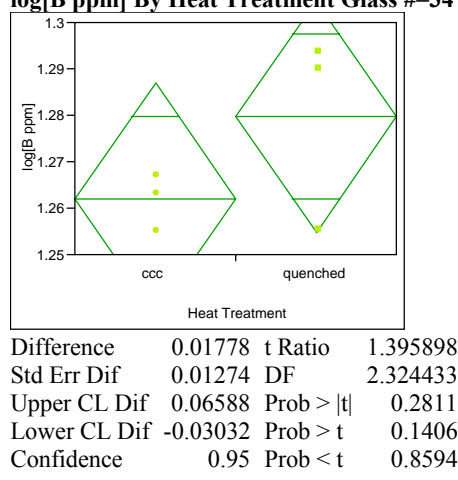

$\log [\mathrm{Li}$ ppm] By Heat Treatment Glass \#=34

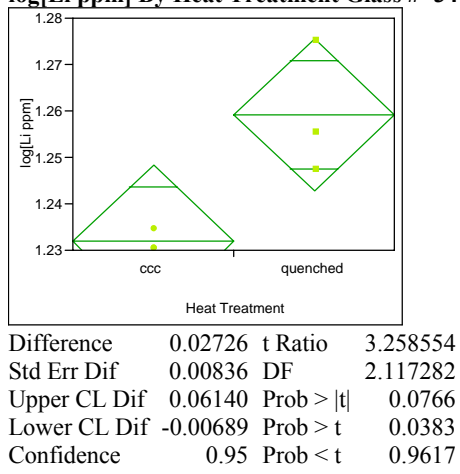

$\log [$ Na ppm] By Heat Treatment Glass \#=34

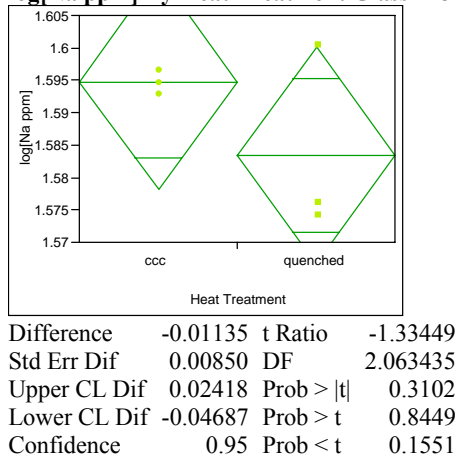

$\log [$ Si ppm] By Heat Treatment Glass \#=34

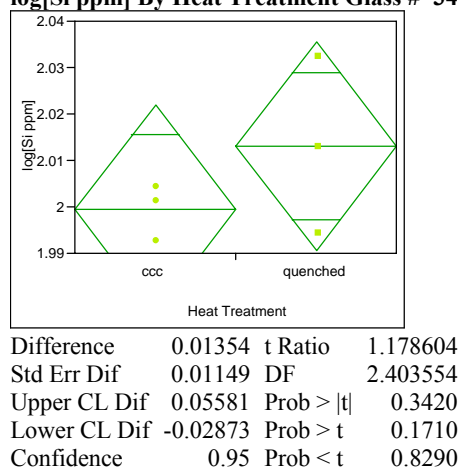

t Test: quenched-ccc

Assuming unequal variances

$\log [$ B ppm $]$ By Heat Treatment Glass \#=35

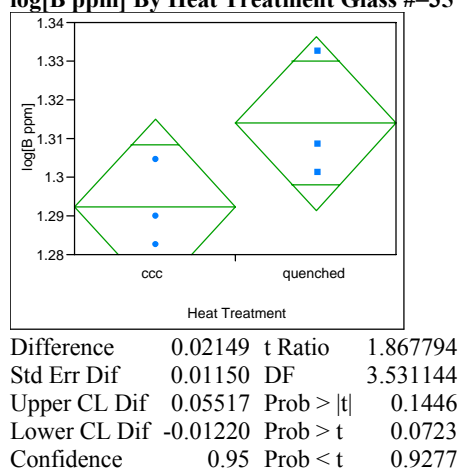

$\log [\mathrm{Li}$ ppm] By Heat Treatment Glass \#=35

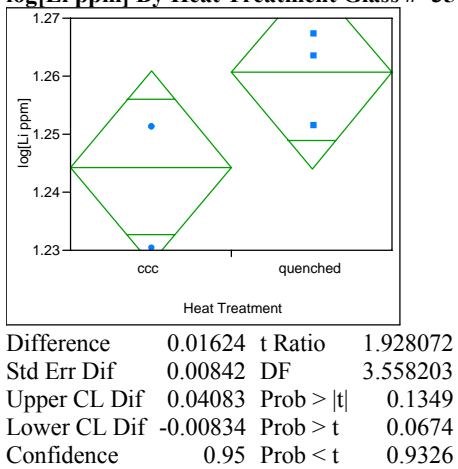

$\log [\mathrm{Na}$ ppm] By Heat Treatment Glass \#=35

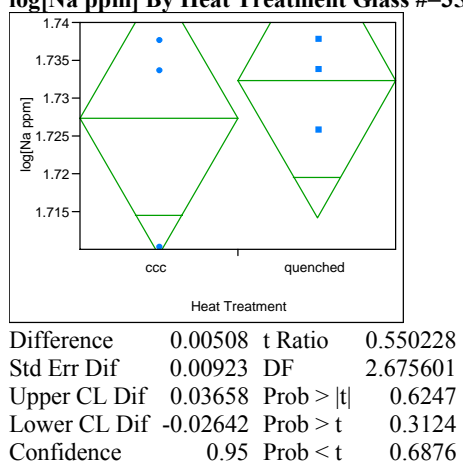

$\log [$ Si ppm] By Heat Treatment Glass \#=35

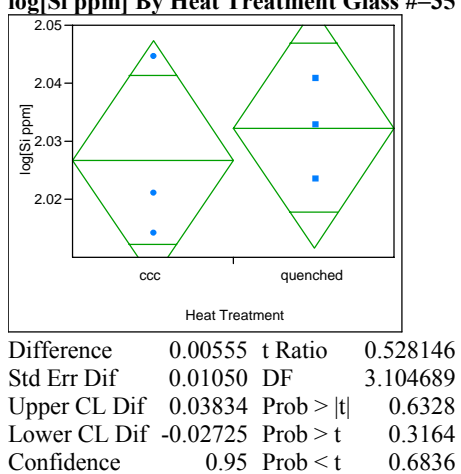


Exhibit F8. Effects of Heat Treatment for Study Glasses by Compositional View (continued)

Composition=measured

Variability Chart for log NL[B (g/L)]
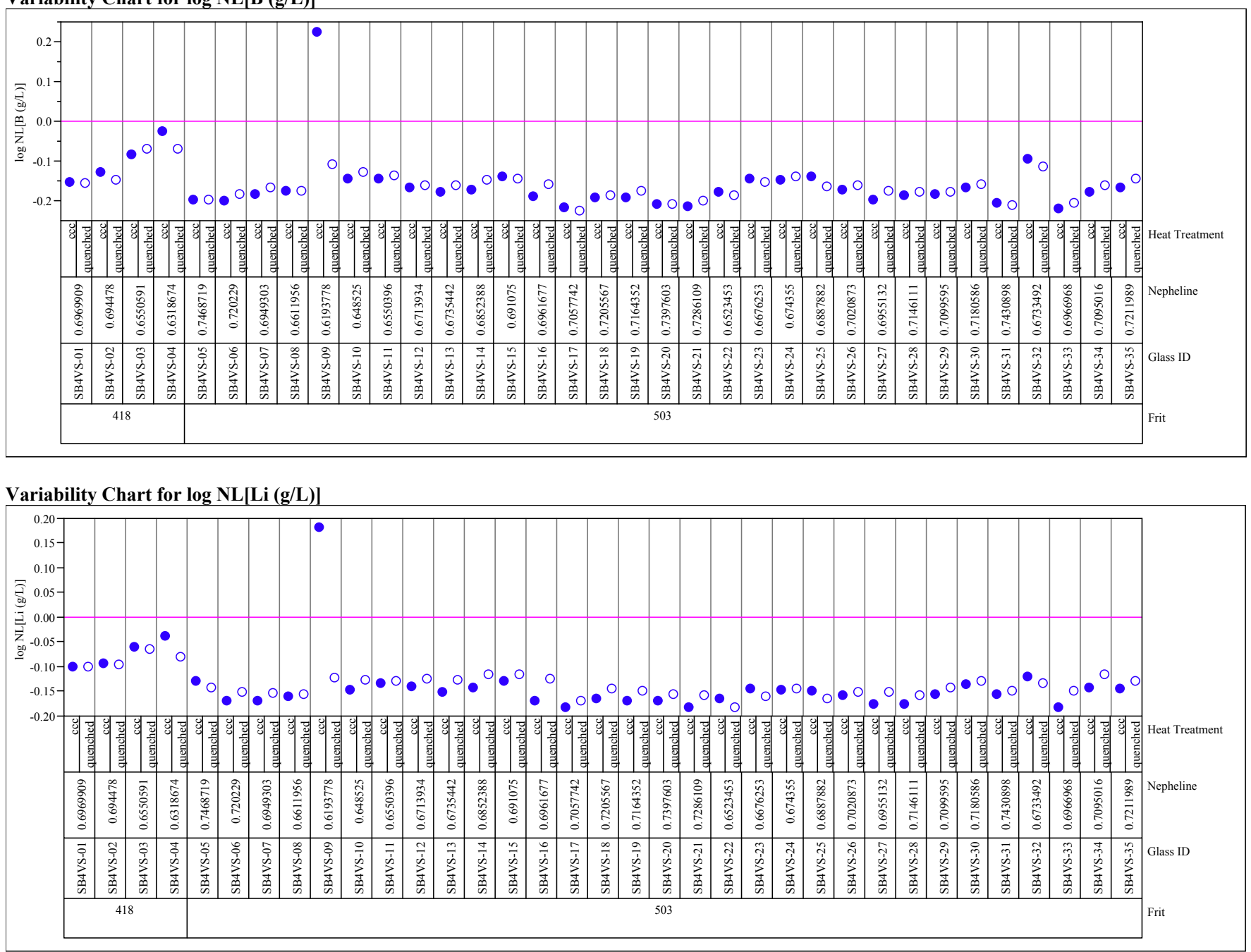
Exhibit F8. Effects of Heat Treatment for Study Glasses by Compositional View (continued)

Composition=measured

Variability Chart for log NL[Na (g/L)]

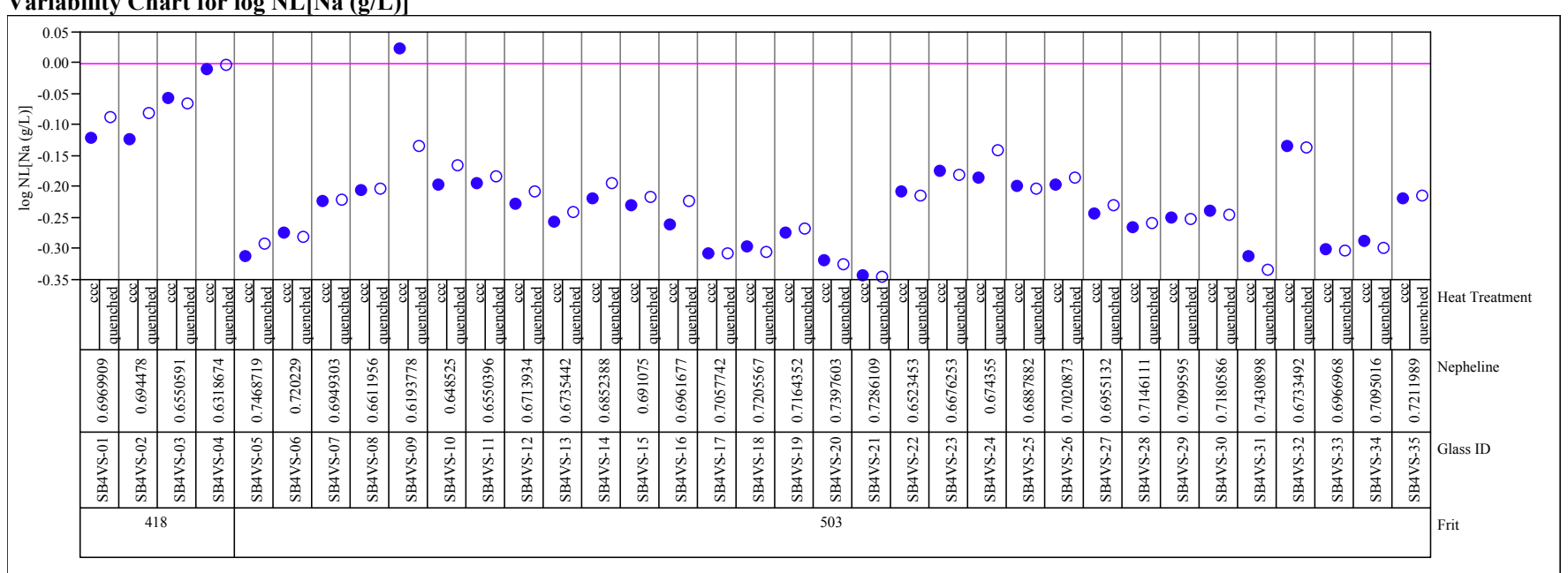

Variability Chart for $\log$ NL[Si (g/L)]

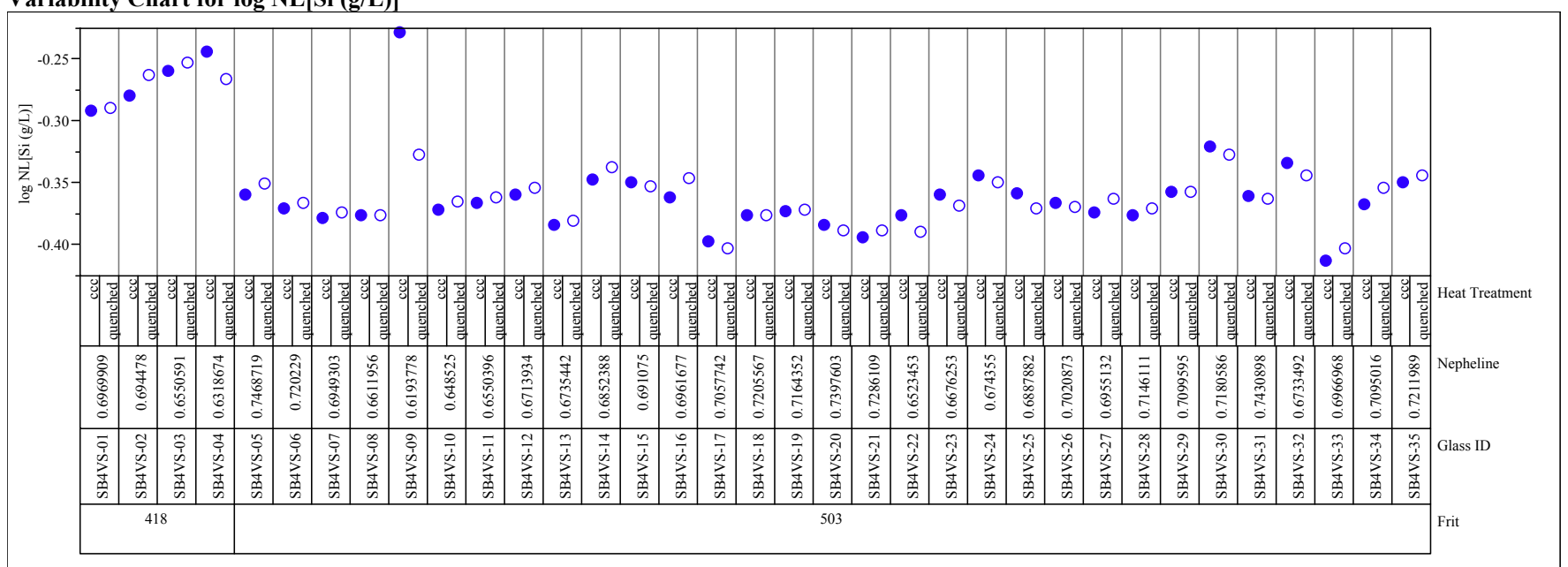


Exhibit F8. Effects of Heat Treatment for Study Glasses by Compositional View (continued)

Composition=measured bc

Variability Chart for log NL[B (g/L)]
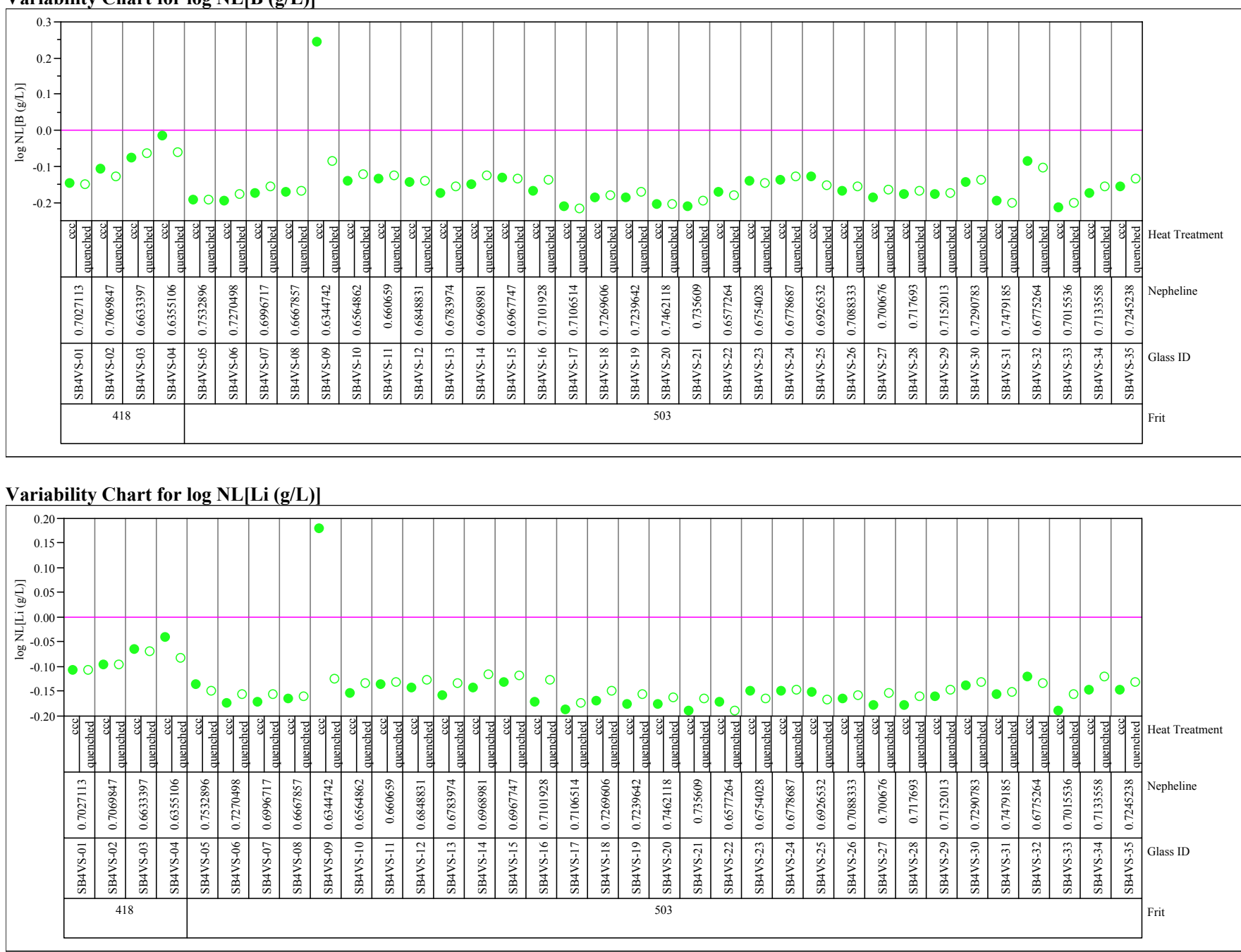
Exhibit F8. Effects of Heat Treatment for Study Glasses by Compositional View (continued)

Composition=measured bc

Variability Chart for $\log \mathrm{NL}[\mathrm{Na}(\mathrm{g} / \mathrm{L})$

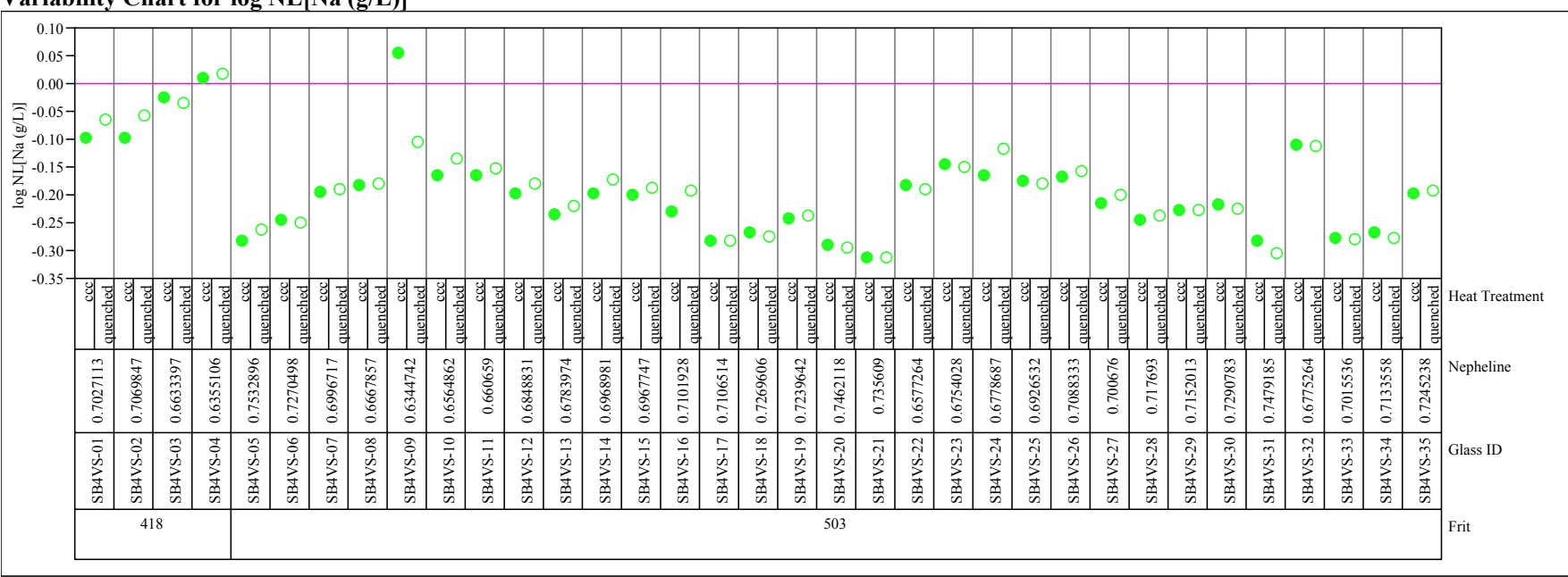

Variability Chart for $\log \mathrm{NL}[\mathrm{Si}(\mathrm{g} / \mathrm{L})]$

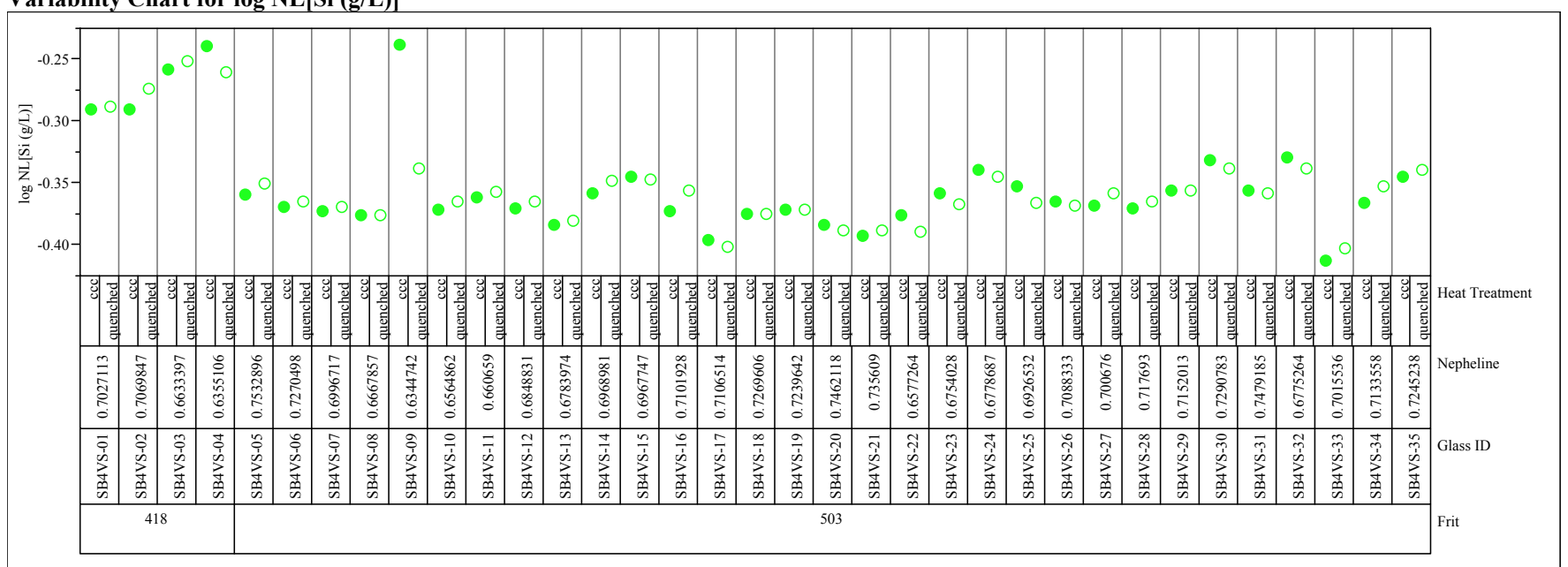


Exhibit F8. Effects of Heat Treatment for Study Glasses by Compositional View (continued)

Composition=targeted

Variability Chart for $\log$ NL[B (g/L)]

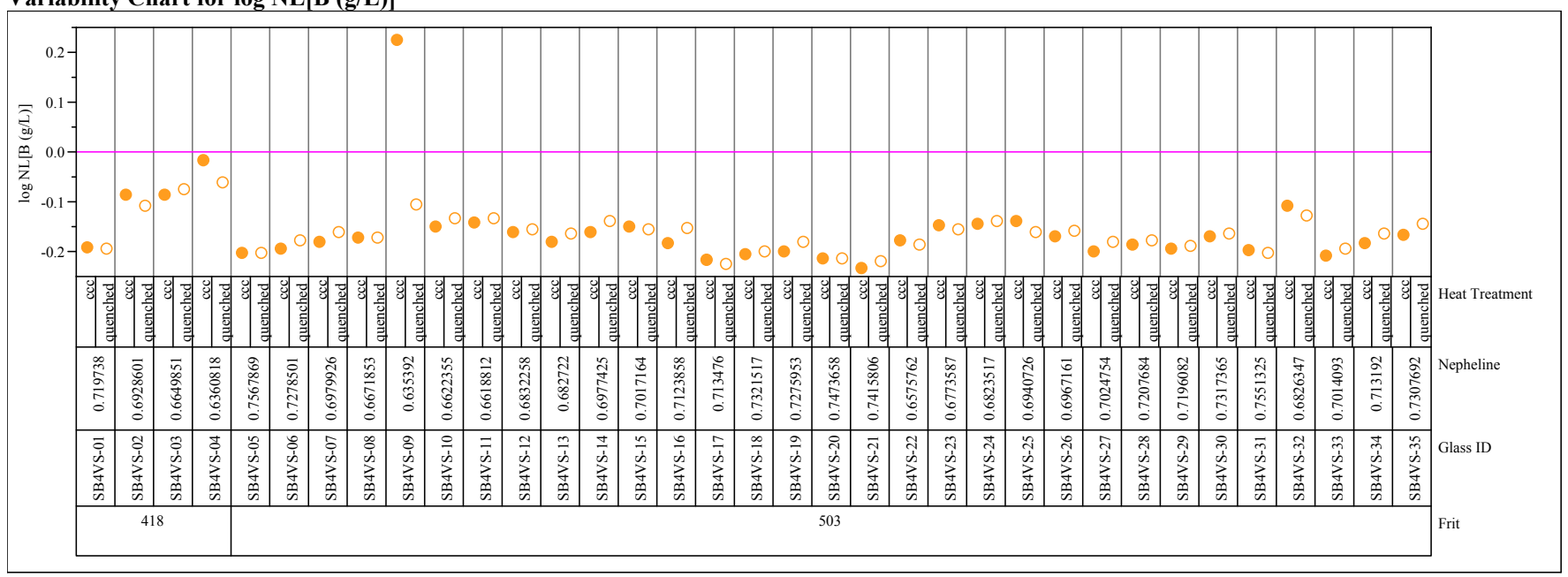

Variability Chart for $\log \mathrm{NL}[\mathrm{Li}(\mathrm{g} / \mathrm{L})]$

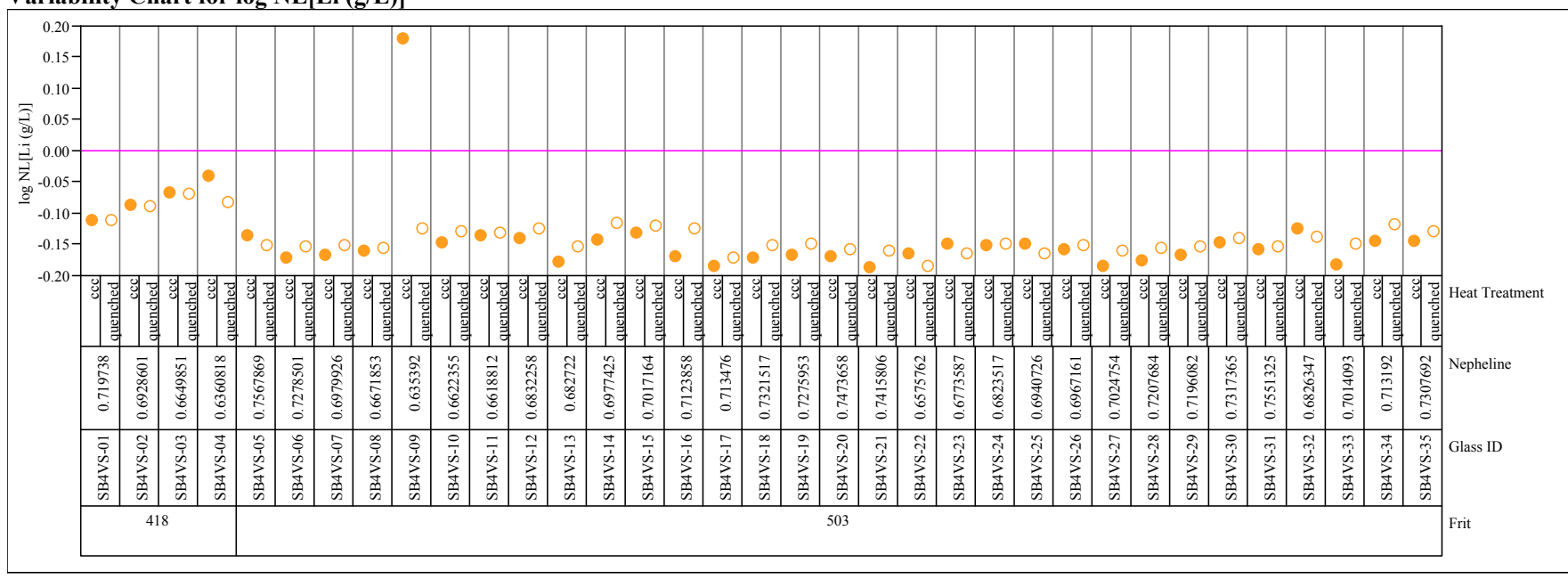


Exhibit F8. Effects of Heat Treatment for Study Glasses by Compositional View (continued)

Composition=targeted

Variability Chart for log NL[Na (g/L)]

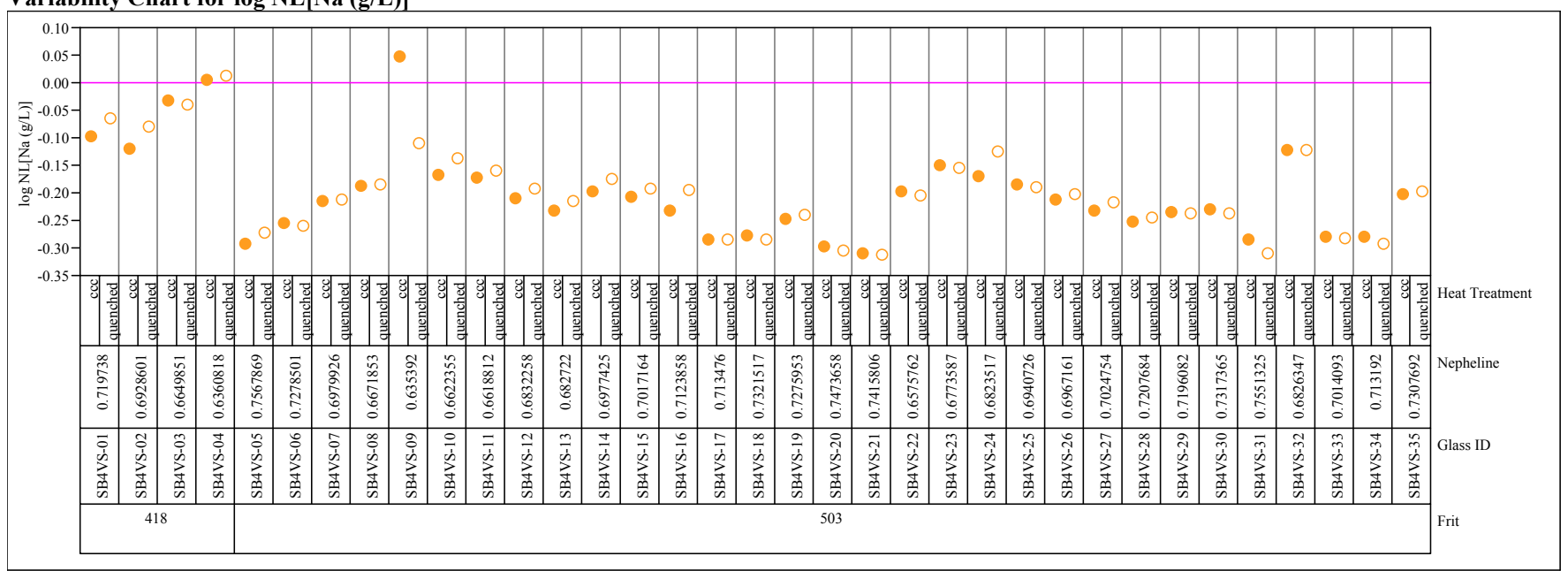

Variability Chart for $\log \mathrm{NL}[\mathrm{Si}(\mathrm{g} / \mathrm{L})]$

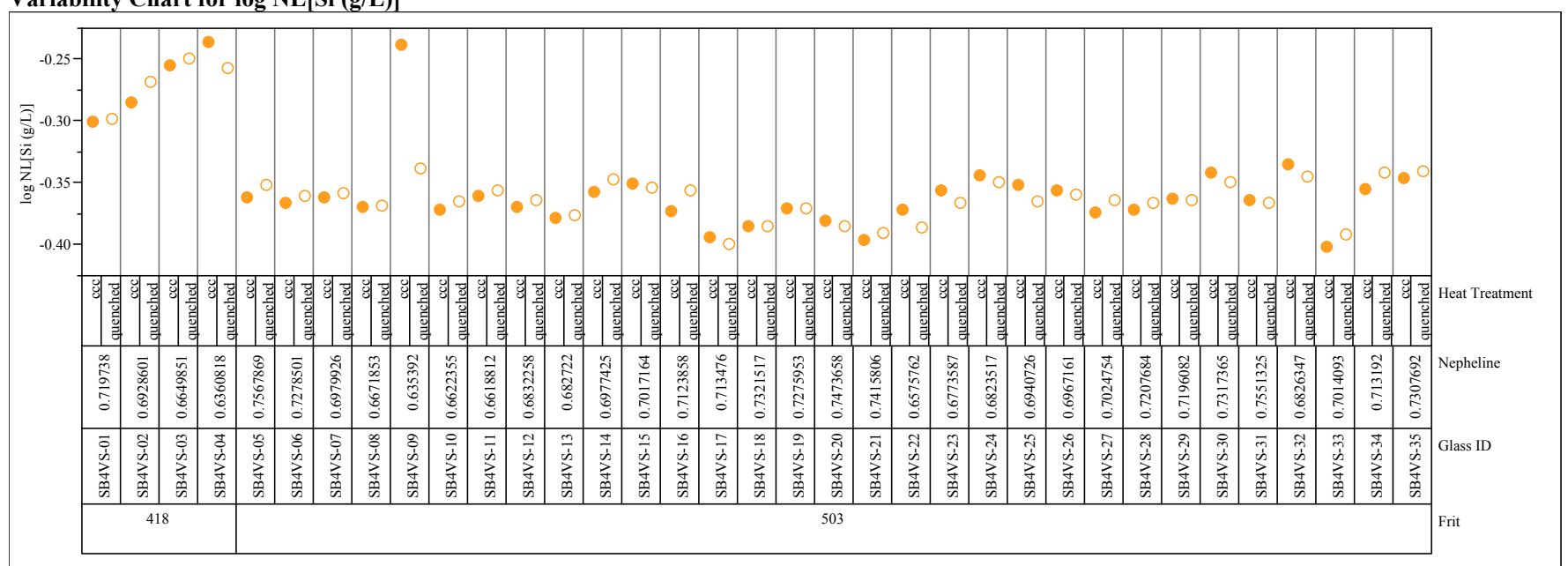


Exhibit F9. del $\mathbf{G p}\left(\Delta \mathbf{G}_{\mathrm{p}}\right)$ Predictions versus Common Logarithm Normalized Leachate $(\log \mathrm{NL}[]$.$) for B, Li, Na, and Si Over All Compositional Views and Heat Treatments$

\begin{tabular}{ll|l|}
\hline & Heat Treatment & Composition \\
\hline 6 & 1 ccc & measured \\
\hline 0 & 2 ccc & measured jc \\
\hline 0 & 4 ccc & targeted \\
\hline 0 & 5 quencillutd & Intedsur ed \\
\hline 0 & 6 quenched & mcasurcd jc \\
\hline
\end{tabular}

Bivariate Fit of $\log$ NL[B (g/L)] By del Gp

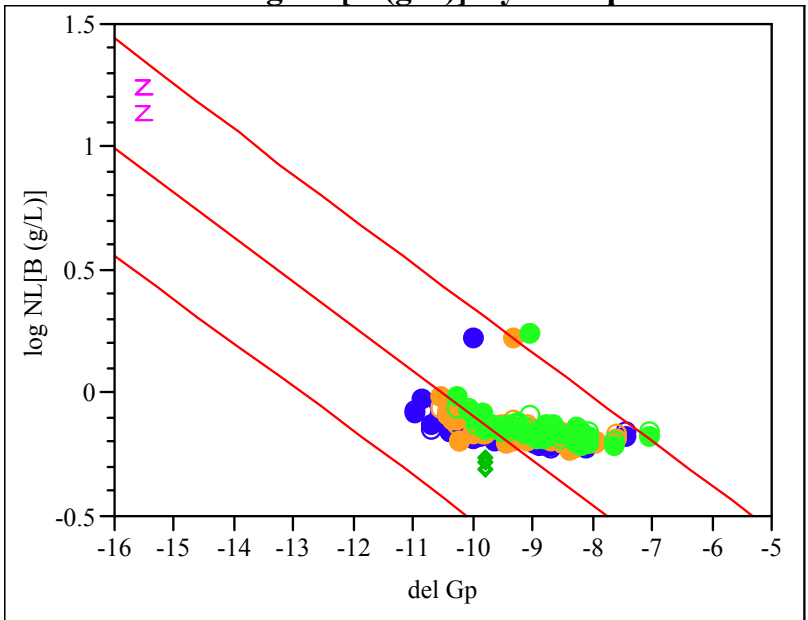

Bivariate Fit of $\log \mathrm{NL}[\mathrm{Li}(\mathrm{g} / \mathrm{L})]$ By del Gp

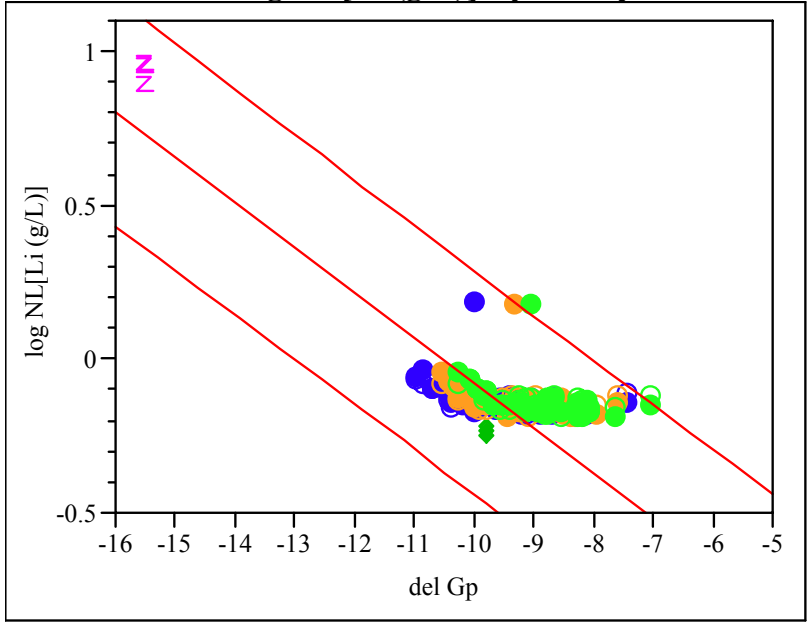

Bivariate Fit of $\log \mathrm{NL}[\mathrm{Na}(\mathrm{g} / \mathrm{L})]$ By del Gp

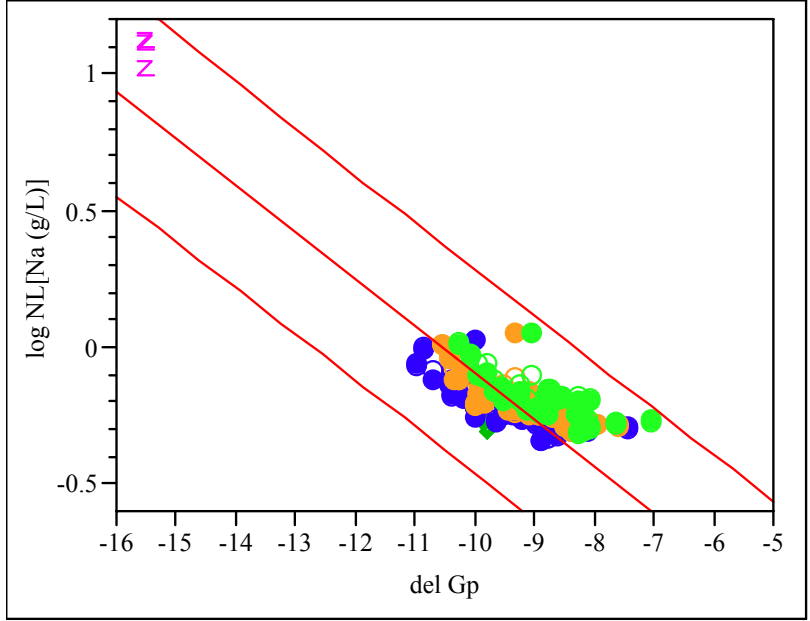

Bivariate Fit of $\log \mathrm{NL}[\mathrm{Si}(\mathrm{g} / \mathrm{L})]$ By del Gp

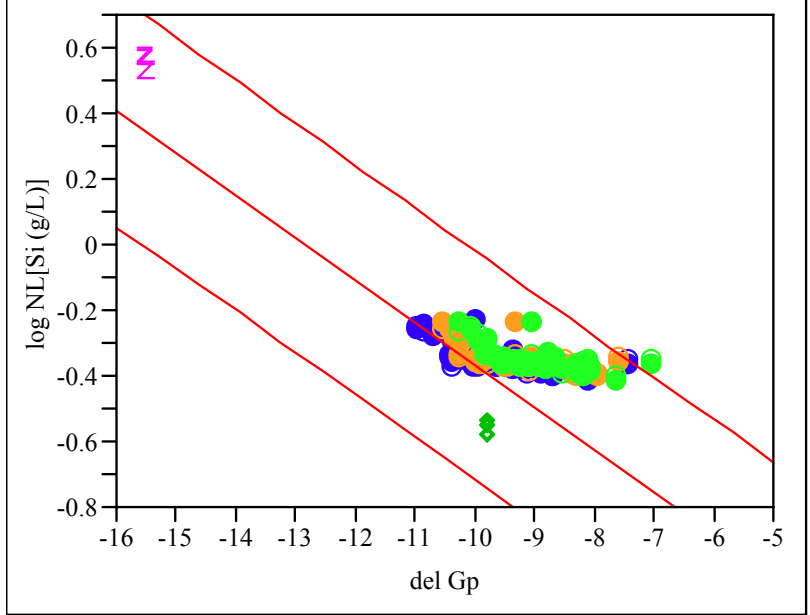


Exhibit F10. del Gp $\left(\Delta G_{p}\right)$ Predictions versus Common Logarithm Normalized Leachate $(\log \mathrm{NL}[]$.$) for B, Li, Na, and Si Over All Compositional Views for Quenched Glasses$

\begin{tabular}{lr|l|l|} 
Legend & \multicolumn{2}{c|}{ Heat Treatment } & Composition \\
\hline$\bullet$ & 1 & ccc & measured \\
\hline$\bullet$ & 2 & ccc & measured bc \\
\hline$\circ$ & 3 & ccc & targeted \\
\hline$\circ$ & 4 & quenched & measured \\
\hline$\circ$ & 5 & quenched & measured bc \\
\hline$\circ$ & 6 & quenched & targeted \\
\hline
\end{tabular}

Bivariate Fit of $\log$ NL[B (g/L)] By del Gp

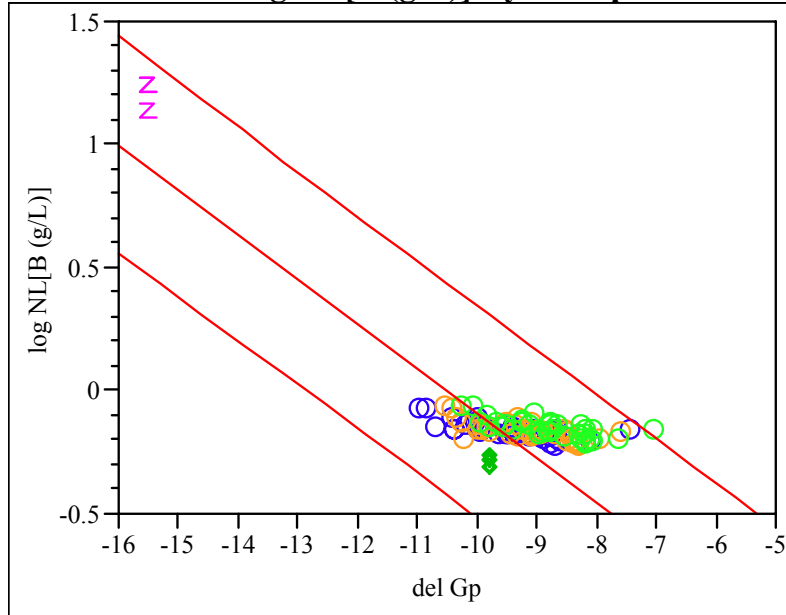

Bivariate Fit of log NL[Na (g/L)] By del Gp

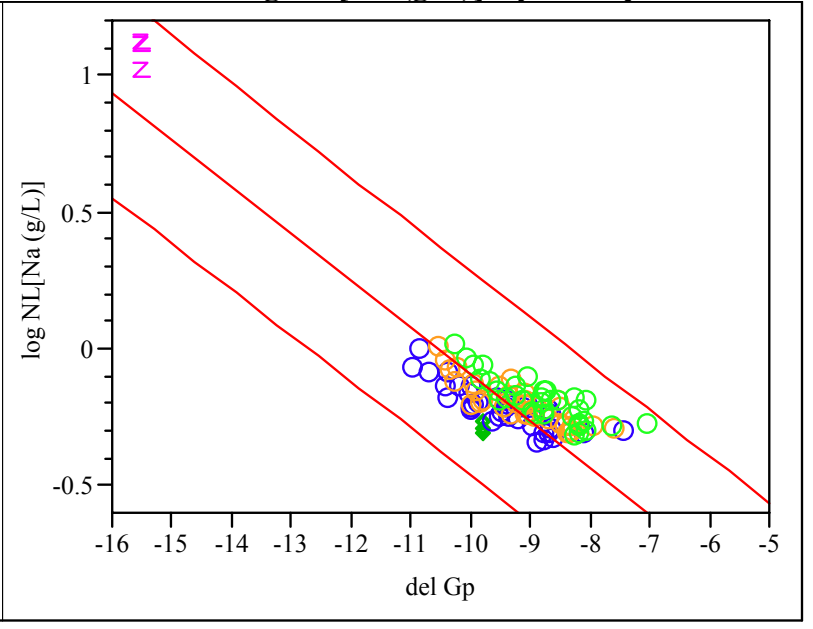

Bivariate Fit of $\log \mathrm{NL}[\mathrm{Li}(\mathrm{g} / \mathrm{L})]$ By del Gp

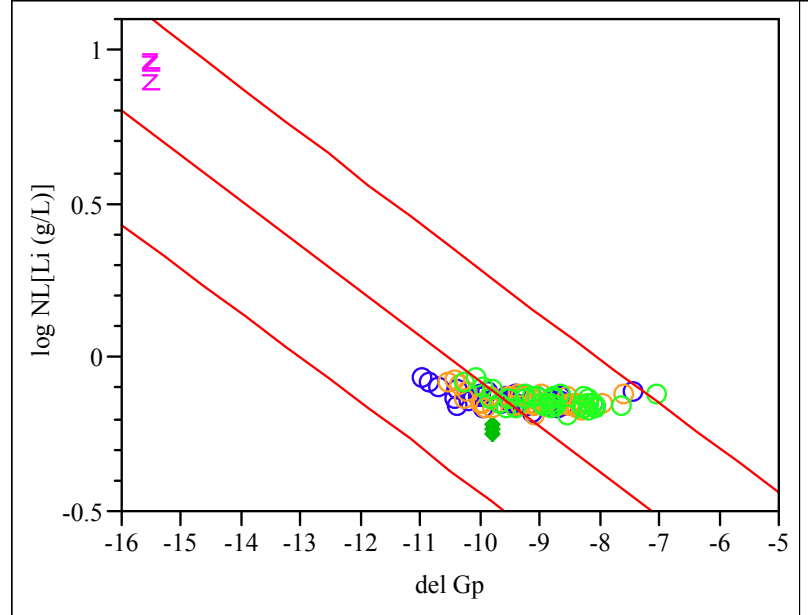

Bivariate Fit of $\log \mathrm{NL}[\mathrm{Si}(\mathrm{g} / \mathrm{L})]$ By del Gp

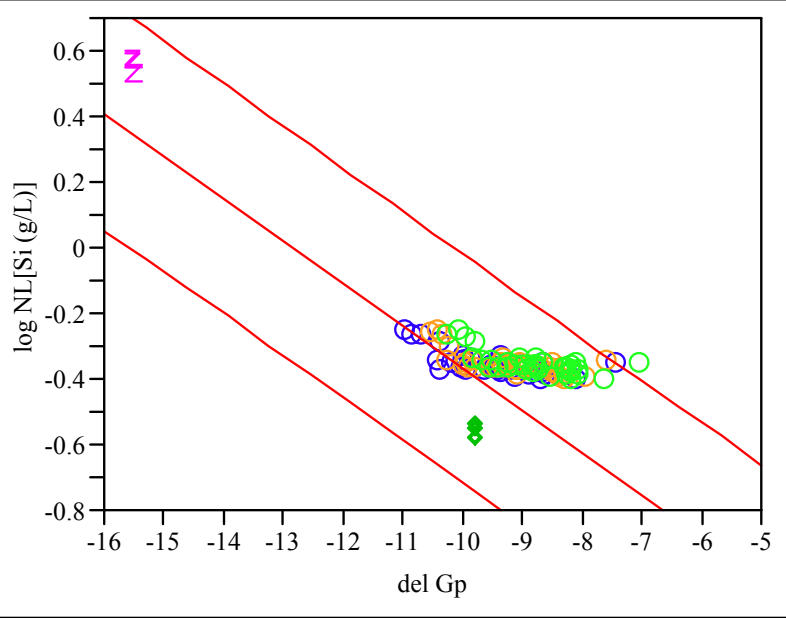


Exhibit F11. del $G p\left(\Delta G_{p}\right)$ Predictions versus Common Logarithm Normalized Leachate $(\log \mathrm{NL}[]$.$) for B, Li, Na, and Si Over All Compositional Views for cce Glasses$

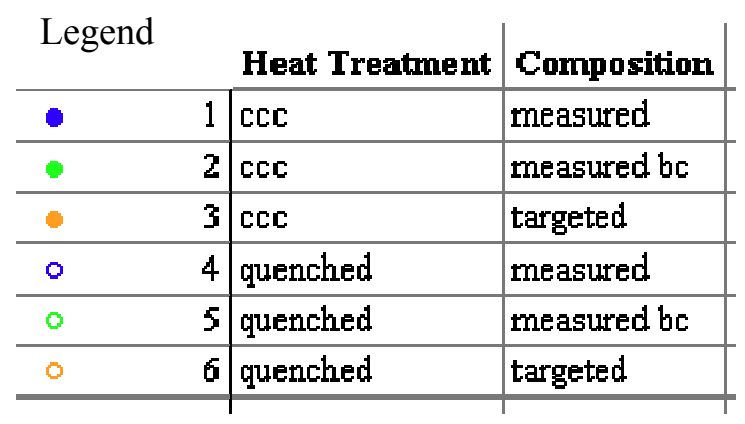

Bivariate Fit of $\log$ NL[B (g/L)] By del Gp

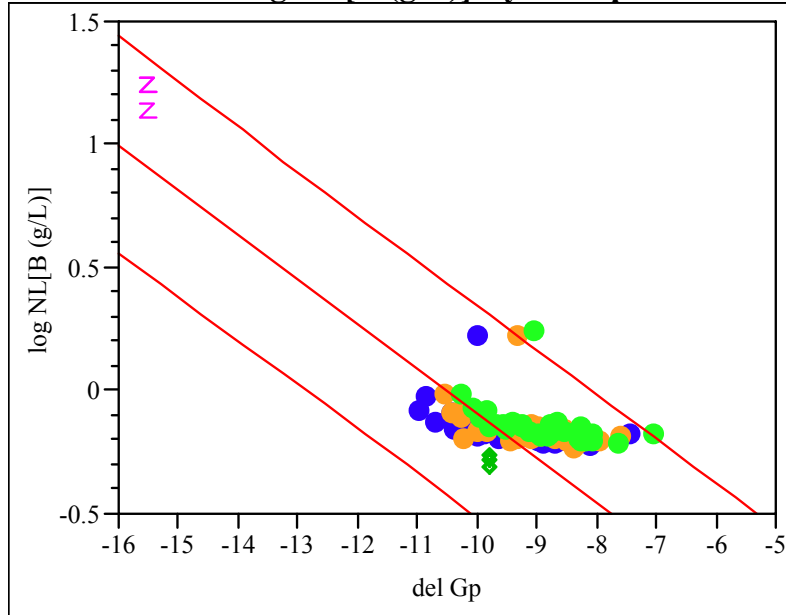

Bivariate Fit of $\log \mathrm{NL}[\mathrm{Na}(\mathrm{g} / \mathrm{L})]$ By del Gp

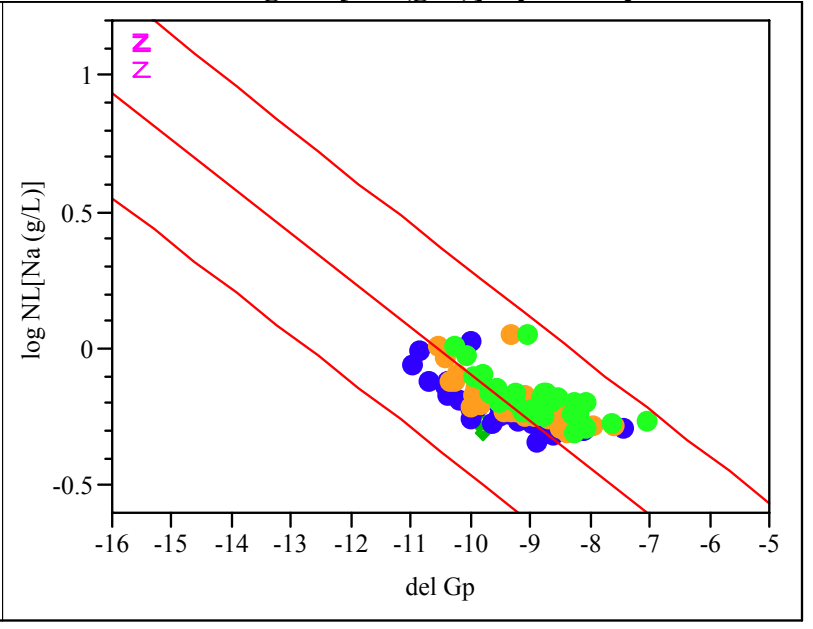

Bivariate Fit of $\log \mathrm{NL}[\mathrm{Li}(\mathrm{g} / \mathrm{L})]$ By del Gp

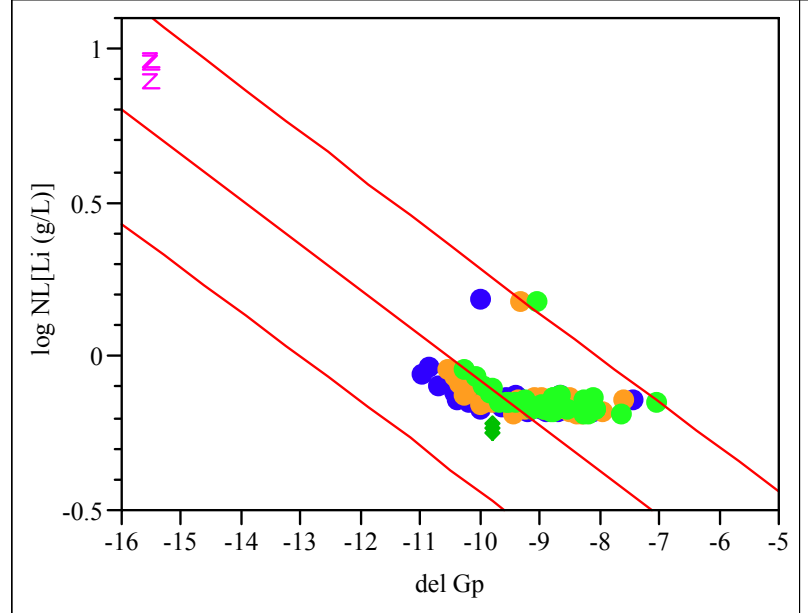

Bivariate Fit of $\log$ NL[Si (g/L)] By del Gp

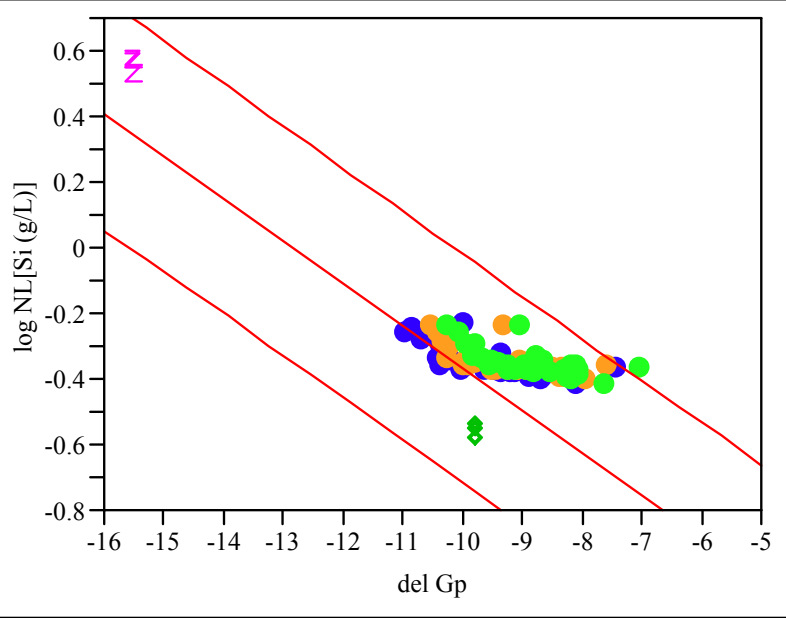


WSRC-STI-2006-00204

Revision 0

This page intentionally left blank. 